Márcio Francisco da Silva

\title{
Modelo DSGE com Fricção Financeira: o caso de uma pequena economia aberta
}



Márcio Francisco da Silva

\section{Modelo DSGE com Fricção Financeira: o caso de uma pequena economia aberta}

Este trabalho apresenta um modelo DSGE, com imperfeições no mercado financeiro, em duas versões: na primeira se supõe uma economia é fechada e na segunda uma economia aberta. As duas versões são estimadas com o uso de técnicas bayesianas, a partir de dados brasileiros.

Universidade de Brasília - UnB

Faculdade de Administração, Contabilidade e Economia - FACE

Programa de Pós-Graduação

Orientador: Joaquim P de Andrade

Brasil

2015 
Márcio Francisco da Silva

Modelo DSGE com Fricção Financeira:

o caso de uma pequena economia aberta/ Márcio Francisco da Silva. - Brasil, 2015-

363 p. : il. (algumas color.) ; $30 \mathrm{~cm}$.

Orientador: Joaquim P de Andrade

Tese (Doutorado) - Universidade de Brasília - UnB

Faculdade de Administração, Contabilidade e Economia - FACE

Programa de Pós-Graduação, 2015.

1. DSGE. 2. Fricções Fianaceiras. I. Joaquim P de Andrade. II. Universidade de Brasília. III. FACE. IV. Modelo DSGE com Fricção Financeira: o caso de uma pequena economia aberta 


\section{Márcio Francisco da Silva \\ Modelo DSGE com Fricção Financeira: o caso de uma pequena economia aberta}

Este trabalho apresenta um modelo DSGE, com imperfeições no mercado financeiro, em duas versões: na primeira se supõe uma economia é fechada e na segunda uma economia aberta. As duas versões são estimadas com o uso de técnicas bayesianas, a partir de dados brasileiros.

Trabalho aprovado. Brasil, 2015:

Joaquim P de Andrade

Orientador

Professor

Daniel Cajueiro

Professor

José Angelo A. Divino

Professor

Fábia Aparecida

Professor

Roberto Ellery

Brasil

2015 



\section{Agradecimentos}

Ao meu orientador, professor Joaquim P. de Andrade e à minha esposa Verônica Couto de Araújo Lima, pela paciência e por acreditarem em mim. Agradeço também à família e amigos pelo apoio em todos os momentos. 



\section{Resumo}

Neste trabalho foram analisadas duas extensões do modelo proposto por Gerali et all (2010). Na primeira versão são introduzidos um setor produtor de imóveis e uma modalidade de empréstimos às famílias impacientes com base no salário esperado. Estas mudanças têm como objetivo mimetizar duas características importantes da economia brasileira: a importância do setor de construção civil e do empréstimo consignado para o ciclo de negócios brasileiro. Na segunda versão do modelo foram incluidas as transações da economia doméstica com o exterior nos setores de bens (importando insumos e exportando bens finais) e financeiro (captação de poupança externa por meio dos bancos). Isto possibilita analisar a importância dos choques externos vis-à-vis os choques originados do setor financeiro para a economia brasileira.

Palavras-chaves: DSGE. Fricções Financeiras. Economia Aberta. 



\section{Abstract}

This study analyzes two extensions of the model proposed by Gerali et al (2010). In the first one, a housing producing sector was introduced. In addition to that a different form of loans to impatient households is considered that is based on the expected wage of households. When the family takes new loans, her ability of borrowing depends on their expected wage. These changes are intended to mimic two important characteristics of the Brazilian economy: the role of housing sector in the business cycle and the supply of payroll loans. In the second extension of the model, the environment was changed to a small open economy where the transactions of goods (importing raw materials and exporting finished goods) and financial sector (foreign savings funding through banks) to the rest of the world is taken into account. This makes it possible to analyze the importance of external shocks vis-a-vis the shocks arising from the financial sector to the Brazilian economy.

Key-words: DSGE. Financial Frictions. Open Economy. 



\section{Lista de ilustrações}

Figura 1 - Panorama do Modelo . . . . . . . . . . . . . . . . . . . . . . . 39

Figura 2 - Variáveis....................... 60

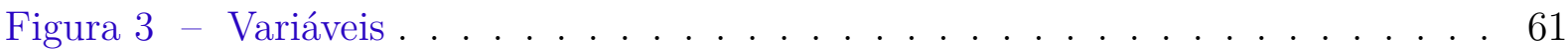

Figura 4 - Efeito de um choque tecnológico . . . . . . . . . . . . . . 71

Figura 5 - Efeito de um choque tecnológico . . . . . . . . . . . . . 71

Figura 6 - Efeito de um choque de demanda no consumo . . . . . . . . . 72

Figura 7 - Efeito de um choque de demanda no consumo . . . . . . . . . . 72

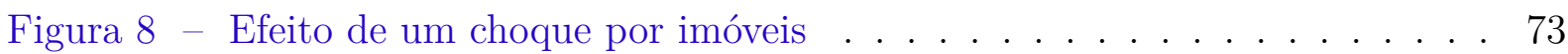

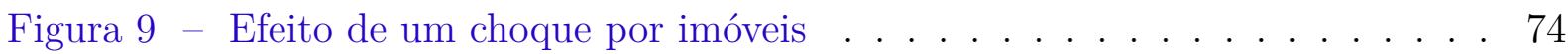

Figura 10 -Efeito de um choque de política monetária . . . . . . . . . . 74

Figura 11 -Efeito de um choque de política monetária . . . . . . . . . . . 75

Figura 12 -Efeito de um choque no capital bancário . . . . . . . . . . . . 76

Figura 13 -Efeito de um choque no capital bancário . . . . . . . . . . . . 76

Figura 14 -Efeito de um choque na demanda por imóveis . . . . . . . . . . 77

Figura 15 -Efeito de um choque na demanda por imóveis . . . . . . . . . . . 77

Figura 16 -Efeito de um choque na oferta de imóveis . . . . . . . . . . . 78

Figura 17 -Efeito de um choque na oferta de imóveis . . . . . . . . . . . . . 78

Figura 18 -Panorama do Modelo . . . . . . . . . . . . . . . . . . . 83

Figura 19 -Variáveis. . . . . . . . . . . . . . . . . . . . . . 98

Figura 20 -Variáveis . . . . . . . . . . . . . . . . . . . . . . . . . . . . . . . 99

Figura 21 -Efeito de um choque na inflação externa . . . . . . . . . . . . . . . 109

Figura 22 -Efeito de um choque na inflação externa . . . . . . . . . . . . . . 110

Figura 23 -Efeito de um choque no prêmio de risco . . . . . . . . . . . . . . 110

Figura 24 -Efeito de um choque no prêmio de risco . . . . . . . . . . . . . 111

Figura 25 -Efeito de um choque de política monetária . . . . . . . . . . . . 112

Figura 26 -Efeito de um choque de política monetária . . . . . . . . . . . . . . 112

Figura 27 -Efeito de um choque no capital bancário . . . . . . . . . . . . . . 113

Figura 28 -Efeito de um choque no capital bancário . . . . . . . . . . . . . . 113

Figura 29 -Efeito de um choque na renda externa . . . . . . . . . . . . . . 114

Figura 30 -Efeito de um choque na renda externa . . . . . . . . . . . . . 115

Figura 31 -Efeito de um choque no capital bancário . . . . . . . . . . . . . . 115

Figura 32 -Efeito de um choque no capital bancário . . . . . . . . . . . . . 116

Figura 33 -Efeito de um choque tecnológico . . . . . . . . . . . . . . . 117 
Figura 34 -Efeito de um choque tecnológico . . . . . . . . . . . . . . 118

Figura 35 -Efeito de um choque de política monetária . . . . . . . . . . . . 118

Figura 36 -Efeito de um choque de política monetária . . . . . . . . . . . . . . 119

Figura 37 -Efeito de um choque no capital bancário . . . . . . . . . . . . . . . . 119

Figura 38 -Efeito de um choque no capital bancário . . . . . . . . . . . . . . . . 120

Figura 39 -Efeito de um choque no debt-to-income . . . . . . . . . . . . . 127

Figura 40 -Efeito de um choque no debt-to-income . . . . . . . . . . . . . . 128

Figura 41 -Efeito de um choque no debt-to-income . . . . . . . . . . . . . . . 128

Figura 42 -Efeito de um choque no debt-to-income . . . . . . . . . . . . . . 129

Figura 43 -Efeito de um choque no debt-to-income . . . . . . . . . . . . . . . 129

Figura 44 -Efeito de um choque no debt-to-income . . . . . . . . . . . . . . 130

Figura 45 -Efeito de um choque em mk_bw . . . . . . . . . . . . . . 131

Figura 46 -Efeito de um choque em mk_bw . . . . . . . . . . . . . 132

Figura 47 -Efeito de um choque em mk_bw . . . . . . . . . . . . . . 132

Figura 48 -Efeito de um choque em mk_bw . . . . . . . . . . . . . . 133

Figura 49 -Efeito de um choque em mk_bw . . . . . . . . . . . . . . 133

Figura 50 -Efeito de um choque em mk_bw . . . . . . . . . . . . 134

Figura 51 -Efeito de um choque em e j . . . . . . . . . . . . . . . 135

Figura 52 -Efeito de um choque em $\mathrm{e} \_\mathrm{j} \ldots \ldots \ldots \ldots$

Figura 53 -Efeito de um choque em e j . . . . . . . . . . 136

Figura 54 -Efeito de um choque em e j . . . . . . . . . . . . . 137

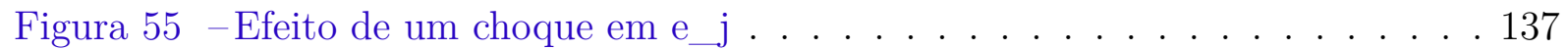

Figura 56 -Efeito de um choque em e j . . . . . . . . . . . . . . 138

Figura 57 -Efeito de um choque em $\mathrm{I}^{h} \ldots \ldots \ldots$. . . . . . . . . . . . . . . . . . .

Figura 58 -Efeito de um choque em $\mathrm{I}^{h} \ldots \ldots$. . . . . . . . . . . . . 140

Figura 59 -Efeito de um choque em $\mathrm{I}^{h} \ldots \ldots \ldots$. . . . . . . . . . . 140

Figura 60 -Efeito de um choque em $\mathrm{I}^{h} \ldots \ldots \ldots$. . . . . . . . . . . 141

Figura 61 -Efeito de um choque em $\mathrm{I}^{h} \ldots \ldots \ldots \ldots 14$

Figura 62 -Efeito de um choque em $\mathrm{I}^{h} \ldots \ldots$. . . . . . . . . . . . . . . 142

Figura 63 -Efeito de um choque tecnológico . . . . . . . . . . . . . . . . 143

Figura 64 -Efeito de um choque tecnológico . . . . . . . . . . . . . . . . . 144

Figura 65 -Efeito de um choque tecnológico . . . . . . . . . . . . . . . 144

Figura 66 -Efeito de um choque tecnológico . . . . . . . . . . . . . . . . . . 145

Figura 67 -Efeito de um choque tecnológico . . . . . . . . . . . . . . . 145

Figura 68 -Efeito de um choque tecnológico . . . . . . . . . . . . . 146

Figura 69 -Efeito de um choque no capital bancário . . . . . . . . . . . . . . 147

Figura 70 -Efeito de um choque no capital bancário . . . . . . . . . . . . . . . . 148

Figura 71 -Efeito de um choque no capital bancário . . . . . . . . . . . . . . . 148

Figura 72 -Efeito de um choque no capital bancário . . . . . . . . . . . . . . 149 
Figura 73 -Efeito de um choque no capital bancário . . . . . . . . . . . . . . . 149

Figura 74 -Efeito de um choque no capital bancário . . . . . . . . . . . . . . . . 150

Figura 75 -Efeito de um choque no loan-to-value dos empresários . . . . . . . . . 151

Figura 76 -Efeito de um choque no loan-to-value dos empresários . . . . . . . . 152

Figura 77 -Efeito de um choque no loan-to-value dos empresários . . . . . . . . 152

Figura 78 -Efeito de um choque no loan-to-value dos empresários . . . . . . . . . 153

Figura 79 -Efeito de um choque no loan-to-value dos empresários . . . . . . . . . 153

Figura 80 -Efeito de um choque no loan-to-value dos empresários . . . . . . . . . 154

Figura 81 -Efeito de um choque no loan-to-value das famílias impacientes . . . . . 155

Figura 82 -Efeito de um choque no loan-to-value das famílias impacientes . . . . 156

Figura 83 -Efeito de um choque no loan-to-value das famílias impacientes . . . . . 156

Figura 84 -Efeito de um choque no loan-to-value das famílias impacientes . . . . . 157

Figura 85 -Efeito de um choque no loan-to-value das famílias impacientes . . . . . 157

Figura 86 -Efeito de um choque no loan-to-value das famílias impacientes . . . . . 158

Figura 87 -Efeito de um choque no Mark-up de salários . . . . . . . . . . . . . . . 159

Figura 88 -Efeito de um choque no Mark-up de salários . . . . . . . . . . . . . . 160

Figura 89 -Efeito de um choque no Mark-up de salários . . . . . . . . . . . . . . 160

Figura 90 -Efeito de um choque no Mark-up de salários . . . . . . . . . . . . . . 161

Figura 91 -Efeito de um choque no Mark-up de salários . . . . . . . . . . . . . . . 161

Figura 92 -Efeito de um choque no Mark-up de salários . . . . . . . . . . . . . . . 162

Figura 93 -Efeito de um choque em $\mathrm{mk}_{b} h \ldots \ldots$. . . . . . . . . . 163

Figura 94 -Efeito de um choque em $\mathrm{mk}_{b} h \ldots \ldots$. . . . . . . . . . . . 164

Figura 95 -Efeito de um choque em $\mathrm{mk}_{b} h \ldots \ldots$. . . . . . . . . . . 164

Figura 96 -Efeito de um choque em $\mathrm{mk}_{b} h \ldots \ldots$. . . . . . . . . . . . 165

Figura 97 -Efeito de um choque em $\mathrm{mk}_{b} h \ldots \ldots$. . . . . . . . . . . . 165

Figura 98 -Efeito de um choque em $\mathrm{mk}_{b} h \ldots \ldots$. . . . . . . . . 166

Figura 99 -Efeito de um choque em $\mathrm{mk}_{b} e \ldots \ldots$. . . . . . . . . . 167

Figura 100 -Efeito de um choque em $\mathrm{mk}_{b} e \ldots \ldots$. . . . . . . . . . . . . . 168

Figura 101 -Efeito de um choque em $\mathrm{mk}_{b} e \ldots \ldots$. . . . . . . . . . . . . . 168

Figura 102 -Efeito de um choque em $\mathrm{mk}_{b} e \ldots \ldots$. . . . . . . . . . . . . 169

Figura 103 -Efeito de um choque em $\mathrm{mk}_{b}$ e . . . . . . . . . . . . . . . . . . 169

Figura 104 -Efeito de um choque em $\mathrm{mk}_{b}$ e . . . . . . . . . . . . . . . . . . . . 170

Figura 105 -Efeito de um choque em $\mathrm{mk}_{d} \ldots \ldots$. . . . . . . . . . . . 171

Figura 106 -Efeito de um choque em $\mathrm{mk}_{d} \ldots \ldots$. . . . . . . . . . . . 172

Figura 107 -Efeito de um choque em $\mathrm{mk}_{d} \ldots \ldots$. . . . . . . . . . . . 172

Figura 108 -Efeito de um choque em $\mathrm{mk}_{d} \ldots \ldots$. . . . . . . . . . . . . . 173

Figura 109 -Efeito de um choque em $\mathrm{mk}_{d} \ldots \ldots$. . . . . . . . . . . . 173

Figura 110 -Efeito de um choque em $\mathrm{mk}_{d} \ldots \ldots$. . . . . . . . . . . . . . . 174

Figura 111 -Efeito de um choque em $\mathrm{I}^{k} \ldots \ldots$. . . . . . . . . . . 175 
Figura 112 -Efeito de um choque em $\mathrm{I}^{k} \ldots \ldots \ldots \ldots$. . . . . . . . . 176

Figura 113 -Efeito de um choque em $\mathrm{I}^{k} \ldots \ldots \ldots$. . . . . . . . . . 176

Figura 114 -Efeito de um choque em $\mathrm{I}^{k} \ldots \ldots$. . . . . . . . . . . . . 177

Figura 115 -Efeito de um choque em $\mathrm{I}^{k} \ldots \ldots \ldots$. . . . . . . . . . 177

Figura 116 -Efeito de um choque em $\mathrm{I}^{k} \ldots \ldots \ldots$. . . . . . . . . . . . 178

Figura 117 -Efeito de um choque de PM . . . . . . . . . . . . . . . . . . . 179

Figura 118 -Efeito de um choque de PM . . . . . . . . . . . . . . . . 180

Figura 119 -Efeito de um choque de PM . . . . . . . . . . . . . . . 180

Figura 120 -Efeito de um choque de PM . . . . . . . . . . . . . . . 181

Figura 121 -Efeito de um choque de PM . . . . . . . . . . . . . . . . . 181

Figura 122 -Efeito de um choque de PM . . . . . . . . . . . . . . . . 182

Figura 123 -Efeito de um choque no mark-up de preços . . . . . . . . . . . . . . . 183

Figura 124 -Efeito de um choque no mark-up de preços . . . . . . . . . . . . . . . 184

Figura 125 -Efeito de um choque no mark-up de preços . . . . . . . . . . . . . . . 184

Figura 126 -Efeito de um choque no mark-up de preços . . . . . . . . . . . . . . 185

Figura 127 -Efeito de um choque no mark-up de preços . . . . . . . . . . . . . . . 185

Figura 128 -Efeito de um choque no mark-up de preços . . . . . . . . . . . . . . 186

Figura 129 -Efeito de um choque na demanda por consumo . . . . . . . . . . . . 187

Figura 130 -Efeito de um choque na demanda por consumo . . . . . . . . . . . . 188

Figura 131 -Efeito de um choque na demanda por consumo . . . . . . . . . . . . . 188

Figura 132 -Efeito de um choque na demanda por consumo . . . . . . . . . . . . . 189

Figura 133 -Efeito de um choque na demanda por consumo . . . . . . . . . . . . 189

Figura 134 -Efeito de um choque na demanda por consumo . . . . . . . . . . . . 190

Figura 135 -Efeito de um choque em $\pi^{*} \ldots$. . . . . . . . . . . . . . 191

Figura 136 -Efeito de um choque em $\pi^{*} \ldots$. . . . . . . . . . . . . . . 192

Figura 137 -Efeito de um choque em $\pi^{*} \ldots \ldots$. . . . . . . . . . . . . 192

Figura 138 -Efeito de um choque em $\pi^{*} \ldots$. . . . . . . . . . . . . . 193

Figura 139 -Efeito de um choque em $\pi^{*} \ldots$. . . . . . . . . . . . . . 193

Figura 140 -Efeito de um choque em $\pi^{*} \ldots \ldots$. . . . . . . . . . . . . . . . 194

Figura 141 -Efeito de um choque em $\pi^{*} \ldots \ldots$. . . . . . . . . . . . . . 194

Figura 142 -Efeito de um choque em $\Phi$. . . . . . . . . . . . . . . . . . 195

Figura 143 -Efeito de um choque em $\Phi \ldots \ldots$. . . . . . . . . . . . 196

Figura 144 -Efeito de um choque em $\Phi$. . . . . . . . . . . . . . . . . . . 196

Figura 145 -Efeito de um choque em $\Phi$. . . . . . . . . . . . . . . . . . . . . 197

Figura 146 -Efeito de um choque em $\Phi$. . . . . . . . . . . . . . . . . . 197

Figura 147 -Efeito de um choque em $\Phi$. . . . . . . . . . . . . . . . . . 198

Figura 148 -Efeito de um choque em $\Phi$. . . . . . . . . . . . . . . . . . . . . . . 198

Figura 149 -Efeito de um choque em $\mathrm{K}^{b} \ldots \ldots$. . . . . . . . . . . . . . . 199

Figura 150 -Efeito de um choque em $\mathrm{K}^{b} \ldots \ldots$. . . . . . . . . . . 200 


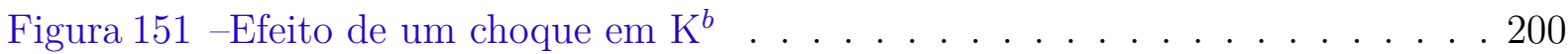

Figura 152 -Efeito de um choque em $\mathrm{K}^{b} \ldots \ldots$. . . . . . . . . . . . . . . . . 201

Figura 153 -Efeito de um choque em $\mathrm{K}^{b} \ldots \ldots$. . . . . . . . . . . . . . 201

Figura 154 -Efeito de um choque em $\mathrm{K}^{b} \ldots \ldots$. . . . . . . . . . . . . 202

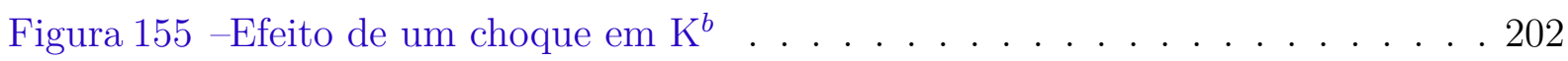

Figura 156 -Efeito de um choque em $R^{*} \ldots$. . . . . . . . . . . . . . . 203

Figura 157 -Efeito de um choque em $R^{*} \ldots$. . . . . . . . . . . . . . . . 204

Figura 158 -Efeito de um choque em $R^{*} \ldots$. . . . . . . . . . . . . . . 204

Figura 159 -Efeito de um choque em $\mathrm{R}^{*} \ldots$. . . . . . . . . . . . . 205

Figura 160 -Efeito de um choque em $\mathrm{R}^{*} \ldots \ldots$. . . . . . . . . . 205

Figura 161 -Efeito de um choque em $R^{*} \ldots \ldots$. . . . . . . . . . 206

Figura 162 -Efeito de um choque em $R^{*} \ldots$. . . . . . . . . . . . 206

Figura 163 -Efeito de um choque em $\mathrm{p}^{Q} \ldots \ldots$. . . . . . . . . . . . 207

Figura 164 -Efeito de um choque em $\mathrm{p}^{Q} \ldots \ldots$. . . . . . . . . . . 208

Figura 165 -Efeito de um choque em $\mathrm{p}^{Q} \ldots \ldots$. . . . . . . . . . . . 208

Figura 166 -Efeito de um choque em $\mathrm{p}^{Q} \ldots \ldots$. . . . . . . . . . . . 209

Figura 167 -Efeito de um choque em $\mathrm{p}^{Q} \ldots \ldots$. . . . . . . . . . . . . . 209

Figura 168 -Efeito de um choque em $\mathrm{p}^{Q} \ldots \ldots$. . . . . . . . . . . . . 210

Figura 169 -Efeito de um choque em $\mathrm{p}^{Q} \ldots \ldots$. . . . . . . . . . . . . 210

Figura 170 -Efeito de um choque em $\mathrm{y}^{*} \ldots \ldots$. . . . . . . . . . . . . . . 211

Figura 171 -Efeito de um choque em $\mathrm{y}^{*} \ldots$. . . . . . . . . . . . . . . 212

Figura 172 -Efeito de um choque em $\mathrm{y}^{*} \ldots \ldots$. . . . . . . . . . . . 212

Figura 173 -Efeito de um choque em $\mathrm{y}^{*} \ldots$. . . . . . . . . . . . . . . 213

Figura 174 -Efeito de um choque em $\mathrm{y}^{*} \ldots \ldots$. . . . . . . . . . . . 213

Figura 175 -Efeito de um choque em $\mathrm{y}^{*} \ldots$. . . . . . . . . . . . . . . 214

Figura 176 -Efeito de um choque em $\mathrm{y}^{*} \ldots \ldots$. . . . . . . . . . 214

Figura 177 -Efeito de um choque no debt-to-income . . . . . . . . . . . . . . 215

Figura 178 -Efeito de um choque no debt-to-income . . . . . . . . . . . . . . . . 216

Figura 179 -Efeito de um choque no debt-to-income . . . . . . . . . . . . . . . 216

Figura 180 -Efeito de um choque no debt-to-income . . . . . . . . . . . . . . . . 217

Figura 181 -Efeito de um choque no debt-to-income . . . . . . . . . . . . . . . 217

Figura 182 -Efeito de um choque no debt-to-income . . . . . . . . . . . . . . . . . . 218

Figura 183 -Efeito de um choque no debt-to-income . . . . . . . . . . . . . . . 218

Figura 184 -Efeito de um choque em mk_bw . . . . . . . . . . . . . . . 219

Figura 185 -Efeito de um choque em mk_bw . . . . . . . . . . . . . 220

Figura 186 -Efeito de um choque em mk_bw . . . . . . . . . . . . . . 220

Figura 187 -Efeito de um choque em mk_bw . . . . . . . . . . . . . . . 221

Figura 188 -Efeito de um choque em mk_bw . . . . . . . . . . . . . . . . 221

Figura 189 -Efeito de um choque em mk_bw . . . . . . . . . . . . . . 222 
Figura 190 -Efeito de um choque em mk_bw . . . . . . . . . . . . . . 222

Figura 191 -Efeito de um choque em e_j . . . . . . . . . . . . . . . . 223

Figura 192 -Efeito de um choque em e j . . . . . . . . . . . . . . . . 224

Figura 193 -Efeito de um choque em e j . . . . . . . . . . . . . . . 224

Figura 194 -Efeito de um choque em e j . . . . . . . . . . . . . . 225

Figura 195 -Efeito de um choque em e_ j . . . . . . . . . . . . . . 225

Figura 196 -Efeito de um choque em e_ j . . . . . . . . . . . . . . 226

Figura 197 -Efeito de um choque em e_j . . . . . . . . . . . . . 226

Figura 198 -Efeito de um choque em $\mathrm{I}^{h} \ldots \ldots$. . . . . . . . . . . . 227

Figura 199 -Efeito de um choque em $\mathrm{I}^{h} \ldots \ldots \ldots$. . . . . . . . . . . 228

Figura 200 -Efeito de um choque em $\mathrm{I}^{h} \ldots \ldots \ldots$. . . . . . . . . . 228

Figura 201 -Efeito de um choque em $\mathrm{I}^{h} \ldots \ldots$. . . . . . . . . . . . . . . 229

Figura 202 -Efeito de um choque em $\mathrm{I}^{h} \ldots \ldots$. . . . . . . . . . . . . 229

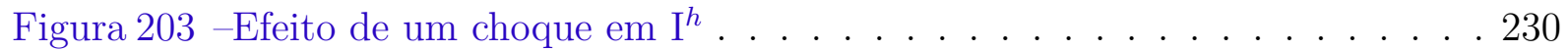

Figura 204 -Efeito de um choque em $\mathrm{I}^{h} \ldots \ldots$. . . . . . . . . . . . . . 230

Figura 205 -Efeito de um choque tecnológico . . . . . . . . . . . . . . . . . 231

Figura 206 -Efeito de um choque tecnológico . . . . . . . . . . . . . . . . 232

Figura 207 -Efeito de um choque tecnológico . . . . . . . . . . . . . . . . 232

Figura 208 -Efeito de um choque tecnológico . . . . . . . . . . . . . . . . . 233

Figura 209 -Efeito de um choque tecnológico . . . . . . . . . . . . . . . 233

Figura 210 -Efeito de um choque tecnológico . . . . . . . . . . . . . . . . 234

Figura 211 -Efeito de um choque tecnológico . . . . . . . . . . . . . . . 234

Figura 212 -Efeito de um choque no loan-to-value dos empresários . . . . . . . 235

Figura 213 -Efeito de um choque no loan-to-value dos empresários . . . . . . . . . 236

Figura 214 -Efeito de um choque no loan-to-value dos empresários . . . . . . . . 236

Figura 215 -Efeito de um choque no loan-to-value dos empresários . . . . . . . . . 237

Figura 216 -Efeito de um choque no loan-to-value dos empresários . . . . . . . . . 237

Figura 217 -Efeito de um choque no loan-to-value dos empresários . . . . . . . . 238

Figura 218 -Efeito de um choque no loan-to-value dos empresários . . . . . . . . 238

Figura 219 -Efeito de um choque no loan-to-value das famílias impacientes . . . . . 239

Figura 220 -Efeito de um choque no loan-to-value das famílias impacientes . . . . . 240

Figura 221 -Efeito de um choque no loan-to-value das famílias impacientes . . . . . 240

Figura 222 -Efeito de um choque no loan-to-value das famílias impacientes . . . . . 241

Figura 223 -Efeito de um choque no loan-to-value das famílias impacientes . . . . . 241

Figura 224 -Efeito de um choque no loan-to-value das famílias impacientes . . . . . 242

Figura 225 -Efeito de um choque no loan-to-value das famílias impacientes . . . . . 242

Figura 226 -Efeito de um choque no Mark-up de salários . . . . . . . . . . . . . . 243

Figura 227 -Efeito de um choque no Mark-up de salários . . . . . . . . . . . . . . . 244

Figura 228 -Efeito de um choque no Mark-up de salários . . . . . . . . . . . . . . . 244 
Figura 229 -Efeito de um choque no Mark-up de salários . . . . . . . . . . . . . 245

Figura 230 -Efeito de um choque no Mark-up de salários . . . . . . . . . . . . . . 245

Figura 231 -Efeito de um choque no Mark-up de salários . . . . . . . . . . . . . . . 246

Figura 232 -Efeito de um choque no Mark-up de salários . . . . . . . . . . . . . 246

Figura 233 -Efeito de um choque em $\mathrm{mk}_{b} h \ldots$. . . . . . . . . . . . . 247

Figura 234 -Efeito de um choque em $\mathrm{mk}_{b} h \ldots \ldots$. . . . . . . . . . . . . 248

Figura 235 -Efeito de um choque em $\mathrm{mk}_{b} h \ldots \ldots$. . . . . . . . . . . . . 248

Figura 236 -Efeito de um choque em $\mathrm{mk}_{b} h \ldots$. . . . . . . . . . . . . . . 249

Figura 237 -Efeito de um choque em $\mathrm{mk}_{b} h \ldots$. . . . . . . . . . . . . . . 249

Figura 238 -Efeito de um choque em $\mathrm{mk}_{b} h \ldots \ldots$. . . . . . . . . . . 250

Figura 239 -Efeito de um choque em $\mathrm{mk}_{b} h \ldots$. . . . . . . . . . . . . . . 250

Figura 240 -Efeito de um choque em $\mathrm{mk}_{b} e \ldots \ldots$. . . . . . . . . . . . 251

Figura 241 -Efeito de um choque em $\mathrm{mk}_{b} e \ldots \ldots$. . . . . . . . . . . . . 252

Figura 242 -Efeito de um choque em $\mathrm{mk}_{b} e \ldots \ldots$. . . . . . . . . . . 252

Figura 243 -Efeito de um choque em $\mathrm{mk}_{b} e \ldots \ldots$. . . . . . . . . . . . 253

Figura 244 -Efeito de um choque em $\mathrm{mk}_{b} e \ldots \ldots$. . . . . . . . . . . . . 253

Figura 245 -Efeito de um choque em $\mathrm{mk}_{b} e \ldots \ldots$. . . . . . . . . . . . 254

Figura 246 -Efeito de um choque em $\mathrm{mk}_{b}$ e . . . . . . . . . . . . . . . 254

Figura 247 -Efeito de um choque em $\mathrm{mk}_{d} \ldots \ldots$. . . . . . . . . . . 255

Figura 248 -Efeito de um choque em $\mathrm{mk}_{d} \ldots \ldots$. . . . . . . . . . 256

Figura 249 -Efeito de um choque em $\mathrm{mk}_{d} \ldots \ldots$. . . . . . . . . . . 256

Figura 250 -Efeito de um choque em $\mathrm{mk}_{d} \ldots \ldots$. . . . . . . . . . . 257

Figura 251 -Efeito de um choque em $\mathrm{mk}_{d} \ldots \ldots$. . . . . . . . . . . 257

Figura 252 -Efeito de um choque em $\mathrm{mk}_{d} \ldots \ldots$. . . . . . . . . . . 258

Figura 253 -Efeito de um choque em $\mathrm{mk}_{d} \ldots \ldots$. . . . . . . . . . 258

Figura 254 -Efeito de um choque em $\mathrm{I}^{k} \ldots$. . . . . . . . . . . . . . 259

Figura 255 -Efeito de um choque em $\mathrm{I}^{k} \ldots \ldots$. . . . . . . . . . . 260

Figura 256 -Efeito de um choque em $\mathrm{I}^{k} \ldots \ldots$. . . . . . . . . . . 260

Figura 257 -Efeito de um choque em $\mathrm{I}^{k} \ldots \ldots$. . . . . . . . . . . . . . 261

Figura 258 -Efeito de um choque em $\mathrm{I}^{k} \ldots$. . . . . . . . . . . . . . . 261

Figura 259 -Efeito de um choque em $\mathrm{I}^{k} \ldots \ldots$. . . . . . . . . . . . 262

Figura 260 -Efeito de um choque em $\mathrm{I}^{k} \ldots \ldots$. . . . . . . . . . . . . . . . 262

Figura 261 -Efeito de um choque de PM . . . . . . . . . . . . . . . . . 263

Figura 262 -Efeito de um choque de PM . . . . . . . . . . . . . . . . . . 264

Figura 263 -Efeito de um choque de PM . . . . . . . . . . . . . . . . 264

Figura 264 -Efeito de um choque de PM . . . . . . . . . . . . . . . . . 265

Figura 265 -Efeito de um choque de PM . . . . . . . . . . . . . . . . 265

Figura 266 -Efeito de um choque de PM . . . . . . . . . . . . . . 266

Figura 267 -Efeito de um choque de PM . . . . . . . . . . . . . 266 
Figura 268 -Efeito de um choque no mark-up de preços . . . . . . . . . . . . . . 267

Figura 269 -Efeito de um choque no mark-up de preços . . . . . . . . . . . . . 268

Figura 270 -Efeito de um choque no mark-up de preços . . . . . . . . . . . . . 268

Figura 271 -Efeito de um choque no mark-up de preços . . . . . . . . . . . . . . . 269

Figura 272 -Efeito de um choque no mark-up de preços . . . . . . . . . . . . . . 269

Figura 273 -Efeito de um choque no mark-up de preços . . . . . . . . . . . . . . . 270

Figura 274 -Efeito de um choque no mark-up de preços . . . . . . . . . . . . . . . 270

Figura 275 -Efeito de um choque na demanda por consumo . . . . . . . . . . . . 271

Figura 276 -Efeito de um choque na demanda por consumo . . . . . . . . . . . . 272

Figura 277 -Efeito de um choque na demanda por consumo . . . . . . . . . . . . 272

Figura 278 -Efeito de um choque na demanda por consumo . . . . . . . . . . . . 273

Figura 279 -Efeito de um choque na demanda por consumo . . . . . . . . . . . . 273

Figura 280 -Efeito de um choque na demanda por consumo . . . . . . . . . . . . 274

Figura 281 -Efeito de um choque na demanda por consumo . . . . . . . . . . . . . 274

Figura 282 -Priors And Posteriors . . . . . . . . . . . . . . . 275

Figura 283 -Priors And Posteriors _. . . . . . . . . . . . . . . . 276

Figura 284 -Priors And Posteriors . . . . . . . . . . . . . . . . . . 277

Figura 285 -Priors And Posteriors . . . . . . . . . . . . . . . 278

Figura 286 -Priors And Posteriors . . . . . . . . . . . . . . . . 279

Figura 287 -Priors And Posteriors _. . . . . . . . . . . . . . . . . . . 279

Figura 288 -Priors And Posteriors . . . . . . . . . . . . . . . . . . . 280

Figura 289 -Priors And Posteriors . . . . . . . . . . . . . . . . . . 281

Figura 290 -Priors And Posteriors . . . . . . . . . . . . . . . . 282

Figura 291 -Priors And Posteriors . . . . . . . . . . . . . . . . . 283

Figura 292 -Priors And Posteriors . . . . . . . . . . . . . . . . . . . 284

Figura 293 -Priors And Posteriors . . . . . . . . . . . . . . . . 285

Figura 294 -Priors And Posteriors . . . . . . . . . . . . . . 286

Figura 295 -Diagnósticos de Convergência Univariado . . . . . . . . . . . . . . . 287

Figura 296 -Diagnósticos de Convergência Univariado . . . . . . . . . . . . . . . . . 287

Figura 297 -Diagnósticos de Convergência Univariado . . . . . . . . . . . . . . . . 288

Figura 298 -Diagnósticos de Convergência Univariado . . . . . . . . . . . . . . . . . 288

Figura 299 -Diagnósticos de Convergência Univariado . . . . . . . . . . . . . . . . . 289

Figura 300 -Diagnósticos de Convergência Univariado . . . . . . . . . . . . . . . . 289

Figura 301 -Diagnósticos de Convergência Univariado . . . . . . . . . . . . . . . . . 290

Figura 302 -Diagnósticos de Convergência Univariado . . . . . . . . . . . . . . . . . 290

Figura 303 -Diagnósticos de Convergência Univariado . . . . . . . . . . . . . . . . . 291

Figura 304 -Diagnósticos de Convergência Univariado . . . . . . . . . . . . . . . . . 291

Figura 305 -Diagnósticos de Convergência Univariado . . . . . . . . . . . . . . . . . 292 
Figura 306 -Diagnósticos de Convergência Univariado . . . . . . . . . . . . . . . . 292

Figura 307 -Diagnósticos de Convergência Univariado . . . . . . . . . . . . . . . . 293

Figura 308 -Diagnósticos de Convergência Univariado . . . . . . . . . . . . . . . . 293

Figura 309 -Diagnósticos de Convergência Univariado . . . . . . . . . . . . . . . . . 294

Figura 310 -Diagnósticos de Convergência Univariado . . . . . . . . . . . . . . . . . 294

Figura 311 -Diagnósticos de Convergência Multivariado . . . . . . . . . . . . . . . . 295

Figura 312 -Diagnósticos de Convergência Univariado . . . . . . . . . . . . . . . . 296

Figura 313 -Diagnósticos de Convergência Univariado . . . . . . . . . . . . . . . . 296

Figura 314 -Diagnósticos de Convergência Univariado . . . . . . . . . . . . . . . . 297

Figura 315 -Diagnósticos de Convergência Univariado . . . . . . . . . . . . . . . . 297

Figura 316 -Diagnósticos de Convergência Univariado . . . . . . . . . . . . . . . . 298

Figura 317 -Diagnósticos de Convergência Univariado . . . . . . . . . . . . . . . . 298

Figura 318 -Diagnósticos de Convergência Univariado . . . . . . . . . . . . . . . . . 299

Figura 319 -Diagnósticos de Convergência Univariado . . . . . . . . . . . . . . . . 299

Figura 320 -Diagnósticos de Convergência Univariado . . . . . . . . . . . . . . . . 300

Figura 321 -Diagnósticos de Convergência Univariado . . . . . . . . . . . . . . . . . 300

Figura 322 -Diagnósticos de Convergência Univariado . . . . . . . . . . . . . . . . . 301

Figura 323 -Diagnósticos de Convergência Univariado . . . . . . . . . . . . . . . . 301

Figura 324 -Diagnósticos de Convergência Univariado . . . . . . . . . . . . . . . . . 302

Figura 325 -Diagnósticos de Convergência Univariado . . . . . . . . . . . . . . . . . 302

Figura 326 -Diagnósticos de Convergência Univariado . . . . . . . . . . . . . . 303

Figura 327 -Diagnósticos de Convergência Univariado . . . . . . . . . . . . . . . . . 303

Figura 328 -Diagnósticos de Convergência Univariado . . . . . . . . . . . . . . . . . 304

Figura 329 -Diagnósticos de Convergência Univariado . . . . . . . . . . . . . . . . . 304

Figura 330 -Diagnósticos de Convergência Univariado . . . . . . . . . . . . . . . . . 305

Figura 331 -Diagnósticos de Convergência Multivariado . . . . . . . . . . . . . 305

Figura 332 -Decomposição Histórica: Produto . . . . . . . . . . . . . . . . . . . . 307

Figura 333 -Decomposição Histórica: Inflação . . . . . . . . . . . . . . . . . 308

Figura 334 -Decomposição Histórica: Investimento em Capital . . . . . . . . . . . . 308

Figura 335 -Decomposição Histórica: Taxa Selic . . . . . . . . . . . . . . . . . . . . 309

Figura 336 -Decomposição Histórica: Produto . . . . . . . . . . . . . . . . . . . . . 309

Figura 337 -Decomposição Histórica: Inflação . . . . . . . . . . . . . . . . . . . 310

Figura 338 -Decomposição Histórica: Investimento em Capital . . . . . . . . . . . . 310

Figura 339 -Decomposição Histórica: Taxa Selic . . . . . . . . . . . . . . . . . . . . 311

Figura 340 -Decomposição Histórica: Produto . . . . . . . . . . . . . . . . . . . . . 311

Figura 341 -Decomposição Histórica: Inflação . . . . . . . . . . . . . . . . . . . . 312

Figura 342 -Decomposição Histórica: Investimento em Capital . . . . . . . . . . . . 312

Figura 343 -Decomposição Histórica: Taxa Selic . . . . . . . . . . . . . . . . . . . . 313 



\section{Lista de tabelas}





\section{Sumário}

I Introdução, Revisão de Literatura e Metodologia 27

1 Introdução . . . . . . . . . . . . . . . 29

2 Revisão de Literatura . . . . . . . . . . . . . . . . . . . . . . . 31

3 Estimação Bayesiana . . . . . . . . . . . . . . . . . 35

II Modelo Para Uma Economia Fechada 37

4 Descrição do Modelo . . . . . . . . . . . . . . . . . . . . . 39

4.1 Família Paciente . . . . . . . . . . . . . . . . . . . . . . . 39

4.2 Família Impaciente . . . . . . . . . . . . . . . . . . . 40

4.3 Mercado de Trabalho . . . . . . . . . . . . . . . . . . 42

4.3.1 Agregadores de Trabalho e Sindicatos . . . . . . . . . . . . . . 42

4.3 .2 Sindicatos: Família Paciente . . . . . . . . . . . . . . . . 43

4.3 .3 Sindicatos: Família Impaciente . . . . . . . . . . . . . . . . . 44

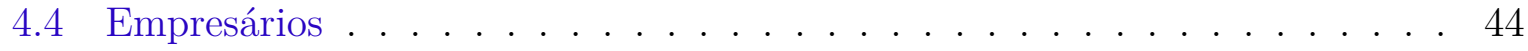

4.5 Demanda por Depósitos e Empréstimos . . . . . . . . . . . . . 47

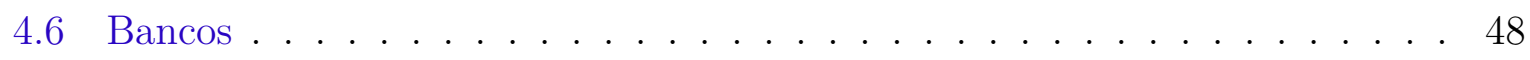

4.6.1 Departamento Atacadista . . . . . . . . . . . . . . . . 48

4.6.2 Departamento Varejista: Setor de Empréstimos _. . . . . . . . . 49

4.6.3 Departamento Varejista: Setor de Depósitos . . . . . . . . . . . 50

4.6 .4 Lucro do Banco . . . . . . . . . . . . . . . . . . . . 51

4.7 Produção de Capital . . . . . . . . . . . . . . . . . . . . . . 51

4.8 Produção de Imóveis $\ldots \ldots \ldots$

4.9 Produção do Bem Final . . . . . . . . . . . . . . . . . . 53

4.10 Política Monetária, Agregação e Equilíbrio . . . . . . . . . . . . . 53

4.10 .1 Monetary policy . . . . . . . . . . . . . . . . . . 53

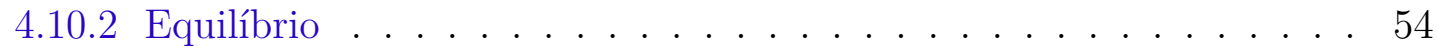

4.11 Equações de Steady State . . . . . . . . . . . . . . . . . 55

5 Base de dados e Calibração . . . . . . . . . . . . . . . 59

5.1 Calibração . . . . . . . . . . . . . . . . . . . 60

6 Resultados. . . . . . . . . . . . . . . . . 65

6.1 Funções de Resposta ao Impulso . . . . . . . . . . . . . . . . . . . . 69 
6.2 O papel das fricções financeiras . . . . . . . . . . . . . . . . . . . 70

6.2.1 Choque Tecnológico . . . . . . . . . . . . . . . . . 70

6.2.2 Choque de demanda no consumo . . . . . . . . . . . . . . . 72

6.2.3 Choque na demanda por imóveis . . . . . . . . . . . . . . 73

6.2.4 Choque de política monetária . . . . . . . . . . . . . . . . 74

6.2.5 Choque no Capital Bancário . . . . . . . . . . . . . . . . 75

6.3 O impacto de mudanças no parâmetro do custo de ajustamento no investimento em imóveis . . . . . . . . . . . . . . . . . . . . . 76

6.4 Conclusão . . . . . . . . . . . . . . . . . . . . . . . . 80

\section{Modelo Para Uma Economia Aberta 81}

7 Descrição do Modelo . . . . . . . . . . . . . . . . . . . . 83

7.1 Famílias, Sindicatos e Produção . . . . . . . . . . . . . . . . . . . 83

7.2 Empresários . . . . . . . . . . . . . . . . . . . . . 85

7.3 Bancos . . . . . . . . . . . . . . . . . . 86

7.3.1 Departamento Atacadista . . . . . . . . . . . . . . . 87

7.3.2 Departamento Varejista . . . . . . . . . . . . . . . . . . . 89

7.4 Agregação e Equilíbrio . . . . . . . . . . . . . . . . . . . . . . . . 89

7.4.1 Equilíbrio . . . . . . . . . . . . . . . . . 89

7.5 Steady State Equations . . . . . . . . . . . . . . . . . . . . 91

8 Base de dados e Calibração . . . . . . . . . . . . . . . . . . . . . 97

8.1 Calibração . . . . . . . . . . . . . . . . . . . . . . . . . 99

9 Resultados . . . . . . . . . . . . . . . . . . 103

9.1 Funções de Resposta ao Impulso . . . . . . . . . . . . . . . . . . . . . . . . 107

9.2 O papel das fricções financeiras . . . . . . . . . . . . . . . . . 108

9.2.1 Choque na Inflação Externa . . . . . . . . . . . . . . . . . . . 109

9.2 .2 Choque no Prêmio de Risco . . . . . . . . . . . . . . . . . . . . . . 110

9.2.3 Choque de política monetária . . . . . . . . . . . . . . . . 111

9.2.4 Choque no Capital Bancário . . . . . . . . . . . . . . . . . . . 113

9.2.5 Choque na Renda Externa . . . . . . . . . . . . . . . . . . . . . . . 114

9.3 O impacto de mudanças no parâmetro de custo de ajustamento do capital bancário . . . . . . . . . . . . . . . . . . . . . . 114

9.4 Comparação entre os modelos de economia fechada e aberta . . . . . . . 117

9.5 Conclusão . . . . . . . . . . . . . . . . . . . . . . . . . 120 
APÊNDICE A Funções de Resposta ao Impulso para Economia Fechada . . . 127

A.1 Efeito de um choque no debt-to-income . . . . . . . . . . . . . . . . . . 127

A.2 Choque no Mark-up de taxa de juros: Empréstimo Consignado . . . . . . . 131

A.3 Choque na demanda por imóveis . . . . . . . . . . . . . . . . . 135

A.4 Choque na oferta de imóveis . . . . . . . . . . . . . . . . . . . 139

A.5 Choque tecnológico . . . . . . . . . . . . . . . . . 143

A.6 Choque no Capital Bancário . . . . . . . . . . . . . . . . . . . . . 147

A.7 Choque no loan-to-value dos empresários . . . . . . . . . . . . . . . . . 151

A.8 Choque no loan-to-value das famílias impacientes . . . . . . . . . . . 155

A.9 Choque no Mark-up de salários . . . . . . . . . . . . . . . . . 159

A.10 Choque no Mark-up de taxa de juros: empréstimos com base em imóveis . 163

A.11 Choque no Mark-up de taxa de juros: empréstimos aos empresários . . . . 167

A.12 Choque no Mark-down de taxa de juros sobre depósitos . . . . . . . . . . . 171

A.13 Choque na Oferta de Capital Físico . . . . . . . . . . . . . . . 175

A.14 Choque de política monetária . . . . . . . . . . . . . . . . . . 179

A.15 Choque no Mark-up de preços . . . . . . . . . . . . . . . . . 183

A.16 Choque na demanda por consumo . . . . . . . . . . . . . . 187

APÊNDICE B Funções de Resposta ao Impulso para Economia Aberta . . . 191

B.1 Choque na inflação externa . . . . . . . . . . . . . . . . . . . . . . . . . 191

B.2 Choque no premio de risco . . . . . . . . . . . . . . . . . . 195

B.3 Choque no Capital Bancário . . . . . . . . . . . . . . . . . . . . . . . . . 199

B.4 Choque na taxa de juros externa . . . . . . . . . . . . . . . . 203

B.5 Choque no preço do insumo importado . . . . . . . . . . . . . . . . 207

B.6 Choque na renda externa . . . . . . . . . . . . . . . . . . . . . 211

B.7 Efeito de um choque no debt-to-income . . . . . . . . . . . . . . . . . 215

B.8 Choque no Mark-up de taxa de juros: Empréstimo Consignado . . . . . . . 219

B.9 Choque na demanda por imóveis . . . . . . . . . . . . . . . . . . 223

B.10 Choque na oferta de imóveis . . . . . . . . . . . . . . . . . . 227

B.11 Choque tecnológico . . . . . . . . . . . . . . . . . . . . 231

B.12 Choque no loan-to-value dos empresários . . . . . . . . . . . . . . . . 235

B.13 Choque no loan-to-value das famílias impacientes . . . . . . . . . . . . . . 239

B.14 Choque no Mark-up de salários . . . . . . . . . . . . . . . . . . . 243

B.15 Choque no Mark-up de taxa de juros: empréstimos com base em imóveis 247

B.16 Choque no Mark-up de taxa de juros: empréstimos aos empresários . . . . 251

B.17 Choque no Mark-down de taxa de juros sobre depósitos . . . . . . . . . . . 255

B.18 Choque na Oferta de Capital Físico . . . . . . . . . . . . . . . . . . . 259

B.19 Choque de política monetária . . . . . . . . . . . . . 263 
B.20 Choque no Mark-up de preços . . . . . . . . . . . . . . 267

B.21 Choque na demanda por consumo . . . . . . . . . . . . . . . 271

APÊNDICE C Priors e Posteriores . . . . . . . . . . . . . . 275

C.1 Economia Fechada . . . . . . . . . . . . . . . . . . . . . . 275

C.2 Economia Aberta . . . . . . . . . . . . . . . . . 280

APÊNDICE D Diagnósticos de Convergência . . . . . . . . . . . . . 287

D.1 Economia Fechada . . . . . . . . . . . . . . . . . . . . 287

D.2 Economia Aberta . . . . . . . . . . . . . . . . . 296

APÊNDICE E Decomposições Históricas . . . . . . . . . . . . . . 307

E.1 Economia Fechada . . . . . . . . . . . . . . . . . . . 307

E.2 Economia Aberta . . . . . . . . . . . . . . . . . . . . . 309

E.2.1 Choques Externos . . . . . . . . . . . . . . 311

Anexos

ANEXO A Script para o Cálculo de Steady-State . . . . . . . . . . . . 317

A.1 Economia Fechada . . . . . . . . . . . . . . . . . . . 317

A.1.1 Função . . . . . . . . . . . . . . . . . . . . 317

A.1.2 solve . . . . . . . . . . . . . . . . . . . . 320

A.2 Economia Aberta . . . . . . . . . . . . . . . . . . . . . . . . . . . . . . . . . . . . . . .

A.2.1 Função . . . . . . . . . . . . . . . . . . . . . . 325

A.2.2 solve . . . . . . . . . . . . . . . . . . . . . . . . . . . 329

ANEXO B Script para a Estimação dos Modelos de Economia Fechada e Aberta . . . . . . . . . . . . . . . . . . 335

B.1 Economia Fechada . . . . . . . . . . . . . . . . . . . . . 335

B.2 Economia Aberta . . . . . . . . . . . . . . . . . . . . . 348 


\section{Parte I}

\section{Introdução, Revisão de Literatura e Metodologia}





\section{Introdução}

A recente crise econômica pôs novamente em relevo a importância de fatores financeiros no comportamento do ciclo de negócios. Enquanto, em tempo normais, o setor financeiro pode minorar friç̧ões financeiras, em tempos de crise este setor pode aumentar a fragilidade do sistema econômico. Em uma economia sem fricção, os fundos emprestáveis fluiriam livremente em direção aos projetos com maior retorno ou para os indivíduos que dão mais valor. Modelos padrões do tipo DSGE incorporam essa característica assumindo agentes representativos que operam em mercados financeiros perfeitos, tendo, dessa forma, acesso ilimitado ao financiamento. Nestes modelos é válido o teorema de Modigliani e Miller, ou seja, a hipótese de mercados perfeitos, informação perfeita, distorções originadas do sistema tributário ou custos de falência. Ou seja, a alocação de fundos entre aos agentes da economia (se nas mãos dos agentes mais produtivos ou não) e a economia pode ser estudada sob a hipótese de agentes representativos. Se esses pressupostos são válidos, então é possível omitir o papel do mercado financeiro na alocação de fundos dentro do sistema econômico. Dessa forma, o pré-requisito para a introdução de restrições que limitem o acesso dos agentes econômicos ao financiamento é a ausência deste teorema. Um número crescente de estudos tem incorporado fatores financeiros em modelos DSGE tendo como objetivo analisar os efeitos de crises financeiras sobre o lado real da economia, ou propor políticas prudenciais para mitigar esses efeitos. O mecanismo pelo que um pequeno choque no sistema financeiro se propaga para o lado real, gerando flutuações de longa duração, é conhecido como acelerador financeiro. Segundo BRÁZDIK et all (2012), as características em mercados financeiros que podem dar origem ao mecanismo do acelerador financeiro podem ser classificados em quatro tipos: restrições de cash-flow, restrições de colateral, limites de financiamento externo e regulação financeira. A literatura em modelos DSGE nos últimos anos têm explorado largamente estes canais de criação do mecanismo acelerador, na tentativa de descobrir qual é o mais adequado para descrever os dados observados e para fazer recomendações de políticas macro prudencias. Entretanto, a maioria desses modelos são descritos como economias fechadas, ignorando a presença de choques potencialmente significativos, como choques no prêmio de risco sobre empréstimos externos ou na demanda por produtos exportados, para a descrição do comportamento de variáveis macroeconômicas como o produto e a inflação. O presente trabalho propõe uma extensão do modelo apresentado em Gerali et all (2010), a fim de torná-lo mais adequado à economia brasileira. Dessa forma são inseridas três modificações em relação ao modelo original: i. Como em Brzoza-Brzezina and Makarski (2009), é criada uma firma produtora de imóveis. Assim como a produtora de capital, esta firma utiliza bens finais e imóveis não depreciados como insumos no processo produtivo. 
O processo de produção é sujeito a custos de ajustamento no investimento em imóveis; ii. Em adição ao uso de imóveis como colateral na obtenção de empréstimos por parte da família impaciente, é permitido uma nova modalidade de empréstimos baseada no valor esperado da renda do salário da família para o próximo período. Esta modificação é uma tentativa de mimetizar o chamado crédito consignado, uma modalidade de concessão de crédito popular na economia brasileira, representando entre $54 \%$ e $70 \%$ da concessão total de crédito pessoal com recursos livres nos trimestres de março de 2011 a março de 2014, de acordo com dados do BACEN; iii. Por último, é suposta uma pequena economia aberta que se relaciona com a resto do mundo por meio da exportação de bens finais e importação de insumo, bem como por meio da captação de recursos externos através dos bancos. Dessa forma o modelo apresenta dois tipos de famílias - pacientes e impacientes - e empresários, que se relacionam com o setor bancário efetuando depósitos ou obtendo empréstimos. Os empréstimos obtidos por famílias impacientes e empresários são relacionados aos valores esperados para o período seguinte do estoque de imóveis e renda do salário, no caso das famílias impacientes, e do capital que possuem, no caso dos empresários. Os mercados de trabalho, produção de bens finais e bancário são caracterizados por competição monopolística - com rigidez de preços, salários e taxas de juros na forma de custos de ajustamento. No entanto, diferente do modelo original, neste trabalho os bancos podem captar recursos do resto do mundo, pagando a taxa de juros vigente no mercado internacional mais um prêmio de risco. As firmas de bens intermediários utilizam um insumo importado no processo produtivo e parte dessa produção é destinada para produtos voltados ao mercado externo. Por fim, além da firma produtora de capital, existe uma firma produtora de imóveis nessa economia. O restante do trabalho é dividido em três seções: a primeira apresenta uma breve revisão da literatura; a segunda apresenta o modelo proposto e a última descreve brevemente o procedimento de estimação que será utilizado. 


\section{Revisão de Literatura}

Bernanke, Gertler e Gilchrist (1999) atribuíram a presença do mecanismo do acelerador financeiro à presença de um prêmio de financiamento externo (originada de um canal de crédito, que limitaria a oferta de recursos externos). Neste tipo de economia os empresários tem um papel crucial para explicar como choques financeiros afetam o lado real da economia. Como em Bernanke e Gertler (1989), e posteriormente em Bernanke, Gertler e Gilchrist (1999) (BGG(1999)), os empresários são os agentes capazes de realizar os projetos de investimento na economia. Uma hipótese central nestes modelos é o de costly state verification proposto em Townsend (1979): dado que os empresários precisam captar poupança das famílias, e que o retorno de cada projeto é observado apenas pelo respectivo empresário, surge um intermediário financeiro que tem como função auditar aqueles empresários que não honraram com seus compromissos. Em modelos mais recentes é dada uma ênfase maior ao intermediário financeiro, que deixa de ser um "véu" para ter um papel próprio em como um choque financeiro se propaga. De forma geral, essas fricções criam um loop entre net worth e a capacidade de alavancagem do agente, amplificando um choque negativo. O efeito final é uma queda no estoque de capital, caracterizando uma crise na economia. A abordagem do acelerador financeiro baseada na restrição de colateral se dá a partir da imposição de um limite à quantia de fundos disponíveis para empréstimo. A disponibilidade de fundos é condicionada à quantia de ativos acumulados pelo devedor, vista como uma espécie de seguro para os credores. O mecanismo acelerador se dá de forma assimétrica de acordo com o tipo de choque e seu tamanho. Quando um empresário é atingido por um choque de produtividade positivo, ele pode responder a este evento aumentando seu consumo ou o tamanho de seu projeto de investimento. $\mathrm{Na}$ ocorrência de choque adverso, o empresário pode responder reduzindo seu consumo ou o uso de insumos. Entretanto, para um choque suficientemente grande, pode ser necessário reduzir o tamanho da planta produtiva. Kiyotaki e Moore (1997), utilizam o framework de Townsend (1979), como BGG (1999), e adotam uma restrição de colateral sob o endividamento devido a contratos incompletos. Nesta economia o produto é produzido por dois setores que se diferenciam pela sua produtividade. Uma segunda característica importante do modelo é que o ativo durável pode ser utilizado para a produção ou como colateral da dívida. Por fim, o capital agregado na economia é fixo, isto implica que investimento é irreversível. Dessa forma, o foco do trabalho está na liquidez de mercado do capital físico. Smets e Wouters (2002) criam um modelo DSGE com rigidez de preços e salários, custo de ajustamento na acumulação de capital e uma variável de capacidade de utilização do capital. Na tentativa de determinar os principais componentes do ciclo de negócios na zona do euro, estes autores estimam o modelo com técnicas bayesianas e concluem que 
choques na oferta de trabalho e de política monetária são as principais fontes de variação no produto, na inflação e na taxa de juros. Iacoviello (2005) estima um modelo novo keynesiano composto por famílias pacientes, impacientes e empresários, a fim de explorar o canal de deflação da dívida sobre a atividade econômica. Para tanto são introduzidas duas importantes características: uma restrição à capacidade de endividamento das famílias impacientes e empresários, relacionado ao valor de mercado dos imóveis e o desenho de contratos de dívidas em termos nominais. Como resultado, o modelo responde de forma assimétrica a choques de demanda e de oferta; choques de demanda são amplificados pelo canal de deflação da dívida, enquanto choques de oferta tem efeito estabilizador. BrzozaBrzezina e Makarski (2009) estimam um modelo para uma pequena economia aberta com dados trimestrais da Polônia, no período de 1997 a 2009. Este modelo se assemelha ao exposto em Gerali et. all (2010), a exceção de se tratar de uma economia aberta com um setor produtor de imóveis e rigidez de preços, salários e taxas de juros do tipo Calvo. De acordo com os autores, o modelo demonstra que a crise financeira de 2008 teve impacto substancial na economia polonesa, reduzindo em PNB desse país em cerca de 1\%. Em Gerali et all (2010), os autores analisam o papel das fricções financeiras no comportamento do produto e da inflação. Para isto é criado um modelo DSGE com competição monopolística nos mercados de bens, de trabalho e bancário; criando rigidez de preços, salários e taxas de juros. Como em Iacoviello (2005), esta economia é habitada por dois tipos de famílias (pacientes e impacientes) e por empresários. As famílias impacientes têm sua capacidade de endividamento relacionada ao valor de mercado esperado do estoque de imóveis que possuem e empresários possuem capacidade de endividamento limitado ao valor esperado do estoque de capital utilizado na produção do bem intermediário. Os resultados do modelo estimado indicam que choques originados do setor bancário resondem pela maior parte da contração da atividade econômica na zona do euro em 2008. Ainda, a rigidez nas taxas de juros parece ter um efeito atenuador dos choques de política monetária, embora a intermediação financeira propague os choques de oferta. Cavalcanti e Vereda (2010) apresentam um modelo DSGE para uma economia aberta inspirado no trabalho de Smets e Wouters (2002). Naquele modelo, porém, o setor de produção é dividido em três tipos de firmas: tradables, non tradables e as sujeitas a preços administrados. Outra característica distintiva, é a presença de um prêmio de risco na captação de empréstimos com o resto do mundo. Castro et all (2011) desenvolvem um modelo DSGE com algumas características que, de acordo com os autores, o torna mais adequado à economia brasileira. São elas: uma autoridade fiscal, perseguindo uma meta de superávit primário; a presença preços administrados; financiamento externo voltado para as exportações e uso de bens importados como insumos na produção. Em uma aplicação para o Brasil do modelo descrito em Gerali et all (2010), Cândido (2012) encontra resultados similares aos do modelo para a zona do euro; embora os dados brasileiros apresentem uma maior rigidez das taxas de juros. Isto, por sua vez, implica em um maior efeito atenuador dos choques 
de política monetária na economia brasileira. 



\section{Estimação Bayesiana}

A estatística bayesiana considera os parâmetros como variáveis aleatórias contendo determinada distribuição de probabilidade. Nesse sentido, o conceito de probabilidade está associado ao grau de conhecimento do pesquisador sobre o espaço de medida de determinado parâmetro. Dessa forma, os parâmetros são estimados atualizando-se o conhecimento apriorístico do pesquisador com base nas informações observadas a cada momento. O ponto de partida é o Teorema de Bayes, que permite o cálculo da distribuição dos parâmetros condicional aos dados (distribuição a posteriori) com base na distribuição incondicional dos parâmetros (distribuição a priori) e na função de verossimilhança:

$$
g(\theta / Y)=g(\theta) \frac{f(Y / \theta)}{f(Y)}
$$

onde $\theta$ é um conjunto definido num espaço de parâmetros $\Theta ; g(\theta)$ é a distribuição apriori; $f(Y / \theta)$ é a função de verossimilhança e a distribuição marginal dos dados é definida por

$$
f(Y)=\int_{\Theta} f(Y / \theta) g(\theta) d \theta
$$

Com base nessa equação, é possível combinar crenças iniciais sobre os valores dos parâmetros com a informação amostral incorporada à função de verossimilhança e obter um conjunto novo de crenças atualizadas. Fernandez-Villaverde (2010) classifica as ferramentas utilizadas para a implementação do método de estimação bayesiano em três grupos distintos compreendendo: (i) os métodos de solução dos modelos, (ii) os métodos de avaliação da sua função de verossimilhança e (iii) os métodos para explorar a função de verossimilhança na determinação da distribuição a posteriori. Em geral, os modelos DSGE não possuem soluções analíticas e as soluções são obtidas a partir de aproximações numéricas em torno do estado estacionário. Um procedimento muito comum consiste na log-linearização do modelo em torno do estado estacionário, formando um sistema linear de expectativas racionais. Uhlig (1995) comenta que o princípio da log-linearização consiste em fazer uma aproximação de Taylor em torno do estado estacionário do modelo, substituindo suas equações de equilíbrio por funções lineares nos log-desvios das variáveis. A aproximação é válida apenas para a dinâmica local em torno do estado estacionário, sendo inadequada para descrever o comportamento do modelo diante de grandes perturbações. Em modelos mais complexos, no entanto, utiliza-se normalmente um procedimento baseado em um método matemático bastante difundido na área computacional, o método das perturbações. Fernandez-Villaverde (2010) comenta que, em modelos DSGE, tal método 
permite encontrar uma solução aproximada a partir da expansão de Taylor da função política que descreve a dinâmica das variáveis do modelo em torno do estado estacionário. $\mathrm{O}$ procedimento de linearização consiste, portanto, em uma aproximação de primeira ordem dessa expansão de Taylor. A etapa seguinte consiste na avaliação da função de verossimilhança. Fernandez-Villaverde (2010) comenta que os métodos de estimação bayesianos são computacionalmente mais fáceis do que os de máxima verossimilhança, mesmo considerando seus algoritmos mais sofisticados. O autor argumenta que os modelos DSGE normalmente apresentam funções de verossimilhança complicadas e com muitas dimensões, repletas de máximos e mínimos locais e de regiões aproximadamente planas, o que se deve geralmente à escassez dos dados e à flexibilidade desses modelos em gerar comportamentos semelhantes para diferentes combinações de valores dos parâmetros. Desse modo, conclui que calcular a integral de uma função, procedimento utilizado na estimação bayesiana, seria bem mais simples do que maximizá-la. A partir de uma representação em espaço de estado da solução do modelo, Fernandez-Villaverde (2010) demonstra como a Teoria de Filtragem pode ser utilizada na avaliação da função de verossimilhança. Caso as equações de estado e de observação sejam lineares e os choques possuam distribuição Normal, é possível utilizar o filtro de Kalman para o cálculo da função de verossimilhança do modelo, com a restrição de que o número de séries observadas seja menor ou igual ao número de choques aleatórios, e assim se evitando que o modelo seja estocasticamente singular. No caso de modelos não lineares com choques não normalmente distribuídos, o processo de filtragem se torna mais complicado, pois a distribuição condicional dos estados não se encaixa em nenhuma família de distribuições conhecida. Nessa situação, Fernandez-Villaverde (2010) menciona que o filtro de partículas, um caso particular do método de Monte Carlo Sequencial, tem sido utilizado com bastante sucesso nesta etapa do procedimento. A última etapa consiste em explorar a função de verossimilhança, com o objetivo de encontrar a distribuição a posteriori dos parâmetros. Se a forma funcional da função de verossimilhança é conhecida e permite a conjugação com a distribuição a priori de cada parâmetro, a distribuição a posteriori pode ser obtida analiticamente. Caso contrário, utilizam-se técnicas computacionais com base em métodos de amostragem, como o método MCMC (Monte Carlo Markov Chain), para a obtenção de aproximações empíricas da distribuição. Em suma, por meio do algoritmo de Metropolis-Hastings, por exemplo, é possível construir uma cadeia de Markov cuja distribuição ergódica converge para a verdadeira distribuição de $g(\theta / Y)$, mesmo não se conhecendo de início sua forma funcional. Finalmente, a distribuição $g(\theta / Y)$ é aproximada pela distribuição empírica gerada por essa cadeia. 
Parte II

Modelo Para Uma Economia Fechada 



\section{Descrição do Modelo}

O modelo apresentado a seguir é baseado no trabalho proposto por Gerali et all (2010), o modelo econômico é expandido para incorporar um novo setor produtivo (produção de imóveis) e um segundo tipo de crédito disponível às famílias impacientes, como uma forma de adicionar empréstimos consignados ao modelo. Esta economia é habitada por famílias pacientes, impacientes e empresários. As famílias ofertam trabalho por meio de sindicatos, consomem, adquirem imóveis e serviços bancários; as famílias pacientes, por serem poupadoras, adquirem contratos de depósito com os diversos bancos existentes na economia, enquanto as famílias impacientes, por serem devedoras, adquirem contratos de empréstimo com os bancos. Os empresários derivam sua utilidade do consumo e da aquisição de imóveis e, assim como as famílias impacientes, obtêm empréstimos dos bancos. O setor produtivo da economia é formado pela produção de bens intermediários, por produtores de bens finais e pelas firmas produtoras de capital e de imóveis. A figura 1 apresenta a estrutura do modelo.

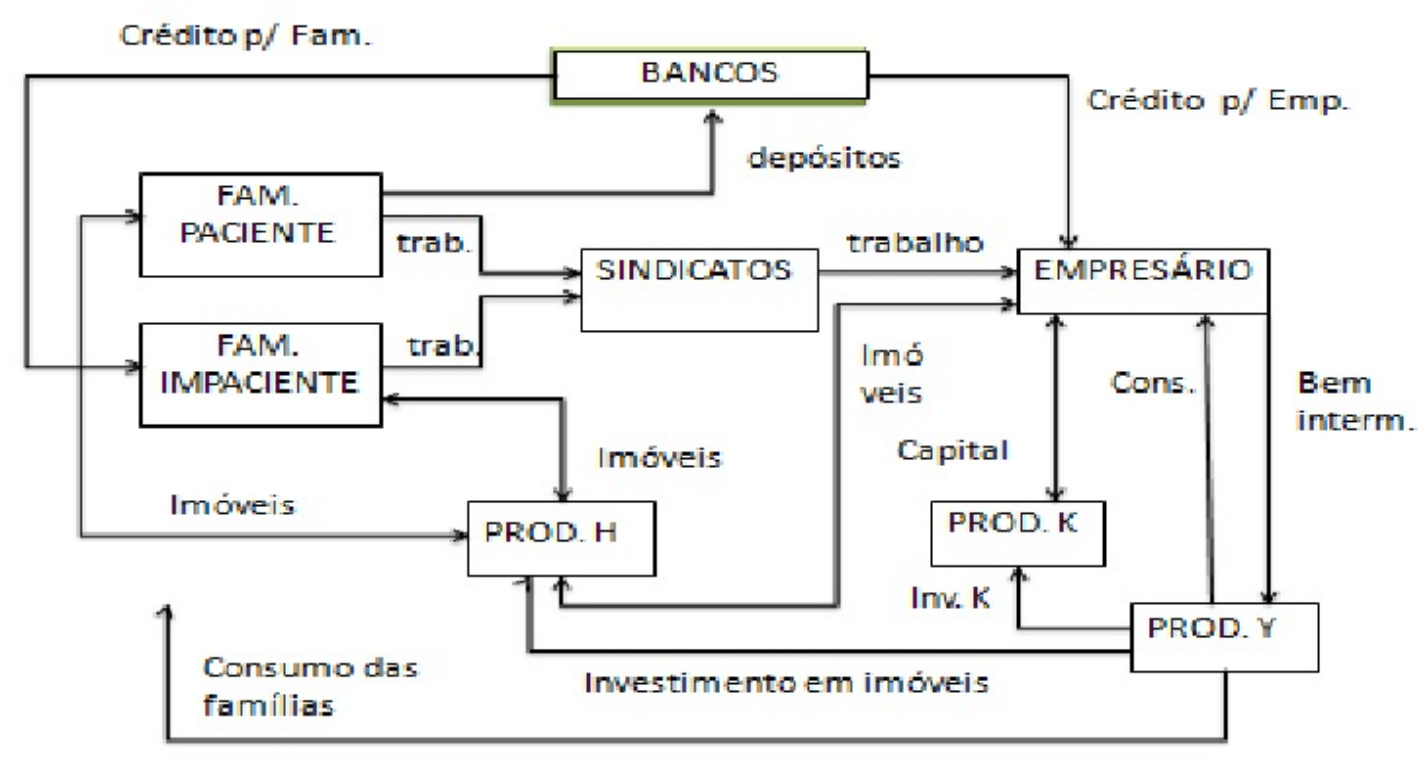

Figura 1: Panorama do Modelo

\subsection{Família Paciente}

Este agente consome bens finais, adquire imóveis, efetua depósitos nos bancos e oferta trabalho por meio de sindicatos. As preferências da família paciente dependem do 
consumo, da quantidade de imóveis que possuem e da quantidade de horas trabalhadas. Desta forma,sua função de utilidade é dada por:

$$
E_{0} \sum_{t=0}^{\infty}\left(\beta_{P}\right)^{t}\left\{\left(1-a^{P}\right) \varepsilon_{t}^{z} \log \left(c_{t}^{P}(i)-a^{P} c_{t-1}^{P}\right)+\varepsilon_{t}^{h} j^{h} \log \left(h_{t}^{P}(i)\right)-\frac{l_{t}^{P}(i)^{1+\phi}}{1+\phi}\right\}
$$

Em que: $c_{t}^{P}(i)$ é o consumo da família em $t ; c_{t-1}^{P}$ é o indice de consumo das famílias pacientes em $t-1 ; h_{t}^{P}(i)$ é o estoque de imóveis e $l_{t}^{P}(i)$ é a quantidade horas trabalhadas.

A formação de hábito no consumo é captada pelo parâmetro $a^{P}$ enquanto a desutilidade do trabalho é parametrizada por $\phi$. Em $t=0$ a família paciente avalia a utilidade esperada em $t>0$ descontada pela taxa $\beta_{P}$; este parâmetro é calibrado de tal forma a garantir que este tipo de família seja poupadora, inclusive em steady state. As preferências da família são afetadas por dois tipos de choque, um que afeta a utilidade do consumo $\varepsilon_{t}^{z}$ e outro que afeta demanda por imóveis $\varepsilon_{t}^{h}$, por fim, $j^{h}$ representa o peso dos imóveis na utilidade do agente. O problema de maximização dessas famílias está sujeito a seguinte restrição orçamentária (expressa em termos reais):

$$
c_{t}^{P}(i)+q_{t}^{h}\left(h_{t}^{P}(i)-\left(1-\delta^{h}\right) h_{t-1}^{P}(i)\right)+d_{t}^{P}(i) \leq w_{t}^{P} l_{t}^{P}(i)+\frac{\left(1+r_{t-1}^{d}\right)}{\pi_{t}} d_{t-1}^{P}(i)+t_{t}^{P}(i)
$$

As despesas, lado esquerdo da desigualdade, são compostas por gastos com consumo, com o acúmulo de imóveis (cujo preço em termos reais é dado por $q_{t}^{h}$ ) e gastos com novos contratos de depósito bancário $d_{t}^{P}$. Sua renda consiste em salário, $w_{t}^{P} l_{t}^{P}$, remuneração pelos depósitos efetuados no período anterior, $\frac{\left(1+r_{t-1}^{d}\right)}{\pi_{t}} d_{t-1}^{P}$, e transferências lump-sum. A escolha ótima de $c_{t}^{p}, h_{t}^{P}$ e $d_{t}^{P}$ produz as seguintes condição de primeira ordem:

$$
\begin{aligned}
\lambda_{t}^{P} & =\varepsilon_{t}^{z} \frac{1-a^{P}}{c_{t}^{P}-a^{P} c_{t-1}^{P}} \\
\lambda_{t}^{P} q_{t}^{h} & =\frac{\varepsilon_{t}^{h} j^{h}}{h_{t}^{P}}+\left(1-\delta^{h}\right) \beta_{P} E_{t}\left[\lambda_{t+1}^{P} q_{t+1}^{h}\right] \\
\lambda_{t}^{P} & =\beta_{P} E_{t}\left\{\lambda_{t+1}^{P} \frac{\left(1+r_{t}^{d}\right)}{\pi_{t+1}}\right\}
\end{aligned}
$$

Em que $\lambda_{t}^{P}$ é o multiplicador de lagrange da restrição orçamentária. A partir das condições de primeira ordem acima é possível derivar a equação de Euler e a demanda por imóveis da família paciente.

\subsection{Família Impaciente}

Assim como a família paciente, este agente consome bens finais, acumula imóveis e oferta trabalho. No entanto, sua participação no mercado bancário se dá por meio 
da captação de empréstimos ofertados pelos bancos, dessa forma, a família impaciente toma empréstimos com os diferentes intermediários financeiros existentes na economia. A família impaciente tem preferências semelhantes às da família paciente, no entanto, é suposto que sua taxa de desconto subjetiva é menor em comparação à paciente, de tal forma a garantir que ela seja uma tomadora de empréstimos, mesmo em steady state. Assim, sua função de utilidade é dada por:

$$
E_{0} \sum_{t=0}^{\infty}\left(\beta_{I}\right)^{t}\left\{\left(1-a^{I}\right) \varepsilon_{t}^{z} \log \left(c_{t}^{I}(i)-a^{I} c_{t-1}^{I}\right)+\varepsilon_{t}^{h} j^{h} \log \left(h_{t}^{I}(i)\right)-\frac{\left(l_{t}^{I}(i)\right)^{1+\phi}}{1+\phi}\right\}
$$

Em que $c_{t}^{I}(i)$ é o consumo corrente da família impaciente; $c_{t-1}^{I}$ é o índice de consumo de agente, em $t-1 ; h^{I}(i)$ é o seu estoque de imóveis e $l^{I}(i)$ representa a quantidade horas trabalhadas pela família impaciente.

A maximização da utilidade da família impaciente é sujeita à seguinte restrição orçamentária (em termos reais):

$c_{t}^{I}(i)+q_{t}^{h}\left(h_{t}^{I}(i)-\left(1-\delta^{h}\right) h_{t-1}^{I}(i)\right)+\frac{1+r_{t-1}^{b H}}{\pi_{t}} b_{t-1}^{I h}(i)+\frac{1+r_{t-1}^{b W}}{\pi_{t}} b_{t-1}^{I w} \leq w_{t}^{I} l_{t}^{I}(i)+b_{t}^{I h}(i)+b_{t}^{I w}(i)+t_{t}^{I}(i)$

Em que os gastos com consumo, aquisição de imóveis e pagamentos de empréstimos efetuados no período anterior $\left(\frac{\left(1+r_{t-1}^{b H}\right)}{\pi_{t}} b_{t-1}^{I h}\right.$ e $\left.\frac{\left(1+r_{t-1}^{b W}\right)}{\pi_{t}} b_{t-1}^{I w}\right)$ são financiados com salário, novos empréstimos $\left(\left(b_{t-1}^{I h}\right.\right.$ e $\left.\left.b_{t-1}^{I w}\right)\right)$ e transferências lump-sum. Cabe notar que a família impaciente tem acesso a dois tipos de empréstimos, um baseado no valor esperado do estoque de imóveis não depreciado (como em Gerali et al (2010)) e outro baseado no valor esperado de salário do agente (o empréstimo consignado). Entretanto, a capacidade da família impaciente em adquirir novos empréstimos, nas duas modalidades, é restrita pelas razões loan-to-value e debt-to-income:

$$
\begin{gathered}
\left(1+r_{t}^{b H}\right) b_{t}^{I h}(i) \leq m_{t}^{I h} E_{t}\left\{\left(1-\delta^{h}\right) q_{t+1}^{h} h_{t}^{I}(i) \pi_{t+1}\right\} \\
\left(1+r_{t}^{b W}\right) b_{t}^{I w}(i) \leq m_{t}^{I w} E_{t}\left\{w_{t+1}^{I} l_{t+1}^{I}(i) \pi_{t+1}\right\}
\end{gathered}
$$

Nas expressões (4.8 e 4.9) acima, $m_{t}^{I h}$ é a razão loan-to-value (LTV) das hipotecas, enquanto, $m_{t}^{I w}$ é a razão debt-to-income (DTI) do salário esperado; estas duas variáveis determinam a capacidade de alavancagem em cada tipo de empréstimo para a família impaciente. 
As CPOs da família impaciente, quando escolhe $c_{t}^{I}, h_{t}^{I} b_{t}^{I w}$, e $b_{t}^{I h}$, de forma ótima, condicionada a (4.7), (4.9) e (4.8), são dadas por ${ }^{1}$ :

$$
\begin{aligned}
\lambda_{t}^{I} & =\varepsilon_{t}^{z} \frac{1-a^{I}}{c_{t}^{I}-a^{I} c_{t-1}^{I}} \\
\lambda_{t}^{I} q_{t}^{h} & =\frac{\varepsilon_{t}^{h} j^{h}}{h_{t}^{I}}+\left(1-\delta^{h}\right) \beta_{I} E_{t}\left\{\lambda_{t+1}^{I} q_{t+1}^{h}+s_{t}^{I h} m_{t}^{I h} q_{t+1}^{h} \pi_{t+1}\right\} \\
\lambda_{t}^{I} & =s_{t}^{I h}\left(1+r_{t}^{b H}\right)+\beta_{I} E_{t}\left\{\lambda_{t+1}^{I} \frac{\left(1+r_{t}^{b H}\right)}{\pi_{t+1}}\right\} \\
\lambda_{t}^{I} & =s_{t}^{I w}\left(1+r_{t}^{b W}\right)+\beta_{I} E_{t}\left\{\lambda_{t+1}^{I} \frac{1+r_{t}^{b W}}{\pi_{t+1}}\right\}
\end{aligned}
$$

em que, $\lambda_{t}^{I}, s_{t}^{I h}$, and $s_{t}^{I w}$ são multiplicadores de lagrange das restrições, em termos reais. Ainda, é assumido que $m_{t}^{I h}$ e $m_{t}^{I w}$ são processos estocásticos $A R(1)$ :

$$
\begin{aligned}
& m_{t}^{I h}=\left(1-\rho_{m I h}\right) \bar{m}^{I h}+\rho_{m I h} m_{t-1}^{I h}+\eta_{t}^{m I h} \\
& m_{t}^{I w}=\left(1-\rho_{m I w}\right) \bar{m}^{I w}+\rho_{m I w} m_{t-1}^{I w}+\eta_{t}^{m I w}
\end{aligned}
$$

com $\eta_{t}^{m I h}$ e $\eta^{m I w}$ representando processos iid normalemte distribuidos com média zero e desvios-padrão iguais a $\sigma_{m I h}$ e $\sigma_{m I w}$. As condições de primeira ordem da família impaciente descrevem o comportamento do consumo, da demanda por imóveis, dos empréstimos consignados e com colateral em imóveis para este agente.

\subsection{Mercado de Trabalho}

O mercado de trabalho é formado por sindicatos e por agregadores de trabalho, estes agregadores demandam os diversos tipos de trabalho ofertado por sindicatos e os transformam em trabalho homogênio, a ser usado pelos empresários para a produção de bens intermediários. Os sindicatos do tipo $s \in\{P, I\}$, que ofertam a variedade de trabalho $m$,determinam o salário $W_{t}^{s}(m)$ a fim de maximizar seu benefício.

\subsubsection{Agregadores de Trabalho e Sindicatos}

Para cada tipo de família há um agregador de trabalho que demanda o tipo de trabalho $(s, m)$ com $m \in[0,1]$. Estes serviços de trabalho são então transformados em uma cesta de trabalho homogênea por meio de uma tecnologia de transformação CES. A cesta de trabalho do tipo $s$ é então vendida aos empresários em um mercado competitivo.

1 Supondo que todas as restrições são satisfeitas com igualdade. 
O objetivo do agregador é maximizar a quantidade de trabalho contratado, sujeito ao custo incorrido para o mesmo. O problema de otimização do agregador é expresso abaixo:

$$
\max _{l_{t}^{s}(m)} l_{t}^{s}=\left[\int_{0}^{1} l_{t}^{s}(m)^{\frac{\varepsilon^{l}-1}{\varepsilon^{l}}} d m\right]^{\frac{\varepsilon^{l}}{\varepsilon^{l}-1}}
$$

s.a.

$$
\int_{0}^{1} W_{t}^{s}(m) l_{t}^{s}(m) d m \leq \bar{E}_{t}
$$

para um dado nível de gastos $\bar{E}_{t}$. A solução do problema acima dá origem à função de demanda por cada tipo de trabalho $m$ dosindicato $s$ :

$$
l_{t}^{s}(m)=\left(\frac{W_{t}^{s}(m)}{W^{s}}\right)^{-\varepsilon^{l}} l_{t}^{s}
$$

Em que, $W_{t}^{s}=\left[\int_{0}^{1} W_{t}^{s}(m)^{1-\varepsilon^{l}} d m\right]^{\frac{1}{1-\varepsilon^{l}}}$ é o índice de salário para a família $s$, como função dos diferentes tipos de trabalho.

Nesta economia existem diferentes sindicatos para cada tipo de trabalhador e cada tipo de serviço ofertado. O trabalhador $i$ oferta os $m$ serviços diferenciados por meio do sindicato correspondente. O sindicato indexado por $(i, m)$ determina o salário nominal $W_{t}^{s}(m)$ a fim de maximizar o benefício esperado de uma variação no salário. O salário nominal é indexado à uma média entre a taxa de inflação passada e a inflação de steady state, dessa forma, quando a variação do salário definido pelo sindicato se desvia da média entre aquelas taxas de inflação, é pago um custo de ajustamento no salário.

\subsubsection{Sindicatos: Família Paciente}

Para as famílias pacientes, o benefício de um aumento no salário é dado pela possibilidade de um aumento no consumo, ou seja, a utilidade marginal do consumo. Assim, $W_{t}^{P}(m)$ é escolhido de tal forma que maximize

$E_{0} \sum_{t=0}^{\infty}\left(\beta_{P}\right)^{t}\left\{\lambda_{t}^{P}(i, m)\left[\frac{W_{t}^{P}(m)}{P_{t}} l_{t}^{P}(i, m)-\frac{\kappa_{w}}{2}\left(\frac{W_{t}^{P}(m)}{W_{t-1}^{P}(m)}-\pi_{t-1}^{\iota_{w}} \pi^{1-\iota_{w}}\right)^{2} \frac{W_{t}^{P}}{P_{t}}\right]-\frac{\left(l_{t}^{P}(i, m)\right)^{1+\phi}}{1+\phi}\right\}$,

sujeito à (4.15).

$\mathrm{Na}$ vizinhança do equilíbrio simétrico, a decisão ótima dos sindicatos do tipo $P$ é sumarizada pela curva de Phillips de salários para as famílias pacientes: 
$\kappa_{w}\left(\pi_{t}^{w^{P}}-\pi_{t-1}^{\iota_{w}} \pi^{1-\iota_{w}}\right) \pi_{t}^{w^{P}}=\beta_{P} E_{t}\left\{\frac{\lambda_{t+1}^{P}}{\lambda_{t}^{P}} \kappa_{w}\left(\pi_{t+1}^{w^{P}}-\pi_{t-1}^{\iota_{w}} \pi^{1-\iota_{w}}\right) \frac{\pi_{t+1}^{w^{P}}}{\pi_{t+1}^{2}}\right\}+\left(1-\varepsilon^{l}\right) l_{t}^{P}+\frac{\varepsilon^{l} l_{t}^{P^{1+\phi}}}{w_{t}^{P} \lambda_{t}^{P}}$

em que $w_{t}^{P}$ é o salário real dos pacientes e $\pi_{t}^{w^{P}}$ é a inflação do salário nominal, dada por

$$
\pi_{t}^{w^{P}}=\frac{w_{t}^{P}}{w_{t-1}^{P}} \pi_{t}
$$

\subsubsection{Sindicatos: Família Impaciente}

Os sindicatos das famílias impacientes, assim como os das famílias pacientes, têm como objetivo maximizar o benefício obtido ao otimizar o salário nominal de seus membros. No caso dos impacientes, entretanto, um aumento no salário permite não apenas um aumento nos gastos como também uma elevação na capacidade de endividamento da família. O problema deste sindicato é dado por:

$E_{0} \sum_{t=0}^{\infty}\left(\beta^{I}\right)^{t}\left\{\left(\lambda_{t}^{I}+s_{t}^{I w} m_{t}^{I w}\right)\left[\frac{W_{t}^{I}(m)}{P_{t}} l_{t}^{I}(i, m)-\frac{\kappa_{w}}{2}\left(\frac{W_{t}^{I}(m)}{W_{t-1}^{I}(m)}-\pi_{t-1}^{\iota_{w}} \pi^{1-\iota_{w}}\right)^{2} \frac{W_{t}^{I}}{P_{t}}\right]-\frac{l_{t}^{I}(i, m)^{1+\phi}}{1+\phi}\right\}$,

sujeito à (4.15).

Na vizinhança do equilíbrio simétrico, a decisão ótima dos sindicatos do tipo $I$ é sumarizada pela curva de Phillips de salários para as famílias impacientes::

$$
\begin{gathered}
\kappa_{w}\left(\pi_{t}^{w^{I}}-\pi_{t-1}^{\iota w} \pi^{1-\iota_{w}}\right) \pi_{t}^{w^{I}}= \\
=\beta_{I} E_{t}\left\{\frac{\lambda_{t+1}^{P}+m_{t+1}^{I w} s_{t+1}^{I w}}{\lambda_{t}^{P}+m_{t}^{I w} s_{t}^{I w}} \kappa_{w}\left(\pi_{t+1}^{w^{I}}-\pi_{t-1}^{\iota w} \pi^{1-\iota_{w}}\right) \frac{\pi_{t+1}^{w^{I}}}{\pi_{t+1}}\right\}+\left(1-\varepsilon^{l}\right) l_{t}^{I}+\frac{\varepsilon^{l} l_{t}^{I+\phi}}{w_{t}^{I}\left(\lambda_{t}^{I}+m_{t}^{I w} s_{t}^{I w}\right)}(4)
\end{gathered}
$$

Em que $w_{t}^{I}$ é o salário real dos impacientes e $\pi_{t}^{w^{I}}$ é a inflação de salários nominal, dada por:

$$
\pi_{t}^{w^{I}}=\frac{w_{t}^{I}}{w_{t-1}^{P}} \pi_{t}
$$

\subsection{Empresários}

Existe um número infinito de empresários contidos no intervalo $(0,1]$. Os empresários são responsáveis pela produção dos bens intermediários nesta economia, combinando trabalho dos dois tipos de família e capital para produzir um bem homogêneo. As preferências desses agentes dependem do consumo $c_{t}^{E}(i)$ e do estoque de imóveis $h_{t}^{E}(i)$; assim 
como no caso das famílias, existe formação de hábito no consumo dos empresários, parametrizado por $a^{E}$. A função de utilidade do empresário é expressa por:

$$
E_{0} \sum_{t=0}^{\infty}\left(\beta_{E}\right)^{t}\left\{\left(1-a^{E}\right) \varepsilon_{t}^{z} \log \left(c_{i}^{E}(i)-a^{E} c_{t-1}^{E}\right)+\varepsilon_{t}^{h} j^{h} \log \left(h_{t}^{E}(i)\right)\right\}
$$

É assumido que a taxa de desconto subjetiva dos empresários $\beta_{E}$ é estritamente menor que $\beta_{P}$, o que implica que - assim como as famílias impacientes - os empresários são tomadores de empréstimos. O problema do empresário é maximizar (4.18), sujeito às seguintes restrições:

$$
\begin{gathered}
c_{t}^{E}(i)+w_{t}^{P} l_{t}^{E, P}(i)+w_{t}^{I} l_{t}^{E, I}(i)+\frac{1+r_{t-1}^{b E}}{\pi_{t}} b_{t-1}^{E}(i)+q_{t}^{k} k_{t}^{E}(i)+q_{t}^{h} h_{t}^{E}(i)+ \\
+\psi\left(u_{t}(i)\right) k_{t-1}^{E}(i)=\frac{y_{t}^{E}(i)}{x_{t}}+b_{t}^{E}(i)+q_{t}^{k}(1-\delta) k_{t-1}^{E}(i)+q_{t}^{h}\left(1-\delta^{h}\right) h_{t-1}^{E}(i)(4.19) \\
y_{t}^{E}(i)=A_{t}^{E}\left[k_{t-1}^{E}(i) u_{t}(i)\right]^{\alpha}\left[l_{t}^{E}(i)\right]^{1-\alpha}(4.20) \\
l_{t}^{E}=\left(l_{t}^{E, P}\right)^{\mu}\left(l_{t}^{E, I}\right)^{1-\mu} \\
\left(1+r_{t}^{b E}\right) b_{t}^{E}(i) \leq m_{t}^{E} E_{t}\left\{q_{t+1}^{k} \pi_{t+1}(1-\delta) k_{t}^{E}(i)+q_{t+1}^{h} \pi_{t+1}\left(1-\delta^{h}\right) h_{t}^{E}\right\},
\end{gathered}
$$

Em que: $\delta$ é a taxa de depreciação do capital, $q_{t}^{k}$ é o seu preço em termos reais, $\psi\left(u_{t}\right) k_{t-1}^{E}$ é o custo real estabelecido para um dado nível de $u_{t}$ (taxa de ultilização do capital), com $\psi\left(u_{t}\right)=\xi_{1}\left(u_{t}-1\right)+\frac{\xi_{2}}{2}\left(u_{t}-1\right)^{2}, \frac{1}{x_{t}}=\frac{P_{t}^{w}}{P_{t}}$ o preço relativo do bem intermediário $y_{t}^{E}$ no mercado competitivo, $A_{t}^{E}$ é a produtividade total dos fatores, $l_{t}^{E}$ é a quantidade total de trabalho utilizad pelo empresário - que combina trabalho paciente e impaciente - sendo $\mu$ o share do trabalho paciente no trabalho total; por último, $m_{t}^{E}$ é a razão LTV dos empresários. Assim, como no caso das famílias impacientes, $m_{t}^{E}$ segue um processo estocástico:

$$
m_{t}^{E}=\left(1-\rho_{m E}\right) \bar{m}^{E}+\rho_{m E} m_{t-1}^{E}+\eta_{t}^{m E}
$$

Em que $\eta_{t}^{m E}$ é um processo iid normalmente distribuido com média zero e desvio-padrão igual a $\sigma_{m E}$.

De acordo com (4.19), os gastos com consumo, compra de imóveis, pagamentos de empréstimos e os demais incorridos no processo de produção - folha salarial, aquisição 
e utilização do capital- não podem ultrapassar as receitas decorrentes da venda do bem intermediário, de novos empréstimos e da venda dos estoques não depreciados e capital e imóveis. As restrições (4.20) e (4.21) descrevem o processo produtivo no setor, a primeira função nos diz como o trabalho e capital são combinados para a produção do bem e a segunda, como os dois tipos de trabalho são transformados na cesta de trabalho utilizada na função de produção Cobb-Douglas do bem intermediário. Segundo a última restrição (4.22), a captação de novos empréstimos deste agente é limitado pela sua riqueza, sendo $m_{t}^{E}$ a razão loan-to-value de define quanto da riqueza ${ }^{2}$ o banco aceita como colateral nos empréstimos.

Para maximizar a utilidade esperada (dada por 4.18), empresários escolhem de forma ótima o consumo $c_{t}^{E}(i)$, estoque de capital físico $k_{t}^{E}(i)$, estoque de imóveis $h_{t}^{E}(i)$, grau de utilização do capital $u_{t}(i)$, volume de empréstimos demandados $b_{t}^{E}(i)$ e a quantidade demandada de trabalho das famílias $l_{t}^{E, P}(i)$ e $l_{t}^{E, I}(i)$. As escolhas dos empresários são expressas pelas seguintes condições de primeira ordem:

$$
\begin{aligned}
\lambda_{t}^{E} & =\frac{1-a^{E}}{c_{t}^{E}-a^{E} c_{t-1}^{E}} \\
\lambda_{t}^{E} q_{t}^{k} & =E_{t}\left\{s_{t}^{E} m_{t}^{E} q_{t+1}^{k} \pi_{t+1}(1-\delta)+\beta_{E} \lambda_{t+1}^{E}\left[r_{t+1}^{k} u_{t+1}+q_{t+1}^{k}(1-\delta)-\psi\left(u_{t+1}\right)\right]\right\} \\
r_{t}^{k} & =\xi_{1}+\xi_{2}\left(u_{t}-1\right) \\
w_{t}^{P} & =(1-\alpha) \frac{y_{t}^{E}}{x_{t}} \frac{\mu}{l_{t}^{E, P}} \\
w_{t}^{I} & =(1-\alpha) \frac{y_{t}^{E}}{x_{t}} \frac{1-\mu}{l_{t}^{E, I}} \\
\lambda_{t}^{E} q_{t}^{h} & =\frac{\varepsilon_{t}^{h} j^{h}}{h_{t}^{E}}+\left(1-\delta^{h}\right) E_{t}\left\{q_{t+1}^{h}\left(s_{t}^{E} m_{t}^{E} \pi_{t+1}+\beta_{E} \lambda_{t}^{E}\right)\right\} \\
\lambda_{t}^{E} & =s_{t}^{E}\left(1+r_{t}^{b E}\right)+\beta_{E} E_{t}\left\{\lambda_{t+1}^{E} \frac{\left(1+r_{t}^{b E}\right)}{\pi_{t+1}}\right\}
\end{aligned}
$$

Em que $r_{t}^{k} \equiv \frac{1}{x_{t}} \alpha A_{t}^{E}\left(k_{t-1}^{E} u_{t}\right)^{\alpha-1}\left(l_{t}^{E}\right)^{1-\alpha}, \lambda_{t}^{E}$ e $s_{t}^{E}$ são os multiplicadores de Lagrange das restrições orçamentária e de endividamento. As condições de primeira ordem acima definem da demanda do empresário por consumo, imóveis, cesta de empréstimos e insumos para a produção.

$2 \quad$ No presente modelo, a riqueza dos empresários é composta pelo valor dos estoques de capital e de imóveis, em contraste com Gerali et all (2010) que admite apenas o capital no colateral destes agentes. Esta estratégia de modelagem amplifica o papel do setor imobiliário na construção do acelerador financeiro, ao afetar não somente a capacidade de endividamento das famílias impacientes como também dos empresários. 


\subsection{Demanda por Depósitos e Empréstimos}

As famílias e empresários firmam contratos de depósitos e empréstimos com os diversos bancos existentes na economia, criando cestas de produtos financeiros diferenciados ofertados pelos intermediários financeiros. Por hipótese, as cestas de serviços financeiros são do tipo CES com elasticidades iguais a $\varepsilon_{t}^{b I h}>1, \varepsilon_{t}^{b I w}>1, \varepsilon_{t}^{b E}>1$ e $\varepsilon_{t}^{d P}<-1$, para as famílias impacientes, empresários e famílias pacientes, respectivamente. A demanda da família impaciente $i$ pela quantia de empréstimos $b_{t}^{I n}$, com $n \in\{h, w\}$, é derivada a partir do seguinte problema de minimização do custo da dívida:

$$
\begin{aligned}
& \min _{\left\{b_{t}^{I n}(i, j)\right\}} \int_{0}^{1} r_{t}^{b N}(j) b_{t}^{I n}(i, j) d j \\
& \text { s.a. } \\
& {\left[\int_{0}^{1} b_{t}^{I n}(i, j)^{\frac{\varepsilon_{t}^{b N}-1}{\varepsilon_{t}^{b N}}} d j\right]^{\frac{\varepsilon_{t}^{b N}}{\varepsilon_{t}^{b N}-1}} \geq b_{t}^{I n}(i)}
\end{aligned}
$$

Agregando a CPO em $i$, a demanda pelo tipo de empréstimo $n$ no banco $j$ é dada por:

$$
b_{t}^{I n}(j)=\left(\frac{r_{t}^{b N}(j)}{r_{t}^{b N}}\right)^{-\varepsilon_{t}^{b N}} b_{t}^{I n}
$$

Em que $b_{t}^{I n}$ indica a demanda, em termos reais, das famílias pelo empréstimo e $r_{t}^{b N}$ é a taxa de juros média paga nestes empréstimos, definida como:

$$
r_{t}^{b N}=\left[\int_{0}^{1} r_{t}^{b N}(j)^{1-\varepsilon_{t}^{b N}} d j\right]^{\frac{1}{1-\varepsilon_{t}^{b N}}}
$$

De forma análoga, o problema de minimização dos empresários é:

$$
\begin{aligned}
& \min _{\left\{b_{t}^{E}(i, j)\right\}} \int_{0}^{1} r_{t}^{b E}(j) b_{t}^{E}(i, j) d j \\
& \text { s.a. } \\
& {\left[\int_{0}^{1} b_{t}^{E}(i, j)^{\frac{\varepsilon_{t}^{b E}-1}{\varepsilon_{t}^{b E}}} d j\right]^{\frac{\varepsilon_{t}^{b E}}{\varepsilon_{t}^{b E}-1}} \geq b_{t}^{E}(i)}
\end{aligned}
$$

Agregando as CPOs do problema:

$$
b_{t}^{E}(j)=\left(\frac{r_{t}^{b E}(j)}{r_{t}^{b E}}\right)^{-\varepsilon_{t}^{b E}} b_{t}^{E}
$$

Em que, $b_{t}^{E}$ indica a demanda, em termos reais, dos empresários pelo empréstimo, e $r_{t}^{b E}$ é a taxa de juros média paga nestes empréstimos, definida como:

$$
r_{t}^{b E}=\left[\int_{0}^{1} r_{t}^{b E}(j)^{1-\varepsilon_{t}^{b E}} d j\right]^{\frac{1}{1-\varepsilon_{t}^{b E}}}
$$


A demanda da família paciente $i$ por depósitos no banco $j$ é derivada a partir do problema de maximização do rendimento real destes, ou seja:

$$
\max _{\left\{d_{t}^{P}(i, j)\right\}} \int_{0}^{1} r_{t}^{d}(j) d_{t}^{P}(i, j) d j
$$

s.a.

$$
\left[\int_{0}^{1} d_{t}^{P}(i, j)^{\frac{\varepsilon_{t}^{d}-1}{\varepsilon_{t}^{d}}} d j\right]^{\frac{\varepsilon_{t}^{d}}{\varepsilon_{t}^{d}-1}} \leq d_{t}^{P}(i)
$$

Agregando as CPOs em $i$ :

$$
d_{t}^{P}(j)=\left(\frac{r_{t}^{d}(j)}{r_{t}^{d}}\right)^{-\varepsilon_{t}^{d}} d_{t},
$$

Em que, $d_{t}$ é o índice agregado de depósitos e $r_{t}^{d}$ é a taxa média de juros ganha pelas famílias pacientes ao efetuar esses depósitos, definida como:

$$
r_{t}^{d}=\left[\int_{0}^{1} r_{t}^{d}(j)^{1-\varepsilon_{t}^{d}} d j\right]^{\frac{1}{1-\varepsilon_{t}^{d}}} .
$$

\subsection{Bancos}

O setor bancário é composto por infinitos bancos indexados em $j \in[0,1]$, cada banco é composto por um departamento atacadista (tesouraria), respondável por gerenciar a posição de capital do banco, bem como transformar depósitos e recursos próprios em empréstimos; e um departamento varejista. Este departamento, por sua vez, é subdividido em um setor encarregado em captar os depósitos das famílias pacientes e um setor responsável por efetuar os empréstimos às famílias e empresários. Os bancos detêm poder nos mercados de depósitos e nos de empréstimos, embora o "mercado" formado entre a tesouraria e o departamento varejista seja competitivo.

\subsubsection{Departamento Atacadista}

A função do departamento atacadista é gerenciar o capital bancário de forma a manter a razão $\left(K_{t}^{b} / B_{t}\right)$ em seu nível ótimo $\left(\nu^{b}\right)$, para tanto, a tesouraria capta recuros do setor de depósitos e os transforma em empréstimos para o setor de empréstimos do departamento varejista. O gerenciamento do capital bancário é sujeito a custos de ajustamento quadrático, parametrizado por $\kappa_{k b}$, sempre que a razão $\left(K_{t}^{b} / B_{t}\right)$ se desvia de $\nu^{b}$. Dessa forma, o balanço patrimonial do banco é composto por $\left(D_{t}\right)$ e $\left(K_{t}^{b}\right)$, no lado dos passivos e $\left(B_{t}\right)$ no lado dos ativos, ou seja:

$$
B_{t}=D_{t}+K_{t}^{b}
$$


O capital bancário é acumulado por meio de lucros retidos, da seguinte forma:

$$
\pi_{t} K_{t}^{b}=\left(1-\delta^{b}\right) K_{t-1}^{b}(j)+J_{t-1}^{b, n}(j)
$$

Em que, $J_{t}^{b}$ é o lucro obtido no período anterior e $\delta^{b}$ mede os recursos usados no gerenciamento do capital bancário. A tesouraria tem como objetivo maximizar o valor presente do seu fluxo de caixa (em termos reais), escolhendo o volume de depósitos e empréstimos:

$$
\begin{aligned}
\max _{\left\{B_{t}, D_{t}\right\}} E_{0} \sum_{t=0}^{\infty} \Lambda_{0, t}^{P} \quad\{(1 & \left.+R_{t}^{b}\right) B_{t}-B_{t+1} \pi_{t+1}+D_{t+1} \pi_{t+1}-\left(1+R_{t}^{d}\right) D_{t} \\
& \left.+\left(K_{t+1}^{b} \pi_{t+1}-K_{t}^{b}\right)-\frac{\kappa_{k b}}{2}\left(\frac{K_{t}^{b}}{B_{t}}-\nu^{b}\right)^{2} K_{t}^{b}\right\}
\end{aligned}
$$

sujeito à (4.33), sendo $R_{t}^{d}$ e $R_{t}^{b}$ as taxas de depósito e empréstimo no mercado interbancário. Usando essa restrição para $t$ e $t+1$, o problema pode ser reescrito como:

$$
\max _{\left\{B_{t}, D_{t}\right\}} R_{t}^{b} B_{t}-R_{t}^{d} D_{t}-\frac{\kappa_{k b}}{2}\left(\frac{K_{t}^{b}}{B_{t}}-\nu^{b}\right)^{2} K_{t}^{b} .
$$

Combinando as CPOs do problema acima é possível derivar o spread entre as taxas de depósito e empréstimo, como função do grau de alavangem do banco $B_{t} / K_{t}^{d}$,

$$
R_{t}^{b}=R_{t}^{d}-\kappa_{k b}\left(\frac{K_{t}^{b}}{B_{t}}-\nu^{b}\right)\left(\frac{K_{t}^{b}}{B_{t}}\right)^{2} .
$$

É assumido que as bancos possuem acesso a empréstimos do banco central à taxa $r_{t}$. Assim é possível assumir que a taxa de depósitos no interbancário é igual à taxa de política monetária $\left(R_{t}^{d}=r_{t}\right)$.

$$
S_{t}^{W} \equiv R_{t}^{b}-r_{t}=-\kappa_{k b}\left(\frac{K_{t}^{b}}{B_{t}}-\nu^{b}\right)\left(\frac{K_{t}^{b}}{B_{t}}\right)^{2}
$$

Em que $S_{t}^{W}$ é o spread entre as taxas. O lado esquerdo de (4.36) representa o benefício margial de um aumento nos empréstimos e o lado direito o seu custo marginal.

\subsubsection{Departamento Varejista: Setor de Empréstimos}

O banco $j$ capta $B_{t}(j)$ da tesouraria à taxa $R_{t}^{b}$, tais empréstimos são, então, transformados sem qualquer custo em serviços financeiros diferenciados de empréstimos para empresários e famílias impacientes. Dados que os bancos competem monopolisticamente nos mercados de empréstimos, os bancos possuem poder de mercado na determinação das taxas de empréstimo, implicando em mark-ups entre essas taxas e a taxa de política 
monetária $r_{t}$ definida pela autoridade monetária. A determinação das taxas de empréstimo, entretanto, são sujeitas a custos de ajustamento, parametrizados por $\kappa_{b H}, \kappa_{b W}$ e $\kappa_{b E}$, associados a $\left\{r_{t}^{b W}(j),\left\{r_{t}^{b H}(j), r_{t}^{b E}(j)\right\}\right.$, respectivamente. O problema deste setor do departamento varejista é escolher as taxa de empréstimo que maximizam

$$
\begin{array}{r}
E_{0} \sum_{t=0}^{\infty} \Lambda_{0, t}^{P}\left\{r_{t}^{b H}(j) b_{t}^{I}(j)+r_{t}^{b W}(j) b_{t}^{I w}(j)+r_{t}^{b E}(j) b_{t}^{E}(j)-R_{t}^{b} B_{t}(j)\right. \\
-\frac{\kappa_{b H}}{2}\left(\frac{r_{t}^{b H}(j)}{r_{t-1}^{b H}(j)}-1\right)^{2} r_{t}^{b H} b_{t}^{I}-\frac{\kappa_{b W}}{2}\left(\frac{r_{t}^{b W}(j)}{r_{t-1}^{b W}(j)}-1\right)^{2} r_{t}^{b W} b_{t}^{I w} \\
\left.-\frac{\kappa_{b E}}{2}\left(\frac{r_{t}^{b E}(j)}{r_{t-1}^{b E}(j)}-1\right)^{2} r_{t}^{b E} b_{t}^{E}\right\}
\end{array}
$$

sujeito às demandas (4.30), (4.31) e $B_{t}(j)=b_{t}^{I h}(j)+b_{t}^{I w}(j)+b_{t}^{E}(j)$. As CPOs do problema (4.37), após impor o equilibrio simétrico, são expressas por

$$
\begin{array}{r}
1-\varepsilon_{t}^{b s}+\varepsilon_{t}^{b s} \frac{R_{t}^{b}}{r_{t}^{b s}}-\kappa_{b s}\left(\frac{r_{t}^{b s}}{r_{t-1}^{b s}}-1\right) \frac{r_{t}^{b s}}{r_{t-1}^{b s}} \\
+\beta_{P} E_{t}\left\{\frac{\lambda_{t+1}^{s}}{\lambda_{t}^{s}} \kappa_{b s}\left(\frac{r_{t+1}^{b s}}{r_{t}^{b s}}-1\right)\left(\frac{r_{t+1}^{b s}}{r_{t}^{b s}}\right)^{2} \frac{b_{t+1}^{s}}{b_{t}^{s}}\right\}=0,
\end{array}
$$

Em que $\lambda_{t}^{s}$ é o multiplicador de lagrange das restrições (4.7) e (4.19), para $s \in P, E$. As CPOs do problema (4.37) descrevem como as taxas cobradas dos tomadores de empréstimos são determinadas.

\subsubsection{Departamento Varejista: Setor de Depósitos}

O setor de depósitos do banco $j$ tem como função captar a poupança $\left(d_{t}^{P}(j)\right)$ das famílias pacientes e repassá-las à tesouraria a taxa $r_{t}$. Assim como nos mercados de empréstimos, o mercado de depósitos é caracterizado por concorrência monopolística entre os bancos, de tal forma que os bancos podem remunerar os depósitos $r_{t}^{d}(j)$ a uma taxa menor que a cobrada pelo Banco Central $r_{t}$. O problema do departamento de depósitos é expresso por:

$$
\max _{\left\{r_{t}^{d}(j)\right\}} E_{0} \sum_{t=0}^{\infty} \Lambda_{0, t}^{P}\left\{r_{t} D_{t}(j)-r_{t}^{d}(j) d_{t}^{P}(j)-\frac{\kappa_{d}}{2}\left(\frac{r_{t}^{d}(j)}{r_{t-1}^{d}(j)}-1\right)^{2} r_{t}^{d} d_{t}\right\}
$$

sujeito à (4.32) and $D_{t}(j)=d_{t}^{P}(j)$. Após impor o equilíbrio simétrico, a CPO do problema se torna 


$$
\begin{array}{r}
-1+\varepsilon_{t}^{d}-\varepsilon_{t}^{b s} \frac{r_{t}}{r_{t}^{d}}-\kappa_{d}\left(\frac{r_{t}^{d}}{r_{t-1}^{d}}-1\right) \frac{r_{t}^{d}}{r_{t-1}^{d}} \\
+\beta_{P} E_{t}\left\{\frac{\lambda_{t+1}^{P}}{\lambda_{t}^{P}} \kappa_{d}\left(\frac{r_{t+1}^{d}}{r_{t}^{d}}-1\right)\left(\frac{r_{t+1}^{d}}{r_{t}^{d}}\right)^{2} \frac{d_{t+1}}{d_{t}}\right\}=0 .
\end{array}
$$

Assim como no caso do departamento de empréstimos, a CPO do problema (4.39) descreve o comportamento da taxa de juros paga aos depositantes.

\subsubsection{Lucro do Banco}

O lucro do banco é calculado pela soma dos ganhos líquidos em cada um dos departamentos que o compõe. Excluindo transações intrabancárias:

$$
\begin{aligned}
j_{t}^{b}= & r_{t}^{b H} b_{t}^{I h}+r_{t}^{b W} b_{t}^{I w}+r_{t}^{b E} b_{t}^{E}-r_{t}^{d} d_{t} \\
& -\frac{\kappa_{k b}}{2}\left(\frac{K_{t}^{b}}{B_{t}}-\nu^{b}\right)^{2}-K_{t}^{b}-A d j_{t}^{B}
\end{aligned}
$$

Em que $A d j_{t}^{B}$ representa os custos de ajustamento das taxas de juros sobre depósitos e empréstimos. A hipótese de requerimento de capital tem um papel importante na determinação da oferta de crédito no modelo, uma vez que estabelece uma ligação entre os lados real e financeiro da economia. Quando as condições macroeconomicas se deterioram, o lucro do banco, e assim capital bancário, pode ser afetado de forma adversa. O banco pode responder a esse panorama contraindo o acesso ao crédito, o que tornaria a deterioração inicial ainda mais profunda.

\subsection{Produção de Capital}

Como em Gerali et all (2010), a firma produtora de capital opera em um mercado competitivo vendendo o estoque de capital físico novo para os empresários e comprando o estoque antigo não depreciado dos mesmos. Capital novo e antigo são transacionados ao mesmo preço $P_{t}^{k}$ neste mercado. A firma adquire bens de investimento da produtora de bens finais e combina com estoque de capital velho para produzir capital novo de acordo com:

$$
k_{t}=(1-\delta) k_{t-1}+\left[1-\frac{\kappa_{i k}}{2}\left(\frac{i_{t}^{k} \varepsilon_{t}^{q k}}{i_{t-1}^{k}}-1\right)^{2}\right] i_{t}^{k}
$$


Em que $\kappa_{i k}$ é o parâmetro do custo de ajustamento do investimento $i^{k}$ no setor de produção de capital e $\varepsilon_{t}^{q k}$ é o choque de eficiência no investimento. O problema dessa firma é maximizar o valor presente do seu lucro ${ }^{3}$.

$$
\max _{k_{t}, i_{t}^{k}} E_{0} \sum_{t=0}^{\infty} \Lambda_{0, t}^{E}\left\{q_{t}^{k}\left[k_{t}-(1-\delta) k_{t-1}\right]-i_{t}^{k}\right\}
$$

sujeito à (4.42). Em que $q_{t}^{k} \equiv \frac{P_{t}^{k}}{P_{t}}$ é o preço do capital em termos reais. O resultado do problema anterior define a equação de precificação do capital físico.

$$
\begin{aligned}
& 1=q_{t}^{k}\left[1-\frac{\kappa_{i k}}{2}\left(\frac{i_{t}^{k} \varepsilon_{t}^{q k}}{i_{t-1}^{k}}-1\right)^{2}-\kappa_{i k}\left(\frac{i_{t}^{k} \varepsilon_{t}^{q k}}{i_{t-1}^{k}}-1\right) \frac{i_{t}^{k} \varepsilon_{t}^{q k}}{i_{t-1}^{k}}\right] \\
& +\beta_{E} E_{t}\left\{\frac{\lambda_{t+1}^{E}}{\lambda_{t}^{E}} q_{t+1}^{k} \varepsilon_{t+1}^{q k} \kappa_{i k}\left(\frac{i_{t+1}^{k} \varepsilon_{t+1}^{q k}}{i_{t}^{k}}-1\right)\left(\frac{i_{t+1}^{k}}{i_{t}^{k}}\right)^{2}\right\}
\end{aligned}
$$

\subsection{Produção de Imóveis}

O setor produtor de imóveis é modelado de forma análoga ao setor de capital físico; para a produção de novos imóveis a firma utiliza bens de investimento $i^{h}$ e estoques não depreciados de imóveis velhos adquiridos das famílias e empresários, o investimento no setor é sujeito a um custo de ajustamento quarático, parametrizado por $\kappa_{i h}$. A equação de evolução do estoque de imóveis é dada por:

$$
h_{t}=\left(1-\delta^{h}\right) h_{t-1}+\left[1-\frac{\kappa_{i h}}{2}\left(\frac{i_{t}^{h} \varepsilon_{t}^{q h}}{i_{t-1}^{h}}-1\right)^{2}\right] i_{t}^{h}
$$

Em que $\varepsilon_{t}^{q h}$ é um choque de eficiência no investimento em imóveis e $q_{t}^{h} \equiv \frac{P_{t}^{h}}{P_{t}}$ é o preço dos imóveis em termos reais. Então o problema do produtor de imóveis é ${ }^{4}$ :

$$
\max _{h_{t}, i_{t}^{h}} E_{0} \sum_{t=0}^{\infty} \Lambda_{0, t}^{E}\left\{q_{t}^{h}\left[h_{t}-\left(1-\delta^{h}\right) h_{t-1}\right]-i_{t}^{h}\right\}
$$

sujeito à (4.45). A CPO do problema implica que $q_{t}^{h}$, é dado por,

$$
1=q_{t}^{h}\left[1-\frac{\kappa_{i h}}{2}\left(\frac{i_{t}^{h} \varepsilon_{t}^{q h}}{i_{t-1}^{h}}-1\right)^{2}-\kappa_{i h}\left(\frac{i_{t}^{h} \varepsilon_{t}^{q h}}{i_{t-1}^{h}}-1\right) \frac{i_{t}^{h} \varepsilon_{t}^{q h}}{i_{t-1}^{h}}\right]
$$

3 Supondo que os empresários são os donos da firma produtora de capital, a taxa de desconto aplicada ao lucro da firma depende as preferências daquele agente

4 Assim como no caso dos produtores de capital, a firma produtora de imóveis é propriedade dos empresários 


$$
+\beta_{E} E_{t}\left\{\frac{\lambda_{t+1}^{E}}{\lambda_{t}^{E}} q_{t+1}^{h} \varepsilon_{t+1}^{q h} \kappa_{i h}\left(\frac{i_{t+1}^{h} \varepsilon_{t+1}^{q h}}{i_{t}^{h}}-1\right)\left(\frac{i_{t+1}^{h}}{i_{t}^{h}}\right)^{2}\right\}
$$

\subsection{Produção do Bem Final}

As firmas varejistas produzem bens finais comprando bens intermediários dos empresários e os diferenciando sem custo. Em seguida esses bens finais são vendidos em um mercado caracterizado por competição monopolística, ao preço $P_{t}(j)$. Da mesma forma que os salários, os preços são indexados por uma combinação entre a taxa de inflação passada e a de steady state, a rigidez nominal é determinada por um custo de ajustamento quadrático, cujo valor é definido pelo parâmetro $\kappa_{p}$. Os bens finais são então agregados em uma cesta homogênia, utilizada para consumo e investimento. O problema do produtor de bens finais é dado por:

$$
\max _{P_{t}(j)} E_{0} \sum_{t=0}^{\infty} \Lambda_{0, t}\left\{P_{t}(j) y_{t}(j)-P_{t}^{W} y_{t}(j)-\frac{\kappa_{p}}{2}\left(\frac{P_{t}(j)}{P_{t-1}(j)}-\pi_{t-1}^{\iota_{p}} \pi^{1-\iota_{p}}\right)^{2} P_{t} y_{t}\right\}
$$

sujeito à

$$
y_{t}(j)=\left(\frac{P_{t}(j)}{P_{t}}\right)^{-\varepsilon_{t}^{y}} y_{t}
$$

Na vizinhança do equilíbrio simétrico, a condição de primeira ordem dá origem à curva de Phillips de preços não linear

$$
\begin{aligned}
& 1-\varepsilon_{t}^{y}+\frac{\varepsilon_{t}^{y}}{x_{t}}-\kappa_{p}\left(\pi_{t}-\pi_{t-1}^{\iota_{p}} \pi^{1-\iota_{p}}\right) \pi_{t}+ \\
& \beta_{P} E_{t}\left\{\frac{\lambda_{t+1}^{P}}{\lambda_{t}^{P}} \kappa_{P}\left(\pi_{t+1}-\pi_{t}^{\iota_{p}} \pi^{1-\iota_{p}}\right) \pi_{t+1} \frac{y_{t+1}}{y_{t}}\right\}=0 .
\end{aligned}
$$

O lucro das firmas nesse setor é então dado por:

$$
J_{t}^{y}=\left\{1-\frac{1}{x_{t}}-\frac{\kappa_{p}}{2}\left(\pi_{t}-\pi_{t-1}^{\iota_{p}} \pi^{1-\iota_{p}}\right)^{2}\right\} y_{t}
$$

\subsection{Política Monetária, Agregação e Equilíbrio}

\subsubsection{Monetary policy}

Como em Gerali et all (2010), a autoridade monetária determina a taxa de política monetária $r_{t}$, de acordo com a seguite regra de Taylor: 


$$
\left(1+r_{t}\right)=(1+r)^{1-\phi_{R}}\left(1+r_{t-1}\right)^{\phi_{R}}\left(\frac{\pi_{t}}{\pi}\right)^{\phi_{\pi}\left(1-\phi_{R}\right)}\left(\frac{Y_{t}}{Y_{t-1}}\right)^{\phi_{y}\left(1-\phi_{R}\right)} \varepsilon_{t}^{r}
$$

Em que $\phi_{\pi}$ e $\phi_{y}$ são os pesos dados à estabilização da inflação e do produto, respectivamente, $r$ é a taxa nominal de juros em steady state $\phi_{R}$ é o termo de suavização da taxa política e $\varepsilon_{t}^{R}$ é um choque de política monetária, com média zero e desvio-padrão $\sigma_{r}$.

\subsubsection{Equilíbrio}

O equilíbrio do modelo é obtido quando, para um dado sistema de preços, processos exógenos e política econômica (4.52) são satifeitos:

- as restrições orçamentárias (4.2), (4.7) e (4.19) das famílias e empresários;

- as restrições de crédito (4.8), (4.9) (4.22) das famílias impacientes e empresários;

- as demandas por trabalho (4.15) e por endividamento (4.31) dos empresários, por endividamento (4.30) das famílias impacientes, por depositos (4.32) das famílias pacientes e por bens finais (4.49) e

- as equações de acumulação de capital físico, bancário e de imóveis (4.42), (4.34) e (4.45), respectivamente.

E dadas as equaões acima, as CPOS resolvem os problemas:

- das famílias pacientes (4.1), impacientes (4.6) e empresários (4.18);

- dos produtores varejistas (4.48), de imóveis (4.46) e capital (4.43);

- dos bancos, nos departamentos atacadista (4.35) and de empréstimos (4.37) e depositos (4.39).

Markets clearing:

1. Mercado de Bens

$$
y_{t}=c_{t}+i_{t}^{k}+i_{t}^{h}
$$

Em que, $c_{t} \equiv c_{t}^{P}+c_{t}^{I}+c_{t}^{E}$ é o consumo agregado

2. Mercado de imóveis

$$
h_{t}=h_{t}^{P}+h_{t}^{I}+h_{t}^{E}
$$

3. Mercado de trabalho

$$
l_{t}^{P E}=l_{t}^{P} \quad \mathrm{e} \quad+l_{t}^{I E}=l_{t}^{I}
$$


4. Mercado de ativos

$$
B_{t}=b_{t}^{I h}+b_{t}^{I w}+b_{t}^{E} \quad \text { e } \quad D_{t}=d_{t}^{P}
$$

5. Produto

$$
Y_{t}=y_{t}
$$

\subsection{Equações de Steady State}

As equações listadas abaixo descrevem o steady state do modelo:

$$
\begin{gathered}
q^{k}=1 \\
q^{h}=1 \\
x=\frac{\varepsilon^{y}}{\varepsilon^{y}-1} \\
u=1 \\
\pi^{q h}=1 \\
\pi^{w p}=\pi \\
\varepsilon^{z}=1 \\
A^{E}=1 \\
\pi^{w I}=\pi
\end{gathered}
$$




$$
\begin{aligned}
& \varepsilon^{q k}=1 \\
& \varepsilon^{r}=1 \\
& m^{I h}=\bar{m}^{I h} \\
& m^{I w}=\bar{m}^{I w} \\
& m^{E}=\bar{m}^{E} \\
& r^{d}=\frac{\pi}{\beta^{p}}-1 \\
& r=\frac{\varepsilon^{d}-1}{\varepsilon^{d}} r^{d} \\
& r^{b H}=\frac{\varepsilon^{b I h}}{\varepsilon^{b I h}-1} r \\
& r^{b W}=\frac{\varepsilon^{b I w}}{\varepsilon^{b I w}-1} r \\
& r^{b E}=\frac{\varepsilon^{b E}}{\varepsilon^{b E}-1} r \\
& R^{b}=r \\
& \lambda^{P}=\frac{1}{c^{P}} \\
& \lambda^{I}=\frac{1}{c^{I}} \\
& \lambda^{E}=\frac{1}{c^{E}} \\
& s^{I h}=\left(\frac{1}{1+r^{b H}}-\frac{\beta^{I}}{\pi}\right) \lambda^{I}
\end{aligned}
$$




$$
\begin{aligned}
& s^{I w}=\left(\frac{1}{1+r^{b W}}-\frac{\beta^{I}}{\pi}\right) \lambda^{I} \\
& b^{I h}=\frac{1}{1+r^{b H}} m^{I h}\left\{\left(1-\delta^{h}\right) q^{h} h^{I} \pi\right\} \\
& b^{I w}=\frac{1}{1+r^{b W}} m^{I w}\left\{w^{I} l^{I} \pi\right\} \\
& b^{E}=\frac{1}{1+r^{E}} m^{E}\left\{(1-\delta) q^{k} k \pi+\left(1-\delta^{h}\right) q^{h} h^{E} \pi\right\} \\
& h^{p}=\frac{j^{h} \varepsilon^{h}}{\lambda^{p} q^{h}\left(1-\left(1-\delta^{h}\right) \beta^{P}\right)} \\
& h^{I}=\frac{j^{h} \varepsilon^{h}}{\lambda^{I} q^{h}\left(1-\left(1-\delta^{h}\right)\left(s^{I h} m^{I h} \pi+\beta^{I} \lambda^{I}\right)\right)} \\
& h^{E}=\frac{j^{h} \varepsilon^{h}}{\lambda^{E} q^{h}\left(1-\left(1-\delta^{h}\right)\left(s^{E} m^{E} \pi+\beta^{E} \lambda^{E}\right)\right)} \\
& w^{P}=\frac{\varepsilon^{l}}{\varepsilon^{l}-1} \frac{\left(l^{P}\right)^{\phi}}{\lambda^{P}} \\
& w^{I}=\frac{\varepsilon^{l}}{\varepsilon^{l}-1} \frac{\left(l^{I}\right)^{\phi}}{\lambda^{I}+s^{I w} m^{I w}} \\
& w^{P}=\frac{\mu(1-\alpha)}{x} \frac{y^{E}}{l^{P}} \\
& w^{I}=\frac{(1-\mu)(1-\alpha)}{x} \frac{y^{E}}{l^{I}} \\
& \lambda^{E} q^{k}=s^{E} m^{E} q^{k} \pi(1-\delta)+\beta^{E} \lambda^{E}\left[r^{k} u+q^{k}(1-\delta)\right] \\
& r^{k}=\frac{1}{x}^{E}(u k)^{\alpha-1}\left(l^{P}\right)^{\mu(1-\alpha)}\left(l^{I}\right)^{(1-\mu)(1-\alpha)} \\
& r^{k}=\xi_{1} \\
& i^{k}=\delta k
\end{aligned}
$$




$$
\begin{aligned}
& i^{h}=\delta^{h} h \\
& K^{b}=\frac{J^{b}}{\pi-1+\delta^{b}} \\
& J^{y}=\left\{1-\frac{1}{x}\right\} y \\
& J^{b}=r^{b H} b^{I h}+r^{b W} b^{I w}+r^{E} b^{E}-r^{d} d^{P} \\
& h=h^{P}+h^{I}+h^{E} \\
& D=d^{P}=b^{I h}+b^{I w}+b^{E}-K^{b} \\
& c^{p}+q^{h} \delta^{h} h^{P}=w^{P} l^{P}+\left(\frac{1+r^{d}}{\pi}-1\right) d^{P}+J^{y} \\
& c^{I}+q^{h} \delta^{h} h^{I}=w^{I} l^{I}-\left(\frac{1+r^{b H}}{\pi}-1\right) b^{I h}-\left(\frac{1+r^{b W}}{\pi}-1\right) b^{I w} \\
& c^{E}+w^{P} l^{P}+w^{I} l^{I}+e^{r} p^{Q} Q+q^{k} \delta k+q^{h} \delta^{h} h^{E}=\frac{y^{E}}{x}-\left(\frac{1+r^{b E}}{\pi}-1\right) b^{E} \\
& y^{E}=A^{E}(u k)^{\alpha}\left(l^{P}\right)^{\mu(1-\alpha)}\left(l^{I}\right)^{(1-\mu)(1-\alpha)} \\
& y=c^{P}+c^{I}+c^{E}+i^{k}+i^{h} \\
& Y=y
\end{aligned}
$$




\section{Base de dados e Calibração}

A base de dados usada para a estimação do modelo é composta por 32 observações com periodicidade trimestral, compreendidas entre o primeiro trimestre de 2007 e o último trimestre de 2014. As séries foram obtidas por meio dos sites do Banco Central (www.bcb.gov.br), Ibge (www.ibge.gov.br), Ipeadata (www.ipeadata.gov.br) e FGV (portalibre.fgv.br). Abaixo estão descritas as séries utilizadas:

1. Taxa de juros crédito pessoal consignado: Taxa média de juros das novas operações de crédito livre contratadas no período de referência. Taxa ponderada pelo valor das concessões. Não inclui operações referenciadas em taxas regulamentadas, operações vinculadas a recursos do Banco Nacional de Desenvolvimento Econômico e Social (BNDES) ou quaisquer outras lastreadas em recursos compulsórios ou governamentais.

2. Taxa de juros de política monetária: taxa de juros selic

3. Inflação doméstica: Indice de Preços ao ConsumidorAmplo (IPCA)

4. Crédito pessoal consignado total: Saldo em final de período das operações de crédito contratadas com taxas de juros livremente pactuadas entre mutuários e instituições financeiras. Não inclui operações referenciadas em taxas regulamentadas, operações vinculadas a recursos do Banco Nacional de Desenvolvimento Econômico e Social (BNDES) ou quaisquer outras lastreadas em recursos compulsórios ou governamentais.

5. Crédito pessoal não consignado: Saldo em final de período das operações de crédito contratadas com taxas de juros livremente pactuadas entre mutuários e instituições financeiras. Não inclui operações referenciadas em taxas regulamentadas, operações vinculadas a recursos do Banco Nacional de Desenvolvimento Econômico e Social (BNDES) ou quaisquer outras lastreadas em recursos compulsórios ou governamentais.

6. Lucro dos Bancos: Lucro líquido depois do imposto de renda - O lucro líquido depois do imposto de renda (LL) acumulado nos últimos doze meses.

7. Preço dos imóveis: índice de rentabilidade do mercado brasileiro de imóveis comerciais, cujo objetivo é retratar da forma mais abrangente possível a evolução da valorização dos preços e dos rendimentos do segmento de imóveis comerciais em todo o Brasil (IGMI-C). 
8. Consumo: Despesa de Consumo das Famílias.

9. Investimento em máquinas e equipamentos: Formação Bruta de Capital Fixo.

O componente de ciclo das variáveis foi obtido com o uso do filtro HP, definindo-se o parâmetro $\lambda$ igual a 1600; com exceção das séries de inflação (doméstica e externa) e de preço de imóveis, para as quais foram retiradas as médias para o período. As figuras abaixo apresentam as séries transformadas:
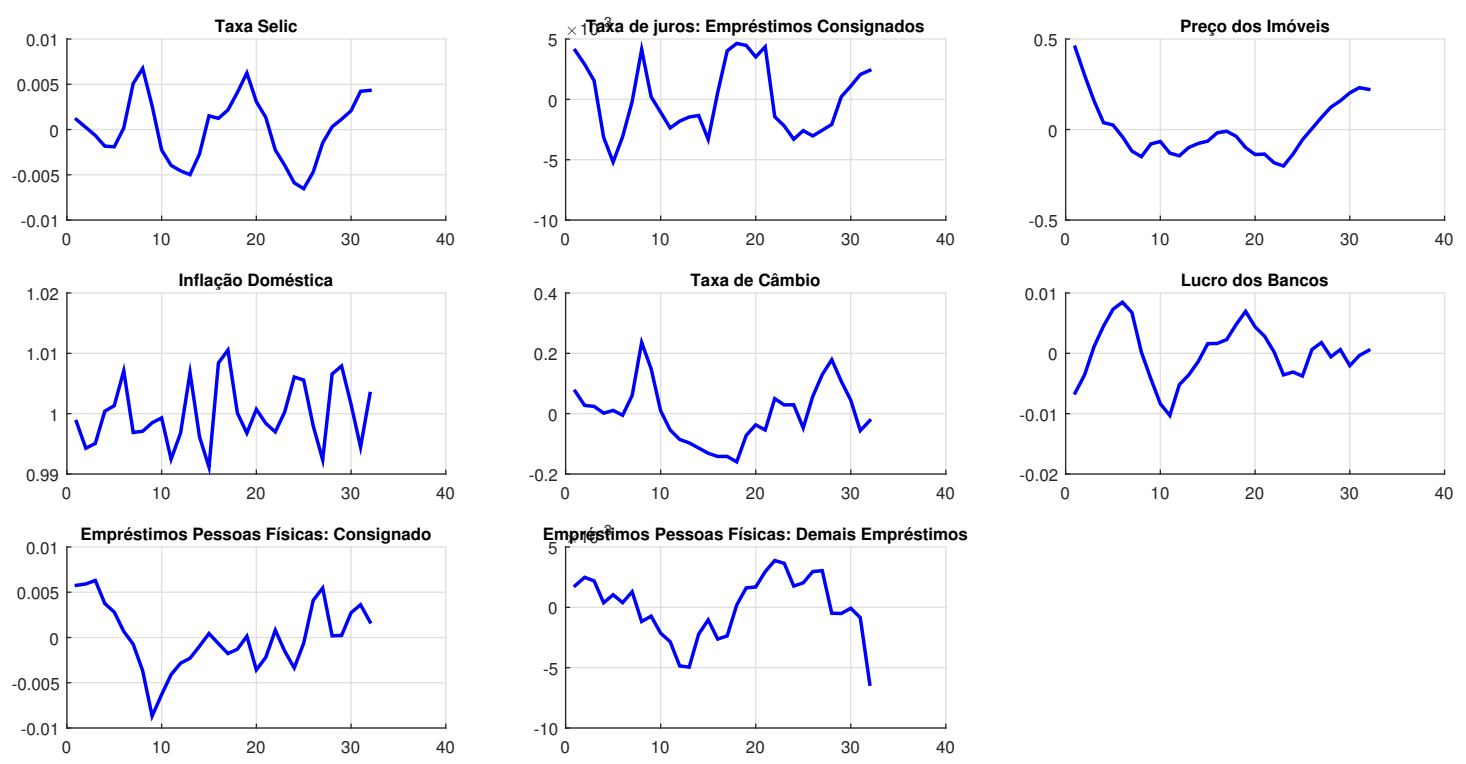

Figura 2: Variáveis

\subsection{Calibração}

A tabela 5.1 apresenta os valores calibrados para os parâmetros que definem o steady state do modelo. Em sua maioria, estes parâmetros foram obtidos a partir de estudos anteriores realizados para a economia brasileira. Em particular; $\beta_{P}, \beta_{I}, \beta_{E}, \delta, \delta_{k b}$, $j^{h}, \phi, \alpha, \mu, \varepsilon_{y}$ e $\varepsilon_{l}$ foram calibrados como em Silva (2012). Os parâmetros $\delta^{h}, \varepsilon^{d}, \varepsilon^{b h}, \varepsilon^{b w}$, e $\varepsilon^{b e}$ e os valores de steady state das variáveis $\pi, m^{I h}, m^{I w}$ e $m^{E}$ foram calibrados para tentar mimetizar a economia brasileira e garantir a existênca do steady state. 

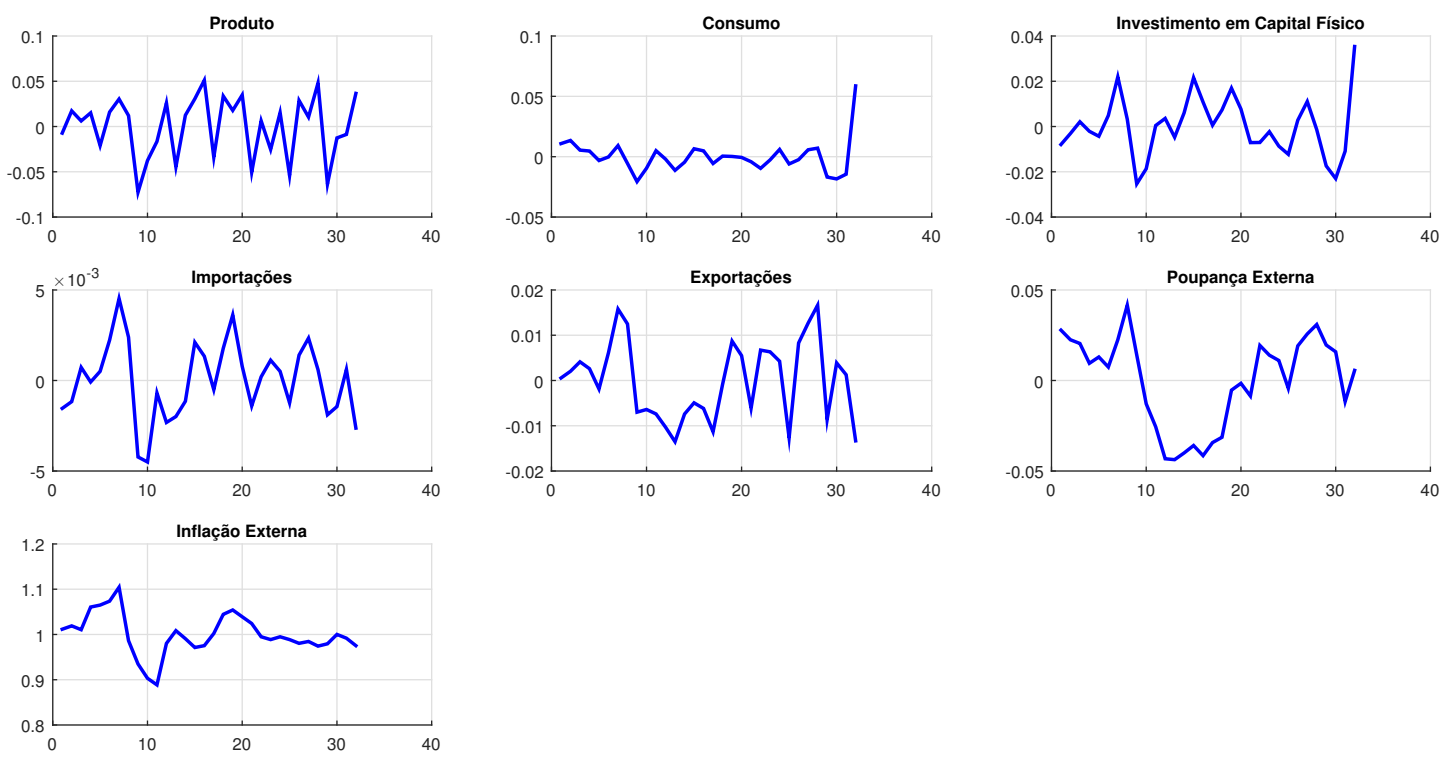

Figura 3: Variáveis 
$\beta_{P}$

$\beta_{I}$

$\beta_{E}$

$\delta$

$\delta^{h}$

$\delta^{k b}$

$\mathrm{j}^{h}$

$\varepsilon^{y}$

$\varepsilon^{l}$

$\varepsilon^{d}$

$\varepsilon^{b h}$

$\varepsilon^{b w}$

$\varepsilon^{b e}$

$\phi$

$\alpha$ taxa de desconto subjetiva: família paciente $\quad 0.989$

taxa de desconto subjetiva: família impaciente 0.96

taxa de desconto subjetiva: empresários $\quad 0.96$

taxa de depreciação do capital 0.035

taxa de depreciação dos imóveis $\quad 0.025$

taxa de depreciação do capital bancário $\quad 0.095$

peso dos imóveis na função de utilidade $\quad 0.2$

mark-up de preços 11

mark-up de salários 3

mark-down taxa de depósitos $\quad-2.62$

mark-up taxa de empréstimos $\quad 5.36$

mark-up taxa de empréstimos $\quad 4.5$

mark-up taxa de empréstimos $\quad 2.73$

Inverso da elasticidade Fish 1

share do capital na função de produção $\quad 0.4$ 
Parâmetros Calibrados height

$\begin{array}{ccc} & \text { Descrição } & \text { Valor } \\ \text { Fonte } & \text { loan-to-value } & 0.06 \\ \mathrm{~m}^{I h} & \text { debt-to-income } & 0.1 \\ \mathrm{~m}^{I w} & \text { loan-to-value } & 0.007 \\ \mathrm{~m}^{E} & \text { inflação doméstica } & 1 \\ \pi & \text { share do trabalho paciente } & 0.8 \\ \mu & \end{array}$


A partir dos valores calibrados para os parâmetros constantes na tabela 5.1, foi possível calcular o steady state para o modelo de economia fechada ${ }^{1}$. A tabela a seguir apresenta as razões de steady state para o modelo estudado:

Razões de Steady State height

Economia Fechada

\begin{tabular}{cc} 
Consumo (\% do Produto) & 0.74647 \\
Investimento em Capital Físico (\% do Produto) & 0.16639 \\
Investimento em Imóveis (\% do Produto) & 0.087147 \\
Empréstimo Agregado (\% do Produto) & 0.05666 \\
Depósito Agregado (\% do Produto) & 0.047028 \\
Empréstimo não consignado às famílias (\% dos Empréstimos) & 0.324934 \\
Empréstimo consignado às famílias (\% dos Empréstimos) & 0.18895 \\
Empréstimo aos empresários (\% dos Empréstimos) & 0.486117 \\
\hline
\end{tabular}

No steady state implicado pela calibração exposta anteriormente, o consumo como proporção do PIB se encontra acima da média histórica, o que pode ser consequência da ausência de gastos correntes do governo no modelo. Já o investimento em máquinas e equipamentos como proporção do produto está próximo à média brasileira de 18\%. Para as variáveis financeiras, no entanto, os parâmetros calibrados se mostraram incapazes de replicar valores compatíveis com a economia brasileira.

$\overline{1}$ Os scripts utilizados para o cálculo do steady state dos modelos se encontram nos anexos 


\section{Resultados}

O modelo anteriormente apresentado foi estimado em duas estapas, inicialmente o modelo foi estimado apenas com as 20 primeiras observações da base de dados, ou seja, com base nas informações contidas entre os anos de 2007 e 2011. Os parâmetros das funções de densidade obtidos como resultado desta primeira estimação foram utilizados na formação das priors para uma nova estimação; desta vez com todas as observações contidas na base de dados. Nas duas rodadas de estimação foram utilizadas 1.000 .000 de iterações para a obtenção da posteriori. As priors e posteriores encontradas na segunda estimação podem ser observadas nos gráficos 282 - 287. Foram estimadas as distribuições de probabilidade para os parâmetros que determinam a dinâmica do modelo,ou seja, custos de ajustamento, parâmetros relacionados à regra de Taylor, formação de hábito no consumo e persistência dos choques. A tabela abaixo apresenta a média e o desvio-padrão estimados: 


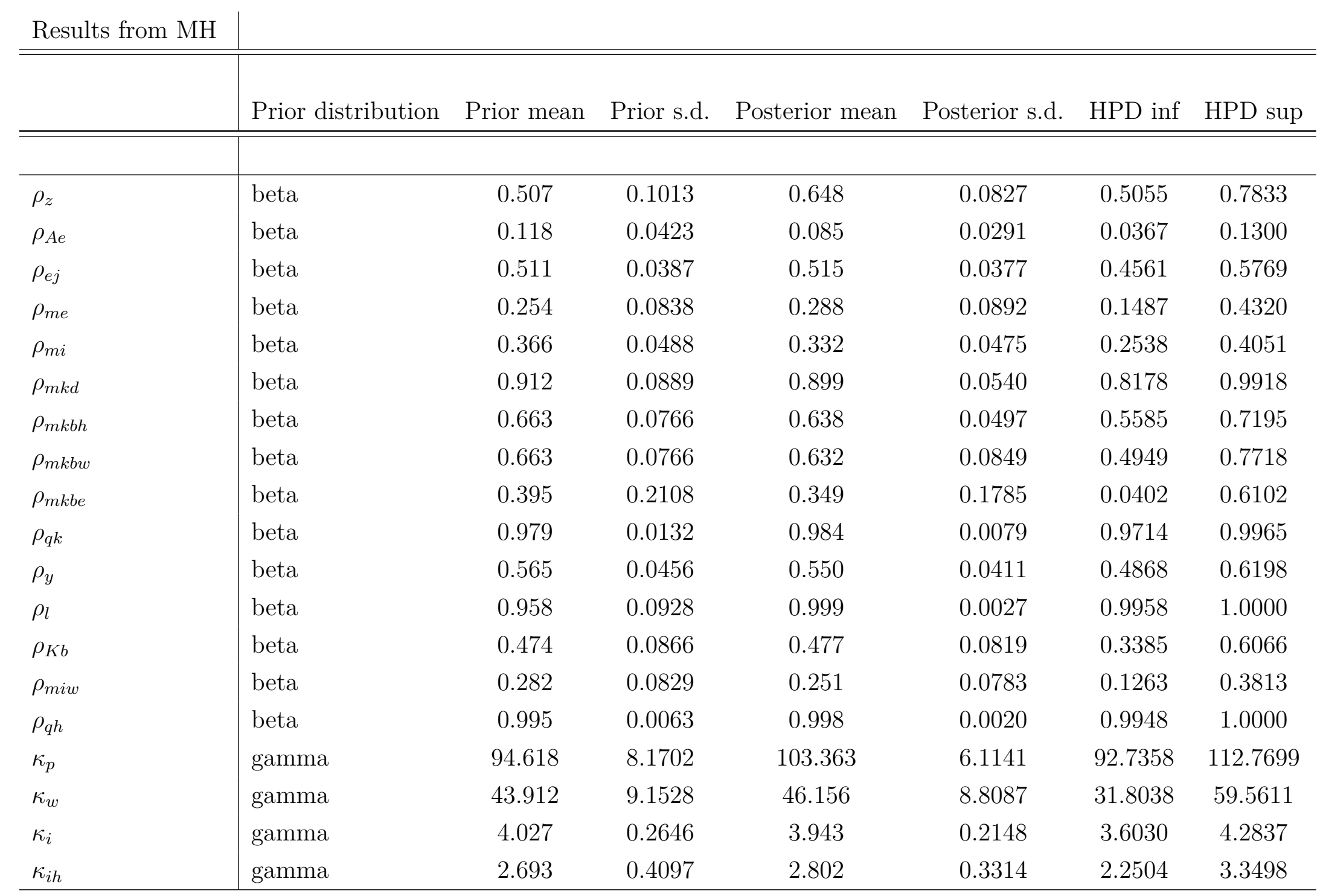




\begin{tabular}{l|lllclcc} 
Results from MH & \multicolumn{7}{l}{} \\
\hline \hline & Prior distribution & Prior mean & Prior s.d. & Posterior mean & Posterior s.d. & HPD inf & HPD sup \\
\hline \hline & & & & & & \\
\hline$\kappa_{d}$ & gamma & 7.928 & 0.8249 & 7.709 & 0.6620 & 6.7101 & 8.8955 \\
$\kappa_{b e}$ & gamma & 2.296 & 0.8032 & 1.943 & 0.6289 & 0.8877 & 2.9048 \\
$\kappa_{b h}$ & gamma & 16.746 & 1.1800 & 16.514 & 0.9055 & 14.9342 & 17.9746 \\
$\kappa_{b w}$ & gamma & 5.812 & 0.6405 & 5.734 & 0.4563 & 4.9742 & 6.4907 \\
$\kappa_{k b}$ & gamma & 0.598 & 0.1535 & 0.430 & 0.0954 & 0.2781 & 0.5844 \\
$\phi_{p i}$ & normal & 2.241 & 0.0957 & 2.275 & 0.0559 & 2.1831 & 2.3642 \\
$\phi_{R}$ & beta & 0.677 & 0.0264 & 0.683 & 0.0213 & 0.6472 & 0.7166 \\
$\phi_{y}$ & gamma & 0.226 & 0.0186 & 0.216 & 0.0182 & 0.1849 & 0.2442 \\
$\iota_{p}$ & beta & 0.836 & 0.0712 & 0.879 & 0.0472 & 0.8047 & 0.9571 \\
$\iota_{w}$ & beta & 0.553 & 0.0625 & 0.619 & 0.0513 & 0.5404 & 0.7050 \\
$\mathrm{a}_{i}$ & beta & 0.968 & 0.0145 & 0.968 & 0.0050 & 0.9600 & 0.9755 \\
\hline
\end{tabular}


A tabela contendo as estimativas para os parâmetros selecionados demonstra baixos valores (medidos pela média) para a persistência de alguns choques, em especial aqueles relacionados ao progresso técnico $\left(\rho_{A e}=0.085\right)$, aos loan-to-values $\left(\rho_{m i}=0.332\right.$, $\left.\rho_{m e}=0.288\right)$, ao debt-to-income $\left(\rho_{m i w}=0.251\right)$ e para o custo de ajustamento do capital bancário $\left(\kappa_{k b}=0.43\right)^{1}$. Ainda com relação aos custos de ajustamento, cabe notar o alto valor para o parâmetro relacionado ao preço do bem final $\left(\kappa_{p}=103.363\right)$ e o fato de que é superior ao custo de ajustamento de salários $\left(\kappa_{w}=46.156\right)$ - a mesma análise é válida para os parâmetros de indexação de preços e de salários, $\iota_{p}=0.879$ e $\iota_{w}=0.619$. Os diagnósticos de convergência dos parâmetros e para o modelo como um todo podem ser vistos nos gráficos 295 - 310 e 311. Com o modelo estimado podemos identificar quais foram os choques mais importantes para a economia brasileira, dentro do período que contém os dados utilizados na estimação. Isto é realizado através da decomposição histórica para as varíaveis selecionadas - produto, inflação,investimento em capital e taxa de juros de política monetária - fixando os valores dos parâmetros nas médias estimadas. Como em Gerali et all (2010), os choques são agrupados em três classificações:

- Macro: choque na preferência por consumo, choque tecnológico, choque na demanda por imóveis, choque no mark-up de preços, choque no mark-up de salários, choque na produção de capital, choque na produção de imóveis;

- PM: choque na regra de Taylor;

- Financeiro: choque na restrição de endividamento com imóveis, choque na restrição de endividamento dos empresários, choque no mark-up da taxa de depósitos, choque no mark-up da taxa de empréstimos, empresários, choque no mark-up da taxa de empréstimos com base em imóveis, choque no capital bancário, choque na restrição de endividamento consignado, choque no mark-up da taxa de empréstimos consignados.

Analisando os gráficos 332, 333, 334 e 335 percebe-se que o choque de política monetária só teve um papel expressivo no comportamento de inflação, para as demais variáveis os choques financeiros são as mais importantes para explicar seu comportamento. É válido notar que, para todas as variáveis analisadas, o conjunto de choques financeiros contribuiu para a queda de seus valores em relação o steady state durante o período em análise. Este comportamento pode ser atribuído à política creditícia efetivada pelo governo, como instrumento de estímulo à demanda interna e aos efeitos da crise internacional. Já o efeito da taxa de juros selic sobre as mesmas variáveis pode ser atribuída à baixa artificial no mesmo período.

1 Como observado em Cândido Silva (2012), o baixo valor para o custo de ajustamento do capital bancário pode ser um reflexo da presença estatal no setor bancário, através do crédito direcionado para o mercado imobiliário e para investimento em máquinas e equipamentos, por meio de agências estatais com a Caixa Econômica e BNDES 


\subsection{Funções de Resposta ao Impulso}

- Choque no debt-to-income: O efeito de um aumento temporário no debt-to-income das famílias impacientes pode ser analisado a partir da IRFs 39 - 44. Um choque nesta variável leva a uma queda no salário das famílias impacientes, devido ao menor esforço dos sindicatos em manter, ou mesmo aumentar, o salário dessas famílias. Porém, percebe-se a despeito da queda no salário, o aumento na capacidade de endividamento da família permite a elevação do consumo e do estoque de imóveis - o que também explicaria a elevação de empréstimos com colateral em imóveis. Também é válido notar que embora este choque tenha uma persistência baixa, seus efeitos sobre produto, consumo agregado e investimento (nos setores de capital e imóveis) têm duração longa neste modelo.

- Choque no mark-up da taxa de juros sobre empréstimo consignado: Um choque no mark-up da taxa de juros de empréstimos consignados faz com que a essa taxa aumente, os gráficos 45 - 50 mostram, como esperado, que este choque leva a uma queda nos empréstimos, consumo e estoque de imóveis adquiridos pela família impaciente. Isto leva a uma queda no consumo agregado, no estoque de imóveis para a economia, nos empréstimos agregados e na produção, o que implica em uma redução na taxa de juros de política monetária. Como consequência da redução na taxa política as taxas de depósitos e empréstimos com colateral também diminuem. Entretanto, mesmo com as reduções nas taxas de empréstimo e no total de empréstimos, o lucro do banco sofre um aumento.

- Choque na elasticidade de substituição do trabalho: Um choque positivo na elasticidade de substituição reduz o salário para os dois tipos de família, o que eleva a demanda por trabalho. O aumento na renda das famílias decorrente de mais horas trabalhadas leva a um aumento no consumo e no estoque de imóveis, aumentando a renda dos empresários; bem como o seu consumo e estoque de imóveis - o que por sua vez aumenta o produto agregado. Este mecanismo de propagação por ser visto nos gráficos $87-92$.

- Choque na demanda por imóveis: Este choque faz com que a demanda por imóveis para as famílias em empresário aumente. Para satisfazer à nova demanda, esses agentes reduzem o seu consumo e aumentam as horas trabalhadas. Ainda, para atender ao aumento na procura por imóveis, o setor eleva a produção - o que aumenta o investimento em imóveis e reduz o investimento em capital. Cabe notar que, embora o consumo agregado e o investimento em capital caiam, o produto agregado se torna maior. Isto pode ser observado pelos gráficos 51 - 56 .

- Choque no custo de ajustamento no investimento em imóveis: De acordo com as 
IRFs constantes nos gráficos 57 - 62, o choque de oferta na produção de imóveis faz com que o investimento no setor se reduza e o preço aumente. O aumento em $q_{t}^{h}$ leva os empresários e, posteriormente, as famílias a reduzirem seus estoques de imóveis. O aumento na revenda de imóveis para o setor produtor torna possível o aumento na produção nos primeiros períodos, mesmo com queda no investimento direcionado ao setor. Por fim, a redução de investimentos no setor imobiliário redireciona os recursos da economia para o consumo e investimento em capital.

\subsection{O papel das fricções financeiras}

Para entender o papel do setor financeiro na dinâmica do modelo, são simulados cinco versões do modelo, em que cada uma das imperfeições do setor são retiradas de forma cumulativa:

- Modelo BK - modelo completo

- Modelo SR - neste modelo o custo de ajustmento do é suposto igual à zero; além disso, o capital bancário é retirado do balanço patrimonial dos bancos e transferido para a restrição orçamentária das famílias pacientes. Desta forma, o banco pode contar apenas com depósitos como fonte de recursos para empréstimos.

- Modelo FR - os custos de ajustamento das taxas de juros são supostos iguais a zero, desta forma, as taxas de juros se tornam totalmente flexíveis.

- Modelo FF - as elasticidades de substituição para empréstimos e depósitos tendem ao infinito, de tal forma que o mark-up sobre as taxas de juros definidas pelos bancos se tornam igual a um - ou seja, os bancos perdem o poder de mercado.

- Modelo QNK - os LTVs e o DTI são fixados em seus valores de steady state.

A análise da importância das friç̧ões financeiras é realizada por meio da comparação entre as funções de resposta ao impulso, para algumas variáveis selecionadas ${ }^{2}$, das versões do modelo descritas acima. A seguir estão descritas as IRFs para algus choques constantes no modelo.

\subsubsection{Choque Tecnológico}

Como pode-se perceber pelas funções de resposta ao impulso, os efeitos de um choque tecnológico sobre consumo, investimento e produto se tornam maiores nos modelos FF e QNK, em comparação aos três modelos anteriores. Isto indica que o poder de mercado

2 Especificamente: produto, consumo, investimento em capital físico, inflação, taxa de juros de política monetária, crédito agregado, depósito agregado e capital bancário 

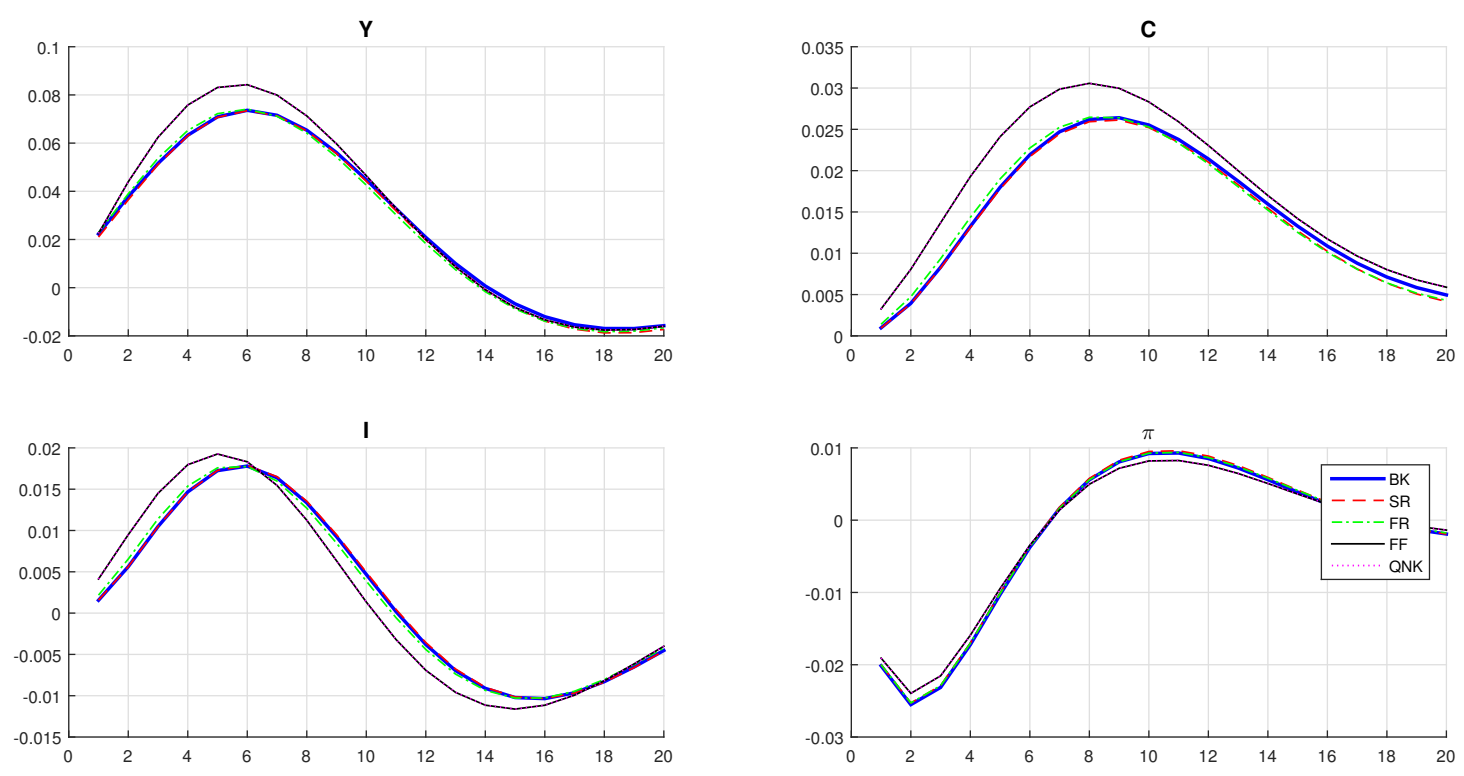

Figura 4: Efeito de um choque tecnológico
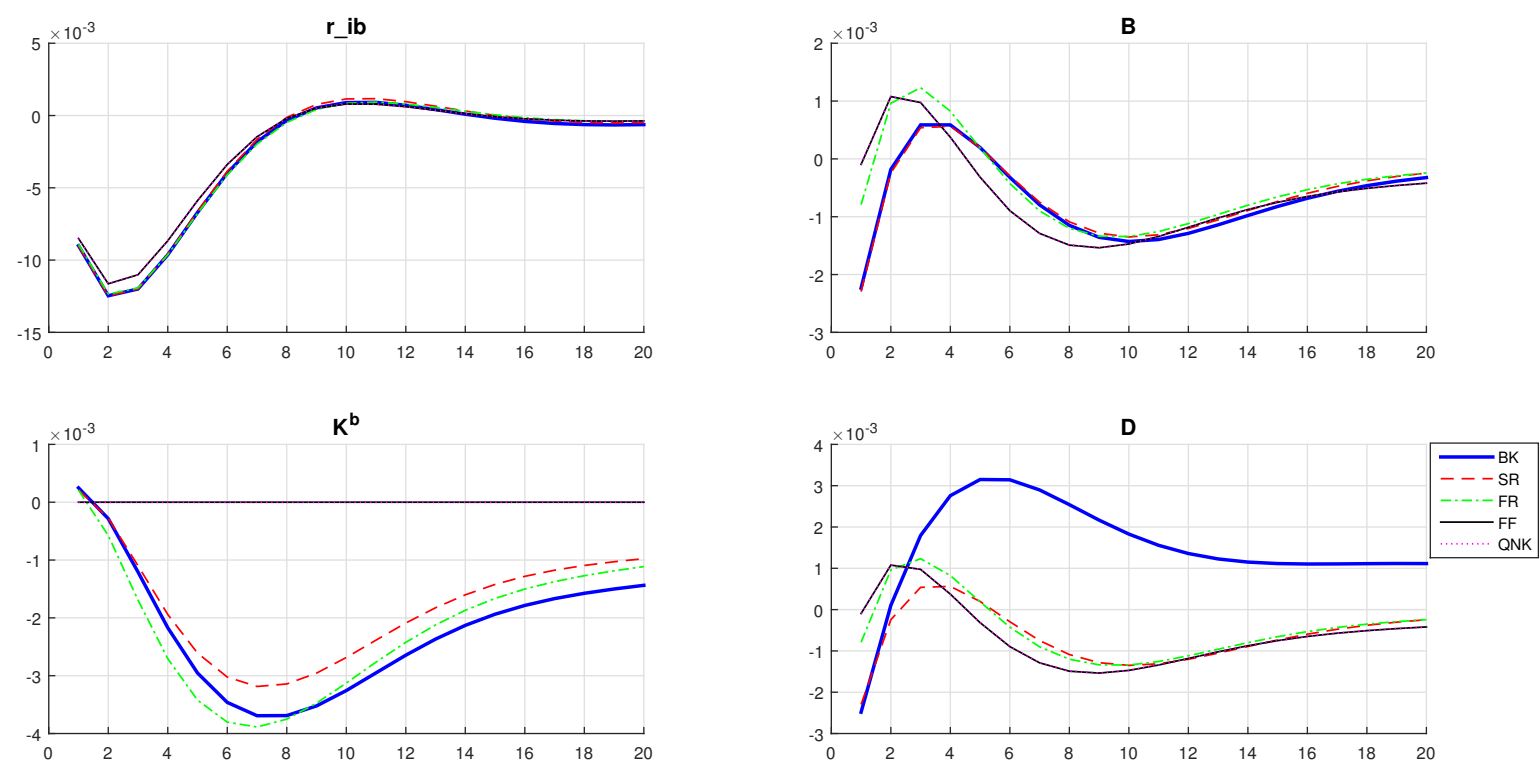

Figura 5: Efeito de um choque tecnológico

dos bancos é a friç̧ão com maior efeito sobre o tamanho do impacto de um choque tecnológico nestas variáveis. Com relação à inflação e à taxa de política monetária, as imperfeições do mercado parecem ter impacto despresível sobre a propagação do choque tecnológico. Para o crédito agregado e o capital bancário, como era de se esperar, a flexibilidade no ajustamento do capital bancário e das taxas de juros definidas pelos bancos reduzem os efeitos do choque tecnológico - para os modelos FF e QNK, o capital bancário não responde ao choque. Para os depósitos é particularmente notória a diferença 
na amplitude do choque entre o modelo BK e os demais, implicando que essa amplitude é grande parte influenciada pela pelas fricções no ajustamento do capital bancário.

\subsubsection{Choque de demanda no consumo}
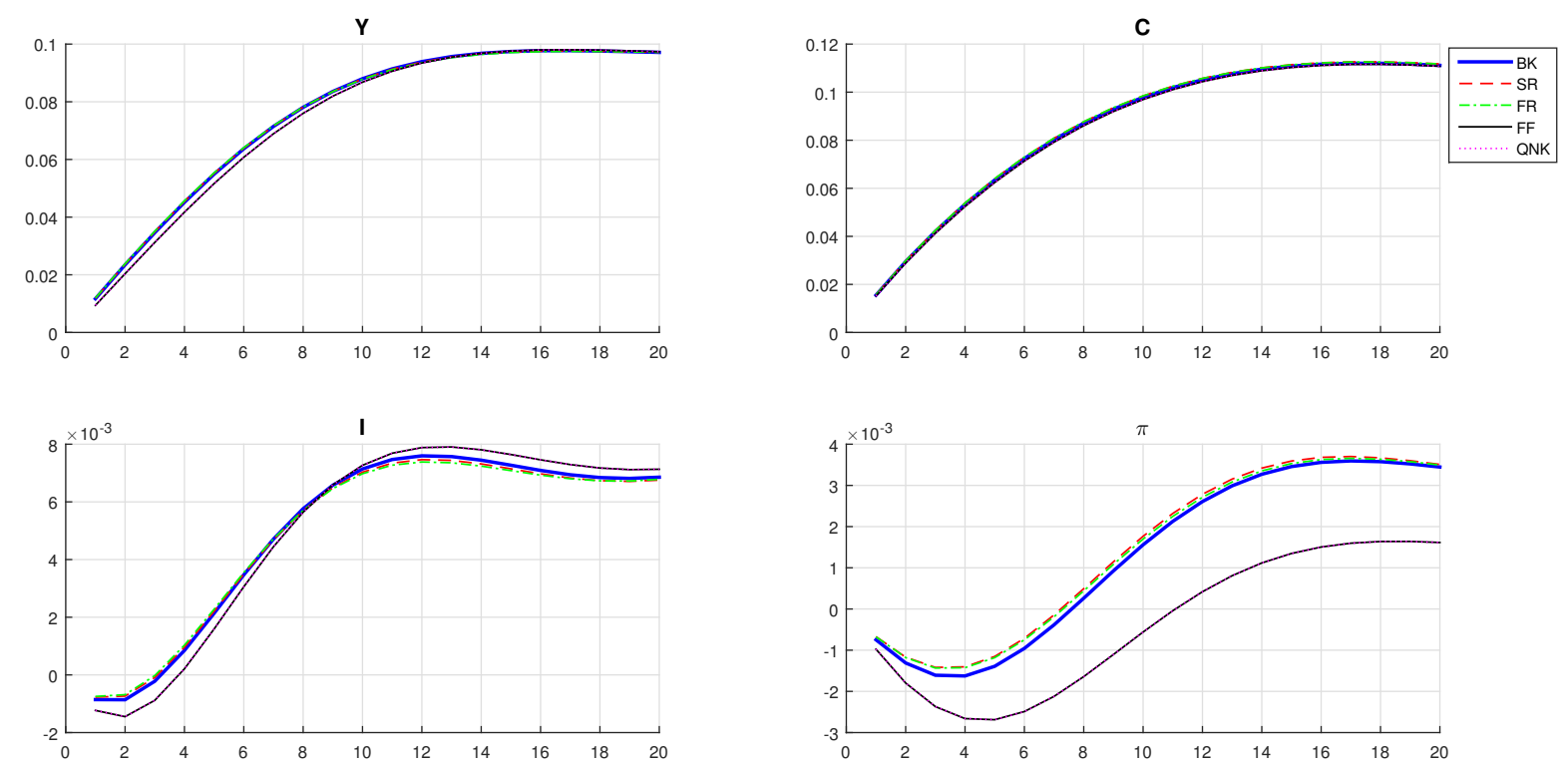

Figura 6: Efeito de um choque de demanda no consumo
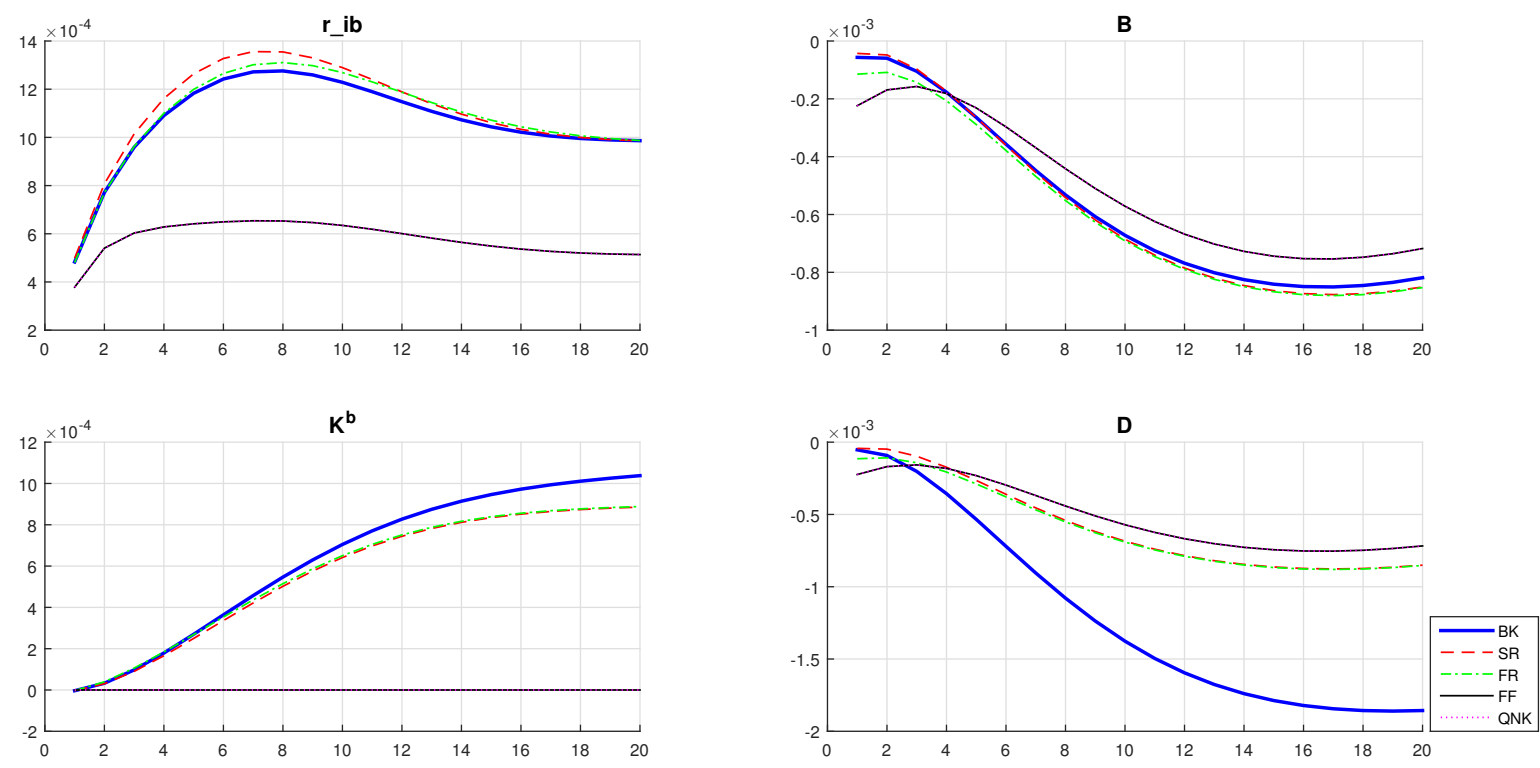

Figura 7: Efeito de um choque de demanda no consumo

Quando analisamos a importância das imperfeições do setor financeiro sobre a propagação do choque sobre o consumo, encontramos um quadro oposto ao do choque 
tecnológico, no que tange às variáveis reais; embora a presença de poder de mercado tenha um efeito importante sobre a dinâmica da inflação de preços, para um dado choque no consumo, o mesmo não ocorre com as demais variáveis. Isto pode ser percebido por meio da comparação entre as IRFs das versões FF e QNK com as versões BK, SR e FR; enquanto a inflação para os três últimos modelos permanece maior em comparação os modelos FF e QNK, as dinâmicas do consumo, produto e investimento são semelhantes para as cinco versões do modelo. Para taxa de política monetária e as demais variáveis financeiras, há um nítido descolamento das IRFs para dois grupos: o formado pelos modelos BK, SR e FR, e o formado por FF e QNK - em que o choque tem maior amplitude no primeiro grupo.

\subsubsection{Choque na demanda por imóveis}
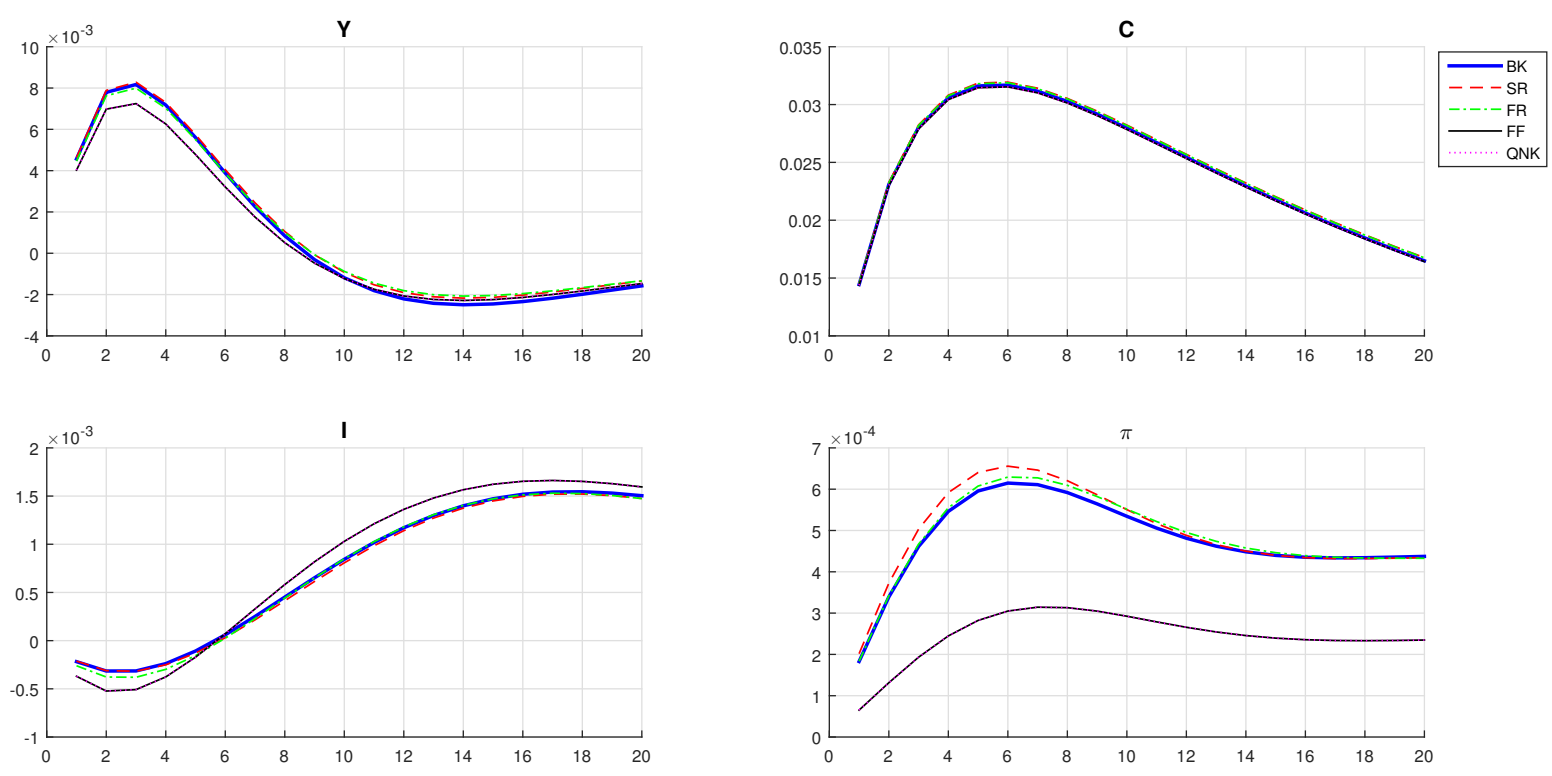

Figura 8: Efeito de um choque por imóveis

A interação entre as fricções financeiras e o choque de demanda por imóveis é semelhante ao caso do choque de consumo; o efeito do poder de mercado é maior na dinâmica da inflação, enquanto, para o consumo e o investimento, não se observa diferença significante entre as IRFs para as versões do modelo. Para o produto, percebe-se que para as três primeiras versões o impacto do choque na demanda por imóveis é ligeiramente superior para os 8 primeiros períodos; com relação ao investimento, a amplitude do choque é ligeiramente superior para os modelos FF e QNK. No que diz respeito à taxa de política monetária e as demais variáveis financeiras, novamente os modelos BK, SR e FR exibem uma maior sensibilidade aos choque, em comparação às demais versões do modelo. 

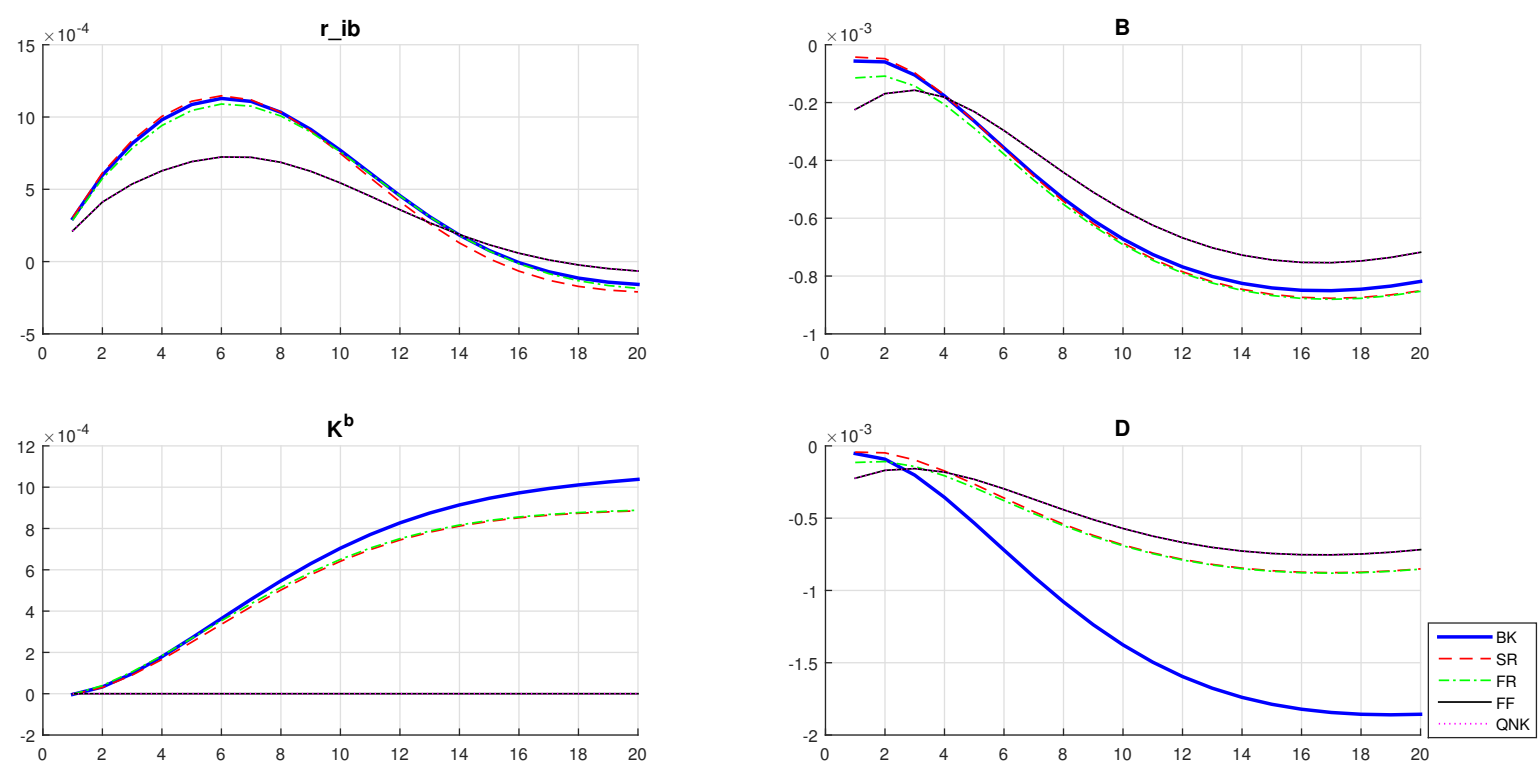

Figura 9: Efeito de um choque por imóveis

\subsubsection{Choque de política monetária}
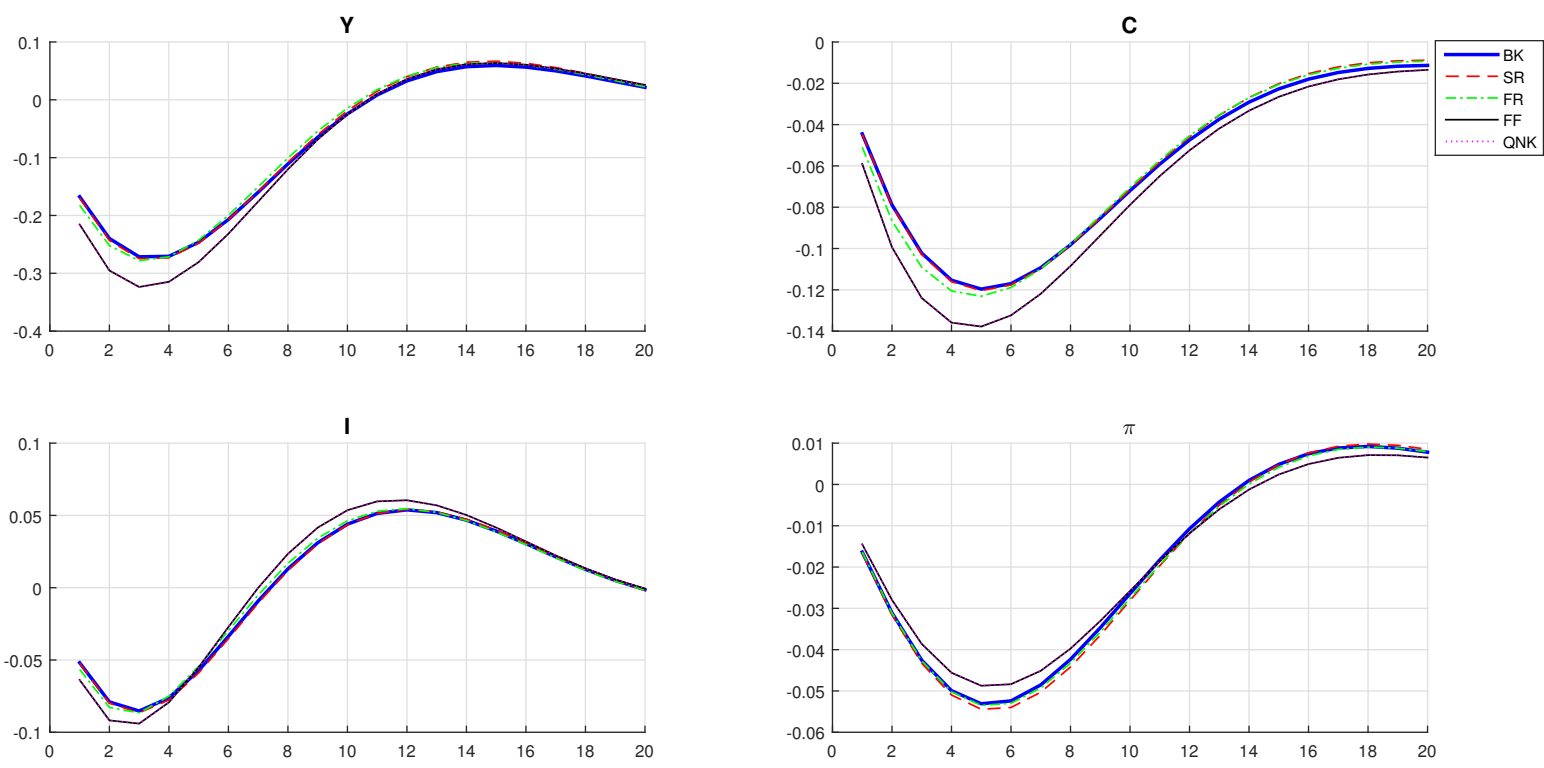

Figura 10: Efeito de um choque de política monetária

O efeito da interação entre o choque de política monetária e as imperfeições no setor bancário nas dinâmicas do investimento em capital e inflação não parece de grande importância, dada a proximidade entre as IRFs para as versões do modelo. Para o produto e o consumo, entretanto, o choque de política monetária tem um efeito ligeiramente maior nos modelos sem poder de mercado, ao menos nos 10 primeiros períodos. Quanto ao 

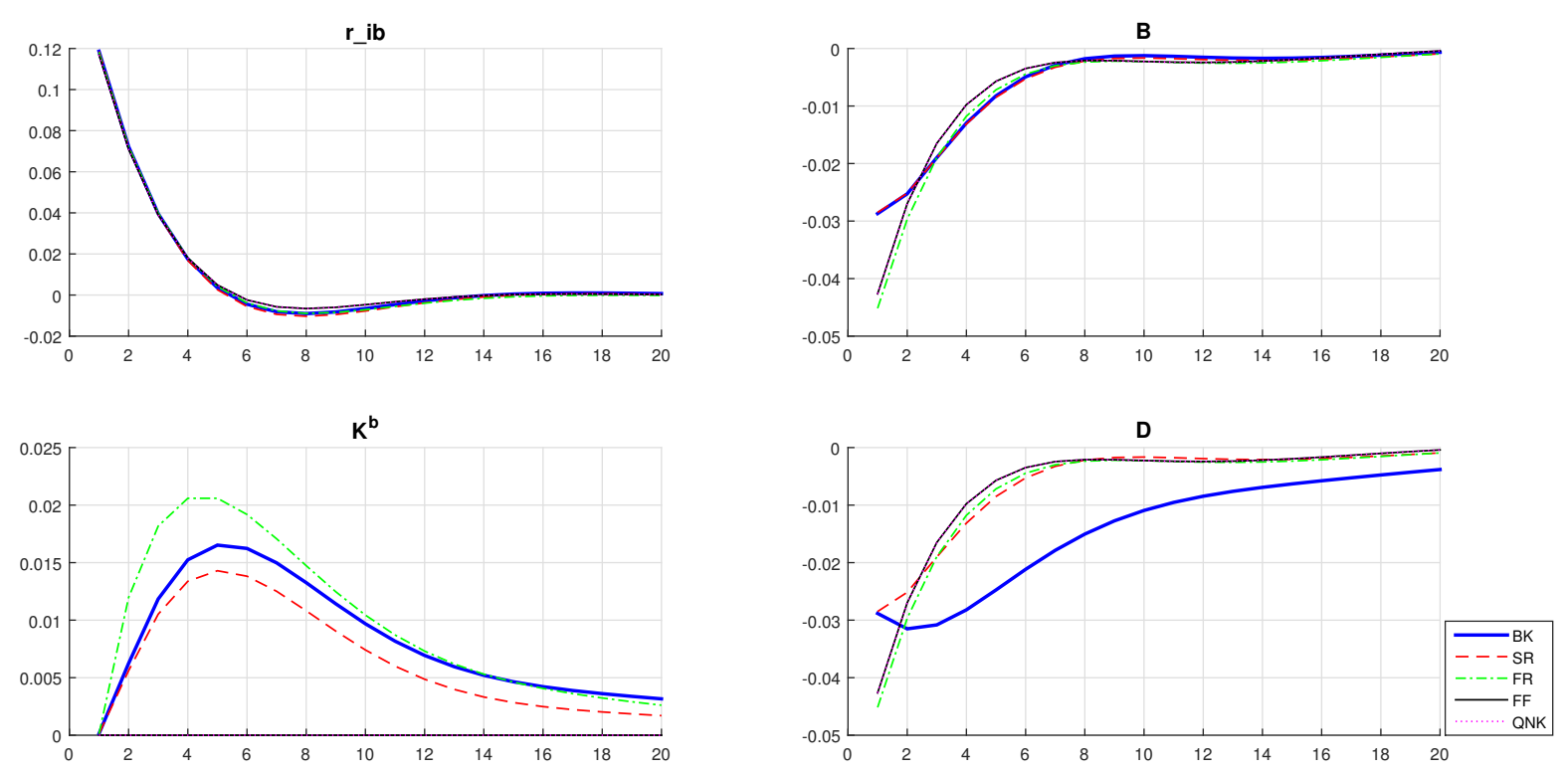

Figura 11: Efeito de um choque de política monetária

capital bancário, percebe-se que o choque tem maior efeito sobre o modelo sem custos de ajustamento (FR), embora, curiosamente, nos modelos SR, FF e QNK o impacto do choque de política monetária seja menor em comparação do modelo completo (BK). Já para os depósitos, a amplitude do choque é maior no modelo BK, embora o impacto inicial seja igual para os modelos BK e SR. Por útimo, há pouca - ou nenhuma - diferença nas dinâmicas da taxa de juros de política monetária e no crédito agregado para as cinco versões do modelo.

\subsubsection{Choque no Capital Bancário}

Na presença de um choque no capital bancário, as fricções mais influenciam as dinâmicas para o produto, investimento em capital, consumo, inflação, taxa de política monetária e empréstimos agregados são o custo de ajustamento no capital bancário e, novamente, o poder de mercado do bancos. Isto pode ser depreendido a partir das distâncias entre as funções de resposta ao impulso entre o modelo BK e os modelos SR e FR, e entre esses dois modelos e os modelos FF e QNK. Embora a flexibilidade na determinação do capital bancário e nas taxas de juros amplifiquem o choque sobre as variáveis reais, nos modelos sem poder de mercado o choque tem efeito nulo sobre estas variáveis. Para o capital bancário e os depósitos no entanto, ocorre o inverso; as fricções no setor bancário amplificam o efeito do choque - para os depósitos, em particular, o tamanho do choque no modelo BK é desproporcionalmente maior em comparação às demais versões do modelo. 

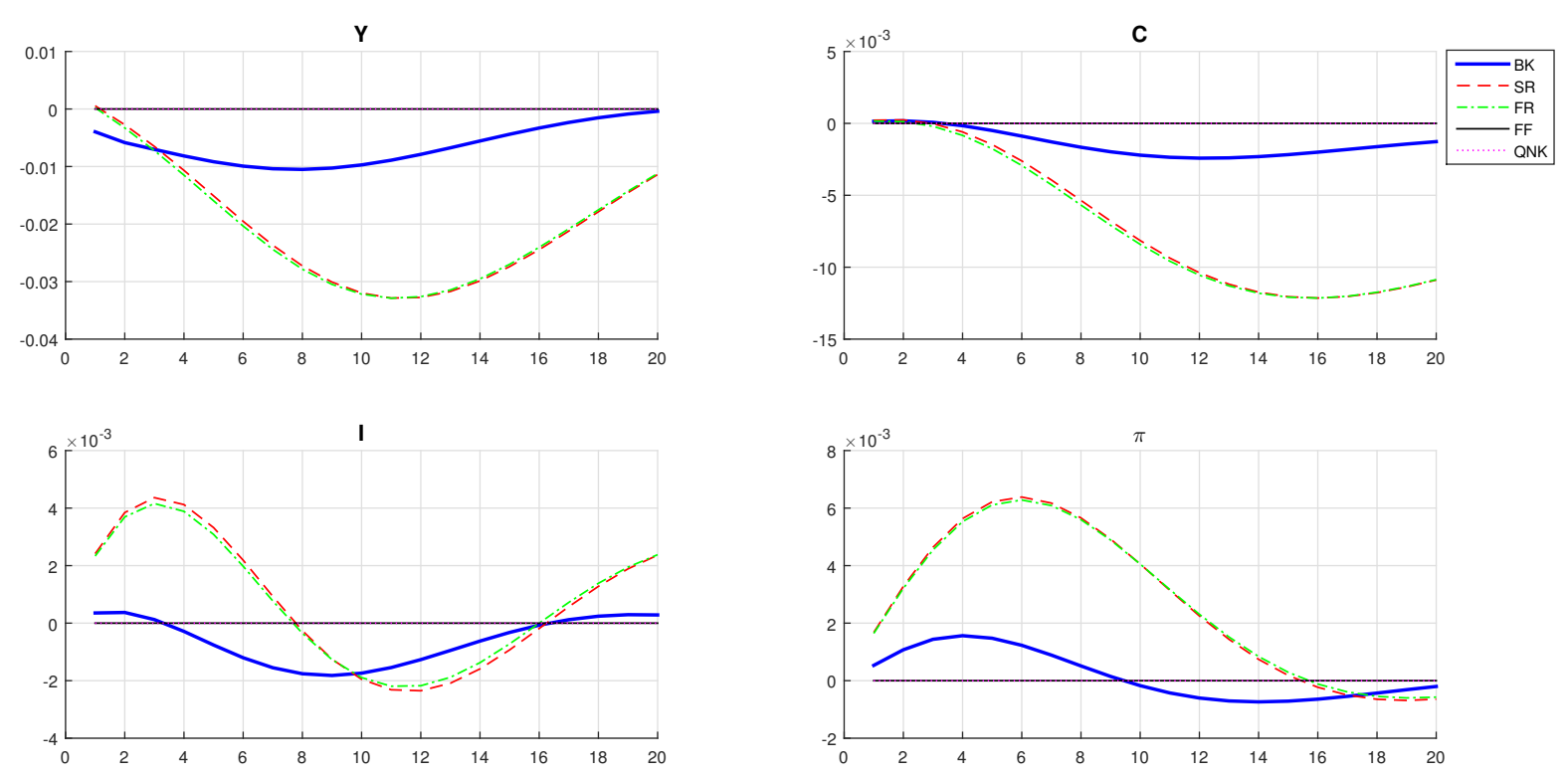

Figura 12: Efeito de um choque no capital bancário
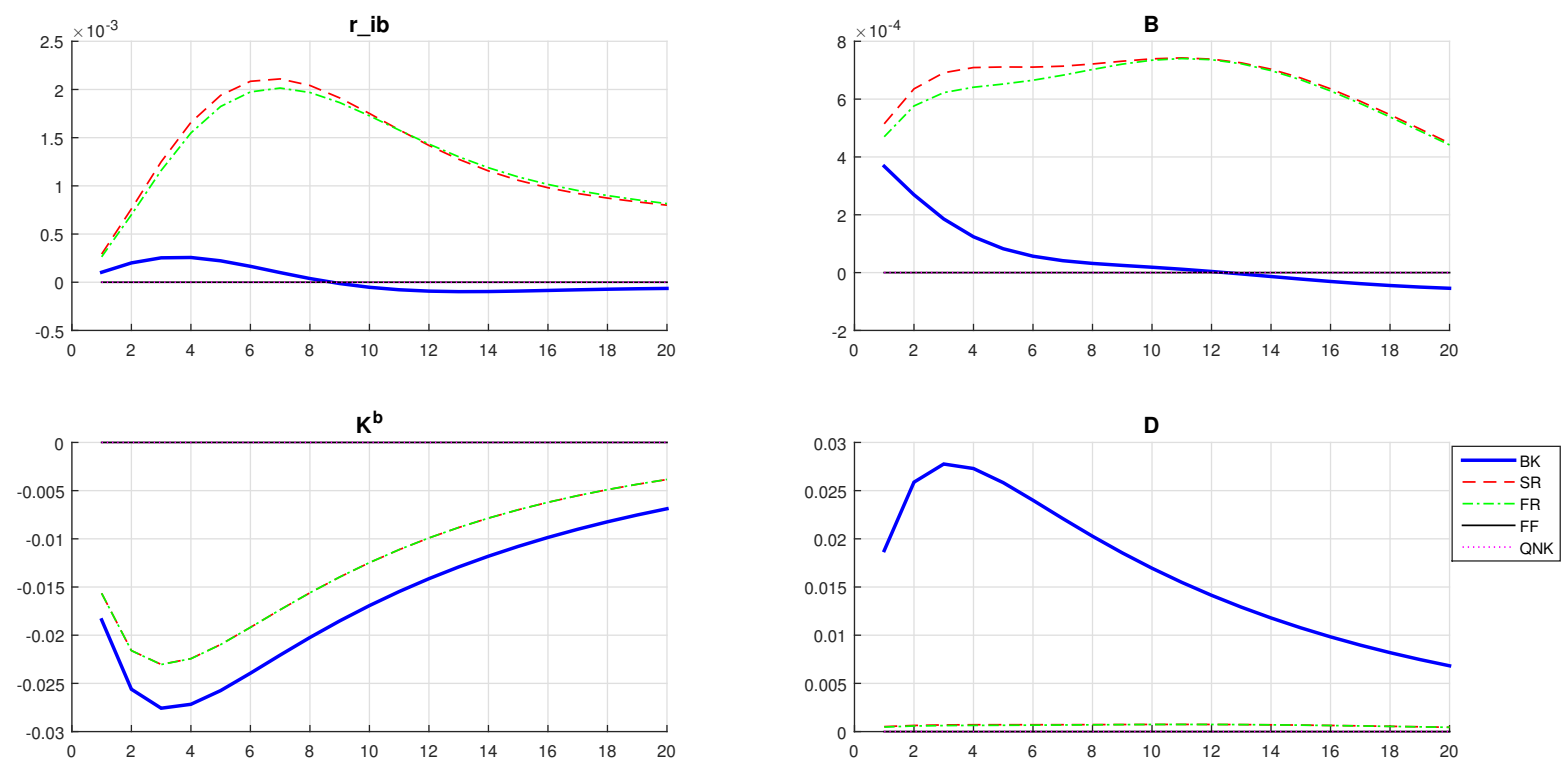

Figura 13: Efeito de um choque no capital bancário

\subsection{O impacto de mudanças no parâmetro do custo de ajustamento no investimento em imóveis}

Como já foi mensionado, uma das diferenças entre o modelo apresentado e o modelo proposto por Gerali et all (2010) é apresença de um setor produtor de imóveis, em contraste com a hipótese de oferta fixa. Um questionamento que surge com o relaxamento da hipótese de oferta fixa é: como a produção de imóveis deve afetar o acelerador finan- 
ceiro? A fim de responder a este questionamento, comparamos as funções de resposta ao impulso para os choques na oferta e na demanda por imóveis supondo três valores diferentes do custo de ajustamento do investimento em imóveis: $\kappa_{i h}=0$ (sem custo de ajustamento), $\kappa_{i h}=$ média estimada e $\kappa_{i h}=30$ (aproximadamente 10 vezes o valor estimado) e comparando o comportamento do produto, consumo, investimento em capital, inflação, taxa de juros de política monetária, total de empréstimos na economia, estoque de imóveis e preço do imóveis.
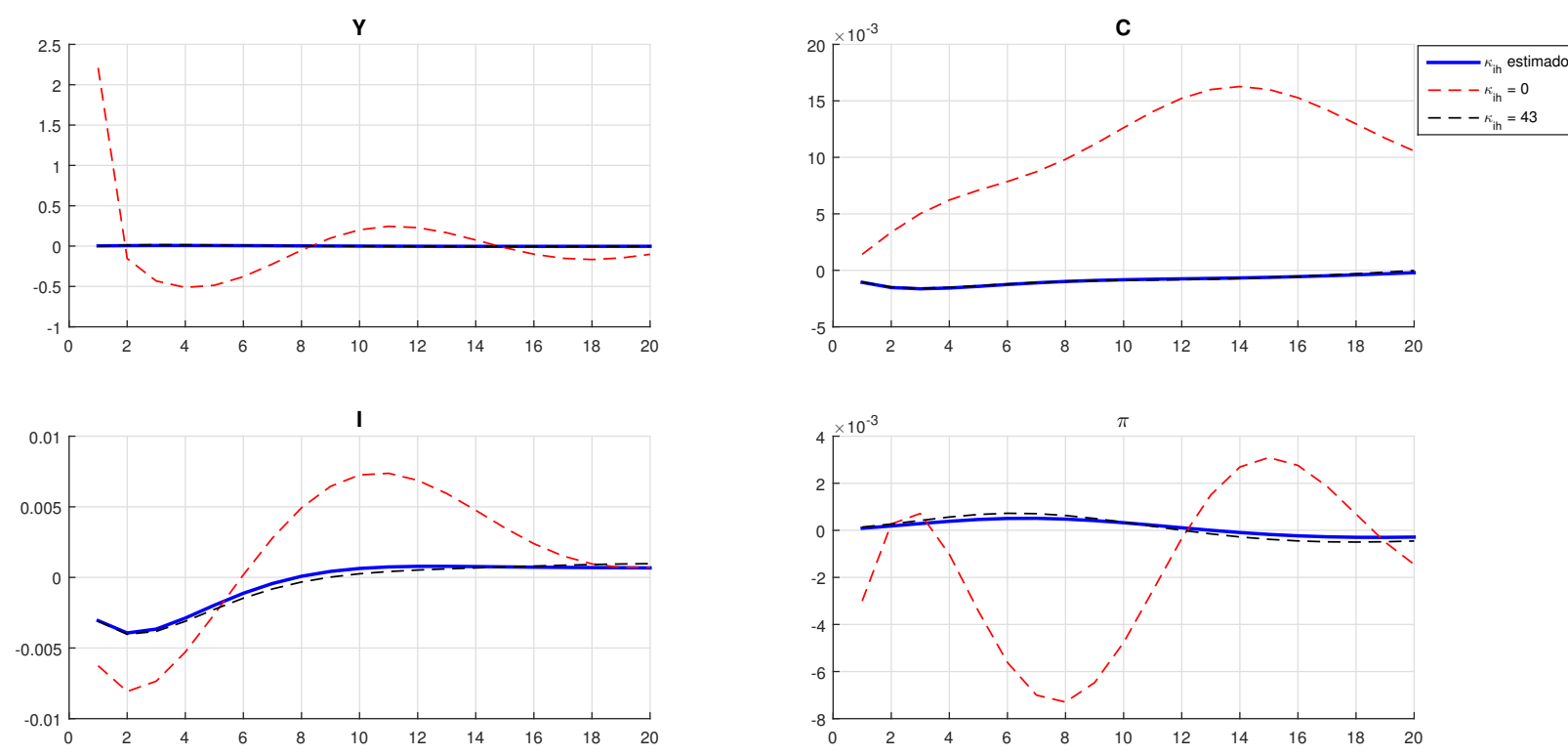

Figura 14: Efeito de um choque na demanda por imóveis
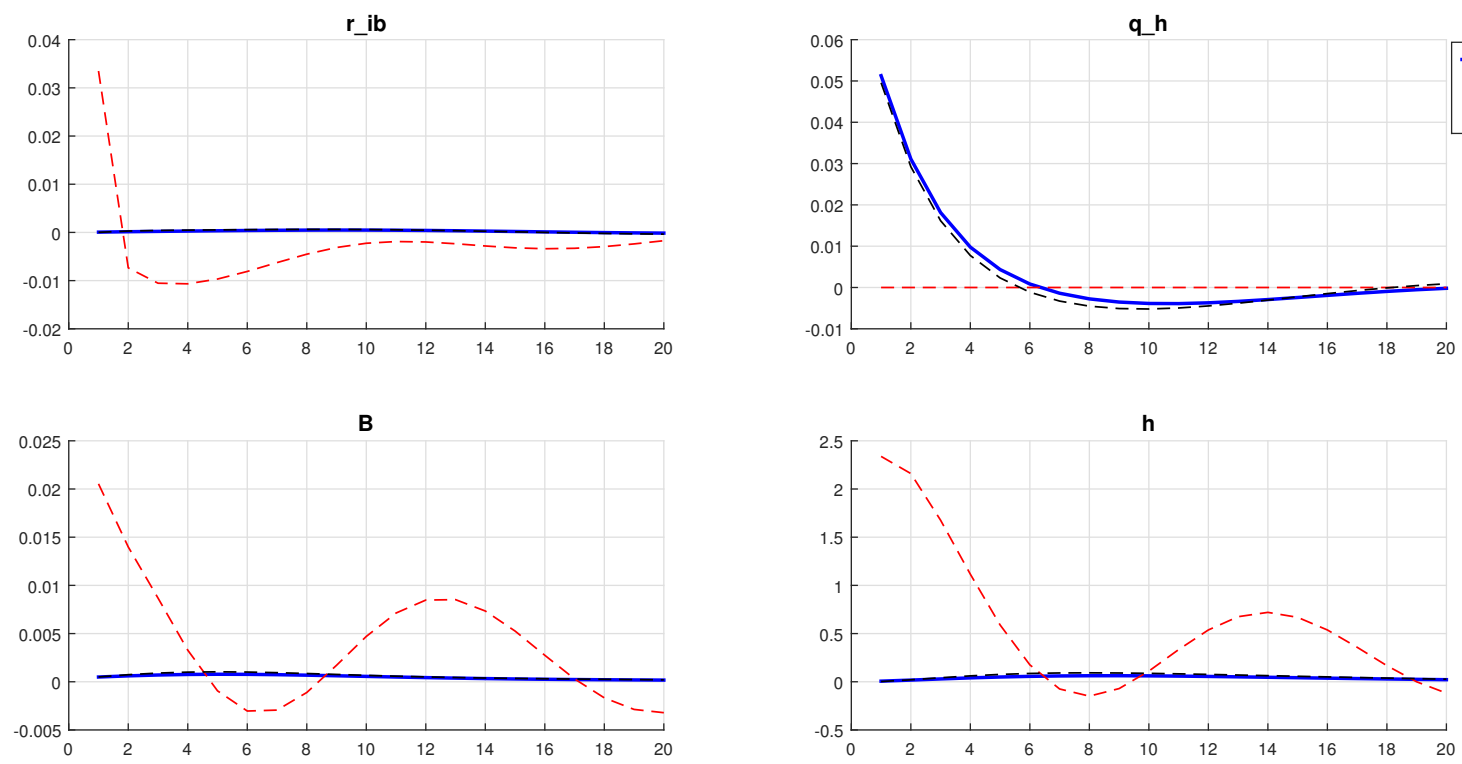

Figura 15: Efeito de um choque na demanda por imóveis 

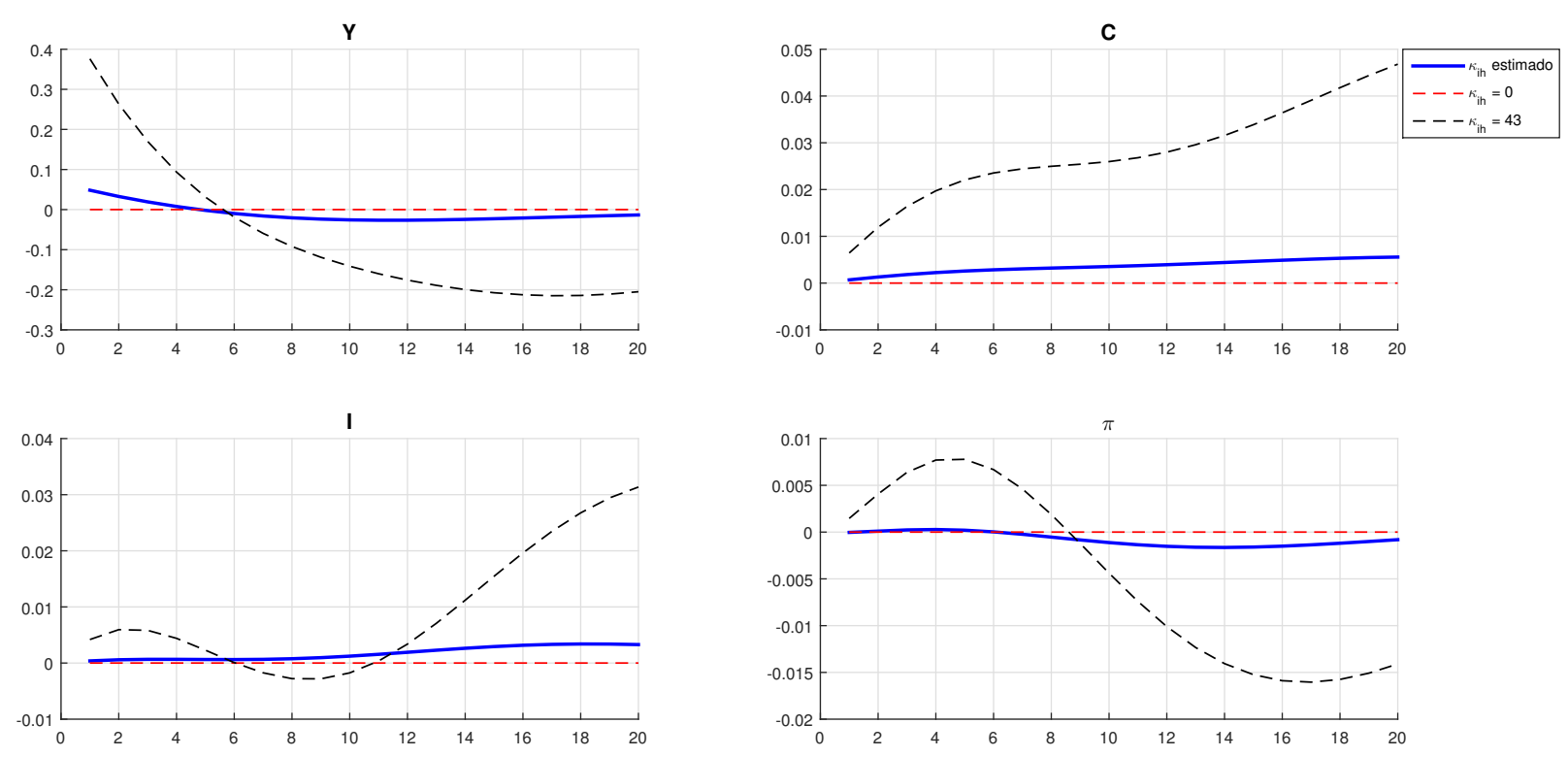

Figura 16: Efeito de um choque na oferta de imóveis
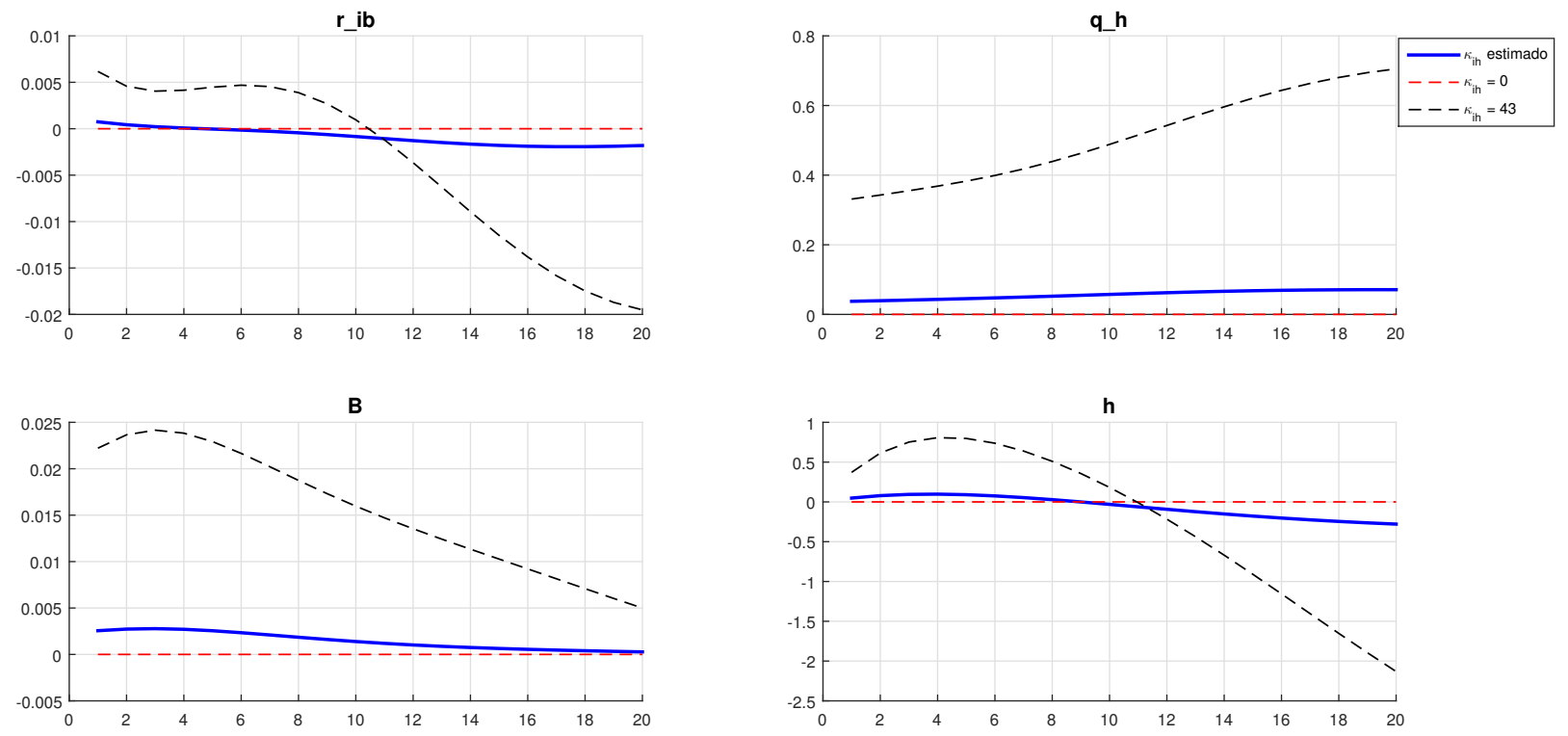

Figura 17: Efeito de um choque na oferta de imóveis

Como pode ser visto a partir da comparação dos gráficos 14 - 15 e 16 - 17, o efeito do custo de ajustamento no setor de imóveis sobre o acelerador financeiro depende do tipo de choque que a economia sofre. Para um choque de demanda por imóveis, as variáveis têm uma resposta maior no modelo sem custo de ajustamento (com exceção do preço do capital). Isto ocorre porque o setor consegue responder rapidamente ao aumento na demanda de tal forma que o valor do colateral das famílias e empresários aumenta, mesmo que o preço dos imóveis não varie com o choque. Para um choque originado no 
lado da oferta, o modelo com maior custo de ajustamento apresenta também o maior acelerador. Neste caso, entretanto, o efeito sobre o colateral dos empréstimos se dá via aumento no preço dos imóveis. Observe que, para os modelos com custo de ajustamento diferente de zero, o aumento no preço dos imóveis é grande o suficiente para compensar a queda subsequente no estoque de imóveis. 


\subsection{Conclusão}

Neste modelo foram introduzidos um setor produtor de imóveis e uma segunda modalidade de empréstimos para as famílias impacientes (o empréstimo consignado), na estrutura proposta em Gerali et all (2010). Após estimar o modelo foi possível analisar os efeitos de choques nestes setores, bem como o papel exercido pelas imperfeições no setor bancário e no setor produtor de imóveis.

Como pôde ser observado, um choque na razão debt-to-income, embora leve a uma redução no salário das famílias impacientes, estimula a produção agregada, dado seus efeitos sobre o crédito total da economia. Um aumento inesperado no mark-up sobre a taxa de juros de empréstimo consignado, embora aumente o lucro dos bancos, reduz o crédito disponível na economia. Os choques no setor imobiliário demonstram a importância deste na economia; um choque de demanda, embora redirecione recursos antes utilizados para consumo e investimento em máquinas e equipamentos, estimula a procura de imóveis em montante suficiente para elevar o produto agregado e quantidade de crédito disponível na economia. Já um choque de oferta, apesar de seus efeitos adversos sobre o setor, provoca um aumento na oferta de crédito via aumento no valor do colateral utilizado por famílias e empresários - visto que o choque tem como um dos efeitos o aumento no preço das imóveis.

Com relação às fricções financeiras, percebe-se, através da comparação entre as IRFs, que as mais importantes estão relacionadas ao capital bancário e ao poder de mercado na determnação pelos bancos das taxas de juros sobre os depósitos e empréstimos. Por fim, com relação ao efeito de fricções na oferta de imóveis sobre a dinâmica da economia, esta depende fundamentalmente da fonte do choque: para um choque na demanda por imóveis o custo de ajustamento do investimento neste setor tende a amortacer os efeitos deste choque; quando o choque ocorre na oferta de imóveis, o custo de ajustamente tende a amplificar seus efeitos. 
Parte III

Modelo Para Uma Economia Aberta 



\section{Descrição do Modelo}

O modelo a seguir é uma extensão daquele apresentado para uma economia fechada, supõe-se agora que a economia doméstica afetua transações com outras economias nos mercados de bens e financeiro. No mercado de bens, os empresários demandam insumos importados para a produção de bens intermediários enquanto parte da cesta de bens finais é exportada para outras economias. Em relação ao setor bancário, os intermediários financeiros podem se tornam aptos a captar poupança externa para aumentar o crédito na economia doméstica. Para que a exporsição do modelo não se torne repetitiva, serão listadas apenas as CPOs para os agentes que não tiveram seus problemas de otimização alterados. A figura 18 apresenta a estrutura do modelo abaixo de forma resumida.

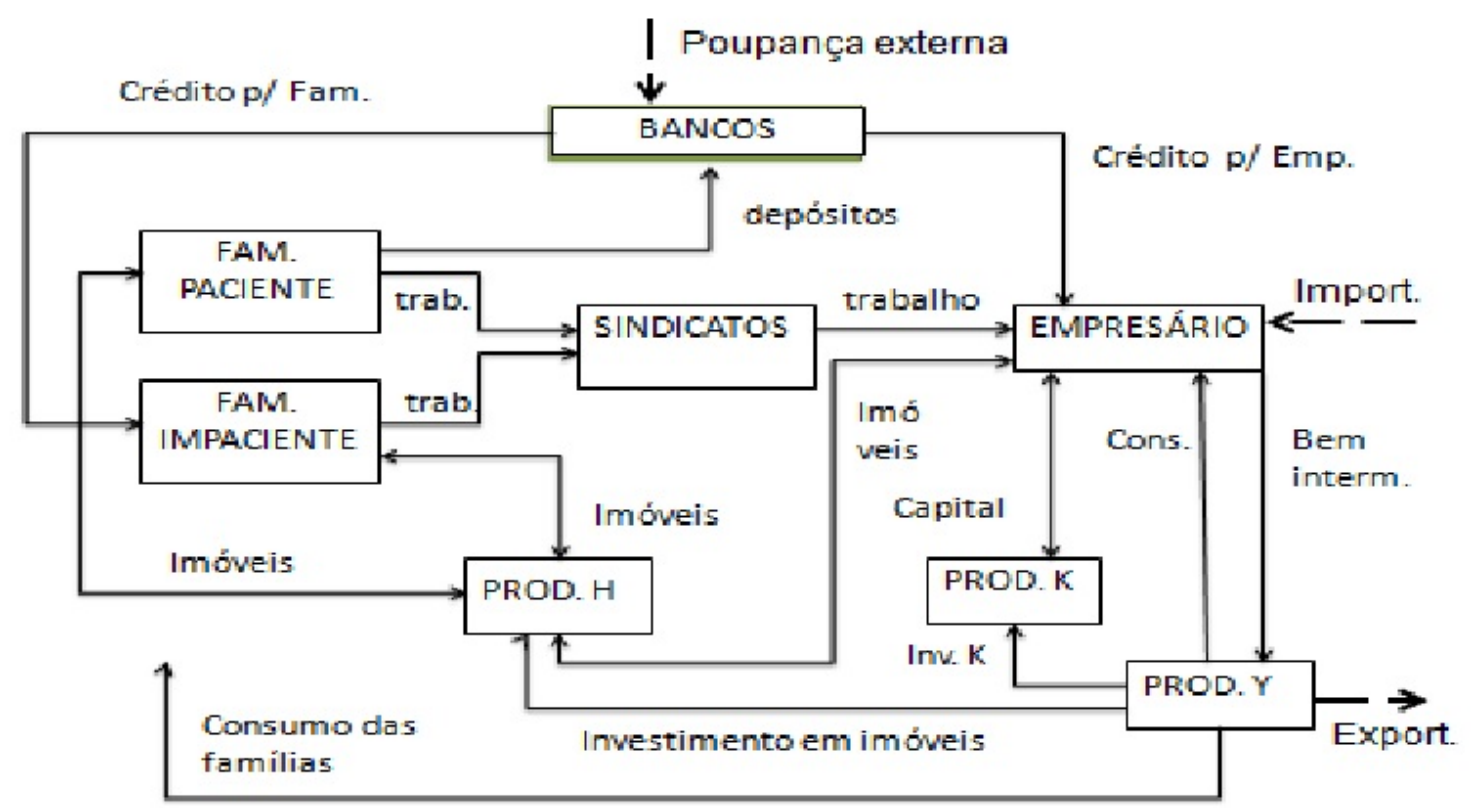

Figura 18: Panorama do Modelo

\subsection{Famílias, Sindicatos e Produção}

- Famílias Pacientes: as famílias poupadoras maximizam (4.1), sujeita à (4.2), resultando nas seguintes CPOs,

$$
\lambda_{t}^{P}=\varepsilon_{t}^{z} \frac{1-a^{P}}{c_{t}^{P}-a^{P} c_{t-1}^{P}}
$$




$$
\begin{aligned}
\lambda_{t}^{P} q_{t}^{h} & =\frac{\varepsilon_{t}^{h} j^{h}}{h_{t}^{P}}+\left(1-\delta^{h}\right) \beta_{P} E_{t}\left[\lambda_{t+1}^{P} q_{t+1}^{h}\right] \\
\lambda_{t}^{P} & =\beta_{P} E_{t}\left\{\lambda_{t+1}^{P} \frac{\left(1+r_{t}^{d}\right)}{\pi_{t+1}}\right\}
\end{aligned}
$$

- Famílias Impacientes: as famílias tomadoras de empréstimos maximizam (4.6) sujeita à (4.7),(4.8) e (4.9), resultando nas seguintes CPOs,

$$
\begin{aligned}
\lambda_{t}^{I} & =\varepsilon_{t}^{z} \frac{1-a^{I}}{c_{t}^{I}-a^{I} c_{t-1}^{I}} \\
\lambda_{t}^{I} q_{t}^{h} & =\frac{\varepsilon_{t}^{h} j^{h}}{h_{t}^{I}}+\left(1-\delta^{h}\right) \beta_{I} E_{t}\left\{\lambda_{t+1}^{I} q_{t+1}^{h}+s_{t}^{I h} m_{t}^{I h} q_{t+1}^{h} \pi_{t+1}\right\} \\
\lambda_{t}^{I} & =s_{t}^{I h}\left(1+r_{t}^{b H}\right)+\beta_{I} E_{t}\left\{\lambda_{t+1}^{I} \frac{\left(1+r_{t}^{b H}\right)}{\pi_{t+1}}\right\} \\
\lambda_{t}^{I} & =s_{t}^{I w}\left(1+r_{t}^{b W}\right)+\beta_{I} E_{t}\left\{\lambda_{t+1}^{I} \frac{1+r_{t}^{b W}}{\pi_{t+1}}\right\}
\end{aligned}
$$

- Sindicatos das Famílias Pacientes: o sindicato as famílias pacientes tem como objetivo maximizar o benefício líquido de uma variação no salário nominal, sujeito à demanda (4.15). A partir desse problema, é possível derivar a curva de Phillips de salário para os poupadores,

$\kappa_{w}\left(\pi_{t}^{w^{P}}-\pi_{t-1}^{\iota w} \pi^{1-\iota w}\right) \pi_{t}^{w^{P}}=\beta_{P} E_{t}\left\{\frac{\lambda_{t+1}^{P}}{\lambda_{t}^{P}} \kappa_{w}\left(\pi_{t+1}^{w^{P}}-\pi_{t-1}^{\iota w} \pi^{1-\iota w}\right) \frac{\pi_{t+1}^{w^{P}}}{\pi_{t+1}}\right\}+\left(1-\varepsilon^{l}\right) l_{t}^{P}+\frac{\varepsilon^{l} l_{t}^{P^{1+\phi}}}{w_{t}^{P} \lambda_{t}^{P}}$

- Sindicatos das Famílias Impacientes: resolvendo um problema similar ao dos sindicatos das famílias pacientes, é possível encontrar uma curva de Phillips para os salários das famílias impacientes,

$$
\begin{gathered}
\kappa_{w}\left(\pi_{t}^{w^{I}}-\pi_{t-1}^{\iota w} \pi^{1-\iota w}\right) \pi_{t}^{w^{I}}= \\
=\beta_{I} E_{t}\left\{\frac{\lambda_{t+1}^{P}+m_{t+1}^{I w} s_{t+1}^{I w}}{\lambda_{t}^{P}+m_{t}^{I w} s_{t}^{I w}} \kappa_{w}\left(\pi_{t+1}^{w^{I}}-\pi_{t-1}^{\iota w} \pi^{1-\iota w}\right) \frac{\pi_{t+1}^{w^{I}}{ }^{2}}{\pi_{t+1}}\right\}+\left(1-\varepsilon^{l}\right) l_{t}^{I}+\frac{\varepsilon^{l} l_{t}^{I^{1+\phi}}}{w_{t}^{I}\left(\lambda_{t}^{I}+m_{t}^{I w} s_{t}^{I w}\right)}(
\end{gathered}
$$

- Produtores de Capital e de Imóveis: a produção no setor de capital (imobiliário), se dá pela combinação de bens de investimento $i_{t}^{k}\left(i_{t}^{h}\right)$ com estoque velha de capital (imóveis). A partir do problema de maximização dos lucros nestes setores encontramse as equações de precificação do capital e imóveis,

$$
1=q_{t}^{k}\left[1-\frac{\kappa_{i k}}{2}\left(\frac{i_{t}^{k} \varepsilon_{t}^{q k}}{i_{t-1}^{k}}-1\right)^{2}-\kappa_{i k}\left(\frac{i_{t}^{k} \varepsilon_{t}^{q k}}{i_{t-1}^{k}}-1\right) \frac{i_{t}^{k} \varepsilon_{t}^{q k}}{i_{t-1}^{k}}\right]
$$




$$
\begin{aligned}
& +\beta_{E} E_{t}\left\{\frac{\lambda_{t+1}^{E}}{\lambda_{t}^{E}} q_{t+1}^{k} \varepsilon_{t+1}^{q k} \kappa_{i k}\left(\frac{i_{t+1}^{k} \varepsilon_{t+1}^{q k}}{i_{t}^{k}}-1\right)\left(\frac{i_{t+1}^{k}}{i_{t}^{k}}\right)^{2}\right\} \\
& 1=q_{t}^{h}\left[1-\frac{\kappa_{i h}}{2}\left(\frac{i_{t}^{h} \varepsilon_{t}^{q h}}{i_{t-1}^{h}}-1\right)^{2}-\kappa_{i h}\left(\frac{i_{t}^{h} \varepsilon_{t}^{q h}}{i_{t-1}^{h}}-1\right) \frac{i_{t}^{h} \varepsilon_{t}^{q h}}{i_{t-1}^{h}}\right] \\
& +\beta_{E} E_{t}\left\{\frac{\lambda_{t+1}^{E}}{\lambda_{t}^{E}} q_{t+1}^{h} \varepsilon_{t+1}^{q h} \kappa_{i h}\left(\frac{i_{t+1}^{h} \varepsilon_{t+1}^{q h}}{i_{t}^{h}}-1\right)\left(\frac{i_{t+1}^{h}}{i_{t}^{h}}\right)^{2}\right\}
\end{aligned}
$$

- Produtores de Bens Finais: embora a cesta de bens finais possa ser exportada, o problema de otimização das firmas produtoras de bens finais permanece inalterado. Desta forma a curva de Phillips de preços permanece,

$$
\begin{aligned}
& 1-\varepsilon_{t}^{y}+\frac{\varepsilon_{t}^{y}}{x_{t}}-\kappa_{p}\left(\pi_{t}-\pi_{t-1}^{\iota_{p}} \pi^{1-\iota_{p}}\right) \pi_{t}+ \\
& \beta_{P} E_{t}\left\{\frac{\lambda_{t+1}^{P}}{\lambda_{t}^{P}} \kappa_{P}\left(\pi_{t+1}-\pi_{t}^{\iota_{p}} \pi^{1-\iota_{p}}\right) \pi_{t+1} \frac{y_{t+1}}{y_{t}}\right\}=0 .
\end{aligned}
$$

- Autoridade Monetária: na condução da política monetária, o banco central a taxa básica de juros da economia doméstica seguindo a seguinte regra de Taylor,

$$
\left(1+r_{t}\right)=(1+r)^{1-\phi_{R}}\left(1+r_{t-1}\right)^{\phi_{R}}\left(\frac{\pi_{t}}{\pi}\right)^{\phi_{\pi}\left(1-\phi_{R}\right)}\left(\frac{Y_{t}}{Y_{t-1}}\right)^{\phi_{y}\left(1-\phi_{R}\right)} \varepsilon_{t}^{r}
$$

\subsection{Empresários}

Como no modelo anterior, a produção de bens intermediários $y_{t}^{E}$ é realizada pelos empresários. Como em Cavalcanti e Vereda (2010), para que isto ocorra, o emprésário deve combinar trabalho, capital e insumo importado $Q_{t}$ por meio de uma tecnologia de produção do tipo Cobb-Douglas. O problema de otimização deste agente se torna então,

$\max _{c_{t}^{E}, h_{t}^{E}, b_{t}^{E}, l_{t}^{E, P}, l_{t}^{E, I}, k_{t}^{E}, u_{t}, Q_{t}} E_{0} \sum_{t=0}^{\infty}\left(\beta_{E}\right)^{t}\left\{\left(1-a^{E}\right) \varepsilon_{t}^{z} \log \left(c_{i}^{E}(i)-a^{E} c_{t-1}^{E}\right)+\varepsilon_{t}^{h} j^{h} \log \left(h_{t}^{E}(i)\right)\right\}$

s.a.

$$
\begin{aligned}
& c_{t}^{E}(i)+w_{t}^{P} l_{t}^{E, P}(i)+w_{t}^{I} l_{t}^{E, I}(i)+e_{t}^{r} p_{t}^{Q} Q_{t}(i)+\frac{1+r_{t-1}^{b E}}{\pi_{t}} b_{t-1}^{E}(i)+q_{t}^{k} k_{t}^{E}(i)+q_{t}^{h} h_{t}^{E}(i)+ \\
& \quad+\psi\left(u_{t}(i)\right) k_{t-1}^{E}(i)=\frac{y_{t}^{E}(i)}{x_{t}}+b_{t}^{E}(i)+q_{t}^{k}(1-\delta) k_{t-1}^{E}(i)+q_{t}^{h}\left(1-\delta^{h}\right) h_{t-1}^{E}(i)
\end{aligned}
$$




$$
\begin{gathered}
y_{t}^{E}(i)=A_{t}^{E}\left[k_{t-1}^{E}(i) u_{t}(i)\right]^{\alpha_{k}}\left[l_{t}^{E}(i)\right]^{\alpha_{l}}\left[Q_{t}(i)\right]^{1-\alpha_{l}-\alpha_{k}} \\
l_{t}^{E}=\left(l_{t}^{E, P}\right)^{\mu}\left(l_{t}^{E, I}\right)^{1-\mu} \\
\left(1+r_{t}^{b E}\right) b_{t}^{E}(i) \leq m_{t}^{E} E_{t}\left\{q_{t+1}^{k} \pi_{t+1}(1-\delta) k_{t}^{E}(i)+q_{t+1}^{h} \pi_{t+1}\left(1-\delta^{h}\right) h_{t}^{E}\right\},
\end{gathered}
$$

Em que $p_{t}^{Q}$ é o preço do insumo importado em moeda estrangeira e $e_{t}^{r}$ é a taxa de câmbio real em moeda nacional. Ainda, $p_{t}^{Q}$ segue o processo estocástico abaixo:

$$
p_{t}^{Q}=\left(1-\rho_{p Q}\right) \bar{p}^{Q}+\rho_{p Q} p_{t-1}^{Q}+\eta_{t}^{p Q}
$$

Sendo $\eta_{t}^{p Q}$ é um processo iid normalmente distribuido com média zero e desvio-padrão igual a $\sigma_{p Q}$. As condições de primeira ordem dos empresários definem a evolução do consumo, a taxa de utilização do capital e as demandas por imóveis, trabalho das famílias, capital e insumo importado.

$$
\begin{aligned}
\lambda_{t}^{E} & =\frac{1-a^{E}}{c_{t}^{E}-a^{E} c_{t-1}^{E}} \\
\lambda_{t}^{E} q_{t}^{k} & =E_{t}\left\{s_{t}^{E} m_{t}^{E} q_{t+1}^{k} \pi_{t+1}(1-\delta)+\beta_{E} \lambda_{t+1}^{E}\left[r_{t+1}^{k} u_{t+1}+q_{t+1}^{k}(1-\delta)-\psi\left(u_{t+1}\right)\right]\right\} \\
r_{t}^{k} & =\xi_{1}+\xi_{2}\left(u_{t}-1\right) \\
w_{t}^{P} & =\alpha_{l} \frac{y_{t}^{E}}{x_{t}} \frac{\mu}{l_{t}^{E, P}} \\
w_{t}^{I} & =\alpha_{l} \frac{y_{t}^{E}}{x_{t}} \frac{1-\mu}{l_{t}^{E, I}} \\
e_{t}^{r} p_{t}^{Q} & =\left(1-\alpha_{l}-\alpha_{k}\right) \frac{y_{t}^{E}}{x_{t}} \frac{1}{Q_{t}} \\
\lambda_{t}^{E} q_{t}^{h} & =\frac{\varepsilon_{t}^{h} j^{h}}{h_{t}^{E}}+\left(1-\delta^{h}\right) E_{t}\left\{q_{t+1}^{h}\left(s_{t}^{E} m_{t}^{E} \pi_{t+1}+\beta_{E} \lambda_{t}^{E}\right)\right\} \\
\lambda_{t}^{E} & =s_{t}^{E}\left(1+r_{t}^{b E}\right)+\beta_{E} E_{t}\left\{\lambda_{t+1}^{E} \frac{\left(1+r_{t}^{b E}\right)}{\pi_{t+1}}\right\}
\end{aligned}
$$

Em que $r_{t}^{k} \equiv \frac{1}{x_{t}} \alpha_{k} A_{t}^{E}\left[k_{t-1}^{E} u_{t}\right]^{\alpha_{k}-1} l_{t}^{E \alpha_{l}} Q_{t}^{1-\alpha_{l}-\alpha_{k}}$

\subsection{Bancos}

Os bancos têm a função de mediar todas as transações financeiras entre a economia nacional e estrangeiro e entre os agentes domésticos neste modelo. É por isso que elas têm 
uma importância significativa na estrutura de nesta economia hipotética. Logo, somente os bancos estão aptos a receber depósitos de famílias pacientes e poupança externa e ofertar crédito para as famílias impacientes e empresários. Neste setor é estruturado da seguinte forma: cada banco $j \in[0,1]$ é dividido em dois departamentos: a tesouraria e unidade de varejo. A função da tesouraria é para gerir a posição de capital para evitar desvios do capital bancário em relação ao seu valor ótimo.

O capital dos bancos é relativamente fixo no curto prazo, mas é ajustado ao longo tempo por lucros acumulados de períodos subsequentes. Assim, os bancos fazem a curto prazo ajustes na sua oferta de crédito por meio de suas operações no interbancário mercado, comprando $\left(D_{t}\right)$ e $B_{t}^{*}$ e vendendo $\left(B_{t}\right)$.

A unidade de varejista, por sua vez, tem dois departamentos, um para empréstimos às famílias e empresários, e outro para depósitos das famílias. O mercado de varejo bancário é caracterizada por concorrência monopolista, permitindo poder de mercado para cada banco, para que eles possam ajustar suas as taxas de empréstimo e de depósito em resposta a choques cíclicos ou outras condições da economia. Mas, para isso, eles estão sujeitos a custos de ajustamento quando eles desviam-se das taxas estabelecidas no período anterior. Ou seja, os bancos financiam seus empréstimos $B_{t}$ com depósitos de pacientes $D_{t}$, poupança externa $B^{*}$ e famílias com patrimônio próprio $K^{b}$.

\subsubsection{Departamento Atacadista}

O departamento atacadista capta recursos não somente do setor de depósitos do departamento varejista como também de outras economias. Desta forma, o balanço patrimonial dos bancos contém empréstimos $B_{t}$ ao setor de empréstimos do banco como ativo e depósitos $D_{t}$, capital bancário $K_{t}^{b}$ e empréstimos externos denominados em moeda doméstica $e_{t}^{r} B_{t}^{*}$ no lado do passivo.

$$
B_{t}(j)=D_{t}(j)+K_{t}^{b}(j)+e_{t}^{r} B_{t}^{*}(j)
$$

Quando os bancos domésticos capta empréstimo de outras economias, eles devem pagar uma dada taxa de juros internacional $\left(R^{*},\right)$ e um prêmio de risco expresso por:

$$
\Phi_{t}=\exp \left(-\zeta \frac{e_{t}^{r} B_{t}^{*}}{K_{t}^{b}}\right) \varepsilon_{t}^{\Phi}
$$

É válido notar que o prêmio de risco depende da relação $\frac{e_{t}^{r} B_{t}^{*}}{K_{t}^{b}}$, desta forma o banco, no gerenciamento do capital deve levar em conta não somente o requerimento de capital, dado por $\nu^{b}$, como também o prêmio de risco pago nos empréstimos com o exterior. A acumulação de capital bancário é expresso por: 


$$
\pi_{t} K_{t}^{b}(j)=\left(1-\delta^{b}\right) K_{t-1}^{b}(j)+J_{t-1}^{b, n}(j)
$$

O problema de maximização de lucro, em termos reais, do departamento atacadista é:

$$
\begin{aligned}
& \max _{\left\{B_{t}, D_{t}, B_{t}^{*}\right\}} E_{0} \sum_{t=0}^{\infty} \Lambda_{0, t}^{P}\left\{\left(1+R_{t}^{b}\right) B_{t}-B_{t+1} \pi_{t+1}+D_{t+1} \pi_{t+1}-\left(1+R_{t}^{d}\right) D_{t}\right. \\
& -\left(1+R_{t}^{*}\right) \Phi_{t} e_{t+1}^{r} \frac{\pi_{t+1}}{\pi_{t+1}^{*}} B_{t}^{*}+e_{t+1}^{r} B_{t+1}^{*} \\
& \left.+\left(K_{t+1}^{b} \pi_{t+1}-K^{b}\right)-\frac{\kappa_{k b}}{2}\left(\frac{K_{t}^{b}}{B_{t}}-\nu^{b}\right)^{2} K_{t}^{b}\right\}
\end{aligned}
$$

sujeito à restrição do balanço patrimonial $B_{t}=D_{t}+e_{t}^{r} B_{t}^{*}+K_{t}^{b}$ e a definição de prêmio de risco, dada por (7.25). Ainda, é assumido que $R_{t}^{*}$ segue o processo

$$
R_{t}^{*}=\left(1-\rho_{R^{*}}\right) \bar{R}^{*}+\rho_{R^{*}} R_{t-1}^{*}+\eta_{t}^{R^{*}}
$$

Combinando as condições de primeira ordem para $D_{t}$ e $B_{t}$ é possível derivar uma equação para o spread entre as taxas de depósito e empréstimo no mercado interbancário,

$$
R_{t}^{b}=R_{t}^{d}-\kappa_{k b}\left(\frac{K_{t}^{b}}{B_{t}}-\nu^{b}\right)\left(\frac{K_{t}^{b}}{B_{t}}\right)^{2}
$$

Como no modelo para economia fechada, o spread entre as taxas de juros depende relação entre o capital bancário e os empréstimos realizados. Combinando as condições de primeira ordem para $D_{t}$ e $B_{t}^{*}$, encontra-se uma equação de paridade (UIP) entre as taxas externa e de política monetária para a economia doméstica - supondo novamente que $R_{t}^{d}=r_{t}$ :

$$
\left(1+R_{t}^{*}\right) \Phi_{t}\left(1-\zeta \frac{e_{t}^{r} B_{t}^{*}}{K_{t}^{b}}\right) E_{t}\left\{\frac{e_{t+1}^{r}}{e_{t}^{r}} \frac{\pi_{t+1}}{\pi_{t+1}^{*}}\right\}=1+R_{t}^{d}
$$

De acordo com a equação acima, a taxa de juros doméstica de política monetária é igual a taxa de juros externa ajustada pelo prêmio de risco - multiplicada pela variação esperada da taxa de câmbio real e pela razão entre a inflação doméstica e externa. A inflação externa, assim como a taxa de juros, é modelada como um processo estocástico $A R(1)$ :

$$
\pi_{t}^{*}=\left(1-\rho_{\pi^{*}}\right) \bar{\pi}^{*}+\rho_{\pi^{*}} \pi_{t-1}^{*}+\eta_{t}^{\pi^{*}}
$$

Em que $\eta_{t}^{\pi^{*}}$ é um processo iid com média zero e variância igual a $\sigma^{\pi^{*}}$. 


\subsubsection{Departamento Varejista}

O departamento varejista do banco - tanto setor de empréstimos quanto o de depósitos - permanece inalterado em relação ao modelo de economia fechada. Assim, setor de depósitos do banco $j$ tem como objetivo maximizar (??) sujeito à demanda por depósitos por parte das famílias pacientes, dada por (4.32). A condição de primeira ordem define a equação para a determinação da taxa de juros:

$$
\max _{\left\{r_{t}^{d}(j)\right\}} E_{0} \sum_{t=0}^{\infty} \Lambda_{0, t}^{P}\left\{r_{t} D_{t}(j)-r_{t}^{d}(j) d_{t}^{P}(j)-\frac{\kappa_{d}}{2}\left(\frac{r_{t}^{d}(j)}{r_{t-1}^{d}(j)}-1\right)^{2} r_{t}^{d} d_{t}\right\}
$$

De forma análoga, o setor de empréstimos tem como objetivo maximizar sujeito às funções de demanda por empréstimos (4.30) e (4.31) das famílias impacientes e empresários, respecitvamente. A partir das condições de primeira ordem é possível derivar as equações que definem as taxas de empréstimo às famílias impacientes e empresários:

$$
\begin{array}{r}
1-\varepsilon_{t}^{b s}+\varepsilon_{t}^{b s} \frac{R_{t}^{b}}{r_{t}^{b s}}-\kappa_{b s}\left(\frac{r_{t}^{b s}}{r_{t-1}^{b s}}-1\right) \frac{r_{t}^{b s}}{r_{t-1}^{b s}} \\
+\beta_{P} E_{t}\left\{\frac{\lambda_{t+1}^{s}}{\lambda_{t}^{s}} \kappa_{b s}\left(\frac{r_{t+1}^{b s}}{r_{t}^{b s}}-1\right)\left(\frac{r_{t+1}^{b s}}{r_{t}^{b s}}\right)^{2} \frac{b_{t+1}^{s}}{b_{t}^{s}}\right\}=0,
\end{array}
$$

Em que $s \in I h, I w, E$.

Lucro do Banco - calculando o lucro bancário de forma semelhante ao modelo de economia fechada, chega-se à seguinte expressão:

$$
\begin{array}{r}
j_{t}^{b}=r_{t}^{b H} b_{t}^{I h}+r_{t}^{b W} b_{t}^{I w}+r_{t}^{b E} b_{t}^{E}+e_{t}^{r} B_{t}^{*}-r_{t}^{d} d_{t}-\left(1+R_{t-1}^{*}\right) \Phi_{t-1} e_{t}^{r} B_{t-1}^{*} \\
-\frac{\kappa_{k b}}{2}\left(\frac{K_{t}^{b}}{B_{t}}-\nu^{b}\right)^{2}-K_{t}^{b}-A d j_{t}^{B},
\end{array}
$$

\subsection{Agregação e Equilíbrio}

\subsubsection{Equilíbrio}

O equilíbrio do modelo é obtido quando, para um dado sistema de preços, processos exógenos e política econômica (4.52) são satifeitos:

- as restrições orçamentárias (4.2), (4.7) e (4.19) das famílias e empresários;

- as restrições de crédito (4.8), (4.9) (4.22) das famílias impacientes e empresários; 
- as demandas por trabalho (4.15) e por endividamento (4.31) dos empresários, por endividamento (4.30) das famílias impacientes, por depositos (4.32) das famílias pacientes e por bens finais (4.49) e

- as equações de acumulação de capital físico, bancário e de imóveis (4.42), (4.34) e (4.45), respectivamente.

E dadas as equações acima, as CPOS resolvem os problemas:

- das famílias pacientes (4.1), impacientes (4.6) e empresários (4.18);

- dos produtores varejistas (4.48), de imóveis (4.46) e capital (4.43);

- dos bancos, nos departamentos atacadista (7.27) and de empréstimos (4.37) e depositos (4.39).

Market Clearing:

1. Mercado de Bens

$$
y_{t}=c_{t}+i_{t}^{k}+i_{t}^{h}+y_{t}^{e x p}
$$

Em que, $c_{t} \equiv c_{t}^{P}+c_{t}^{I}+c_{t}^{E}$ é o consumo agregado e $y_{t}^{e x p}$ é a cesta de bens exportada, definida por:

$\mathrm{y}_{t}^{\exp }=\left(\frac{1}{e_{t}^{r}}\right)^{-\tau} y_{t}^{*}$

Em que $y_{t}^{*}$ segue o processo $A R(1)$ dado por,

$$
y_{t}^{*}=\left(1-\rho_{y^{*}}\right) \bar{y}^{*}+\rho_{y^{*}} y_{t-1}^{*}+\eta_{t}^{y^{*}}
$$

2. Mercado Imobiliário

$$
h_{t}=h_{t}^{P}+h_{t}^{I}+h_{t}^{E}
$$

3. Mercado de Trabalho

$$
l_{t}^{P E}+l_{t}^{I E}=l_{t}^{P}+l_{t}^{I}
$$

4. Mercado Financeiro

$$
\begin{gathered}
B_{t}=b_{t}^{I h}+b_{t}^{I w}+b_{t}^{E} \\
D_{t}=d_{t}^{P}
\end{gathered}
$$

5. Balanço de Pagamentos

$$
y_{t}^{e x p}-e_{t}^{r} p_{t}^{Q} Q_{t}-\frac{\left(1+R_{t-1}^{*}\right)}{\pi_{t}^{*}} \Phi_{t-1} e_{t}^{r} B_{t-1}^{*}=e_{t}^{r} B_{t}^{*}-\frac{e_{t}^{r} B_{t-1}^{*}}{\pi_{t}^{*}}
$$

6. Produto

$$
Y_{t}=y_{t}-e_{t}^{r} p_{t}^{Q} Q_{t}
$$




\subsection{Steady State Equations}

$$
\begin{gathered}
q^{k}=1 \\
q^{h}=1 \\
p^{Q}=1 \\
\varepsilon^{q k}=1 \\
\varepsilon^{y}-1 \\
\varepsilon^{q h}=1 \\
\varepsilon^{z}=1 \\
\pi^{*}=1 \\
\pi^{w I}=1 \\
\pi^{w p}=\pi
\end{gathered}
$$




$$
\begin{gathered}
\varepsilon^{\Phi}=1 \\
\varepsilon^{r}=1 \\
m^{I h}=\bar{m}^{I h} \\
m^{I w}=\bar{m}^{I w} \\
\lambda^{I}=\frac{1}{c^{P}} \\
r^{E}=\frac{\bar{m}^{E}}{c^{b}} \\
r^{b E}-1 \\
r^{b H}=\frac{\varepsilon^{b E}}{\varepsilon^{b I w}-1} r \\
r^{d}=\frac{\varepsilon^{b I h}}{\varepsilon^{b}}-1 \\
y^{*}=\bar{y}^{*} \\
\varepsilon^{b}
\end{gathered}
$$




$$
\begin{aligned}
& \lambda^{E}=\frac{1}{c^{E}} \\
& s^{I h}=\left(\frac{1}{1+r^{b H}}-\frac{\beta^{I}}{\pi}\right) \lambda^{I} \\
& s^{I w}=\left(\frac{1}{1+r^{b W}}-\frac{\beta^{I}}{\pi}\right) \lambda^{I} \\
& b^{I h}=\frac{1}{1+r^{b H}} m^{I h}\left\{\left(1-\delta^{h}\right) q^{h} h^{I} \pi\right\} \\
& b^{I w}=\frac{1}{1+r^{b W}} m^{I w}\left\{w^{I} l^{I} \pi\right\} \\
& b^{E}=\frac{1}{1+r^{E}} m^{E}\left\{(1-\delta) q^{k} k \pi+\left(1-\delta^{h}\right) q^{h} h^{E} \pi\right\} \\
& h^{p}=\frac{j^{h} \varepsilon^{h}}{\lambda^{p} q^{h}\left(1-\left(1-\delta^{h}\right) \beta^{P}\right)} \\
& h^{I}=\frac{j^{h} \varepsilon^{h}}{\lambda^{I} q^{h}\left(1-\left(1-\delta^{h}\right)\left(s^{I h} m^{I h} \pi+\beta^{I} \lambda^{I}\right)\right)} \\
& h^{E}=\frac{j^{h} \varepsilon^{h}}{\lambda^{E} q^{h}\left(1-\left(1-\delta^{h}\right)\left(s^{E} m^{E} \pi+\beta^{E} \lambda^{E}\right)\right)} \\
& w^{P}=\frac{\varepsilon^{l}}{\varepsilon^{l}-1} \frac{\left(l^{P}\right)^{\phi}}{\lambda^{P}} \\
& w^{I}=\frac{\varepsilon^{l}}{\varepsilon^{l}-1} \frac{\left(l^{I}\right)^{\phi}}{\lambda^{I}+s^{I w} m^{I w}} \\
& w^{P}=\frac{\mu \alpha_{l}}{x} \frac{y^{E}}{l^{P}} \\
& w^{I}=\frac{(1-\mu) \alpha_{l}}{x} \frac{y^{E}}{l^{I}} \\
& e^{r} p^{Q}=\frac{1-\alpha_{l}-\alpha_{k}}{x} \frac{y^{E}}{Q_{t}} \\
& \lambda^{E} q^{k}=s^{E} m^{E} q^{k} \pi(1-\delta)+\beta^{E} \lambda^{E}\left[r^{k} u+q^{k}(1-\delta)\right]
\end{aligned}
$$




$$
\begin{aligned}
& r^{k}=\frac{1}{x} \alpha_{k} A^{E}(u k)^{\alpha_{k}-1}\left(l^{P}\right)^{\mu \alpha_{l}}\left(l^{I}\right)^{(1-\mu) \alpha_{l}}(Q)^{1-\alpha_{l}-\alpha_{k}} \\
& r^{k}=\xi_{1} \\
& i^{k}=\delta k \\
& i^{h}=\delta^{h} h \\
& K^{b}=\frac{J^{b}}{\pi-1+\delta^{b}} \\
& \left(1+R^{*}\right) \Phi\left(1-\zeta \frac{e^{r} B^{*}}{K^{b}}\right) \frac{\pi}{\pi^{*}}=1+r \\
& \Phi=\exp \left(-\zeta \frac{e^{r} B^{*}}{K^{b}}\right) \varepsilon^{\Phi} \\
& J^{y}=\left\{1-\frac{1}{x}\right\} y \\
& J^{b}=r^{b H} b^{I h}+r^{b W} b^{I w}+r^{E} b^{E}-r^{d} d^{P}+\left[1-\frac{\left(1+R^{*}\right)}{\pi^{*}} \Phi\right] e^{r} B^{*} \\
& h=h^{P}+h^{I}+h^{E} \\
& y^{e x p}-e^{r} p^{Q} Q=\left(1+\frac{\left(1+R^{*}\right) \Phi}{\pi^{*}}-\frac{1}{\pi^{*}}\right) e^{r} B^{*} \\
& D=d^{P}=b^{I h}+b^{I w}+b^{E}-e^{r} B^{*}-K^{b} \\
& c^{p}+q^{h} \delta^{h} h^{P}=w^{P} l^{P}+\left(\frac{1+r^{d}}{\pi}-1\right) d^{P}+J^{y} \\
& c^{I}+q^{h} \delta^{h} h^{I}=w^{I} l^{I}-\left(\frac{1+r^{b H}}{\pi}-1\right) b^{I h}-\left(\frac{1+r^{b W}}{\pi}-1\right) b^{I w} \\
& c^{E}+w^{P} l^{P}+w^{I} l^{I}+e^{r} p^{Q} Q+q^{k} \delta k+q^{h} \delta^{h} h^{E}=\frac{y^{E}}{x}-\left(\frac{1+r^{b E}}{\pi}-1\right) b^{E}
\end{aligned}
$$




$$
\begin{gathered}
y^{E}=A^{E}(u k)^{\alpha_{l}}\left(l^{P}\right)^{\mu \alpha_{l}}\left(l^{I}\right)^{(1-\mu) \alpha_{l}}(Q)^{1-\alpha_{l}-\alpha_{k}} \\
y=c^{P}+c^{I}+c^{E}+i^{k}+i^{h}+y^{e x p} \\
y^{e x p}=\left(\frac{1}{e^{r}}\right)^{-\tau} y^{*} \\
Y=y-e^{r} p^{Q} Q
\end{gathered}
$$





\section{Base de dados e Calibração}

A base de dados usada para a estimação do modelo é composta por 32 observações com periodicidade trimestral, compreendidas entre o primeiro trimestre de 2007 e o último trimestre de 2014. As séries foram obtidas por meio dos sites do Banco Central (www.bcb.gov.br), Ibge (www.ibge.gov.br), Ipeadata (www.ipeadata.gov.br), FGV (portalibre.fgv.br) e do Bureau of Labor Statistics (www.bls.gov). Abaixo estão descritas as séries utilizadas:

1. Taxa de juros crédito pessoal consignado: Taxa média de juros das novas operações de crédito livre contratadas no período de referência. Taxa ponderada pelo valor das concessões. Não inclui operações referenciadas em taxas regulamentadas, operações vinculadas a recursos do Banco Nacional de Desenvolvimento Econômico e Social (BNDES) ou quaisquer outras lastreadas em recursos compulsórios ou governamentais.

2. Taxa de juros de política monetária: taxa de juros selic

3. Inflação doméstica: Indice de Preços ao ConsumidorAmplo (IPCA)

4. Divida externa bruta: A estatística da dívida externa compreende o total apurado em determinada data, dos débitos contratuais efetivamente desembolsados e ainda não quitados, de residentes com não residentes, onde haja a obrigatoriedade de pagamento de principal e/ou juros. A dívida externa líquida exclui os ativos de reservas, os haveres de bancos comerciais e os créditos brasileiros no exterior.

5. Crédito pessoal consignado total: Saldo em final de período das operações de crédito contratadas com taxas de juros livremente pactuadas entre mutuários e instituições financeiras. Não inclui operações referenciadas em taxas regulamentadas, operações vinculadas a recursos do Banco Nacional de Desenvolvimento Econômico e Social (BNDES) ou quaisquer outras lastreadas em recursos compulsórios ou governamentais.

6. Crédito pessoal não consignado: Saldo em final de período das operações de crédito contratadas com taxas de juros livremente pactuadas entre mutuários e instituições financeiras. Não inclui operações referenciadas em taxas regulamentadas, operações vinculadas a recursos do Banco Nacional de Desenvolvimento Econômico e Social (BNDES) ou quaisquer outras lastreadas em recursos compulsórios ou governamentais. 
7. Lucro dos Bancos: Lucro líquido depois do imposto de renda - O lucro líquido depois do imposto de renda (LL) acumulado nos últimos doze meses.

8. Taxa de câmbio real: Taxa de Câmbio Efetiva Real

\section{Exportações: Exportações FOB}

10. Importações: Importações de matérias-primas e bens intermediários

11. Preço dos imóveis: índice de rentabilidade do mercado brasileiro de imóveis comerciais, cujo objetivo é retratar da forma mais abrangente possível a evolução da valorização dos preços e dos rendimentos do segmento de imóveis comerciais em todo o Brasil (IGMI-C).

12. Consumo: Despesa de Consumo das Famílias.

13. Investimento em máquinas e equipamentos: Formação Bruta de Capital Fixo.

14. Inflação Externa: Indice de Preços ao Consumidor norte-americano (IPC - EUA).

O componente de ciclo das variáveis foi obtido com o uso do filtro HP, definindo-se o parâmetro $\lambda$ igual a 1600; com exceção das séries de inflação (doméstica e externa) e de preço de imóveis, para as quais foram retiradas as médias para o período. As figuras abaixo apresentam as séries transformadas:
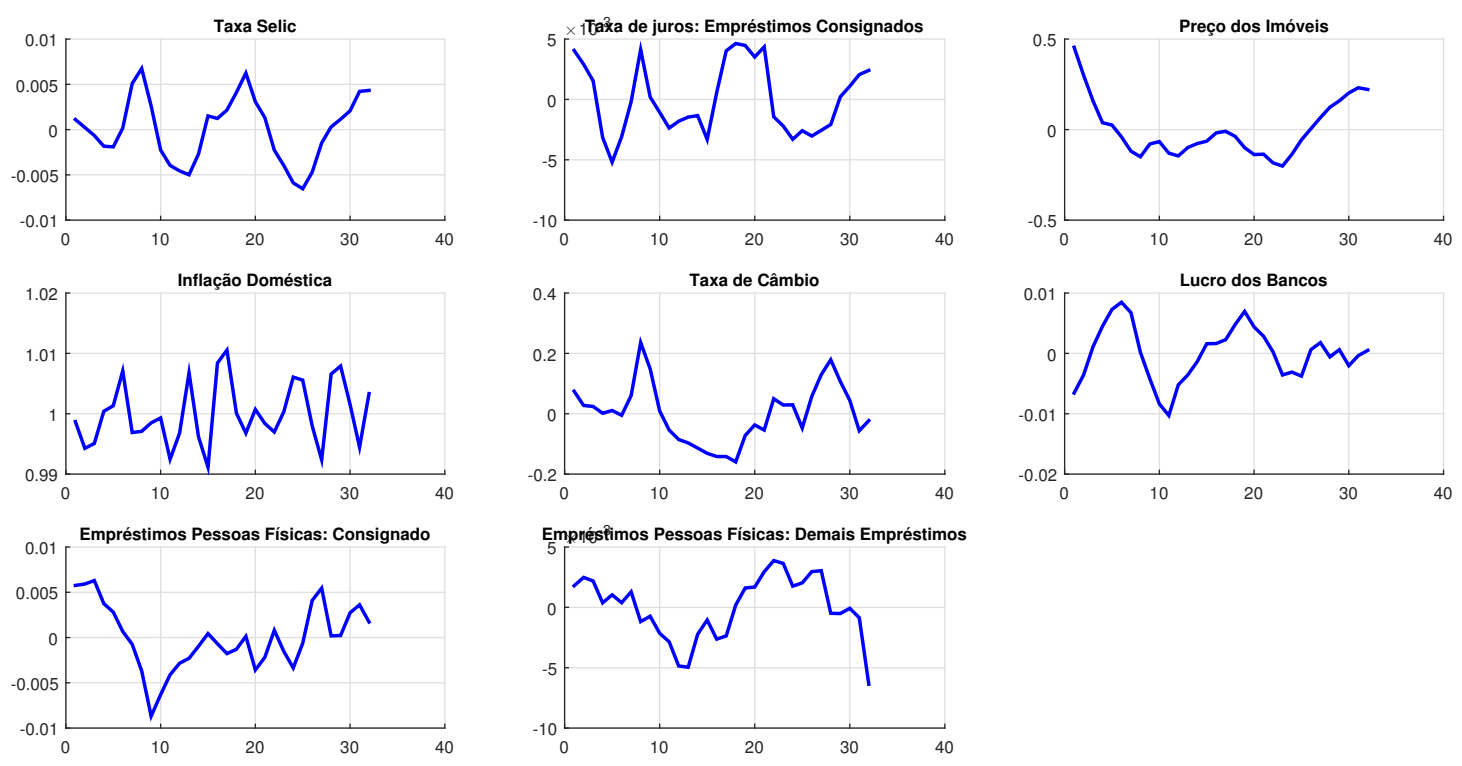

Figura 19: Variáveis 

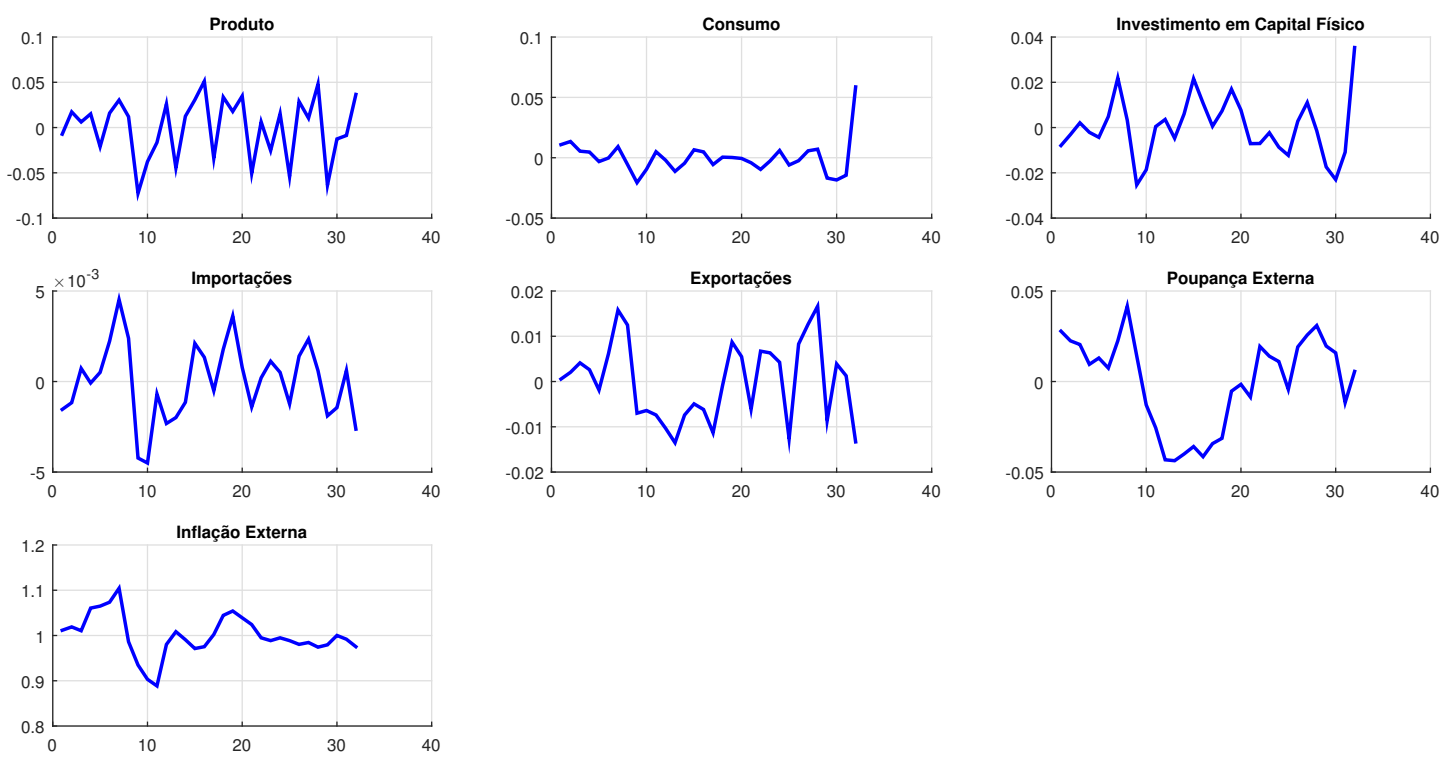

Figura 20: Variáveis

\subsection{Calibração}

A tabela 8.1 apresenta os valores calibrados para os parâmetros que definem o steady state do modelo. Em sua maioria, estes parâmetros foram obtidos a partir de estudos anteriores realizados para a economia brasileira. Em particular; $\beta_{P}, \beta_{I}, \beta_{E}, \delta, \delta_{k b}$, $j^{h}, \phi, \alpha, \mu, \varepsilon_{y}$ e $\varepsilon_{l}$ foram calibrados como em Silva (2012). Os parâmetros $\alpha_{l}, \alpha_{k}$ e $\tau$ foram obtidos em Vereda e Cavalcanti (2010); por fim, os parâmetros $\delta^{h}, \chi, \varepsilon^{d}, \varepsilon^{b h}$, $\varepsilon^{b w}$, e $\varepsilon^{b e}$ e os valores de steady state das variáveis $\pi, \pi^{*}, y^{*}, R^{*}, p^{Q}, m^{I h}, m^{I w}$ e $m^{E}$ foram calibrados para tentar mimetizar a economia brasileira e garantir a existênca do steady state. 
$\beta_{P}$

$\beta_{I}$

$\beta_{E}$

$\delta$

$\delta^{h}$

$\delta^{k b}$

$\mathrm{j}^{h}$

$\varepsilon^{y}$

$\varepsilon^{l}$

$\varepsilon^{d}$

$\varepsilon^{b h}$

$\varepsilon^{b w}$

$\varepsilon^{b e}$

$\phi$

$\alpha$ taxa de desconto subjetiva: família paciente 0.989

taxa de desconto subjetiva: família impaciente 0.96

taxa de desconto subjetiva: empresários $\quad 0.96$

taxa de depreciação do capital 0.035

taxa de depreciação dos imóveis $\quad 0.025$

taxa de depreciação do capital bancário $\quad 0.095$

peso dos imóveis na função de utilidade $\quad 0.2$

mark-up de preços 11

mark-up de salários 3

mark-down taxa de depósitos $\quad-2.62$

mark-up taxa de empréstimos $\quad 5.36$

mark-up taxa de empréstimos $\quad 4.5$

mark-up taxa de empréstimos $\quad 2.73$

Inverso da elasticidade Fish 1

share do capital na função de produção $\quad 0.4$ 
Parâmetros Calibrados height

$$
\text { Descrição }
$$

Valor

Fonte

\begin{tabular}{ccc}
$\mathrm{m}^{I h}$ & loan-to-value & 0.06 \\
$\mathrm{~m}^{I w}$ & debt-to-income & 0.1 \\
$\mathrm{~m}^{E}$ & loan-to-value & 0.007 \\
$\pi$ & inflação doméstica & 1 \\
$\mu$ & share do trabalho paciente & 0.8 \\
$\chi$ & Parâmetro do função de exportação & 0.1 \\
$\tau$ & Parâmetro do função de exportação & -1.1 \\
$\alpha_{k}$ & share do capital na função de produção & 0.4 \\
$\alpha_{l}$ & share do trabalho na função de produção & 0.5 \\
$\zeta$ & Parâmetro do função de prêmio de risco & -0.1 \\
$\pi^{*}$ & inflação externa & 1 \\
$\mathrm{y}^{*}$ & renda externa & 2 \\
$\mathrm{R}^{*}$ & taxa de juros externa & 0.005 \\
$\mathrm{p}^{Q}$ & preço do insumo importado & 1 \\
\hline
\end{tabular}


A partir dos valores calibrados para os parâmetros constantes na tabela 8.1, foi possível calcular o steady state para o de economia aberta ${ }^{1}$. A tabela a seguir apresenta as razões de steady state para o modelo estudado:

Razões de Steady State height

Economia Aberta

\begin{tabular}{cc} 
Consumo (\% do Produto) & 0.73197 \\
Investimento em Capital Físico (\% do Produto) & 0.18294 \\
Investimento em Imóveis (\% do Produto) & 0.12131 \\
Empréstimo Agregado (\% do Produto) & 0.065333 \\
Depósito Agregado (\% do Produto) & 0.053655 \\
Empréstimo não consignado às famílias (\% dos Empréstimos) & 0.258199 \\
Empréstimo consignado às famílias (\% dos Empréstimos) & 0.150143 \\
Empréstimo aos empresários (\% dos Empréstimos) & 0.591658 \\
Exportações (\% do Produto) & 0.10061 \\
Importações (\% do Produto) & 0.10003 \\
Poupança Externa (\% do Produto) & 0.00057067 \\
\hline
\end{tabular}

Os resultados da calibração se assemelham aos obtidos para o modelo de economia fechada; o consumo das famílias como proporção do produto se encontra acima da média histórica para a economia brasileira, enquanto essa razão para o investimento em máquinas e equipamentos se encontra próxima da média histórica. Novamente a calibração do modelo não se mostrou capaz de apresentar valores para as variáveis financeiras compatíveis com a economia brasileira.

$\overline{1}$ Os scripts utilizados para o cálculo do steady state dos modelos se encontram nos anexos 


\section{Resultados}

Inicialmente o modelo foi estimado apenas com as 20 primeiras observações da base de dados, ou seja, com base nas informações contidas entre os anos de 2007 e 2011. Os parâmetros das funções de densidade obtidos como resultado desta primeira estimação foram utilizados na formação das prior s para uma nova estimação, desta vez com todas as observações contidas na base de dados. Nas duas rodadas de estimação foram utilizadas 1.000.000 de iterações para a obtenção da posteriori. As priors e posteriores encontradas na segunda estimação podem ser observadas nos gráficos 288 - 293. Foram estimadas as distribuições de probabilidade para os parâmetros que determinam a dinâmica do modelo,ou seja, custos de ajustamento, parâmetros relacionados à regra de Taylor, formação de hábito no consumo e persistência dos choques. Os gráficos contendo o diagnóstico de convergência para os parâmetros e para o modelo como um todo estão presentes nos gráficos 312 - 330 e 331. A tabela abaixo apresenta a média e o desvio-padrão estimados para as funções densidade de probabilidade desses parâmetros: 


\begin{tabular}{|c|c|c|c|c|c|c|c|}
\hline & Prior distribution & Prior mean & Prior s.d. & Posterior mean & Posterior s.d. & HPD inf & HPD sup \\
\hline$\rho_{z}$ & beta & 0.500 & 0.2500 & 0.980 & 0.0129 & 0.9633 & 0.9983 \\
\hline$\rho_{A e}$ & beta & 0.556 & 0.0348 & 0.598 & 0.0353 & 0.5390 & 0.6546 \\
\hline$\rho_{e j}$ & beta & 0.631 & 0.0274 & 0.636 & 0.0276 & 0.5913 & 0.6815 \\
\hline$\rho_{m e}$ & beta & 0.574 & 0.0500 & 0.495 & 0.0472 & 0.4165 & 0.5722 \\
\hline$\rho_{m i}$ & beta & 0.541 & 0.0476 & 0.556 & 0.0473 & 0.4788 & 0.6343 \\
\hline$\rho_{m k d}$ & beta & 0.938 & 0.0240 & 0.936 & 0.0169 & 0.9092 & 0.9638 \\
\hline$\rho_{m k b h}$ & beta & 0.134 & 0.0407 & 0.132 & 0.0399 & 0.0666 & 0.1959 \\
\hline$\rho_{m k b w}$ & beta & 0.134 & 0.0407 & 0.129 & 0.0391 & 0.0660 & 0.1919 \\
\hline$\rho_{m k b e}$ & beta & 0.605 & 0.0740 & 0.564 & 0.0741 & 0.4415 & 0.6849 \\
\hline$\rho_{q k}$ & beta & 0.902 & 0.0449 & 0.937 & 0.0235 & 0.8996 & 0.9744 \\
\hline$\rho_{y}$ & beta & 0.482 & 0.0377 & 0.517 & 0.0353 & 0.4586 & 0.5751 \\
\hline$\rho_{l}$ & beta & 0.542 & 0.0617 & 0.547 & 0.0635 & 0.4438 & 0.6512 \\
\hline$\rho_{K b}$ & beta & 0.653 & 0.0677 & 0.627 & 0.0662 & 0.5197 & 0.7374 \\
\hline$\rho_{y^{*}}$ & beta & 0.987 & 0.0079 & 0.994 & 0.0034 & 0.9893 & 0.9992 \\
\hline$\rho_{\pi^{*}}$ & beta & 0.824 & 0.0427 & 0.809 & 0.0446 & 0.7366 & 0.8823 \\
\hline$\rho_{R^{*}}$ & beta & 0.216 & 0.0658 & 0.261 & 0.0764 & 0.1371 & 0.3865 \\
\hline$\rho_{p^{Q}}$ & beta & 0.931 & 0.0398 & 0.955 & 0.0195 & 0.9245 & 0.9868 \\
\hline$\rho_{\Phi}$ & beta & 0.230 & 0.0744 & 0.295 & 0.0895 & 0.1496 & 0.4425 \\
\hline
\end{tabular}




\begin{tabular}{|c|c|c|c|c|c|c|c|}
\hline & Prior distribution & Prior mean & Prior s.d. & Posterior mean & Posterior s.d. & HPD inf & HPD sup \\
\hline$\rho_{\text {miw }}$ & beta & 0.570 & 0.0459 & 0.570 & 0.0456 & 0.4939 & 0.6449 \\
\hline$\rho_{q h}$ & beta & 0.500 & 0.2500 & 0.992 & 0.0060 & 0.9843 & 1.0000 \\
\hline$\kappa_{p}$ & gamma & 79.993 & 5.5087 & 84.660 & 5.3698 & 75.7636 & 93.4049 \\
\hline$\kappa_{w}$ & gamma & 60.672 & 7.2980 & 65.605 & 7.7240 & 52.6706 & 77.9993 \\
\hline$\kappa_{i}$ & gamma & 3.049 & 0.2984 & 3.217 & 0.2959 & 2.7265 & 3.6944 \\
\hline$\kappa_{i h}$ & gamma & 4.298 & 0.1496 & 4.274 & 0.1476 & 4.0305 & 4.5167 \\
\hline$\kappa_{d}$ & gamma & 6.473 & 0.3517 & 6.459 & 0.3534 & 5.8786 & 7.0402 \\
\hline$\kappa_{b e}$ & gamma & 0.234 & 0.0440 & 0.221 & 0.0428 & 0.1508 & 0.2900 \\
\hline$\kappa_{b h}$ & gamma & 7.126 & 0.6257 & 7.139 & 0.6314 & 6.1001 & 8.1733 \\
\hline$\kappa_{b w}$ & gamma & 12.808 & 0.9212 & 13.301 & 0.9314 & 11.7673 & 14.8345 \\
\hline$\kappa_{k b}$ & gamma & 0.587 & 0.1344 & 0.385 & 0.0711 & 0.2676 & 0.4997 \\
\hline$\phi_{\pi}$ & normal & 1.783 & 0.0426 & 1.790 & 0.0419 & 1.7221 & 1.8590 \\
\hline$\phi_{R}$ & beta & 0.822 & 0.0283 & 0.871 & 0.0220 & 0.8353 & 0.9070 \\
\hline$\phi_{y}$ & gamma & 0.178 & 0.0272 & 0.173 & 0.0258 & 0.1309 & 0.2152 \\
\hline$\iota_{p}$ & beta & 0.942 & 0.0280 & 0.956 & 0.0214 & 0.9244 & 0.9887 \\
\hline$\iota_{w}$ & beta & 0.799 & 0.0326 & 0.808 & 0.0317 & 0.7560 & 0.8597 \\
\hline$a_{i}$ & beta & 0.918 & 0.0073 & 0.915 & 0.0068 & 0.9040 & 0.9264 \\
\hline
\end{tabular}


Novamente percebe-se o alto valor encontrado para as médias dos custos de ajustamento de preços $\left(\kappa_{p}=84.660\right)$ e salários $\left(\kappa_{w}=65.605\right)$ e o baixo valor encontrado para o custo de ajustamento da taxa de juros sobre empréstimos aos empresários $\left(\kappa_{b e}=0.221\right)$, em comparação aos demais parâmetros dessa categoria. Como um todo, os parâmetros de menor valor médio são as persisências da taxa de juros externa $\left(\rho_{R^{*}}=0.261\right)$, do prêmio de risco $\left(\rho_{\Phi}=0.295\right)$ e dos mark-ups das taxas de juros sobre empréstimos para as famílias impacientes $\left(\rho_{m k \_b h}=0.132\right.$ e $\left.\rho_{m k \_b w}=0.129\right)$. Fixando os valores dos parâmetros em suas médias estimadas, foi realizada a decompoição histórica para o produto, investimento em capital, inflação e taxa de política monetária no período de 2007 a 2014. Para analisar a decomposição no modelo de economia aberta, os choques foram classificados em quatro grupos:

- Macro: choque na preferência por consumo, choque tecnológico, choque na demanda por imóveis, choque no mark-up de preços, choque no mark-up de salários, choque na produção de capital, choque na produção de imóveis;

- PM: choque na regra de Taylor;

- Financeiro: choque na restrição de endividamento com imóveis, choque na restrição de endividamento dos empresários, choque no mark-up da taxa de depósitos, choque no mark-up da taxa de empréstimos, empresários, choque no mark-up da taxa de empréstimos com base em imóveis, choque no capital bancário, choque na restrição de endividamento consignado, choque no mark-up da taxa de empréstimos consignados;

- Externo: choques na taxa de juros internacional, no prêmio de risco, na renda externa, na taxa de inflação externa e no preço dos insumos importados.

De acordo com os gráficos 336, 337, 338 e 339 os choques que compõem o grupo externo explicam a maior parte dos desvios das variáveis em relação aos valores de steady state, em particular nos anos de 2010 e 2011. Outro conjunto de choques que tiveram grande importância no comportamento destas variáveis para o período em análise é grupo de choques originados do setor financeiro, tendo maior importância nos anos de 2012 e 2013. Novamente, de acordo com a decomposição histórica das variáveis, os choques financeiros apresentaram um efeito negativo sobre a dinâmica observada para as variáveis selecionadas, demonstrando os efeitos da política de crédito adotada pelo governo sobre a taxa de política monetária e inflação. Já o efeito dos choques externos sobre as variáveis selecionadas pode ser atribuído ao período de crise internacional. Quando os choques externos são analisados em separado, através dos gráficos 340, 341, 342 e 343, é possível perceber que os choques de prêmio de risco e taxa de juros internacional são osde maior importância, em particular para o ano de 2011. 


\subsection{Funções de Resposta ao Impulso}

- Choque na inflação externa: O choque na inflação externa (analisada por meio dos gráficos 135 - 141) leva a uma apreciação da taxa de câmbio real, incentivando as importações de insumos para a produção e captação de poupança externa. Os insumos importados mais baratos levaram a uma substituição de trabalho por este insumo, elevando a produção e baixando o preço do bem intermediário em relação ao preço do bem final. Em decorrência disto, as firmas produtoras de bens finais têm um lucro maior; o que eleva a renda das famílias pacientes e, por conseguinte, o consumo e compra de imóveis por parte dessas famílias. Isto, por sua vez, incentiva a produção e a renda como um todo. Ao mesmo tempo o aumento na captação de poupança externa eleva o prêmio de risco e diminui a demanda por poupança doméstica. A queda na taxa de desconto para as firmas de bens finais - que depende do multiplicador de Lagrange e da taxa de desconto subjetiva da famílias pacientes - reduz a inflação doméstica, implicando em uma taxa de política monetária menor - o que também reduz as demais taxa de juros da economia.

- Choque Prêmio de risco: O aumento no risco percebido pelos investidores externos, modelado pelo choque no prêmio de risco faz com que o endividamento externo diminua. Esse movimento na dívida externa desvaloriza a taxa de câmbio real, elevando o preço das importações em moeda doméstica. Para manter o equilíbrio no balanço de pagamentos as exportações também se reduzem, levando a uma redução na venda de bens finais e, portanto, no lucro do setor. A queda no lucro reduz o consumo e a compra de imóveis por parte dos agentes pacientes, e por fim, uma redução no nível de atividade econômica. O mecanismo de propagação deste choque pode ser visto por meio dos gráficos 142 - 148.

- Choque no capital bancário: Uma queda no capital bancário leva o banco a reduzir a captação de poupança externa, a fim evitar o aumento no prêmio de risco (como pode ser observado nos gráficos 149 - 155). A valorização da taxa de câmbio real leva a um aumento nas importações de insumo para a produção - permitindo aos empresários substituir o capital físico por insumo importado. A fim de recuperar o lucro e, como consequência, o capital bancário perdido, os bancos aumentam as taxas de juros para empréstimos de tal forma a elevar o spread bancário. Isto leva a uma queda no consumo agregado e na produção de imóveis e capital físico (via queda nos empréstimos às famílias e empresários), porém permite um aumento nas exportações. Desta forma, embora a absorção interna e o PIB sejam menores, a produção de bens finais se torna maior, o que pressiona a taxa de inflação doméstica. O aumento na taxa de inflação leva a um aumento na taxa de juros de política monetária, o que também explica a elevação nas demais taxas de juros da economia 
doméstica. Em particular, o aumento na taxa de juros sobre os depósitos majora a poupança interna, permitindo aos bancos elevar o total de empréstimos, mesmo com a queda no capital bancário e na captação de poupança externa.

- Choque na taxa de juros externa: O aumento na taxa de juros externa tem um efeito similar ao choque no prêmio de risco, como pode ser notado nas IRFs 156 - 162.

- Choque no preço do insumo importado: O choque no preço (expresso nos gráficos 163 - 169) faz com que a demanda por insumo para produção caia. O aumento no preço do insumo leva a uma substituição entre o insumo importado e o trabalho das famílias; embora isto leve a um pequeno aumento na produção de bens intermediários, ela cai rapidamente. Embora ocorra um aumento inicial na quantidade de trabalho empregado, os salários dos dois tipos de famílias se reduzem - o que, em conjunto com a queda no lucro das firmas, explica as reduções no consumo e na aquisição de imóveis agregados. Ainda, o aumento na demanda por insumos desvaloriza a taxa de câmbio real, implicando em uma redução dos empréstimos externose como consequência, do prêmio de risco. Então para satisfazer o aumento inicial nos empréstimos aos empresários e famílias impacientes, os bancos aumentam a captação de poupança interna.

- Choque na renda externa: O aumento na renda externa eleva a demanda por exportações da economia doméstica, como visto nos gráficos 170 - 176. A desvalorização da taxa de câmbio encarece as importações e reduz a captação de poupança externa. A queda nas importações reduz a produção de bens intermediários e demanda por trabalho - embora a queda nos salários tenha permitido um aumento inicial na quantidade de trabalho empregado. A redução nos salários e na produção implicam em uma queda consumo e no estoque de imóveis e capital agregados.

\subsection{O papel das friç̦ões financeiras}

Como no primeiro modelo estudado, o papel das imperfeições no setor bancário é inferido por meio das comparações entre as funções de resposta ao impulso nas versões abaixo:

- Modelo BK - modelo completo

- Modelo SR - neste modelo o custo de ajustmento do é suposto igual à zero; além disso, o capital bancário é retirado do balanço patrimonial dos bancos e transferido para a restrição orçamentária das famílias pacientes. Desta forma, o banco pode contar apenas com depósitos como fonte de recursos para empréstimos. 
- Modelo FR - os custos de ajustamento das taxas de juros são supostos iguais a zero, desta forma, as taxas de juros se tornam totalmente flexíveis.

- Modelo FF - as elasticidades de substituição para empréstimos e depósitos tendem ao infinito, de tal forma que o mark-up sobre as taxas de juros definidas pelos bancos se tornam igual a um - ou seja, os bancos perdem o poder de mercado.

- Modelo QNK - os LTVs e o DTI são fixados em seus valores de steady state.

A análise dos efeitos de cada uma das fricções financeiras é realizada sob os choques na inflação externa, no prêmio de risco, no preço do insumo importado, nas taxas de juros externa e de política monetária, no capital bancário e na renda externa.

\subsubsection{Choque na Inflação Externa}

De acordo com as figuras 21 e 22, os efeitos de um aumento súbito na inflação externa é amplificado pelas imperfeições no mercado financeiro.
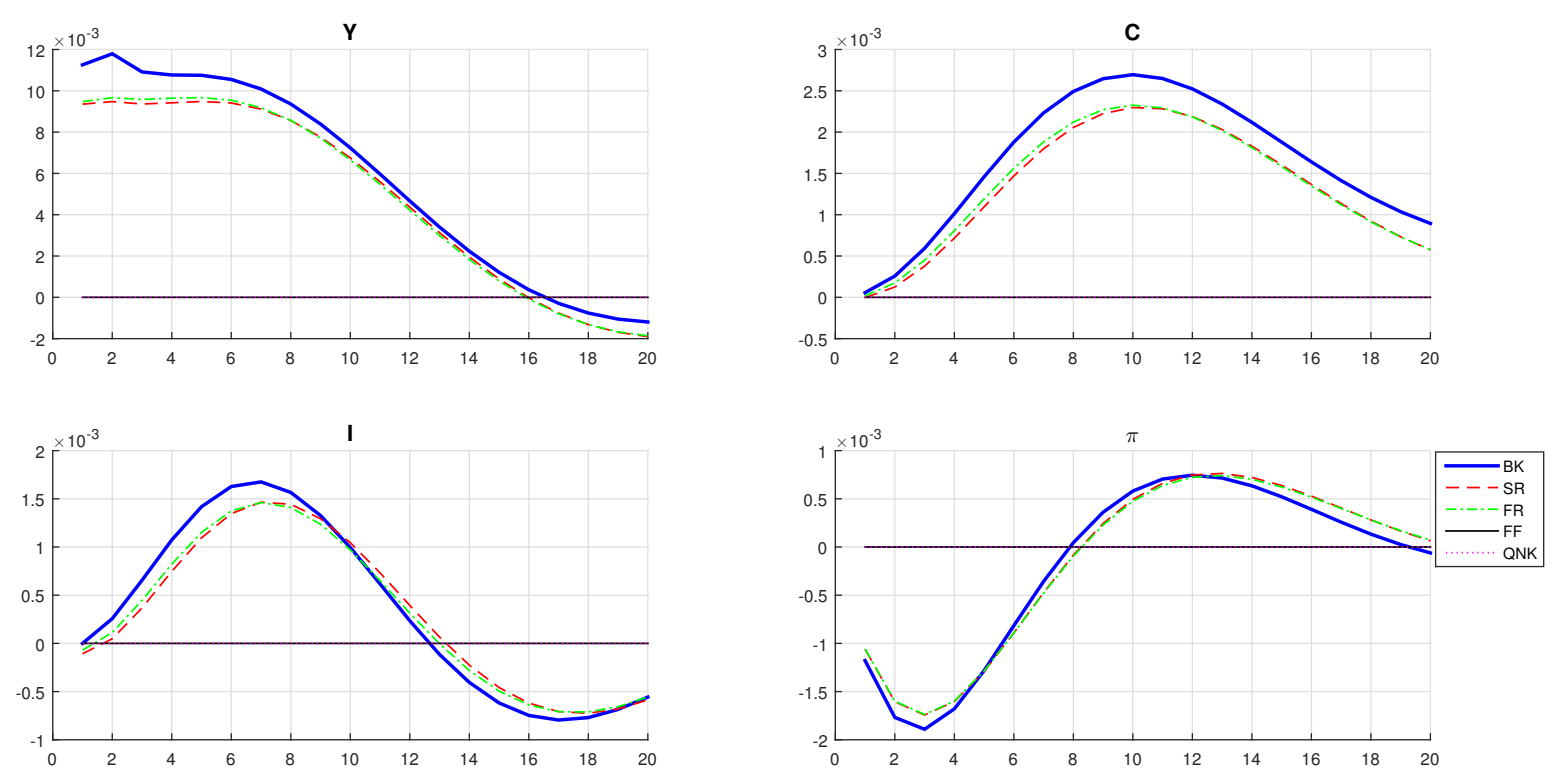

Figura 21: Efeito de um choque na inflação externa

Ao compararmos as funções de resposta ao impulso é possível perceber que o custo de ajustamento no capital bancário tem grande influência sobre comportamento do produto, consumo e investimento em máquinas e equipamentos agregado, particurlamente nos dez primeiros períodos. Para as duas fontes de poupança, doméstica e externa, crédito agregado e mesmo para o capital bancário esse custo de ajustamento é significante apenas para os primeiros períodos. Com relação à inflação doméstica e taxa de juros de política monetária, não se observa uma diferença expressiva entre os modelos BK, SR e FR. 

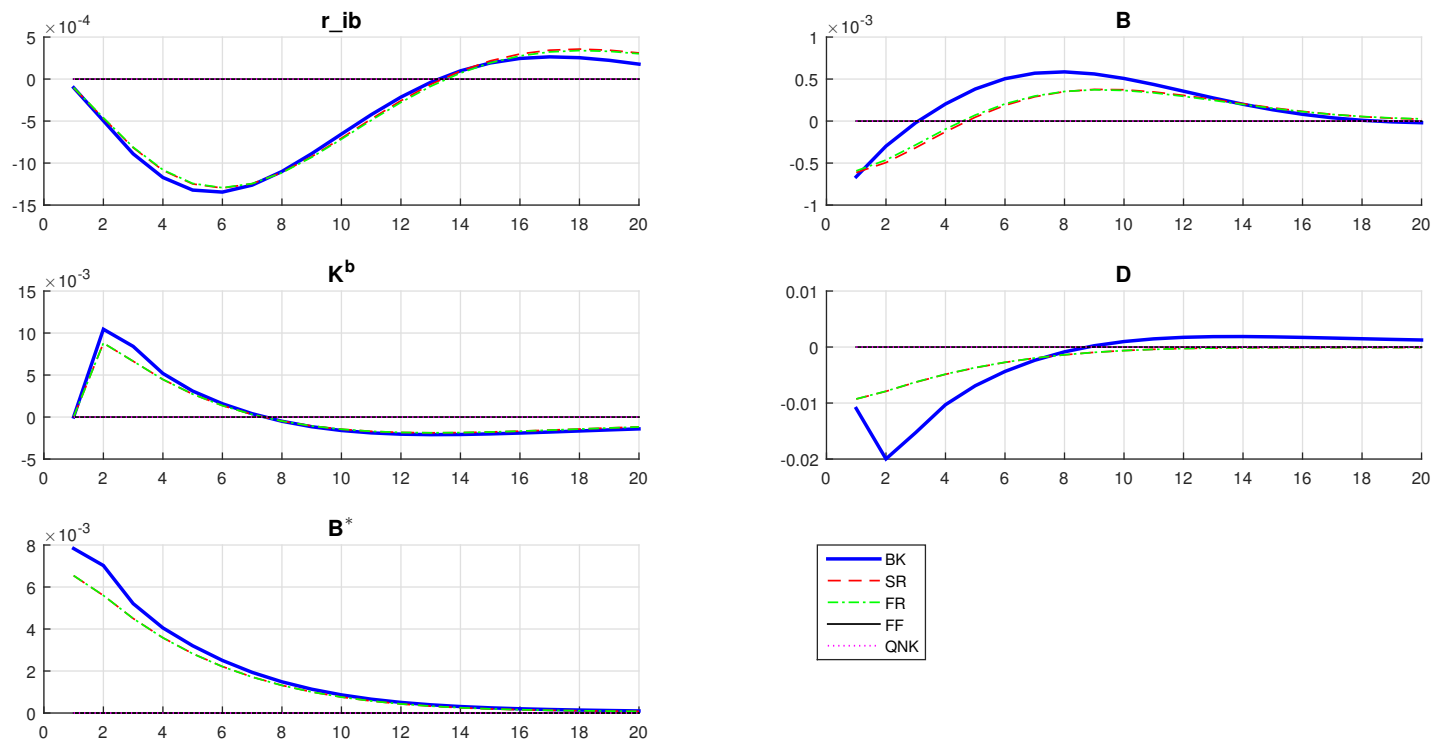

Figura 22: Efeito de um choque na inflação externa

\subsubsection{Choque no Prêmio de Risco}

Observando as figuras 23 e 24, pode-se concluir que o aumento no prêmio de risco cobrado pelos investidores externos tem efeito principalmente sobre a dinâmica do consumo.
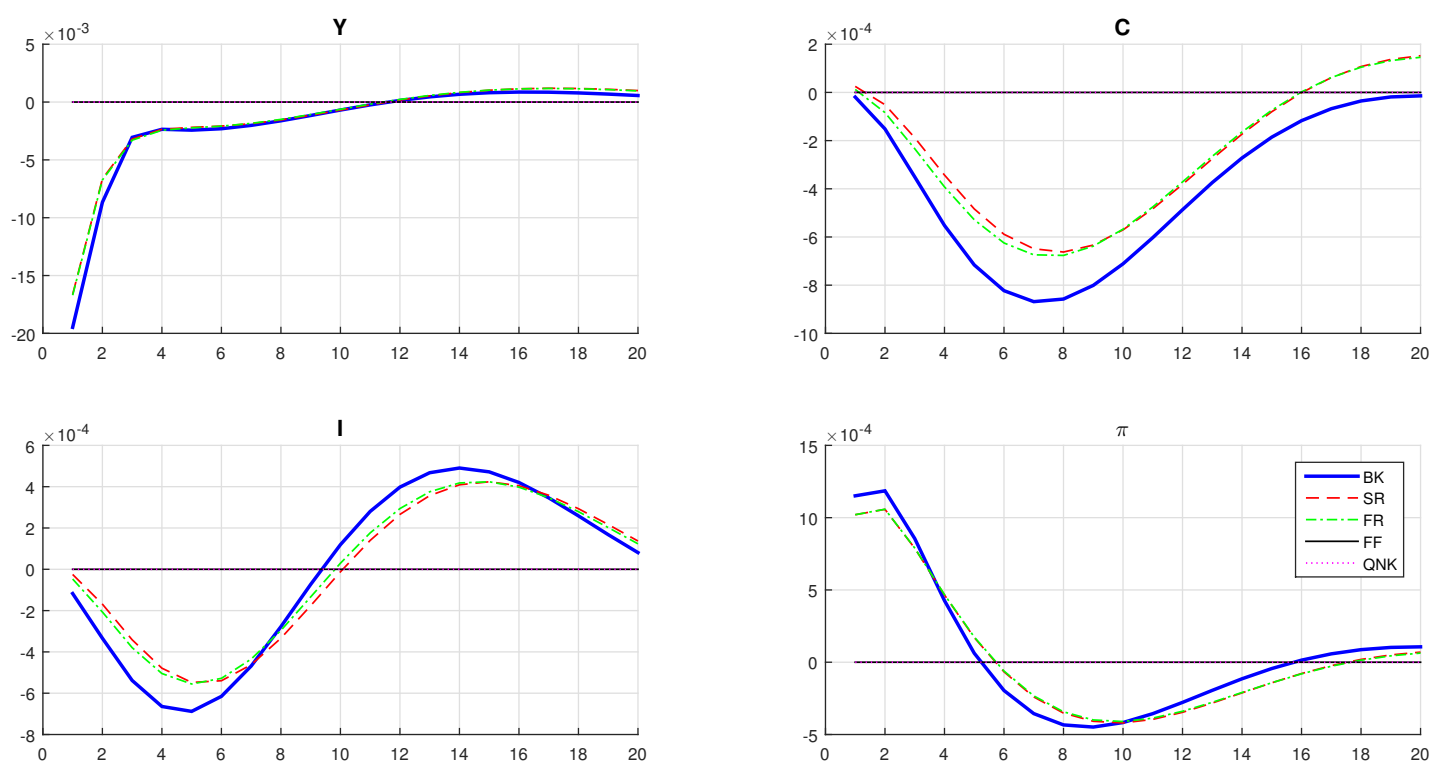

Figura 23: Efeito de um choque no prêmio de risco

Ao observarmos as dinâmicas do produto, taxa de juros de política monetária, capital bancário e poupança externa, percebemos que os custos de ajustamento no capital 

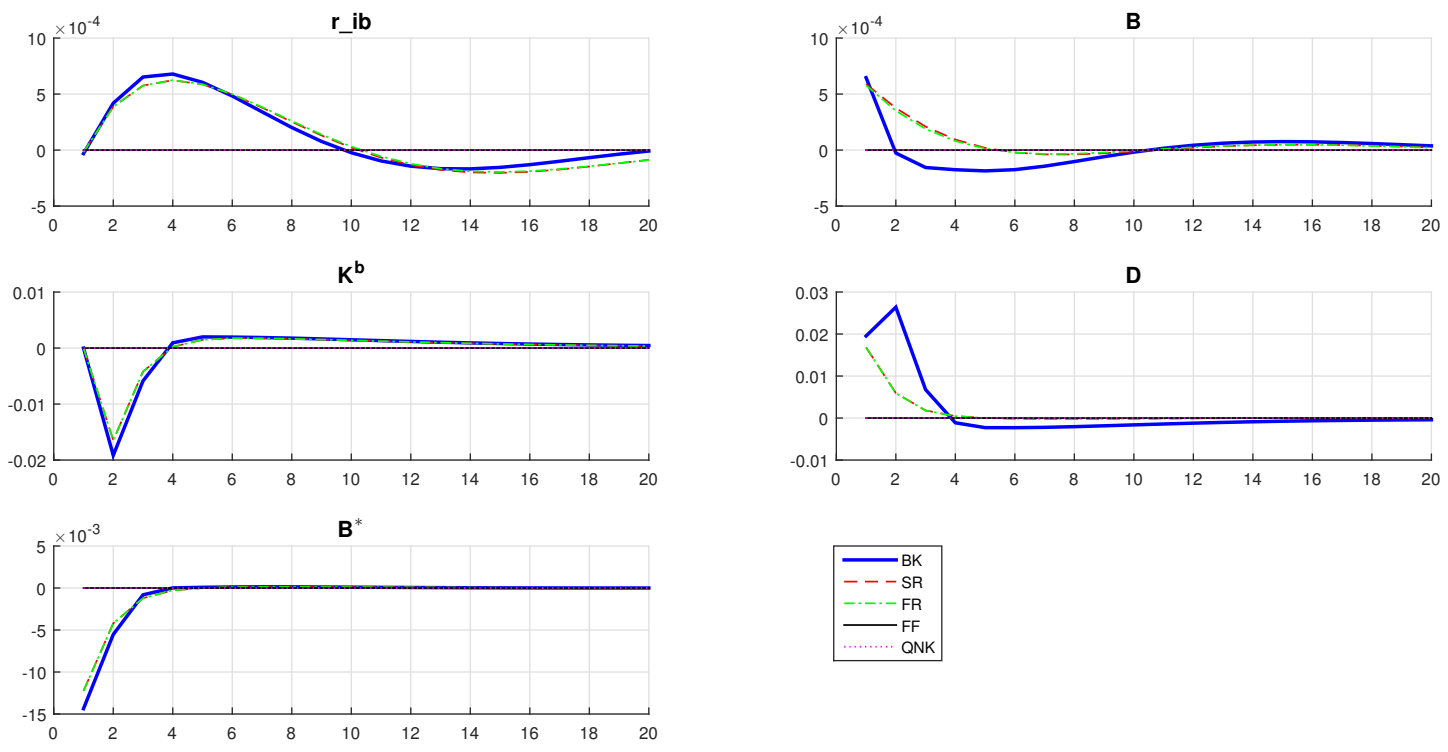

Figura 24: Efeito de um choque no prêmio de risco

bancário e nas taxas de juros não é possível obervar qualquer efeito sobre o tamanho do impacto causado pelo choque - o que leva a uma sobre posição das funções de resposta ao impulso dos modelos BK, SR e FR. Para os depósitos e crédito agregado, o custo de ajustamento no capital bancário tem efeito somente sobre os primeiros trimestres após o choque; no por fim, no que tange à dinâmica do investimento em máquinas e equipamentos e da inflação doméstica, embora o custo de ajustamento do capital amplifique o efeito do choque de prêmio de risco sobre essas variáveis, seu efeito é menor quando comparado ao da dinâmica do consumo agregado.

\subsubsection{Choque de política monetária}

Para um aumento repentino na taxa de juros de política monetária, encontrase um quadro diferente ao exposto nos choques anteriores. No caso presente as fricções financeiras amortecem os efeitos do choque.

$\mathrm{Na}$ análise das quatro primeiras variáveis expostas na figura 25, pode-se agrupar as funções de resposta ao impulso em dois grupos de modelos, aqueles nos quais os bancos possuem poder de mercado (BK, SR e FR) e aqueles em que é suposto que os bancos operam em competição perfeita (FF e QNK). Para o produto agregado, percebe-se uma queda mais acentuada nos modelos que compõem o segundo grupo até o oitavo período, a partir do qual todas as versões tem dinâmica idêntica. No que diz respeito ao consumo agregado, esta separação é ainda mais evidente e de maior persistência. As dinâmicas do investimento agregado e da inflação doméstica parecem pouco afetadas pelas imperfeições do mercado financeiro. 

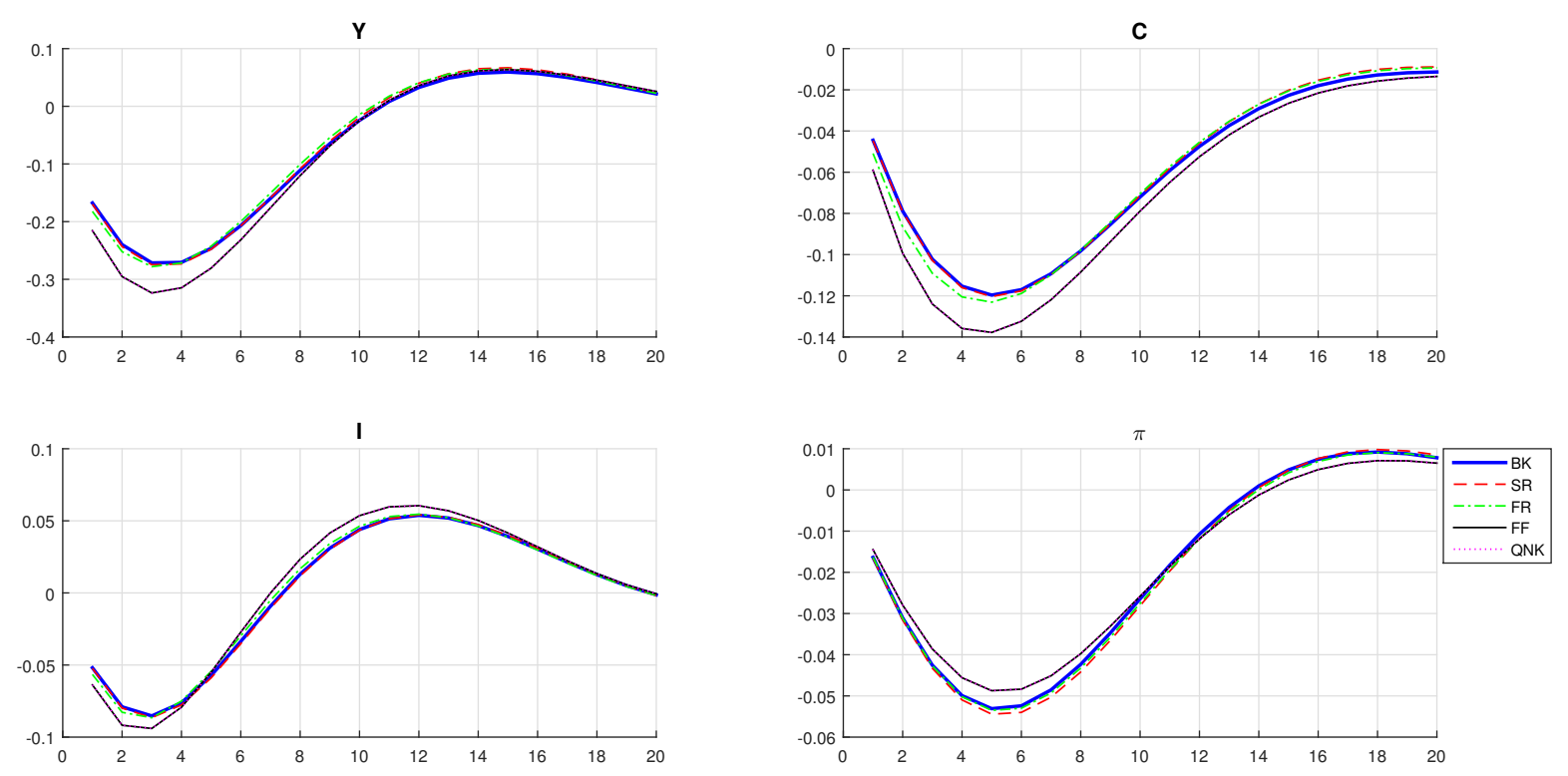

Figura 25: Efeito de um choque de política monetária
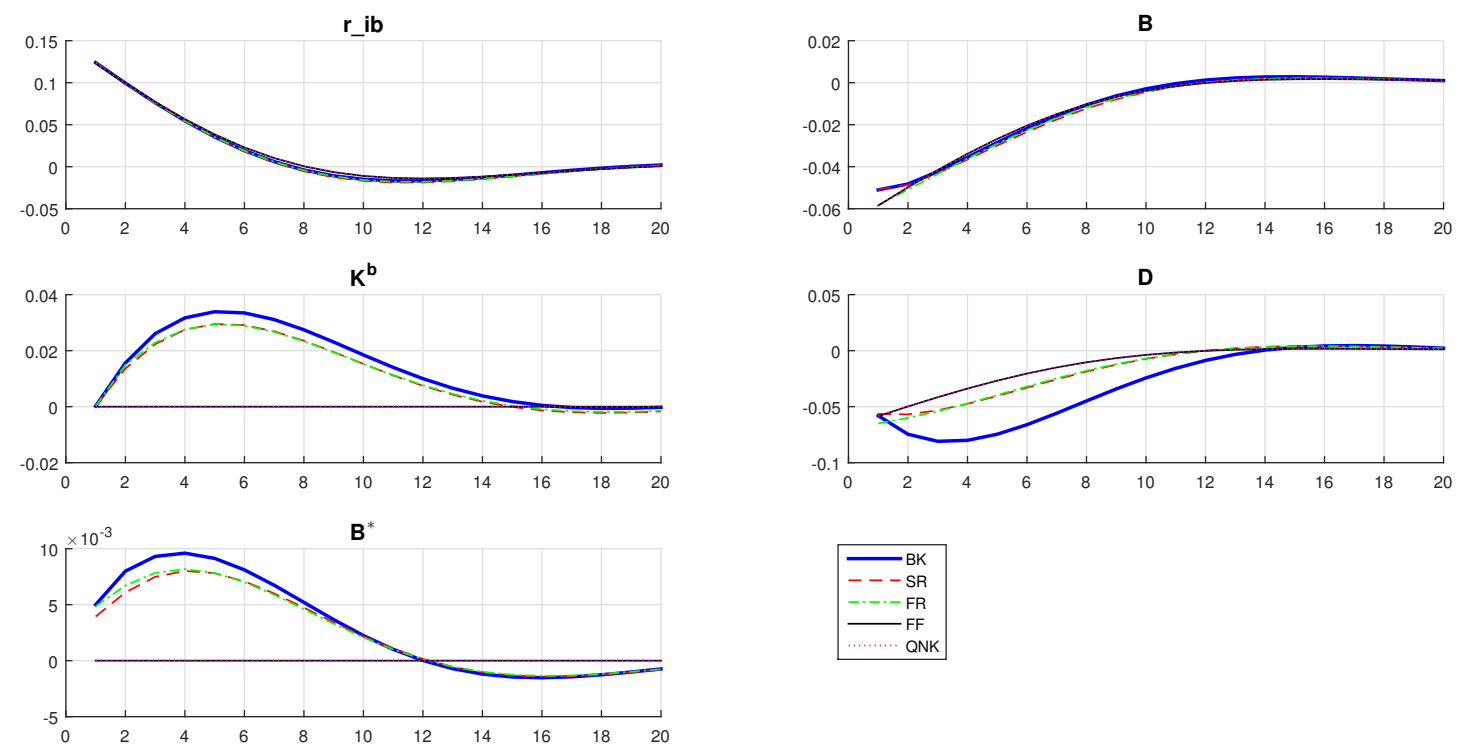

Figura 26: Efeito de um choque de política monetária

As variáveis restantes são plotadas na figura 26, para a taxa de política monetária e crédito agregado as fricções no mercado financeiro não parecem ter efeito sobre a dinâmica destas variáveis. Com relação às variáveis restantes, encontra-se novamente o papel predominante do custo de ajustamento do capital bancário e dos mark-ups sobre as taxas de juros no tamanho do efeito do choque de política monetária sobre a economia. Para estas variáveis, o choque é amplificado pelas fricções financeiras. 


\subsubsection{Choque no Capital Bancário}

De acordo com as figuras 27 e 32, a interação entre o choque no capital bancário e as fricções financeiras tem o efeito esperado para os modelos BK, SR e FR.
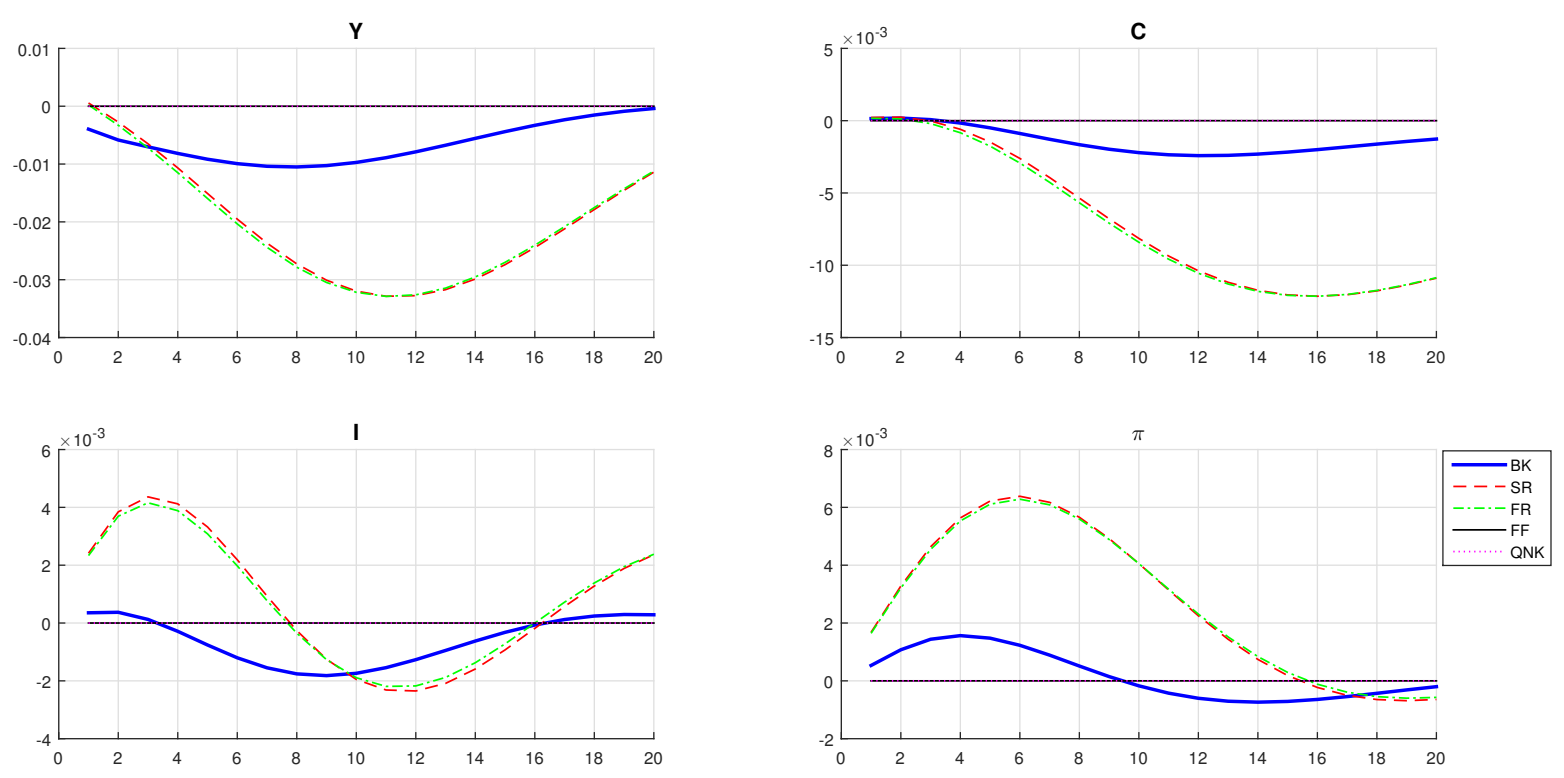

Figura 27: Efeito de um choque no capital bancário
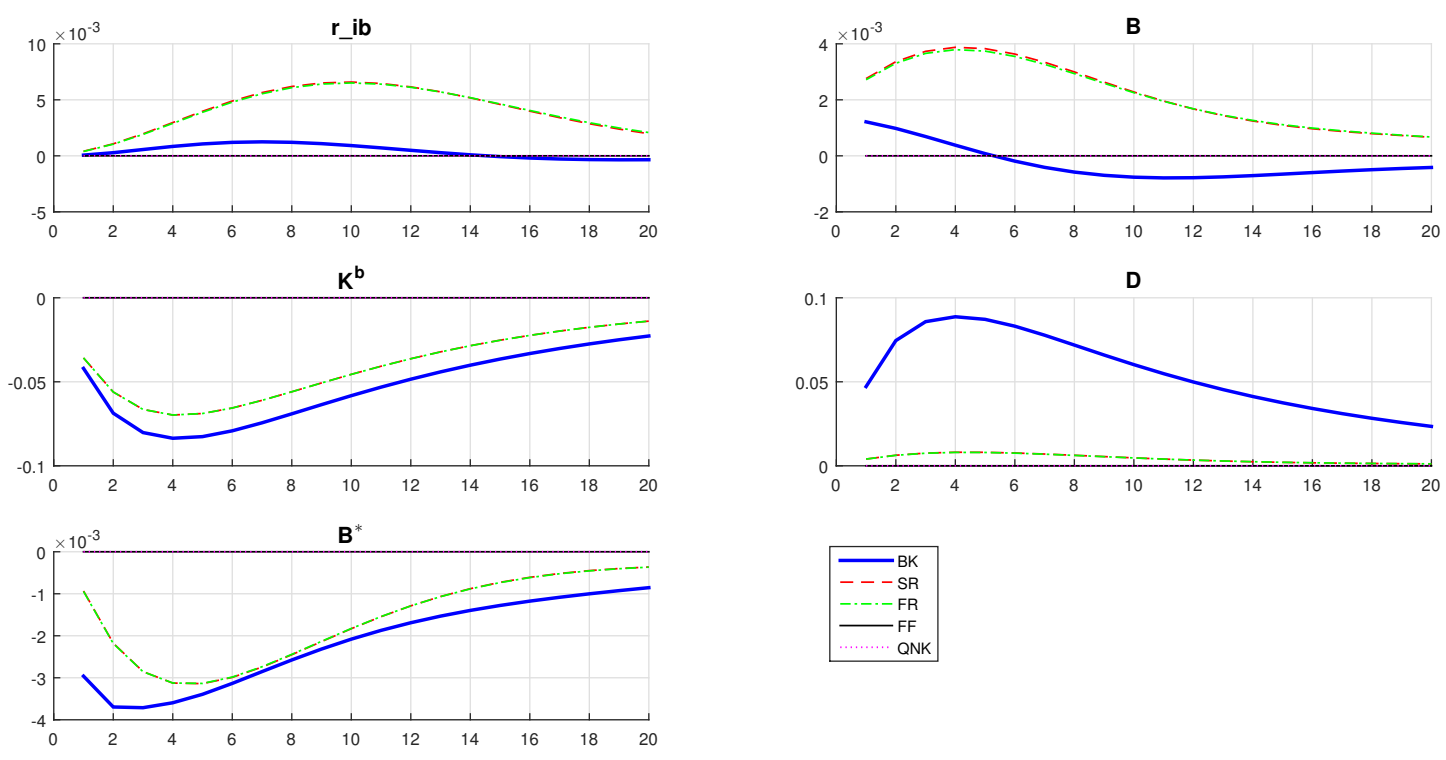

Figura 28: Efeito de um choque no capital bancário

Para o produto, consumo, investimento, inflação doméstica, taxa de juros de política monetária e crédito agregado os modelos SR e FR apresentam uma volatilidade maior em comparação ao modelo benchmark. Já para o capital bancário, poupança externa e 
poupança doméstica ocorre o inverso, os modelos com mais friç̧ões são os mais afetados pela crise no setor bancário. Ainda, os modelos FF e QNK, em que é suposta a ausência poder de mercado dos bancos para as taxas de empréstimo e depósito não apresentam resposta ao choque no capital bancário para qualquer uma das variáveis analisadas.

\subsubsection{Choque na Renda Externa}

Por fim, as figuras 29 e 30 expressam os efeitos de um aumento na renda externa para os cinco modelos considerados.
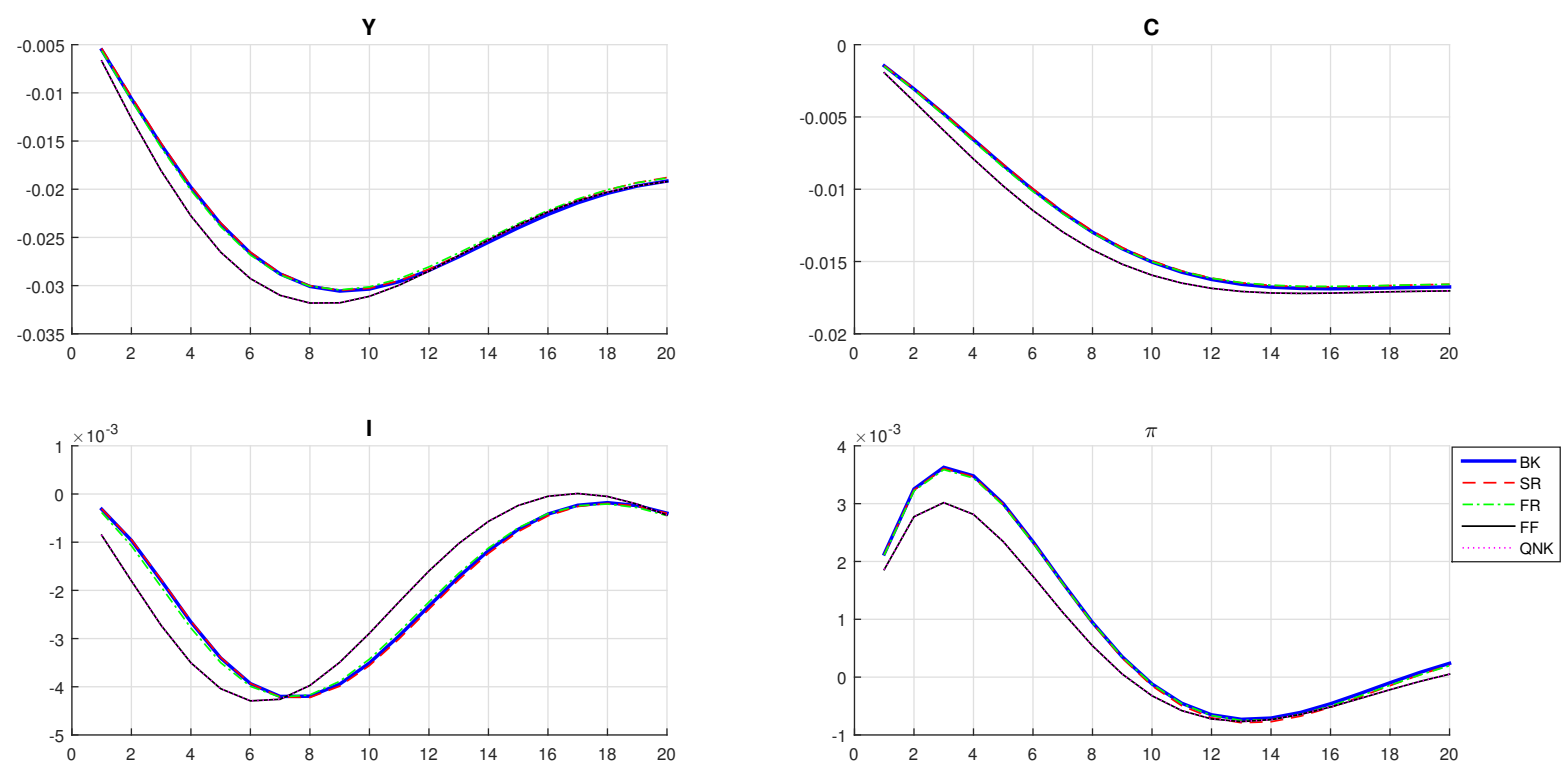

Figura 29: Efeito de um choque na renda externa

Novamente, no que diz respeito ao produto, consumo, investimento, inflação, taxa de política monetária, capital bancário, poupança externa e crédito agregado é possível definir dois grupos de modelos a partir da ausência, ou não, do poder de mercado dos bancos. Para o produto, consumo e investimento, os modelos FF e QNK apresentam uma maior sensibilidade ao choque na renda externa. Já no que tange à inflação doméstica, taxa de juros de política monetária e crédito agregado ocorre o inverso. Em particular, para o capital bancário e poupança externa, não há resposta dos modelos FF e QNK ao choque.

\subsection{O impacto de mudanças no parâmetro de custo de ajustamento do capital bancário}

Entre os resultados obtidos no modelo proposto em Gerali et all (2010), está a conclusão de que custo de ajustamento no capital bancário tem um importante impacto 

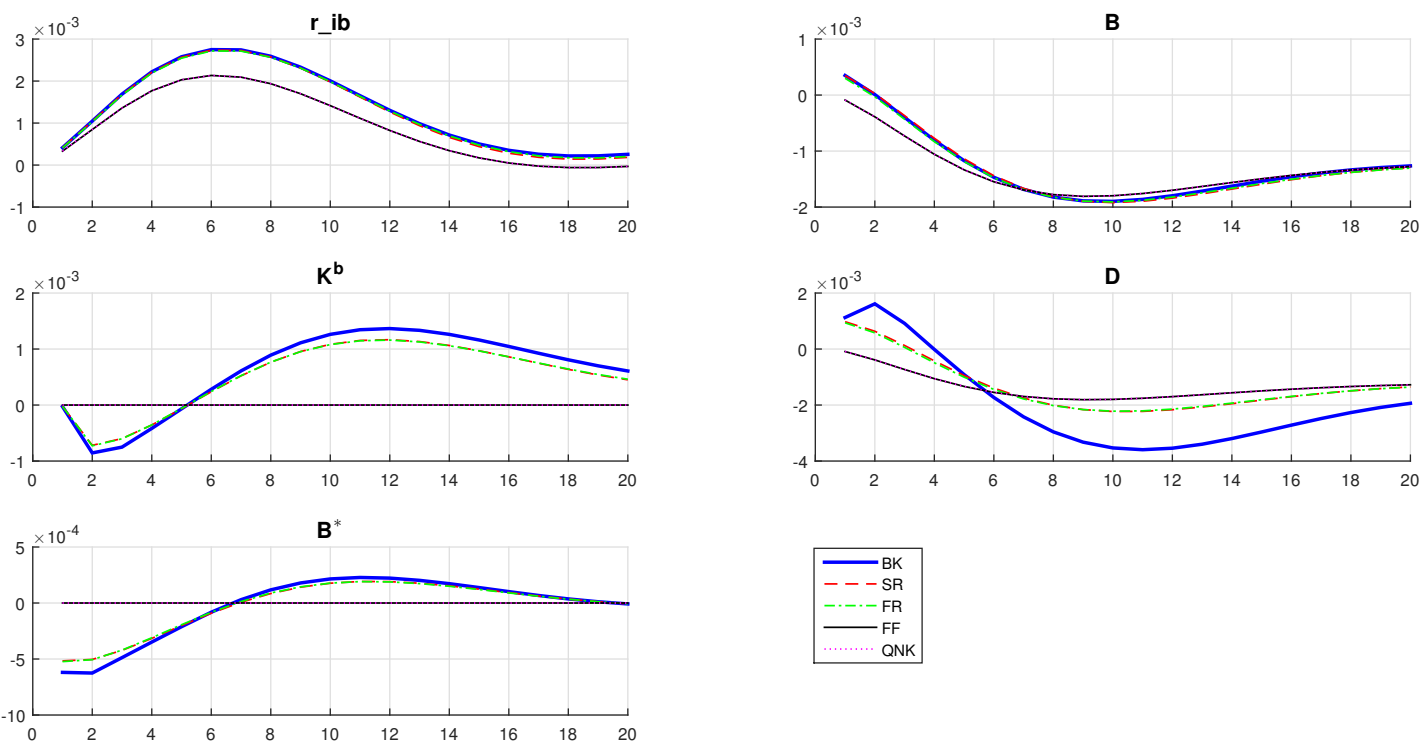

Figura 30: Efeito de um choque na renda externa

sobre o tamanho do efeito de um choque no capital bancário sobre a economia. Esta conclusão foi alcançada simulando o modelo para dois valores calibrados do custo de ajustamento. Na presente seção esse esperimento será repetido a fim de se investigar em que medida os resultados se mantém para uma economia aberta. Desta forma serão comparadas as funções de resposta ao impulso de um choque no capital bancário, supondo dois valores para o parâmetro de custo de ajustamento: no primeiro caso este prâmetro é calibrado pela media estimada e no segundo ele é multiplicado por 10.
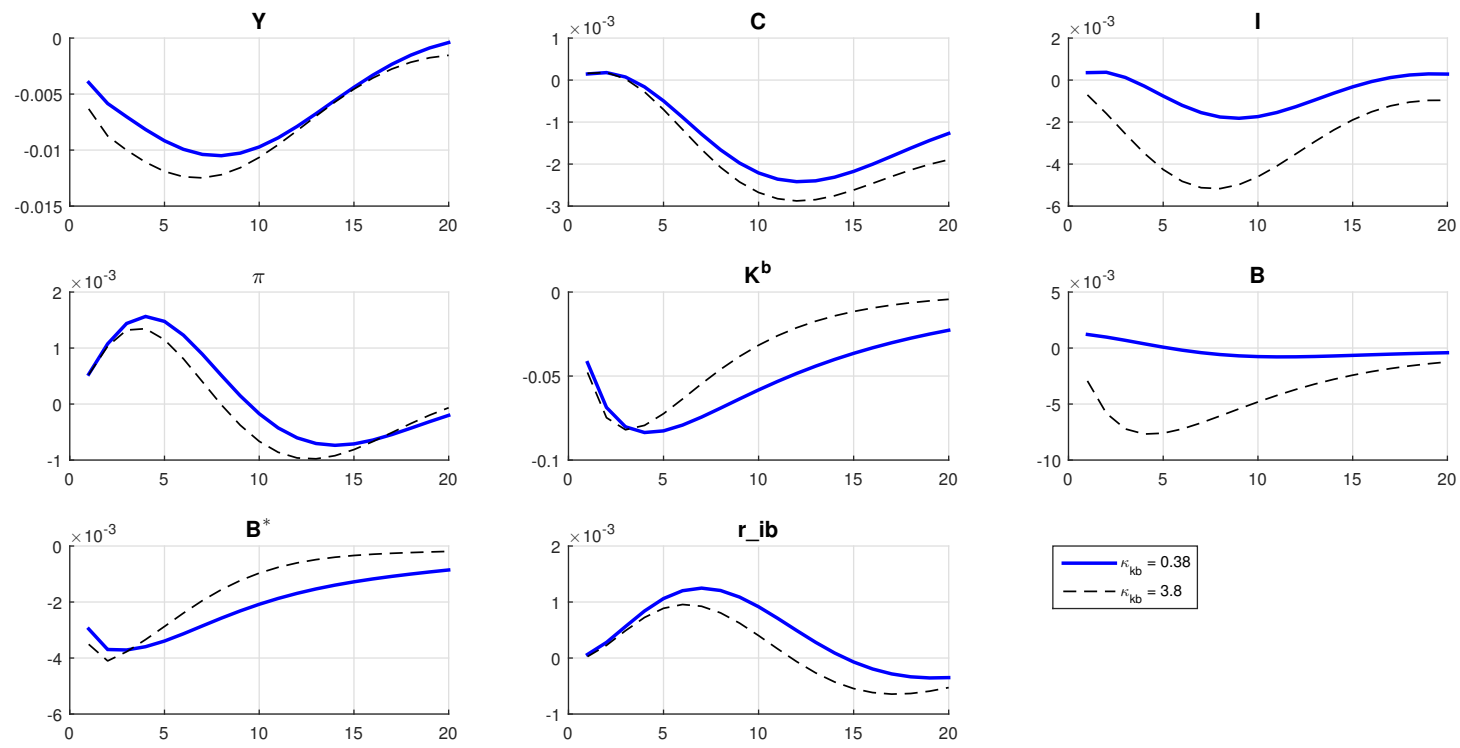

Figura 31: Efeito de um choque no capital bancário 

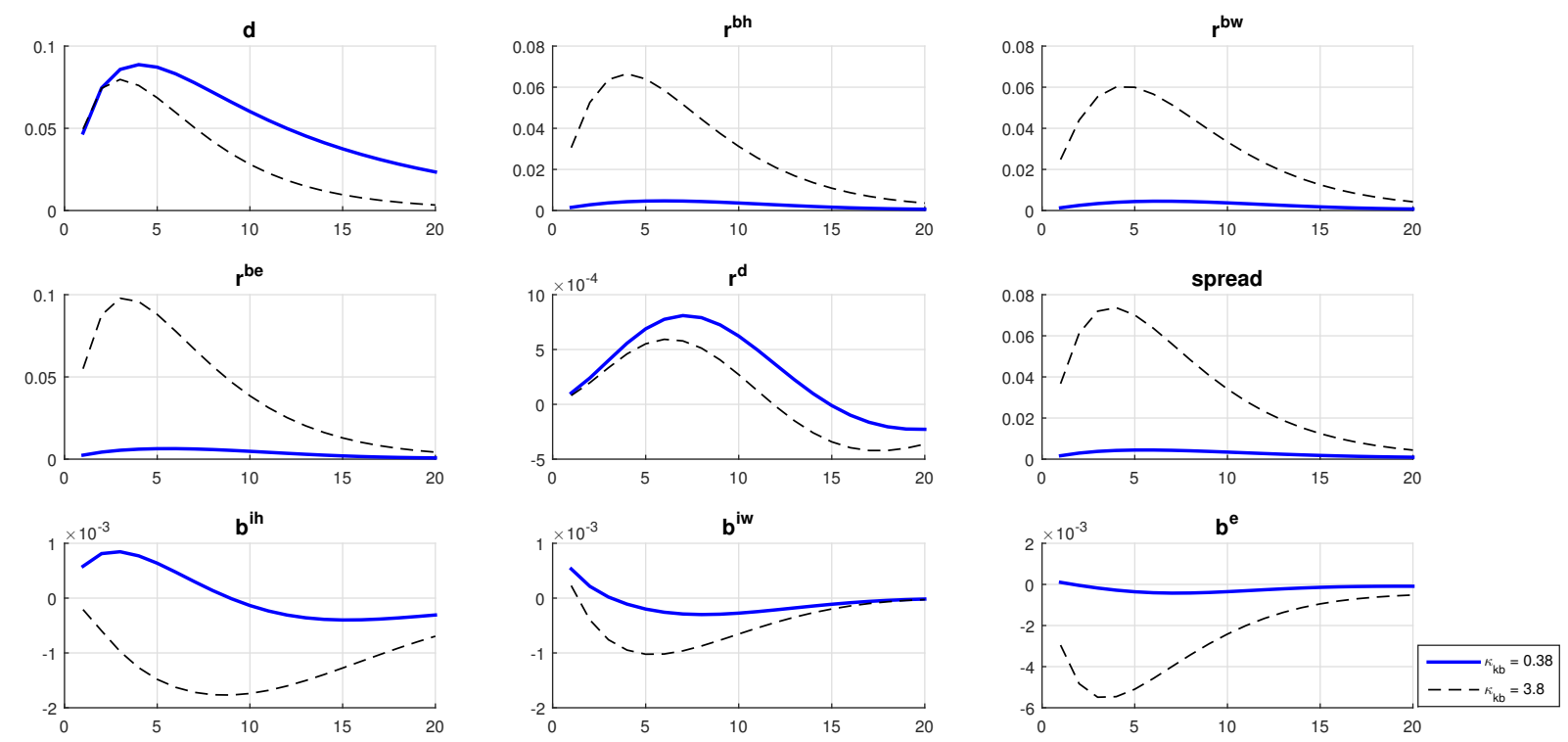

Figura 32: Efeito de um choque no capital bancário

As figuras 31 e 32 reportam a simulação do choque no capital bancário para algumas das variáveis do modelo. Após o choque os bancos se tornam excessivamente alavancados, para recompor o capital perdido os bancos aumentam o spread entre as taxas de empréstimo e captação, como forma de elevar o lucro - e dessa forma, o capital bancário. Isso leva a uma queda na demanda por empréstimos por parte das famílias e empresários, implicando em uma contração no nível de atividade econômica. Em particular, o aumento nas taxas de juros, explicada pelo aumento na taxa de política monetária - em reação ao movimento da taxa de inflação - e pelo aumento no spread bancário reduz o empréstimo aos empresários e, portanto, o nível de investimento em capital - levando a uma substituição de capital físico por trabalho e insumo importado. O aumento na demanda por trabalho explica o porquê o empréstimo consignado aumenta (no modelo calibrado pela média estimada). Para satisfazer a esse aumento na demanda por empréstimo consignado, os bancos aumentam a captação de poupança doméstica, elevando a remuneração pelos depósitos às famílias pacientes. A queda no capital bancário também leva a um aumento no prêmio de risco demandado pelos investidores internacionais, o que diminui sua disposição em financiar a economia doméstica. $\mathrm{O}$ aumento no parâmetro de custo de ajustamento do capital bancário parece ter efeito similar ao exposto em Gerali et all (2010), embora a queda inicial tenha sido amplificada, o maior custo no desvio da razão $K^{b} / B$ em relação ao valor ótimo obriga os bancos a elevar ainda mais o spread bancário a fim de acelerar a recuperação do capital bancário. Isto não só torna a queda nos empréstimos às famílias com colateral em imóveis e aos empresários ainda maior como também faz com que os empréstimos consignados também se caiam - o que torna a demanda por depósitos menor em relação ao modelo calibrado pela média estimada. Desta forma, a queda no produto, 
consumo e investimento tornam ainda maiores. Por fim, a rápida recuperação no capital bancário também favore a retomada dos empréstimos com o exterior, na medida em que reduz o prêmio de risco.

\subsection{Comparação entre os modelos de economia fechada e aberta}

Nesta seção a comparação entre os resultados obtidos nos modelos de economia fechada e economia aberta é realizada por meio da comparação entre as funções de resposta ao impulso. Para tornar estes modelos diretamente comparáveis, os parâmetros que governam a dinâmica em ambos os modelos são calibrados em valores iguais. Desta forma, os parâmetros de custo de ajustamento para capital bancário, taxas de juros, e investimentos nos setores de capital físico e imóveis são todos calibrados em 10, enquanto os parâmetros de persistência dos choques são calibrados em 0.9 ; por fim é suposto que o desvio-padrão dos choques é igual a 0.01 .
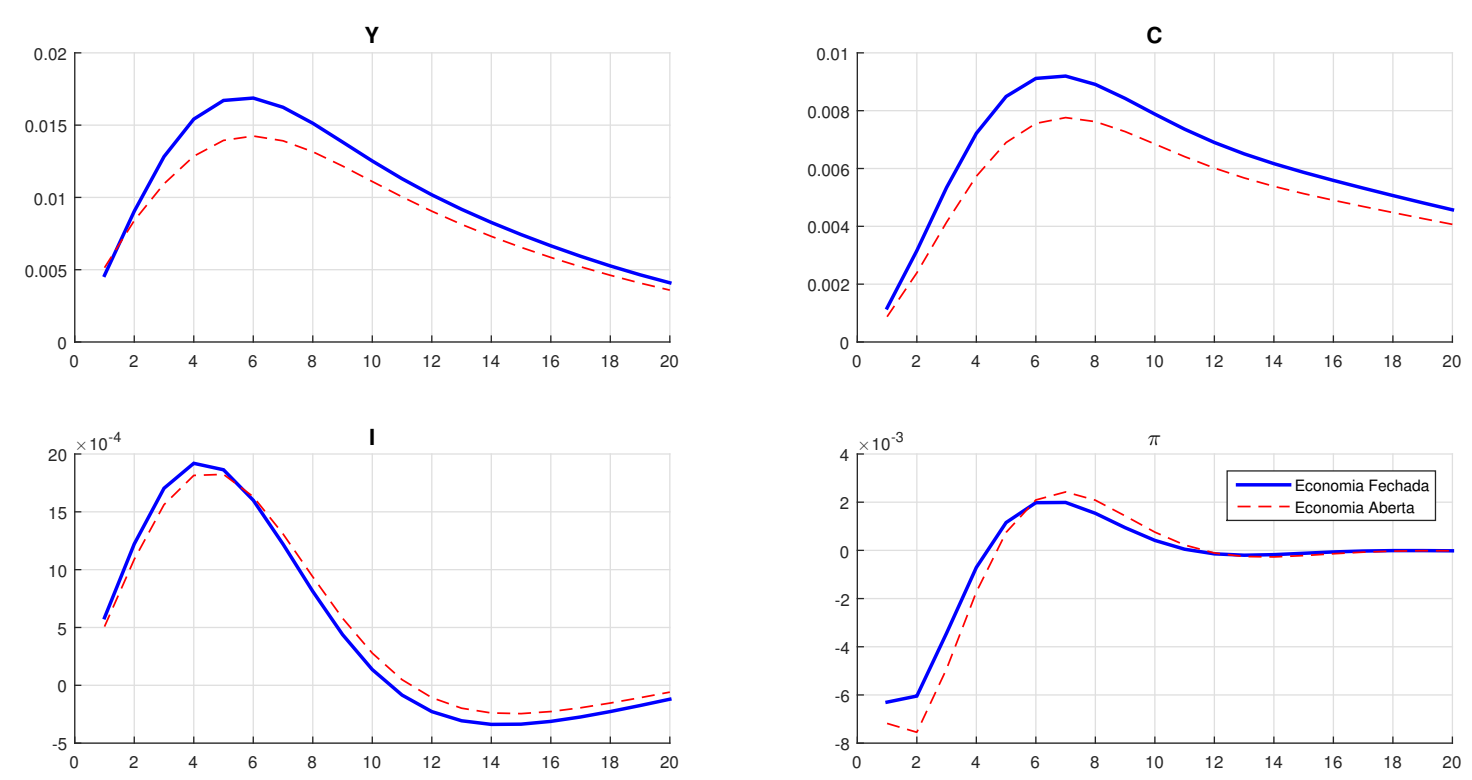

Figura 33: Efeito de um choque tecnológico

O choque tecnológico causa um aumento na produtividade dos insumos utilizados na produção de bens intermediários. Isto reduz o número de horas trabalhadas necessárias, dos dois tipos de famílias, e aumenta seus salários. O aumento na renda das famílias eleva o consumo e a aquisição de imóveis na economia, o que aumenta o produto agregado e a taxa de inflação doméstica. A autoridade monetária reage a este panorama de maior inflação elevando a taxa de juros de política monetária, o que implica em maiores taxas de juros para empréstimos e depósitos. Este aumento nas taxas reduz os empréstimos aos empresários e os empréstimos com colateral em imóveis às famílias impacientes - embora os empréstimos consignados aumentem como fruto da elevação no salário das famílias 

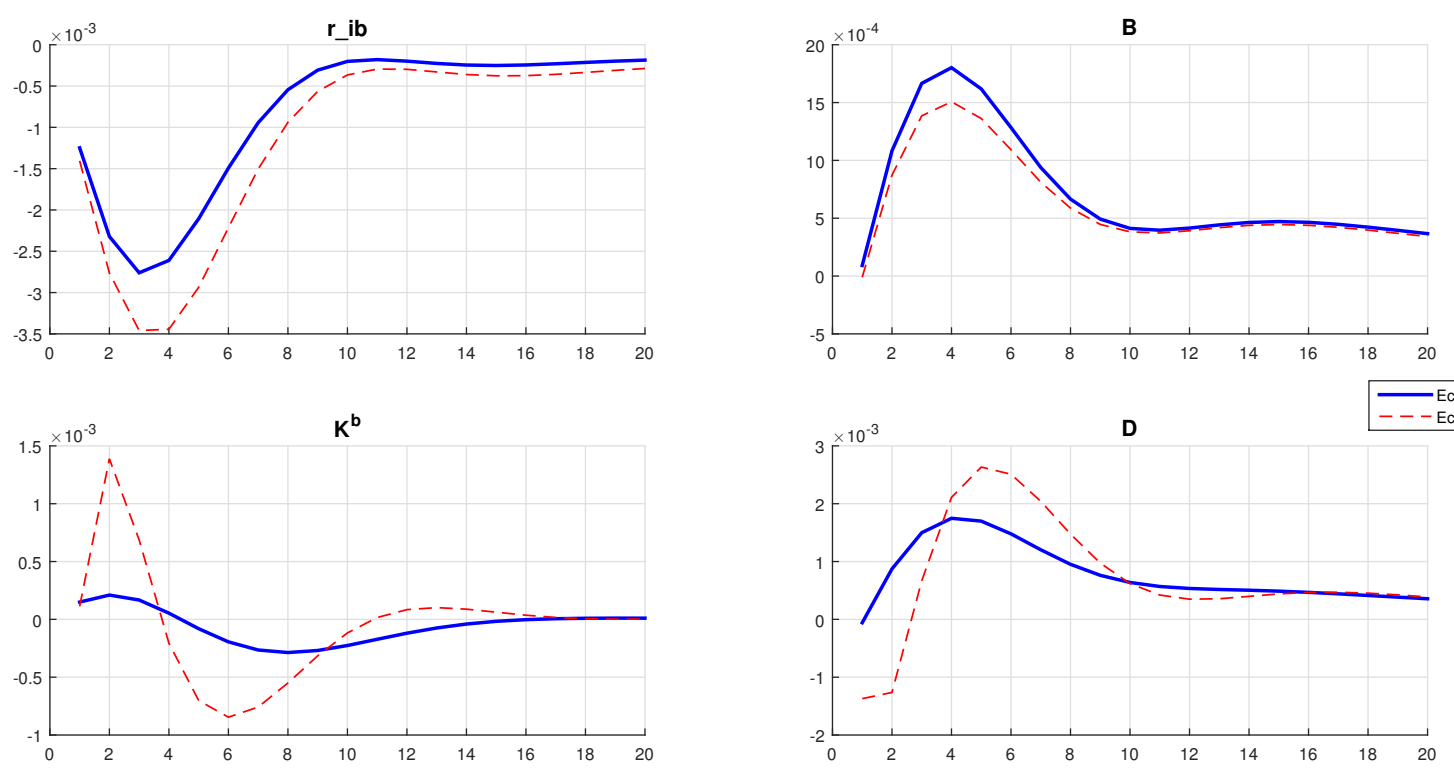

Figura 34: Efeito de um choque tecnológico

impacientes. Para a economia aberta, parte do aumento na produção deixa a economia doméstica por meio das exportações. Isto diminui o efeito do choque tecnológico, tornando o desvio em relação ao steady state para o consumo, produto e investimento menores em comparação caso para uma economia fechada.
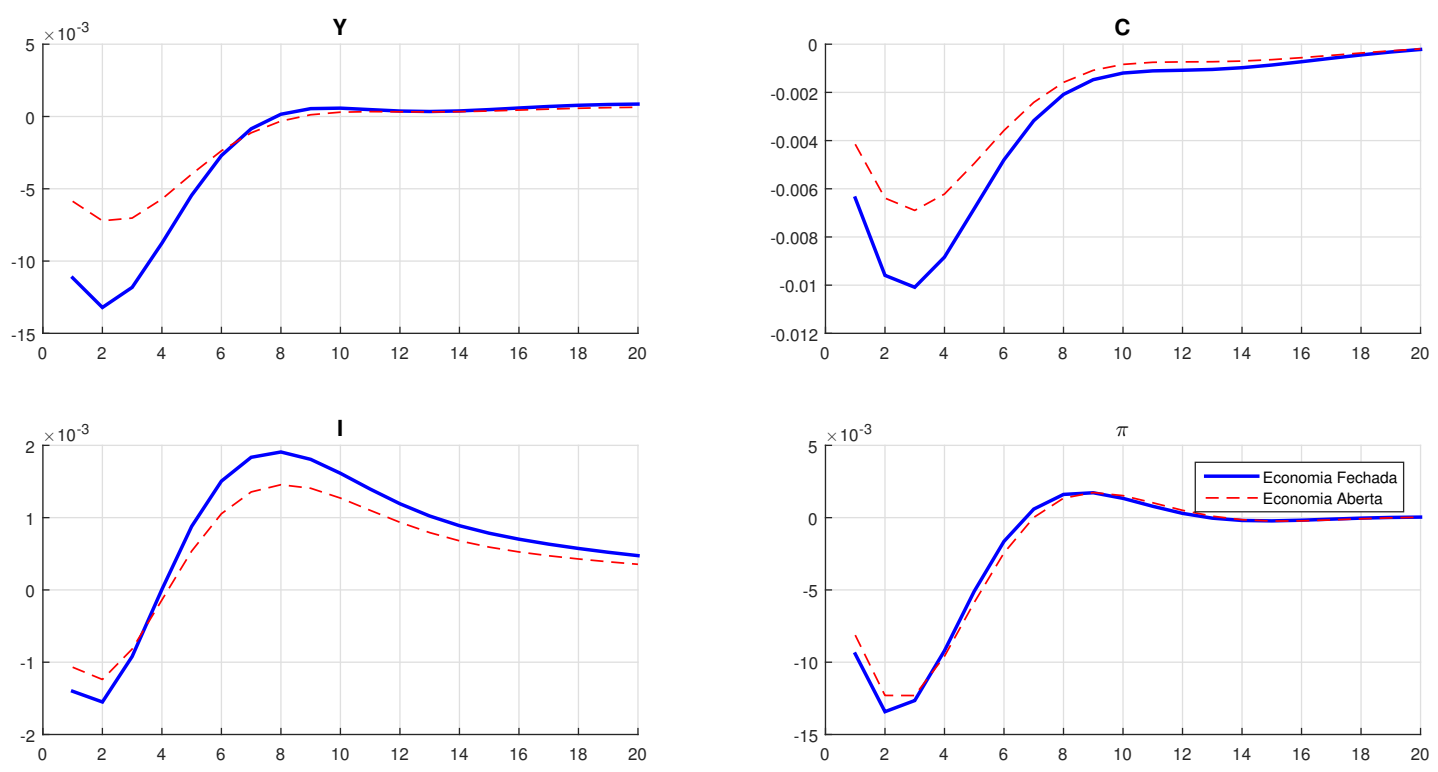

Figura 35: Efeito de um choque de política monetária

Um aumento inesperado no instrumento de política monetária eleva as demais taxas de juros da economia doméstica. Isto reduz a demanda por consumo, imóveis e empréstimos para as famílias e empresários. A queda na renda dos empresários derivada 

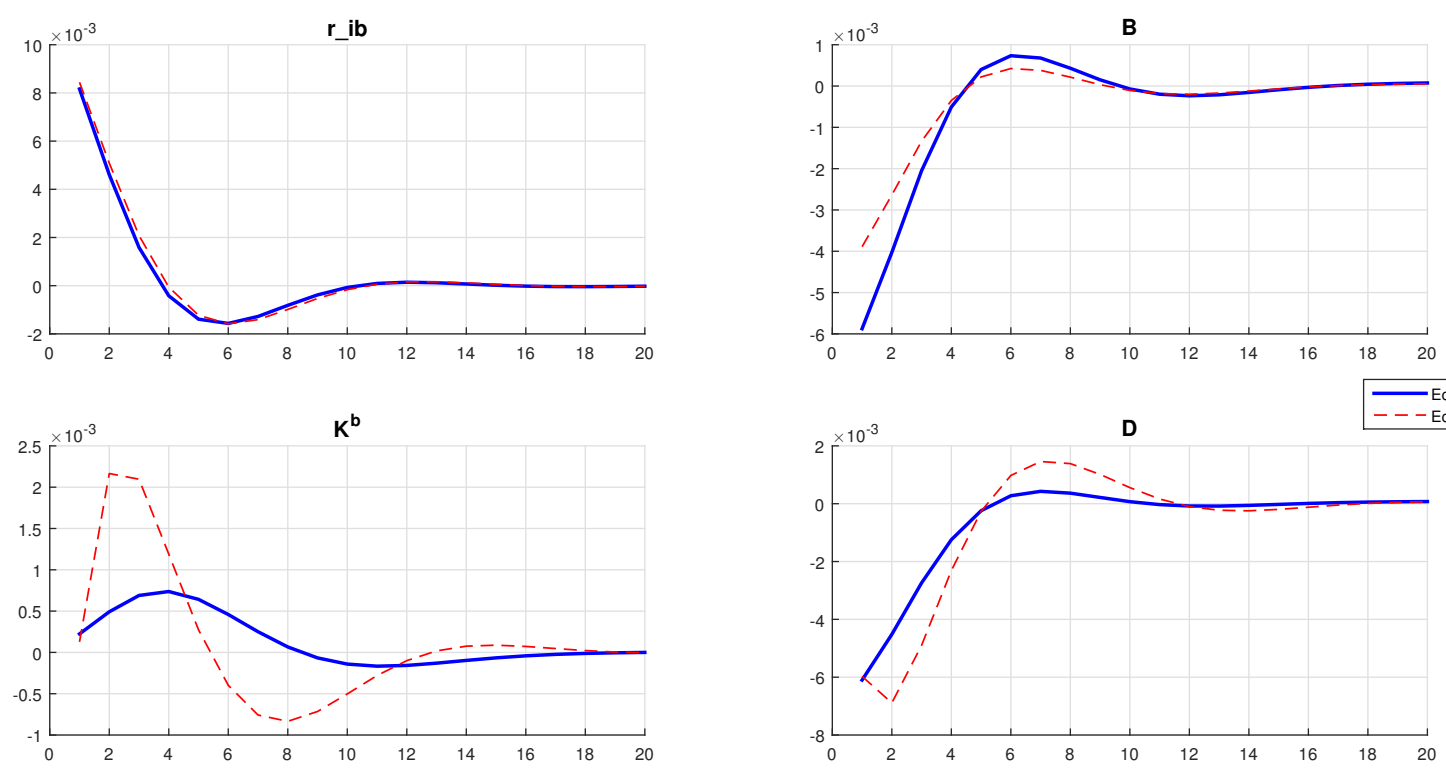

Figura 36: Efeito de um choque de política monetária

da queda nas vendas de bens intermediários e do aumento no custo do endividamento leva a uma redução no investimento agregado em capital físico - o que aprofunda a queda no nível de atividade econômica e na taxa de inflação. Para a economia aberta, o aumento na taxa de política monetária atrai poupança externa, impliando em uma desvalorização cambial. O câmbio real desvalorizado incentiva as exportações, diminuindo o tamanho do choque adverso.
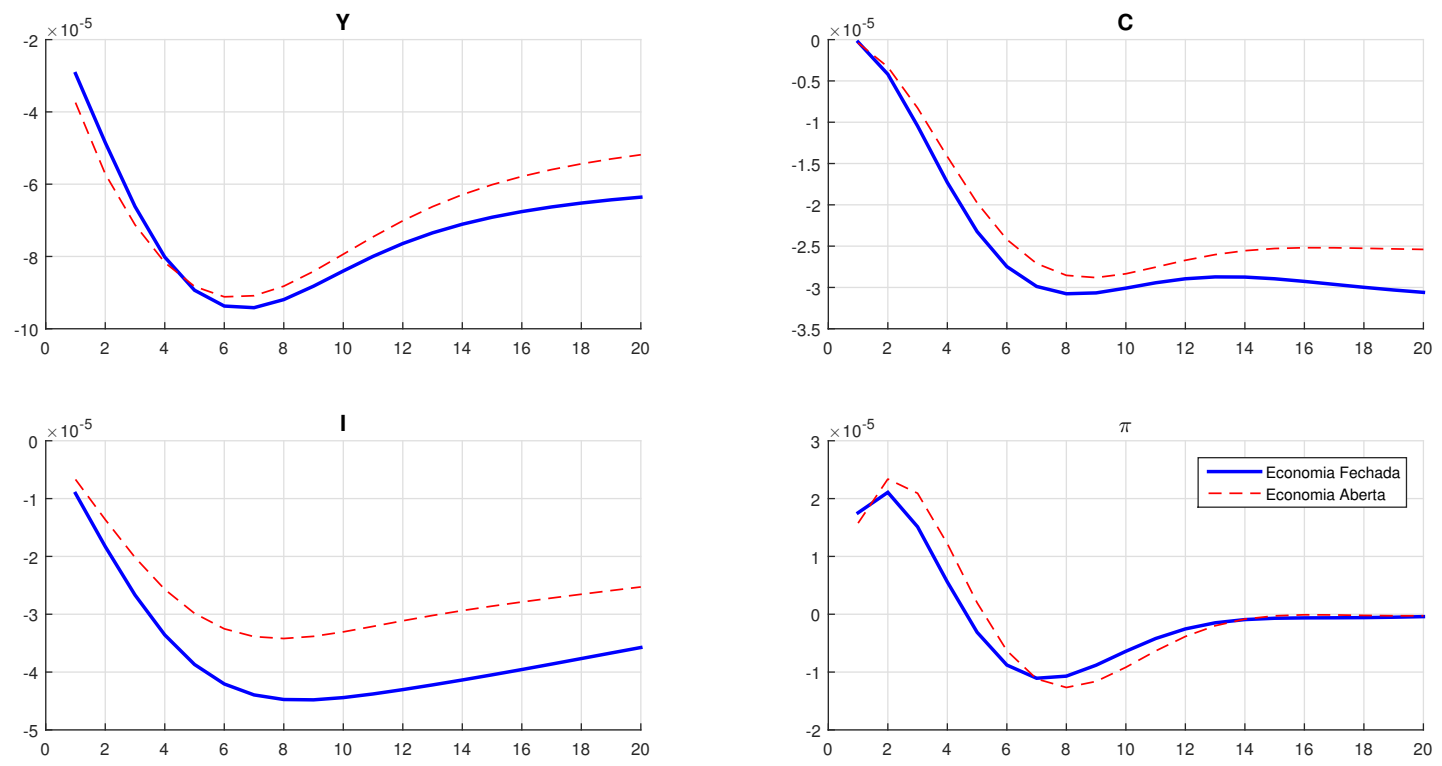

Figura 37: Efeito de um choque no capital bancário 

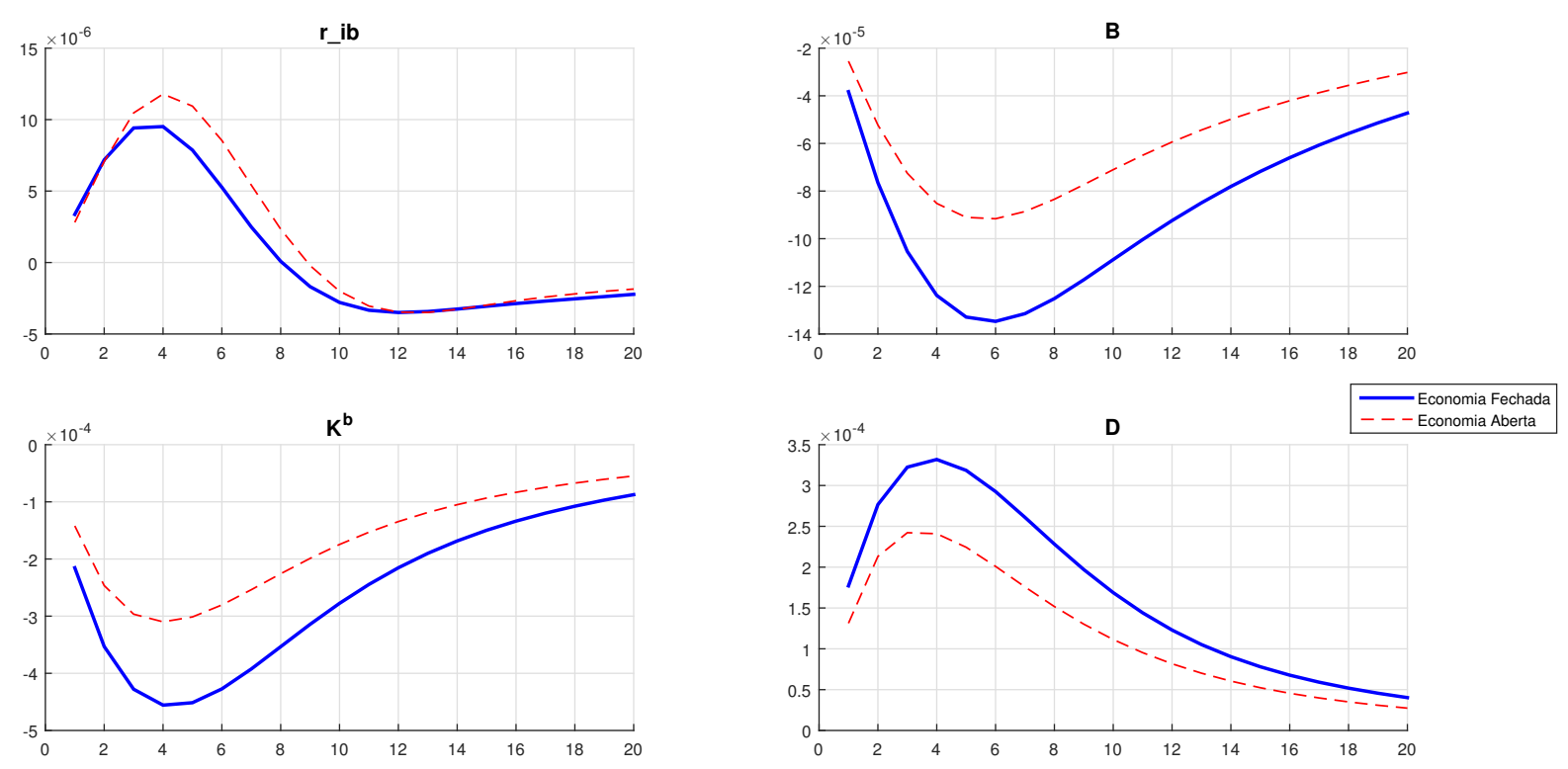

Figura 38: Efeito de um choque no capital bancário

Em ambas as versões do modelo, um choque no capital bancário induz um aumento nas taxas sobre depósitos e empréstimos por parte de bancos como forma de recompor o capital bancário perdido. Esta estratégia permite aos bancos superar a crise no setor mais rapidamente, porém leva a economia a uma depressão. Na versão para economia aberta, entretanto, o aumento das exportações minimiza o impacto negativo sobre o ciclo de negócios provocado pela reação dos bancos ao choque no capital bancário.

\subsection{Conclusão}

Por meio da decomposição histórica para o modelo de economia aberta foi possível constatar a importância dos choques externos para explicar a evolução da economia brasileira no período em análise - em particular aqueles ligados ao prêmio de risco e à taxa de juros internacional. Com relação a importância das fricções financeiras na dinâmica do modelo, percebe-se novamente que as imperfeições de maior influência sobre a amplitude dos choques são aquelas relacionadas ao ajustamento no capital bancário e ao poder de mercado.

Em resumo, para os choques na inflação externa, no prêmio de risco e na taxa de juros externa; os custos de ajustamento no capital bancário e taxas de juros ampliam os efeitos destes choques sobre o produto, consumo, investimento em capital, inflação doméstica, empréstimos e depósito agregado - porém tem pouco ou nenhum efeito sobre a taxa de políica monetária, capital bancário e poupança externa. Em particular, a ausência de poder de mercado parece ter anulado os efeitos desses choques sobre o modelo. Cabe ainda 
notar que para os efeitos dos choque no prêmio de risco e na taxa de juros internacional sobre o produto, a presença de custos de ajustamento é o único fator relevante.

Com relação aos choques de política monetária e renda externa, o produto e o consumo exibem uma resposta maior na ausência de custos de ajustamento, enquanto o investimento e a inflação doméstica respondem mais aos modelos com custo de ajustamento. Novamente, o único fator aperentemente relevante é a presença dos custos de ajustamento sobre capital bancário e taxas de juros. Já as variáveis financeiras mantém o comportamento descrito anteriormente. Por fim, para o choque no capital bancário, a presença de custo de ajustamente no mesmo amortece o efeito do choque sobre o produto, consumo, investimento, inflação, empréstimo agregado e taxa de juros de política monetária, enquanto a ausência de poder de mercado sobre as taxas de juros de empréstimos e depósitos anula o efeito por completo para estas variáveis analisadas. Para o capital bancário, depósitos e poupança externa ocorre o oposto: as fricções financeiras ampliam os efeitos de um aumento repentino na renda externa.

No que diz respeito ao efeito de variações no custo de ajustamento do capital bancário, o modelo conserva a propriedade apresentada em Gerali et all (2010), ou seja, mesmo para uma economia apta a captar poupança externa, uma crise financeira é tanto maior quanto maior for o custo de ajustamento no capital bancário. Por fim, na comparação entre funções de resposta ao impulso para os modelos de economia fechada e aberta, percebe-se que os choques têm um efeito maior no modelo de economia fechada - com exceção da dinâmica do capital bancário, isso pode ser explicado pelo fato do prêmio de risco depender da relação entre o endividamento externo e o capital bancário, isto impõe um custo adicional para os bancos de um desvio do valor dessa variável em relação ao seu valor de steady state. 



\section{Referência Bibliográfica}

AGÉNOR, P. R. ALPER, K. SILVA, L. Pereira. Capital requirements and business cycles with credit market imperfections. Journal of Macroeconomics. n 34, p. 687-705, 2012.

BERNANKE, Ben. S. GERTLER, Mark. GILCHRIST, Simon. The financial accelerator in a quantitative business cycle framework. Handbook of Macroeconomics. 1999. Capítulo 21, p. 1342-1393.

BRANDI, Vinícius Ratton. Avaliação de de Políticas Macroprudenciais em um Modelo Novo Keynesiano com Intermediação Financeira. 2013. 165 f. Tese - Faculdade de Administração, Contabilidade e Economia, Universidade de Brasília, Brasília.

BRÁZDIK, Frantisek. HLAVÁCEK, Michal. MARSAL, Ales. Survey of Research on Financial Sector Modeling within DSGE Models: What Central Banks Can Learn from It. Journal of Economics and Finance. n 3, p. 252-277, 2012.

BRZOZA-BRZEZINA, Michal. MAKARSKI, Krzysztof. Credit Crunch in a Small Open Economy. Munich Personal RePEc Archive. n. 18595, p. 1-45, 2009.

BRUNNERMEIER, Markus K. EISENBACH, Thomas M. SANNIKOV, Sannikov. Macroeconomics with Financial Frictions: A Survey. Working Paper. p. 1-93, 2012.

CASTRO, Marcos R. et all. SAMBA: Stochastic Analytical Model with a Bayesian Approach. Working Paper. n 239, p. 1-139, 2011.

DIB, Ali. Monetary Policy in Estimated Models of Small Open and Closed Economies. Working Paper. n 27, p. 1-40, 2003.

CAVAlCANTI, Marco A. F. H. VEREDA, Luciano. Modelo Dinâmico Estocástico de Equilíbrio Geral (DSGE) para a Economia Brasileira: Versão 1. Texto para Discussão. n 1479, p. 1-100, Brasília, 2010.

GERALI, Andrea. et al. Credit and banking in a DSGE model of the euro area. Journal of Money, Credit and Banking. v. 42, n 6, p. 108-141, 2010.

GERTLER, Mark.; KARADI, Peter. A model of unconventional monetary policy. Journal of Monetary Economics. Working Paper. p. 1-40, 2011.

GOMES, Victor. PESSÔA, Samuel A.; VELOSO, Fernando A. Evolução da Produtividade Total dos Fatores na Economia Brasileira: Uma Análise Comparativa. Pesquisa e Planejamento Econômico. v 33, n 3, p. 390-434, 2003.

IACOVIELLO, Matteo. Housing Prices, Borrowing Constraints, and Monetary Policy in Business Cycle. American Economic Review. p. 739-764, 2005. 
KIYOTAKI, Nobuhiro. Credit and Business Cycles. The Japanese Economic Review. v 49, n 1, p. 18-35, 1998.

KIYOTAKI, Nobuhiro. MOORE, John. Credit cycles. Journal of Political Economy. 1997.

SACHSIDA, Adolfo. ELLERY Jr, Roberto de Góes. GOMES, Victor. Business cycle fluctuations in Brazil. Revista Brasileira de Economia. 2002.

SILVA, Gilvan Cândido. Avaliando o Mecanismo de Transmissão da Política Monetária por meio do Canal do Crédito: Estimação Bayesiana em Modelos DSGE com Fricções Financeiras. 2012. 104 f. Tese - Faculdade de Administração, Contabilidade e Economia, Universidade de Brasília, Brasília.

SMETS, Frank. WOUTERS, Raf. An Estimated Stochastic Dynamic General Equilibrium Model of The Euro Area. Working Paper. n. 171, p. 1-69, 2002.

VILLAVERDE, Jésus Fernandez. The econometrics of DSGE models. p. 1-47, 2010. 
Apêndices 

APÊNDICE A - Funções de Resposta ao Impulso para Economia Fechada

A.1 Efeito de um choque no debt-to-income
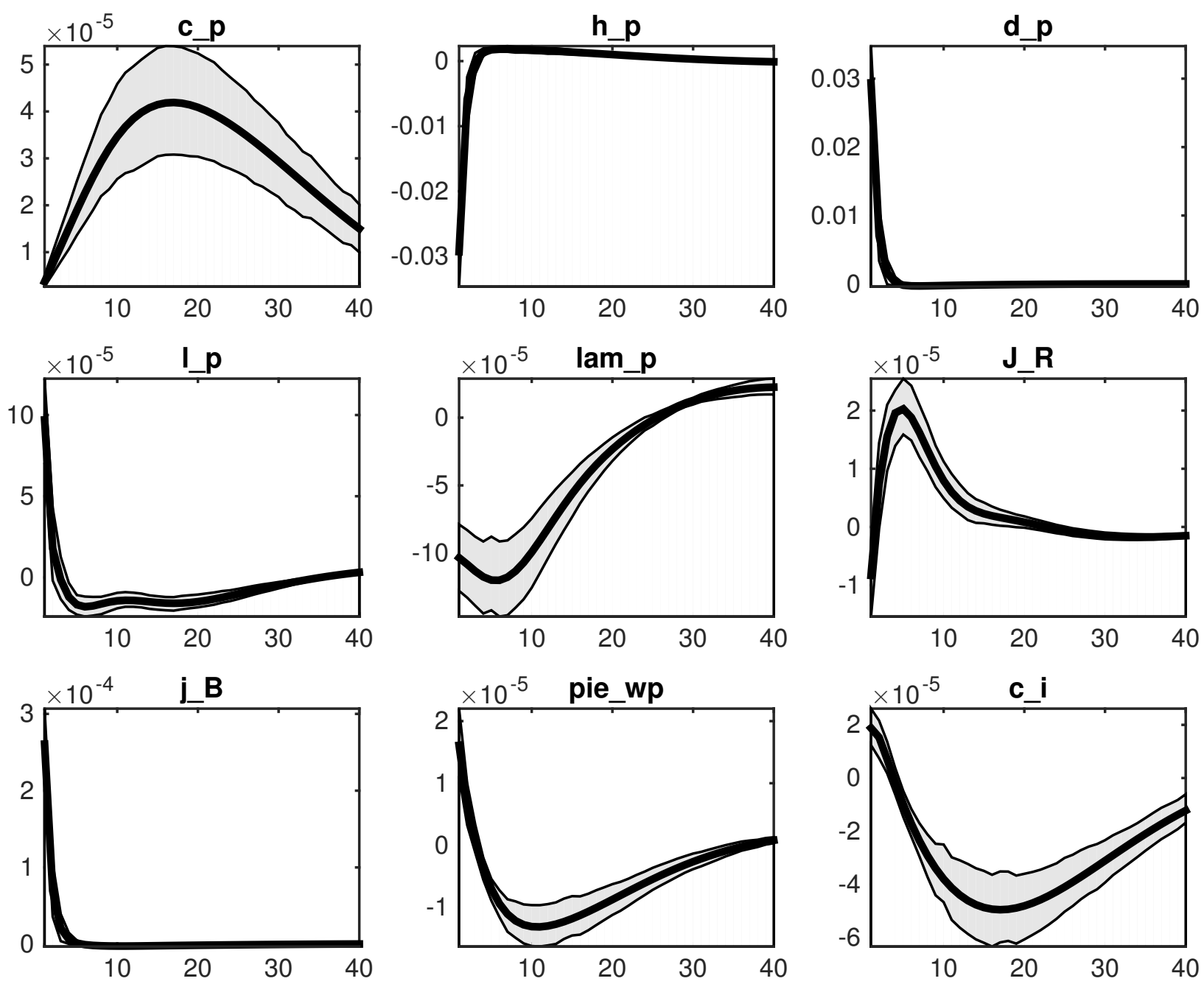

Figura 39: Efeito de um choque no debt-to-income 

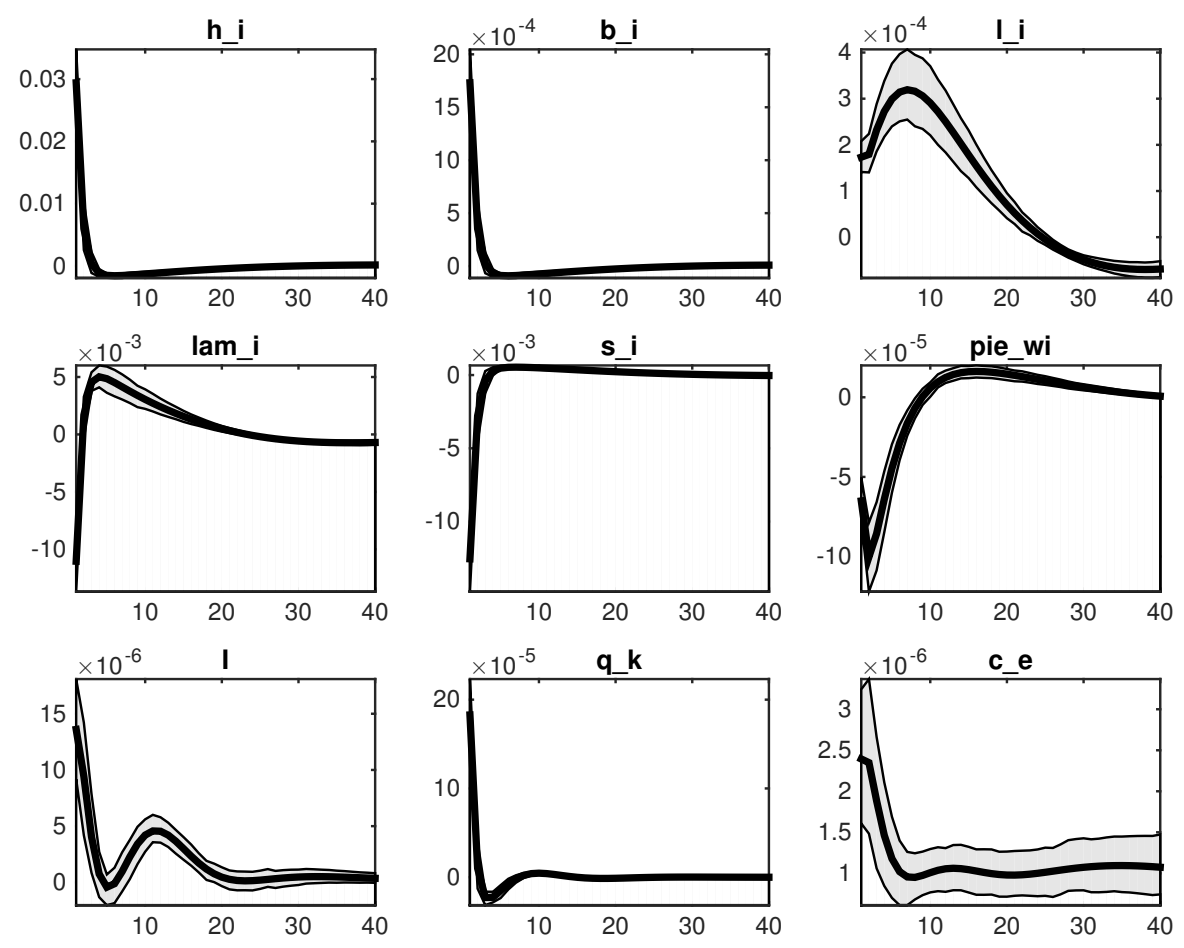

Figura 40: Efeito de um choque no debt-to-income
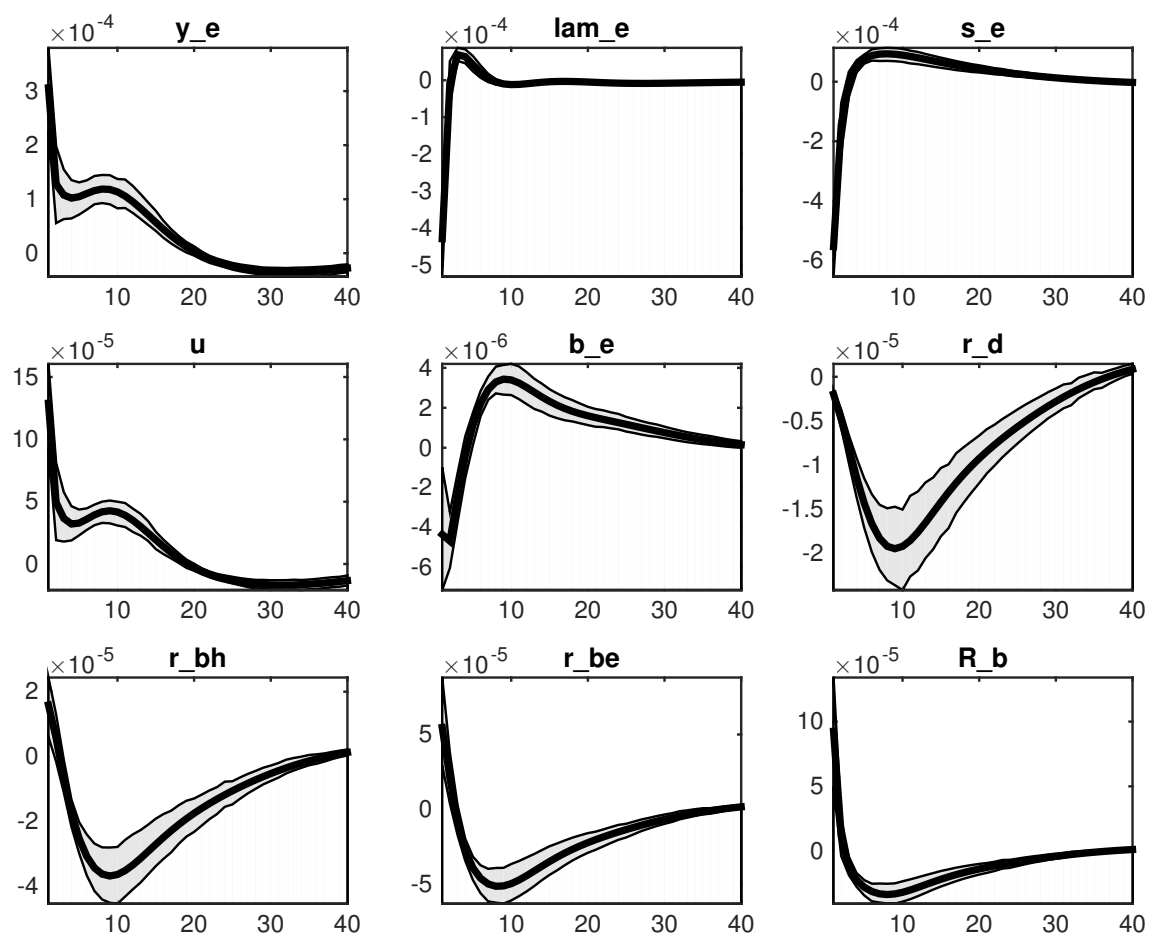

Figura 41: Efeito de um choque no debt-to-income 

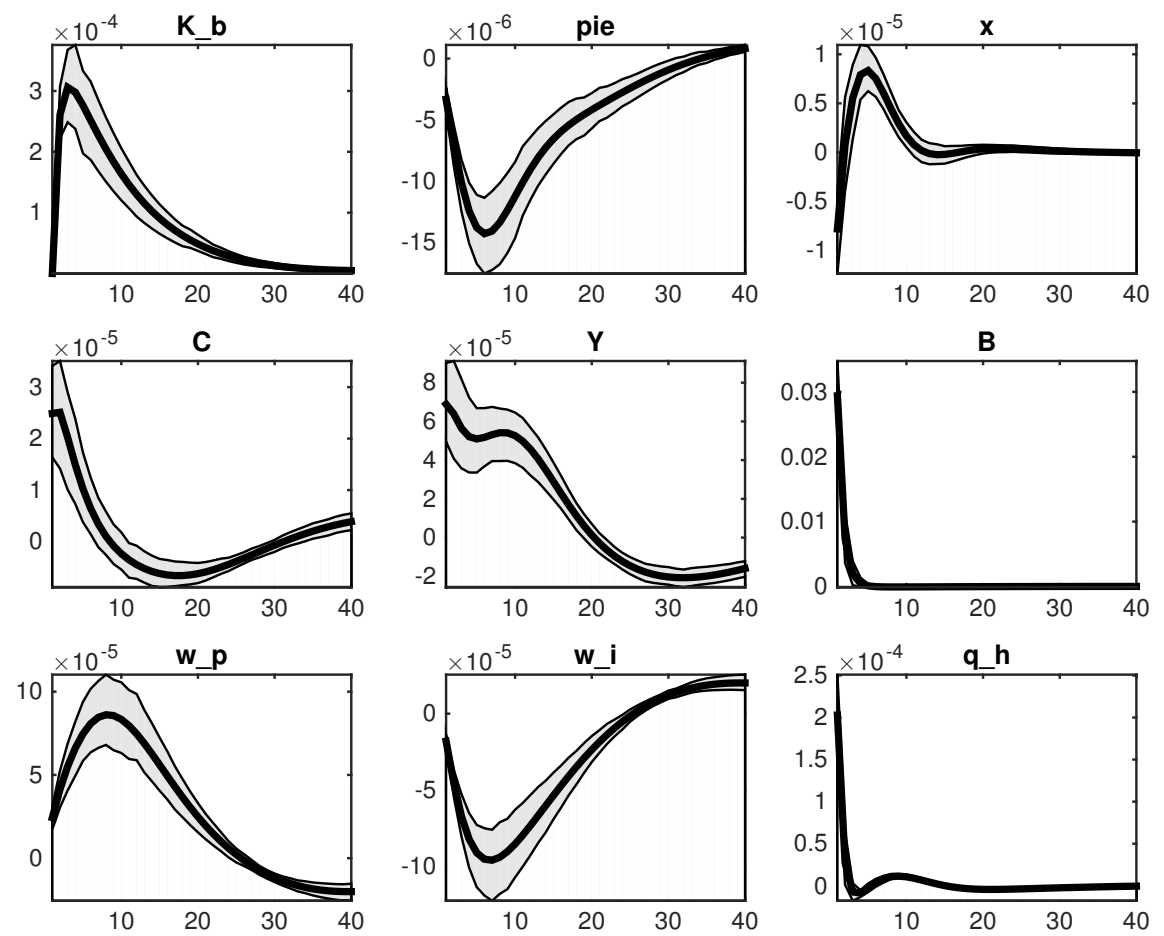

Figura 42: Efeito de um choque no debt-to-income
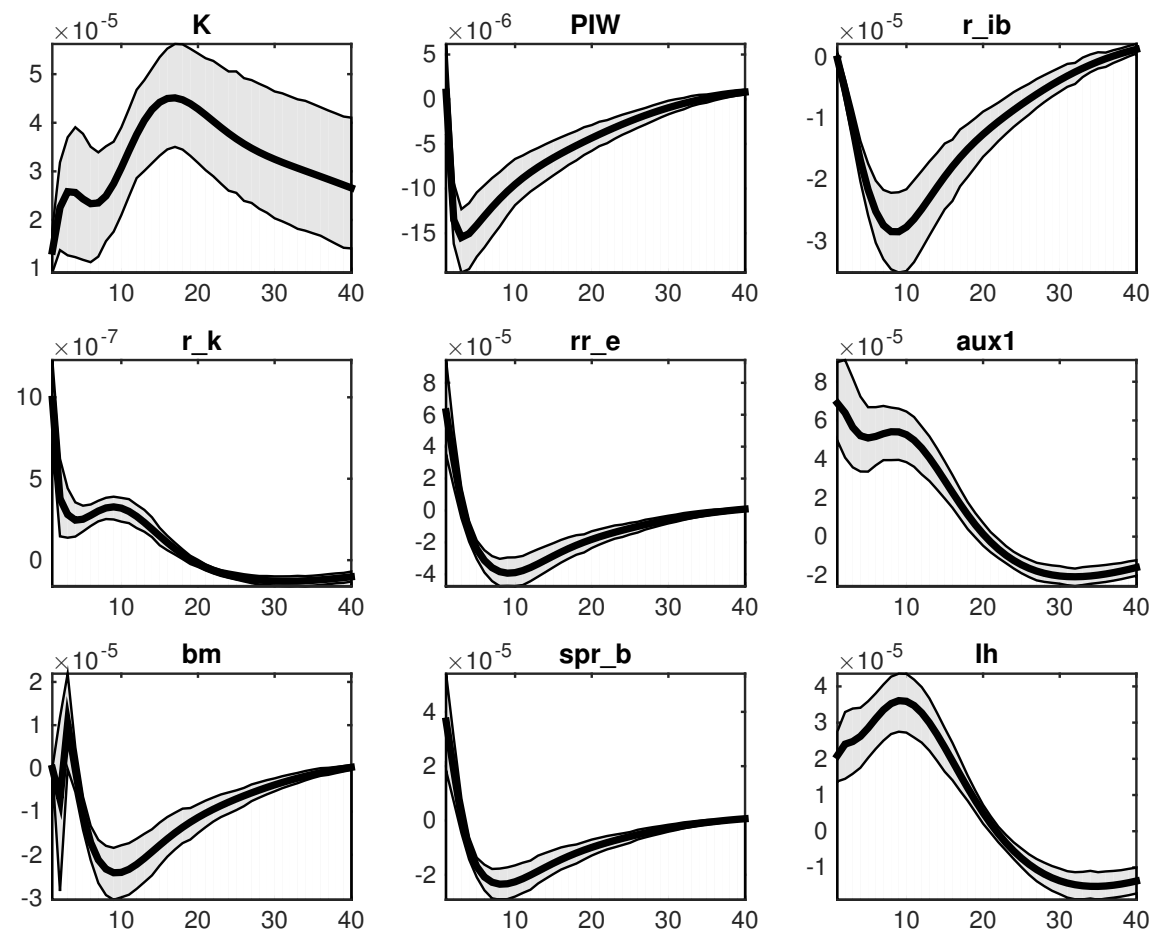

Figura 43: Efeito de um choque no debt-to-income 

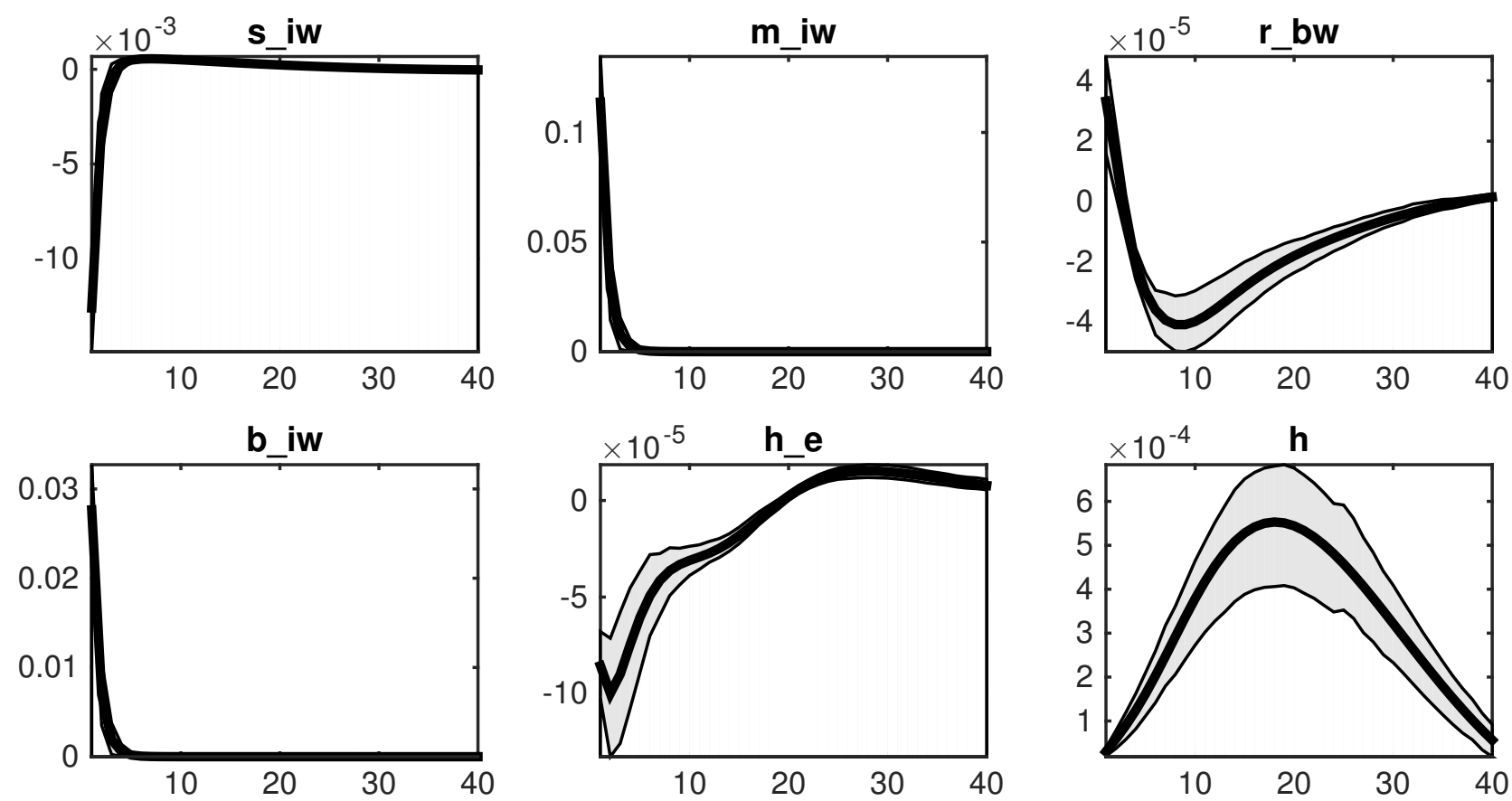

Figura 44: Efeito de um choque no debt-to-income 
A.2 Choque no Mark-up de taxa de juros: Empréstimo Consignado
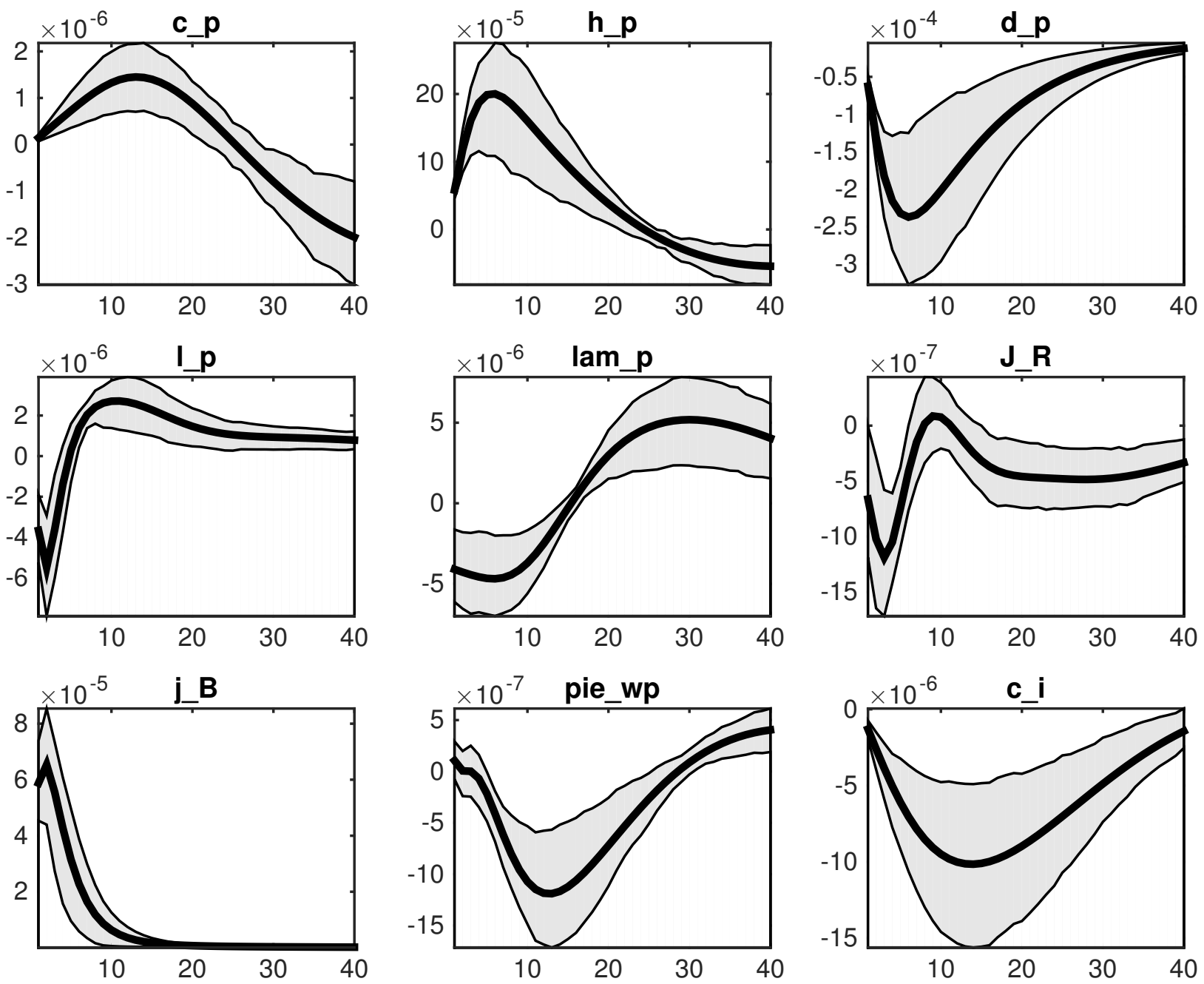

Figura 45: Efeito de um choque em mk_bw 

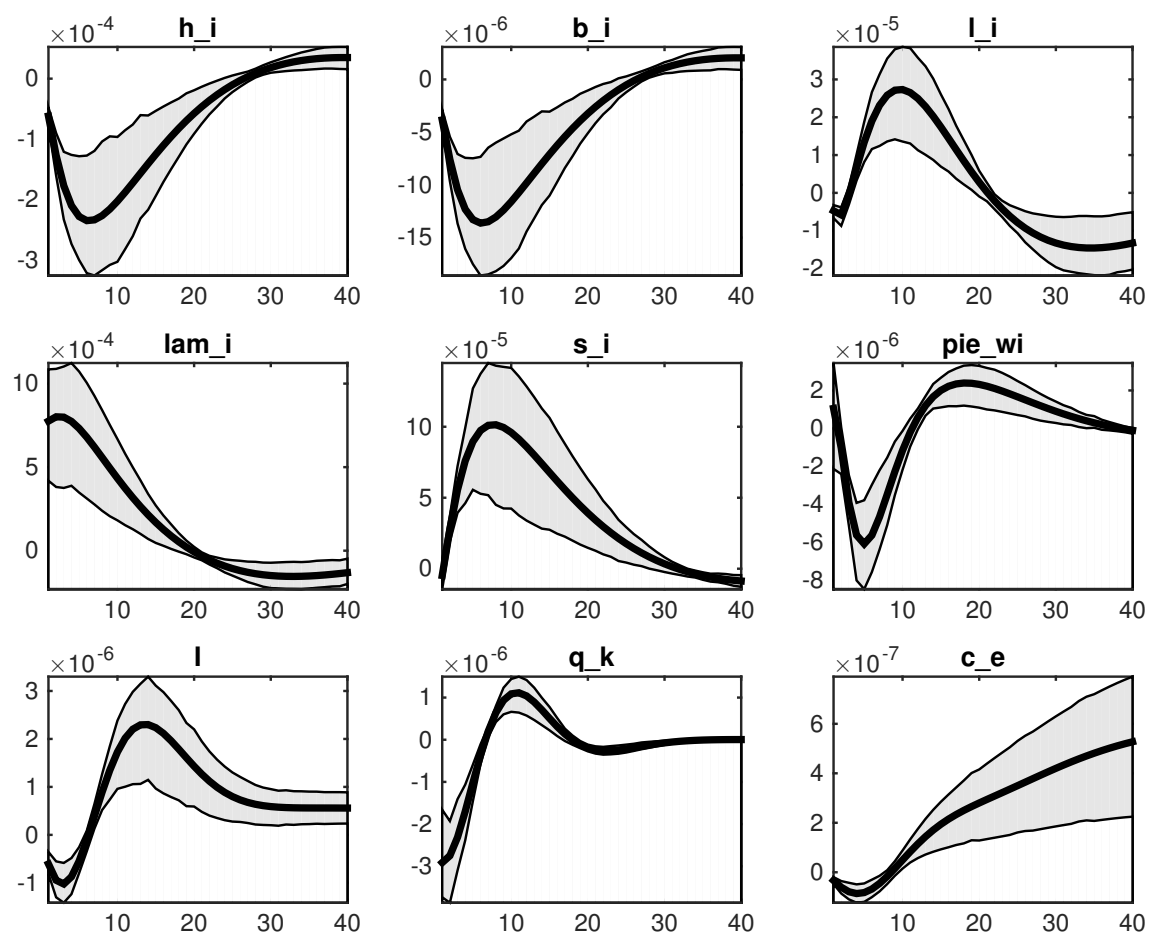

Figura 46: Efeito de um choque em mk_bw
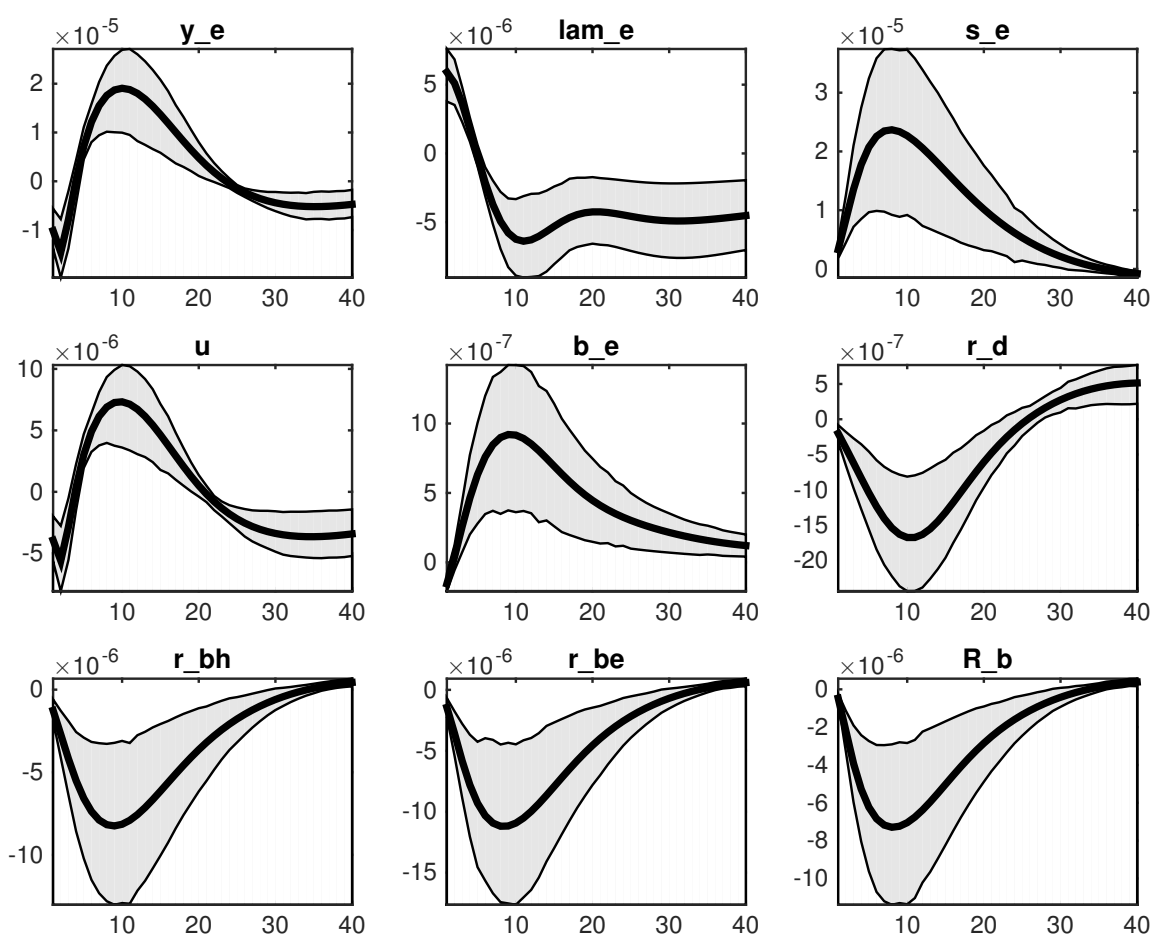

Figura 47: Efeito de um choque em mk_bw 

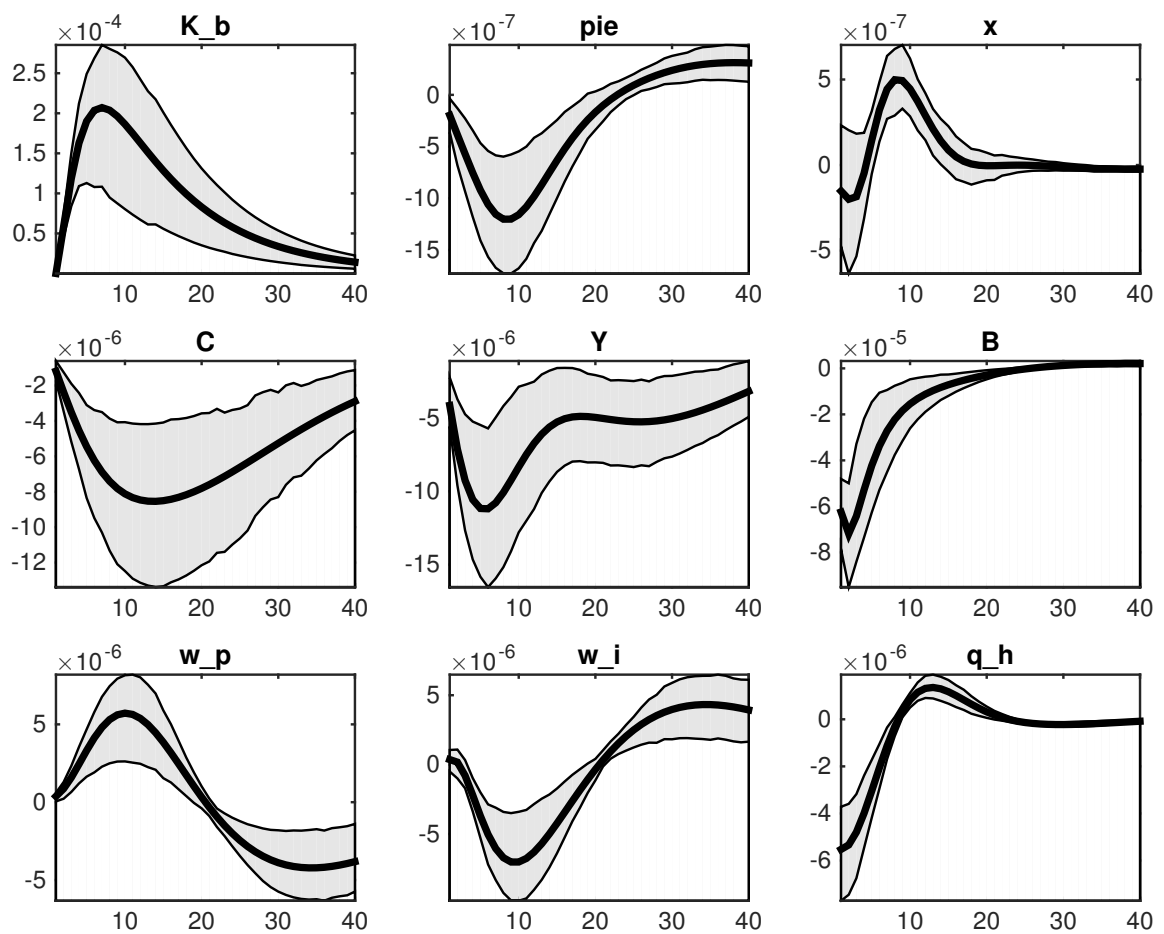

Figura 48: Efeito de um choque em mk_bw
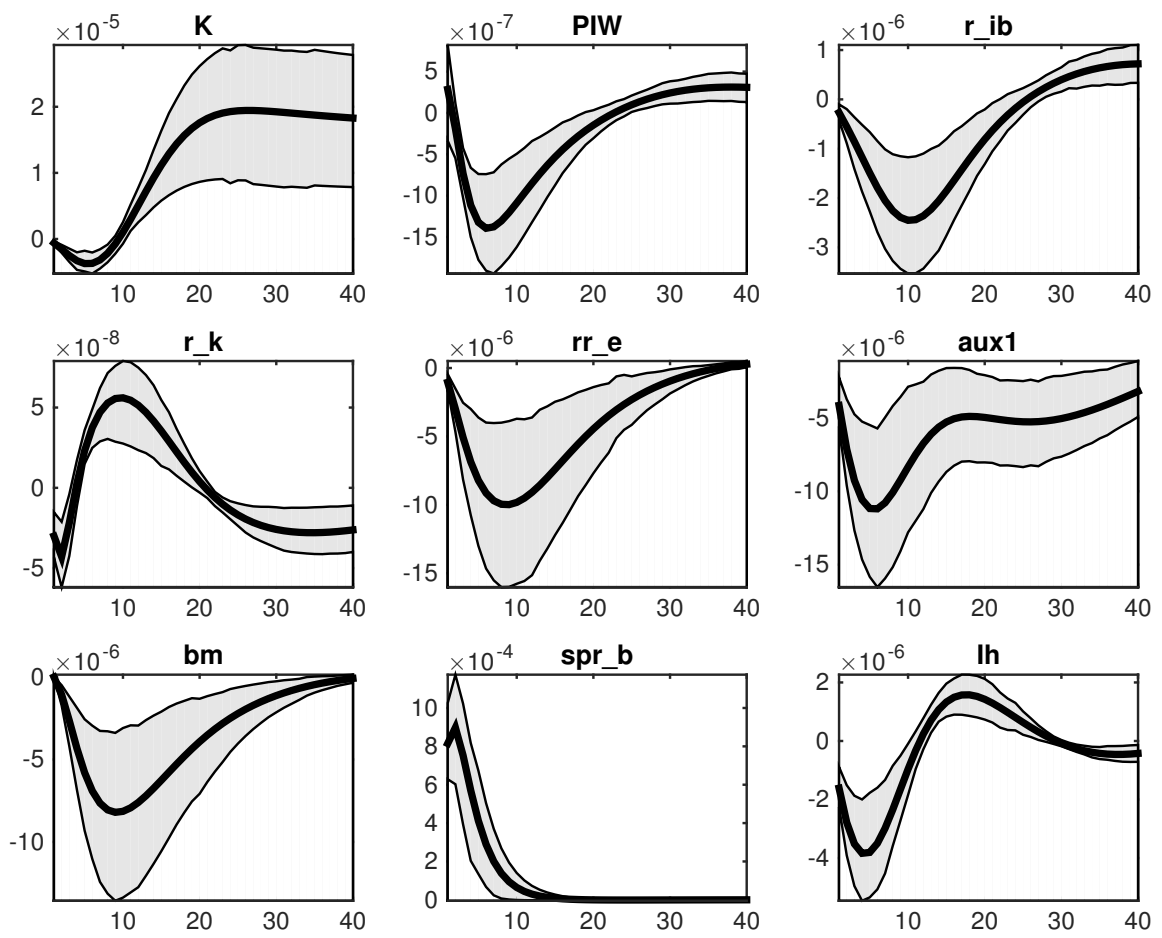

Figura 49: Efeito de um choque em mk_bw 

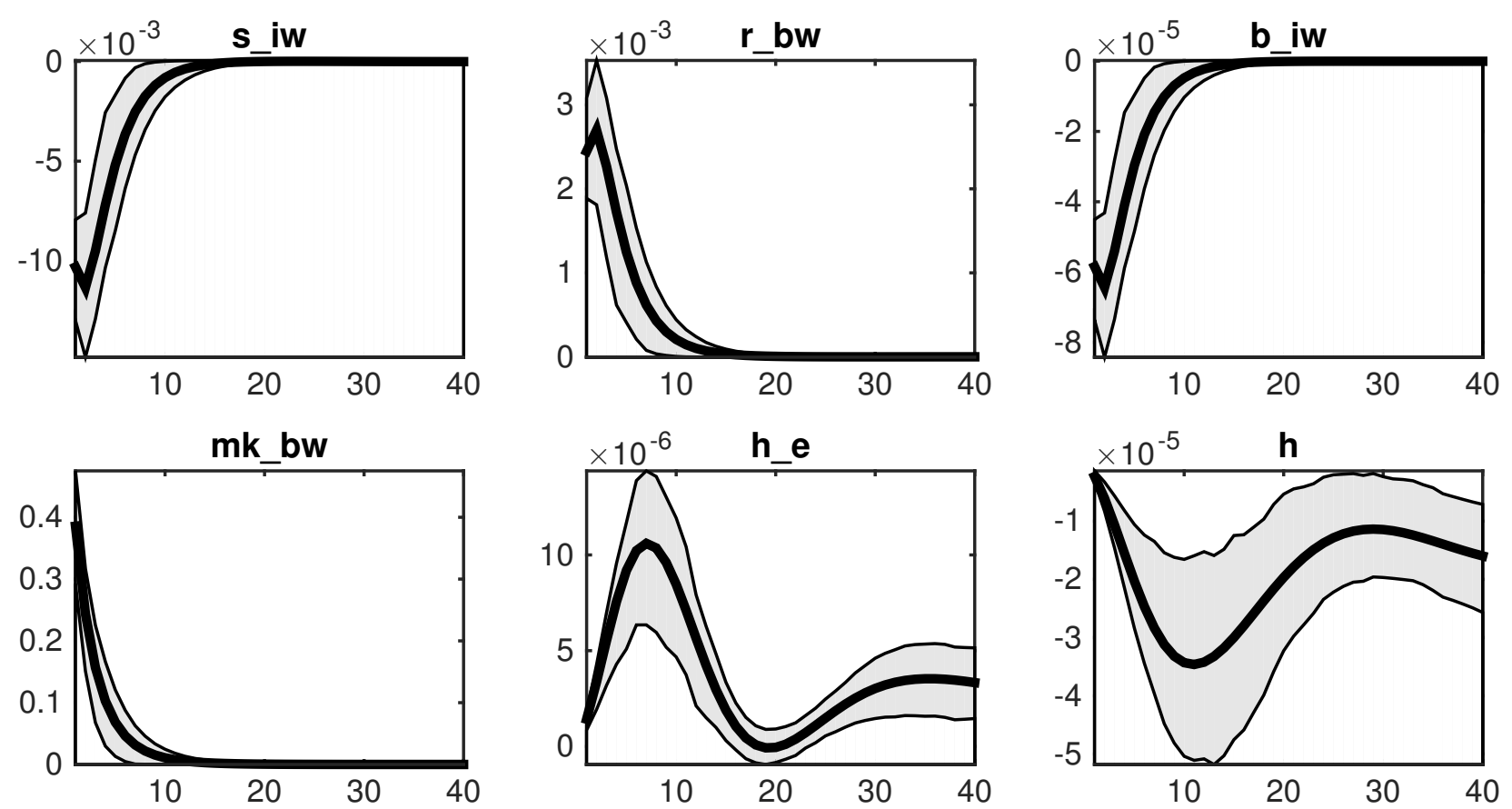

Figura 50: Efeito de um choque em mk_bw 
A.3 Choque na demanda por imóveis
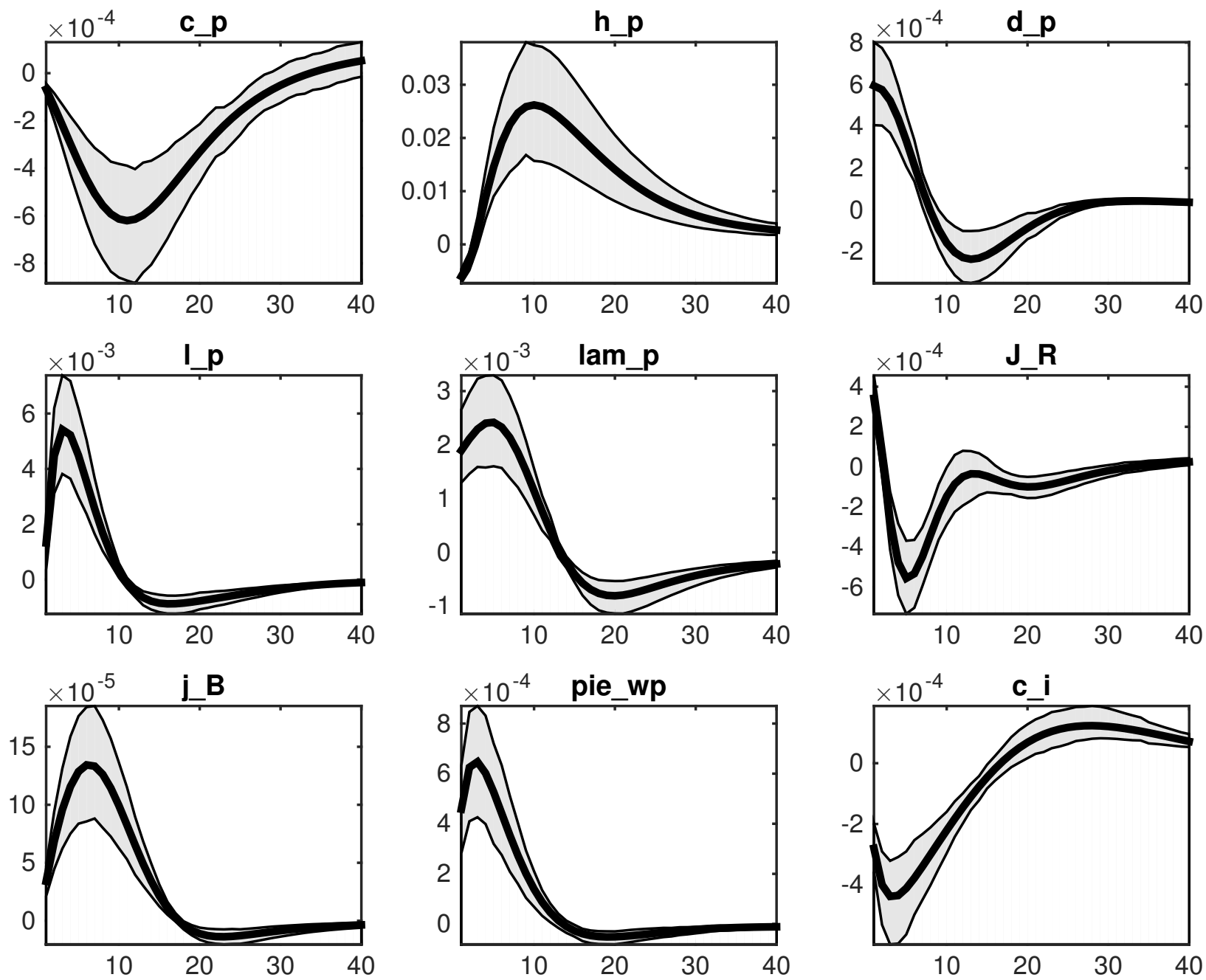

Figura 51: Efeito de um choque em e_j 

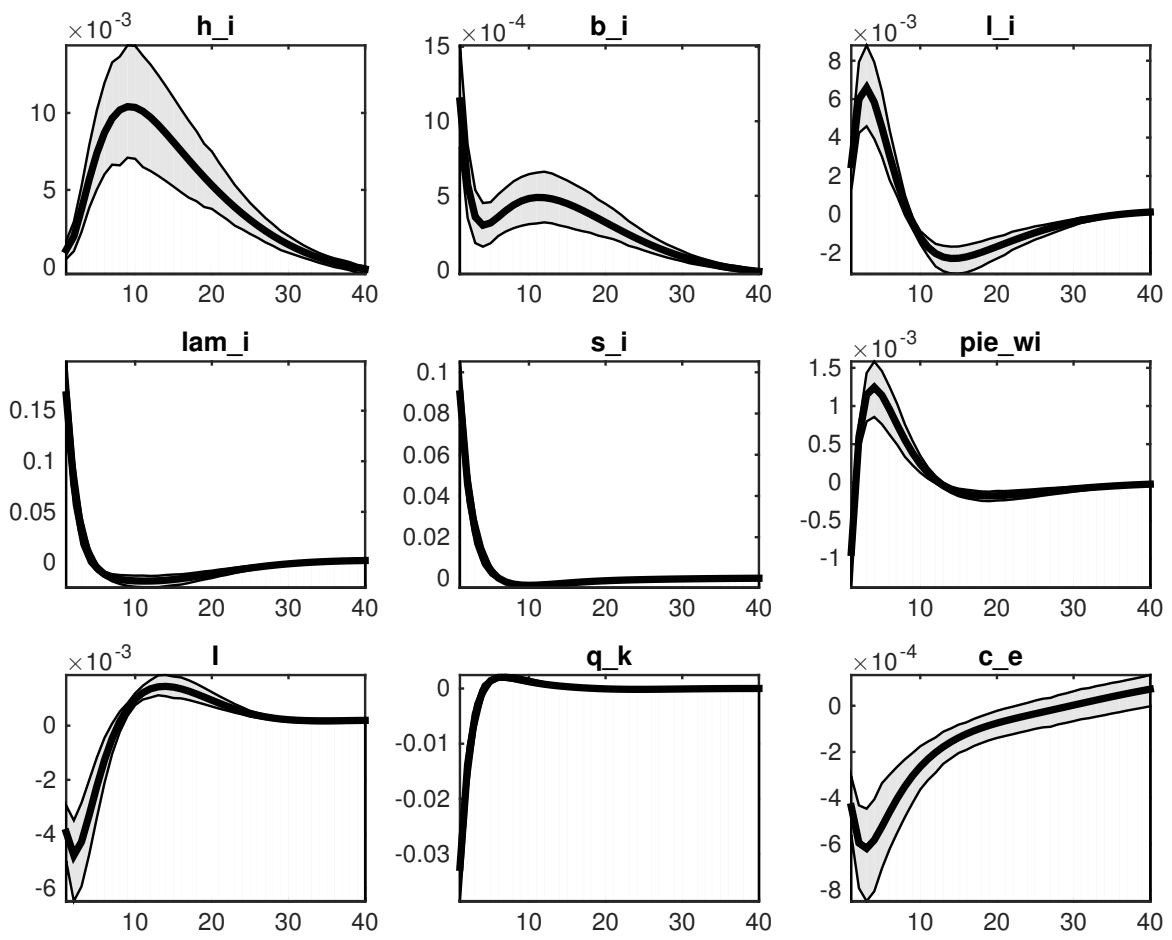

Figura 52: Efeito de um choque em e_j
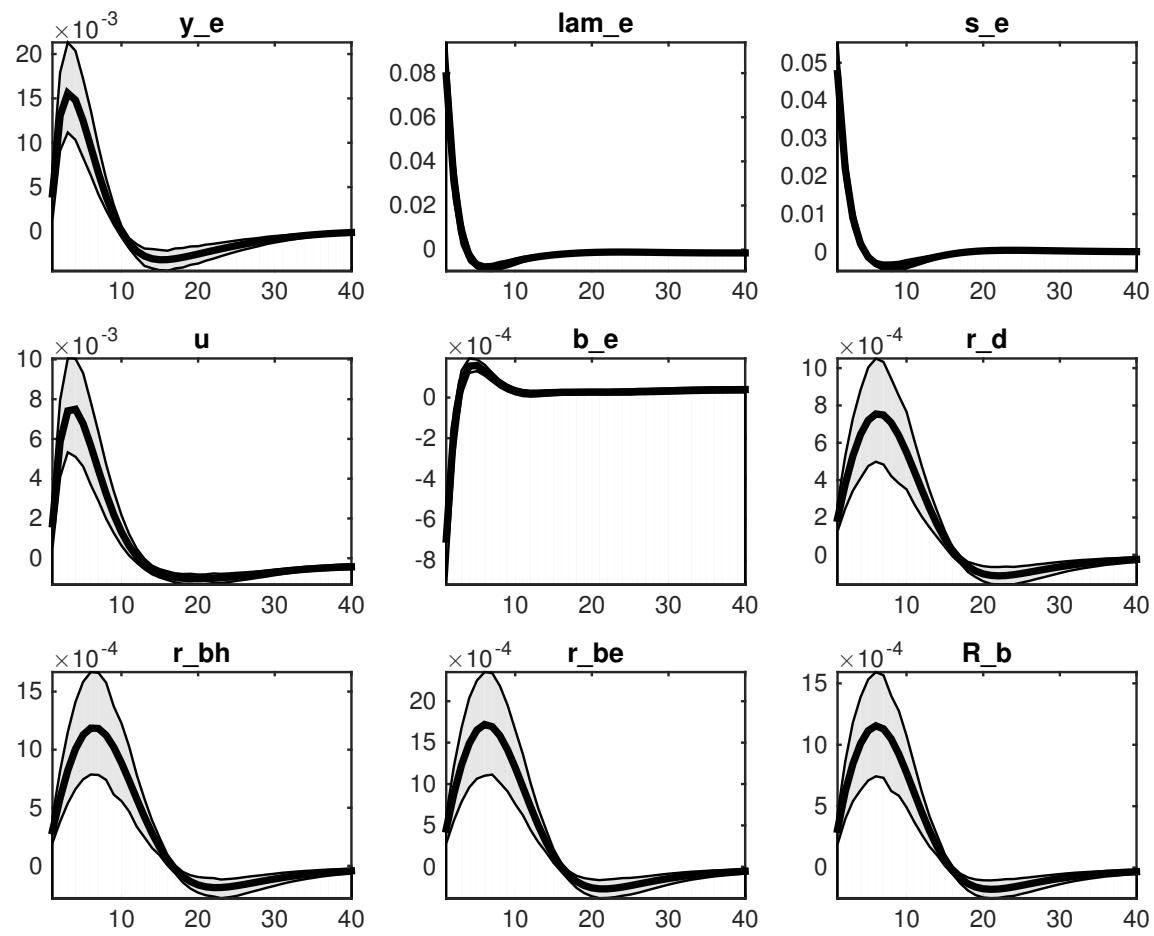

Figura 53: Efeito de um choque em e_j 

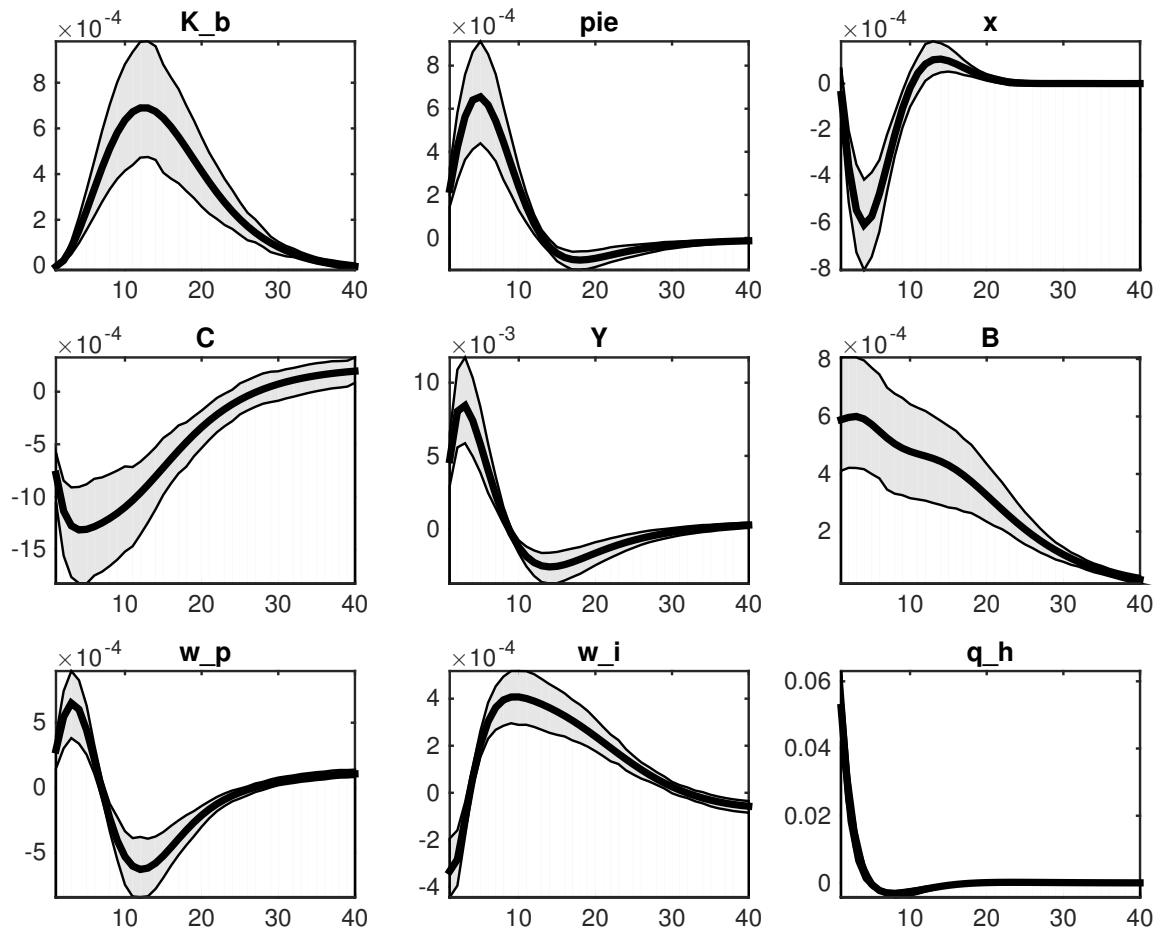

Figura 54: Efeito de um choque em e_j
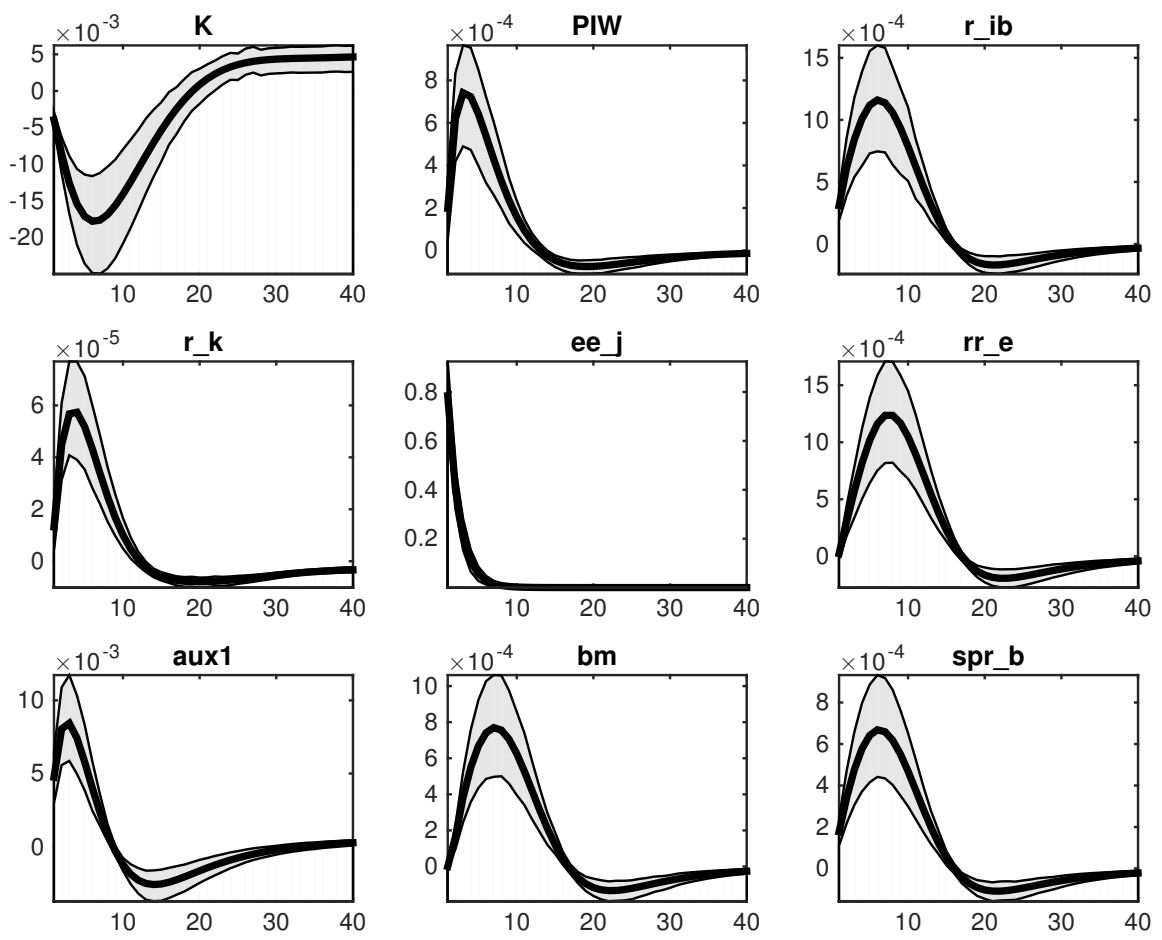

Figura 55: Efeito de um choque em e_j 

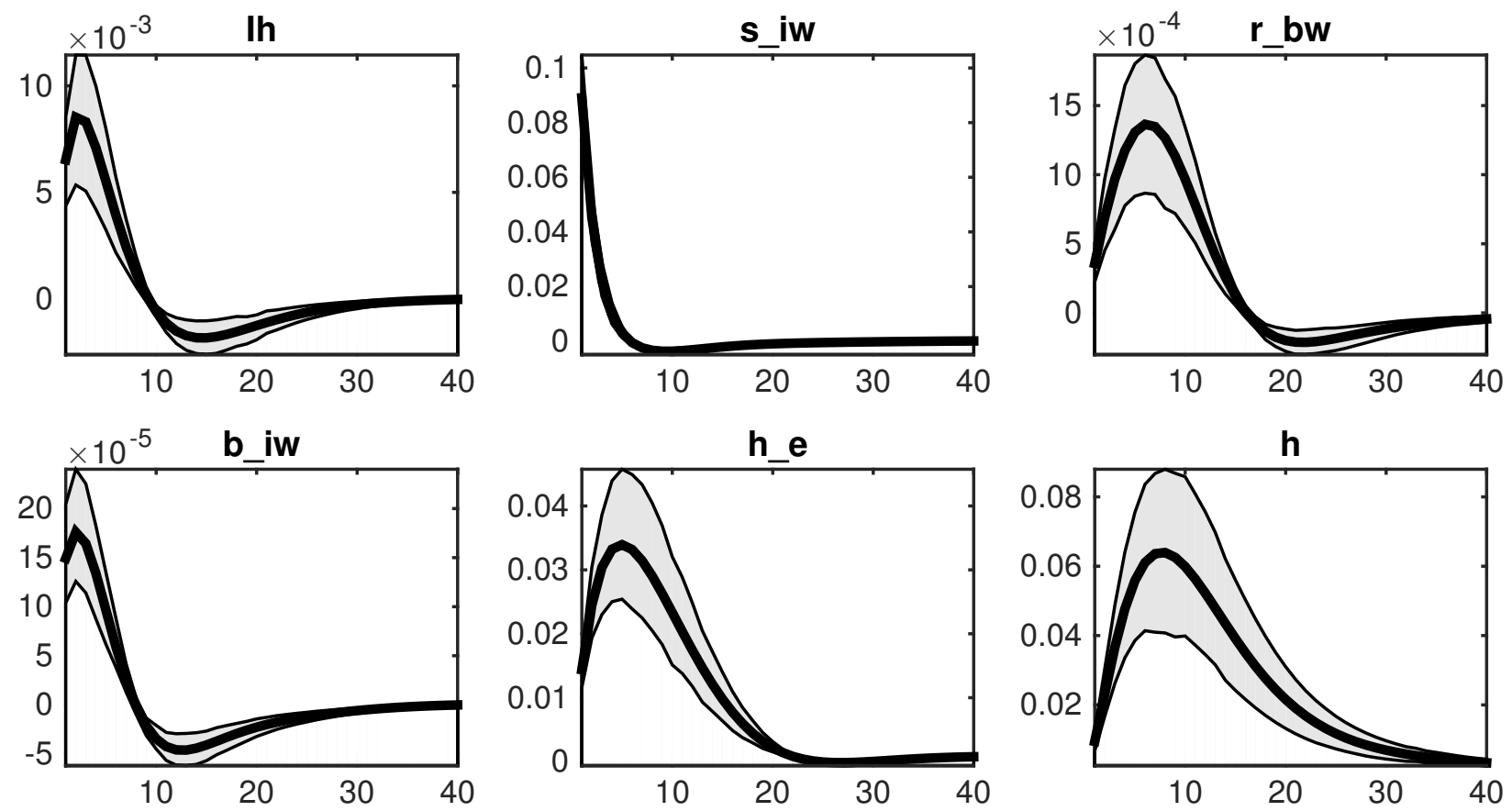

Figura 56: Efeito de um choque em e_j 
A.4 Choque na oferta de imóveis
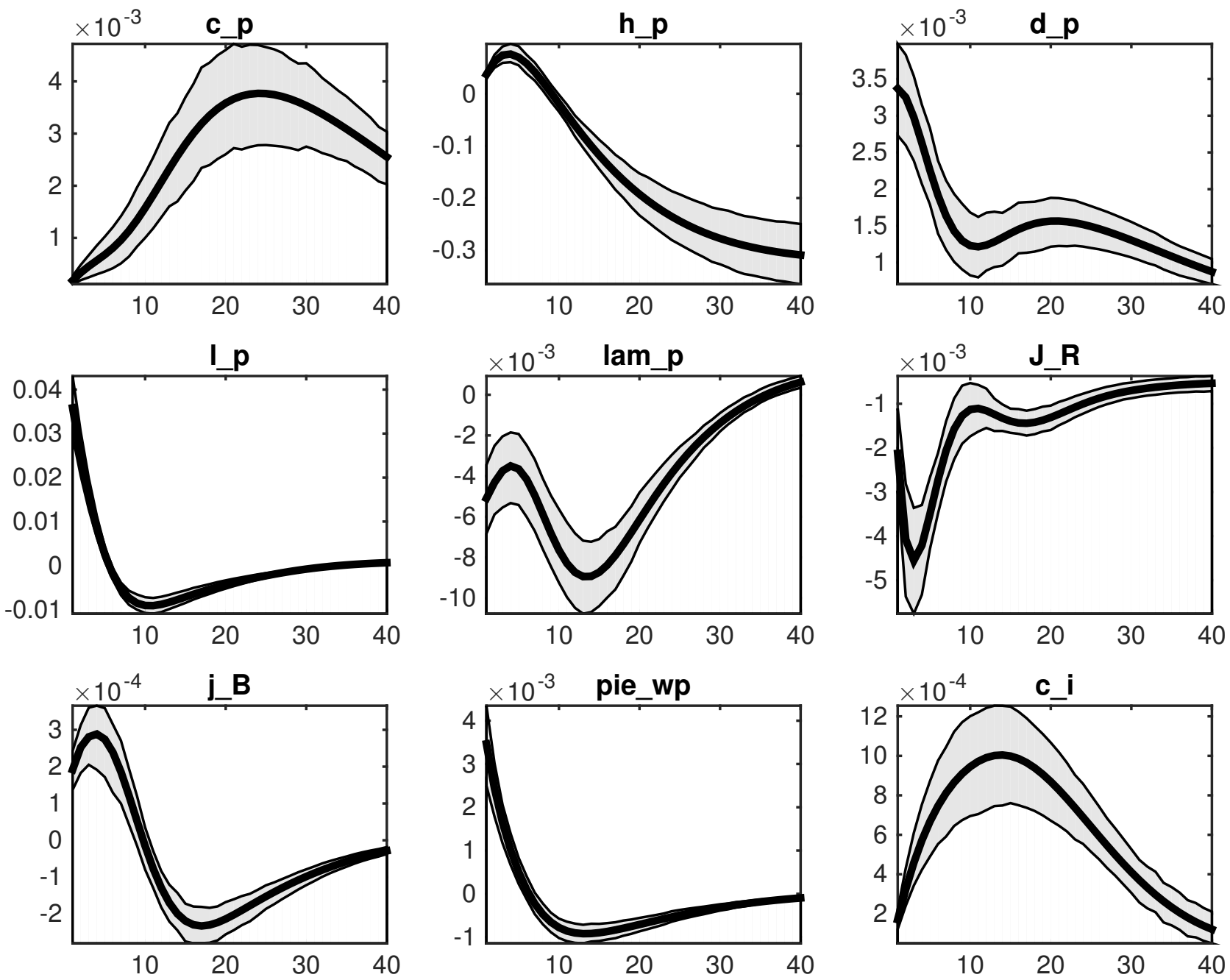

Figura 57: Efeito de um choque em $\mathrm{I}^{h}$ 

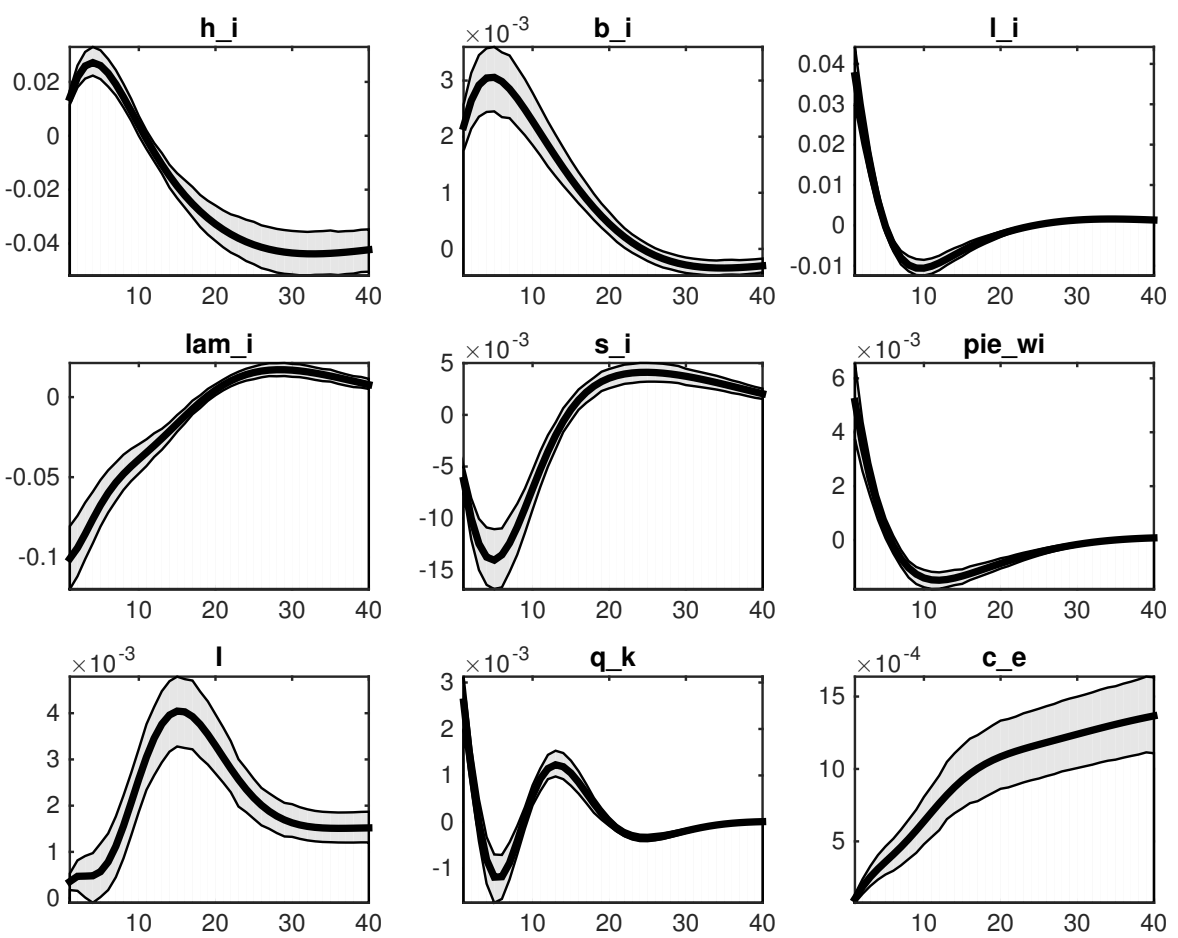

Figura 58: Efeito de um choque em $\mathrm{I}^{h}$
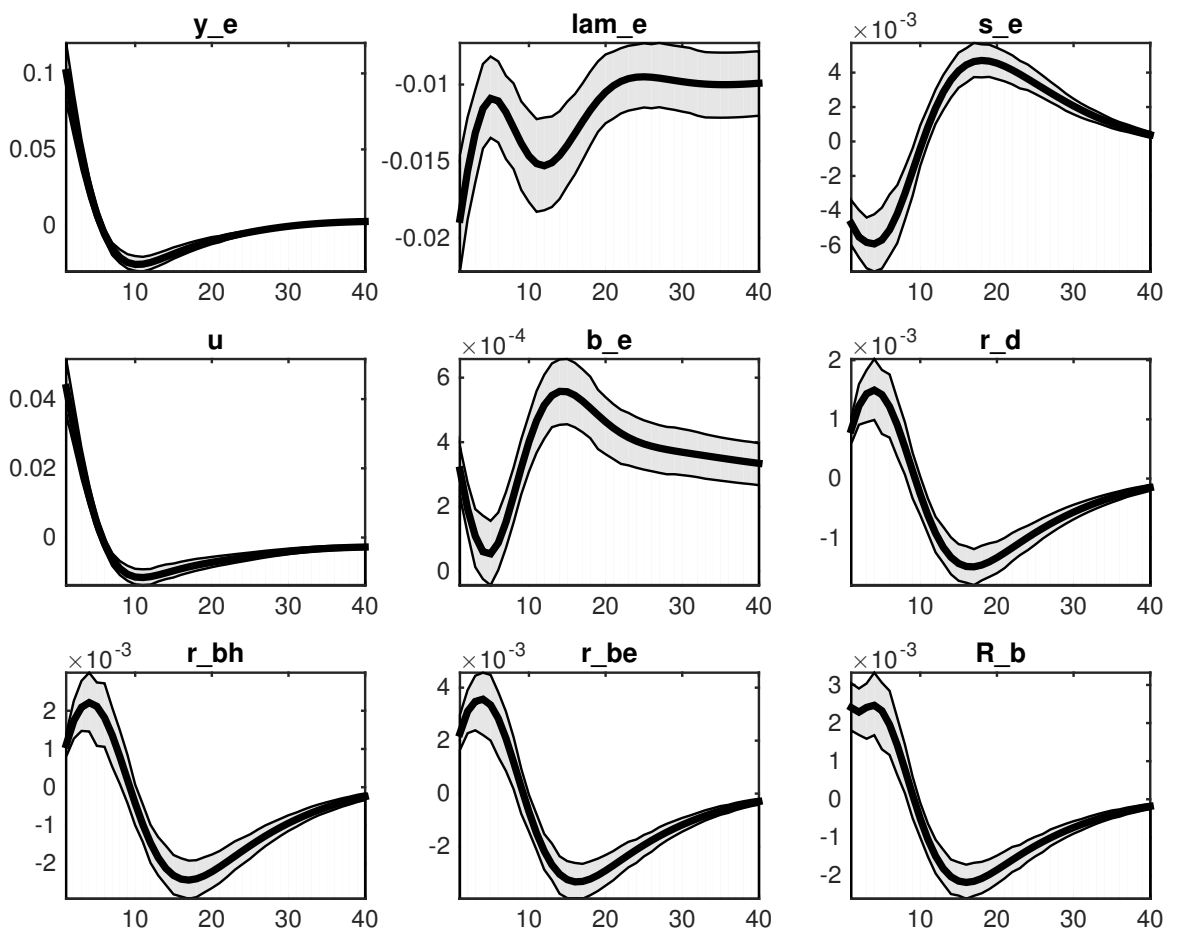

Figura 59: Efeito de um choque em $\mathrm{I}^{h}$ 

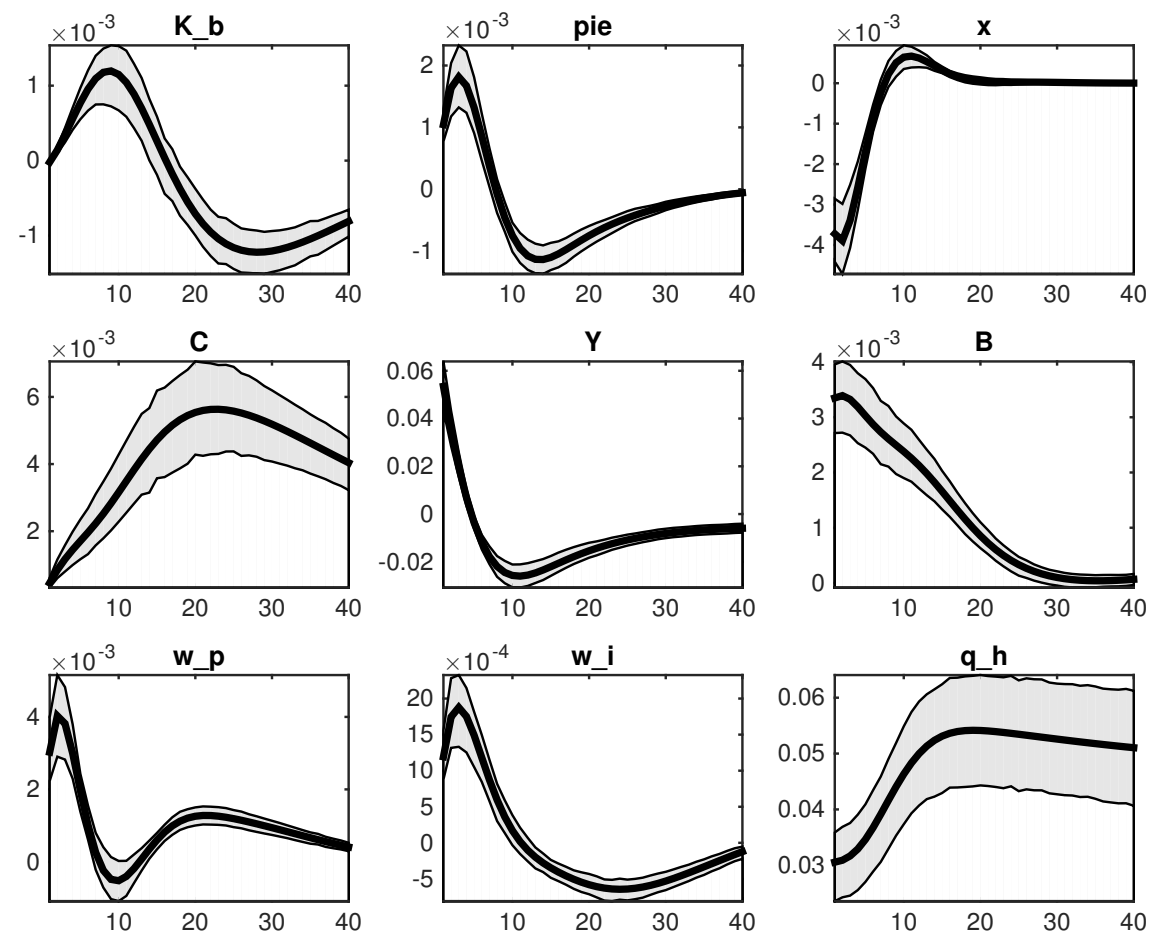

Figura 60: Efeito de um choque em $\mathrm{I}^{h}$
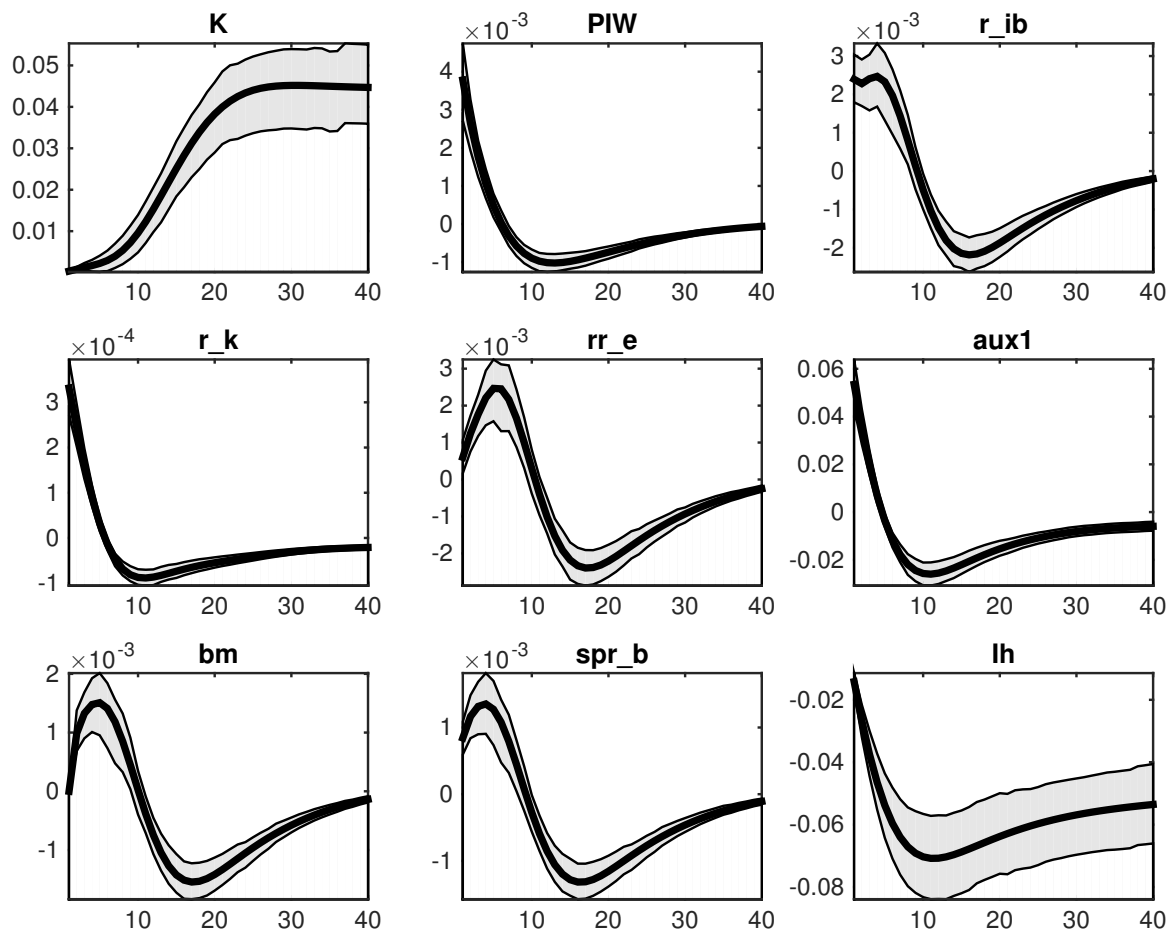

Figura 61: Efeito de um choque em $\mathrm{I}^{h}$ 

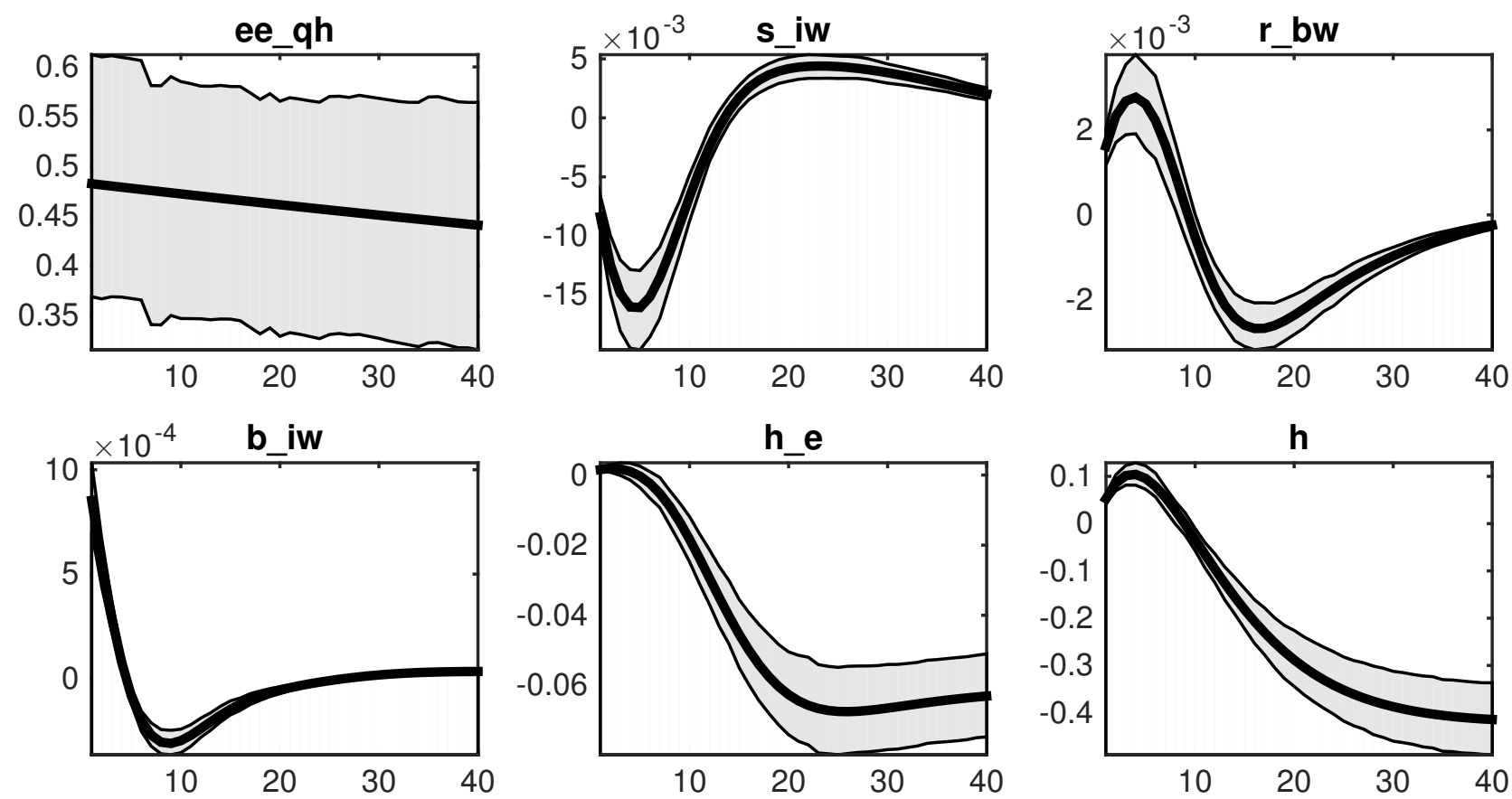

Figura 62: Efeito de um choque em $\mathrm{I}^{h}$ 
A.5 Choque tecnológico
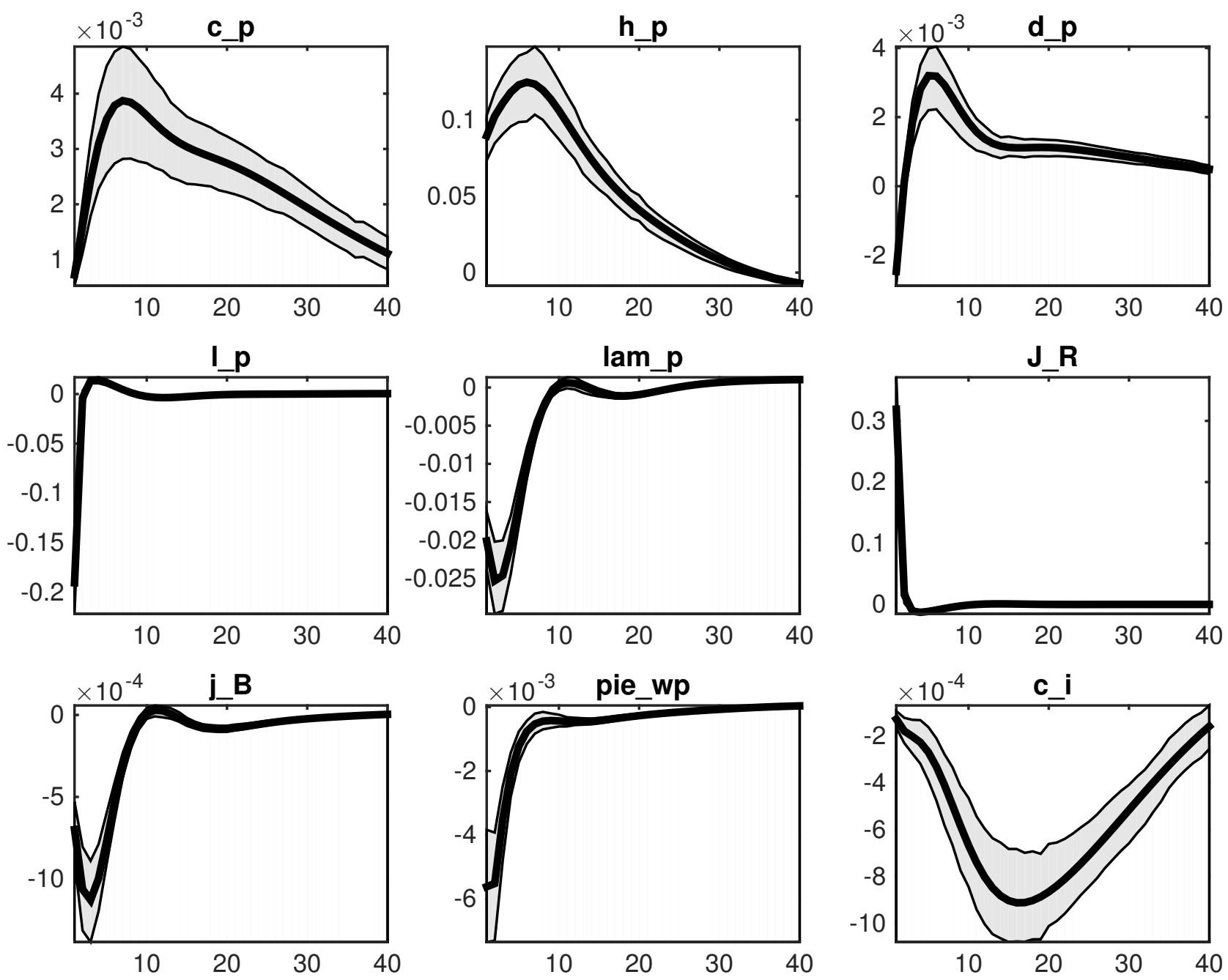

Figura 63: Efeito de um choque tecnológico 

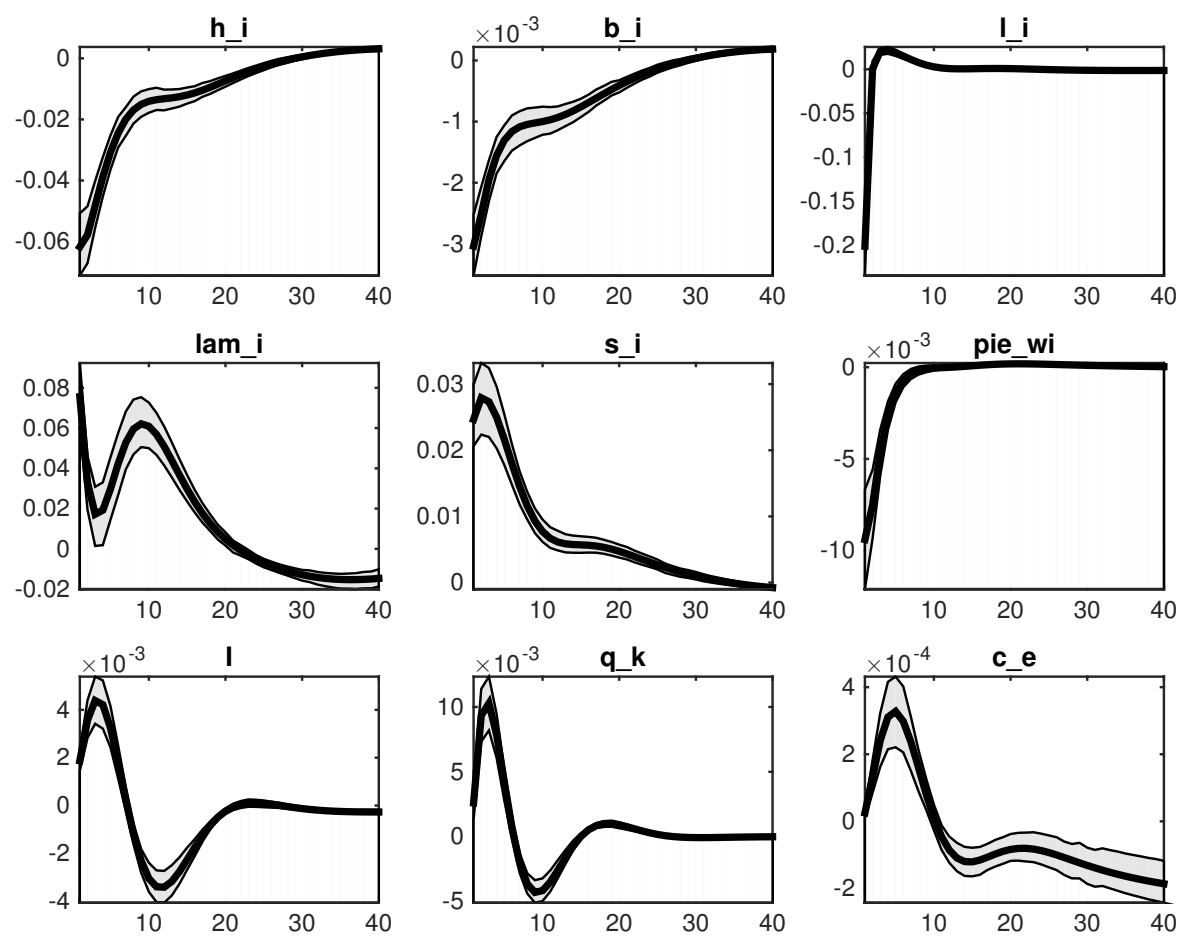

Figura 64: Efeito de um choque tecnológico
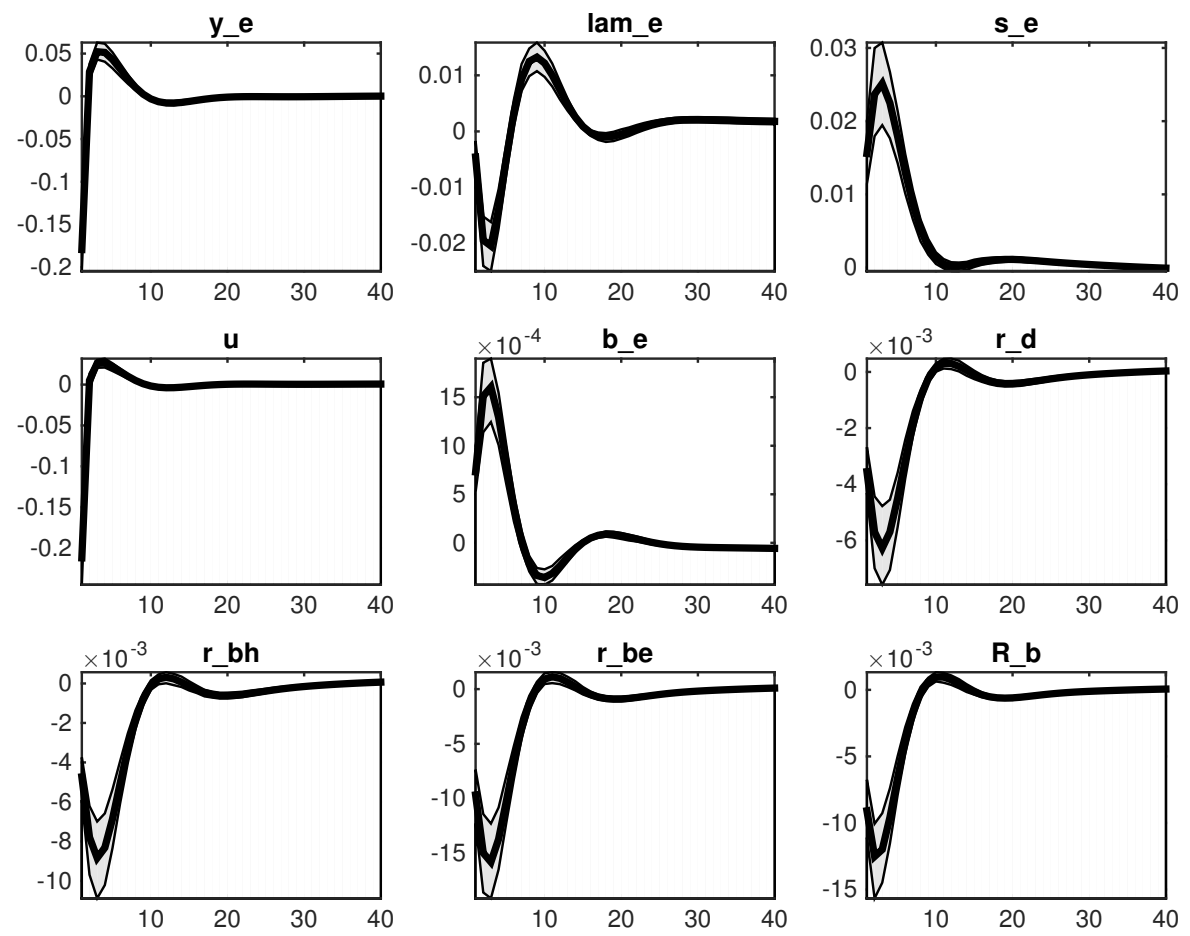

Figura 65: Efeito de um choque tecnológico 

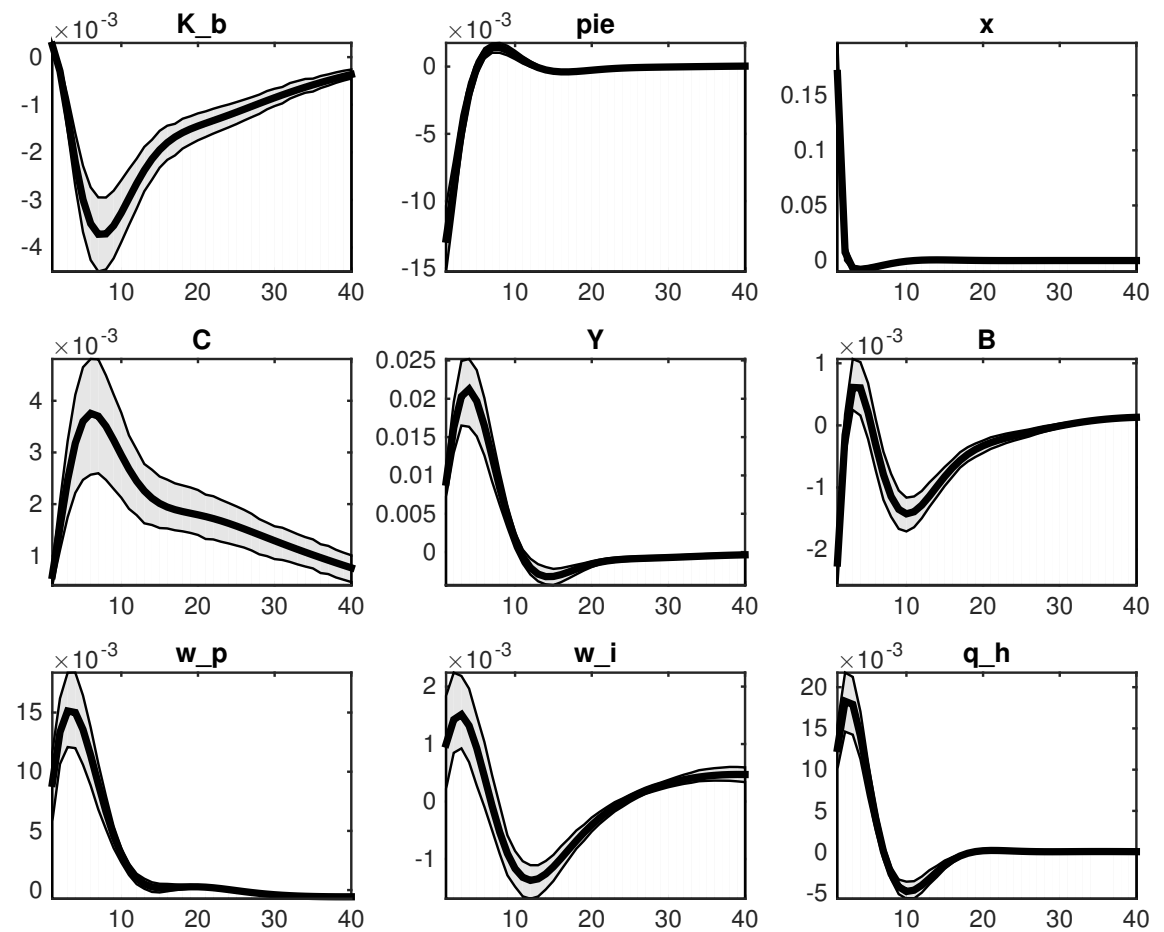

Figura 66: Efeito de um choque tecnológico
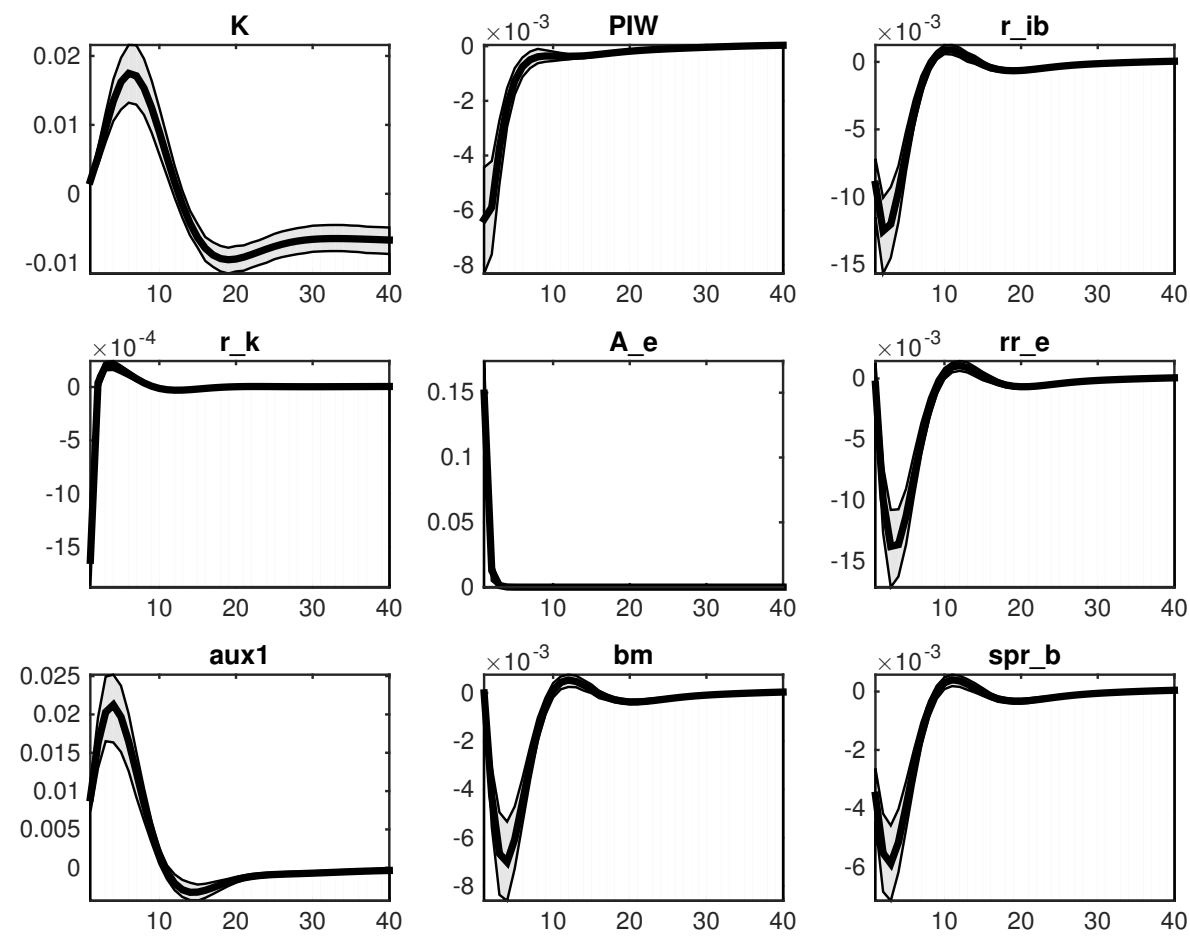

Figura 67: Efeito de um choque tecnológico 

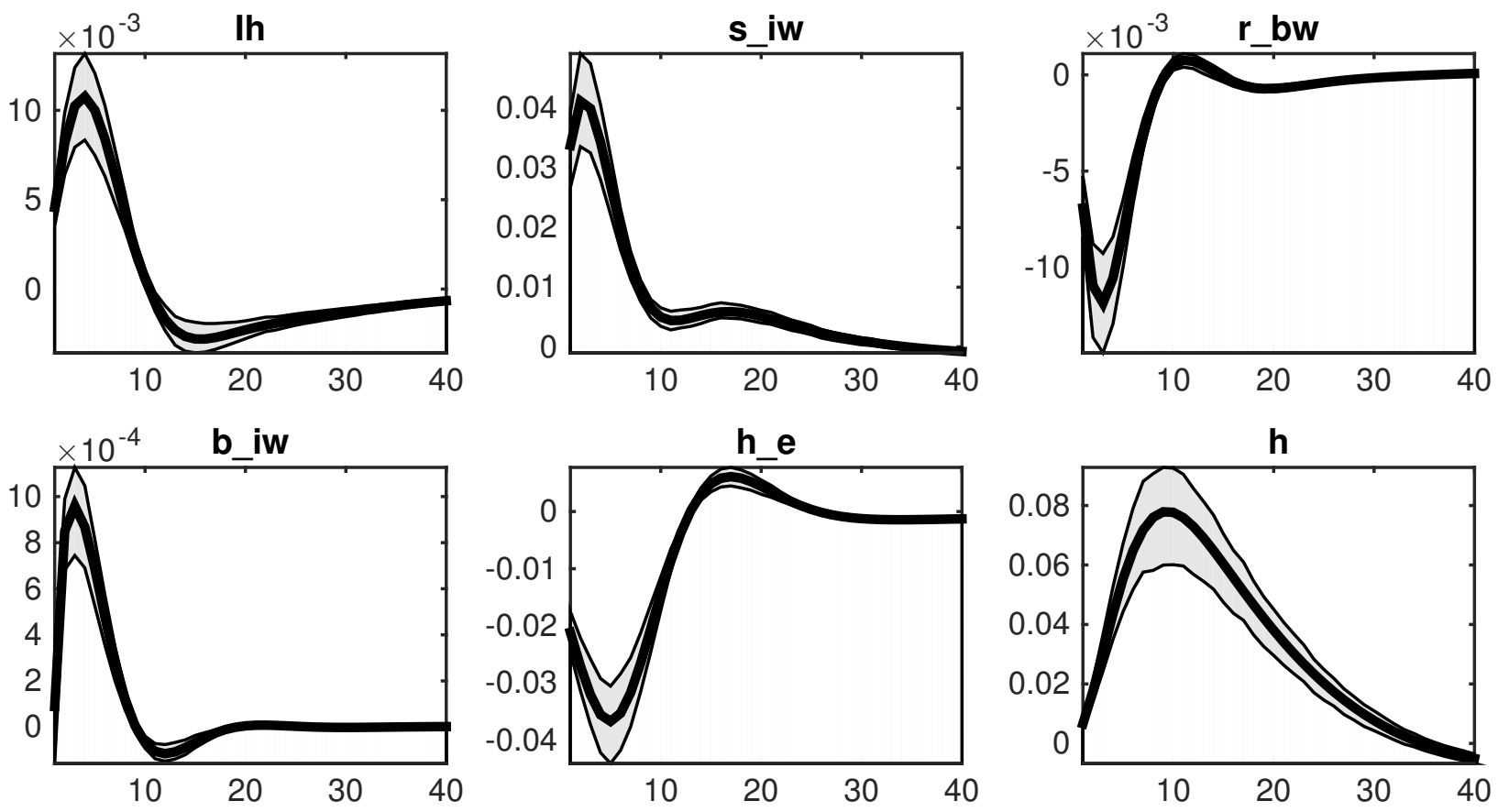

Figura 68: Efeito de um choque tecnológico 


\section{A.6 Choque no Capital Bancário}
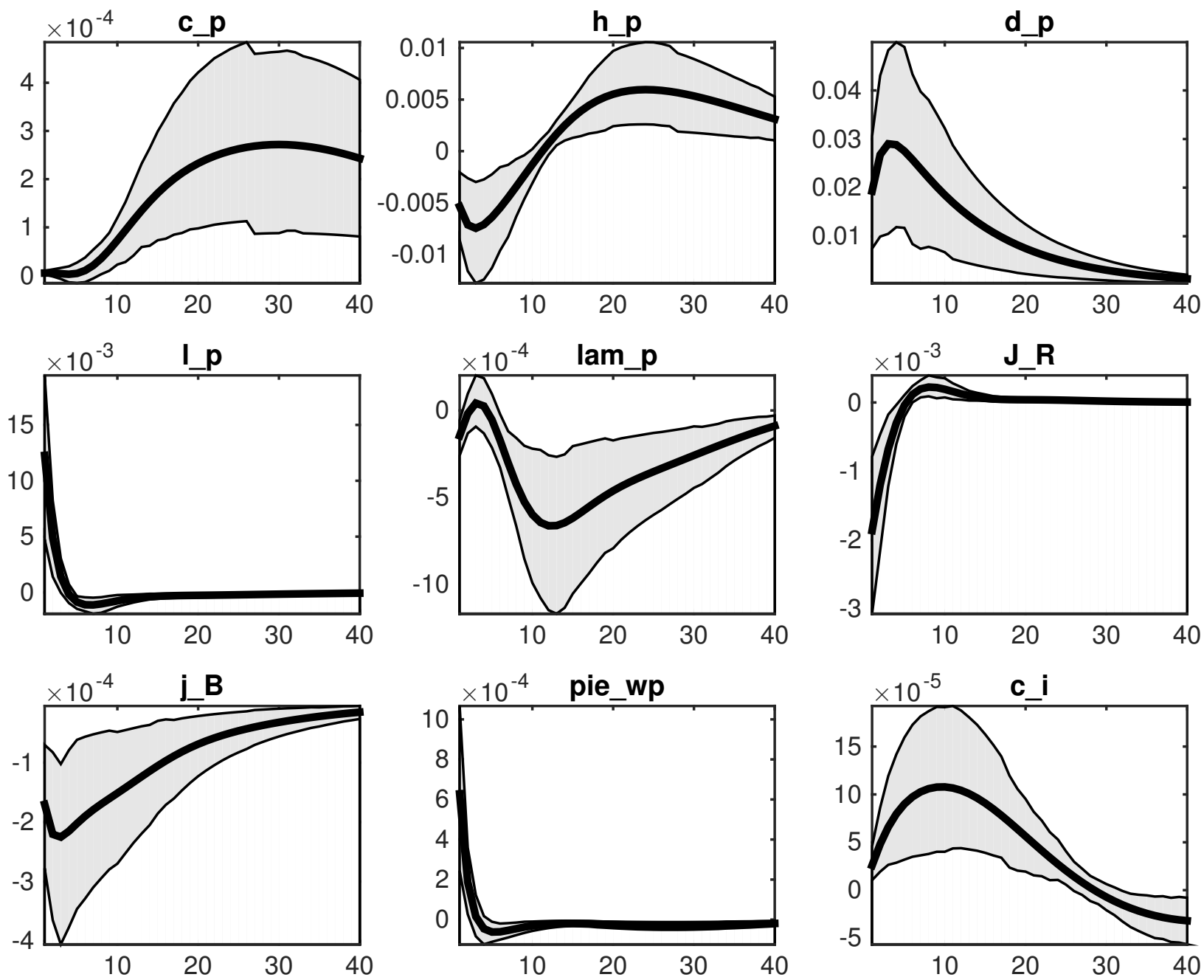

Figura 69: Efeito de um choque no capital bancário 

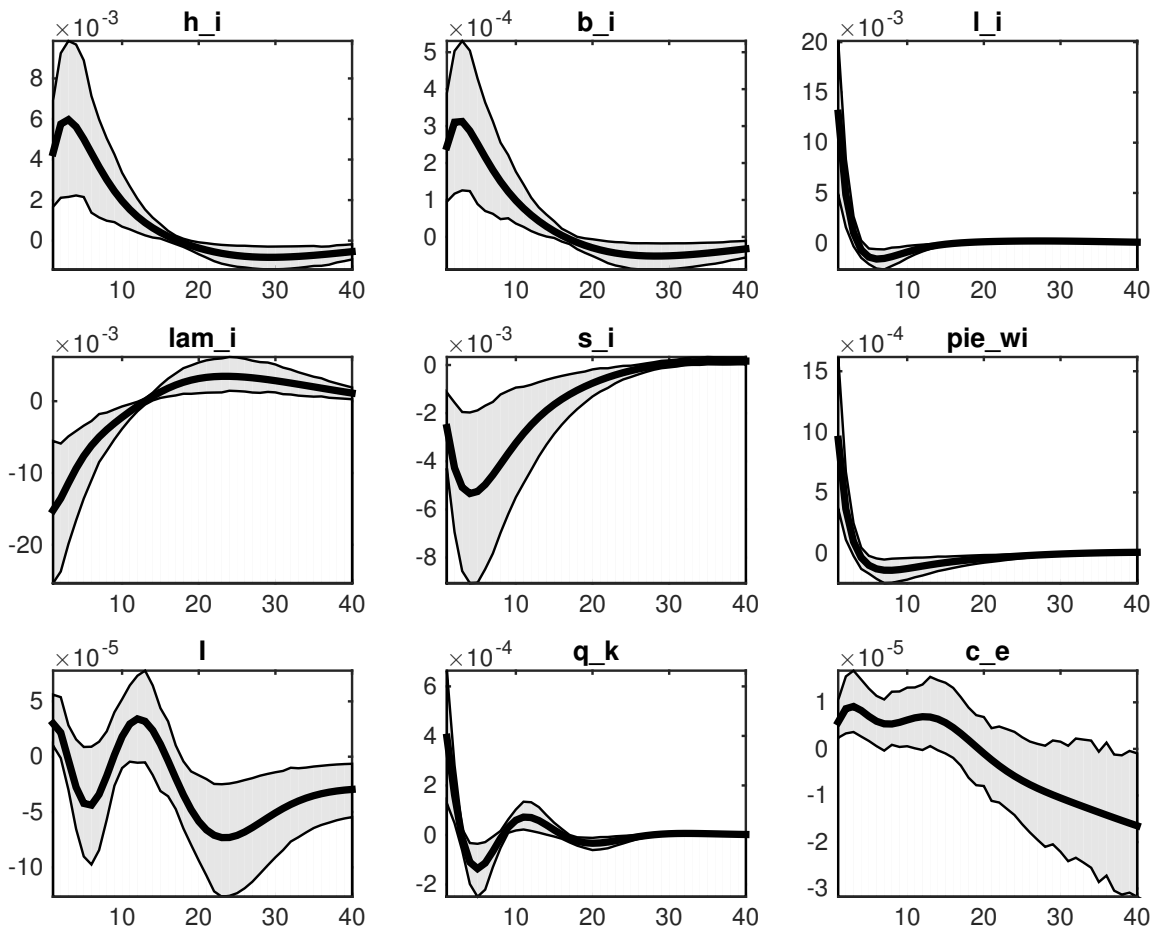

Figura 70: Efeito de um choque no capital bancário
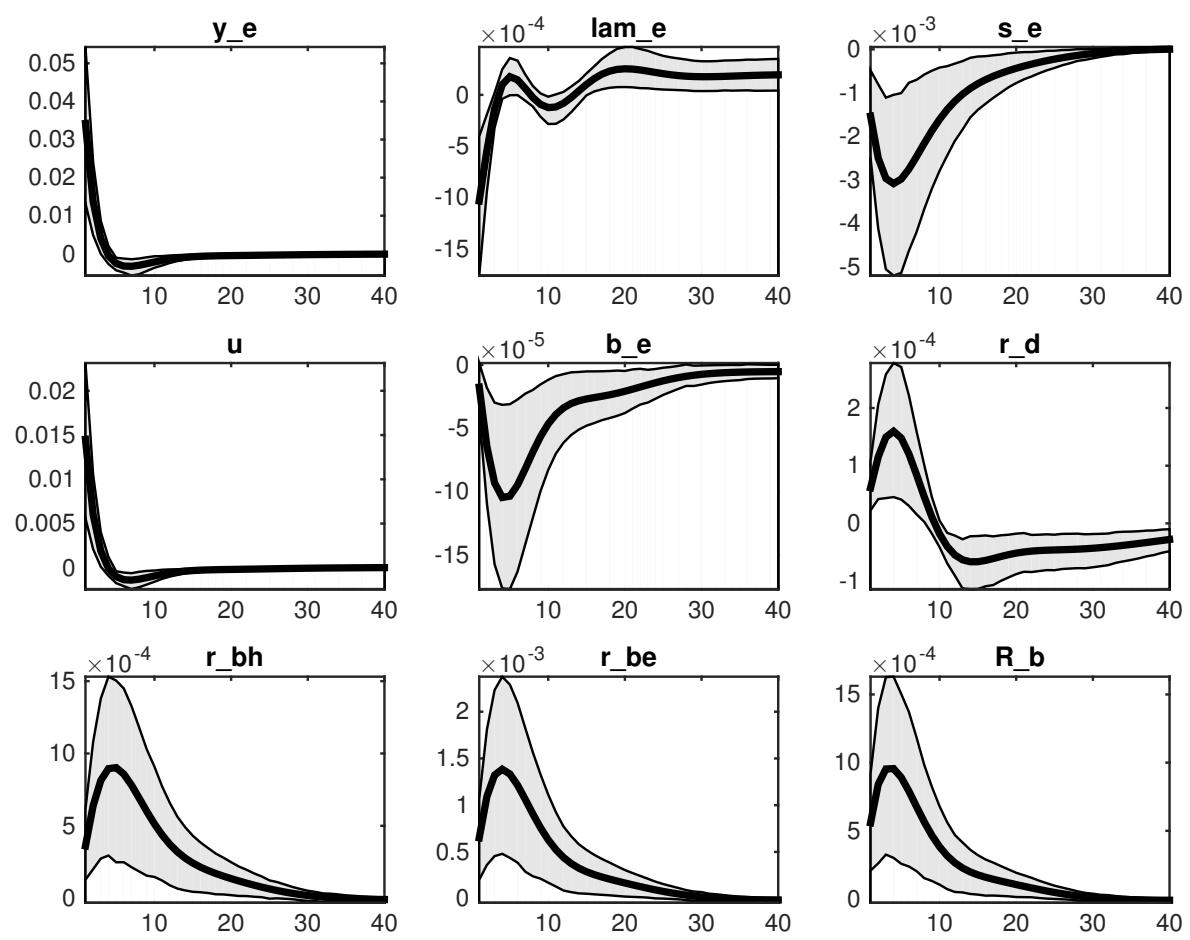

Figura 71: Efeito de um choque no capital bancário 

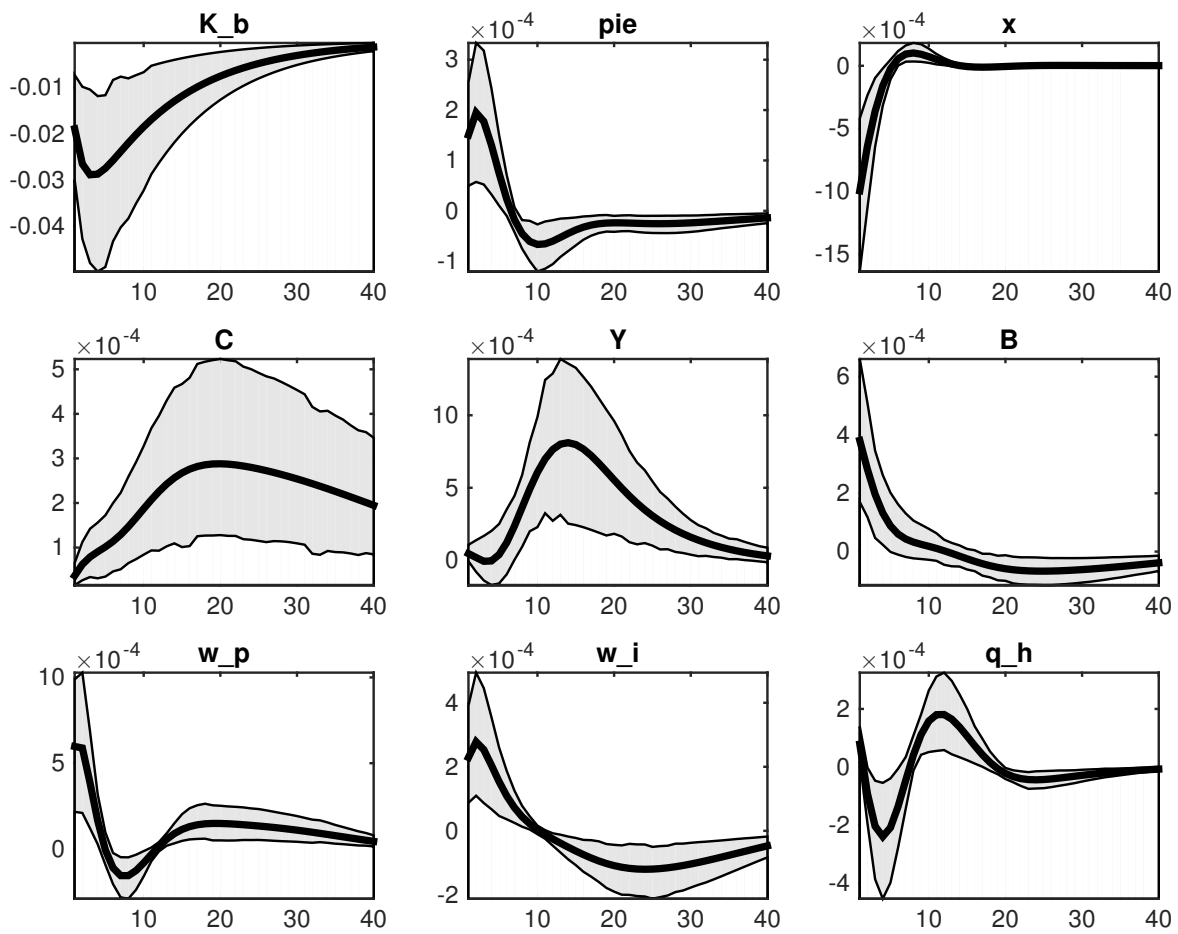

Figura 72: Efeito de um choque no capital bancário
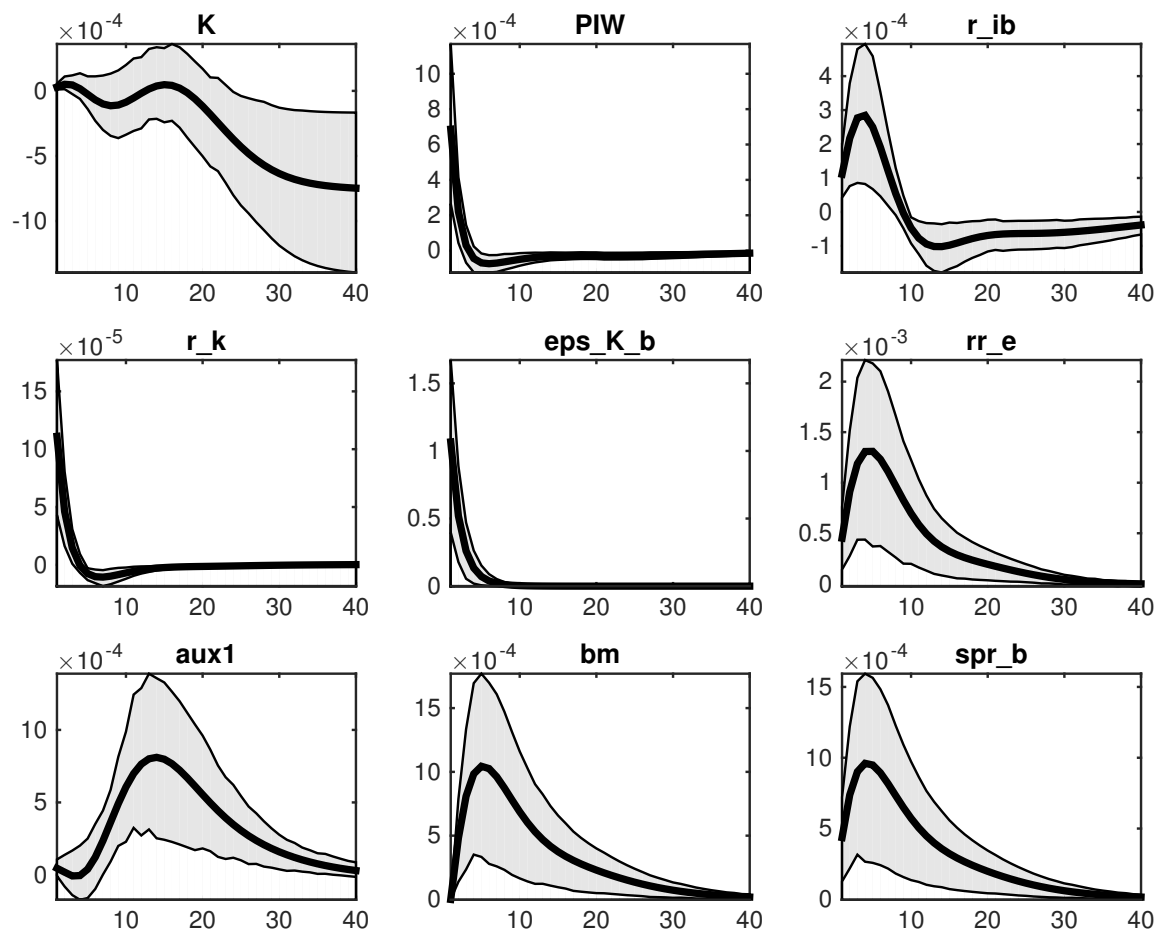

Figura 73: Efeito de um choque no capital bancário 

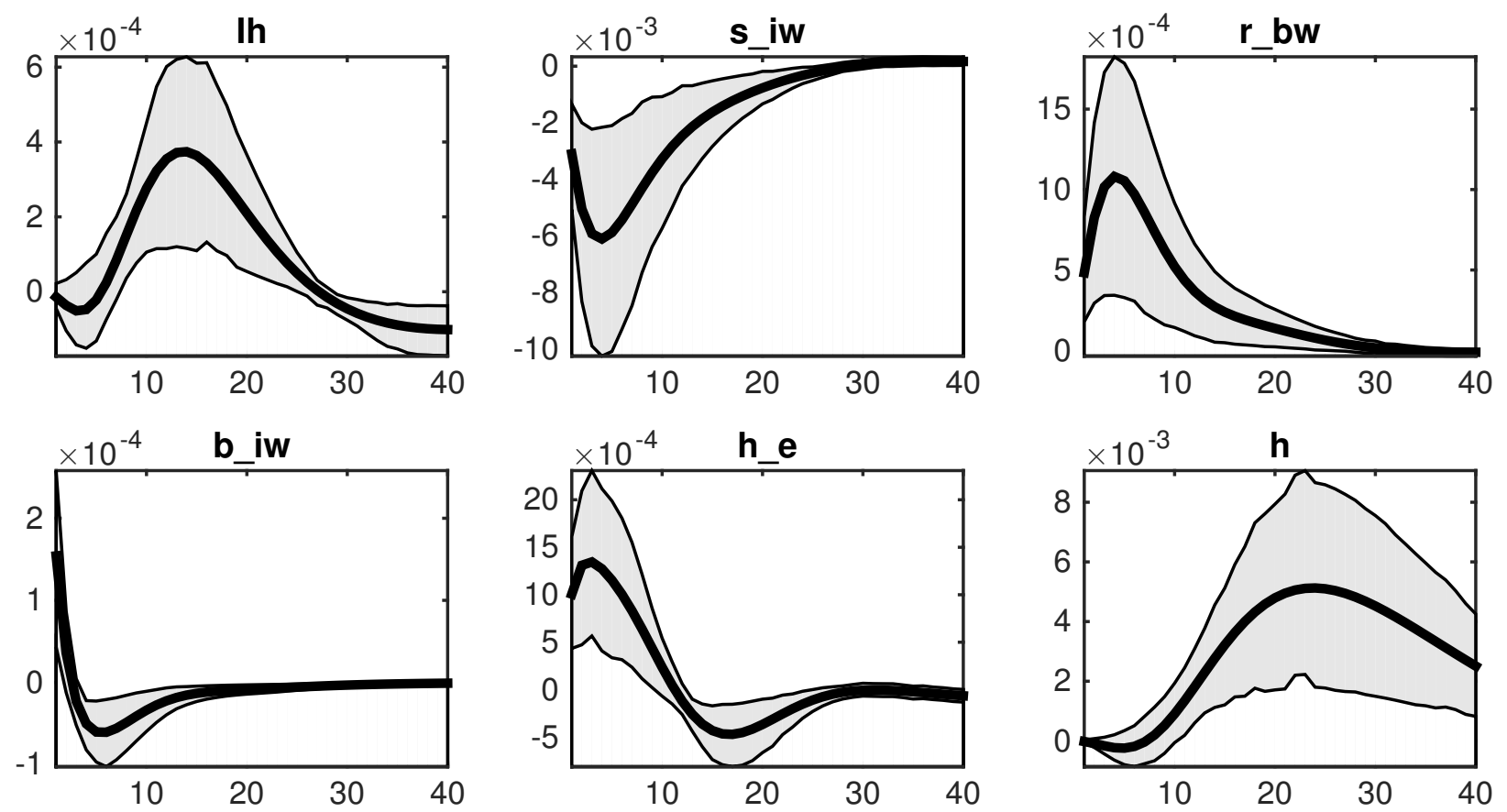

Figura 74: Efeito de um choque no capital bancário 
A.7 Choque no loan-to-value dos empresários
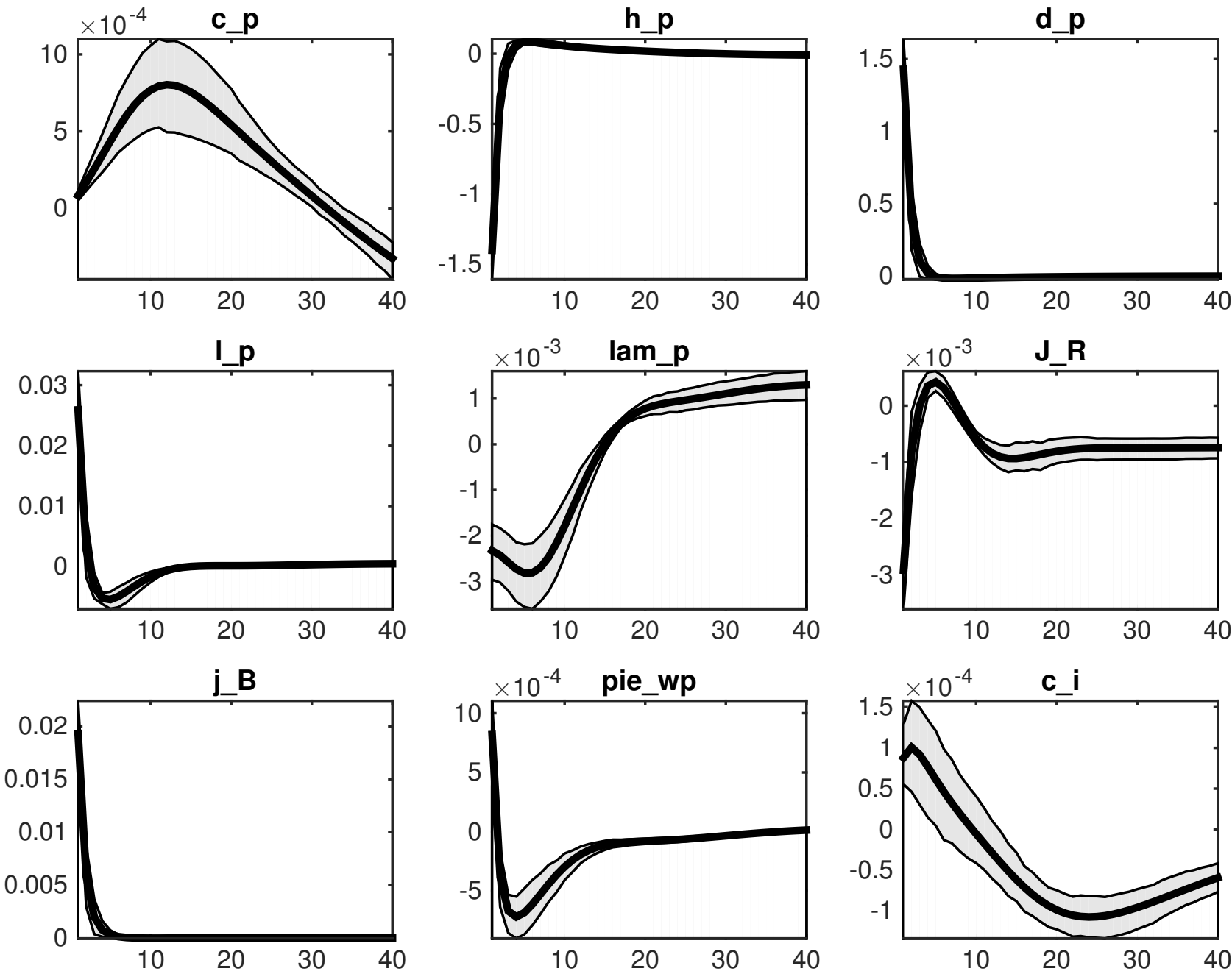

Figura 75: Efeito de um choque no loan-to-value dos empresários 

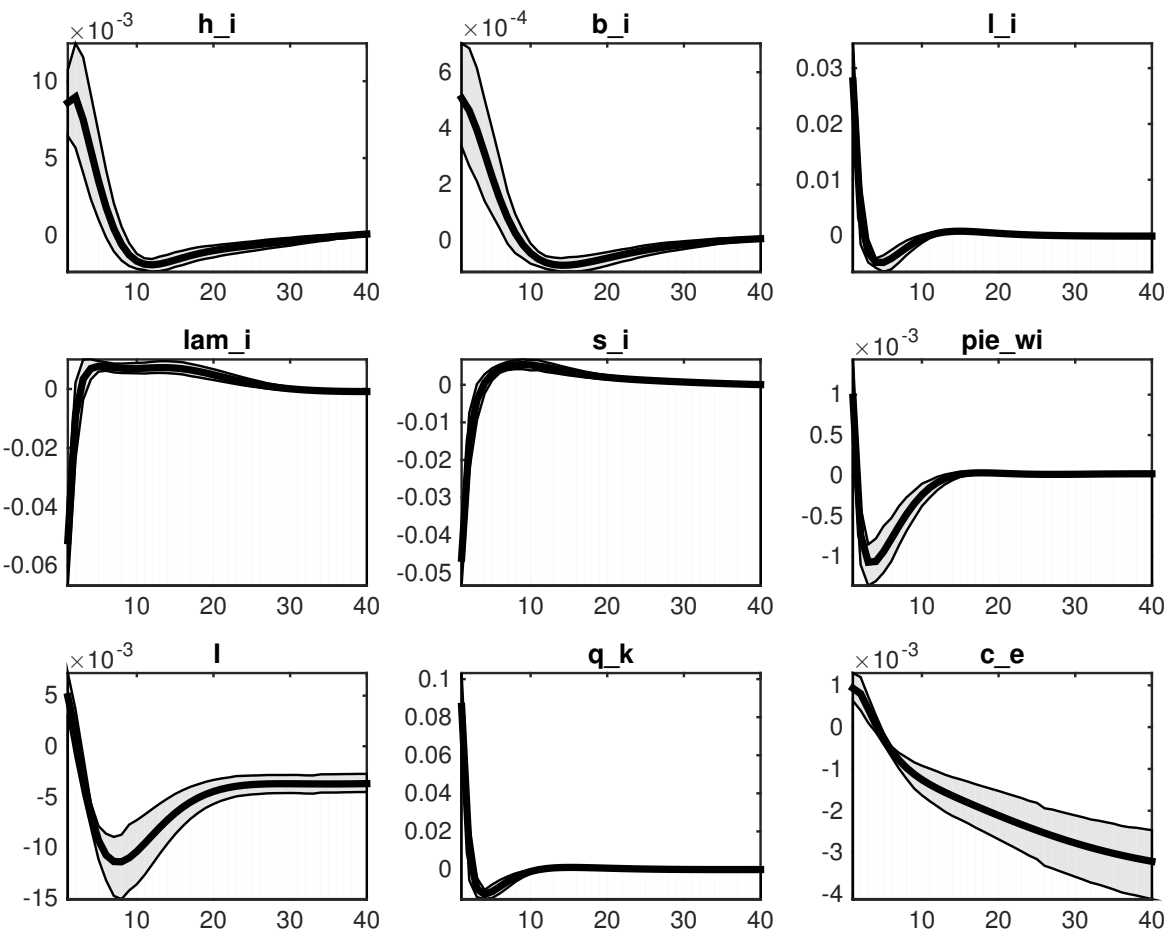

Figura 76: Efeito de um choque no loan-to-value dos empresários
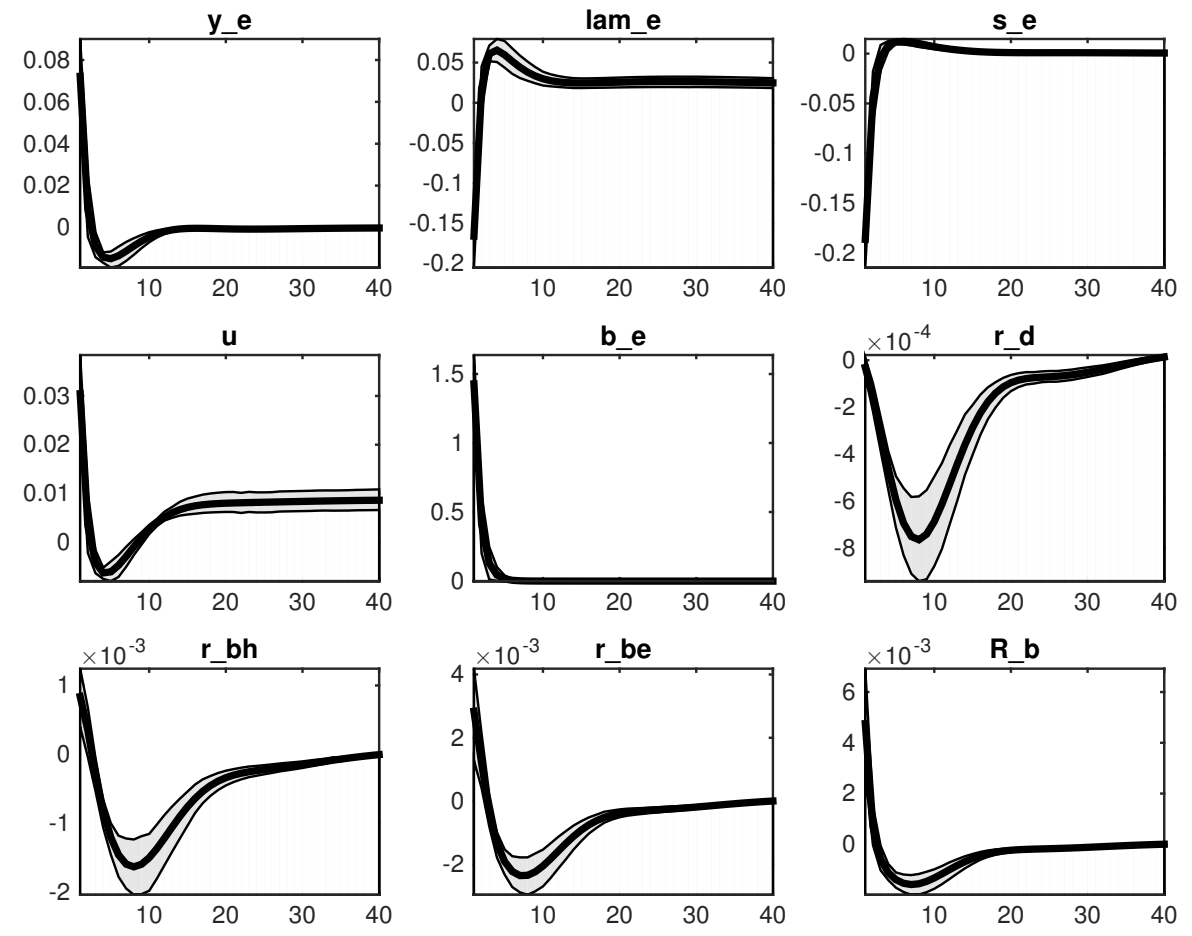

Figura 77: Efeito de um choque no loan-to-value dos empresários 

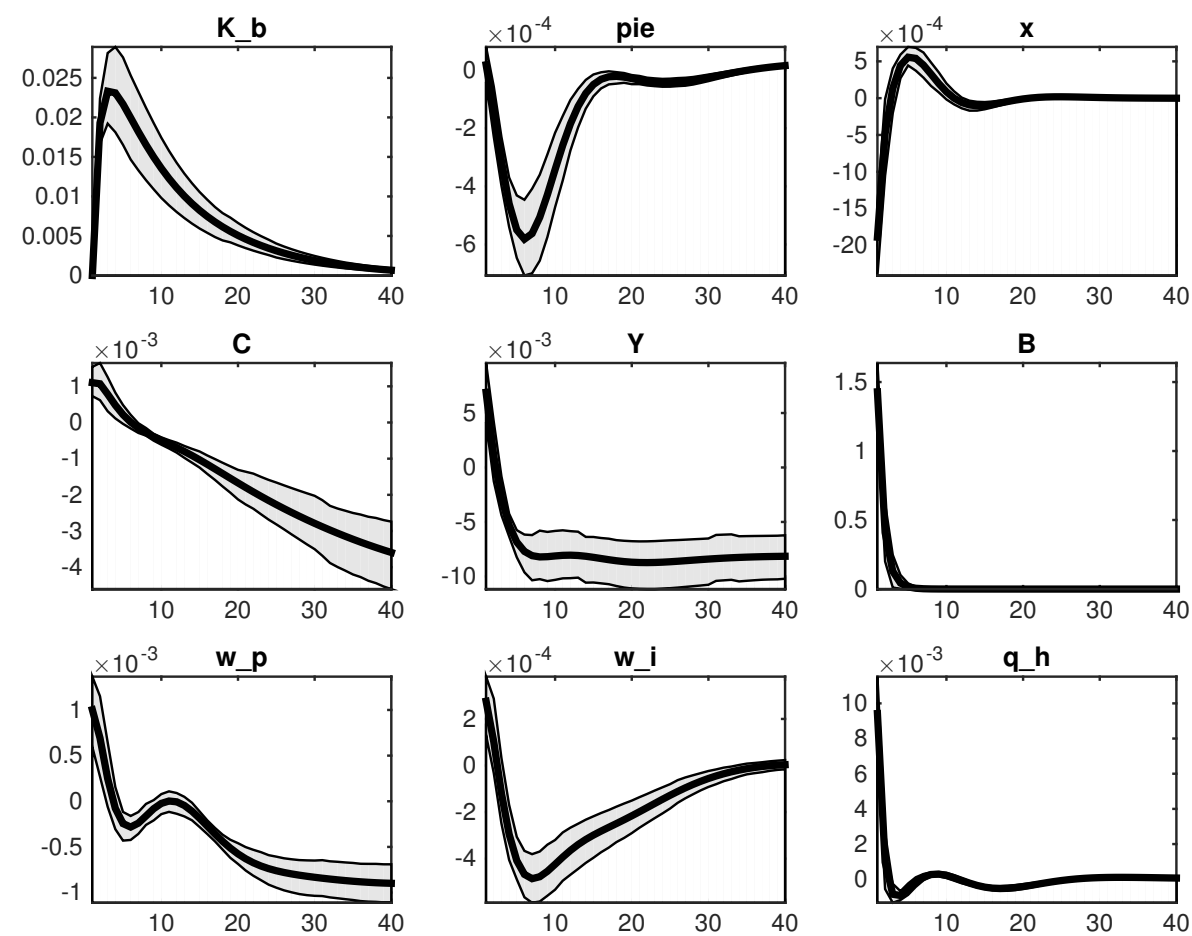

Figura 78: Efeito de um choque no loan-to-value dos empresários
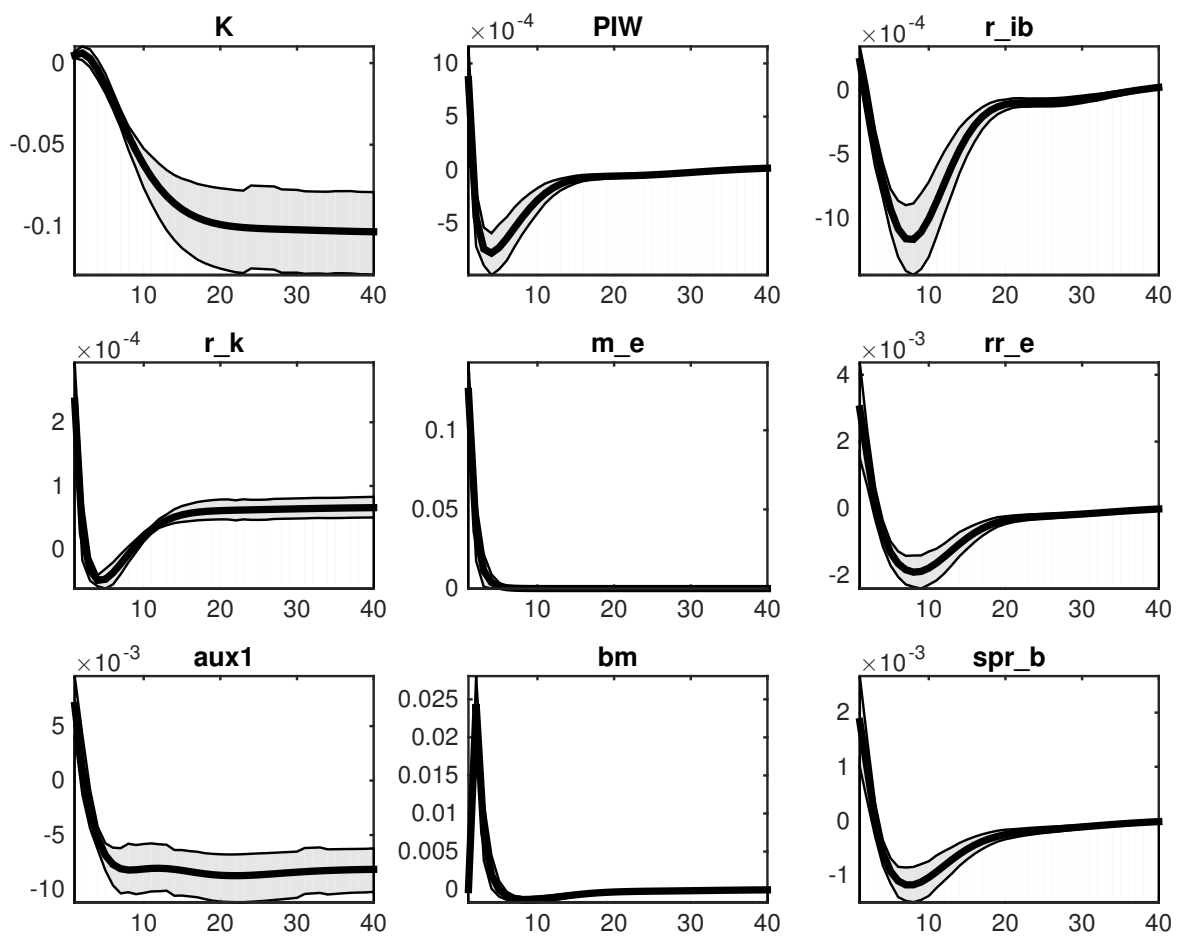

Figura 79: Efeito de um choque no loan-to-value dos empresários 

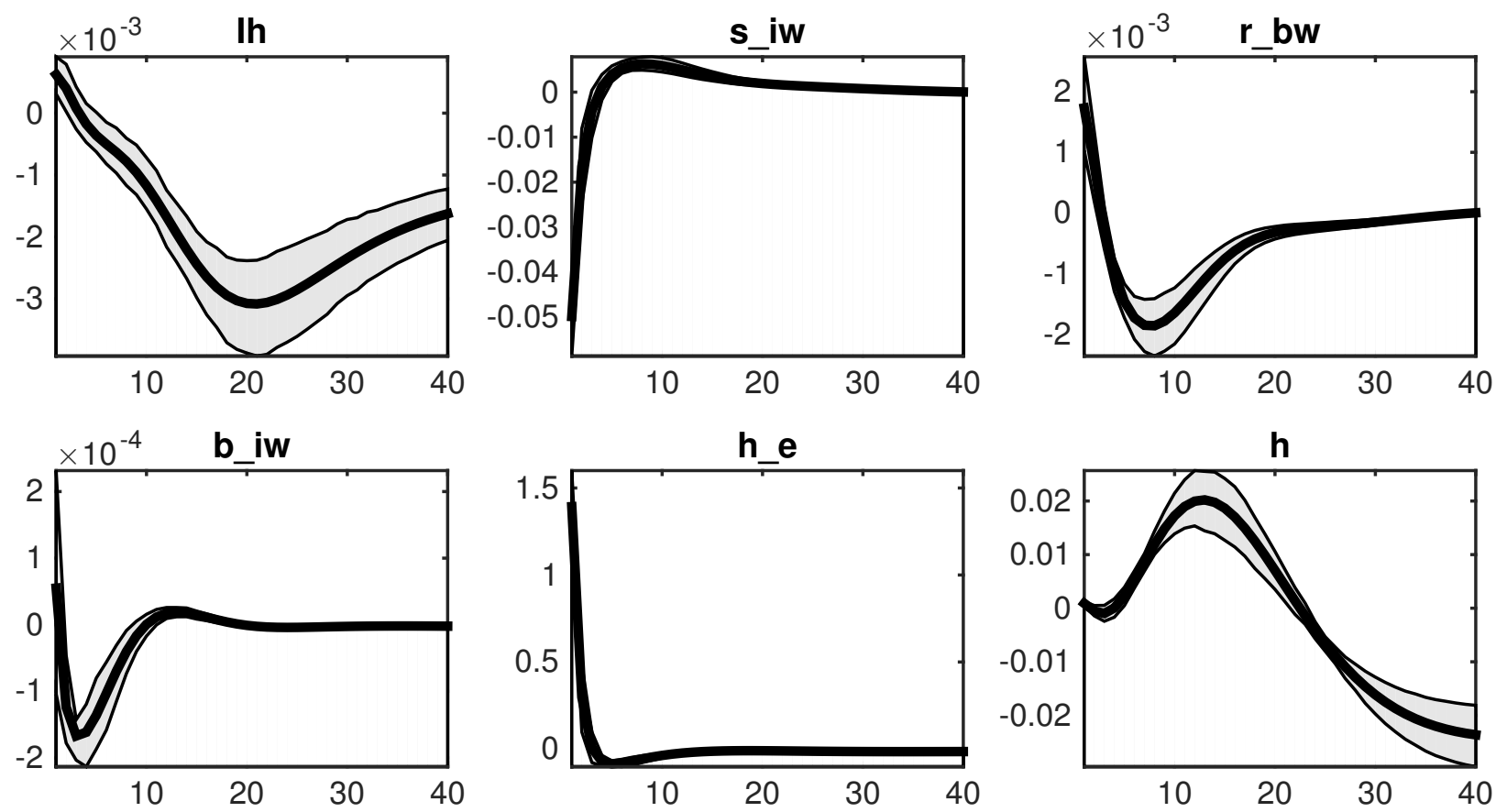

Figura 80: Efeito de um choque no loan-to-value dos empresários 
A.8 Choque no loan-to-value das famílias impacientes
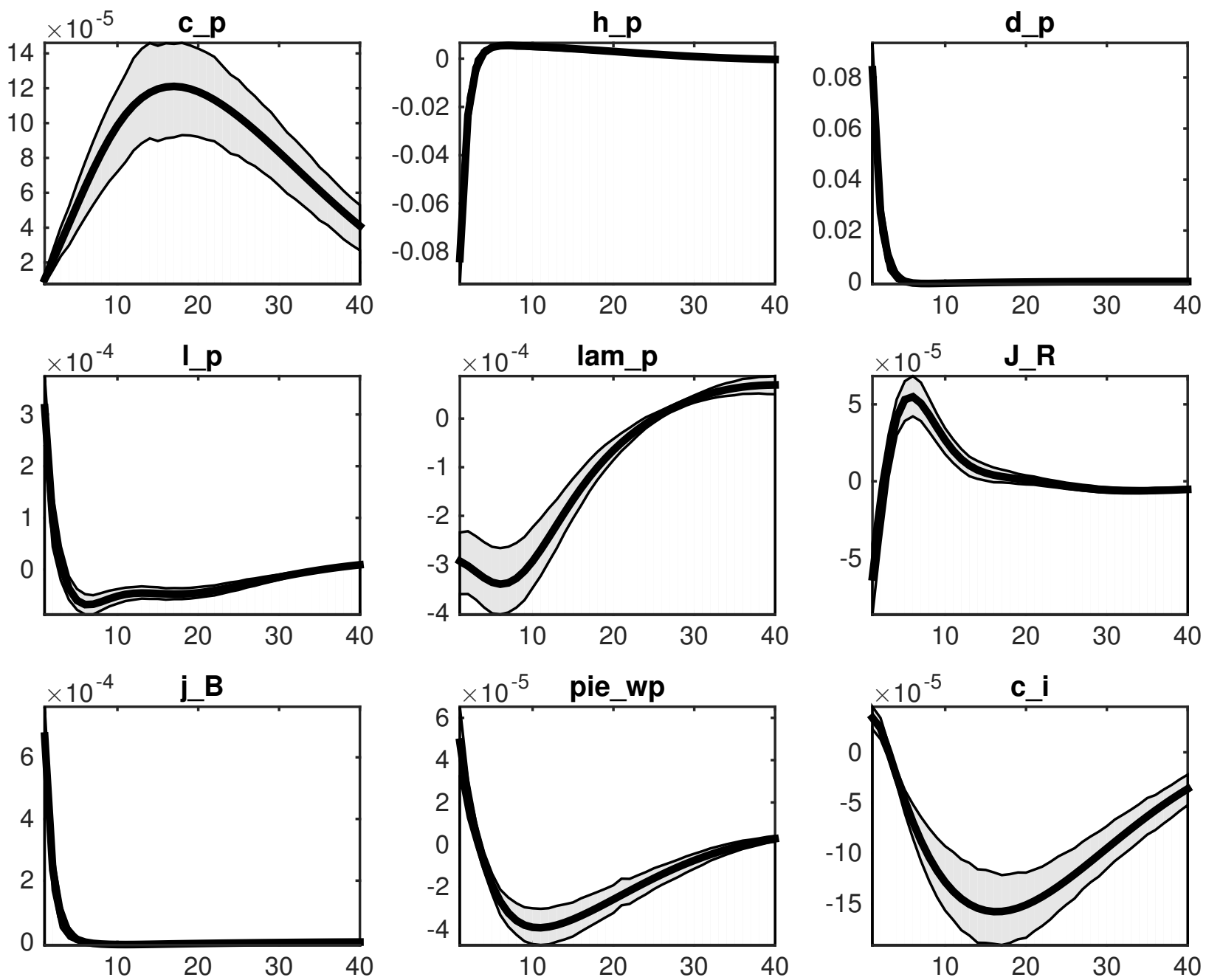

Figura 81: Efeito de um choque no loan-to-value das famílias impacientes 

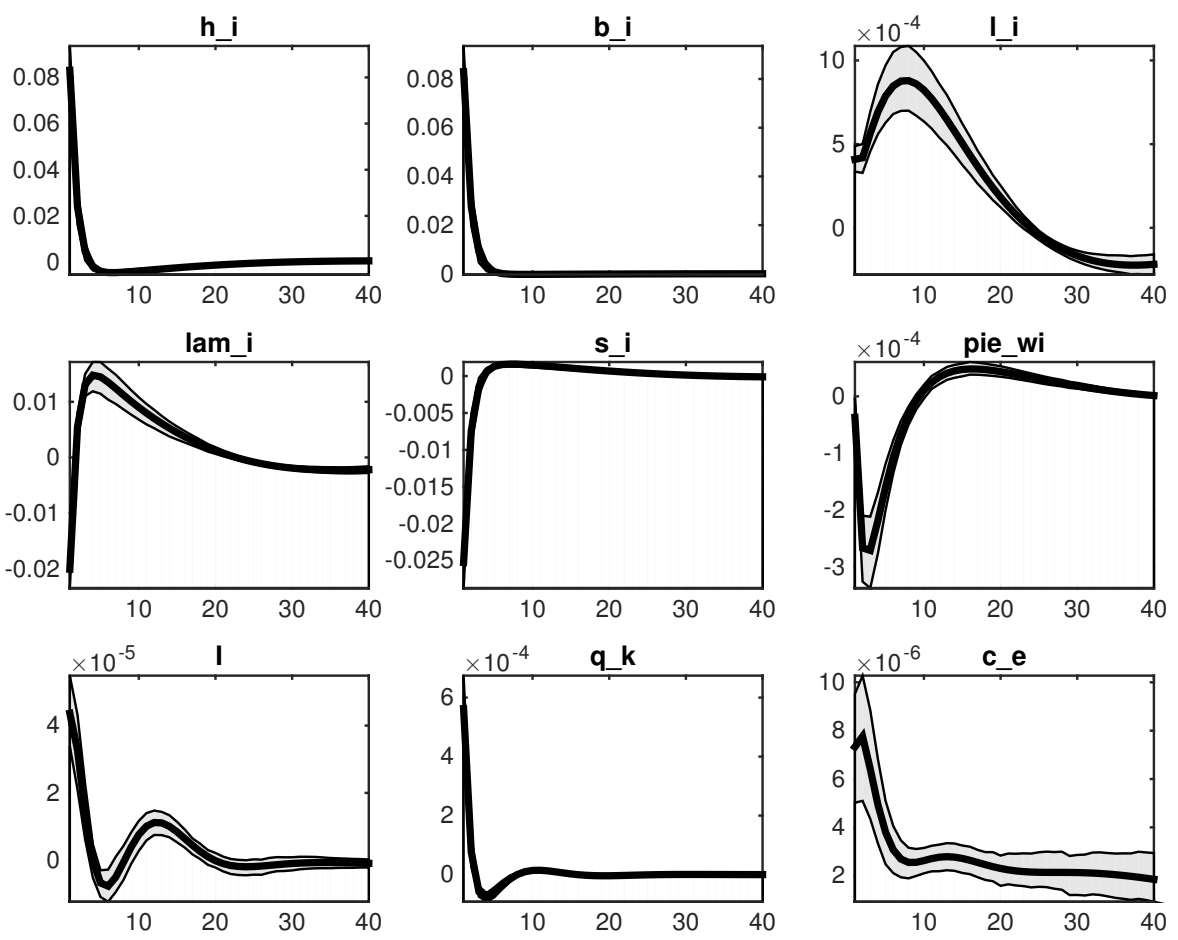

Figura 82: Efeito de um choque no loan-to-value das famílias impacientes
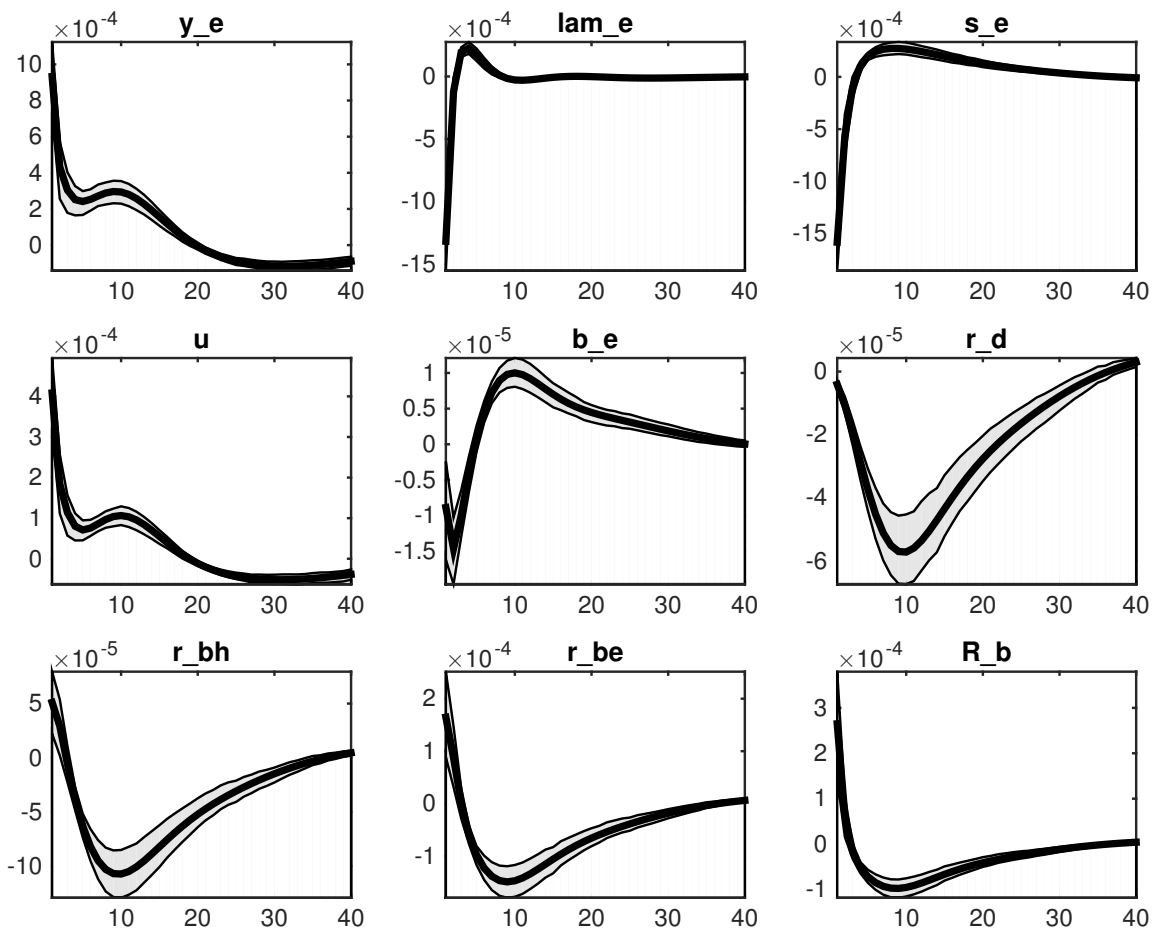

Figura 83: Efeito de um choque no loan-to-value das famílias impacientes 

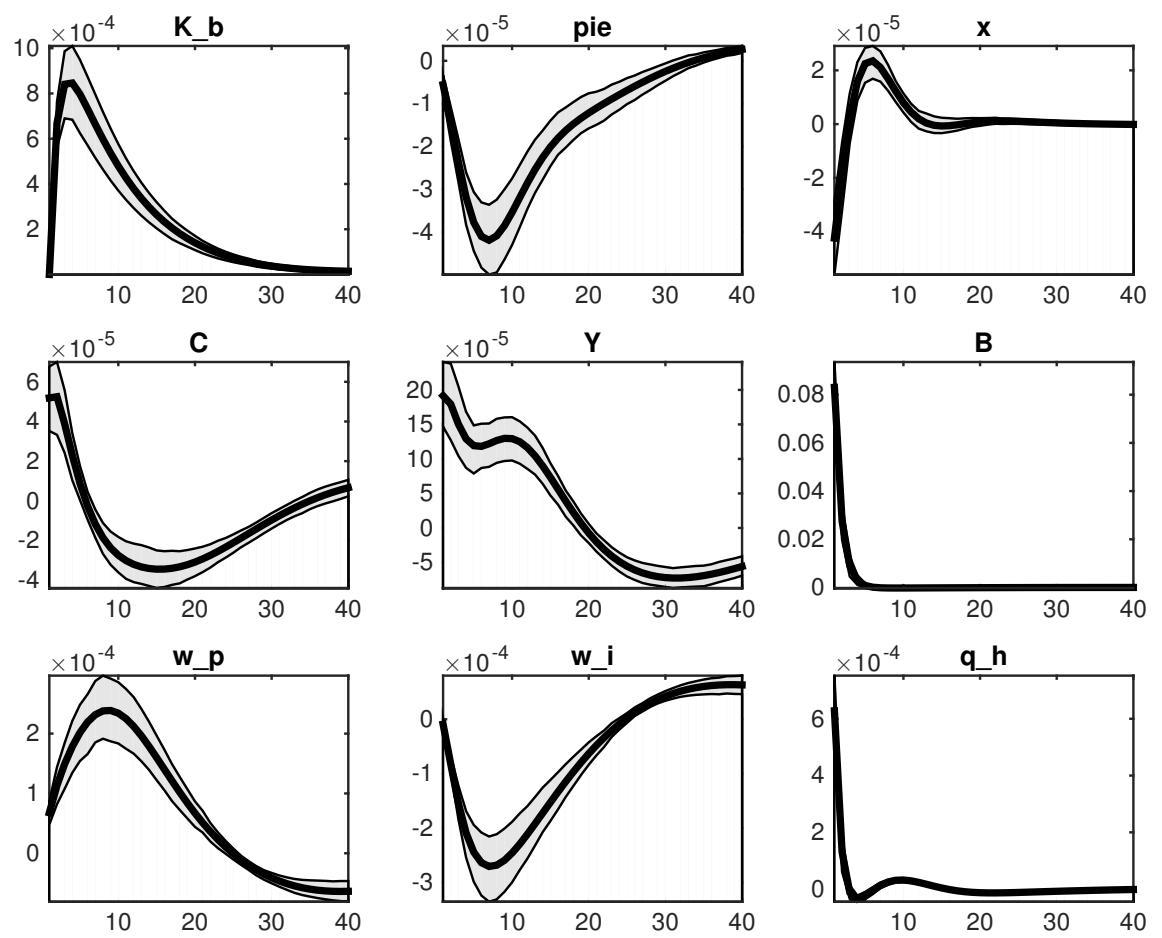

Figura 84: Efeito de um choque no loan-to-value das famílias impacientes
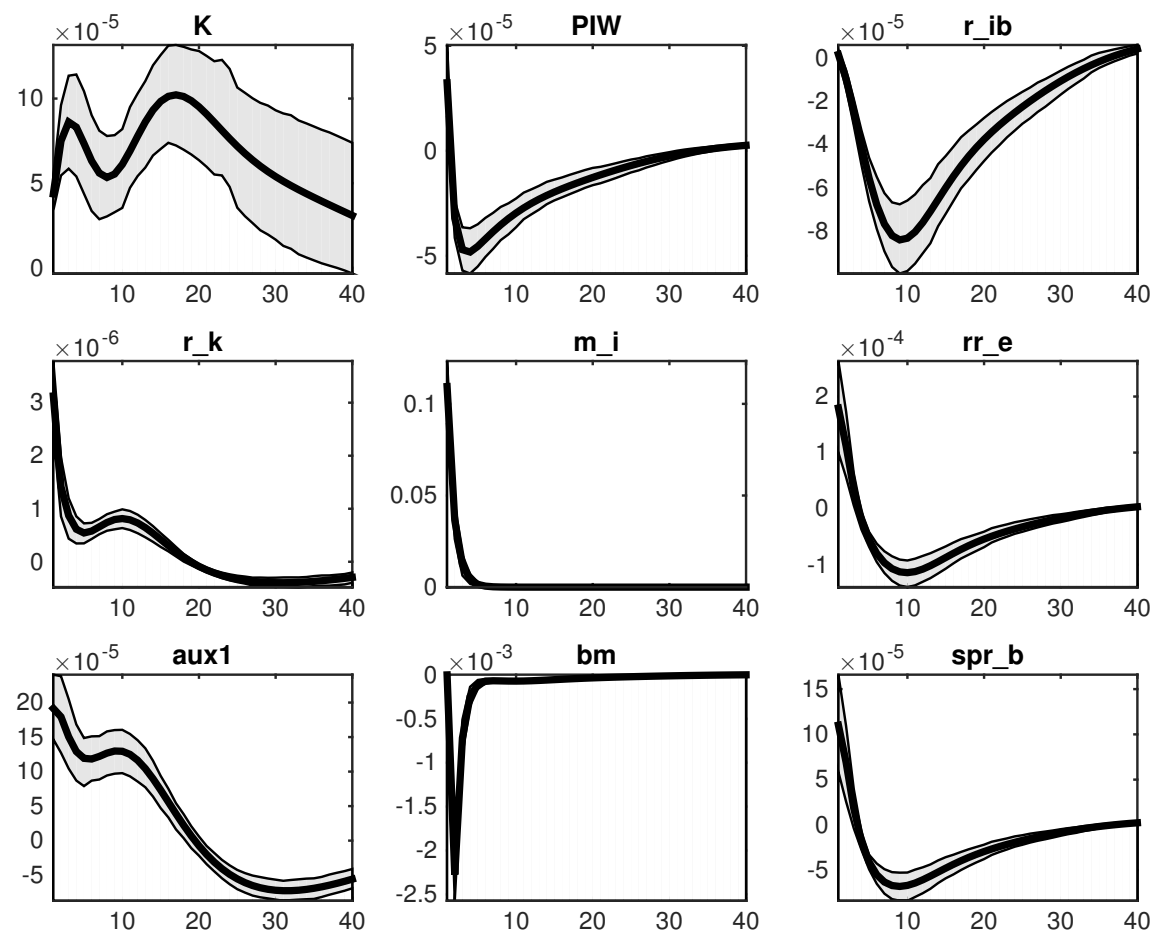

Figura 85: Efeito de um choque no loan-to-value das famílias impacientes 

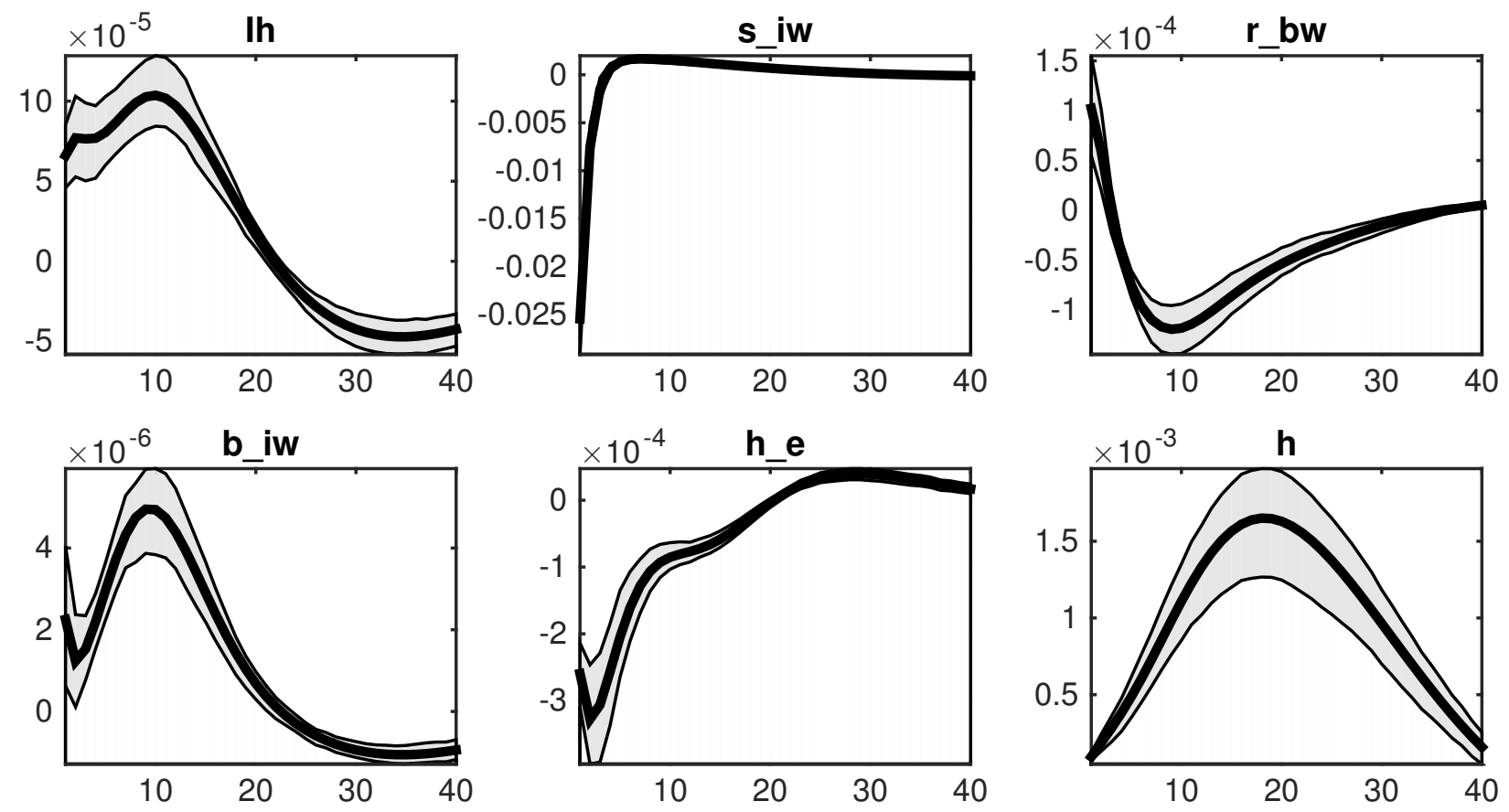

Figura 86: Efeito de um choque no loan-to-value das famílias impacientes 
A.9 Choque no Mark-up de salários
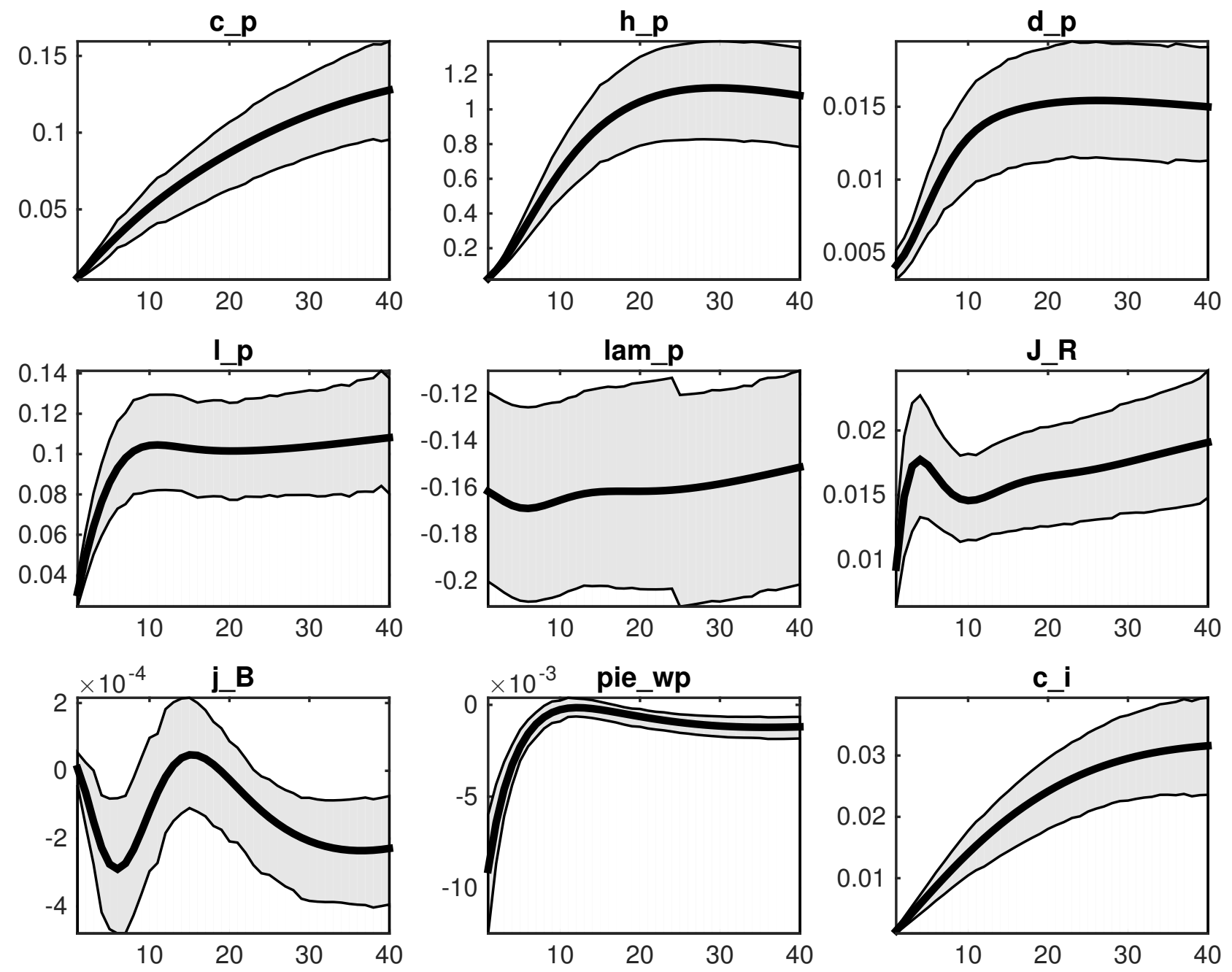

Figura 87: Efeito de um choque no Mark-up de salários 

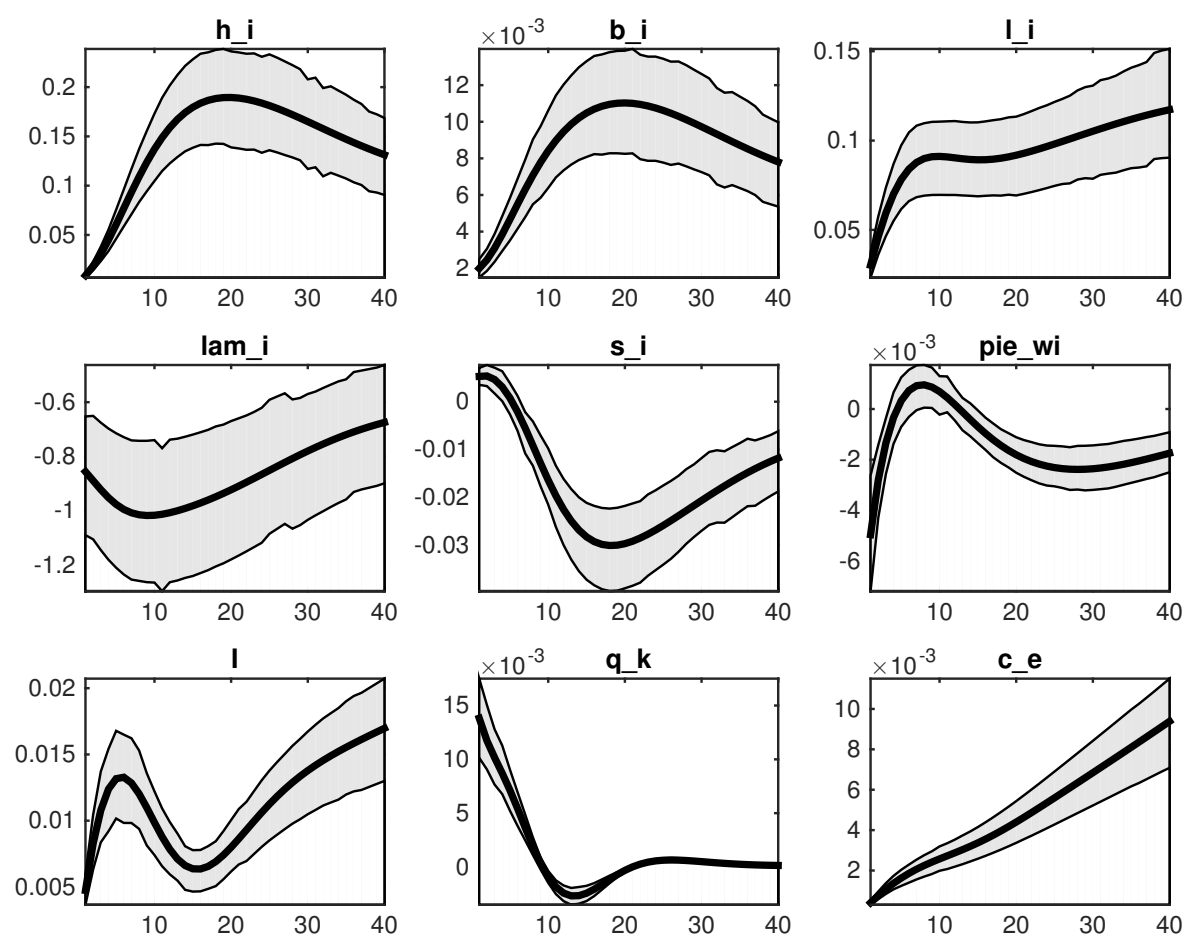

Figura 88: Efeito de um choque no Mark-up de salários
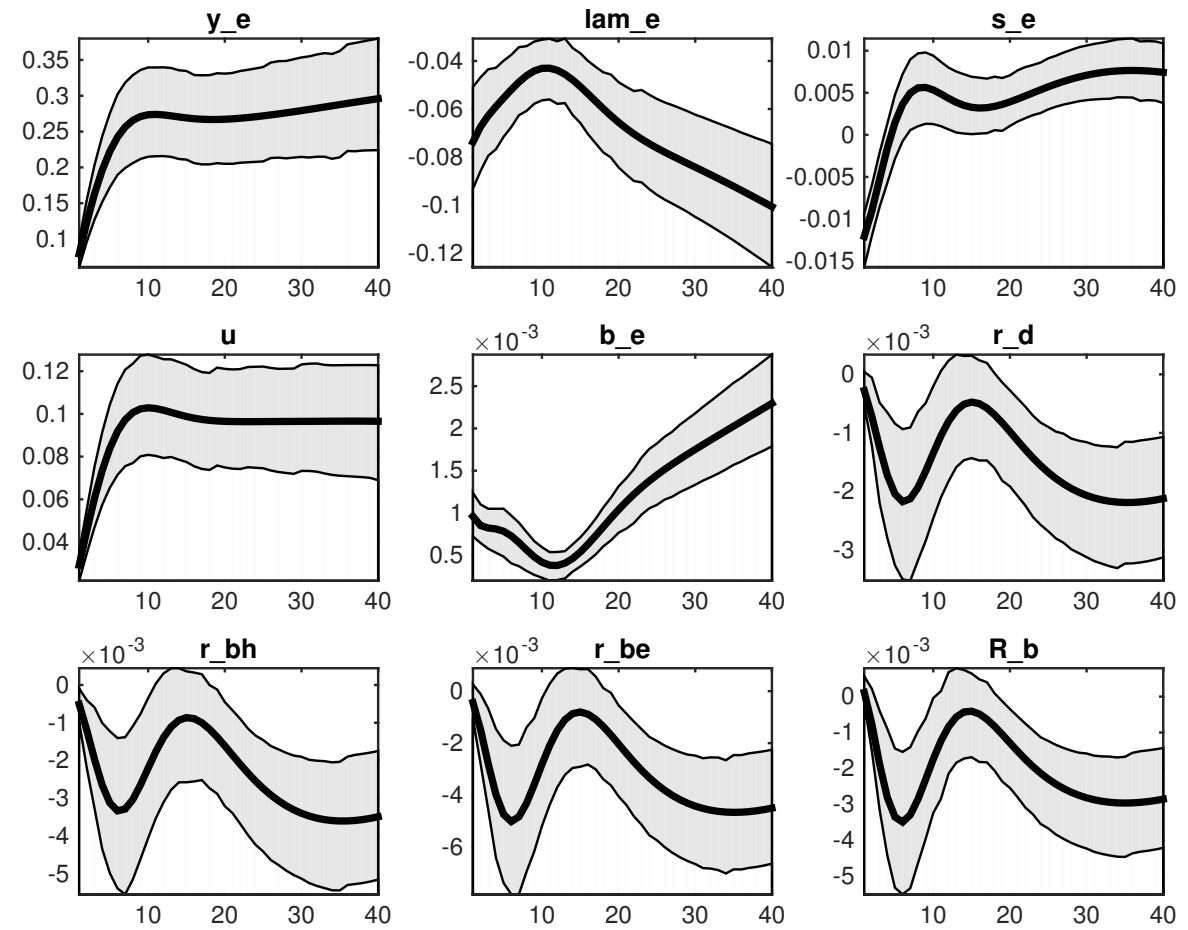

Figura 89: Efeito de um choque no Mark-up de salários 

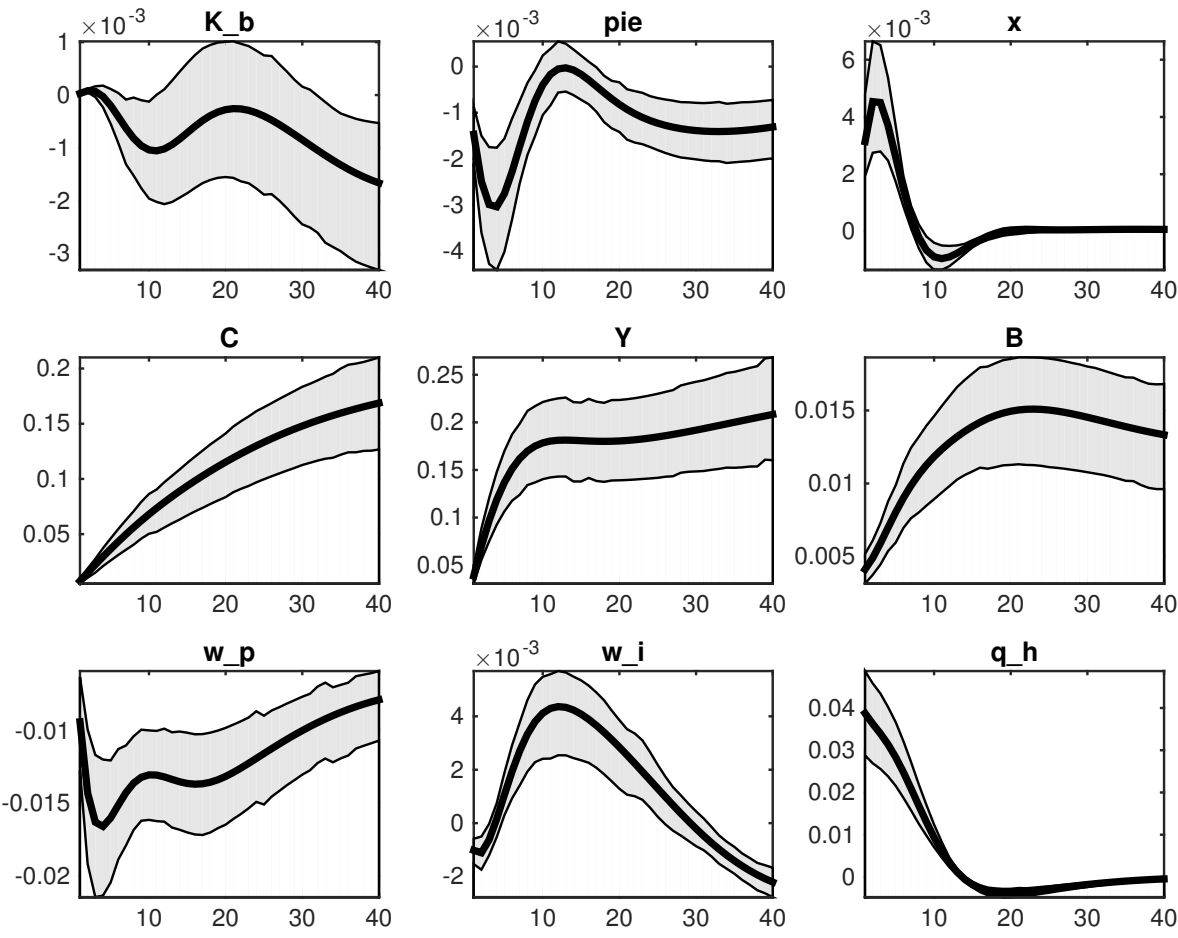

Figura 90: Efeito de um choque no Mark-up de salários
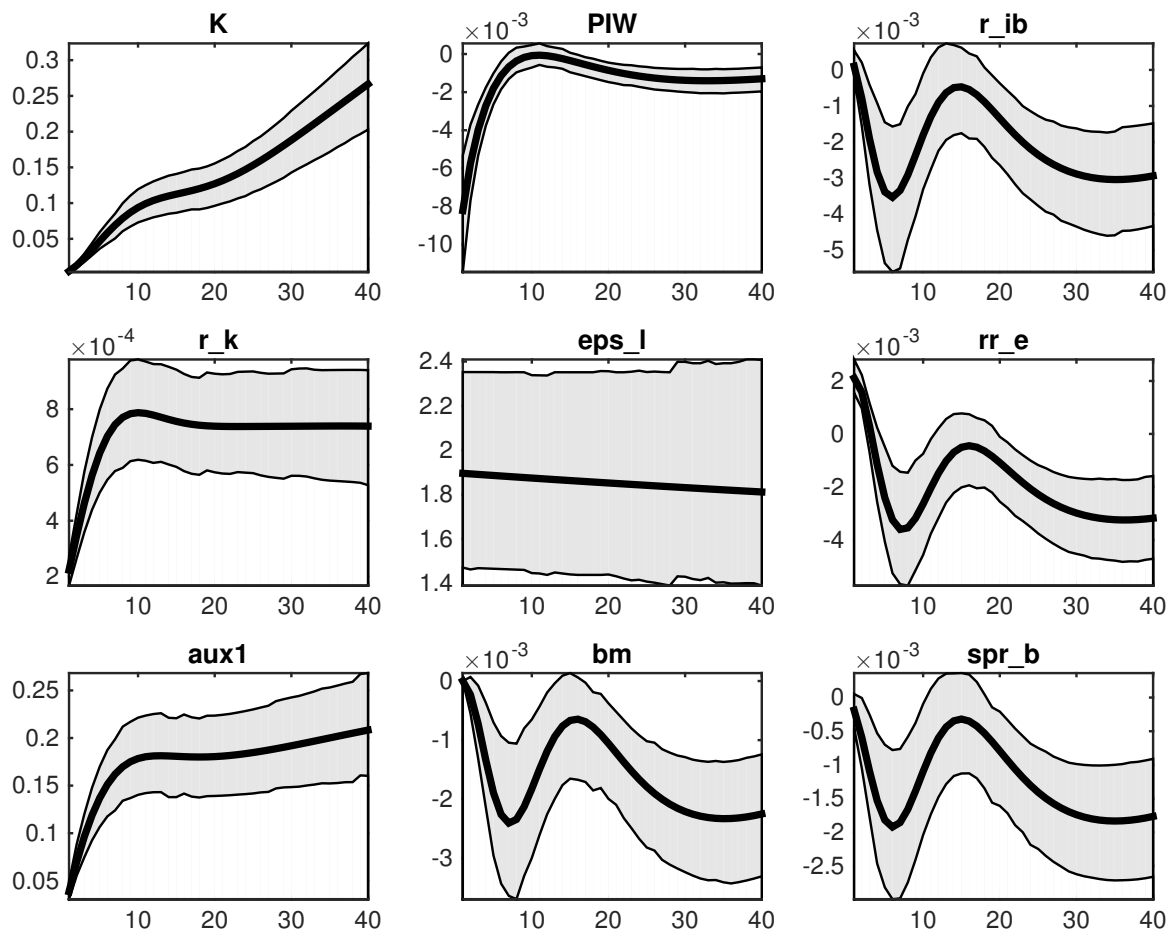

Figura 91: Efeito de um choque no Mark-up de salários 

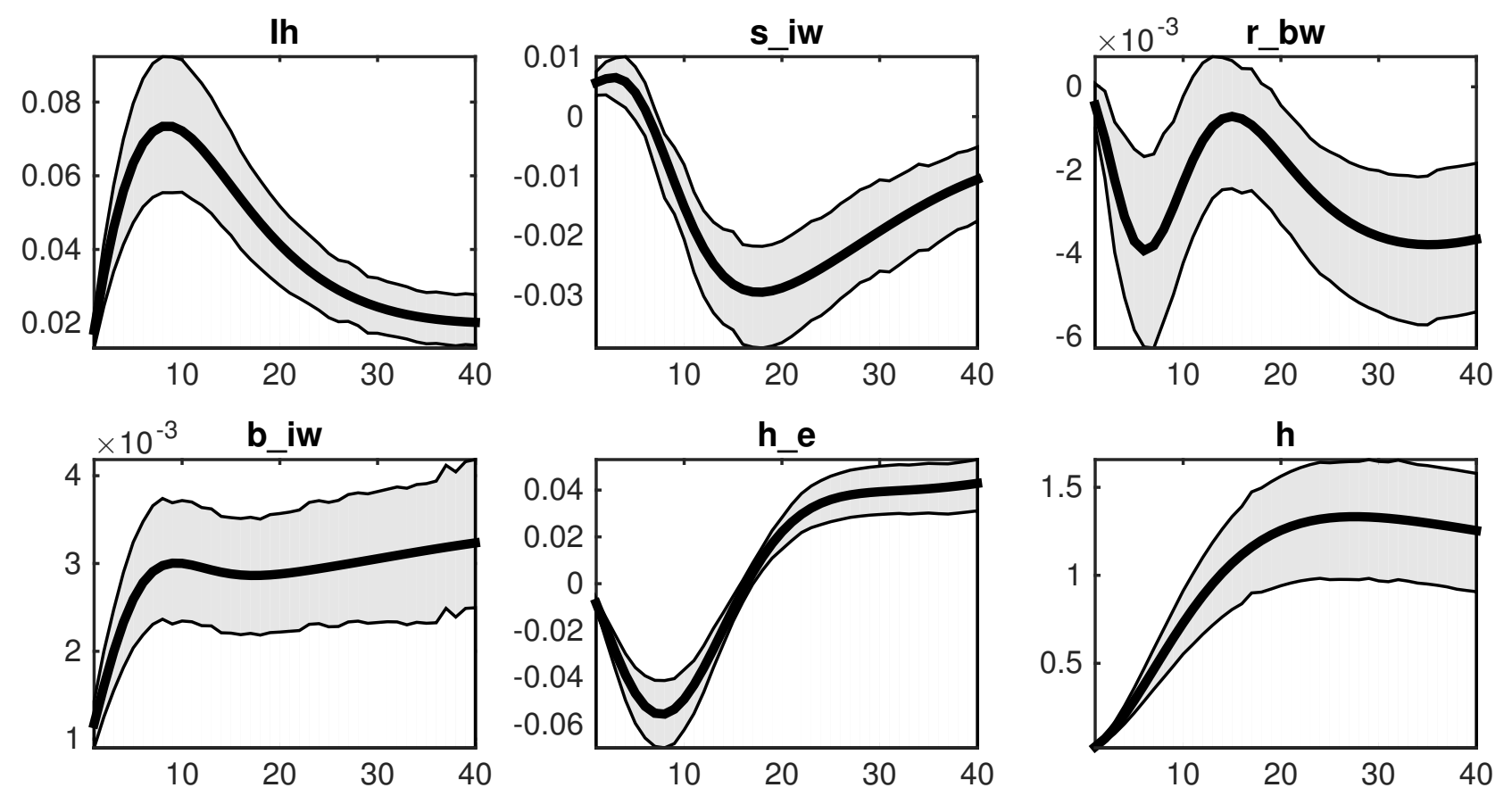

Figura 92: Efeito de um choque no Mark-up de salários 
A.10 Choque no Mark-up de taxa de juros: empréstimos com base em imóveis
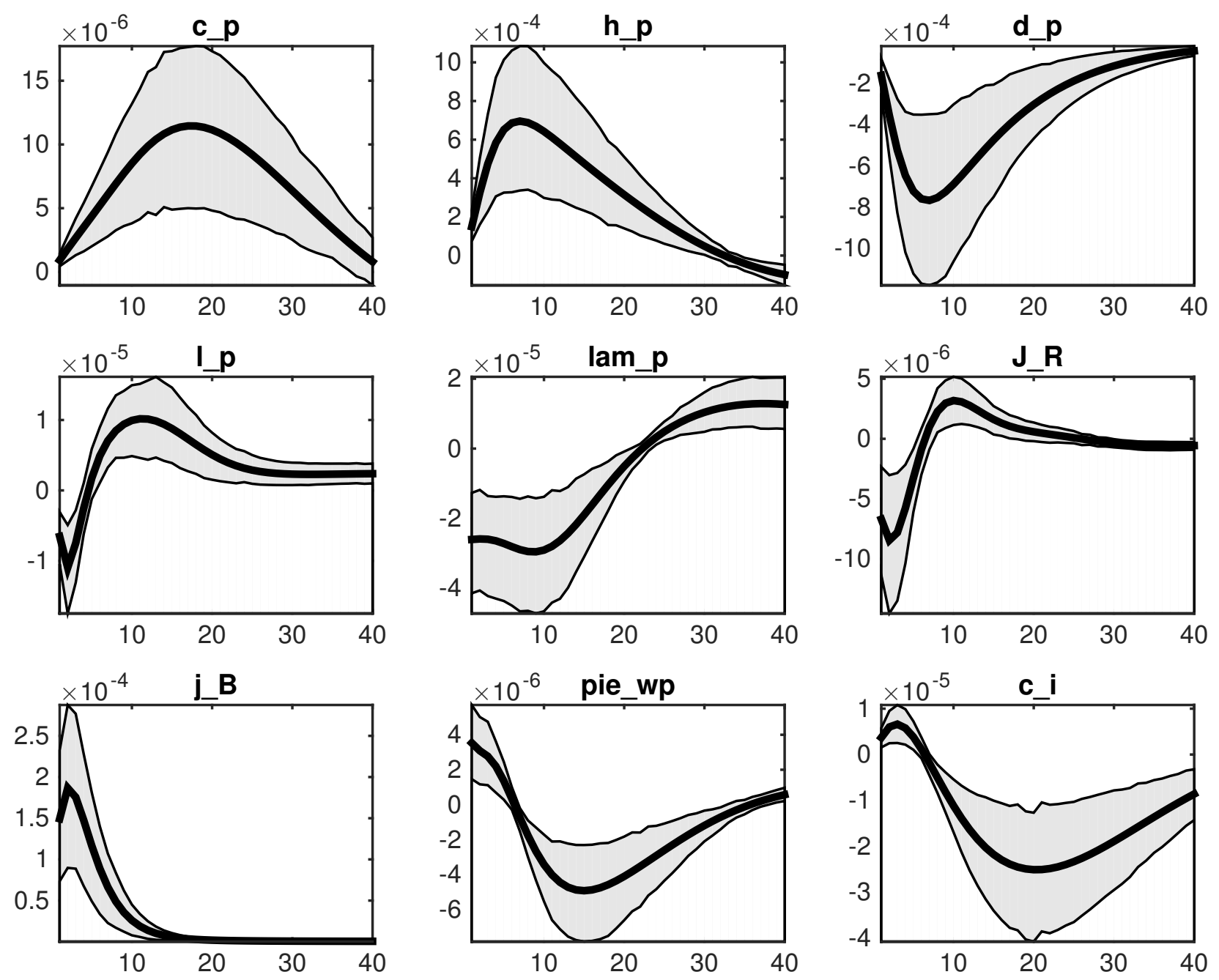

Figura 93: Efeito de um choque $\mathrm{em}^{\mathrm{mk}_{b}} h$ 

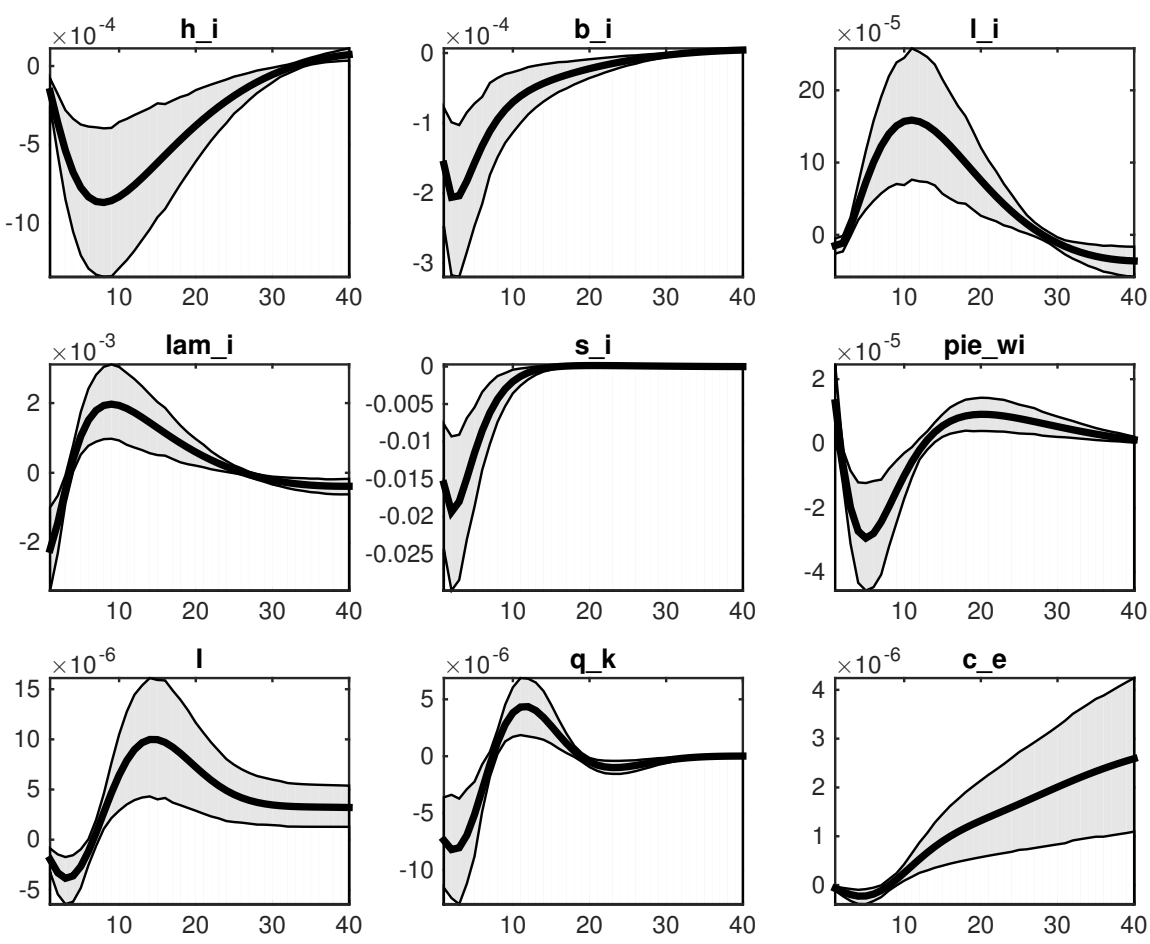

Figura 94: Efeito de um choque em $\mathrm{mk}_{b} h$
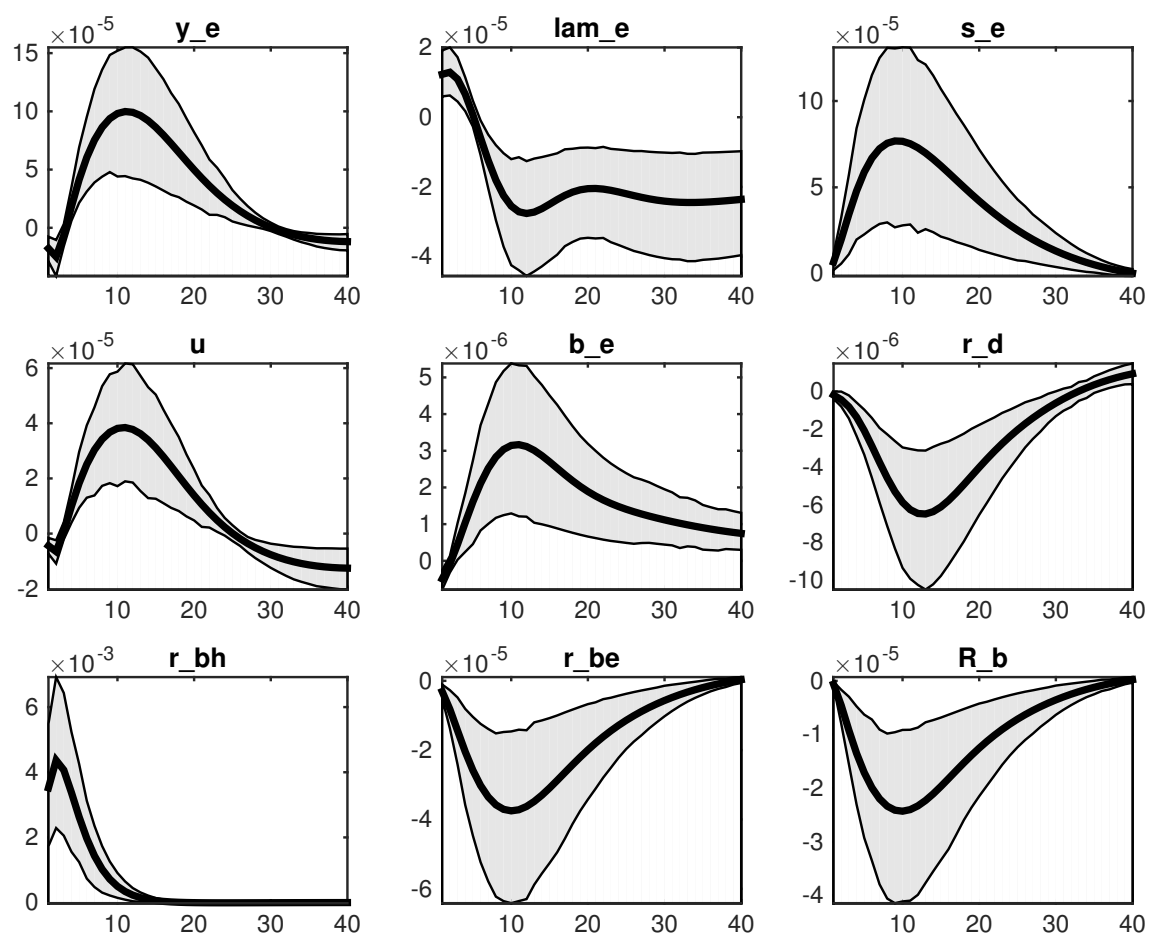

Figura 95: Efeito de um choque $\mathrm{em}^{\mathrm{mk}_{b}} h$ 

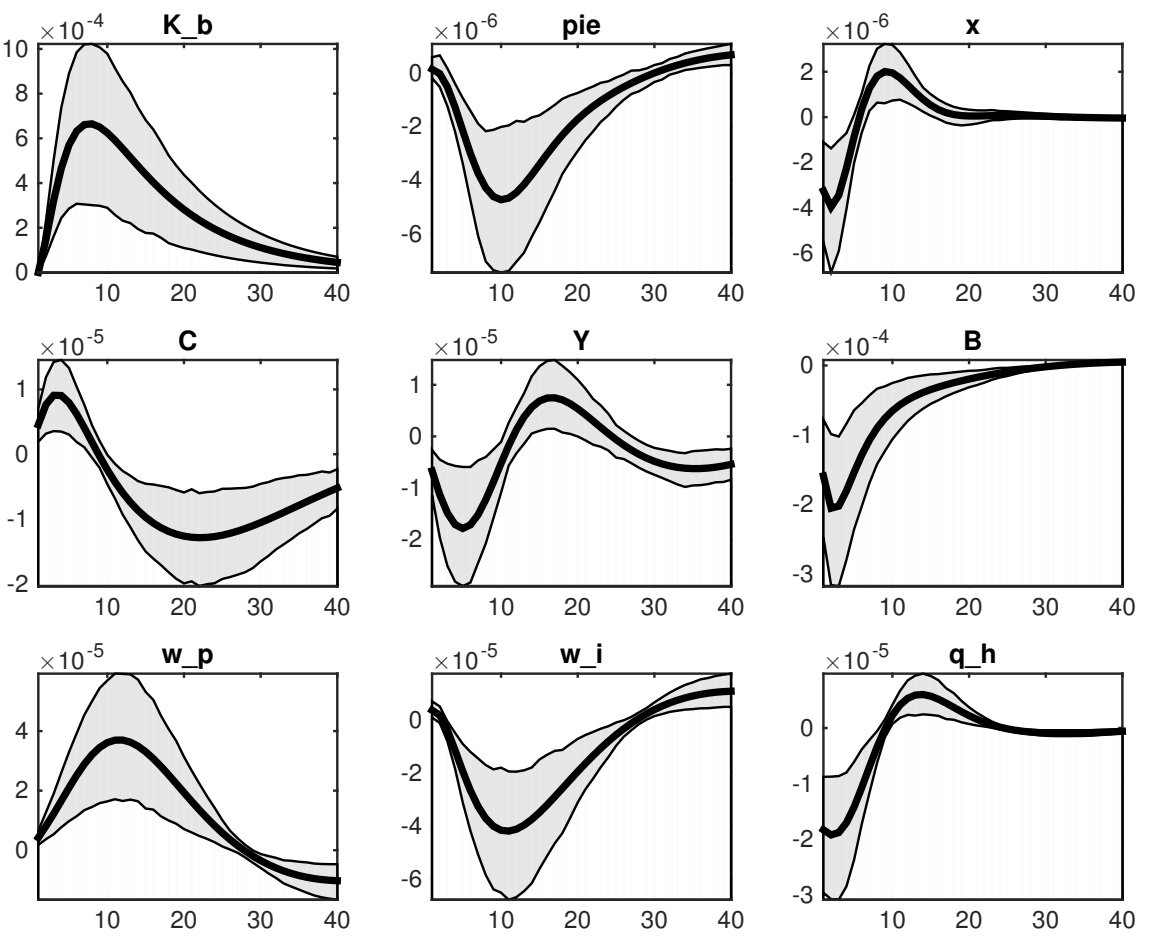

Figura 96: Efeito de um choque em $\mathrm{mk}_{b} h$
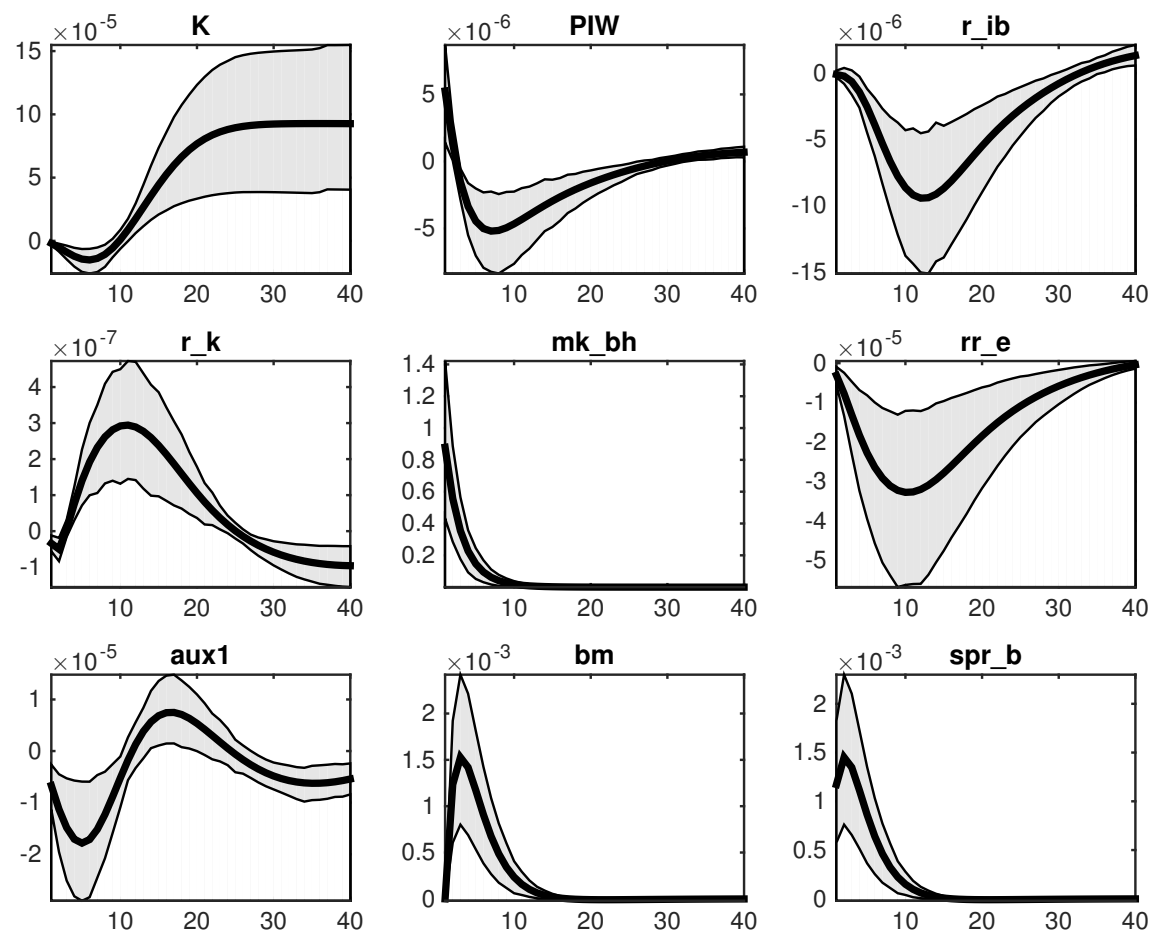

Figura 97: Efeito de um choque em $\mathrm{mk}_{b} h$ 

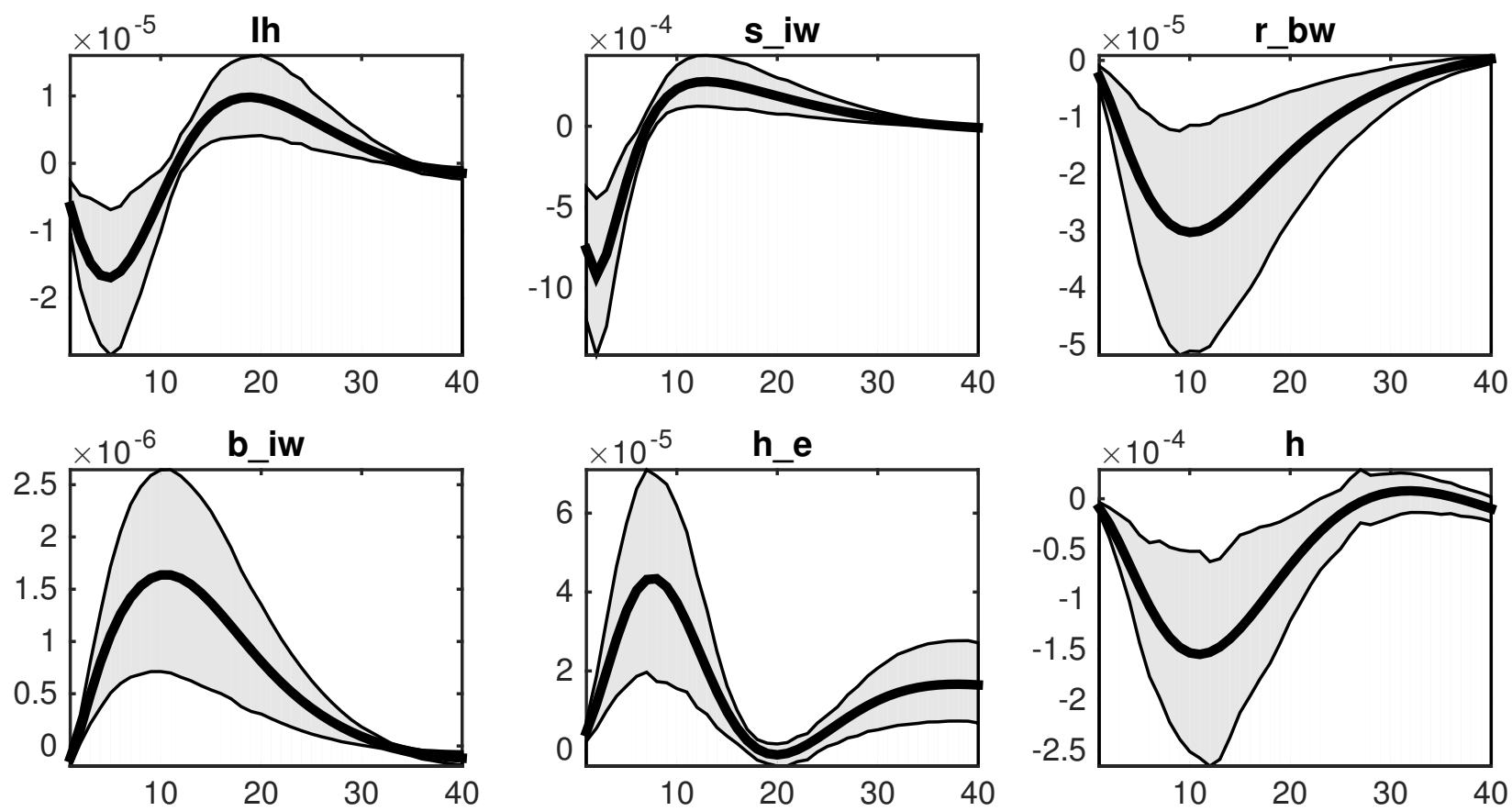

Figura 98: Efeito de um choque $\mathrm{em}^{\mathrm{mk}_{b}} h$ 
A.11 Choque no Mark-up de taxa de juros: empréstimos aos empresários
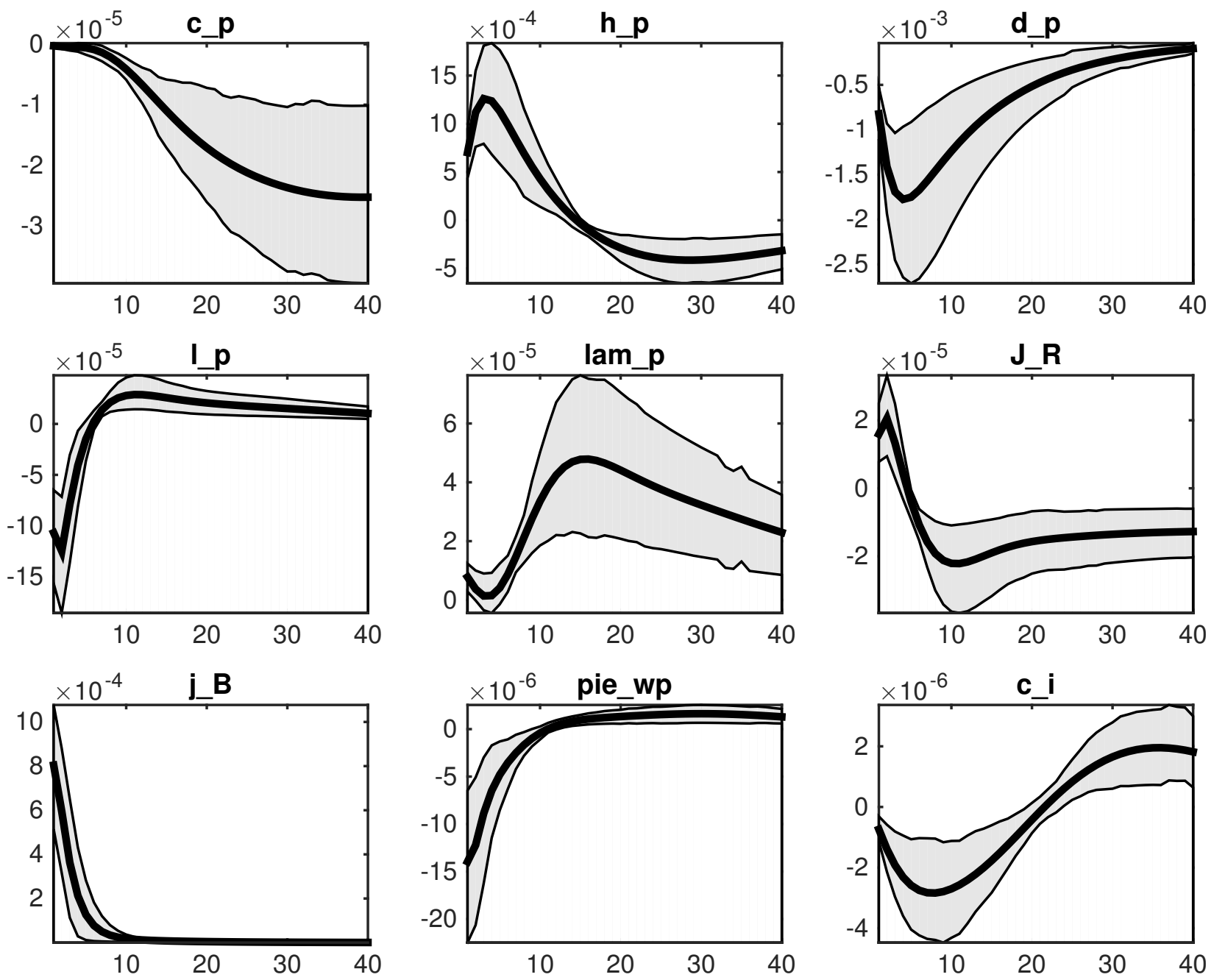

Figura 99: Efeito de um choque em $\mathrm{mk}_{b} e$ 

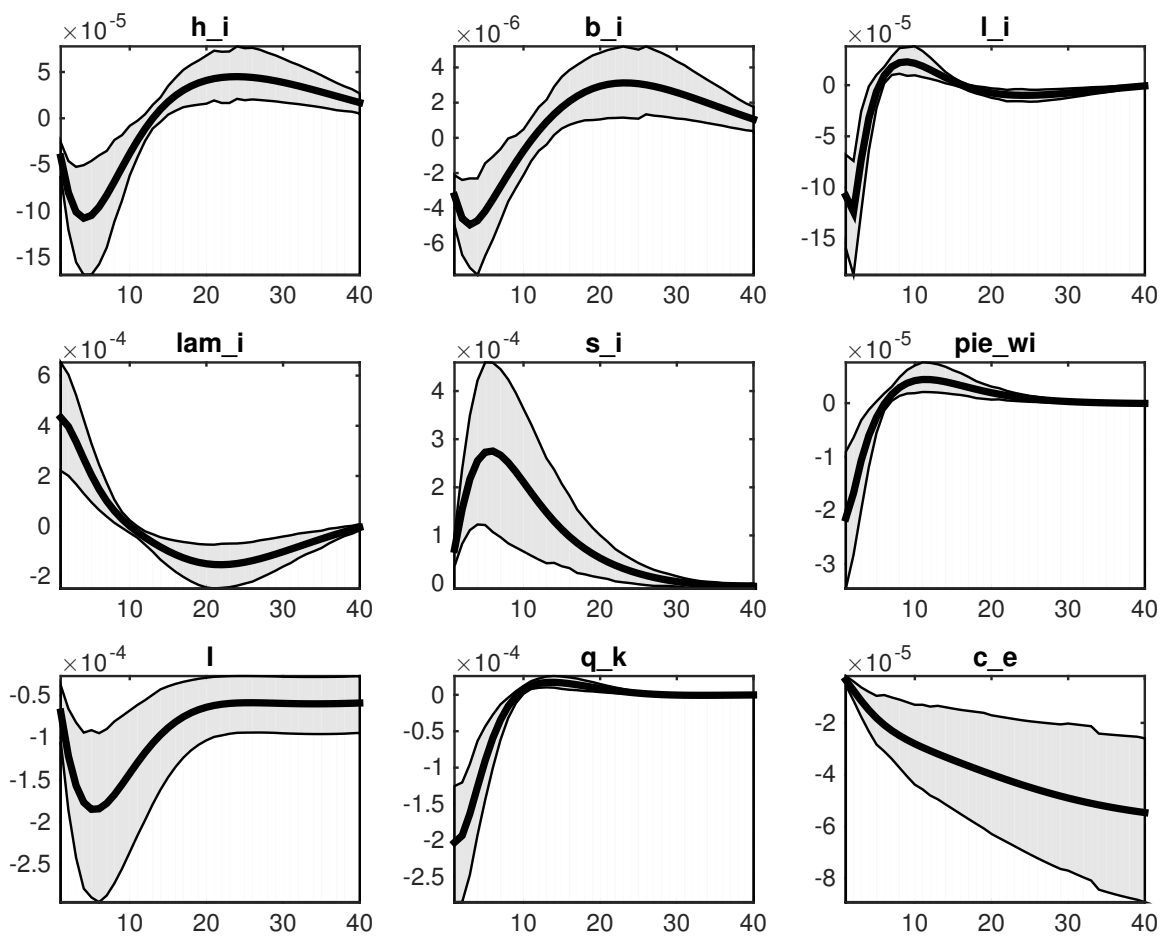

Figura 100: Efeito de um choque em $\mathrm{mk}_{b} e$
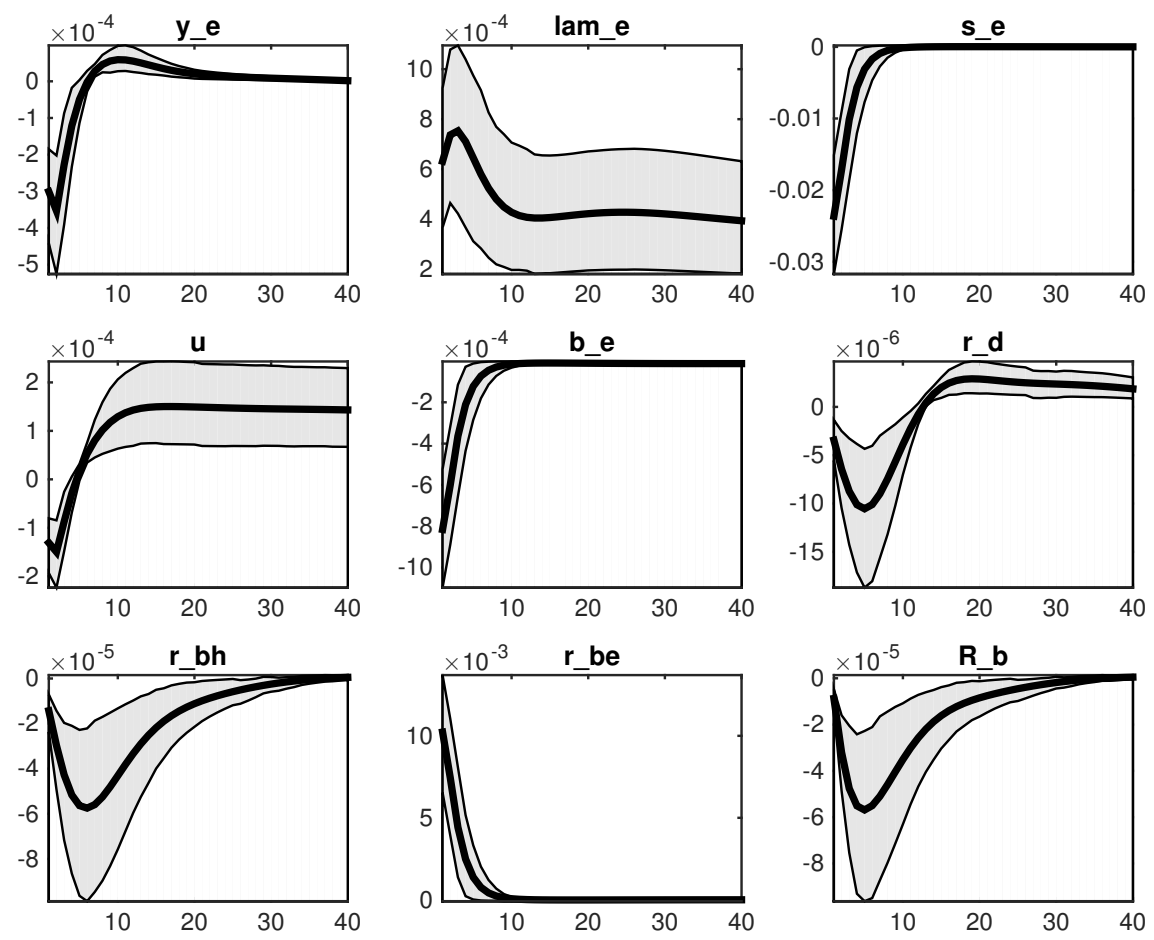

Figura 101: Efeito de um choque em $\mathrm{mk}_{b} e$ 

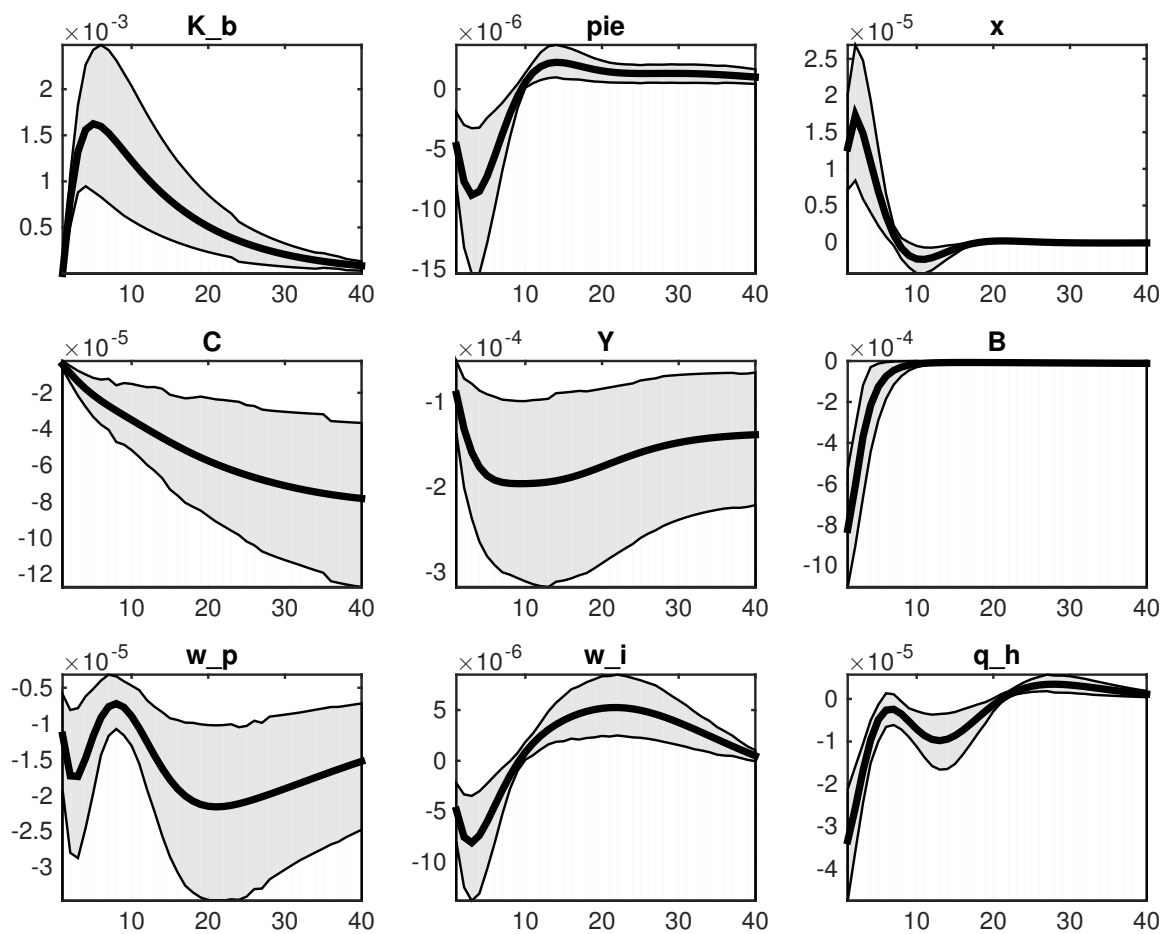

Figura 102: Efeito de um choque em $\mathrm{mk}_{b} e$
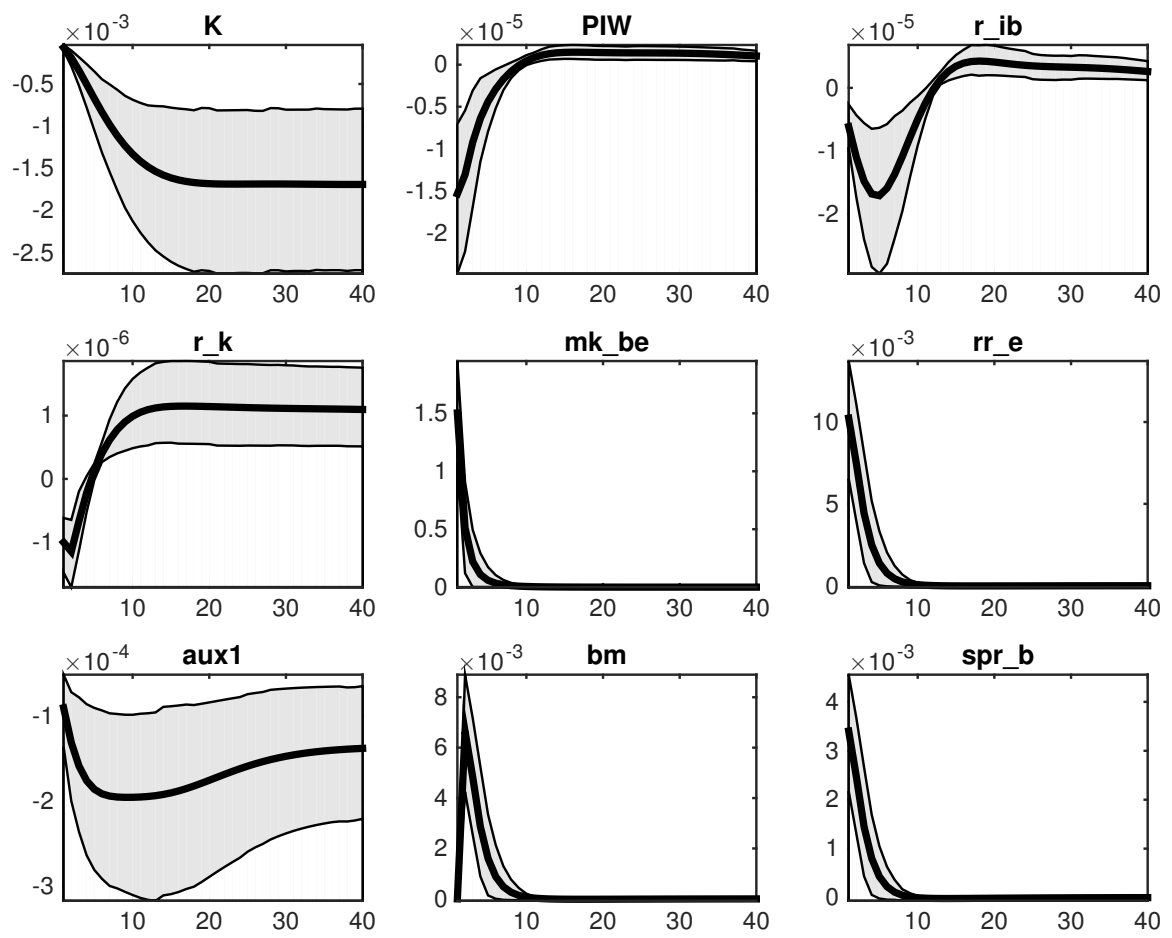

Figura 103: Efeito de um choque em $\mathrm{mk}_{b} e$ 

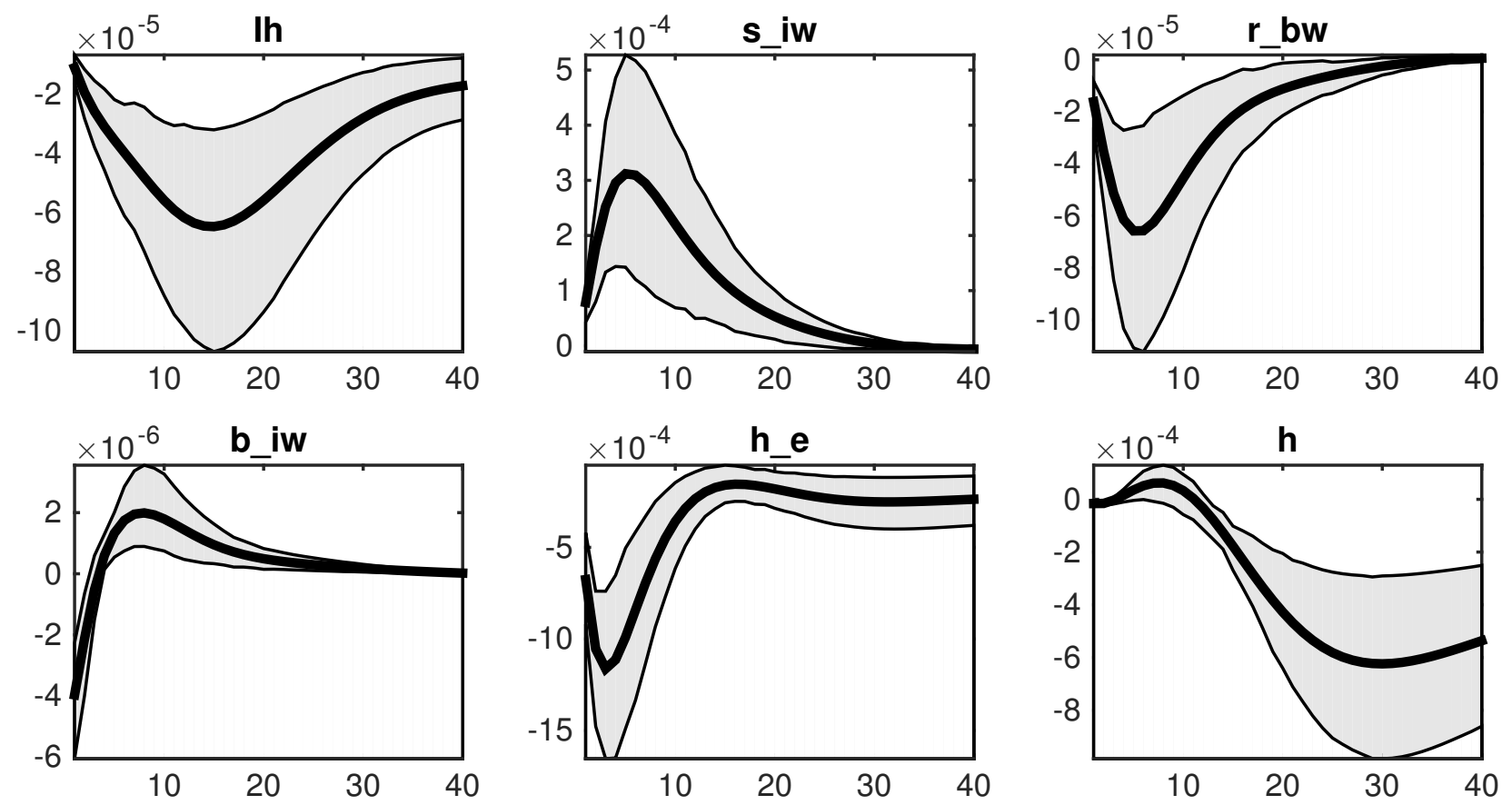

Figura 104: Efeito de um choque $\mathrm{em}^{\mathrm{mk}_{b}} \mathrm{e}$ 
A.12 Choque no Mark-down de taxa de juros sobre depósitos
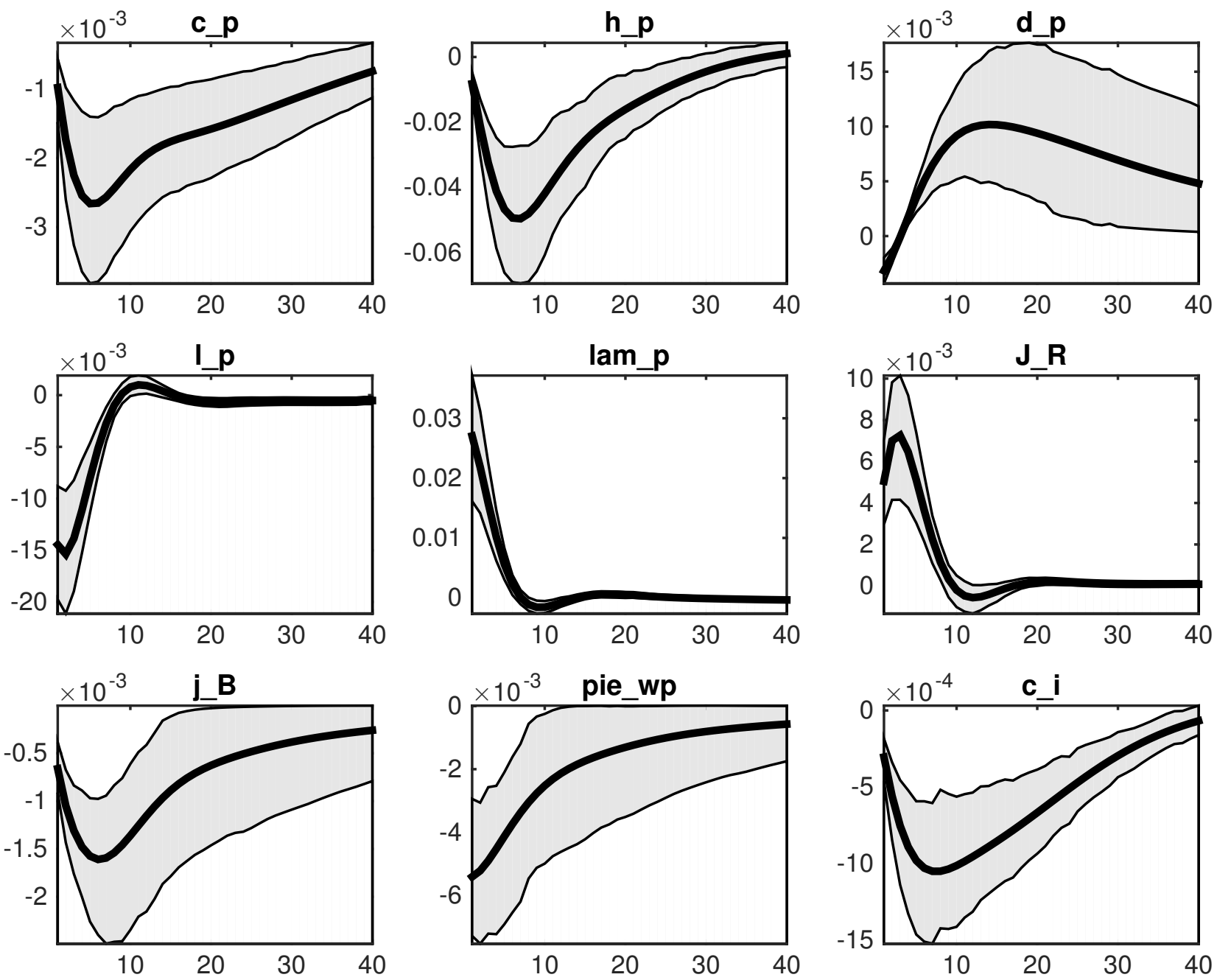

Figura 105: Efeito de um choque em $\mathrm{mk}_{d}$ 

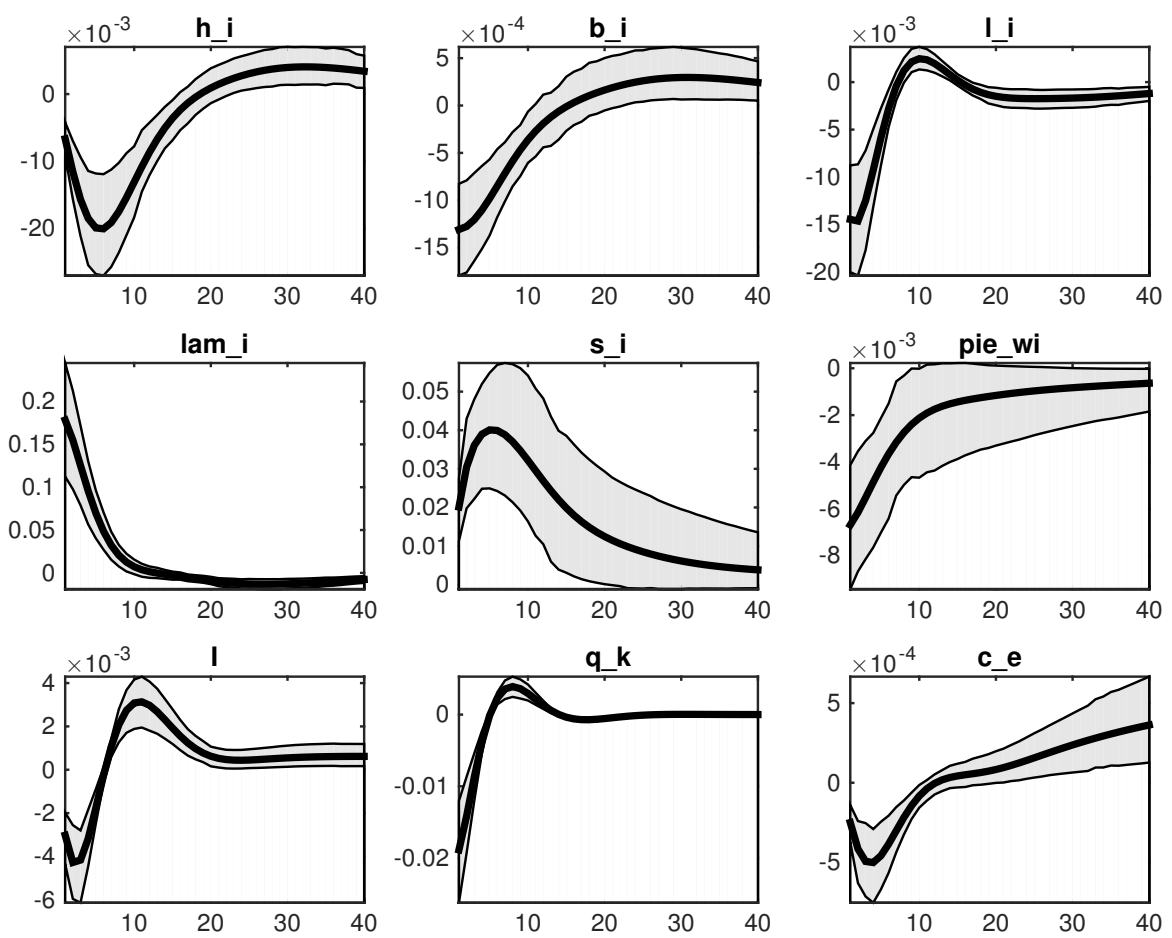

Figura 106: Efeito de um choque em $\mathrm{mk}_{d}$
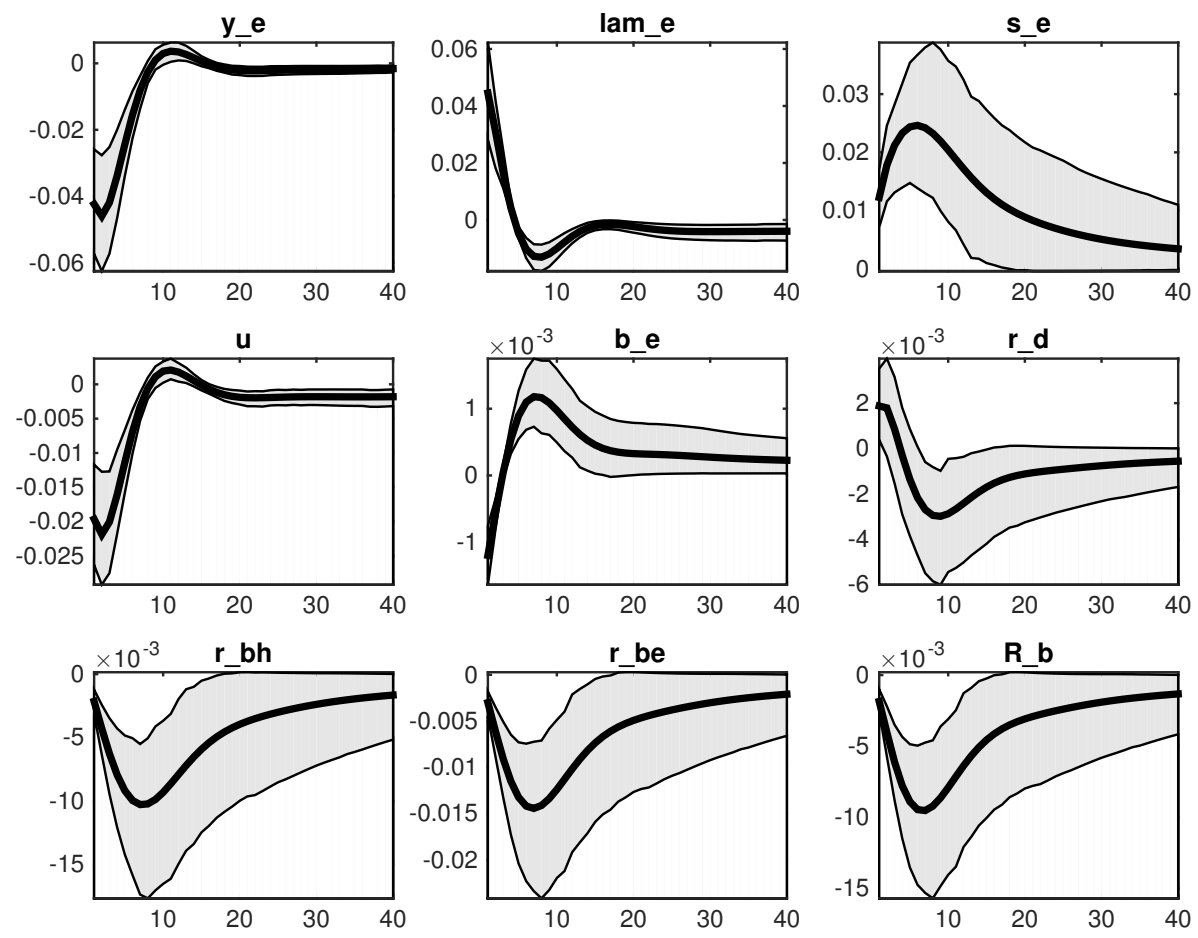

Figura 107: Efeito de um choque em $\mathrm{mk}_{d}$ 

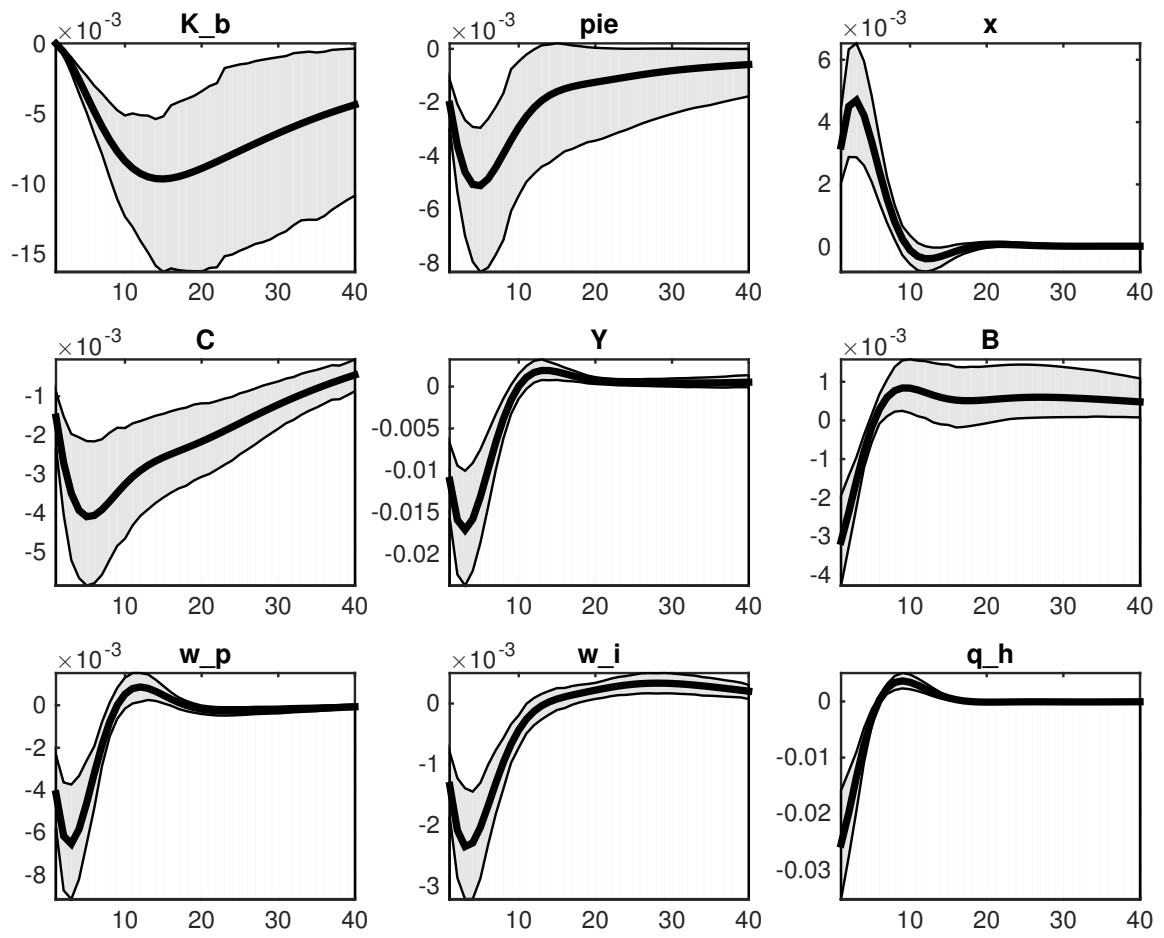

Figura 108: Efeito de um choque em $\mathrm{mk}_{d}$
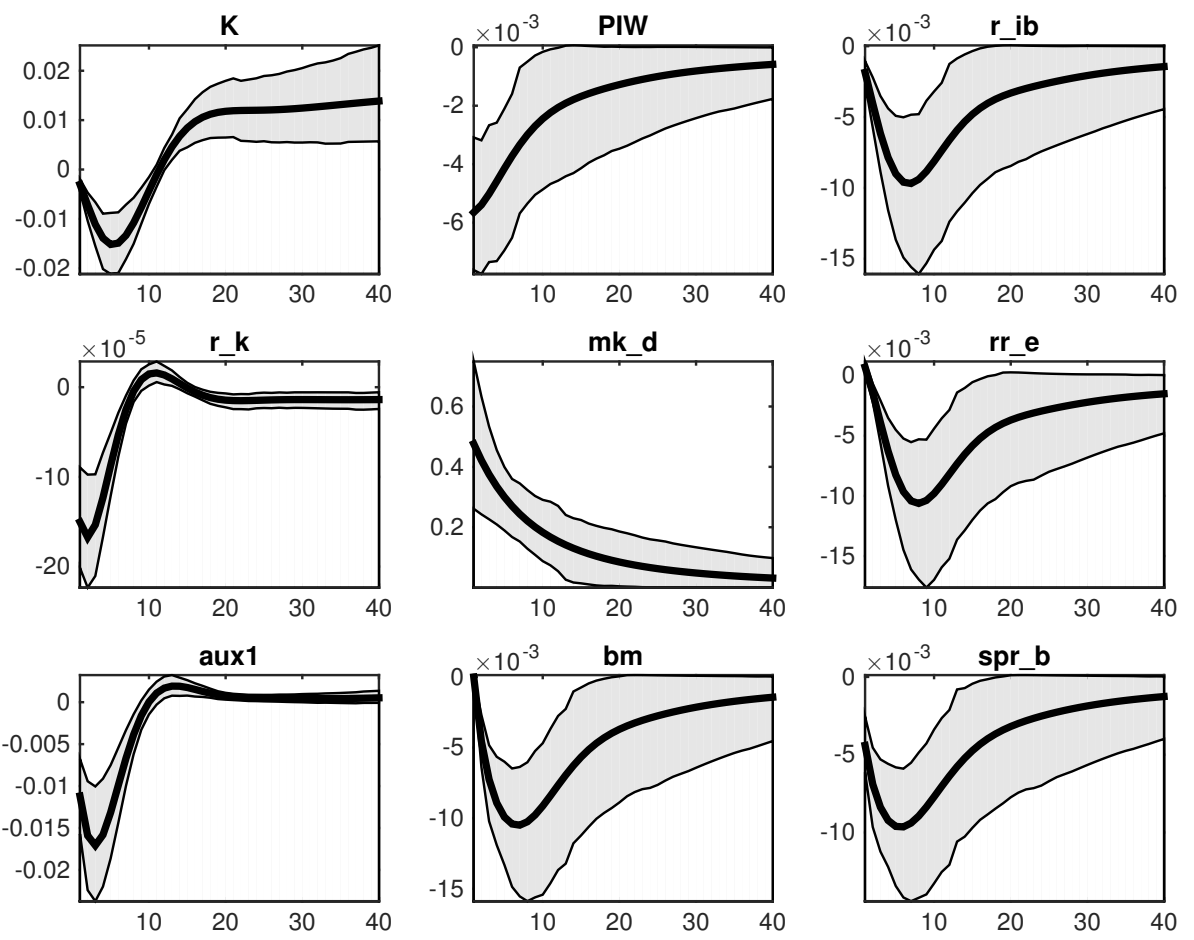

Figura 109: Efeito de um choque em $\mathrm{mk}_{d}$ 

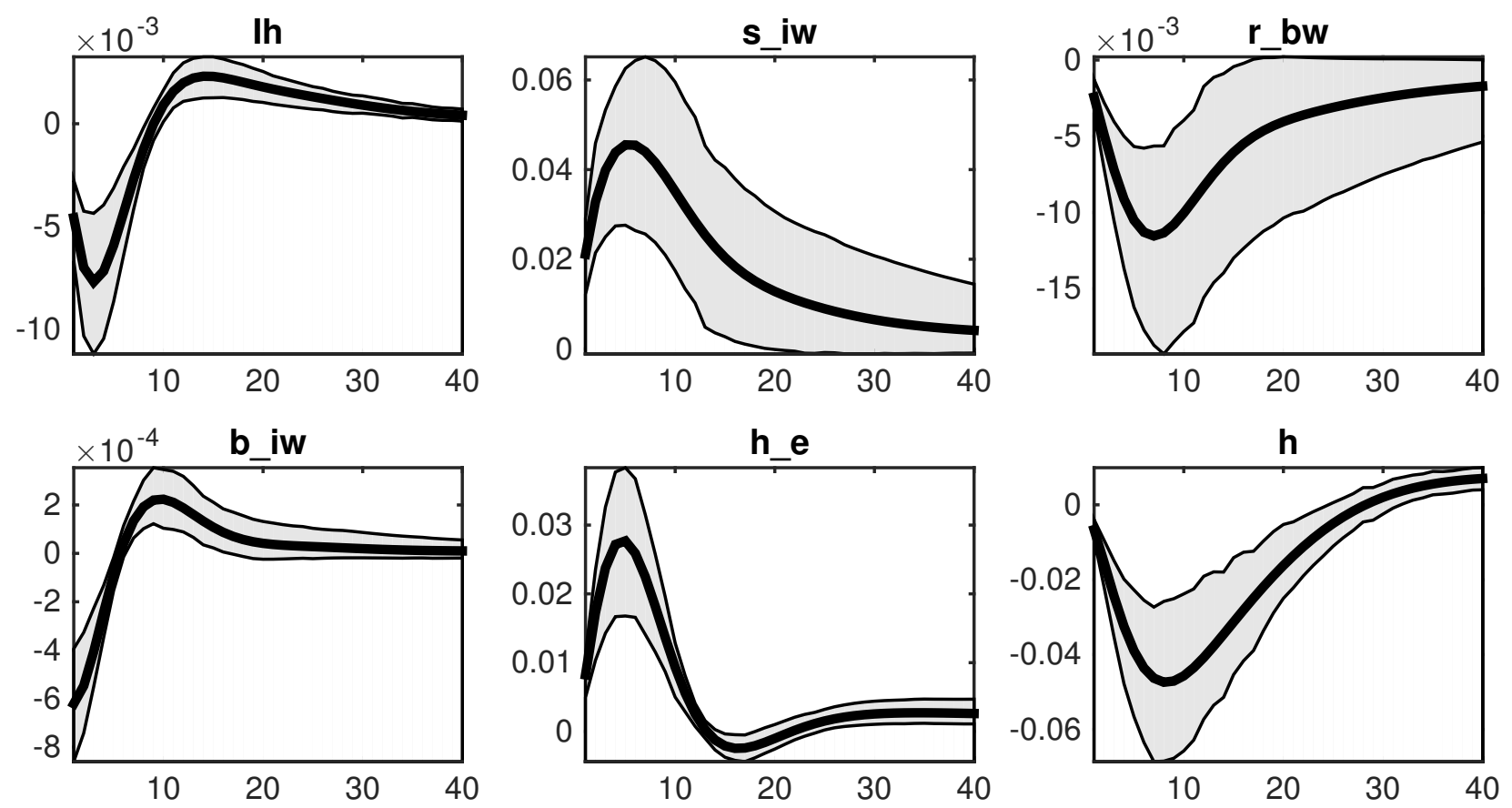

Figura 110: Efeito de um choque em $\mathrm{mk}_{d}$ 
A.13 Choque na Oferta de Capital Físico
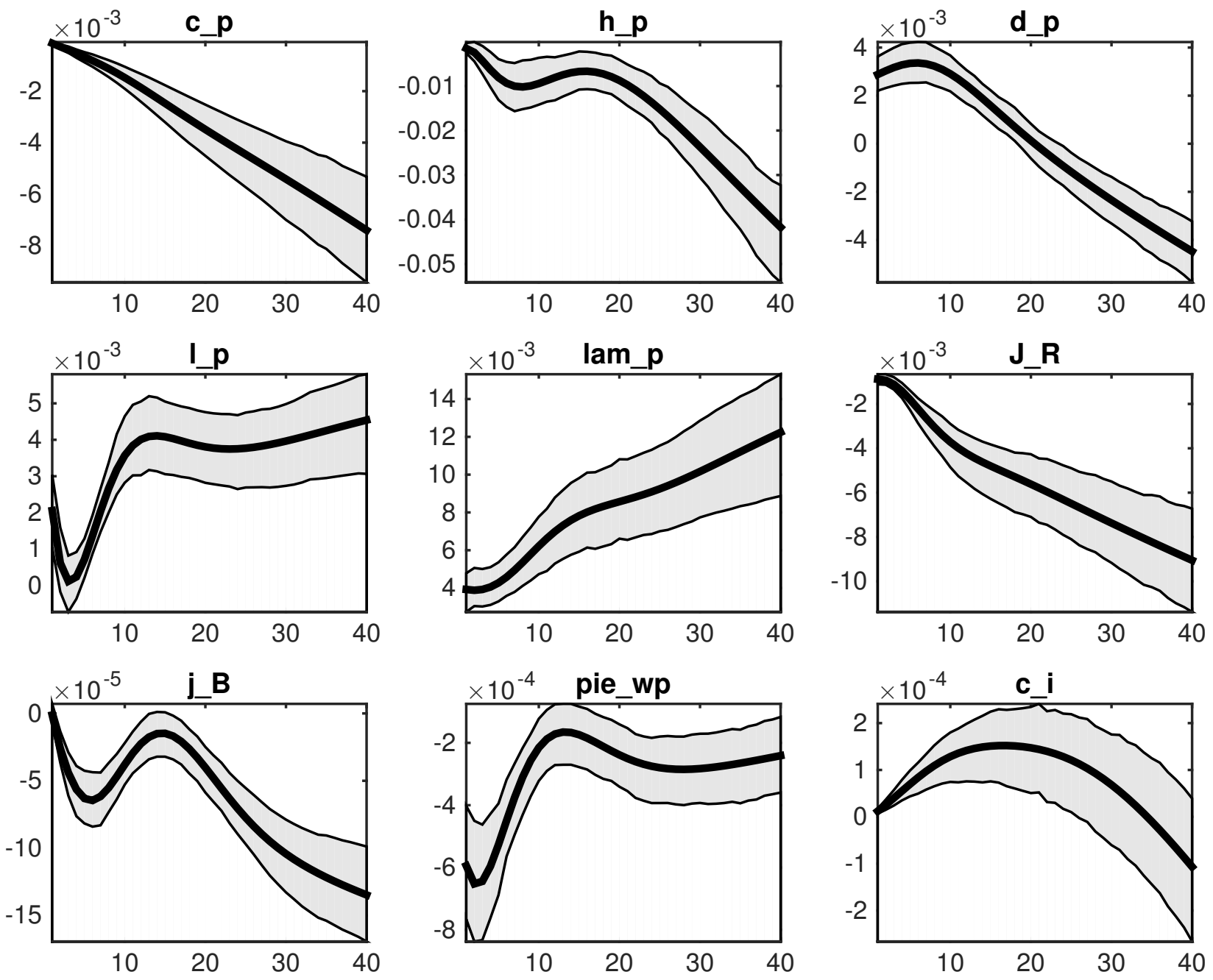

Figura 111: Efeito de um choque em $\mathrm{I}^{k}$ 

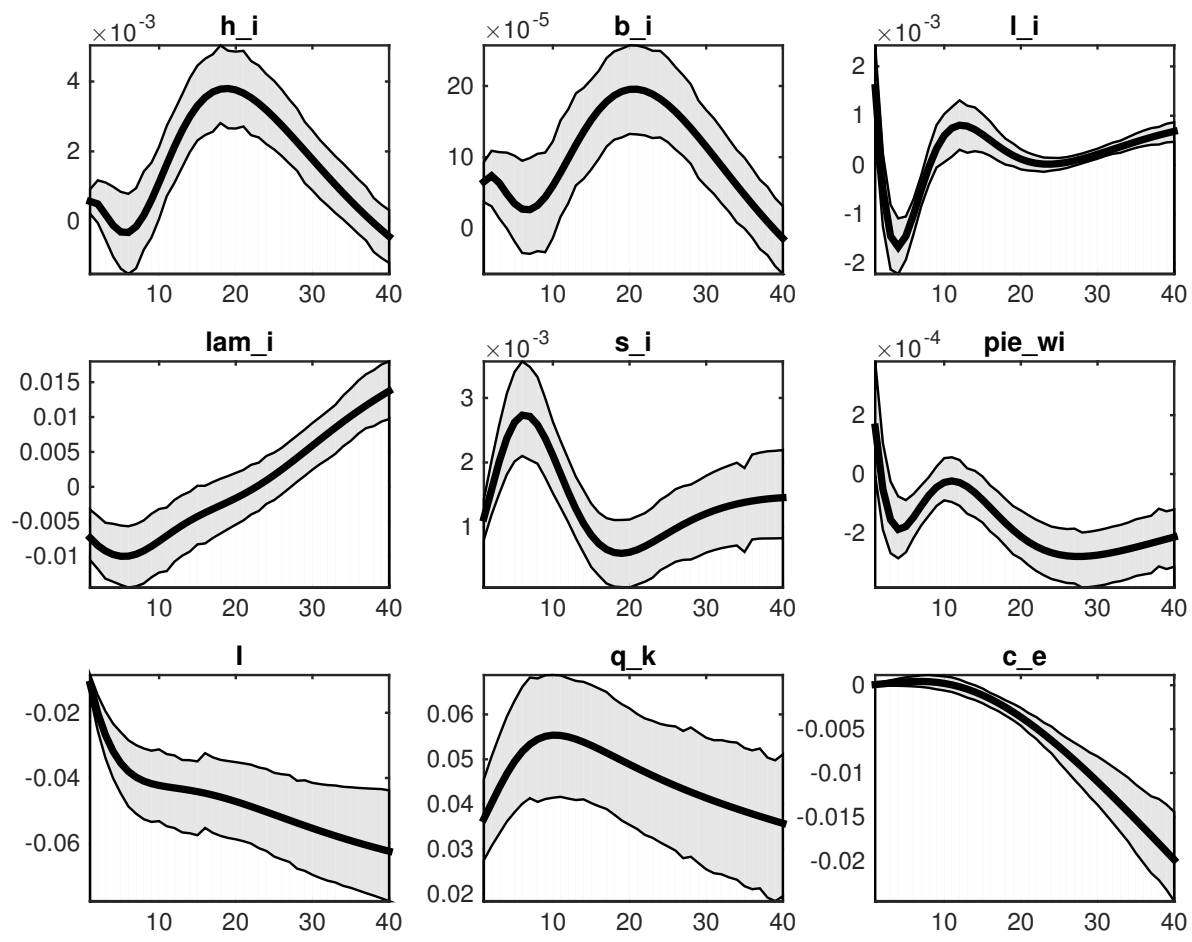

Figura 112: Efeito de um choque em $\mathrm{I}^{k}$
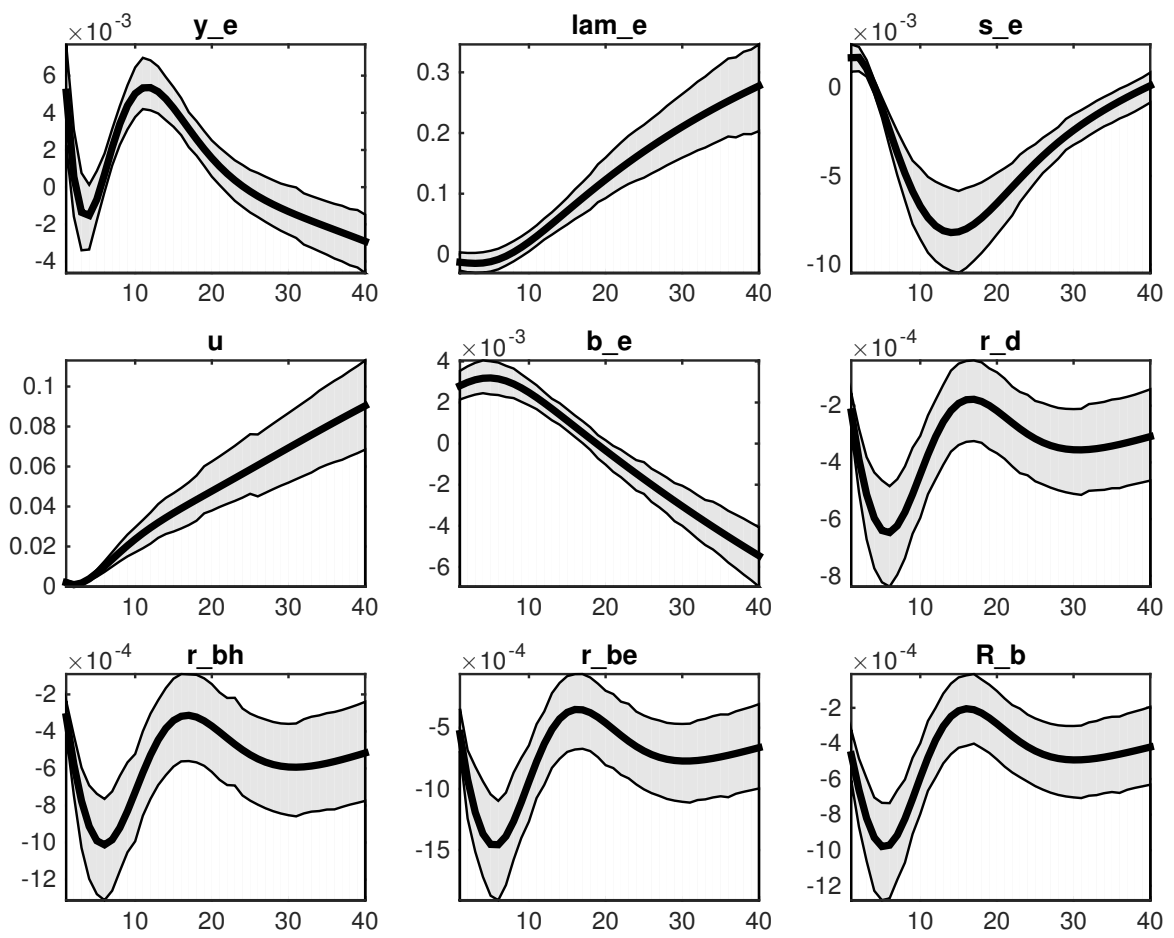

Figura 113: Efeito de um choque em $\mathrm{I}^{k}$ 

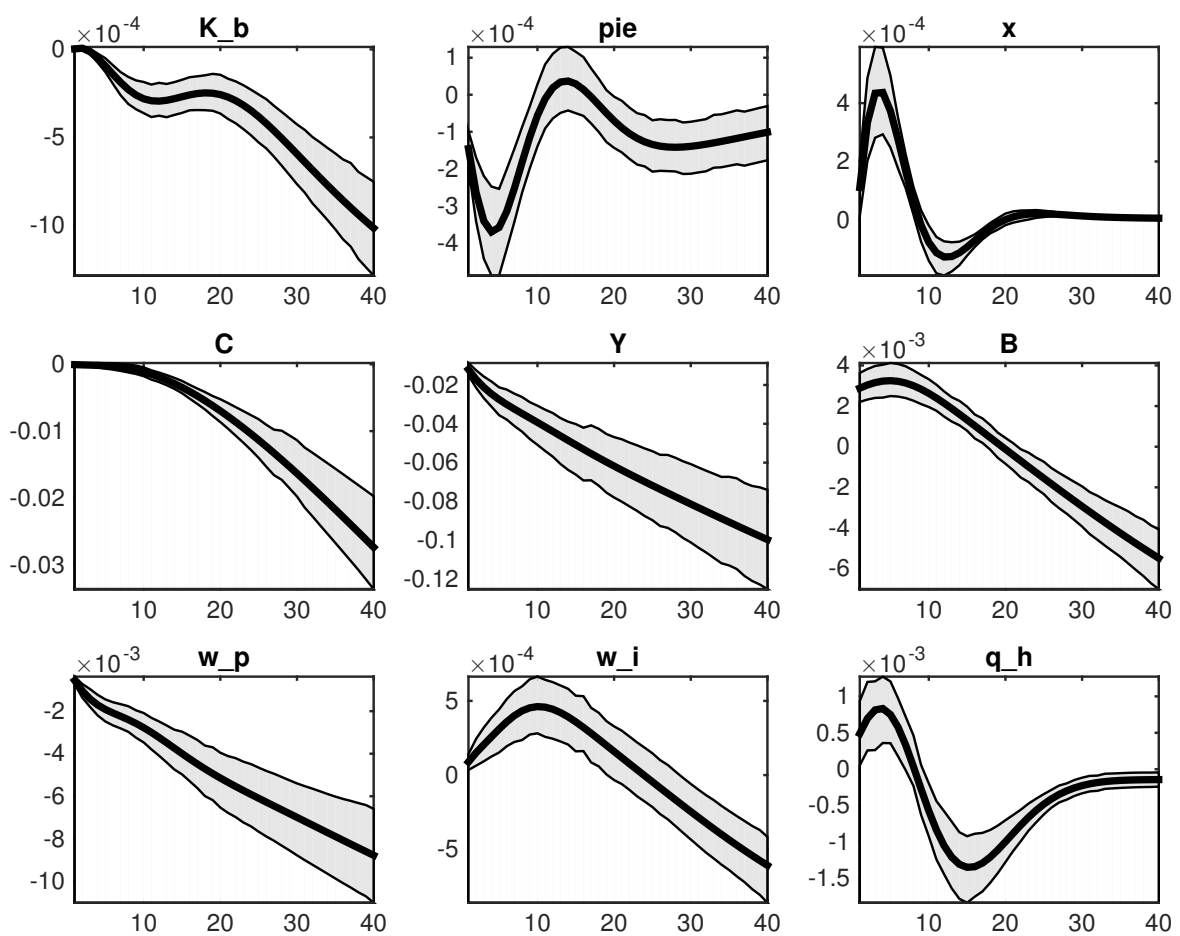

Figura 114: Efeito de um choque em $\mathrm{I}^{k}$
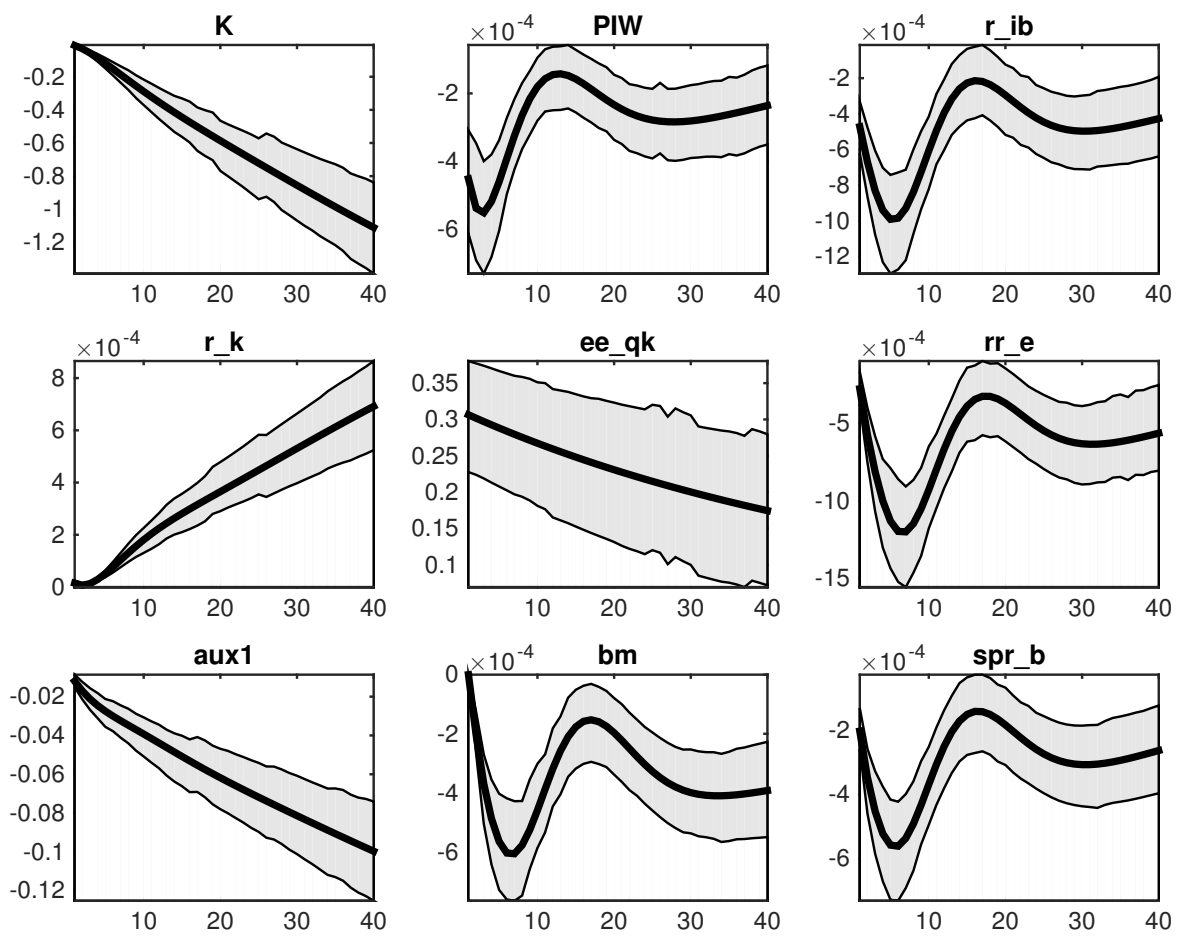

Figura 115: Efeito de um choque em $\mathrm{I}^{k}$ 

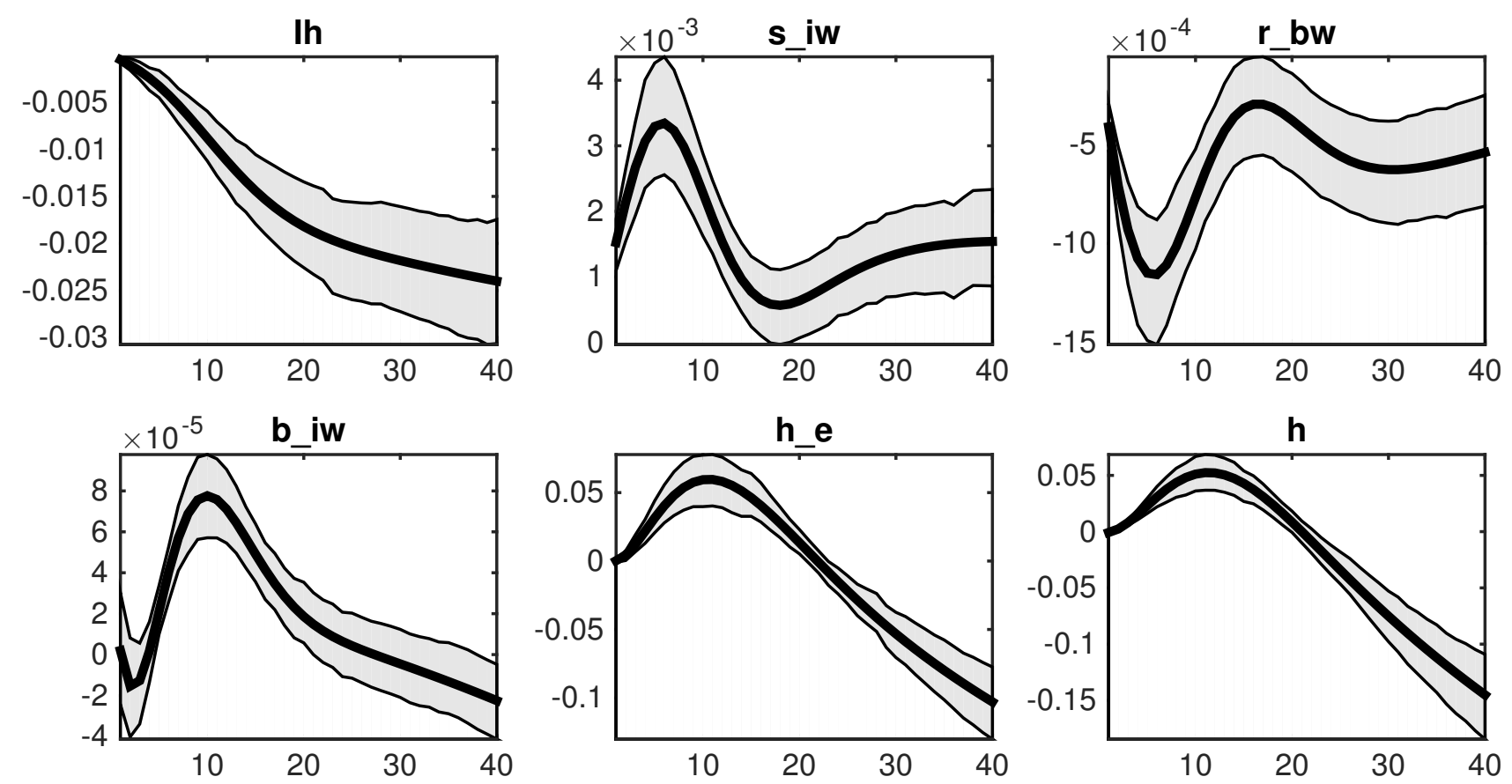

Figura 116: Efeito de um choque em $\mathrm{I}^{k}$ 
A.14 Choque de política monetária
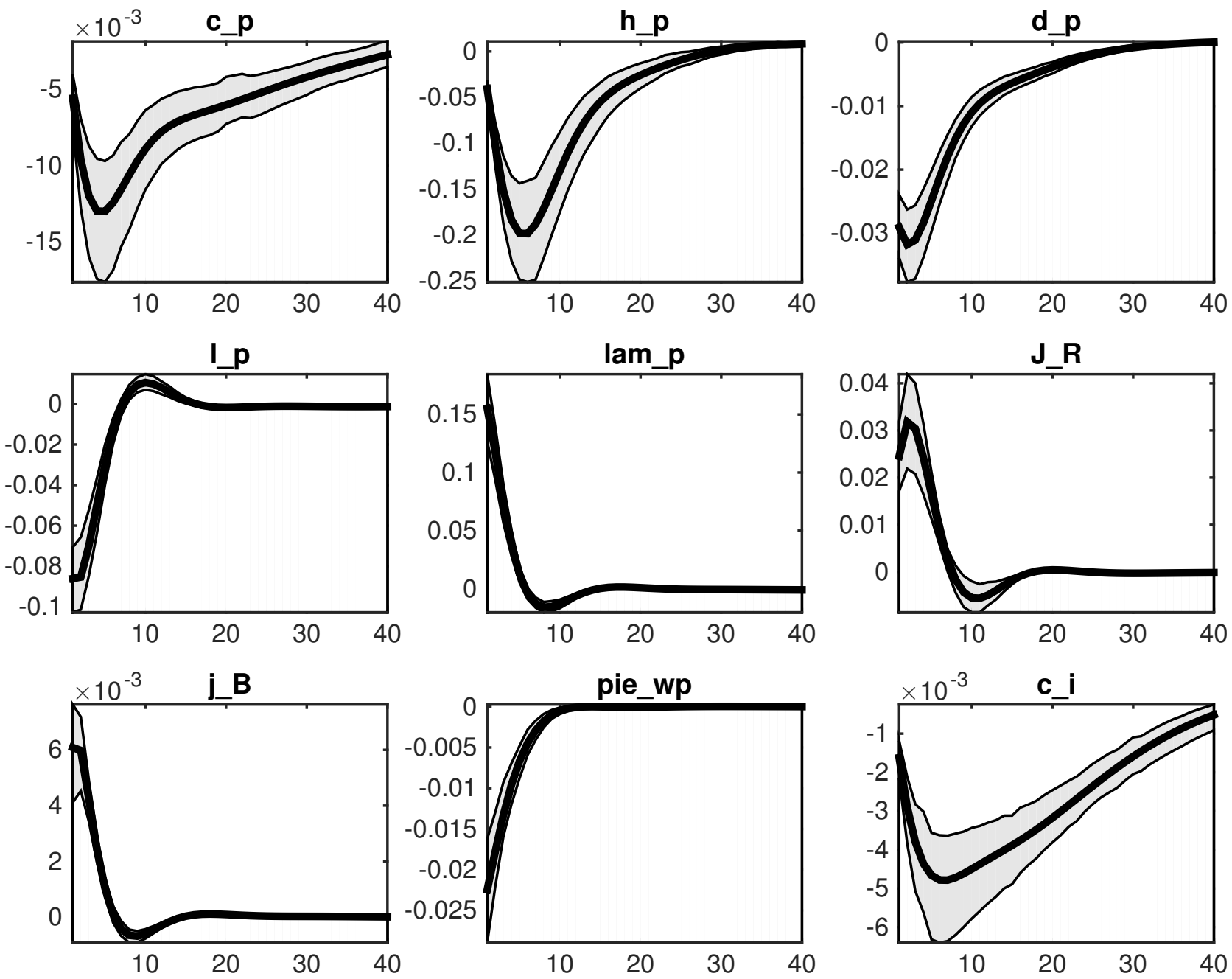

Figura 117: Efeito de um choque de PM 

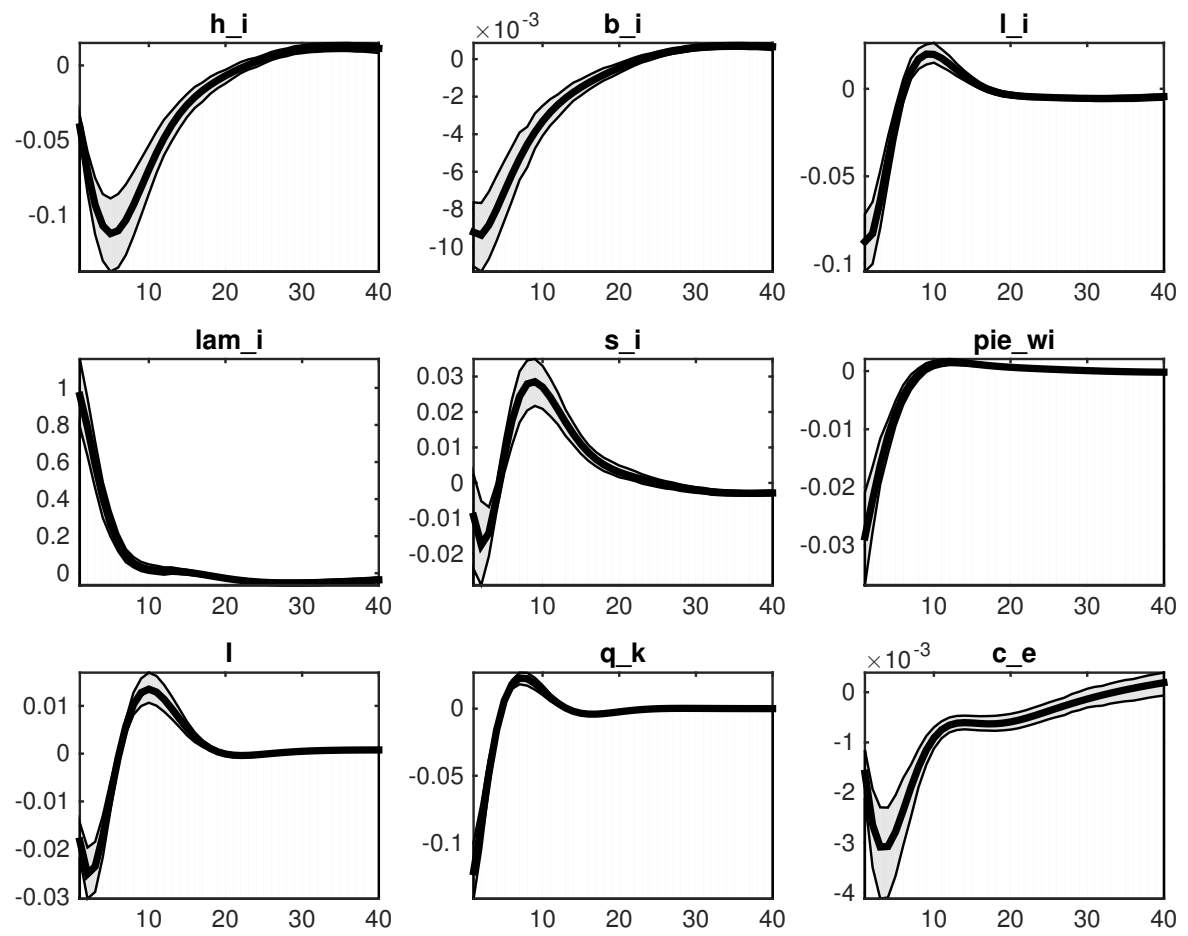

Figura 118: Efeito de um choque de PM
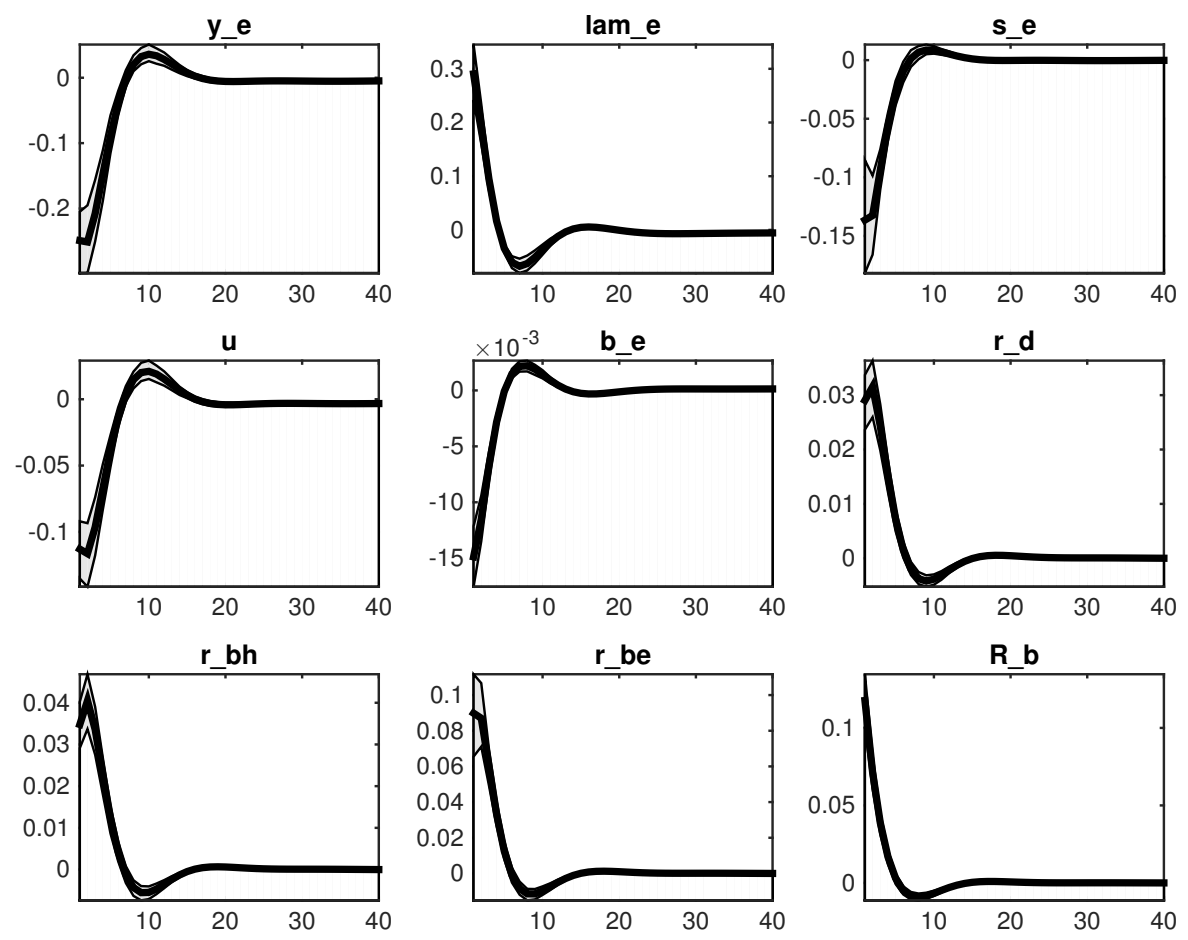

Figura 119: Efeito de um choque de PM 

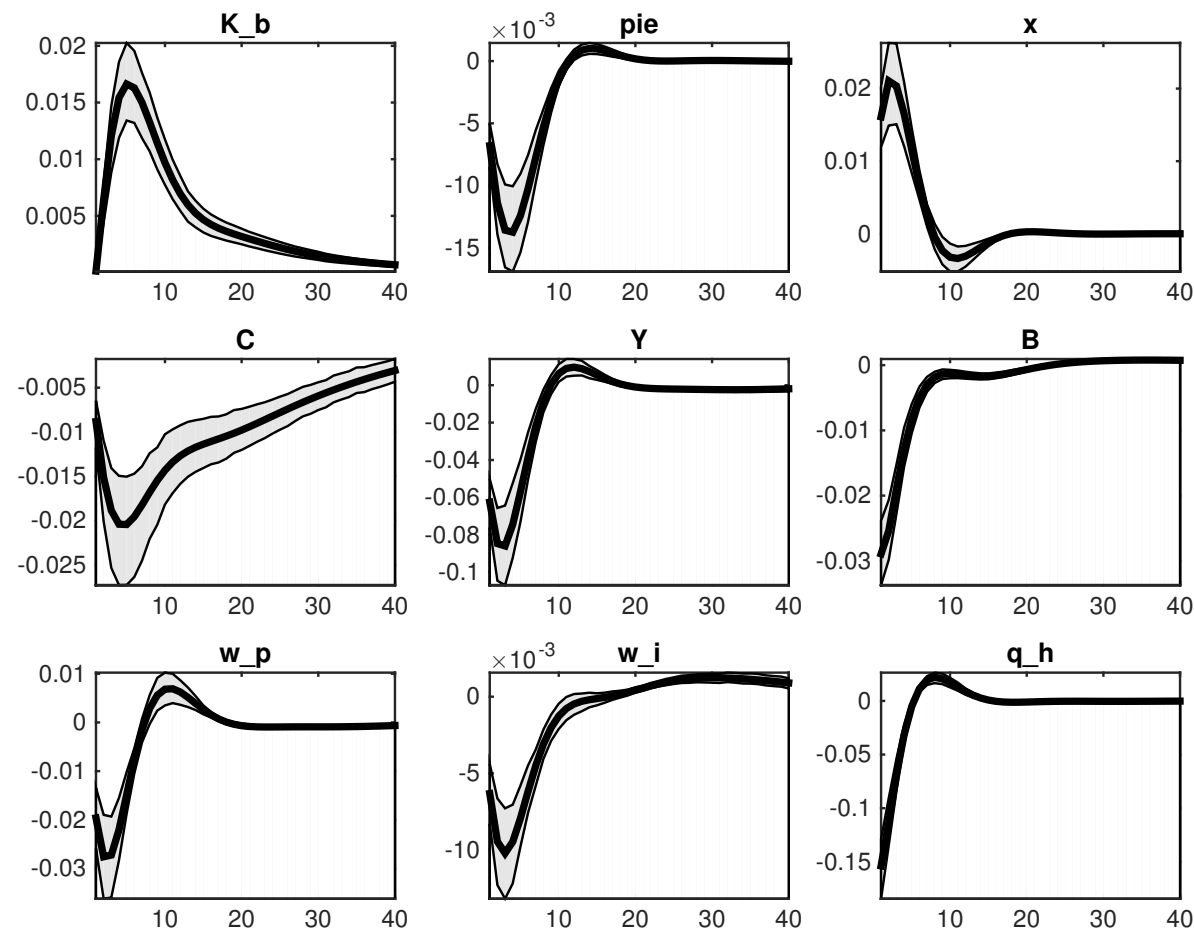

Figura 120: Efeito de um choque de PM
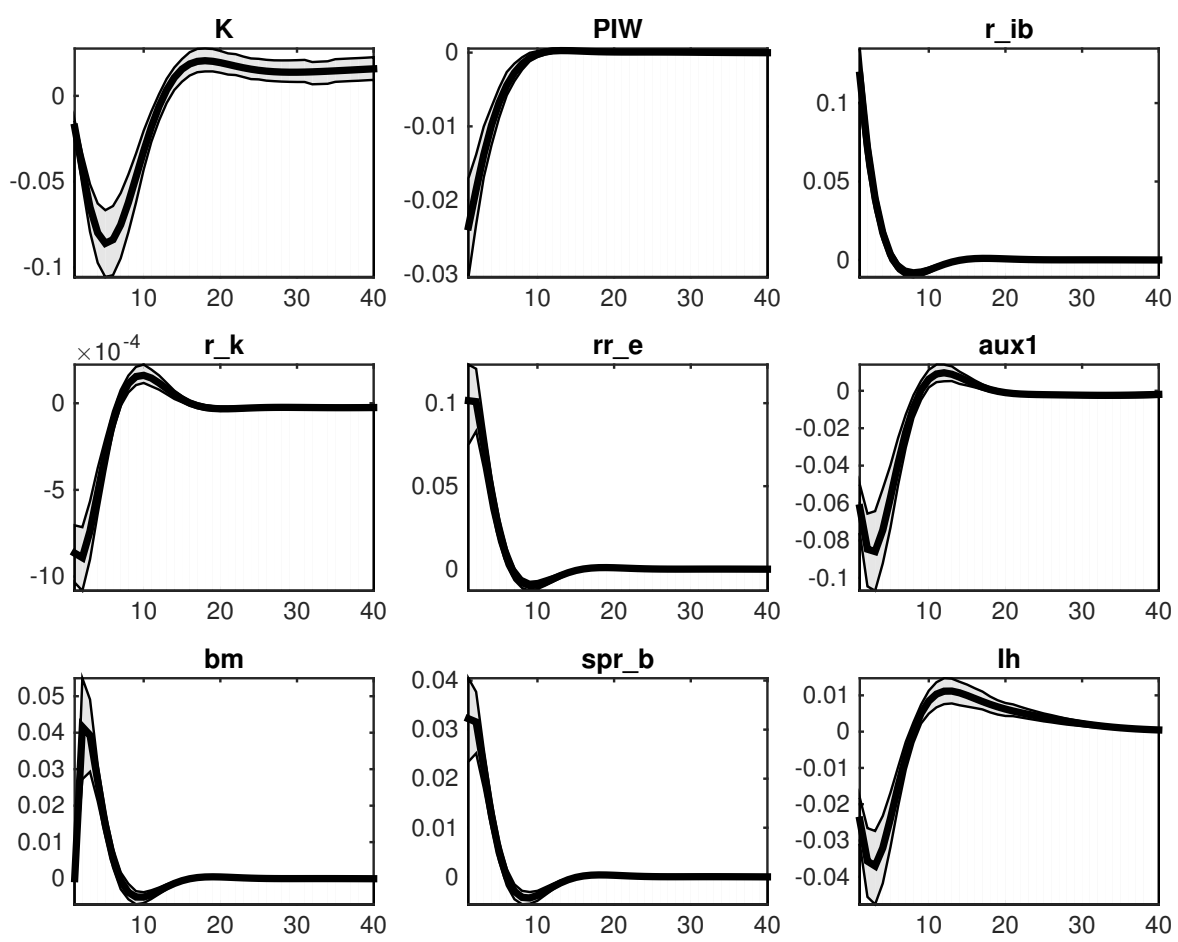

Figura 121: Efeito de um choque de PM 

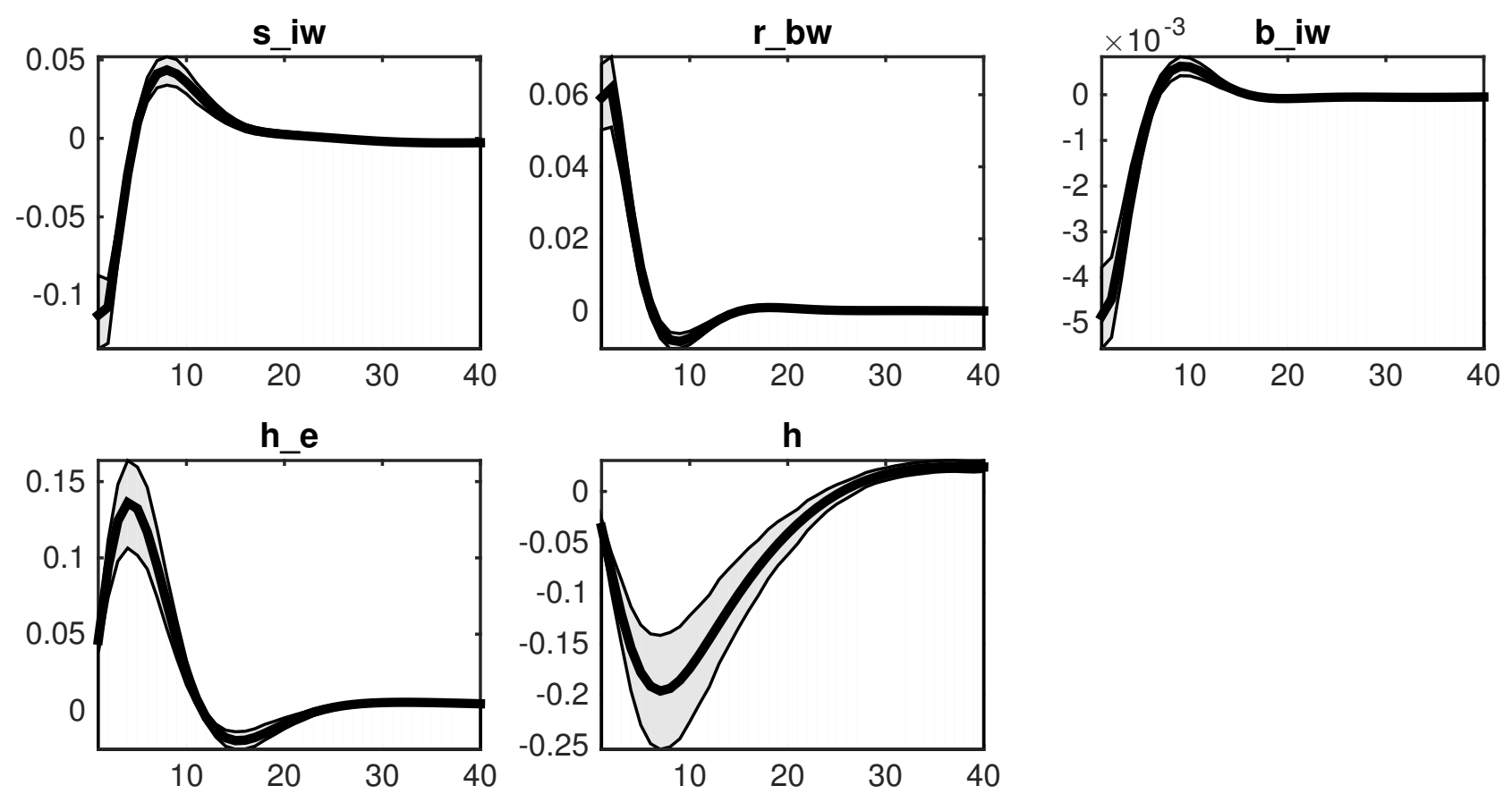

Figura 122: Efeito de um choque de PM 
A.15 Choque no Mark-up de preços
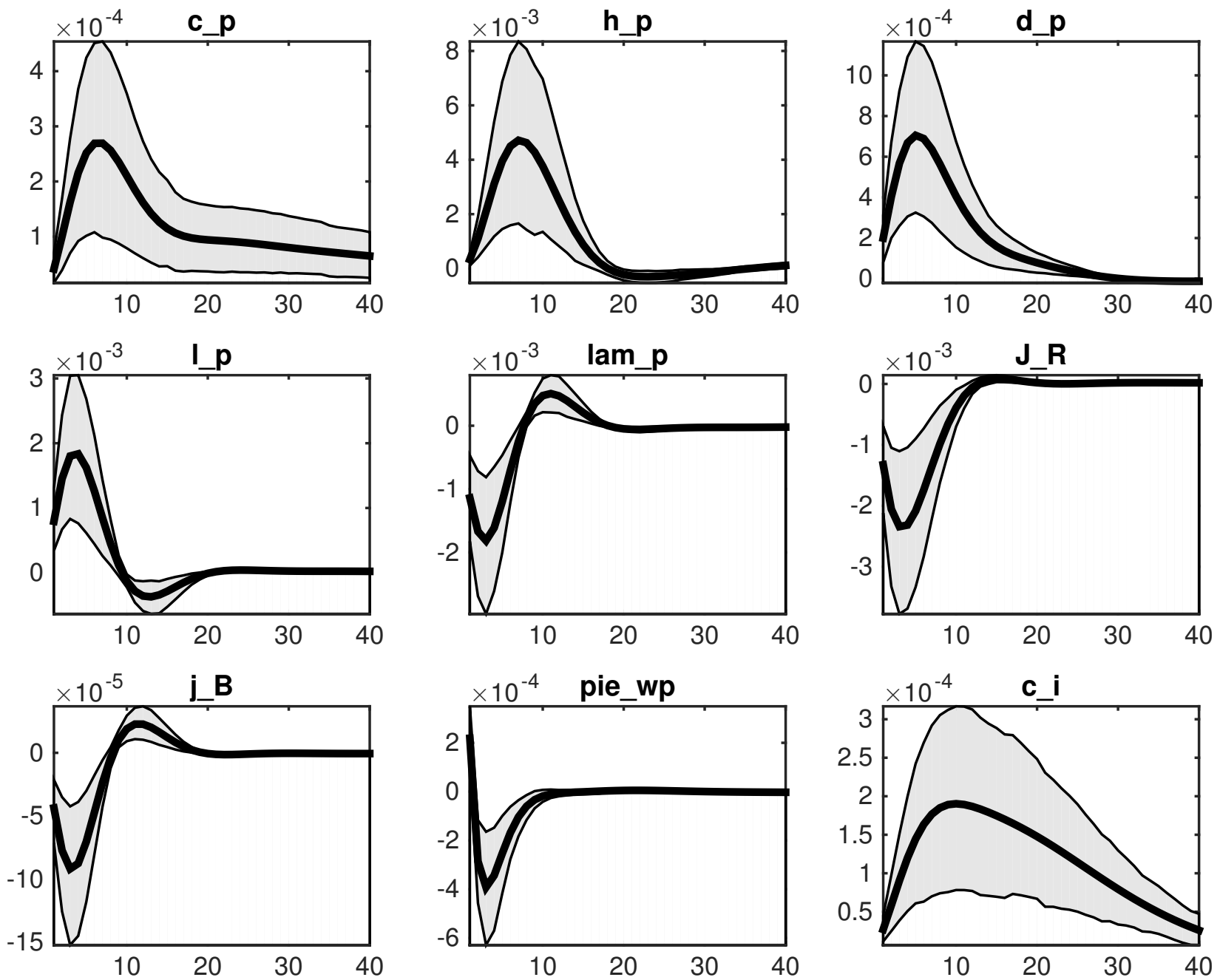

Figura 123: Efeito de um choque no mark-up de preços 

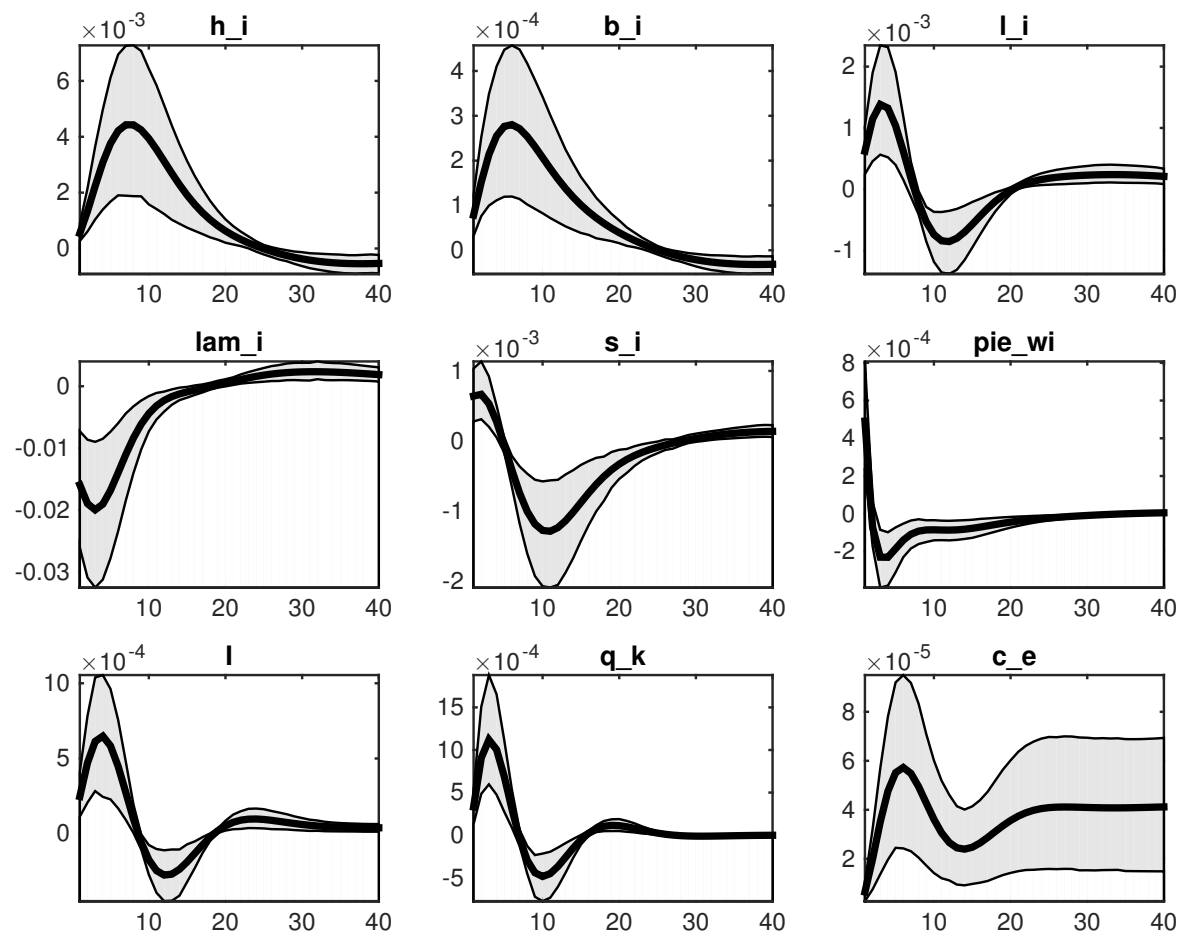

Figura 124: Efeito de um choque no mark-up de preços
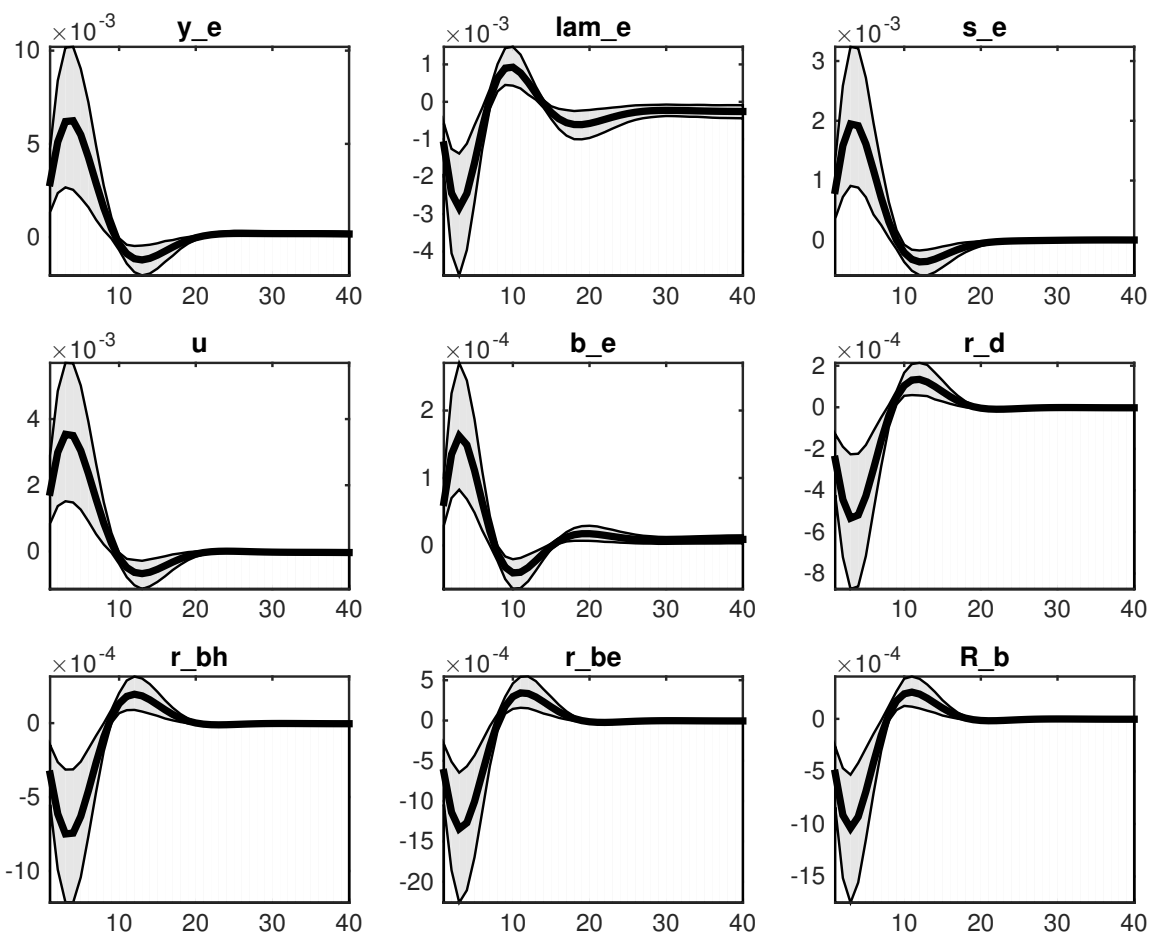

Figura 125: Efeito de um choque no mark-up de preços 

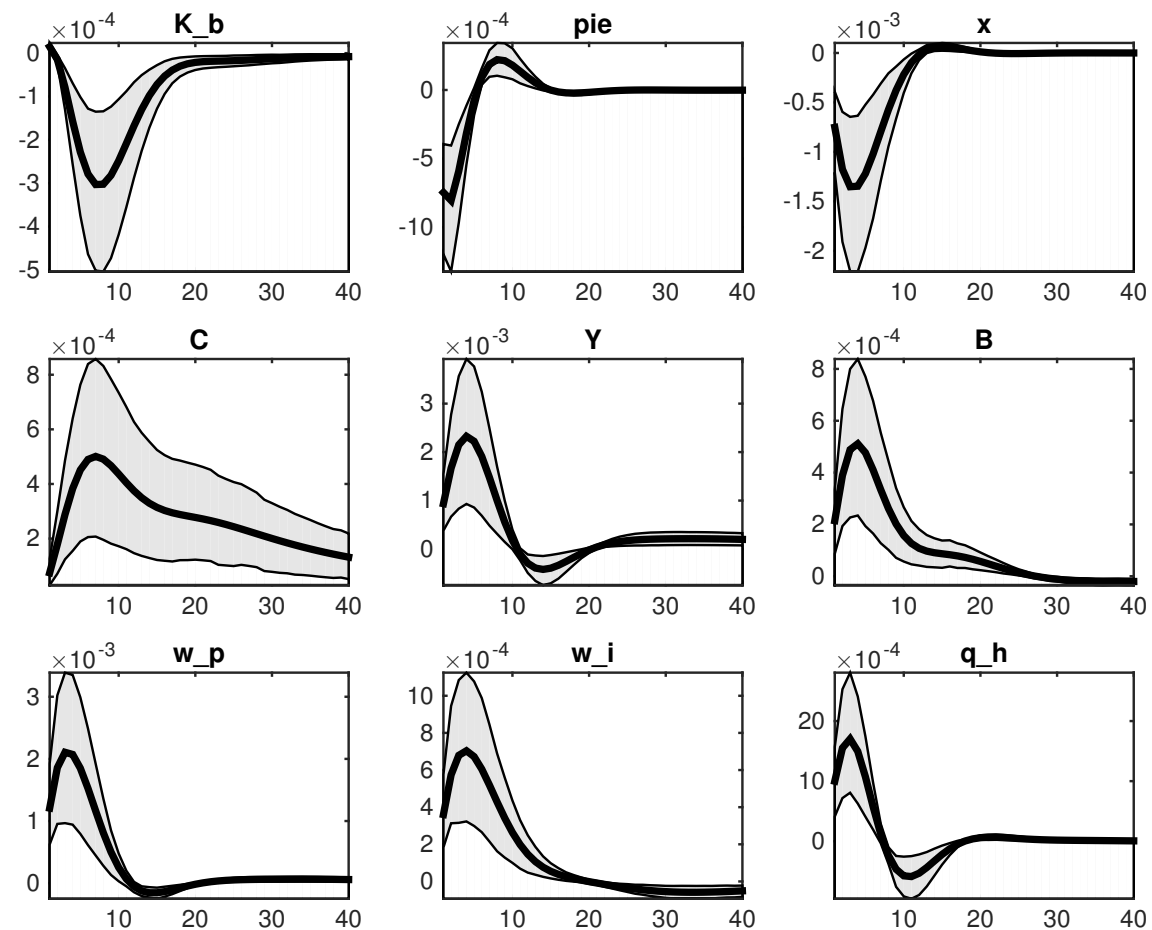

Figura 126: Efeito de um choque no mark-up de preços
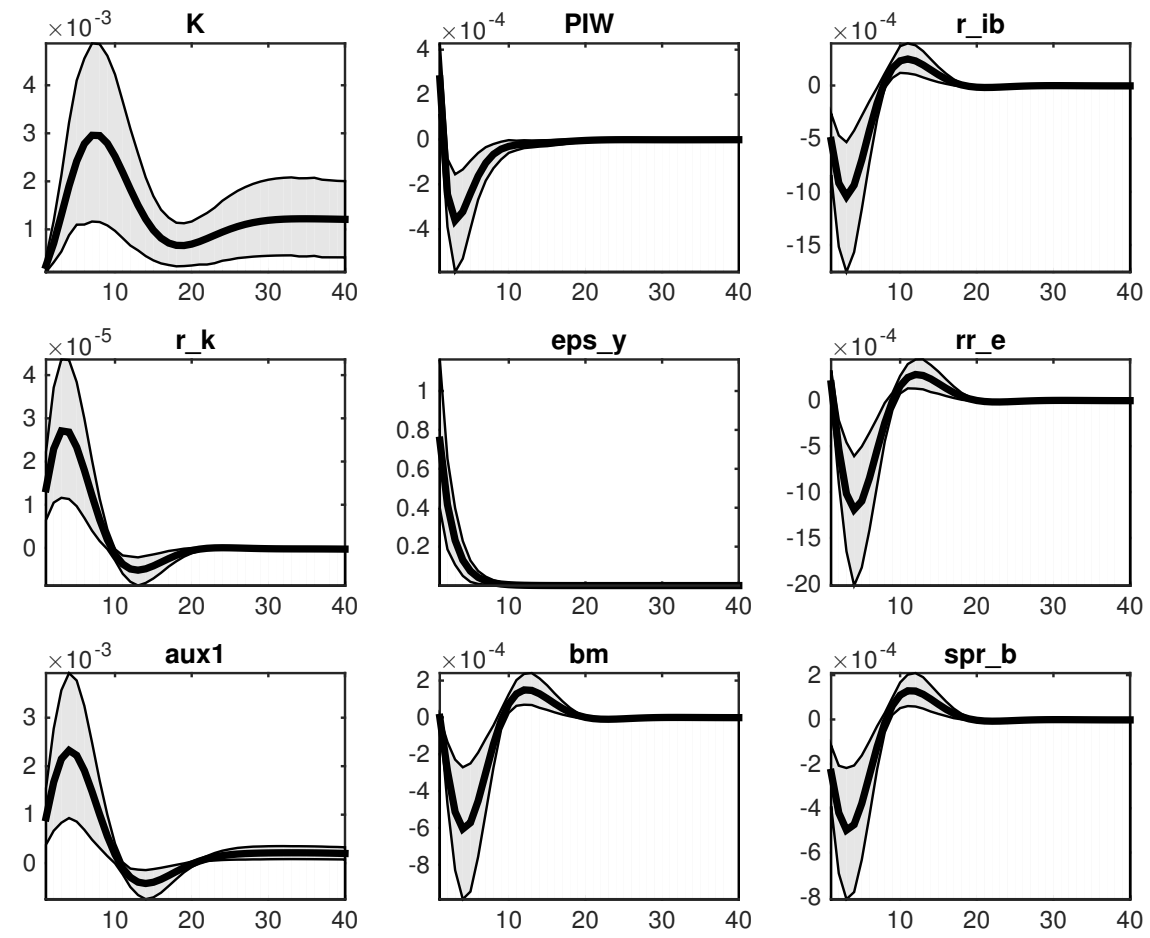

Figura 127: Efeito de um choque no mark-up de preços 

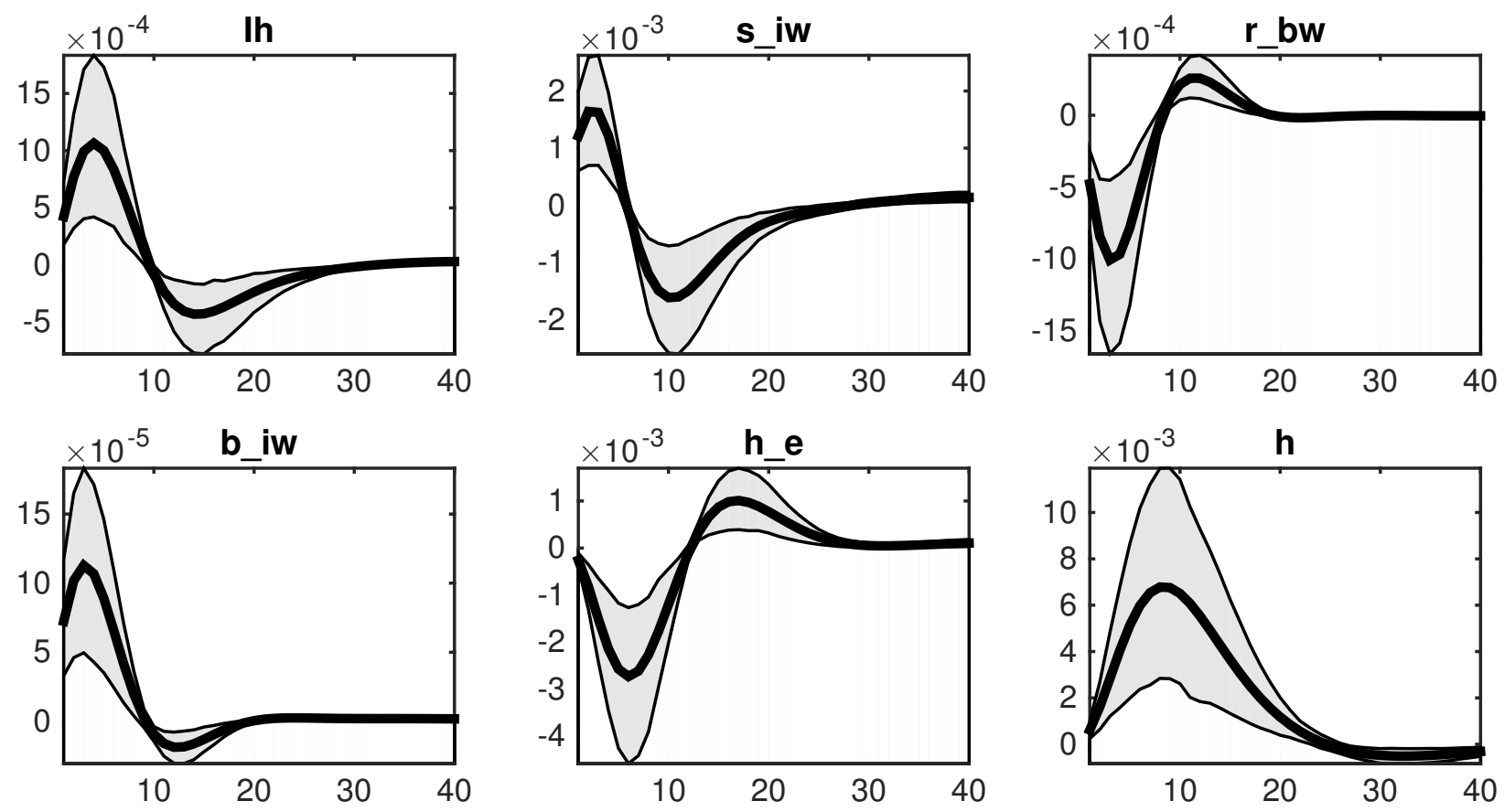

Figura 128: Efeito de um choque no mark-up de preços 
A.16 Choque na demanda por consumo
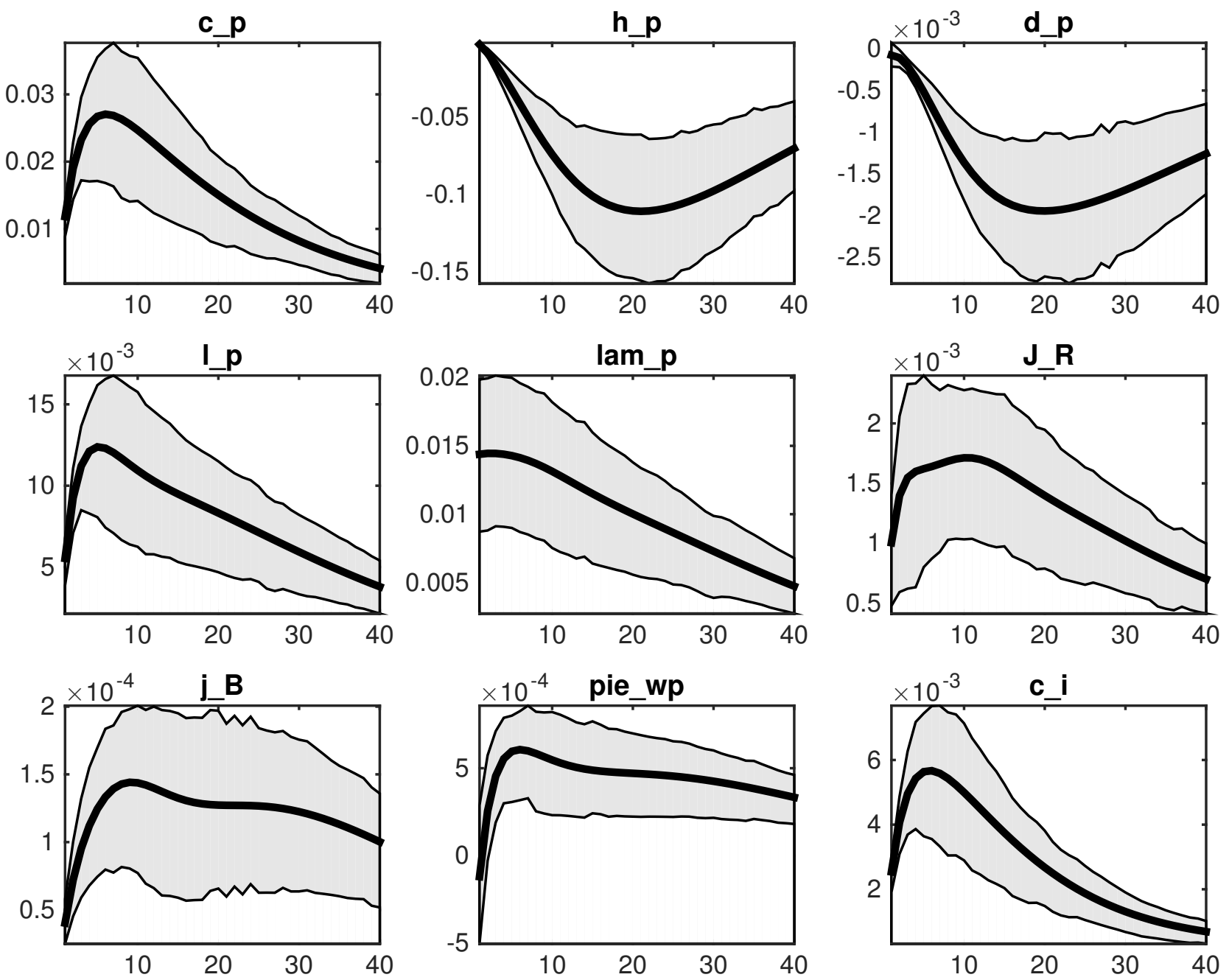

Figura 129: Efeito de um choque na demanda por consumo 

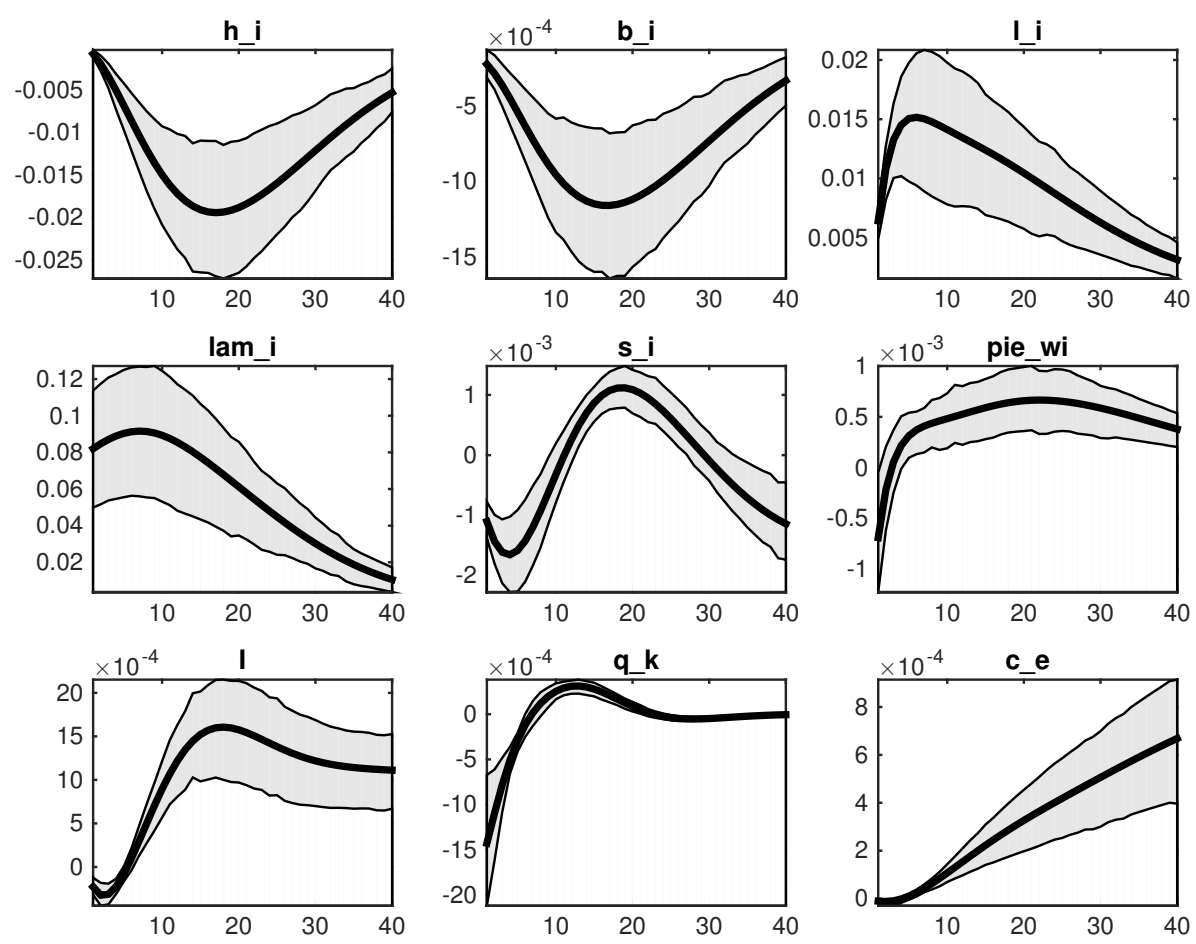

Figura 130: Efeito de um choque na demanda por consumo
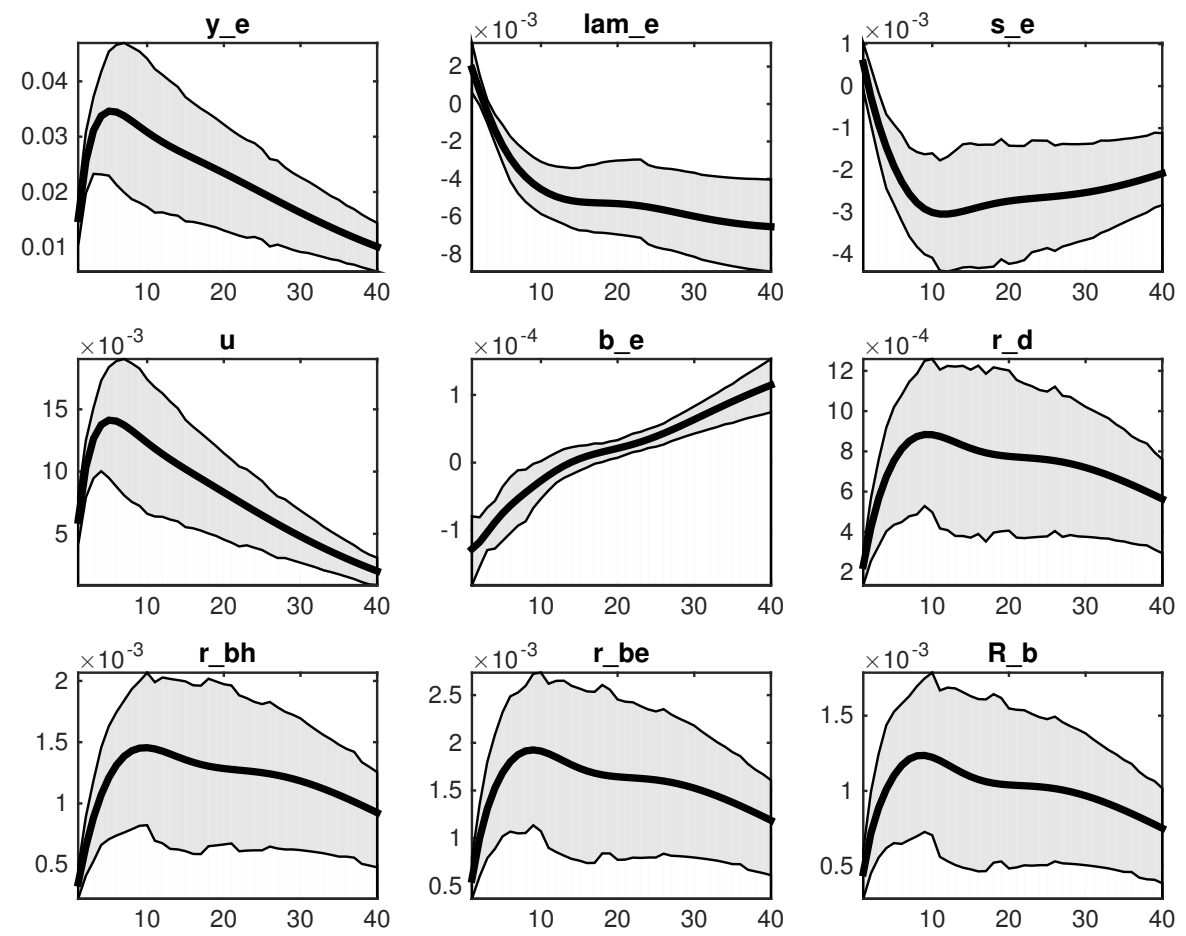

Figura 131: Efeito de um choque na demanda por consumo 

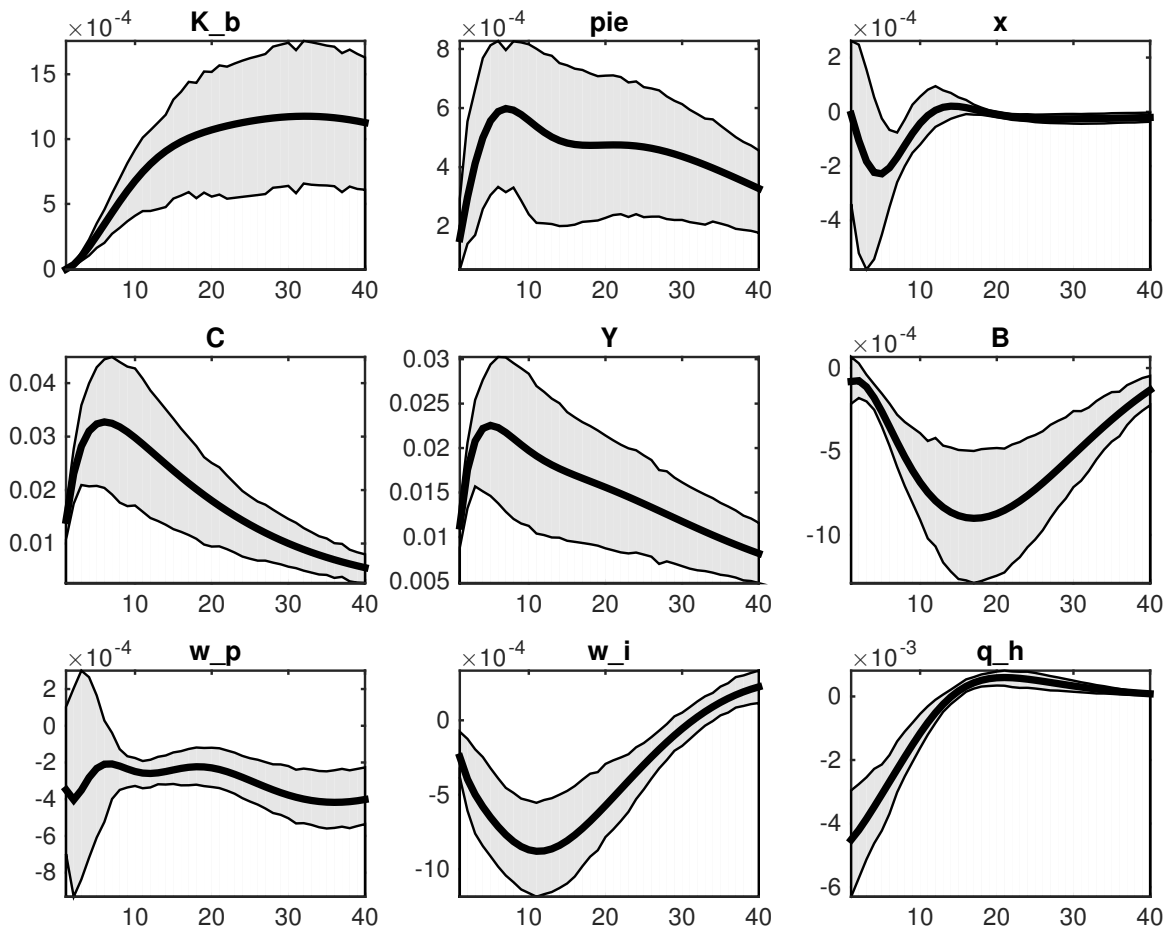

Figura 132: Efeito de um choque na demanda por consumo
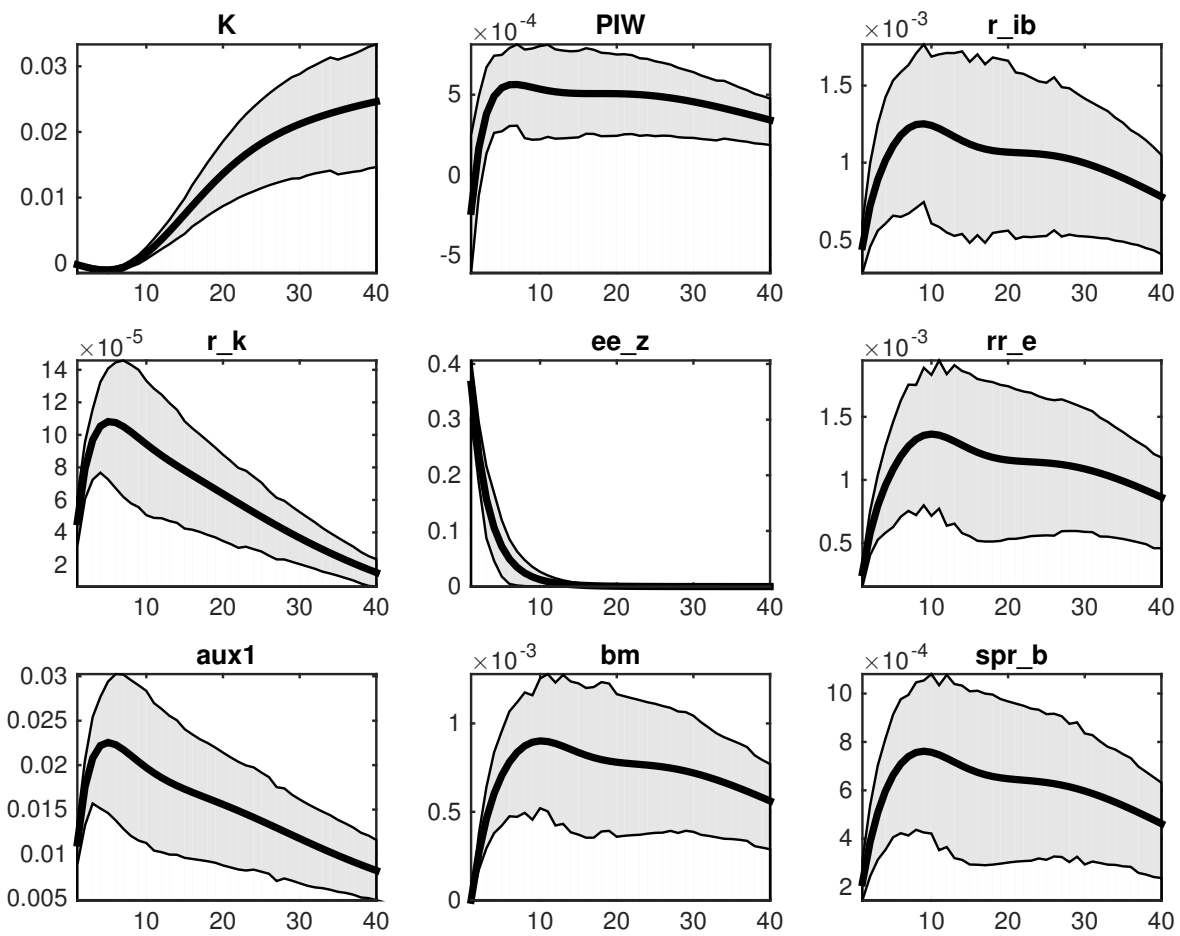

Figura 133: Efeito de um choque na demanda por consumo 

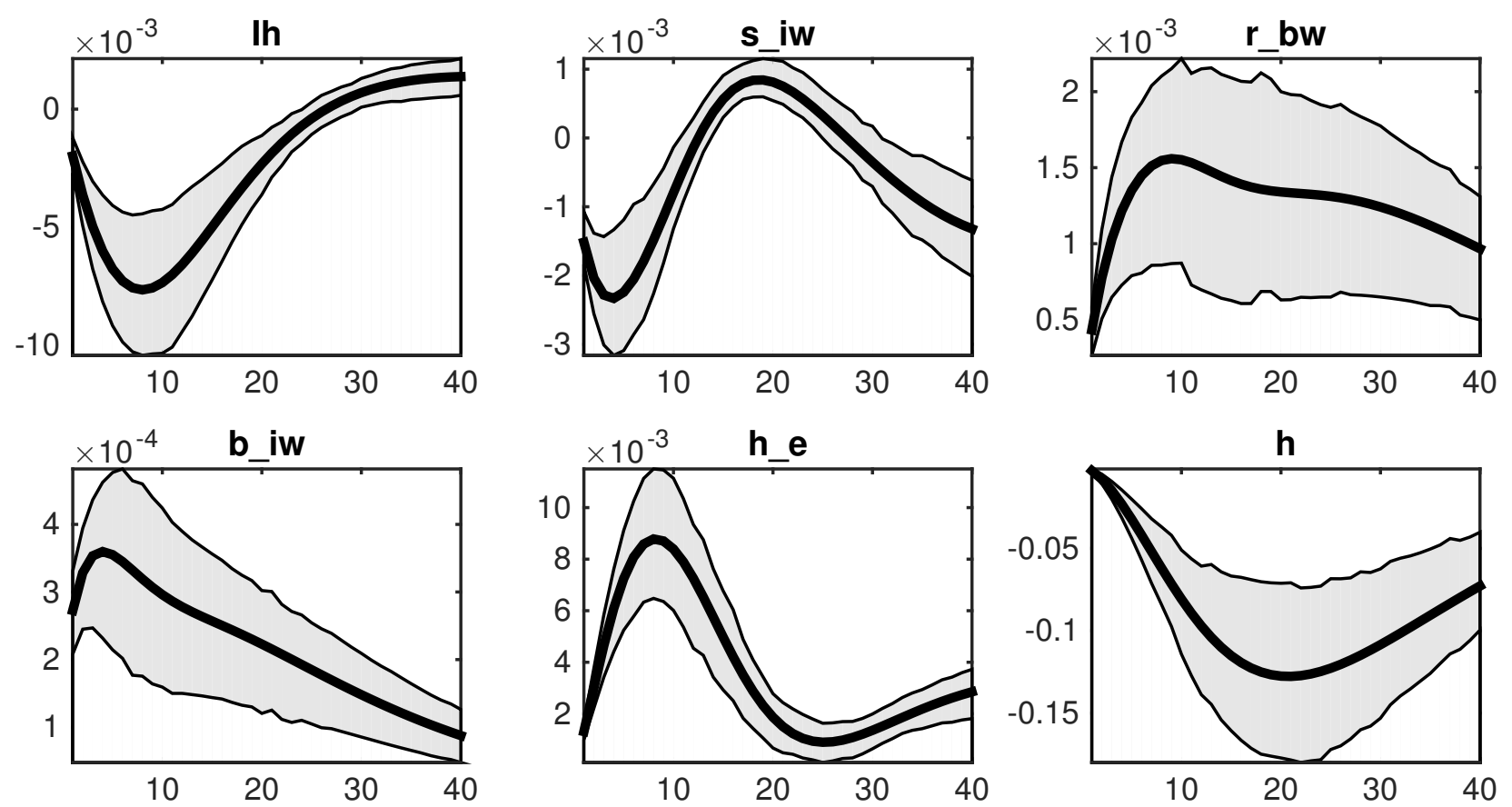

Figura 134: Efeito de um choque na demanda por consumo 
APÊNDICE B - Funções de Resposta ao Impulso para Economia Aberta

B.1 Choque na inflação externa
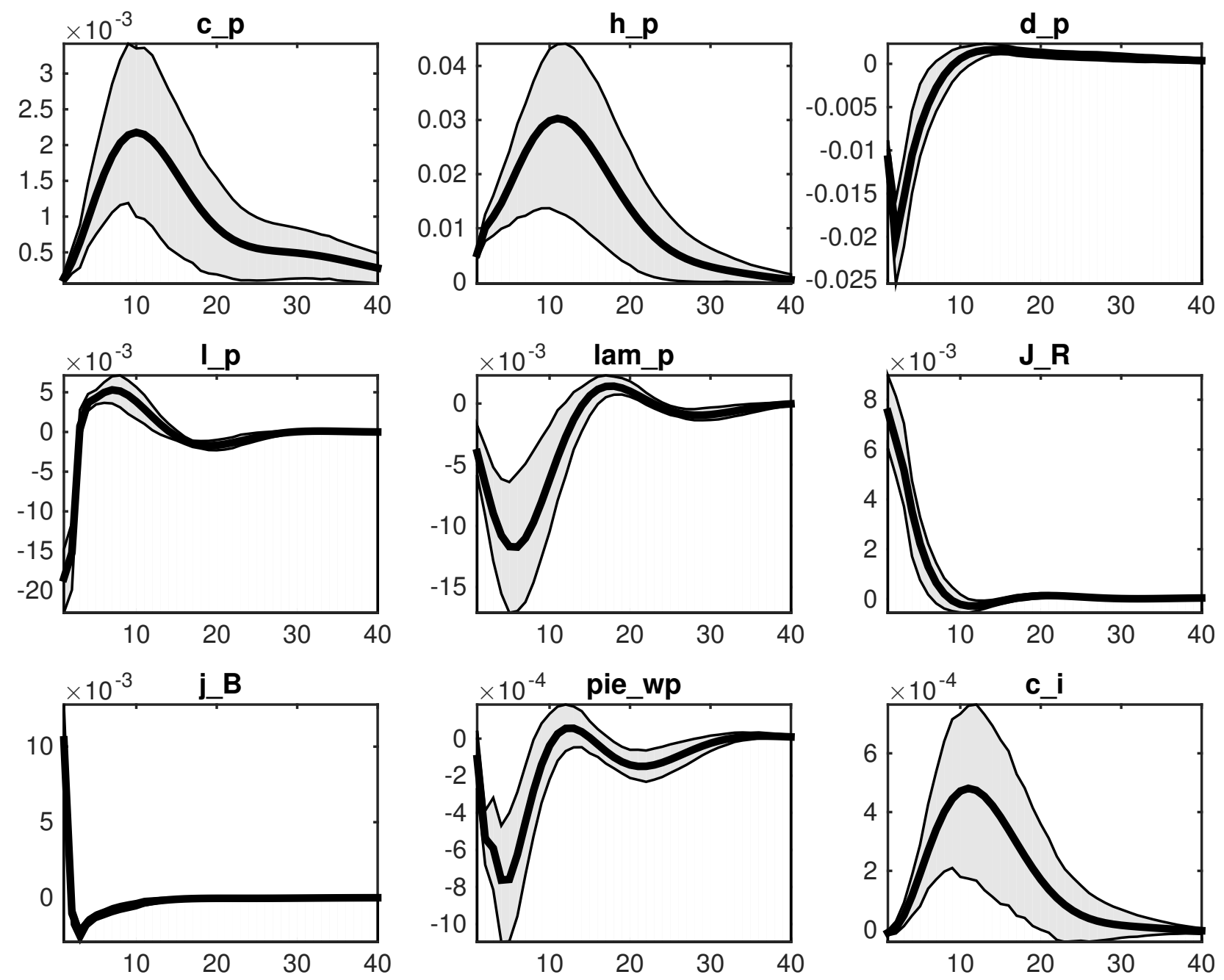

Figura 135: Efeito de um choque em $\pi^{*}$ 

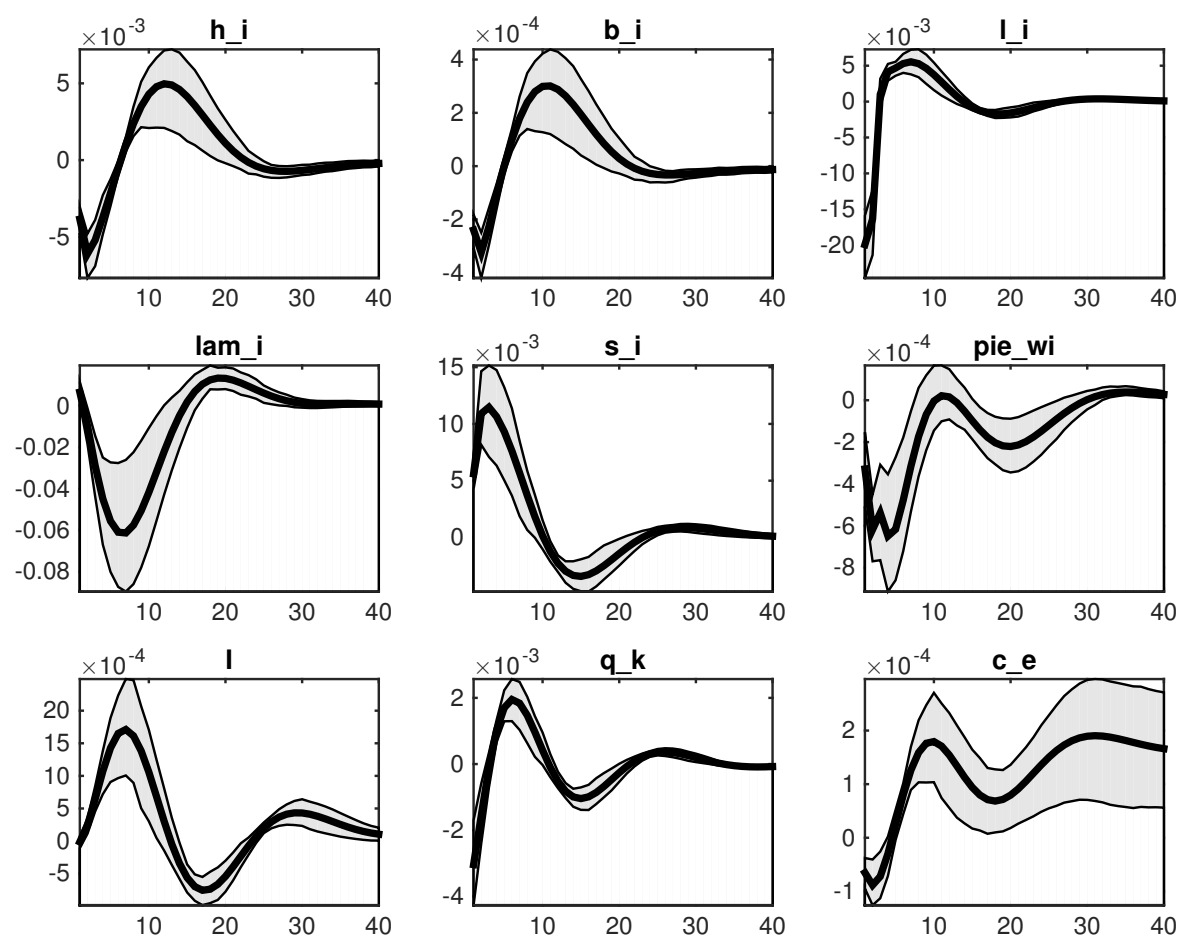

Figura 136: Efeito de um choque em $\pi^{*}$
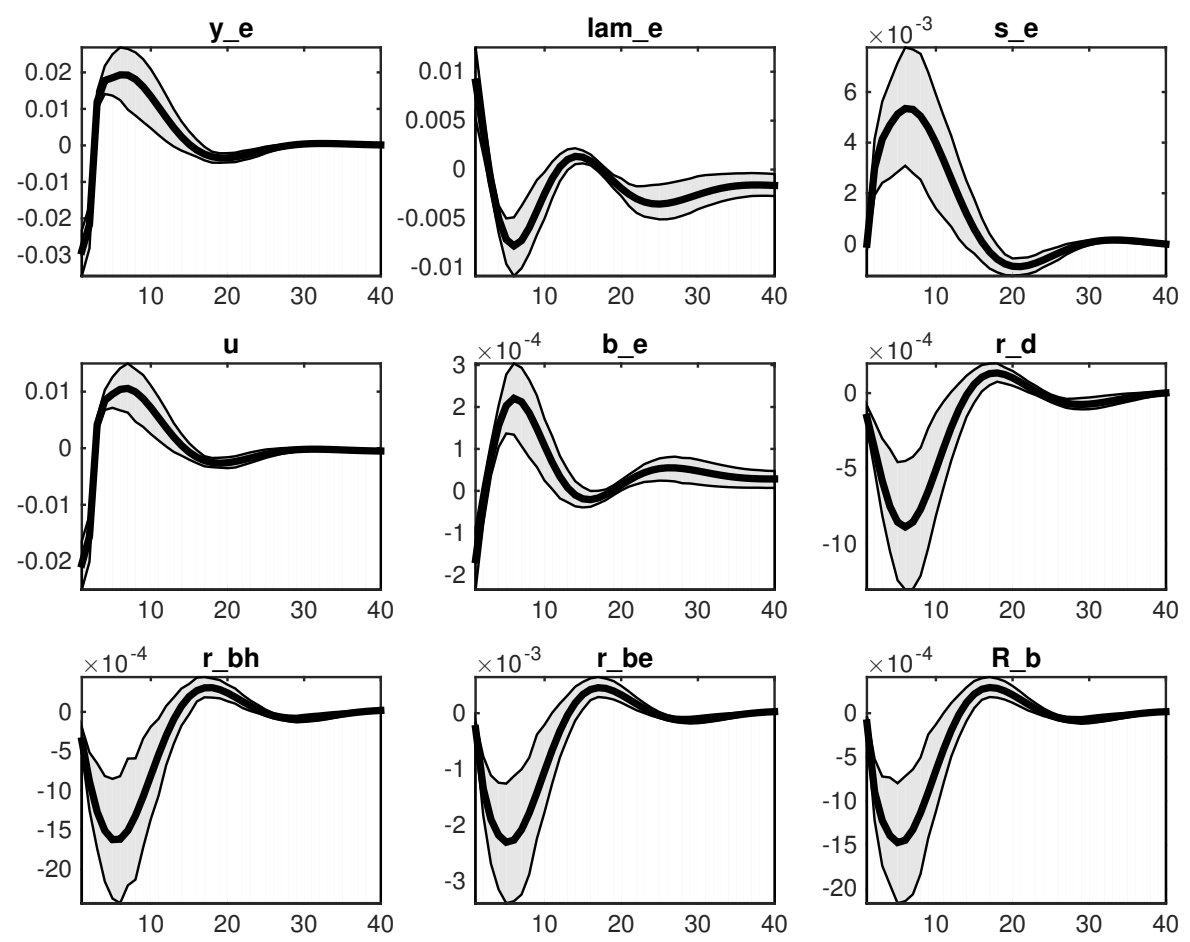

Figura 137: Efeito de um choque em $\pi^{*}$ 

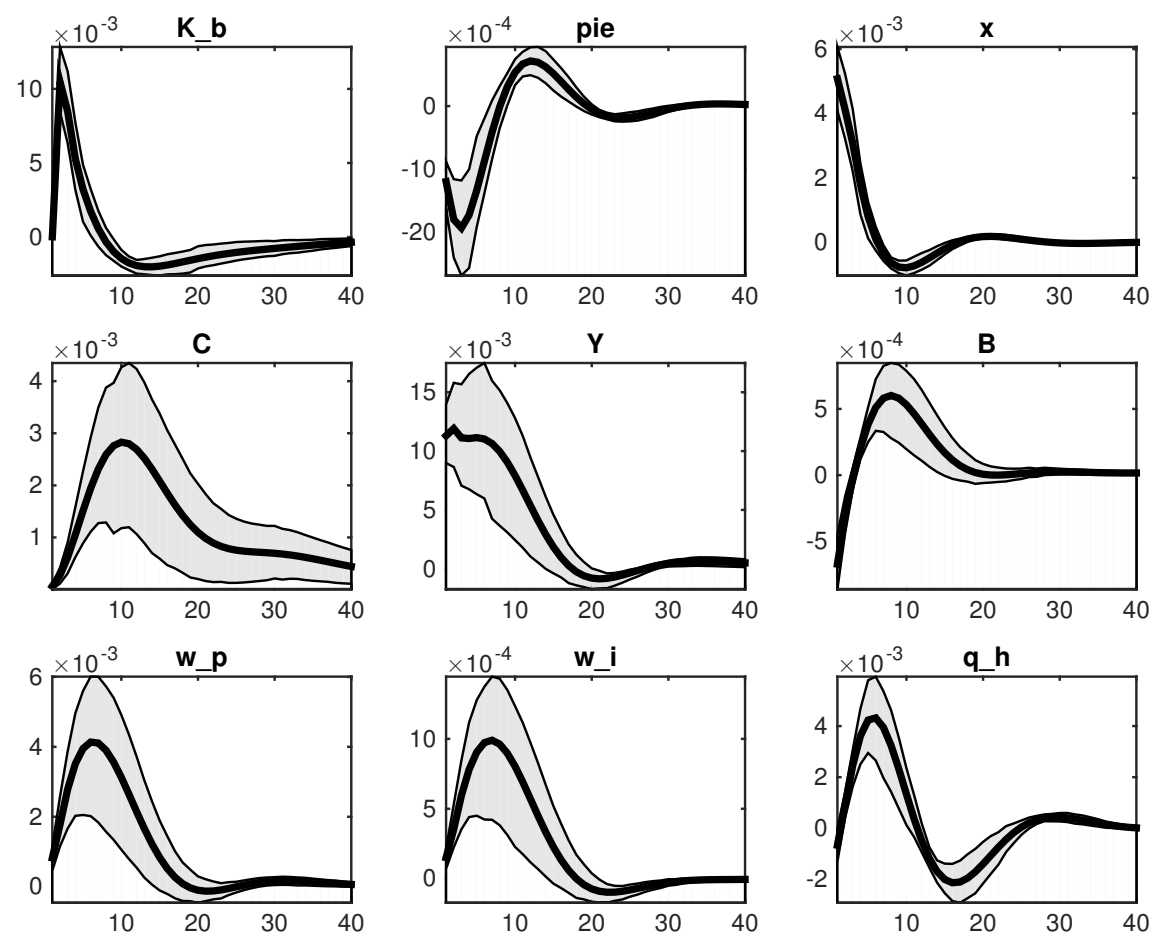

Figura 138: Efeito de um choque em $\pi^{*}$
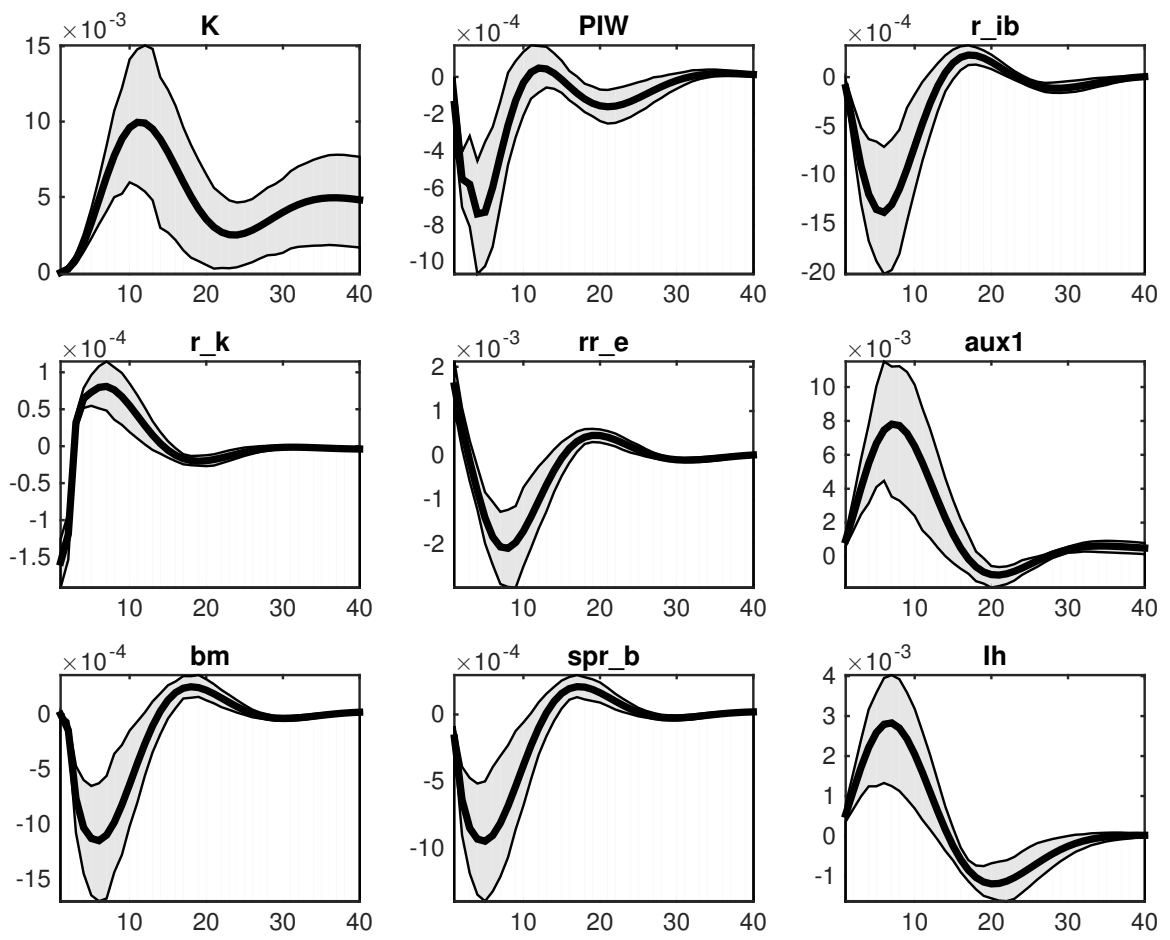

Figura 139: Efeito de um choque em $\pi^{*}$ 

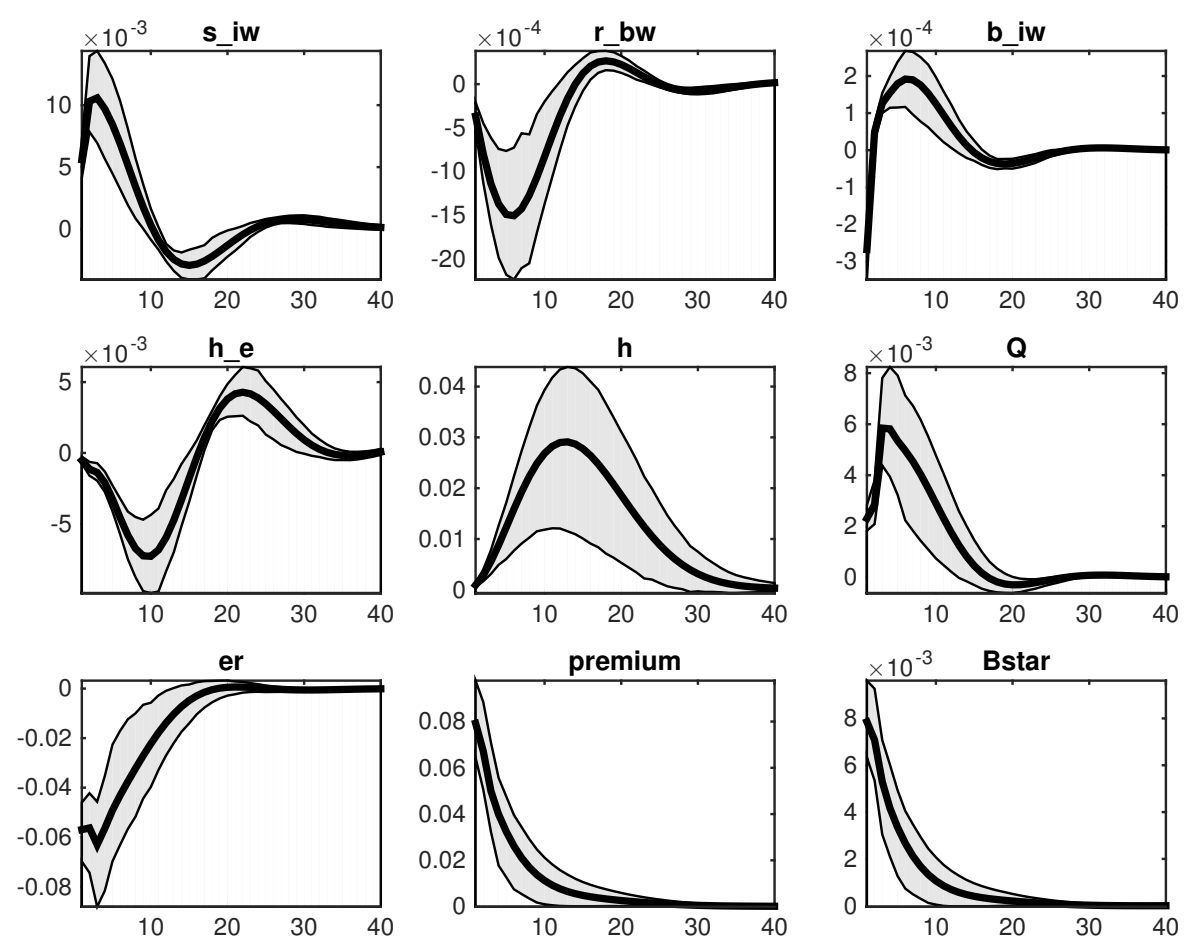

Figura 140: Efeito de um choque em $\pi^{*}$
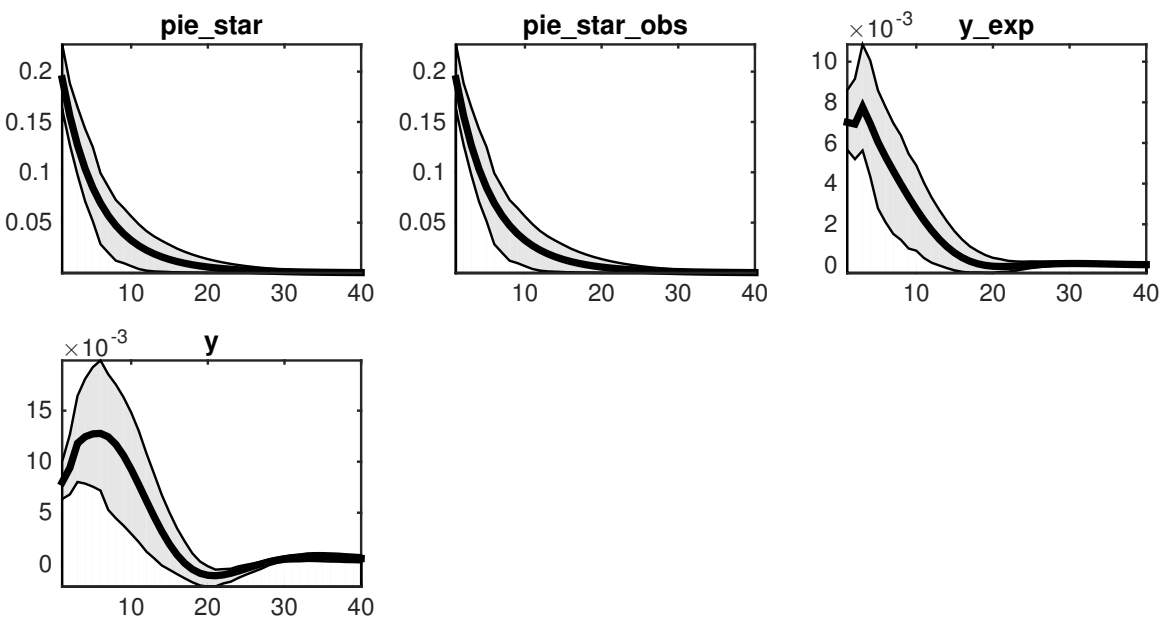

Figura 141: Efeito de um choque em $\pi^{*}$ 
B.2 Choque no premio de risco
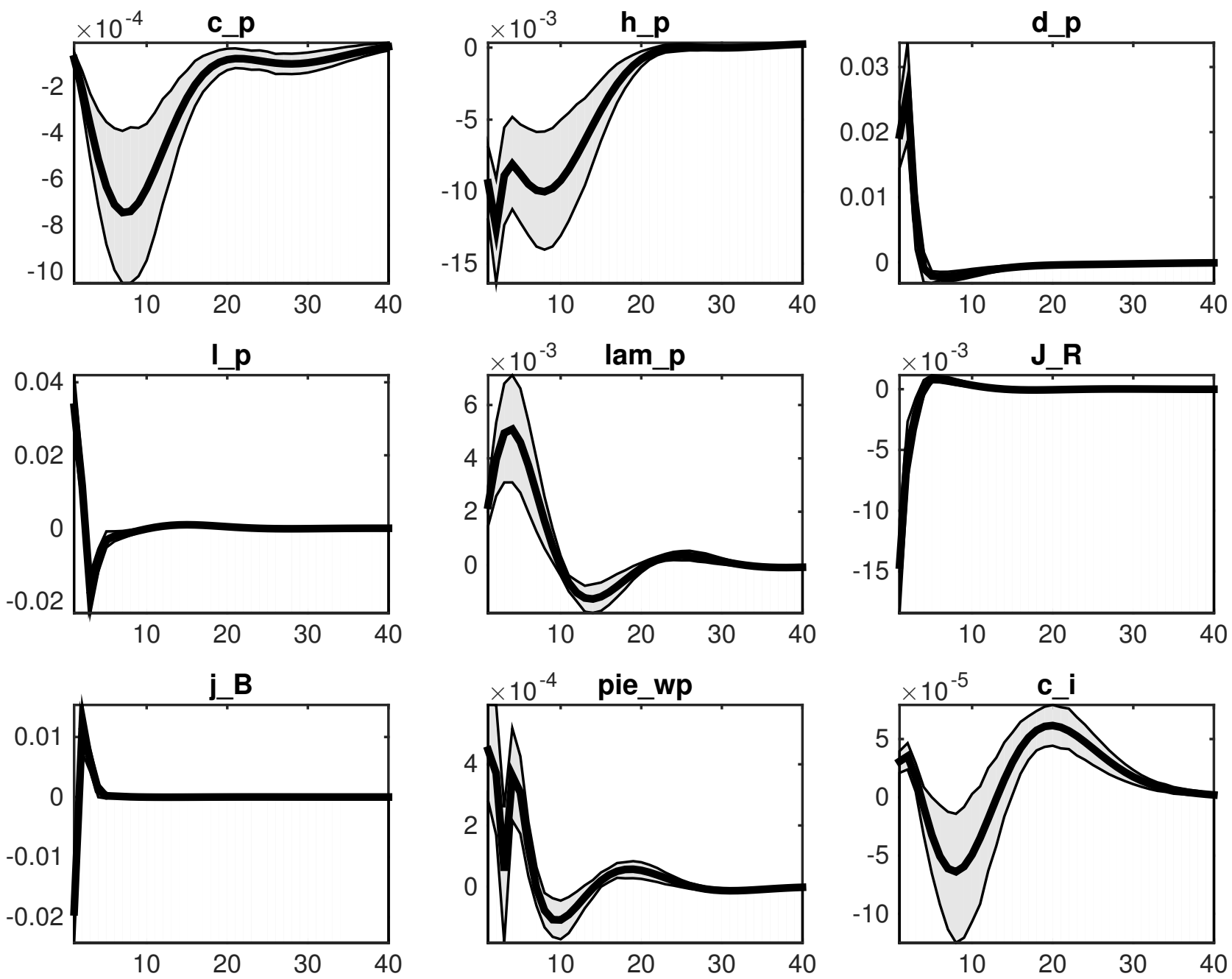

Figura 142: Efeito de um choque em $\Phi$ 

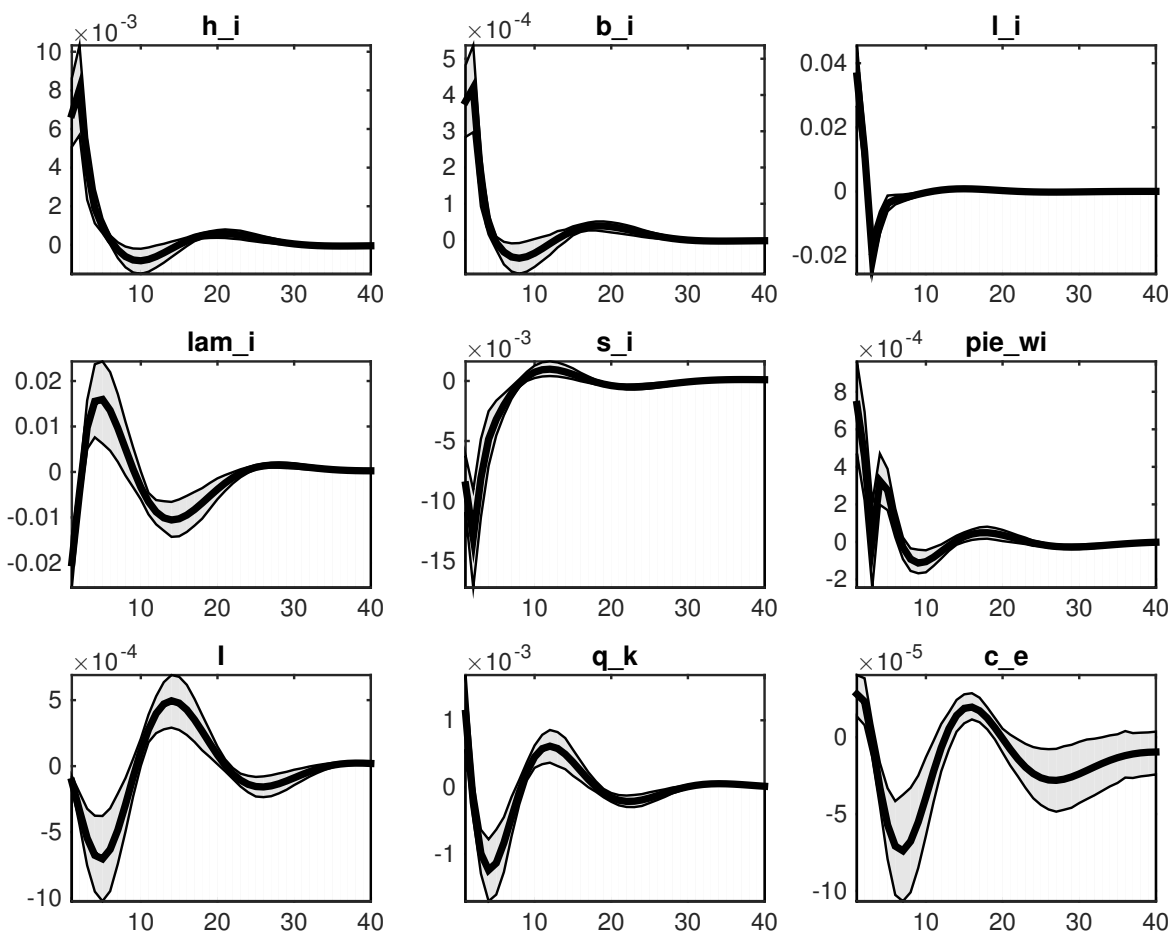

Figura 143: Efeito de um choque em $\Phi$
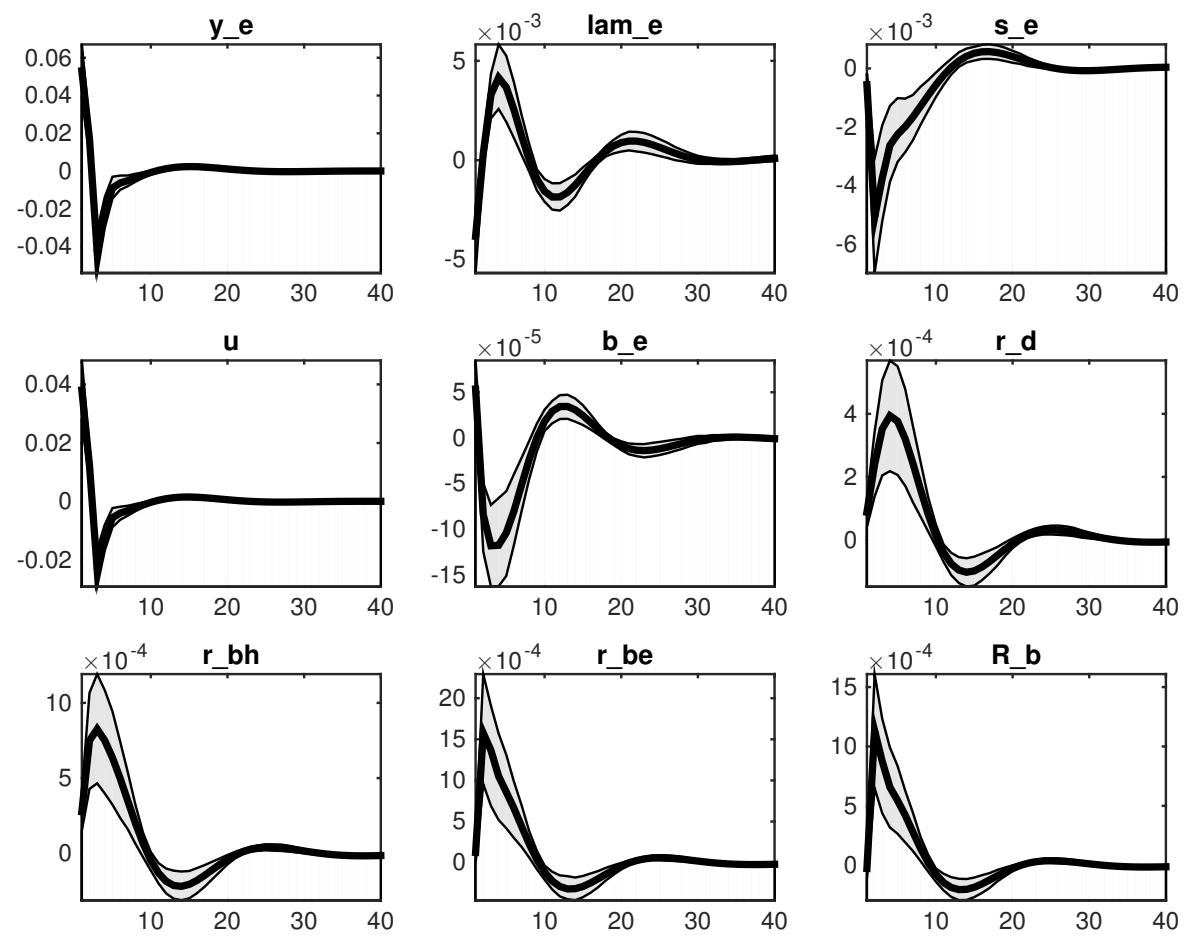

Figura 144: Efeito de um choque em $\Phi$ 

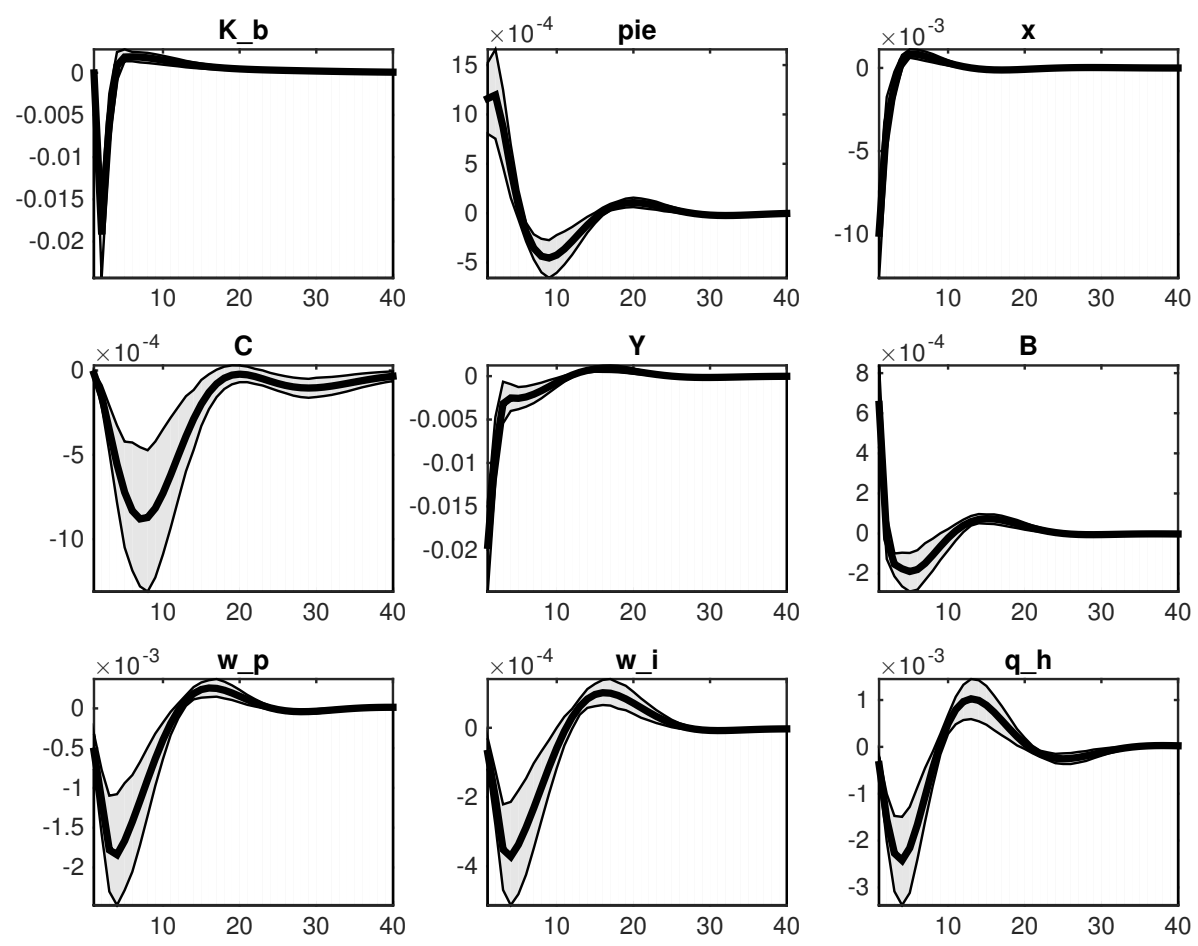

Figura 145: Efeito de um choque em $\Phi$
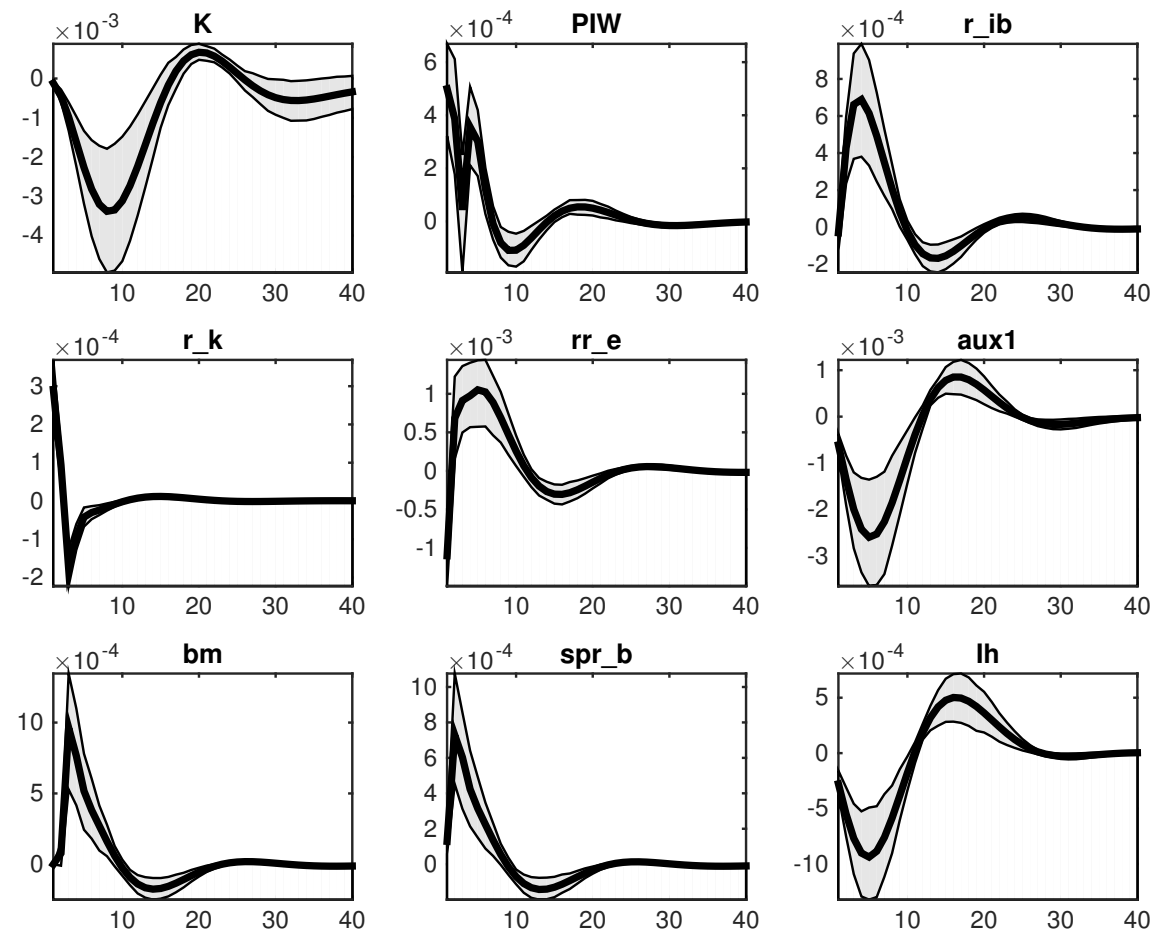

Figura 146: Efeito de um choque em $\Phi$ 

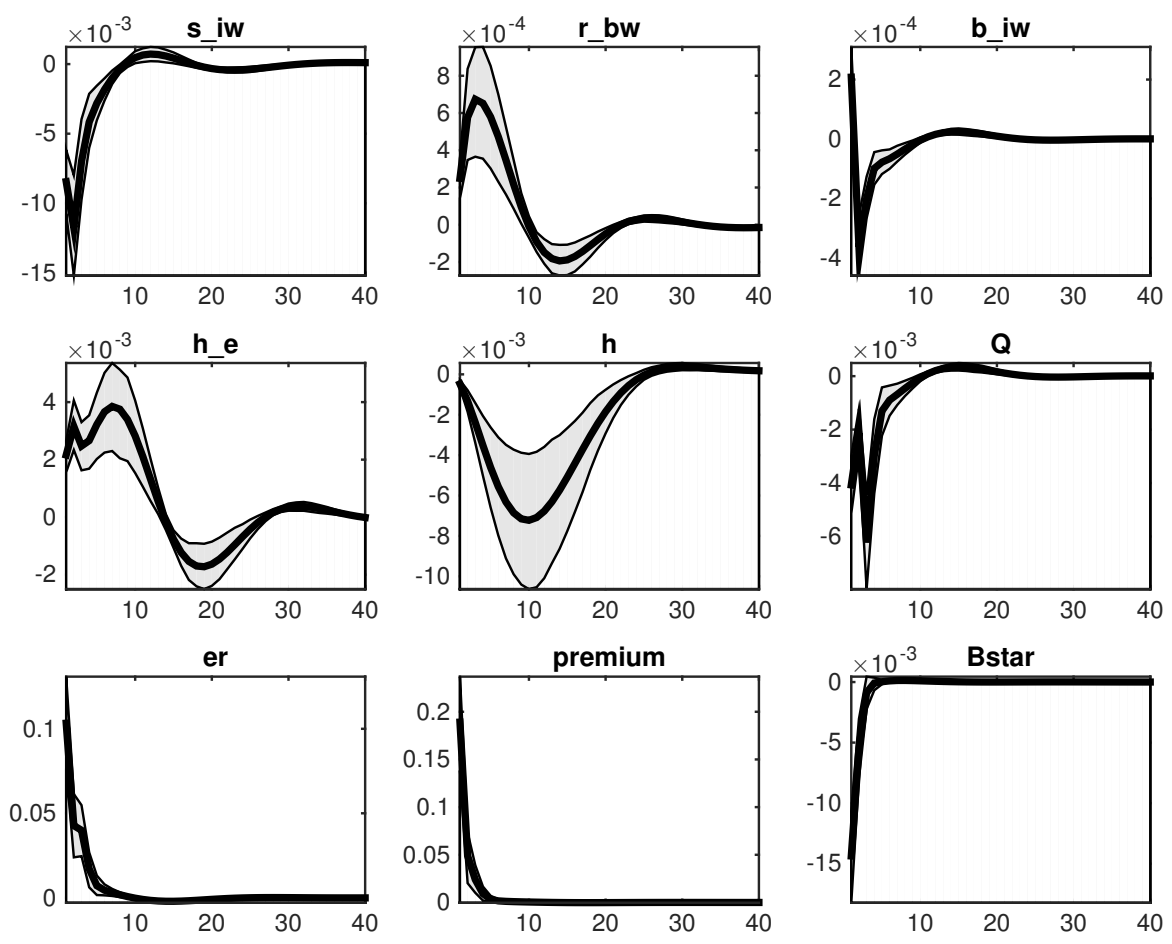

Figura 147: Efeito de um choque em $\Phi$
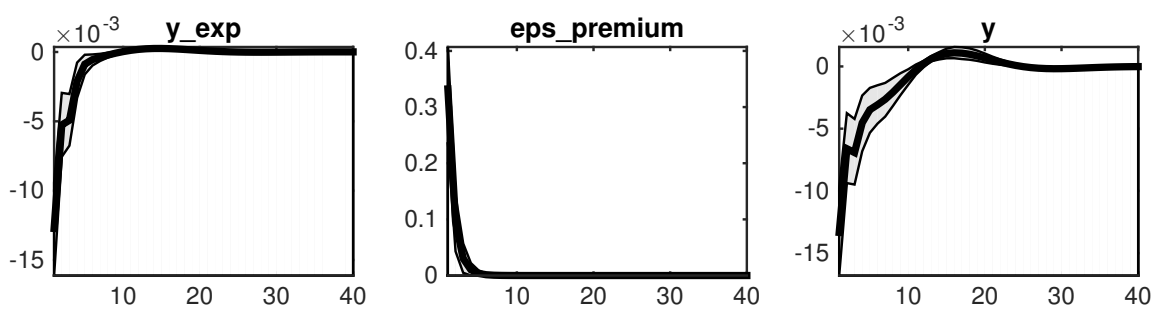

Figura 148: Efeito de um choque em $\Phi$ 


\section{B.3 Choque no Capital Bancário}
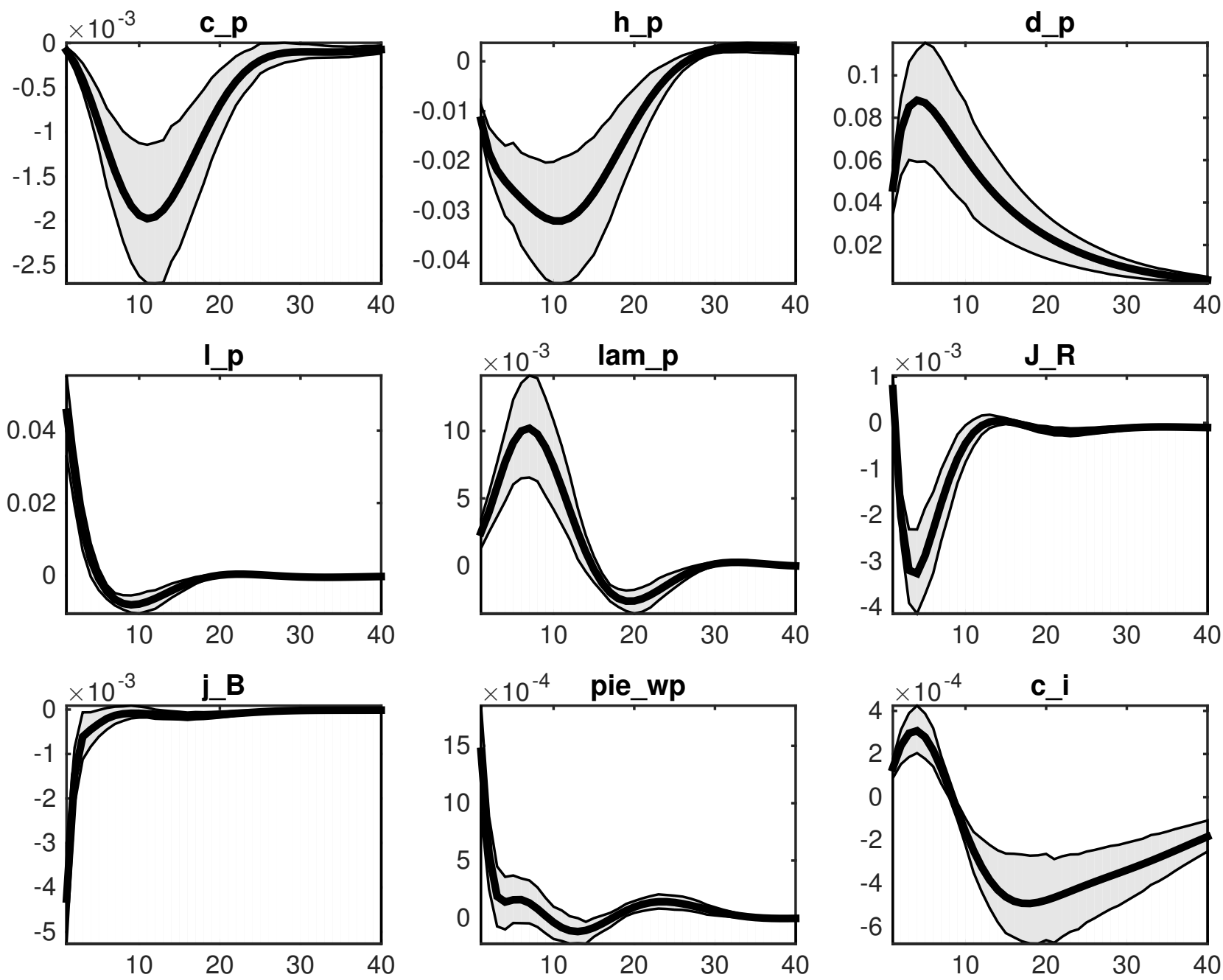

Figura 149: Efeito de um choque em $\mathrm{K}^{b}$ 

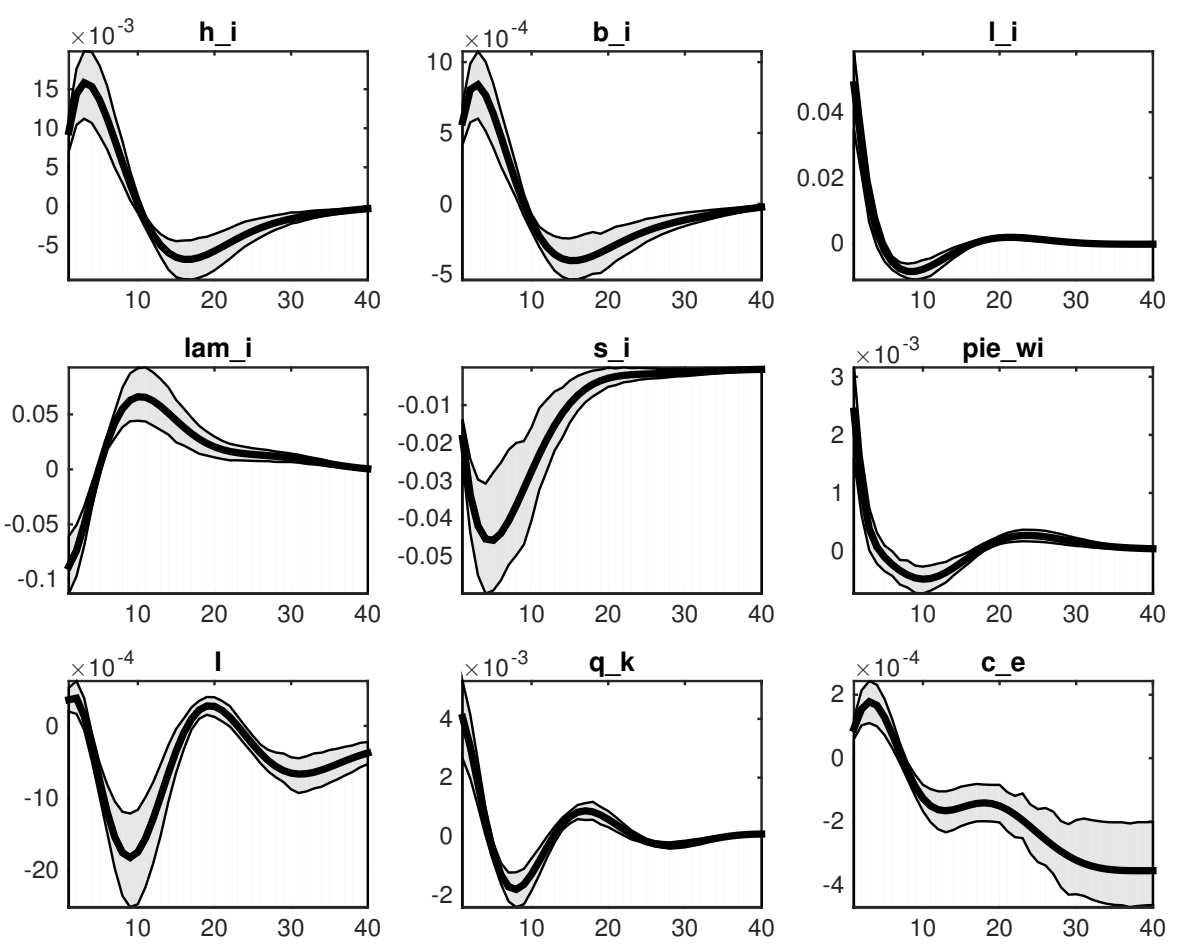

Figura 150: Efeito de um choque em $\mathrm{K}^{b}$
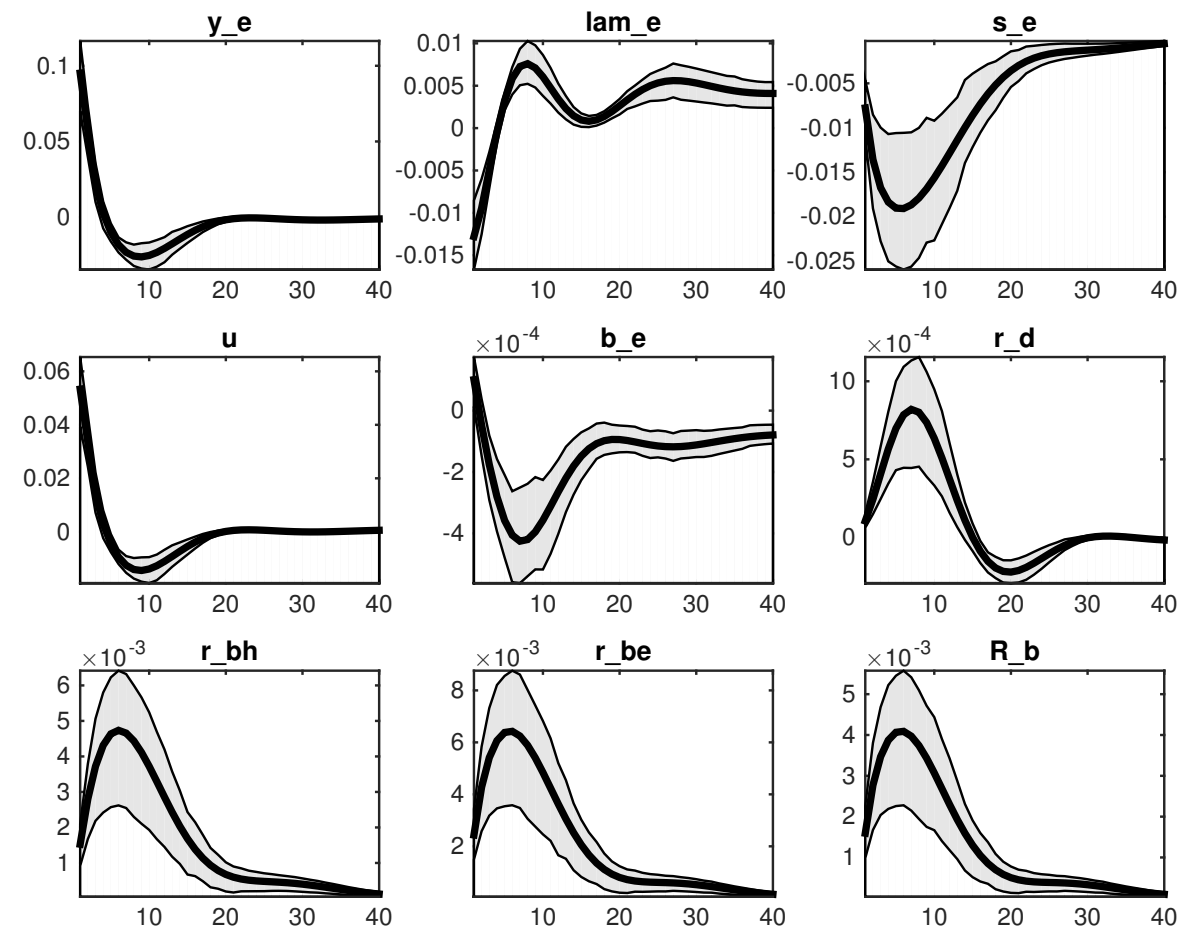

Figura 151: Efeito de um choque em $\mathrm{K}^{b}$ 

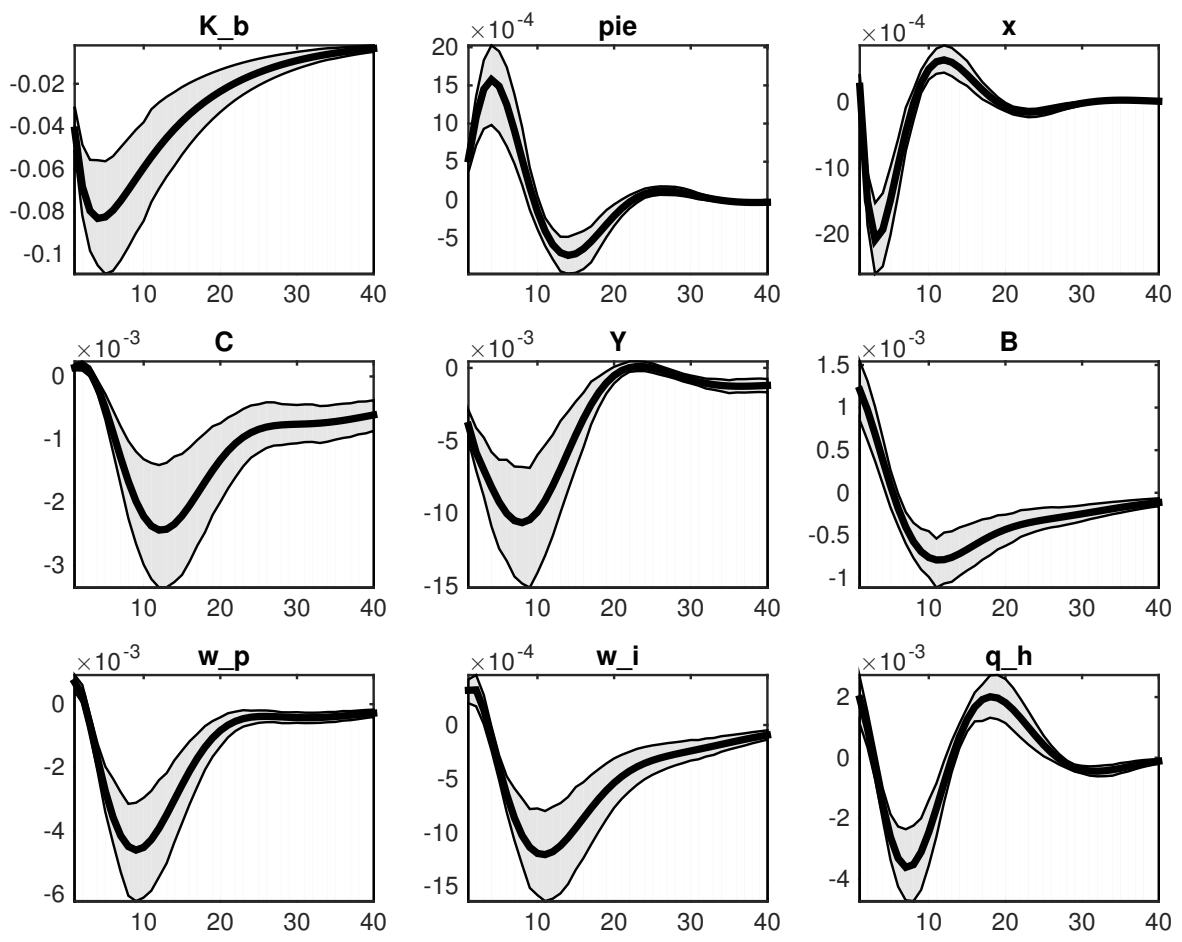

Figura 152: Efeito de um choque em $\mathrm{K}^{b}$
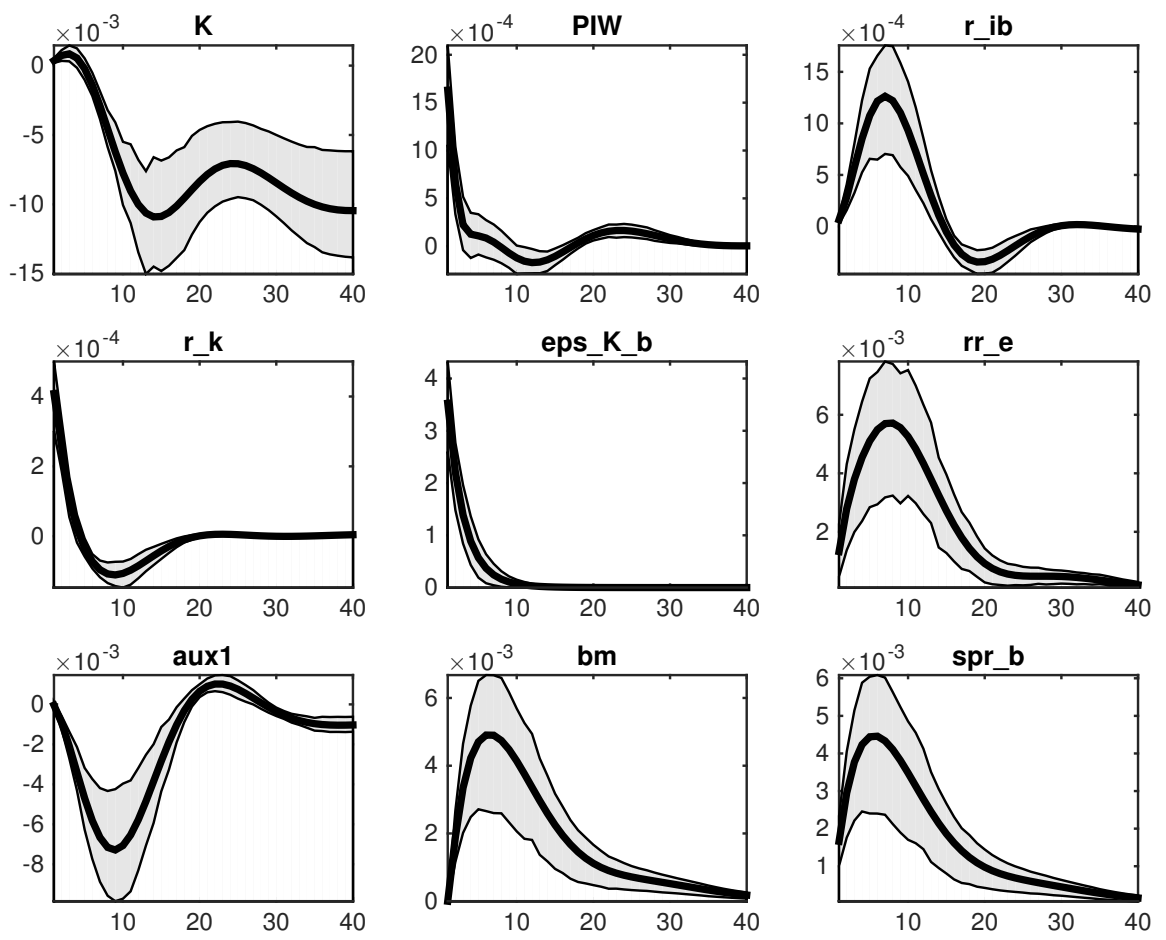

Figura 153: Efeito de um choque em $\mathrm{K}^{b}$ 

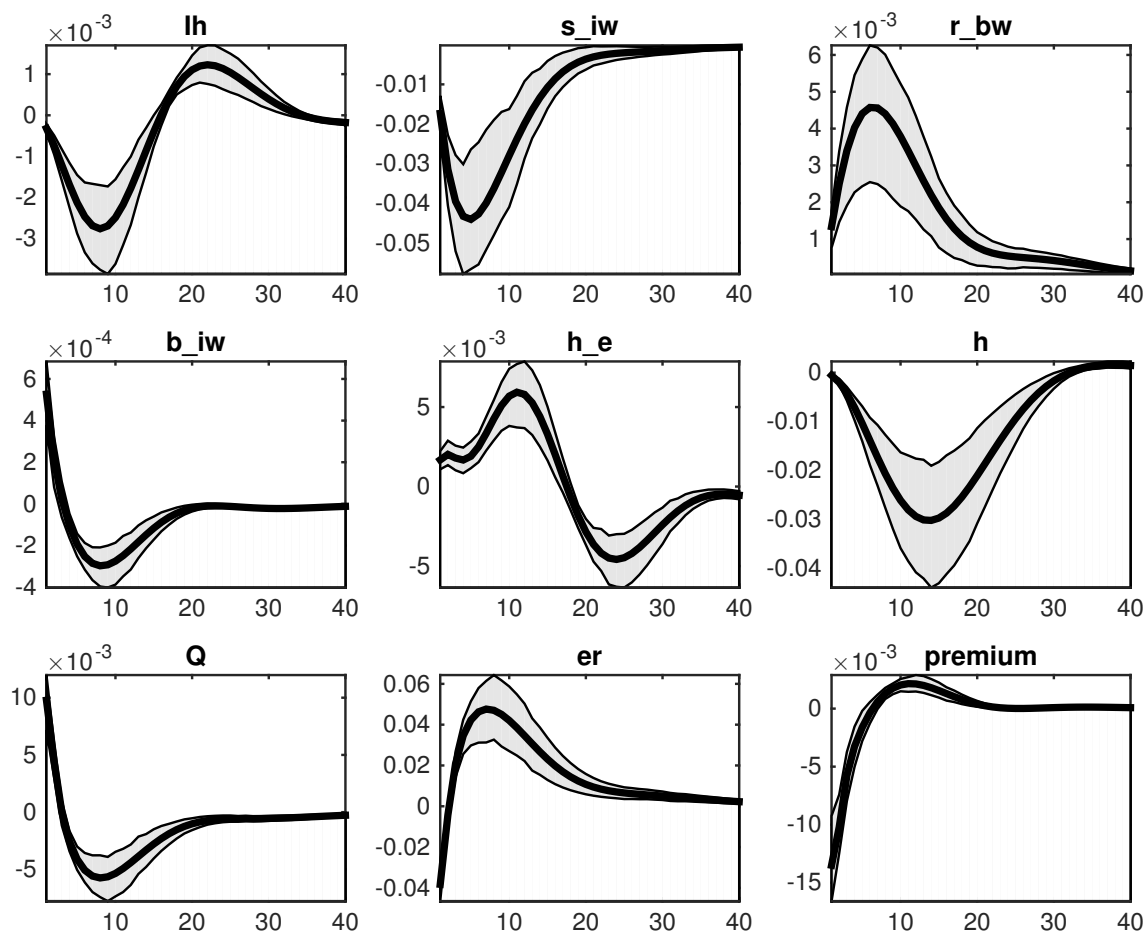

Figura 154: Efeito de um choque em $\mathrm{K}^{b}$
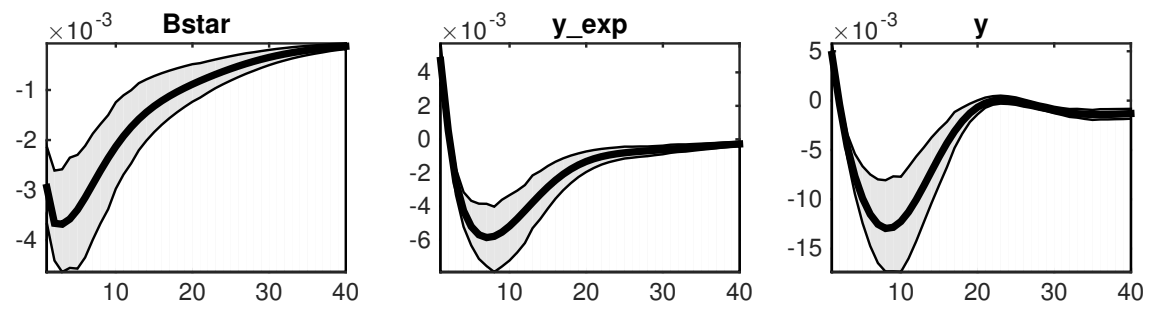

Figura 155: Efeito de um choque em $\mathrm{K}^{b}$ 
B.4 Choque na taxa de juros externa
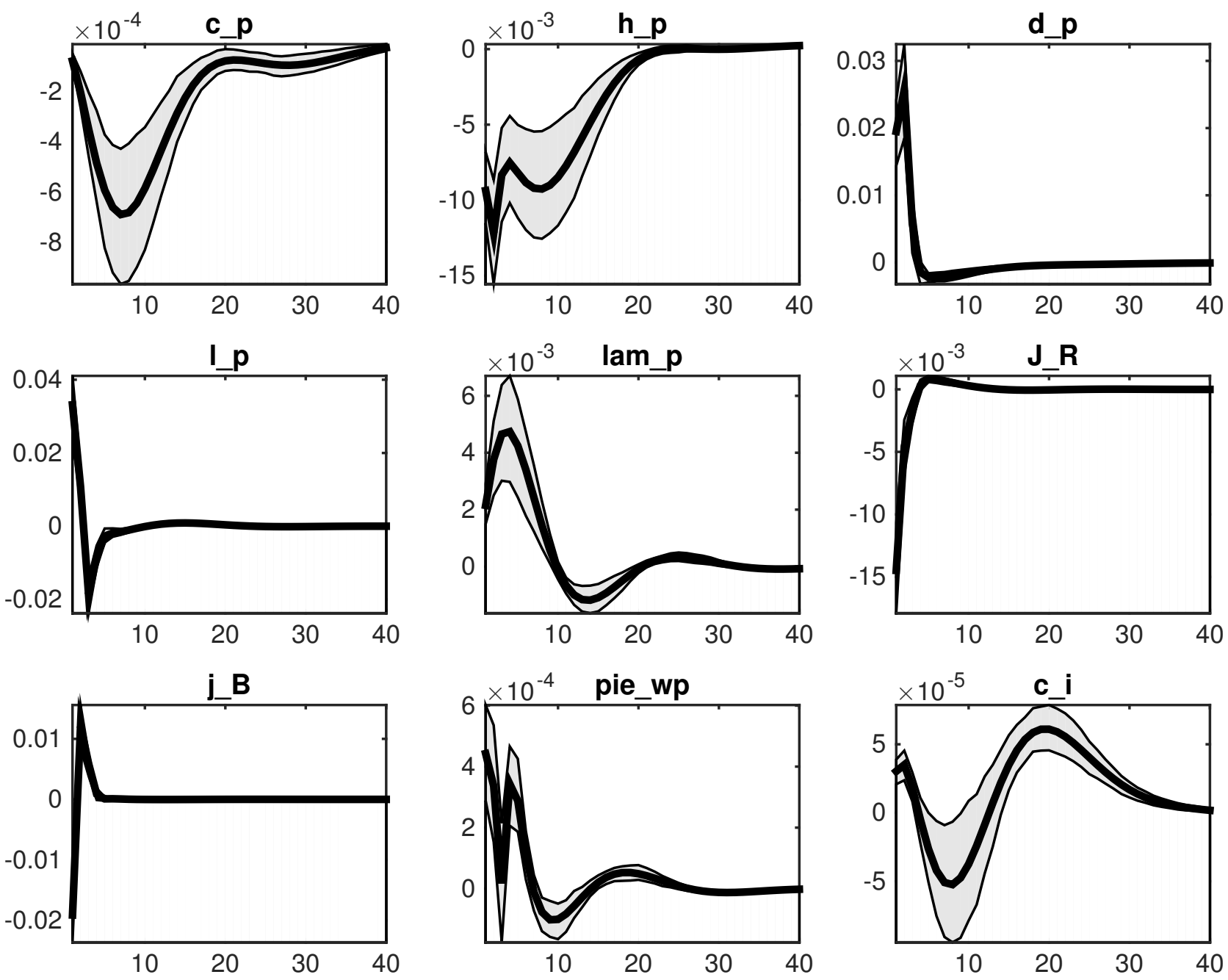

Figura 156: Efeito de um choque em $\mathrm{R}^{*}$ 

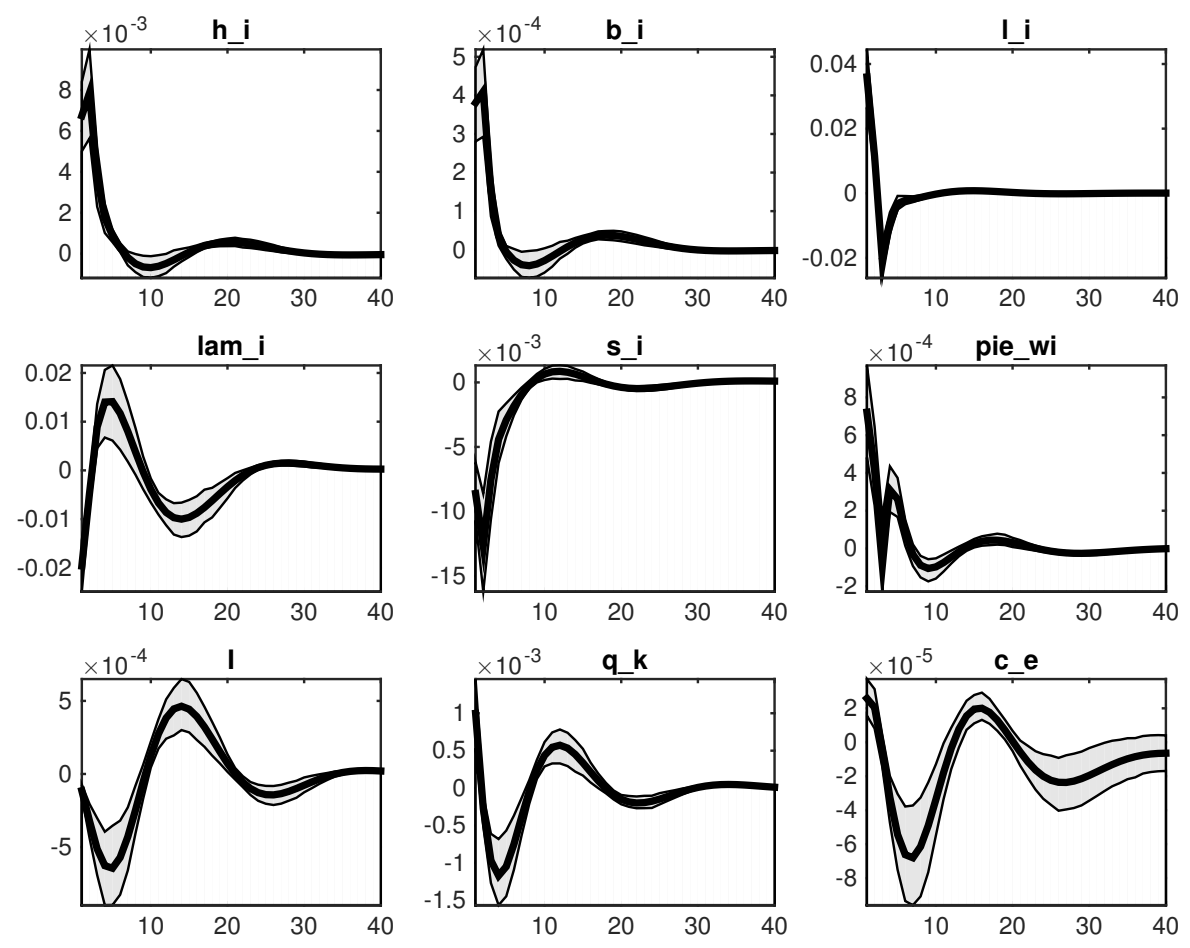

Figura 157: Efeito de um choque em $\mathrm{R}^{*}$
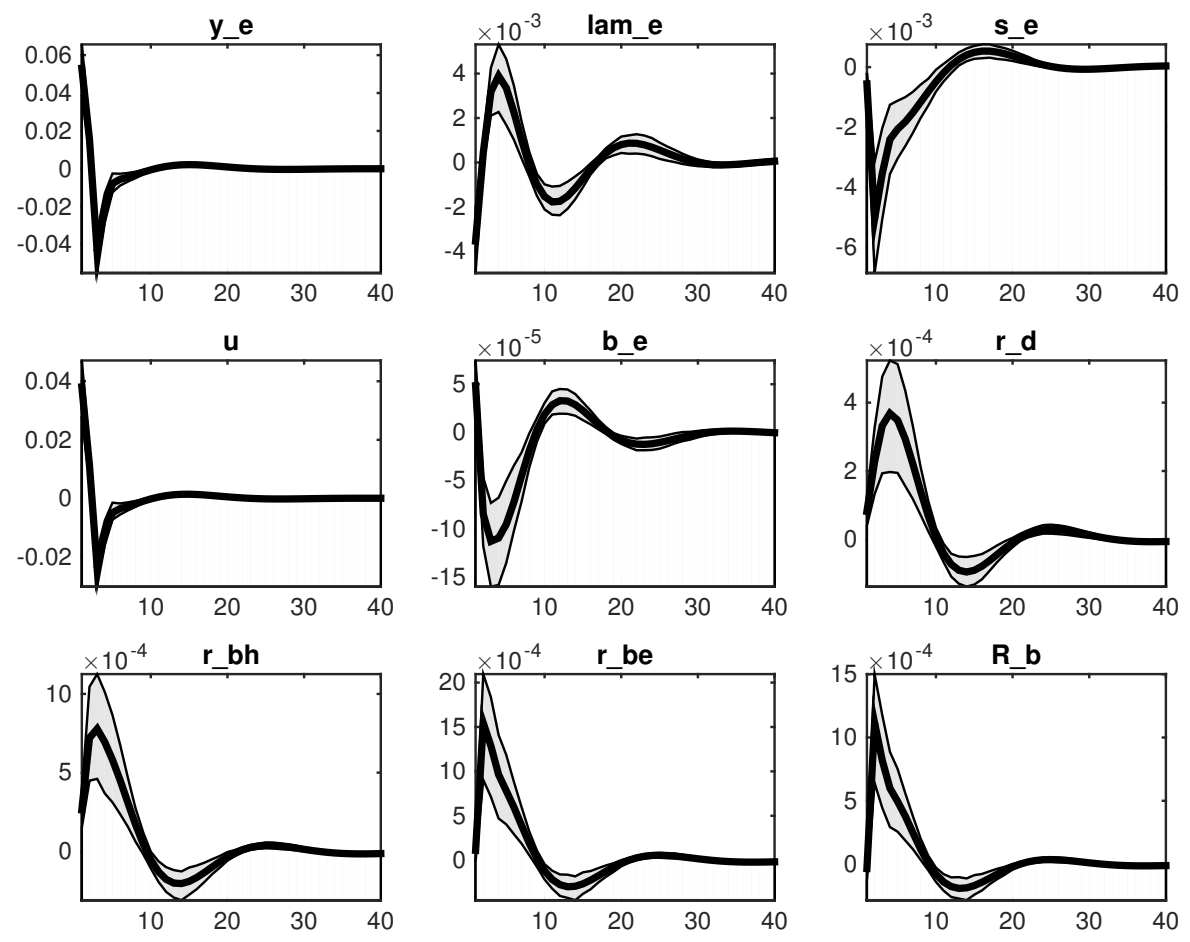

Figura 158: Efeito de um choque em $\mathrm{R}^{*}$ 

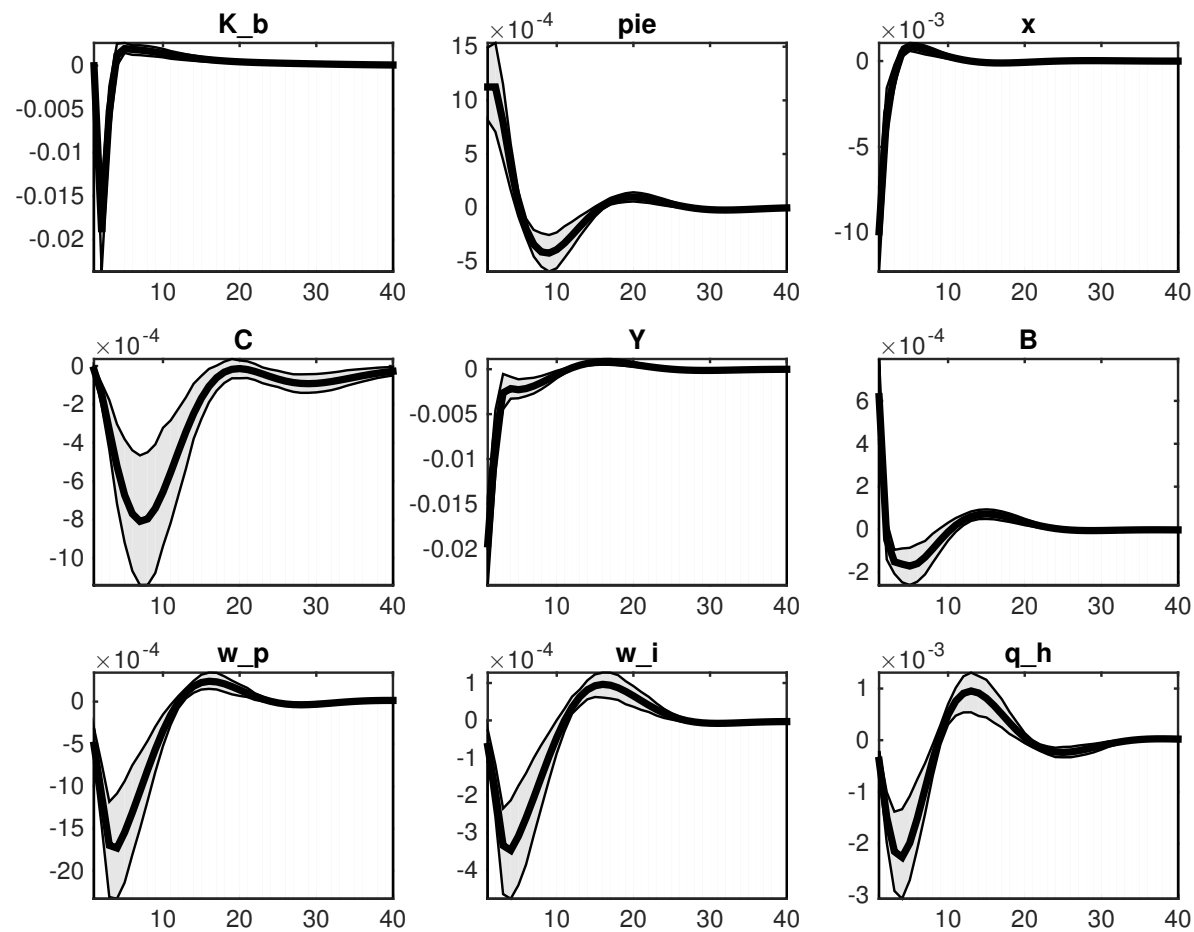

Figura 159: Efeito de um choque em $\mathrm{R}^{*}$
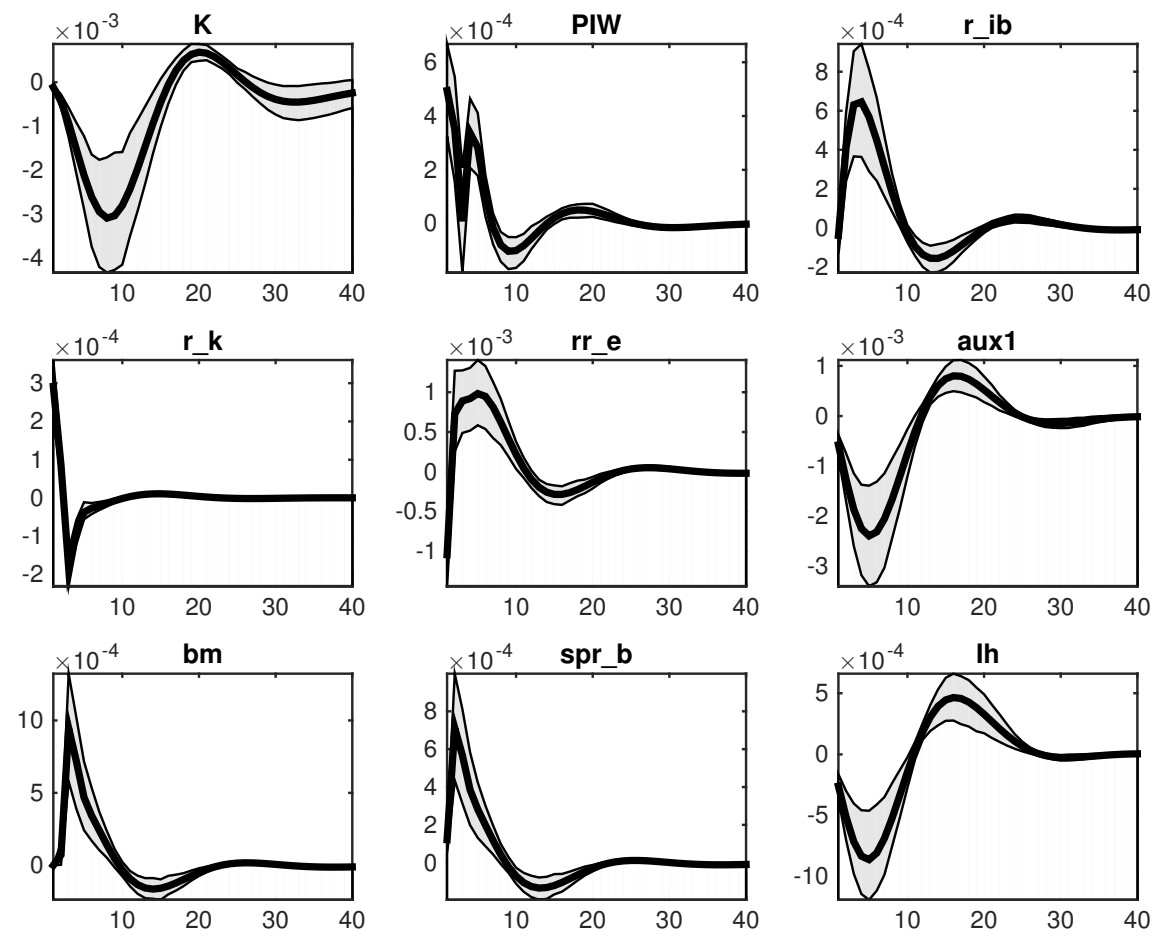

Figura 160: Efeito de um choque em $\mathrm{R}^{*}$ 

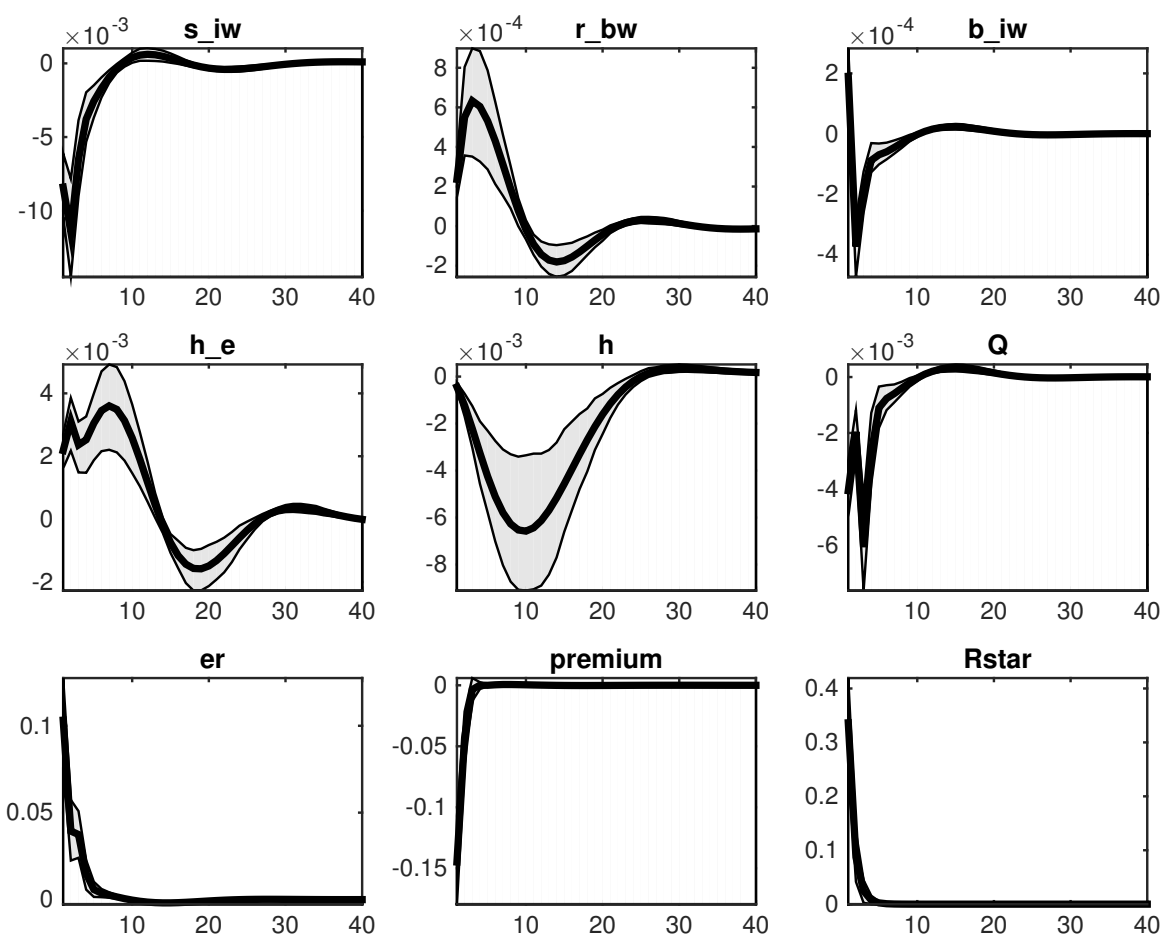

Figura 161: Efeito de um choque em $\mathrm{R}^{*}$
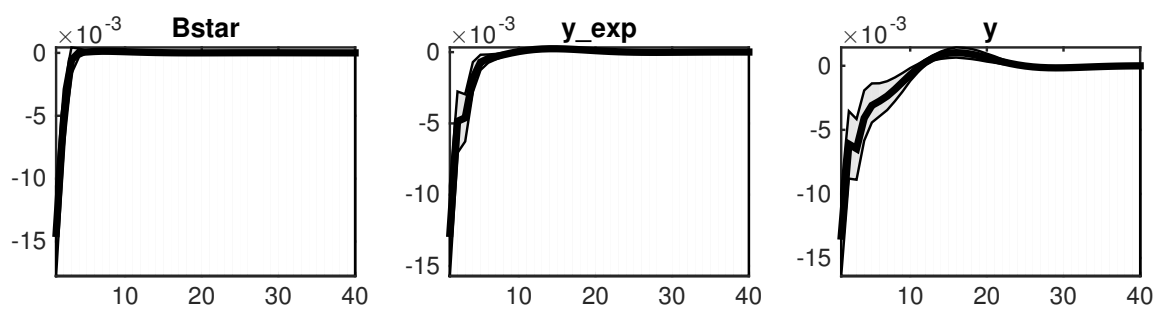

Figura 162: Efeito de um choque em $\mathrm{R}^{*}$ 
B.5 Choque no preço do insumo importado
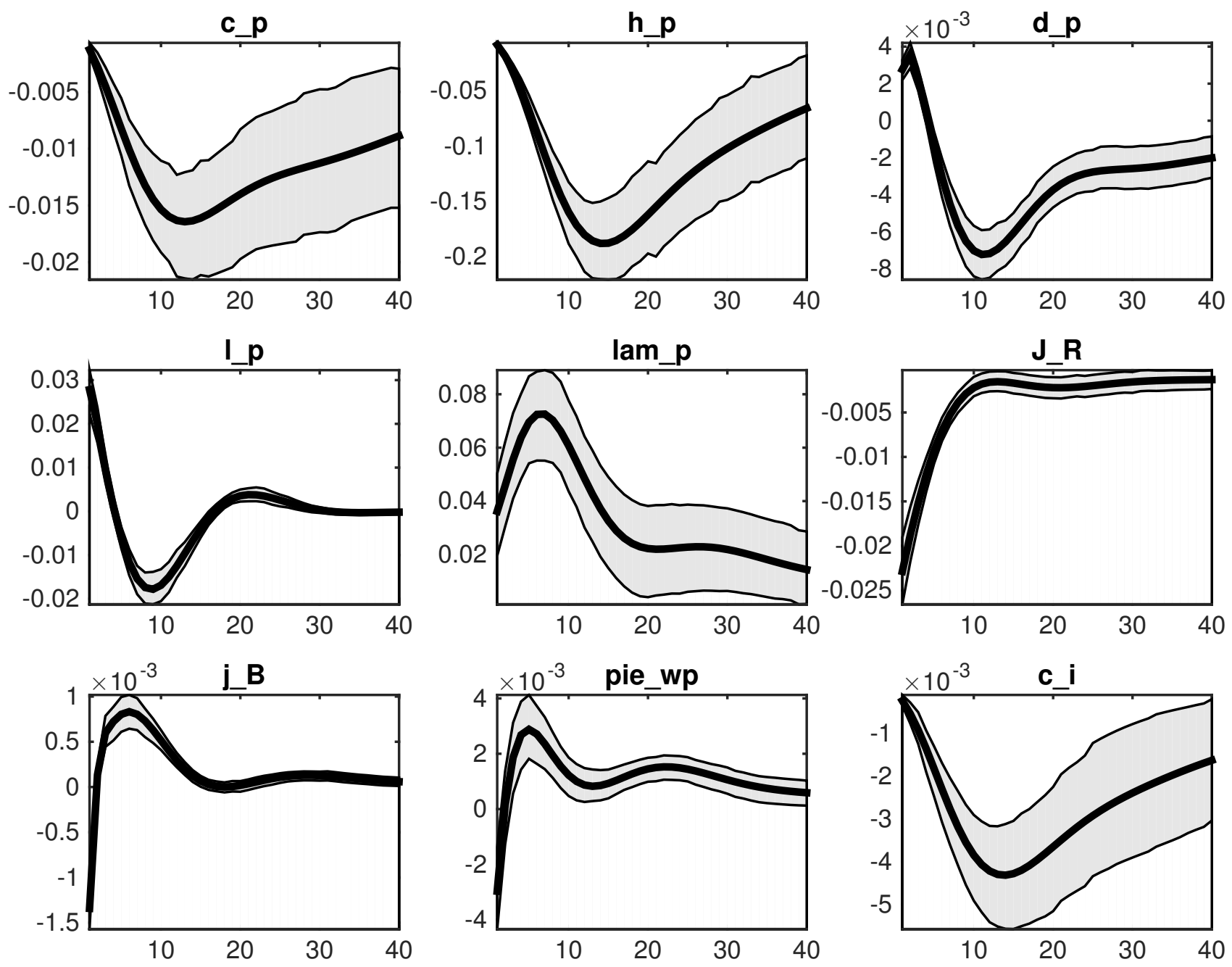

Figura 163: Efeito de um choque em $\mathrm{p}^{Q}$ 

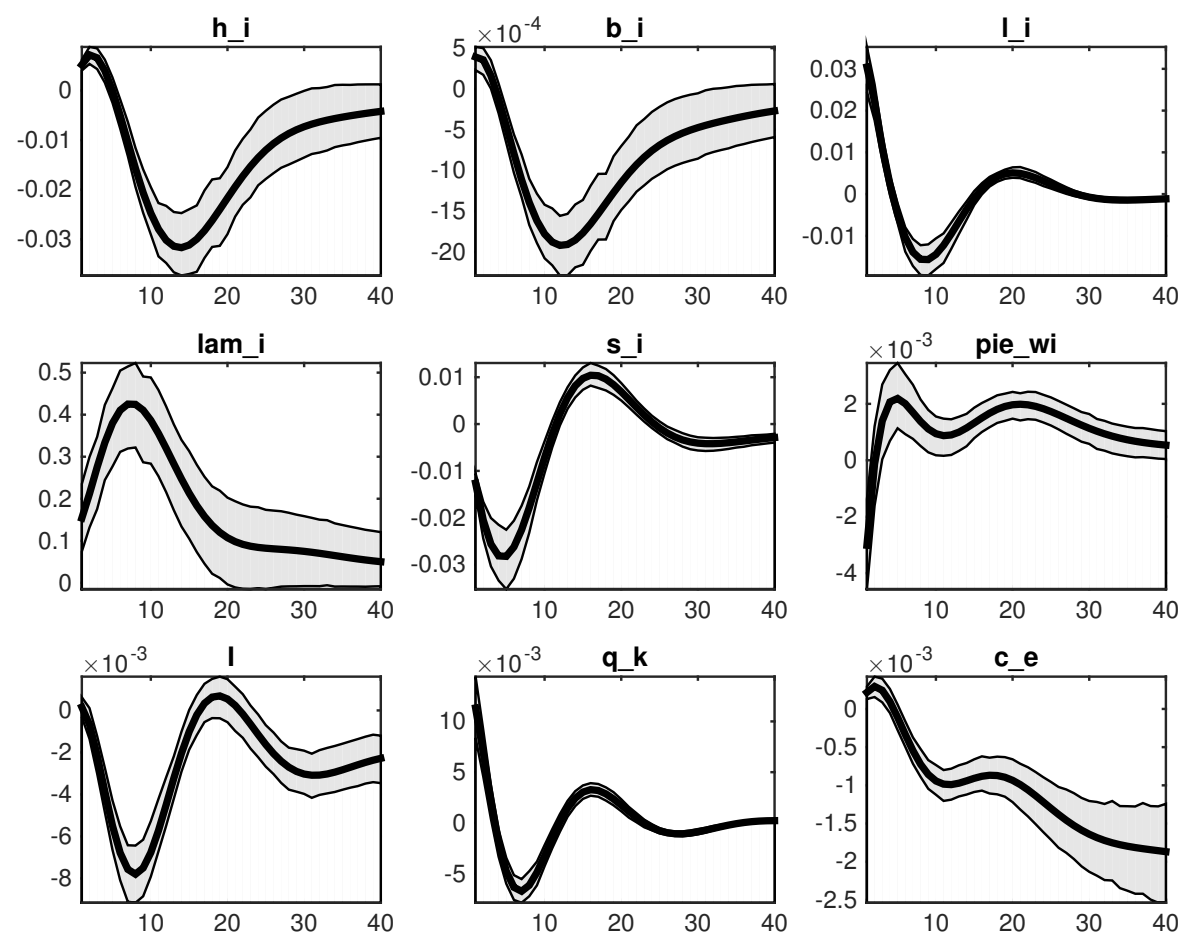

Figura 164: Efeito de um choque em $\mathrm{p}^{Q}$
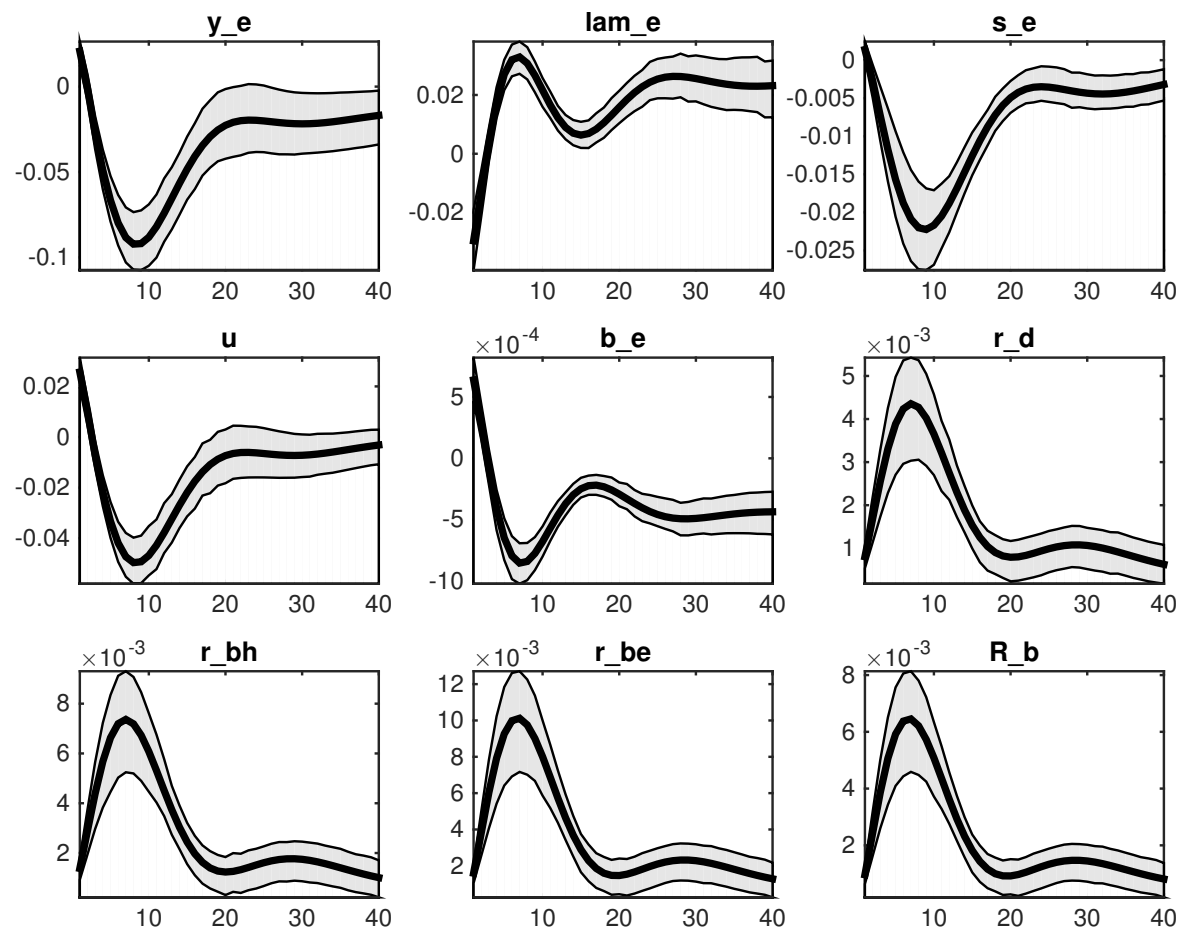

Figura 165: Efeito de um choque em $\mathrm{p}^{Q}$ 

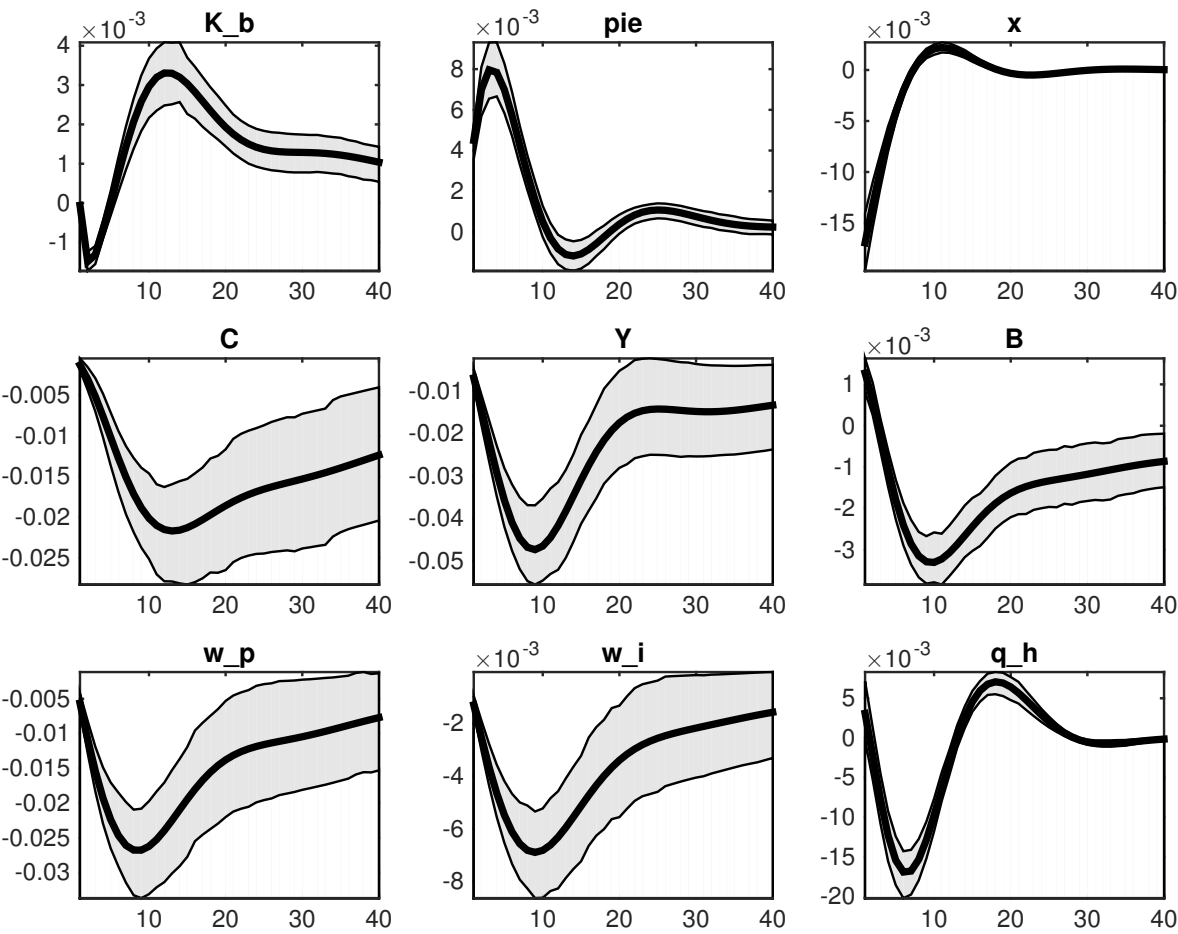

Figura 166: Efeito de um choque em $\mathrm{p}^{Q}$
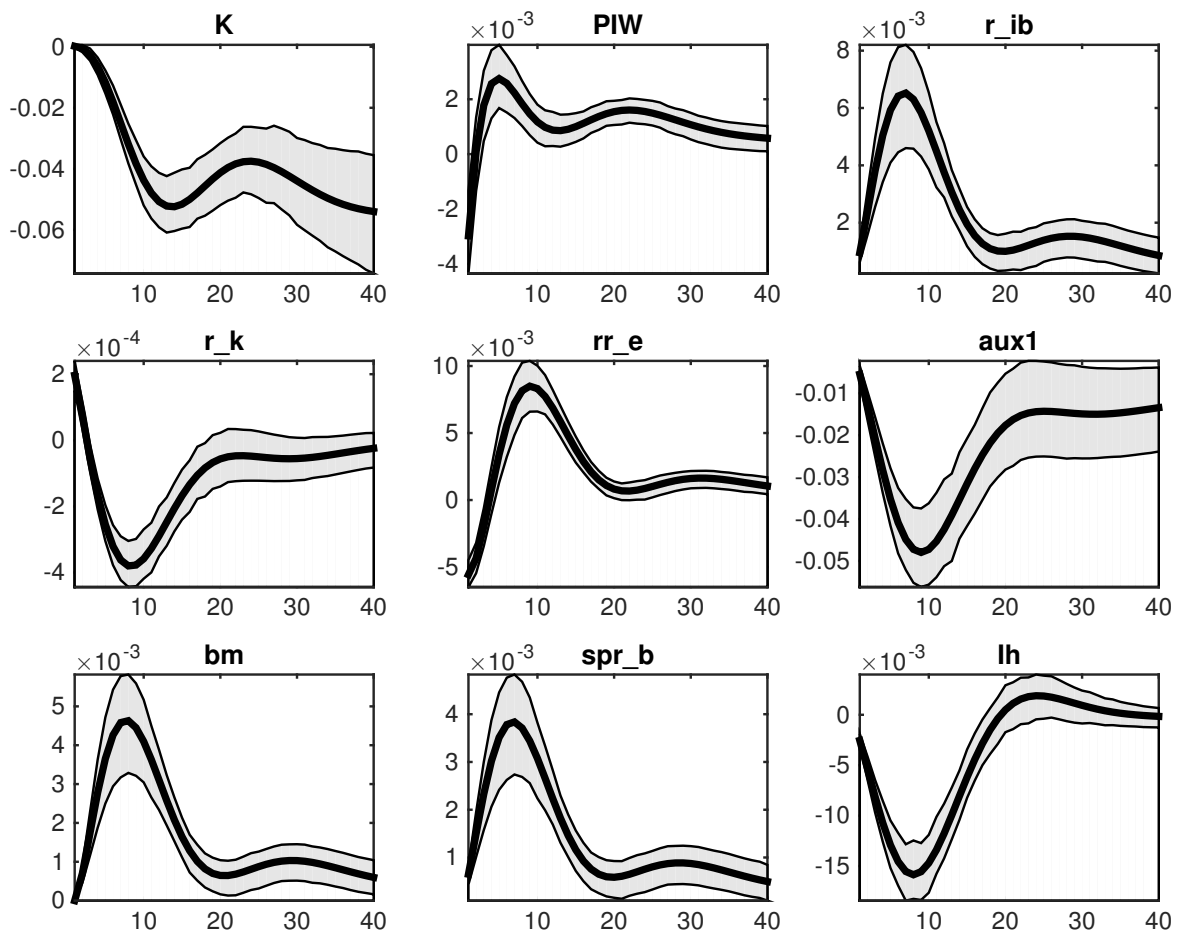

Figura 167: Efeito de um choque em $\mathrm{p}^{Q}$ 

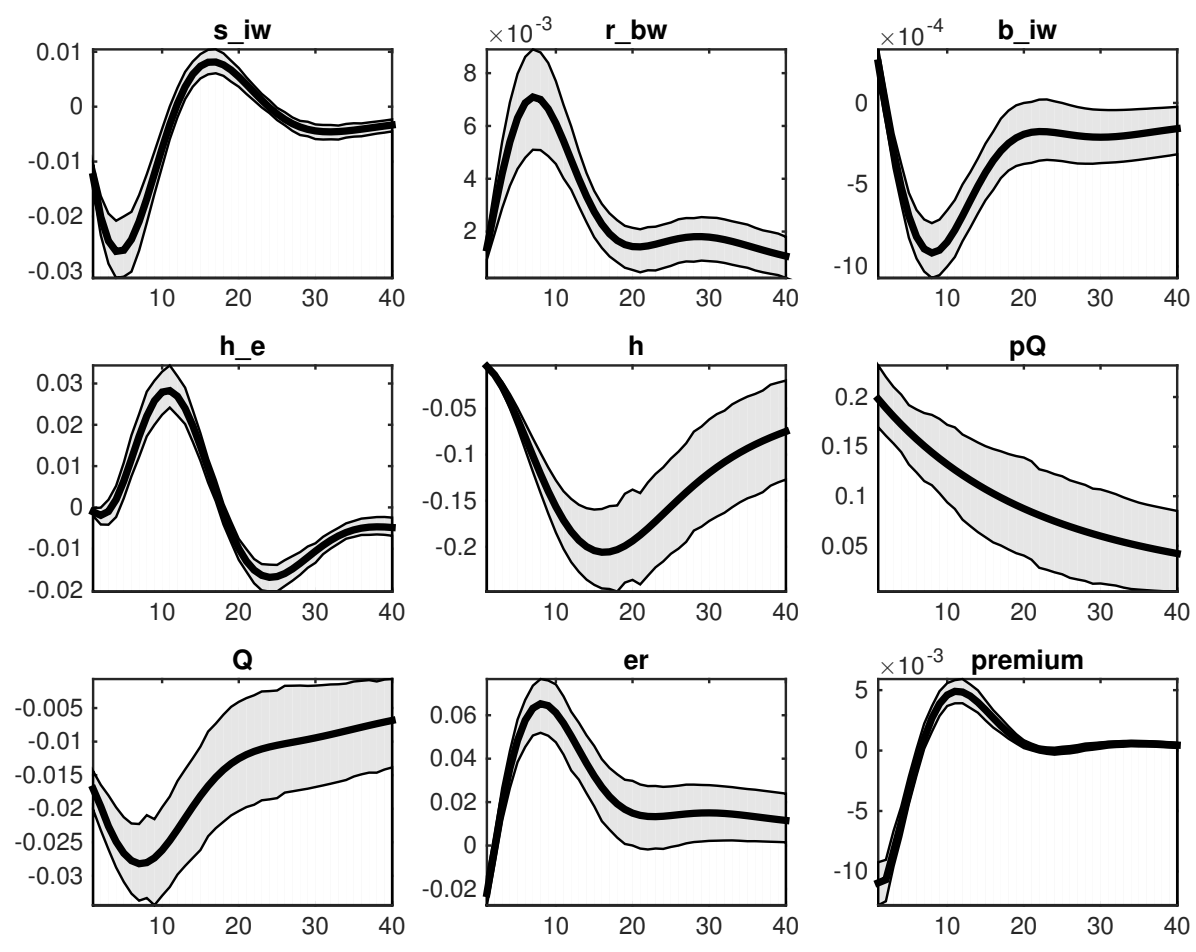

Figura 168: Efeito de um choque em $\mathrm{p}^{Q}$
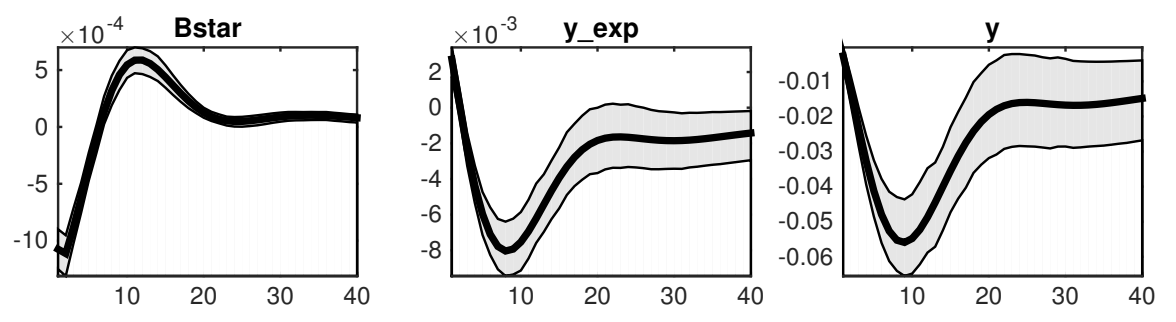

Figura 169: Efeito de um choque em $\mathrm{p}^{Q}$ 
B.6 Choque na renda externa
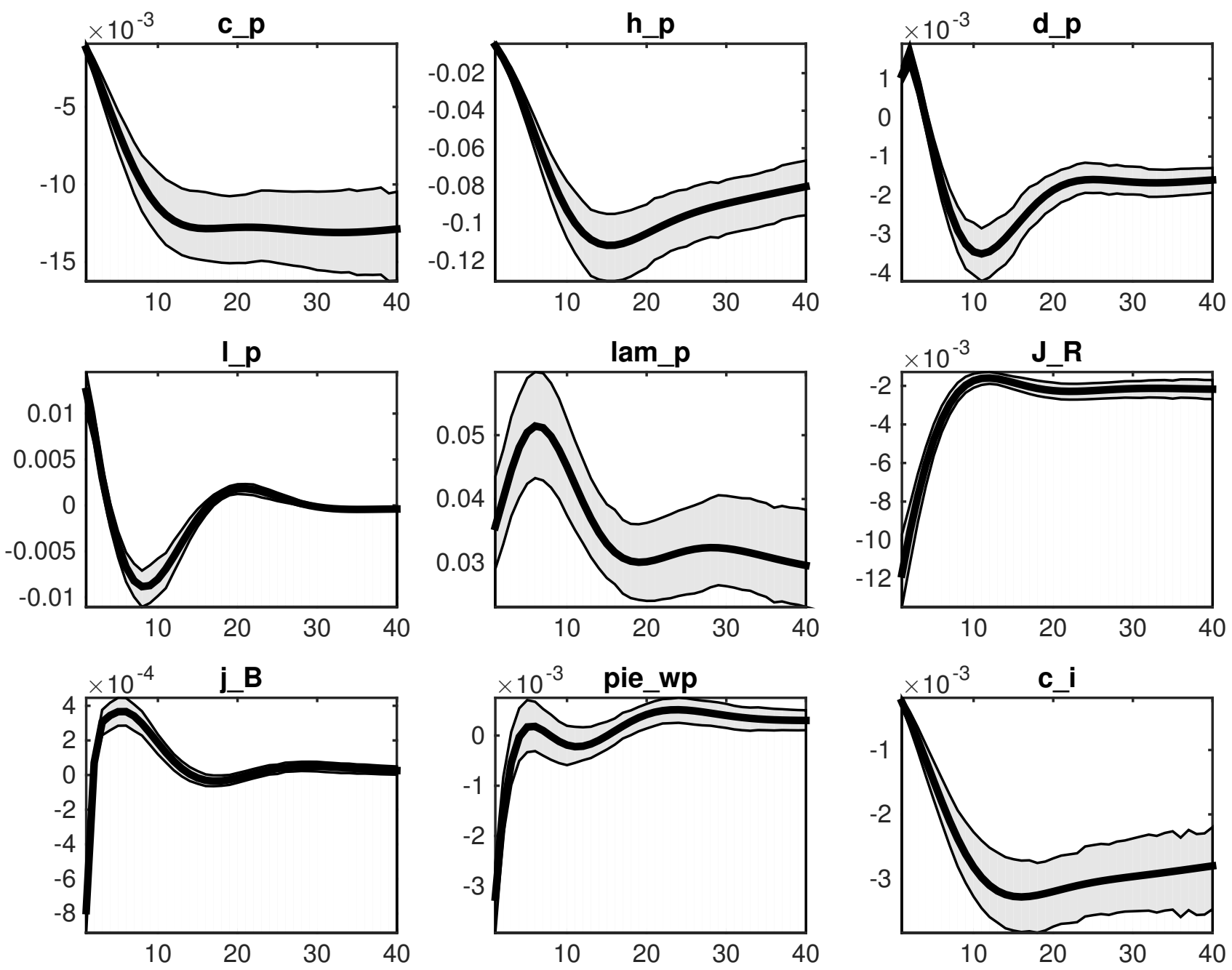

Figura 170: Efeito de um choque em $\mathrm{y}^{*}$ 

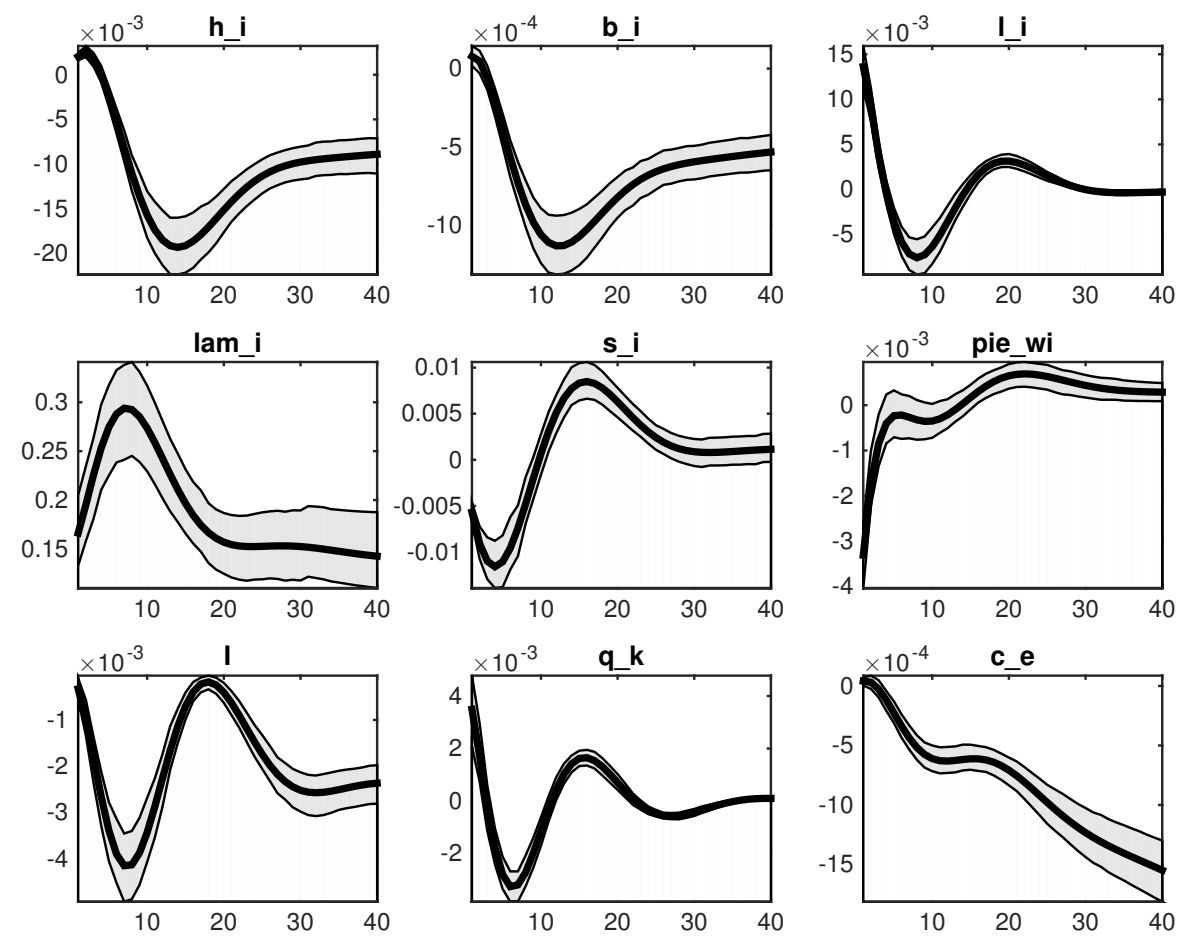

Figura 171: Efeito de um choque em $\mathrm{y}^{*}$
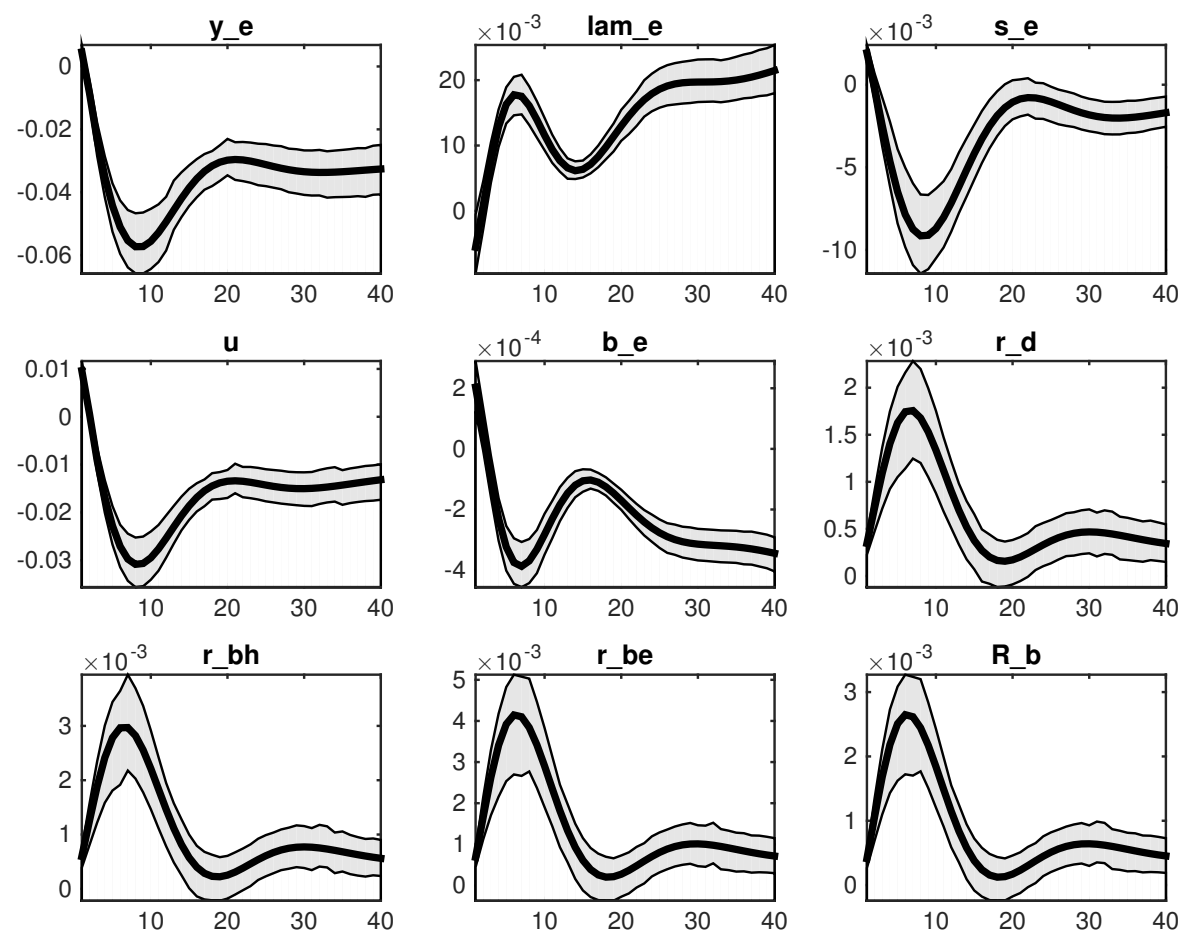

Figura 172: Efeito de um choque em $\mathrm{y}^{*}$ 

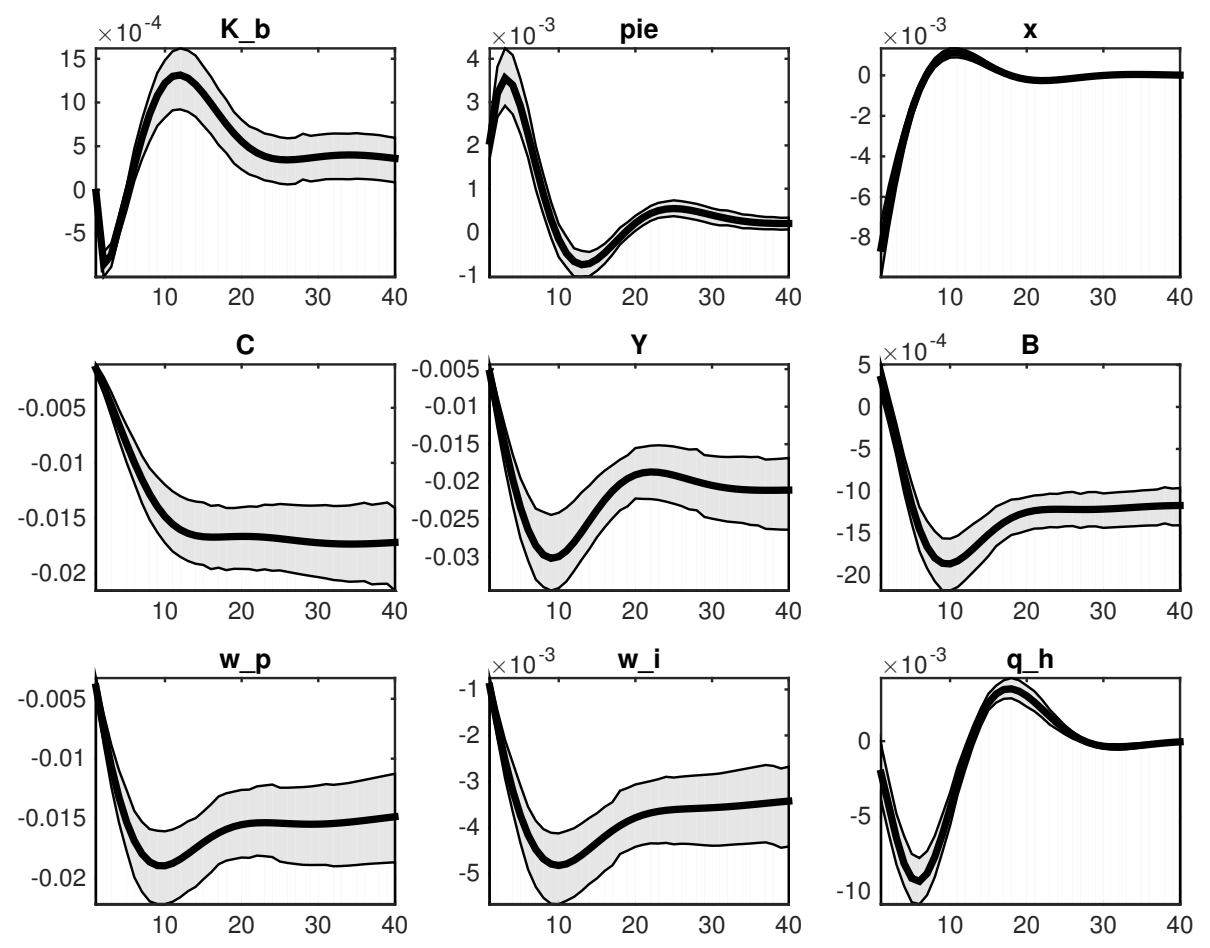

Figura 173: Efeito de um choque em y*
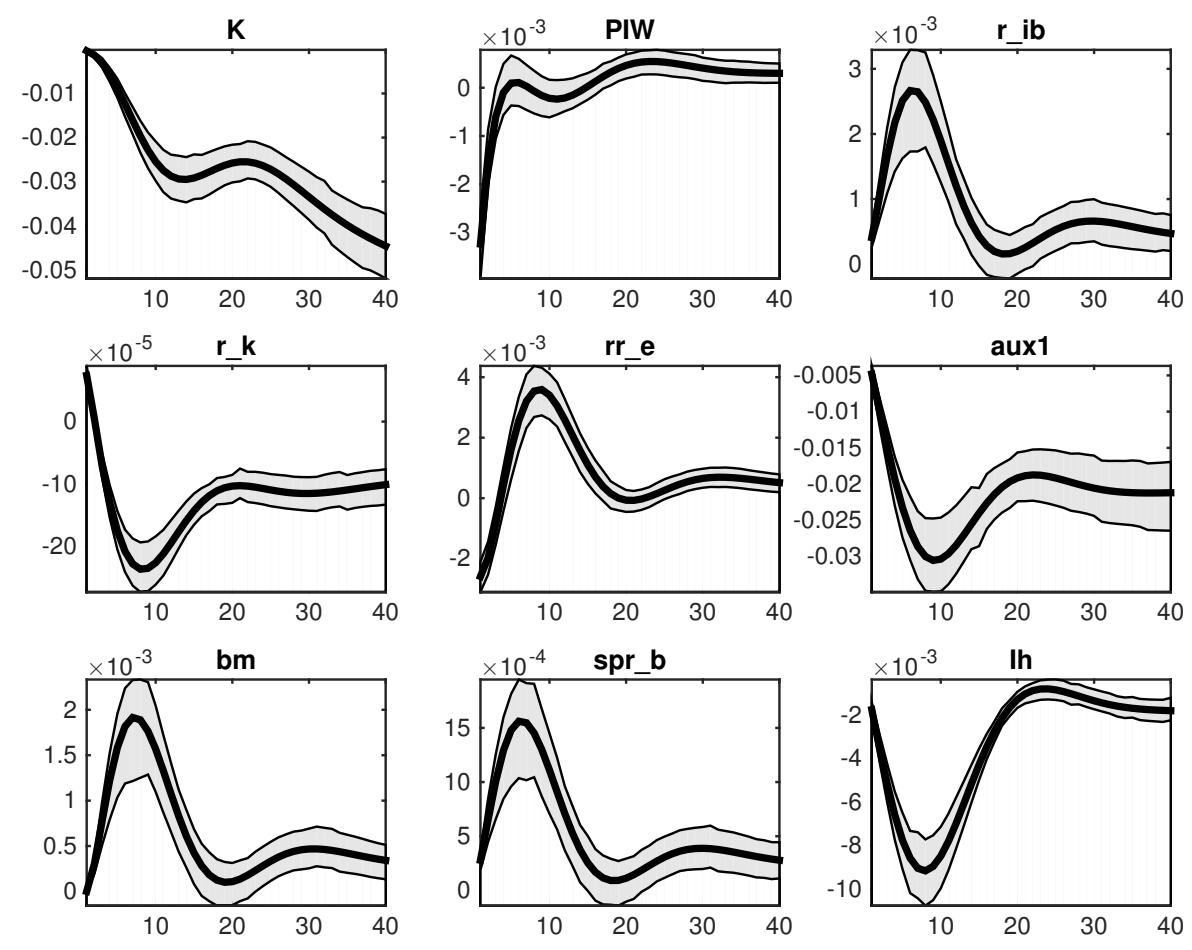

Figura 174: Efeito de um choque em y* 

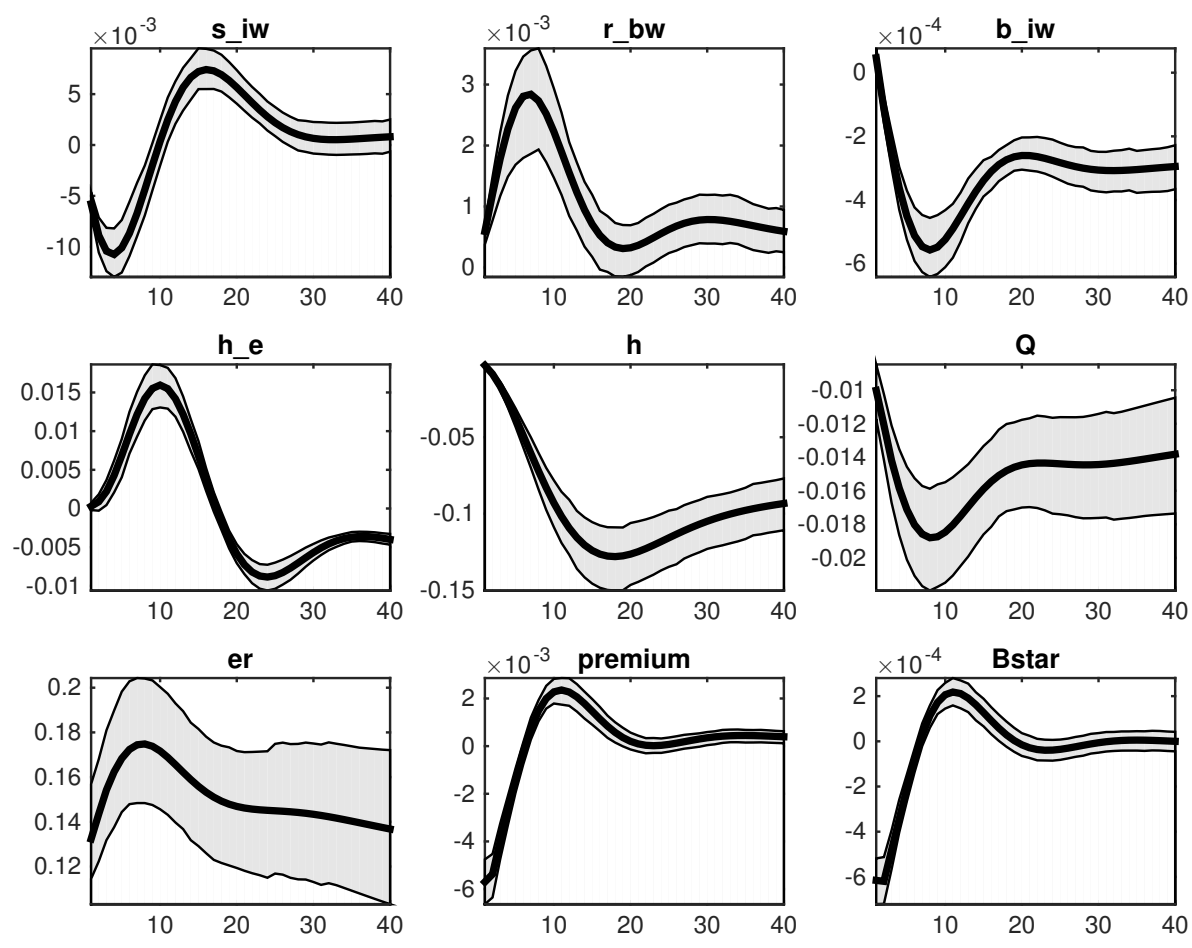

Figura 175: Efeito de um choque em $\mathrm{y}^{*}$
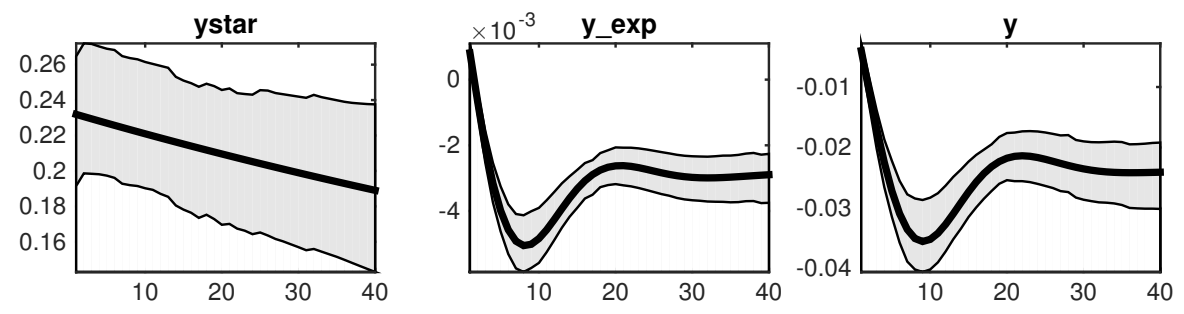

Figura 176: Efeito de um choque em $\mathrm{y}^{*}$ 
B.7 Efeito de um choque no debt-to-income
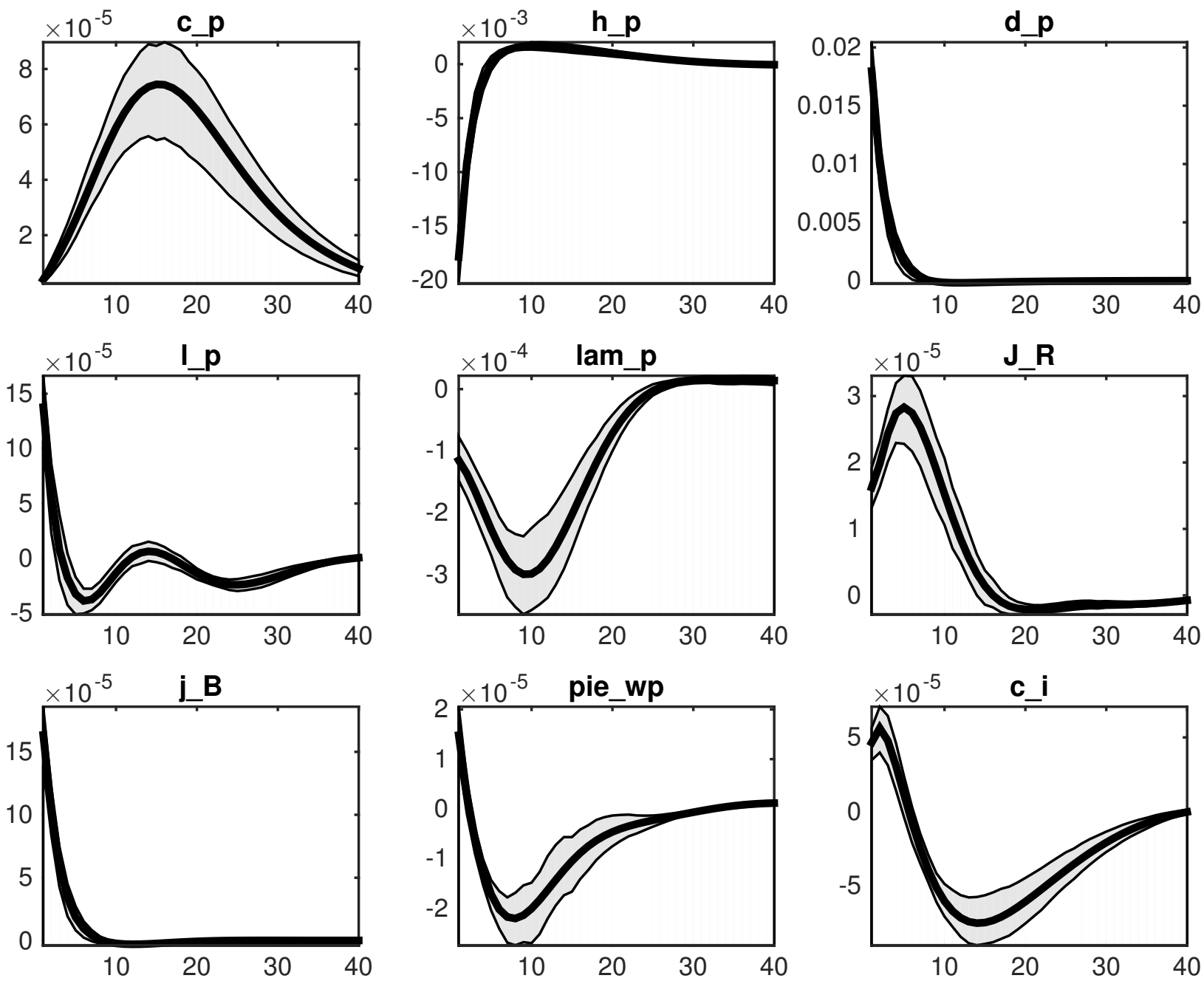

Figura 177: Efeito de um choque no debt-to-income 

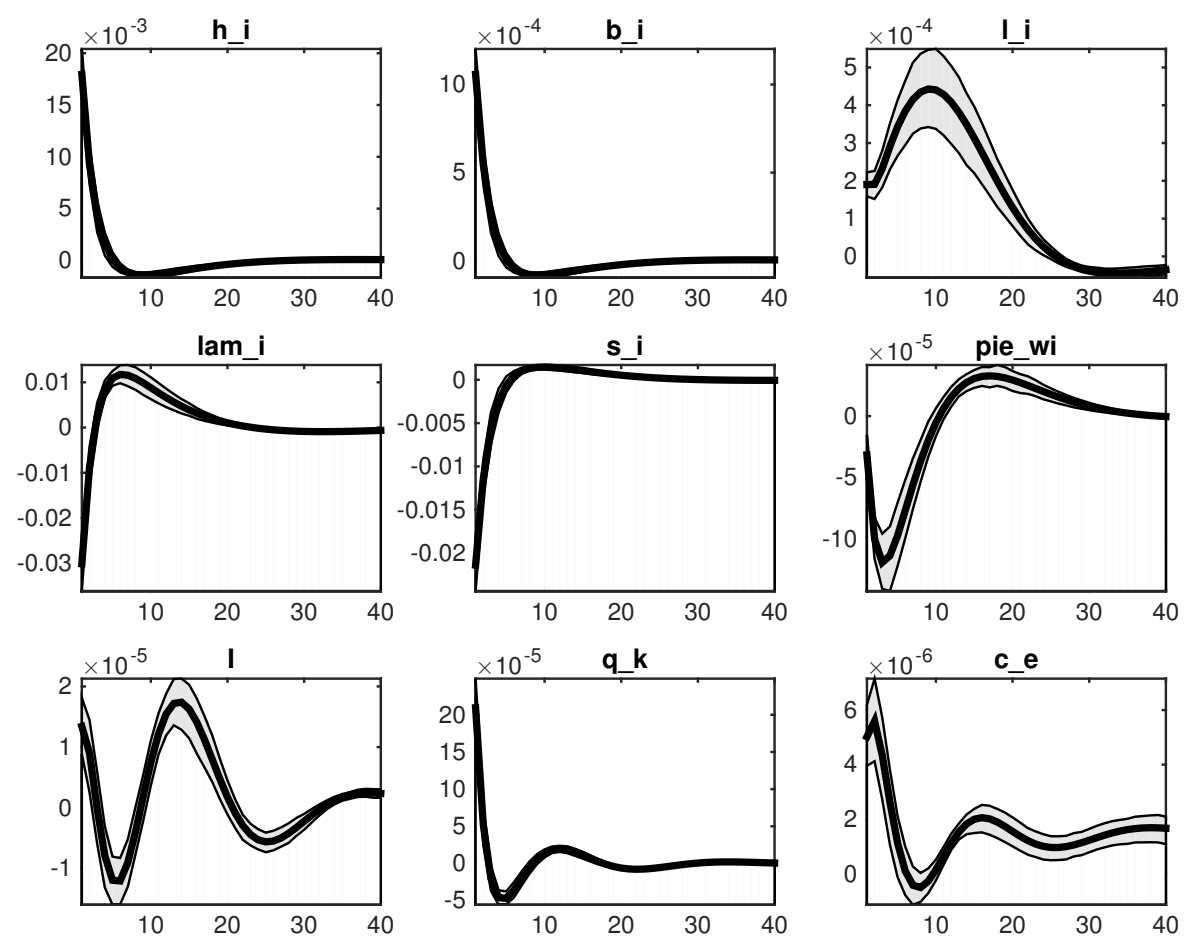

Figura 178: Efeito de um choque no debt-to-income
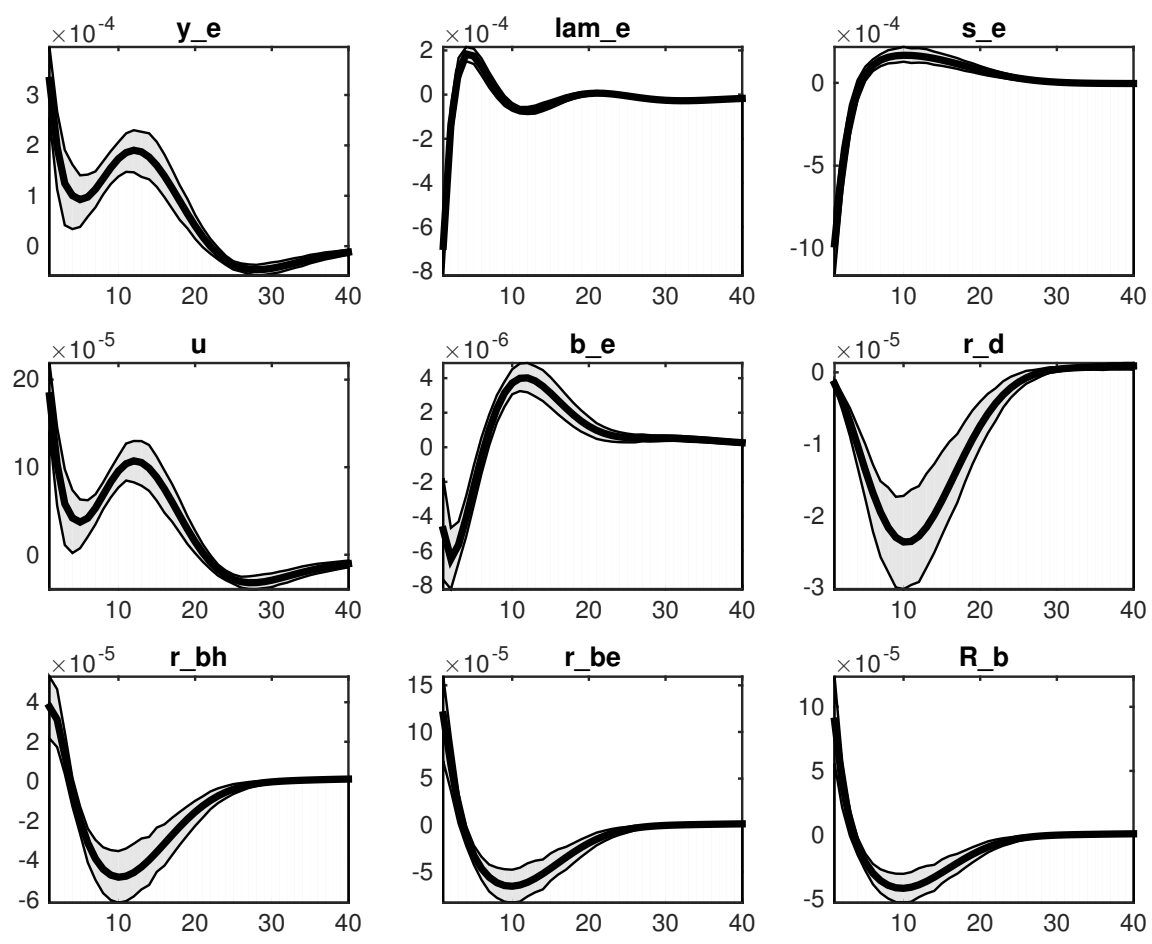

Figura 179: Efeito de um choque no debt-to-income 

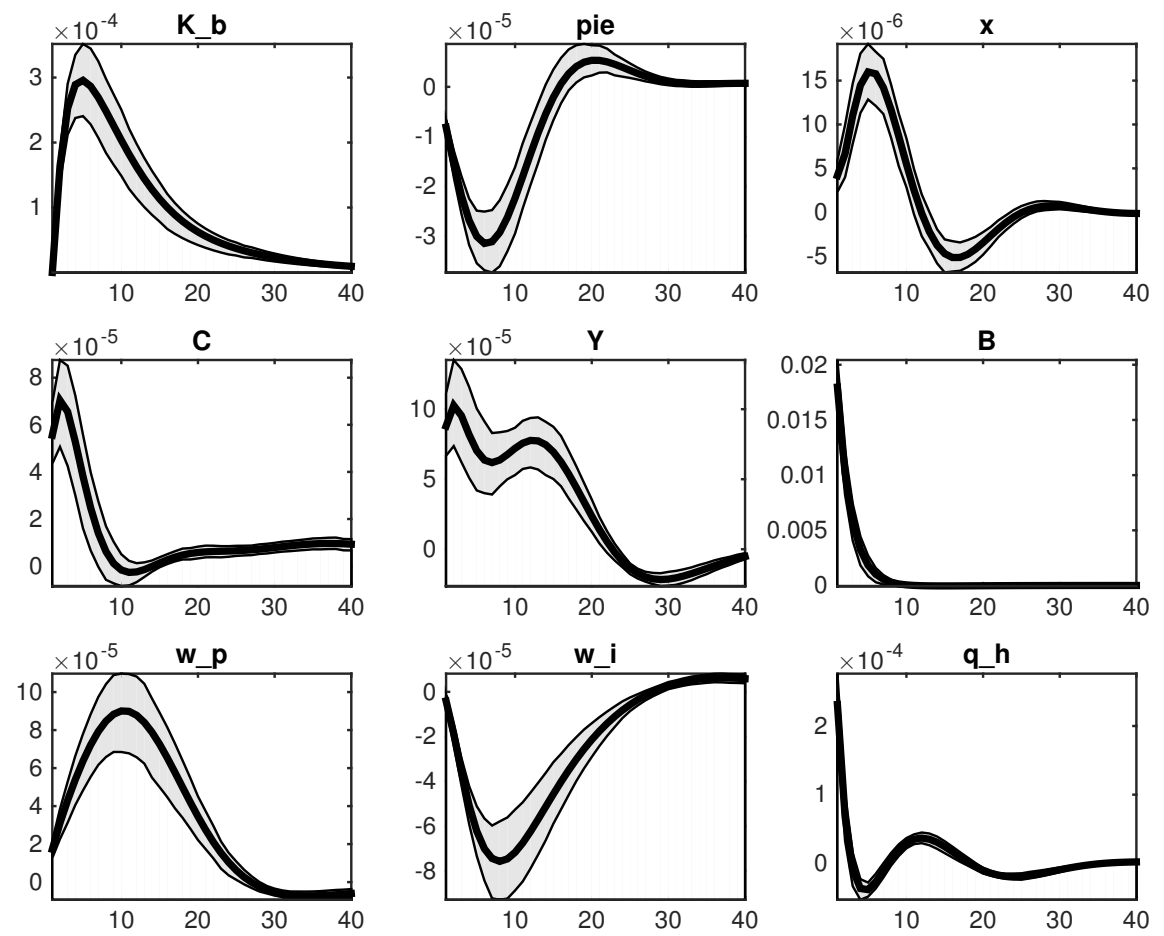

Figura 180: Efeito de um choque no debt-to-income
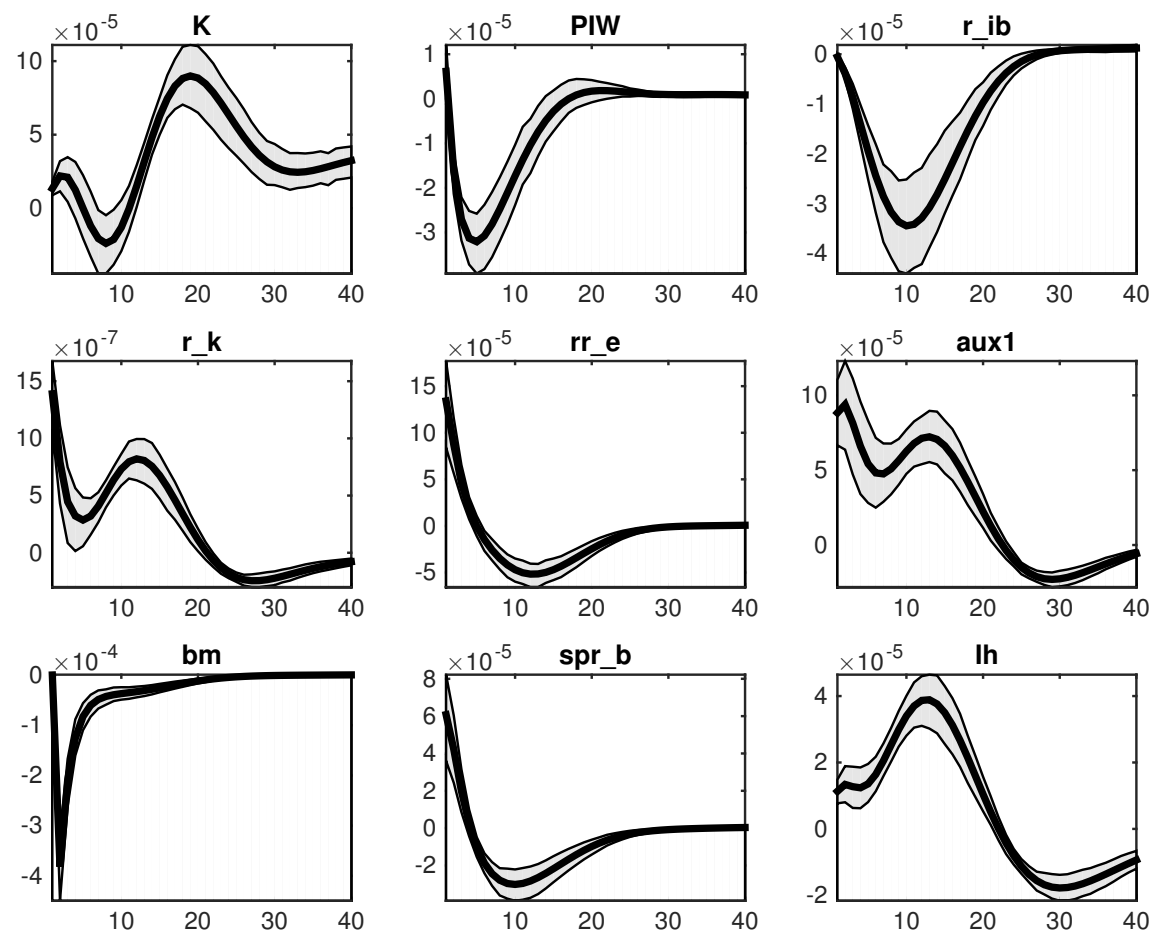

Figura 181: Efeito de um choque no debt-to-income 

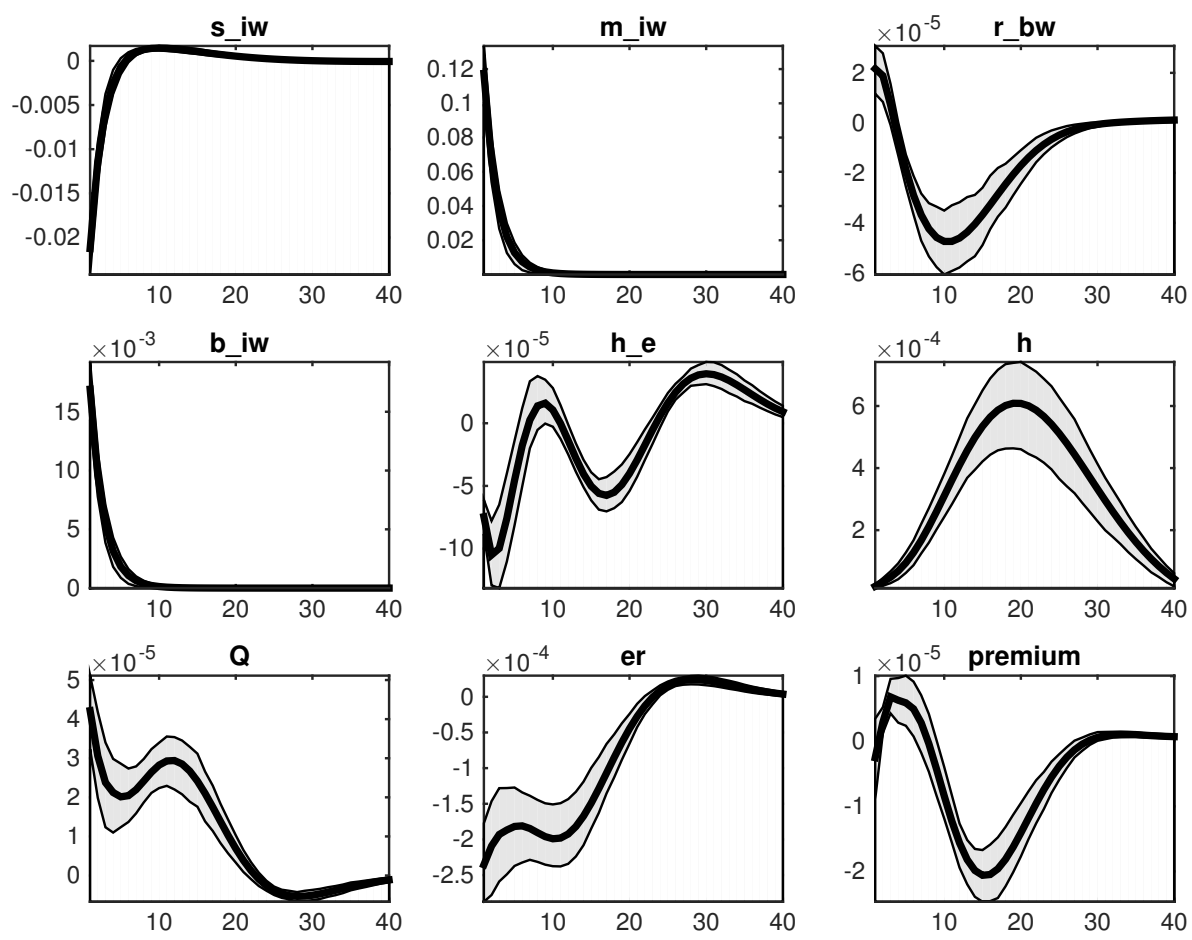

Figura 182: Efeito de um choque no debt-to-income
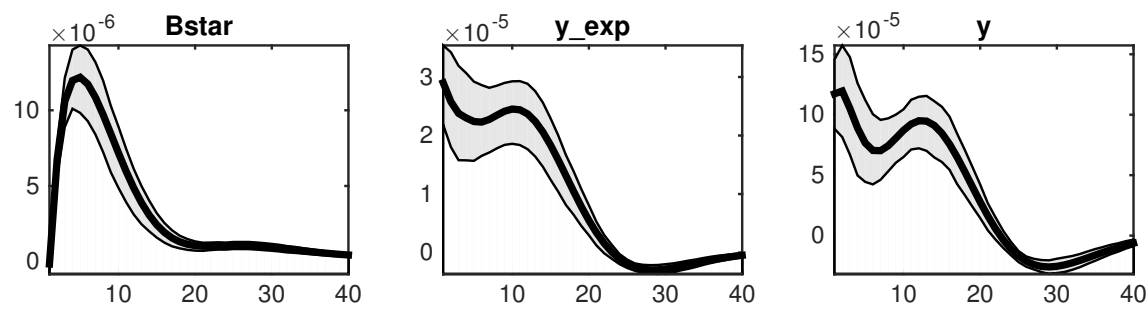

Figura 183: Efeito de um choque no debt-to-income 
B.8 Choque no Mark-up de taxa de juros: Empréstimo Consignado
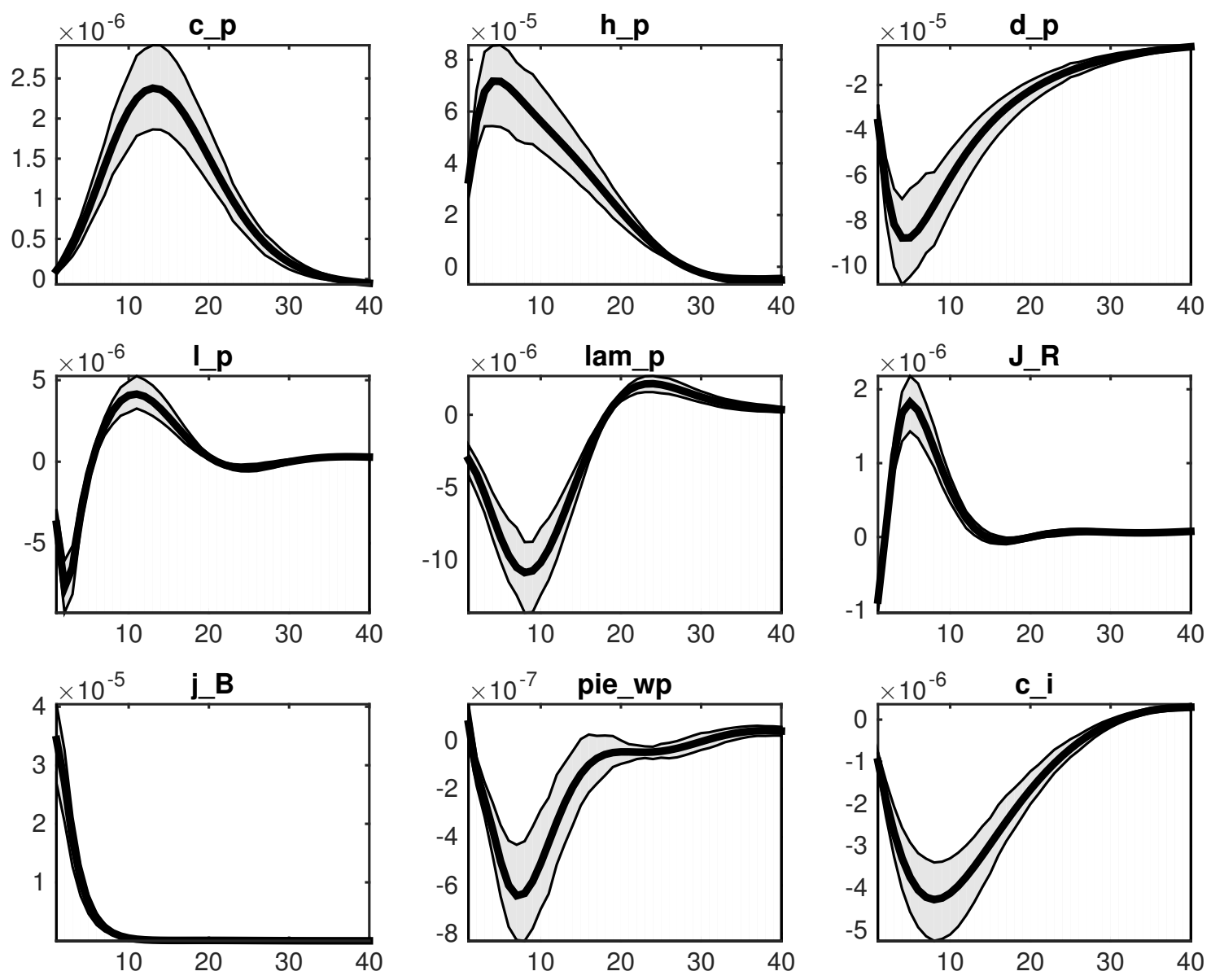

Figura 184: Efeito de um choque em mk_bw 

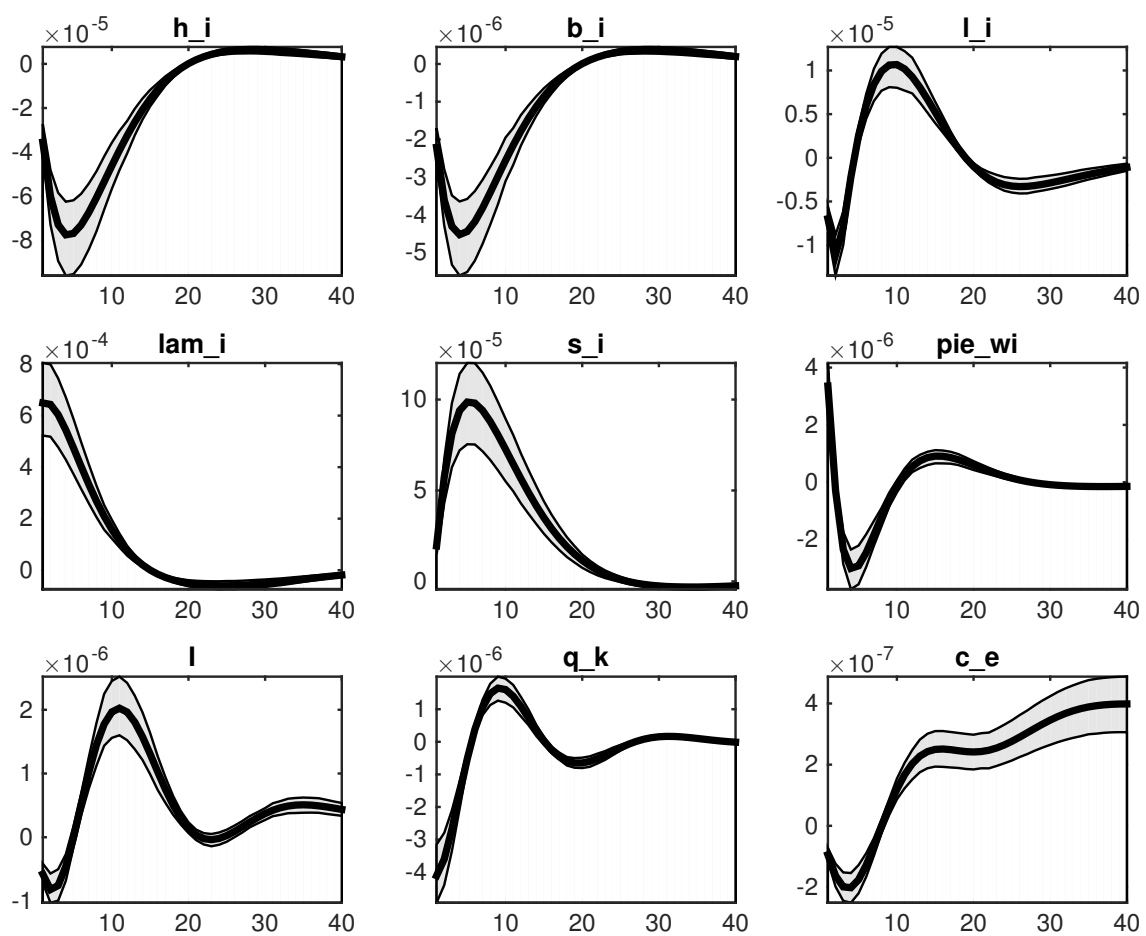

Figura 185: Efeito de um choque em mk_bw
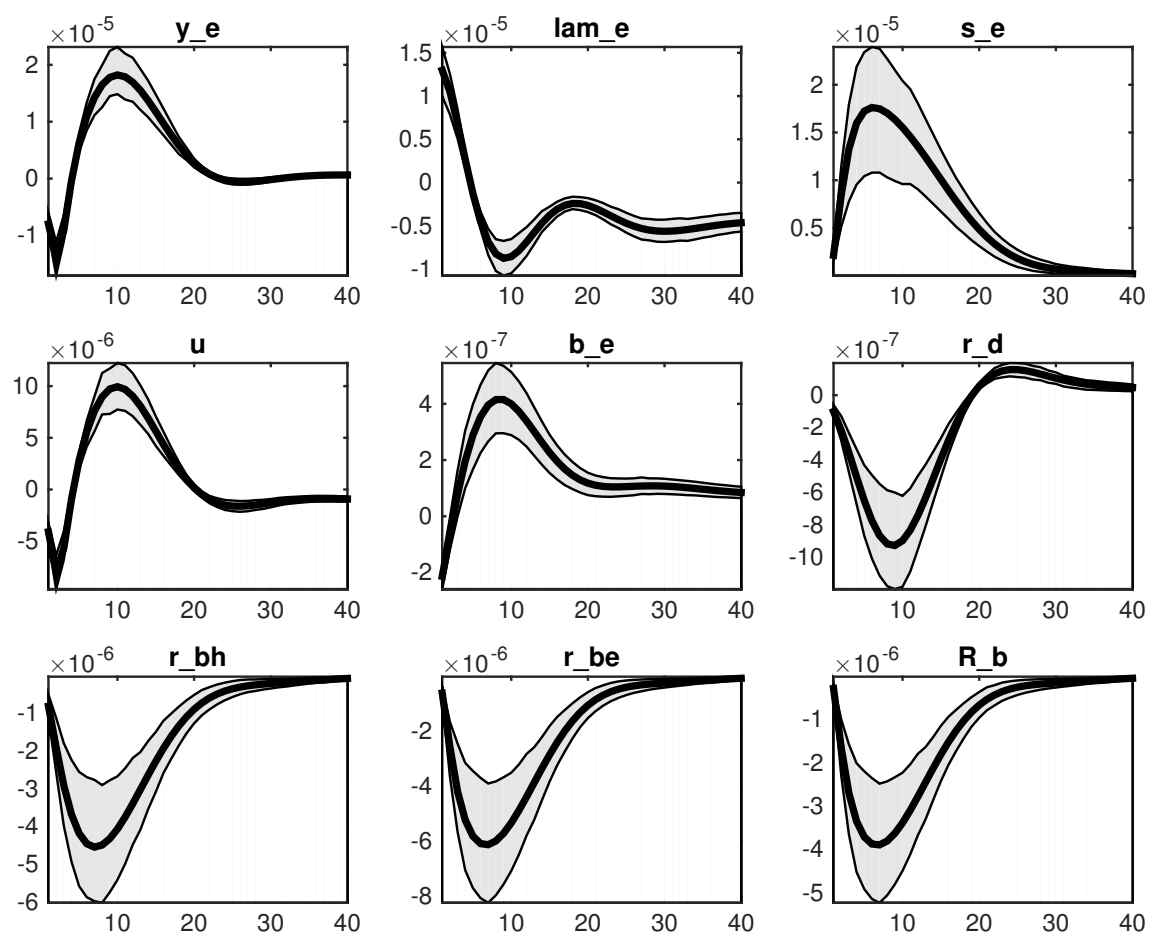

Figura 186: Efeito de um choque em mk_bw 

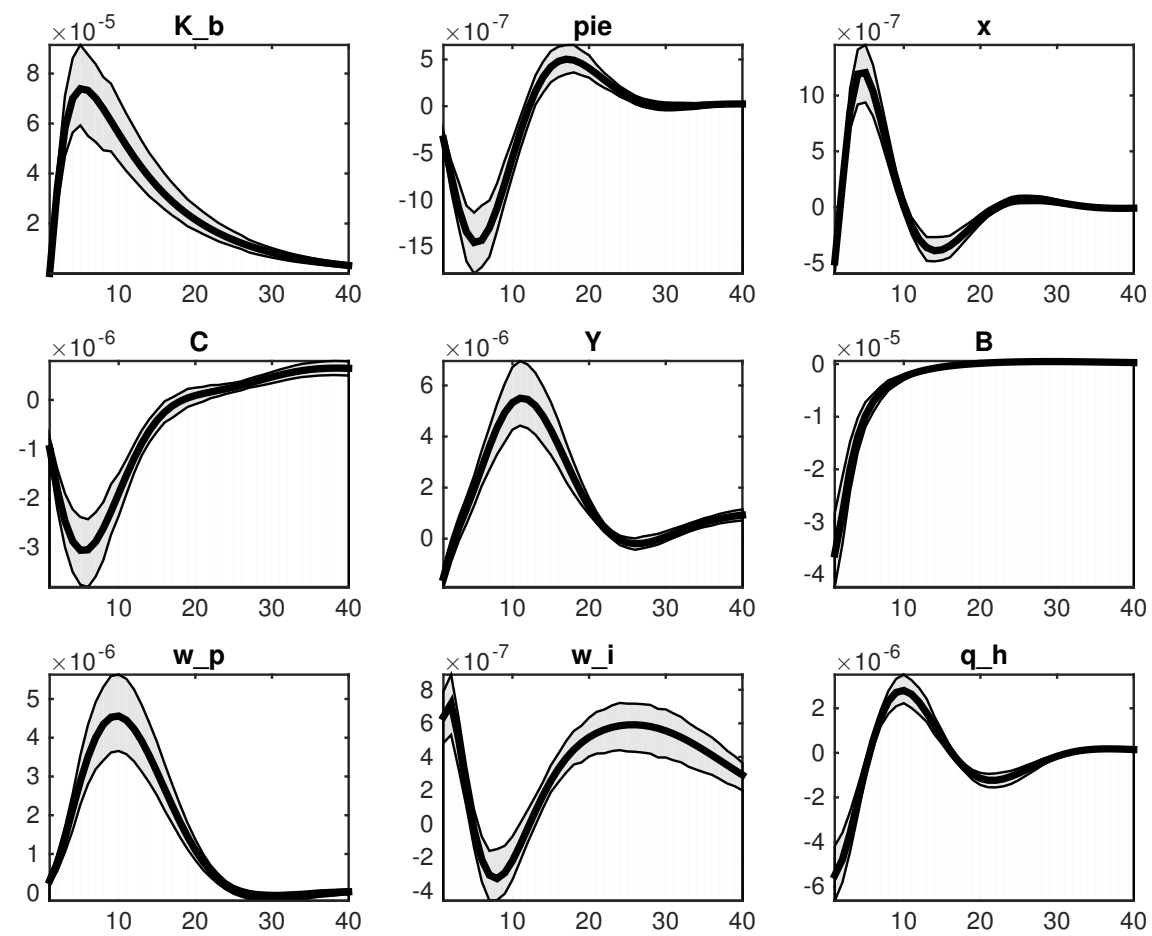

Figura 187: Efeito de um choque em mk_bw
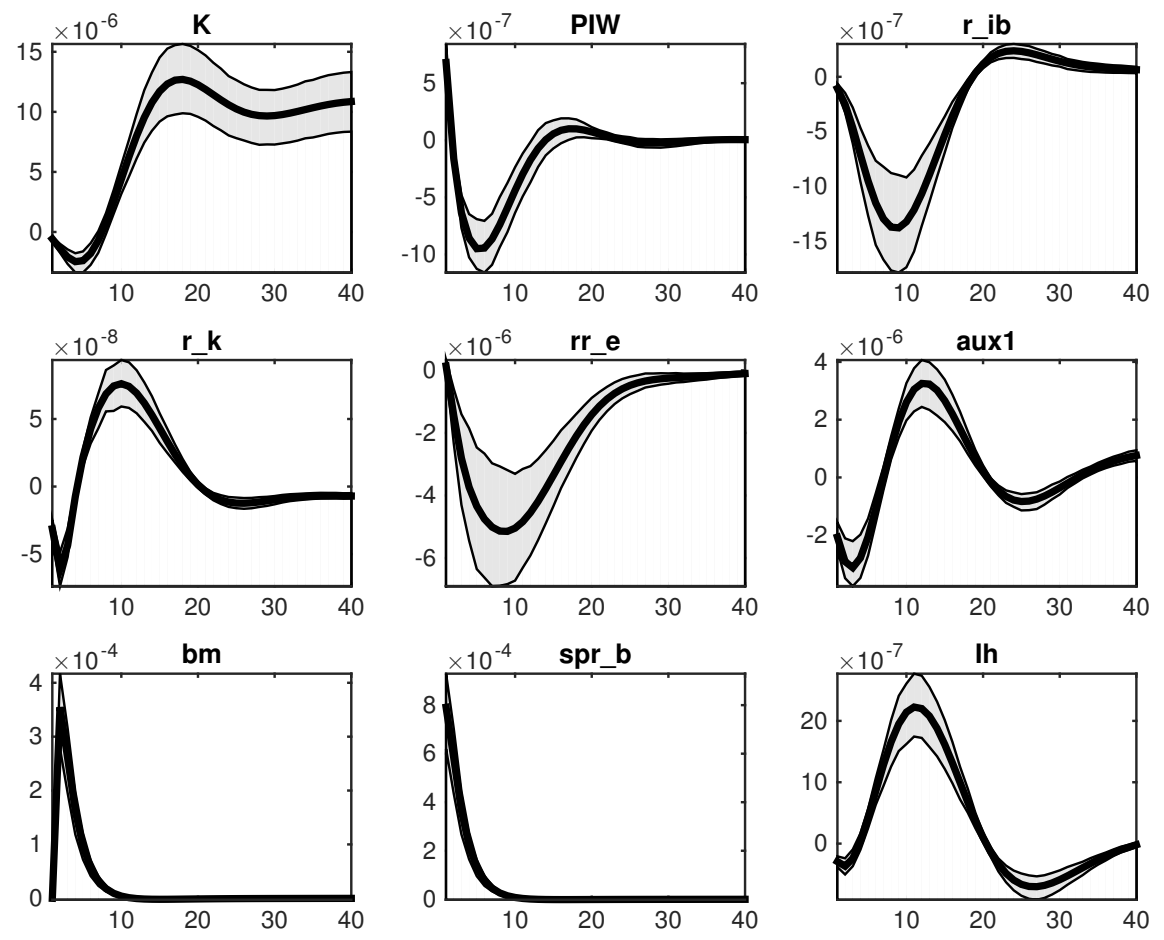

Figura 188: Efeito de um choque em mk_bw 

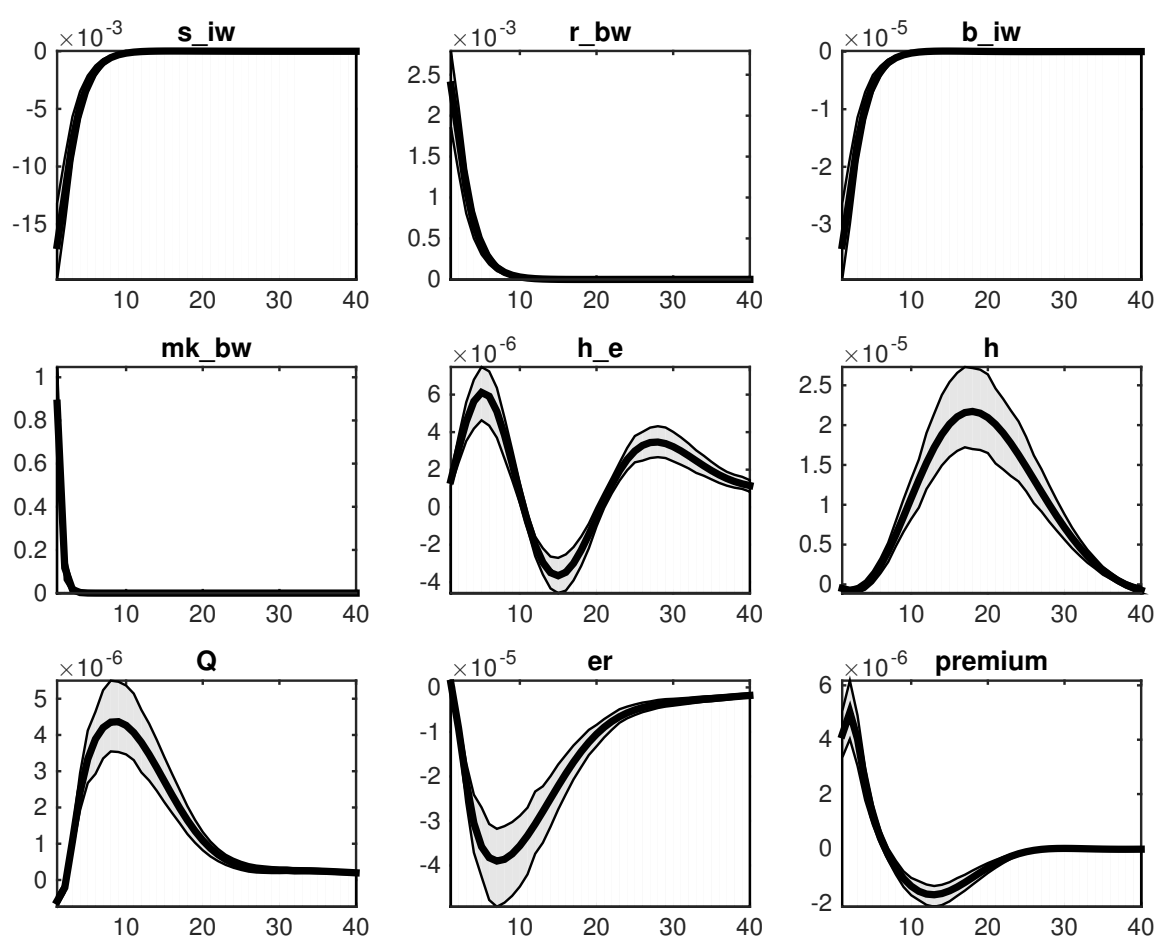

Figura 189: Efeito de um choque em mk_bw
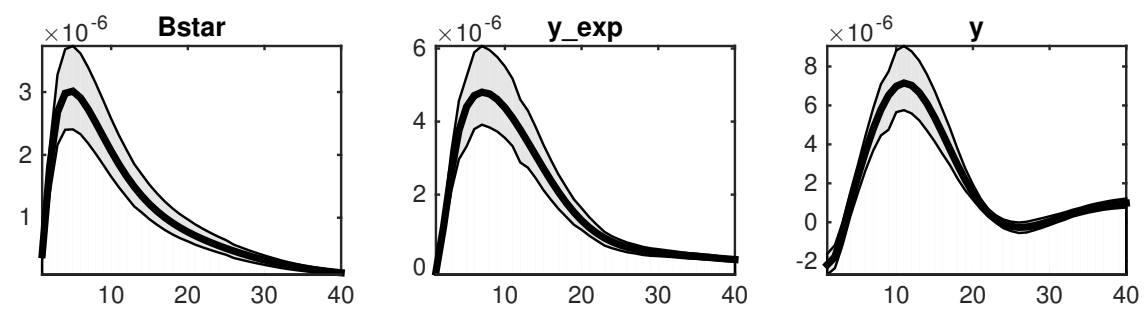

Figura 190: Efeito de um choque em mk_bw 
B.9 Choque na demanda por imóveis
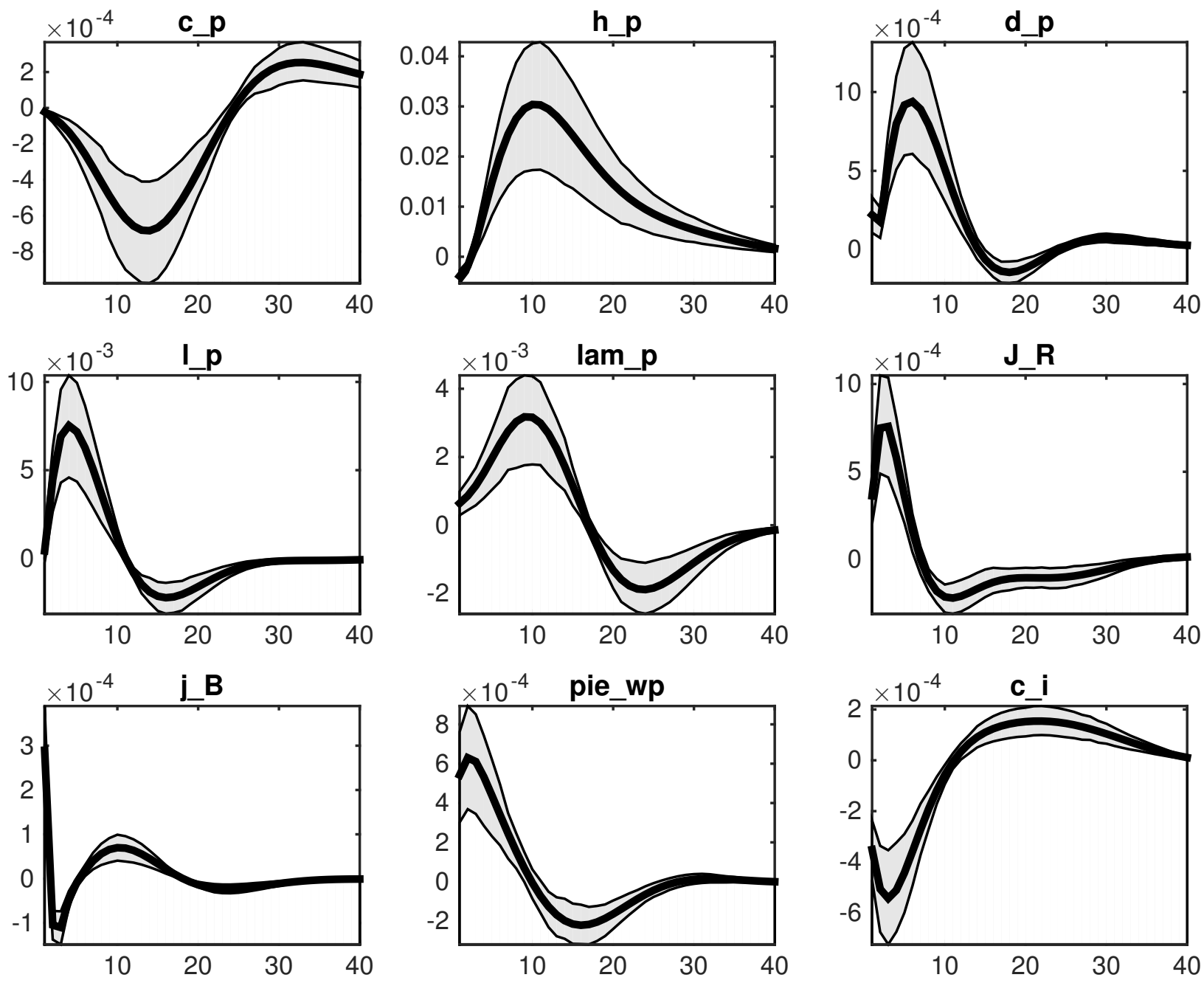

Figura 191: Efeito de um choque em e_j 

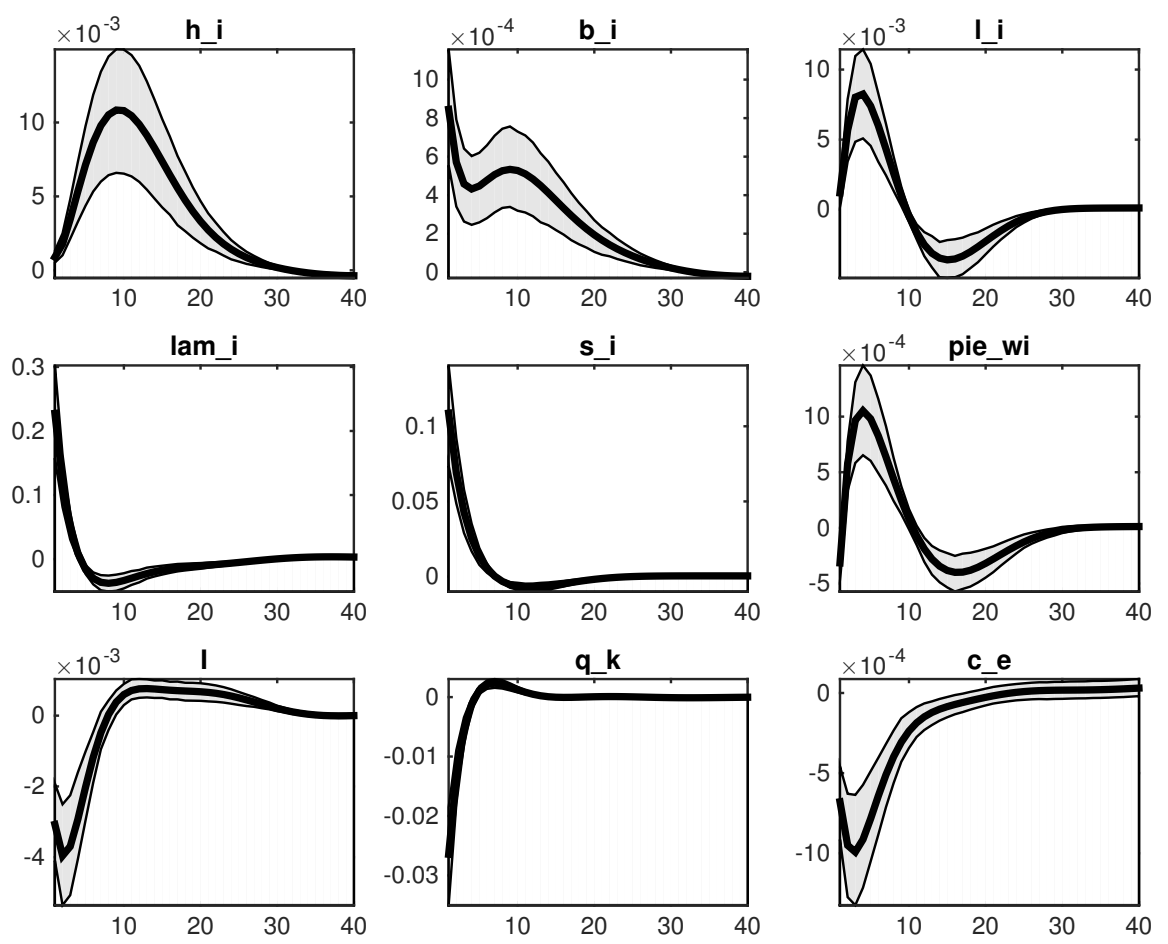

Figura 192: Efeito de um choque em e_j
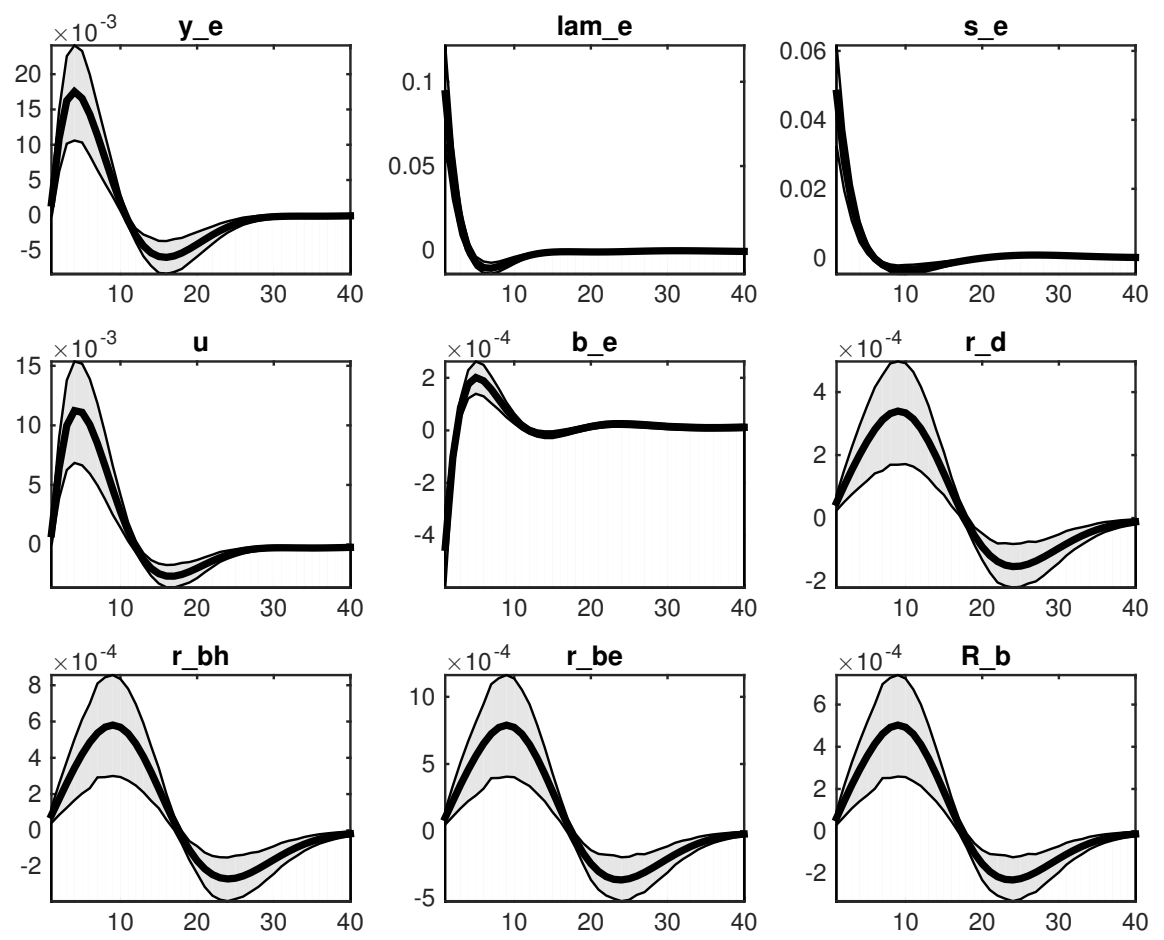

Figura 193: Efeito de um choque em e_j 

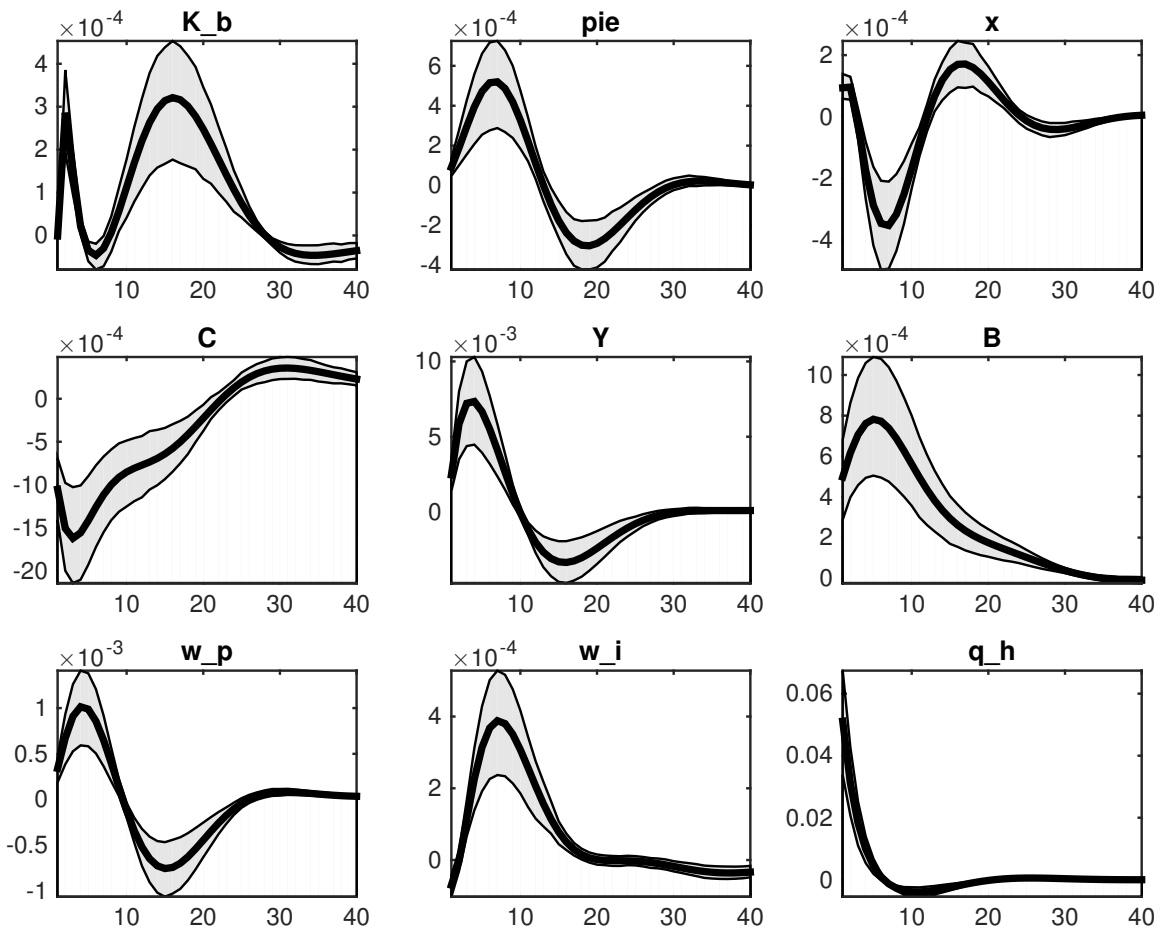

Figura 194: Efeito de um choque em $\mathrm{e} \_\mathrm{j}$
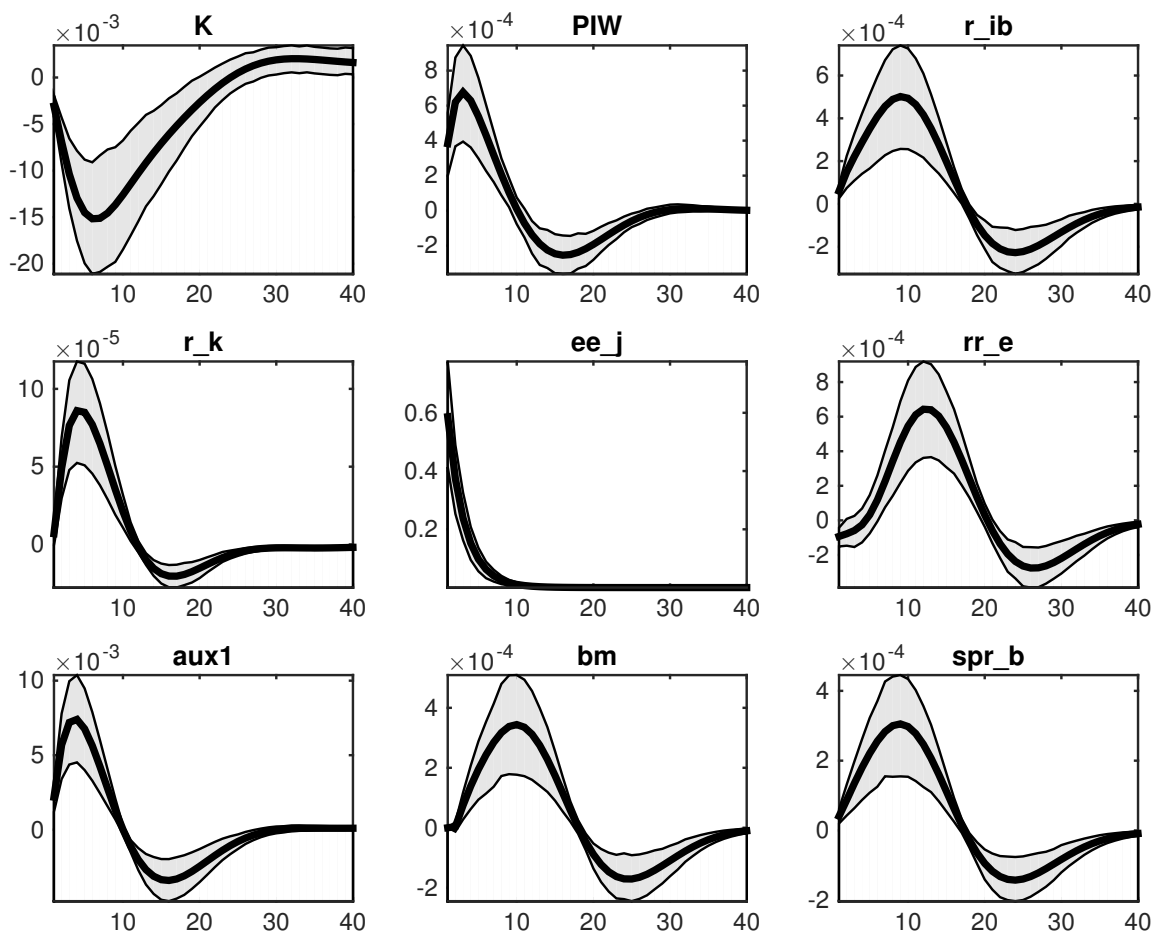

Figura 195: Efeito de um choque em e_ $\mathrm{j}$ 

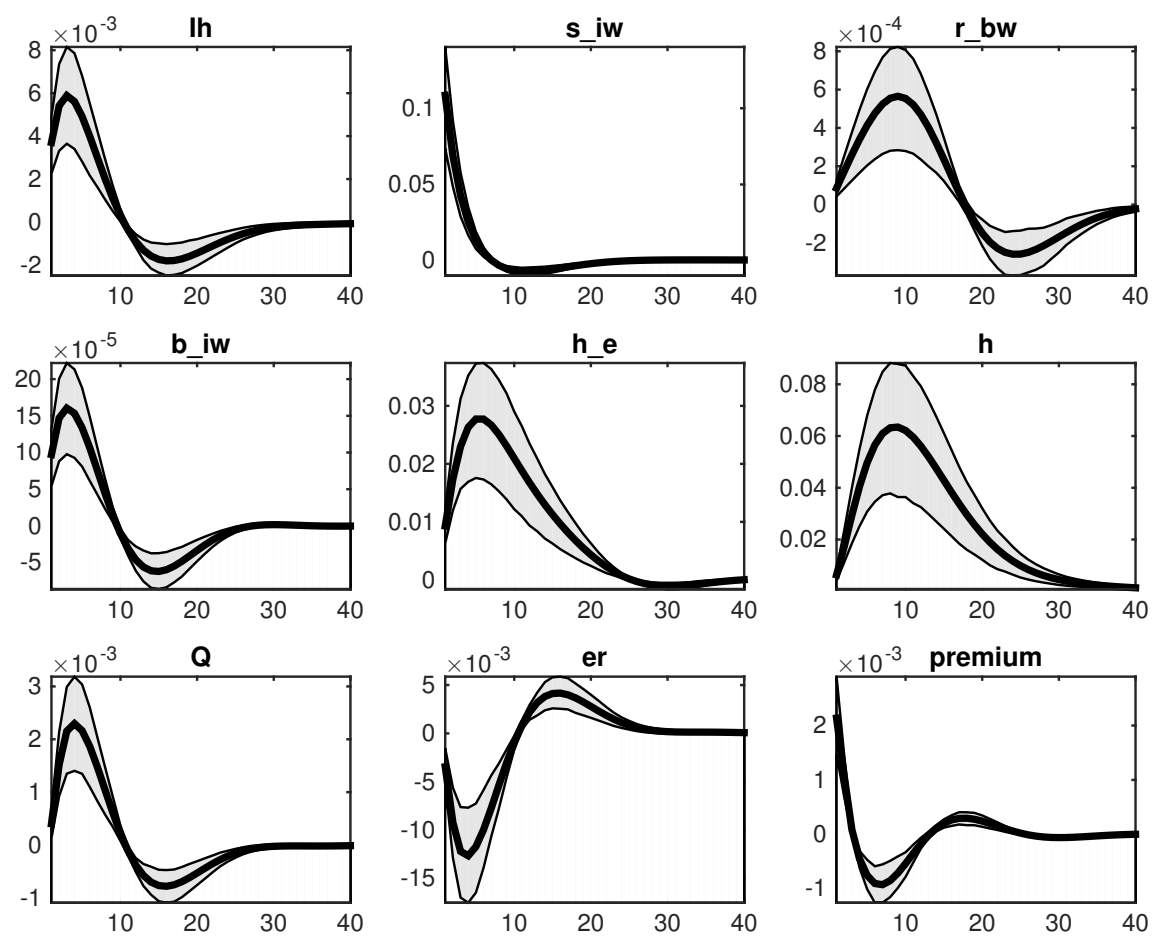

Figura 196: Efeito de um choque em e_ $\mathrm{j}$
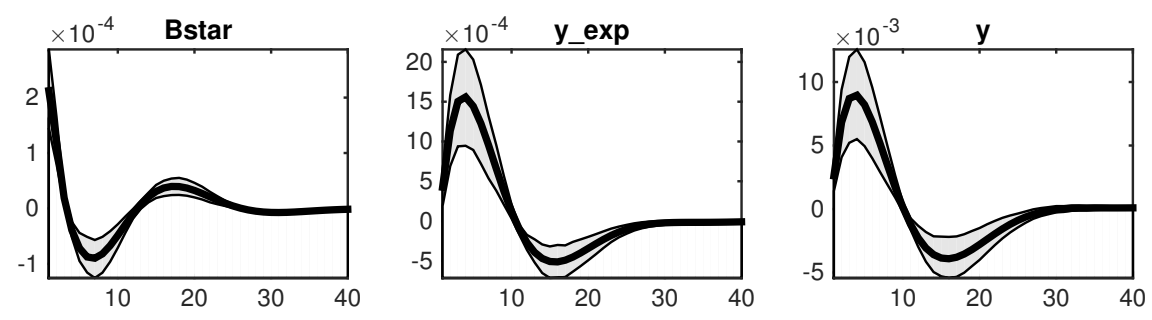

Figura 197: Efeito de um choque em e_j 
B.10 Choque na oferta de imóveis
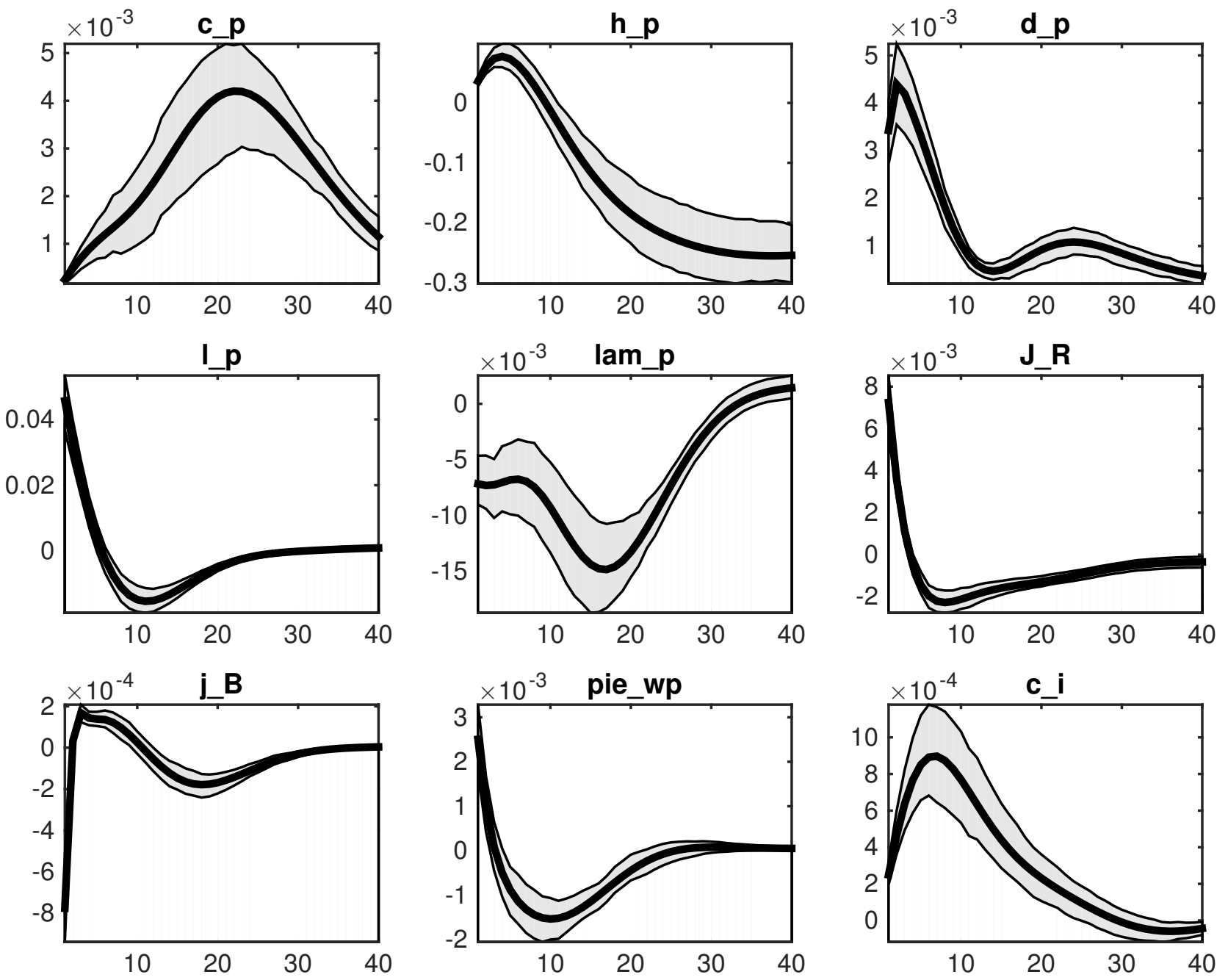

Figura 198: Efeito de um choque em I ${ }^{h}$ 

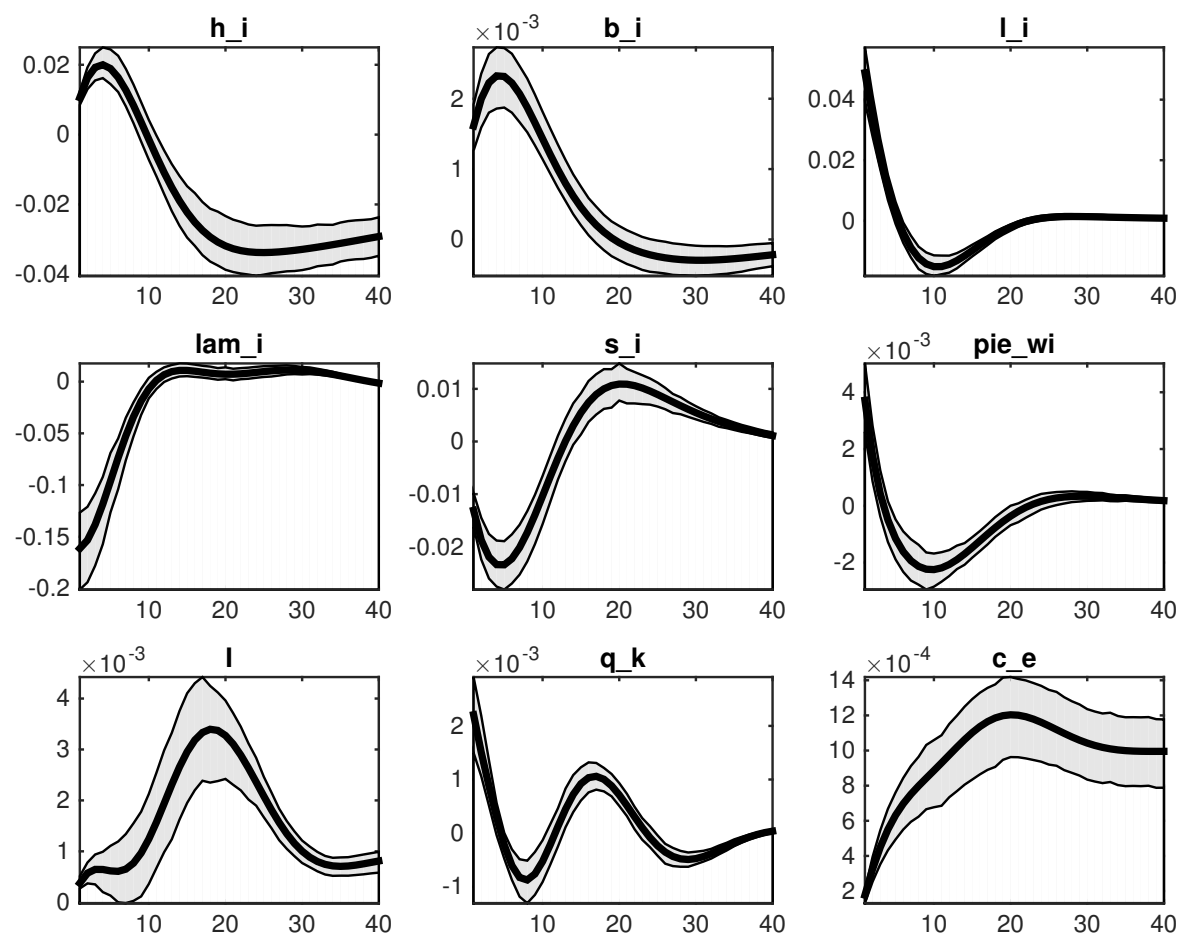

Figura 199: Efeito de um choque em $\mathrm{I}^{h}$
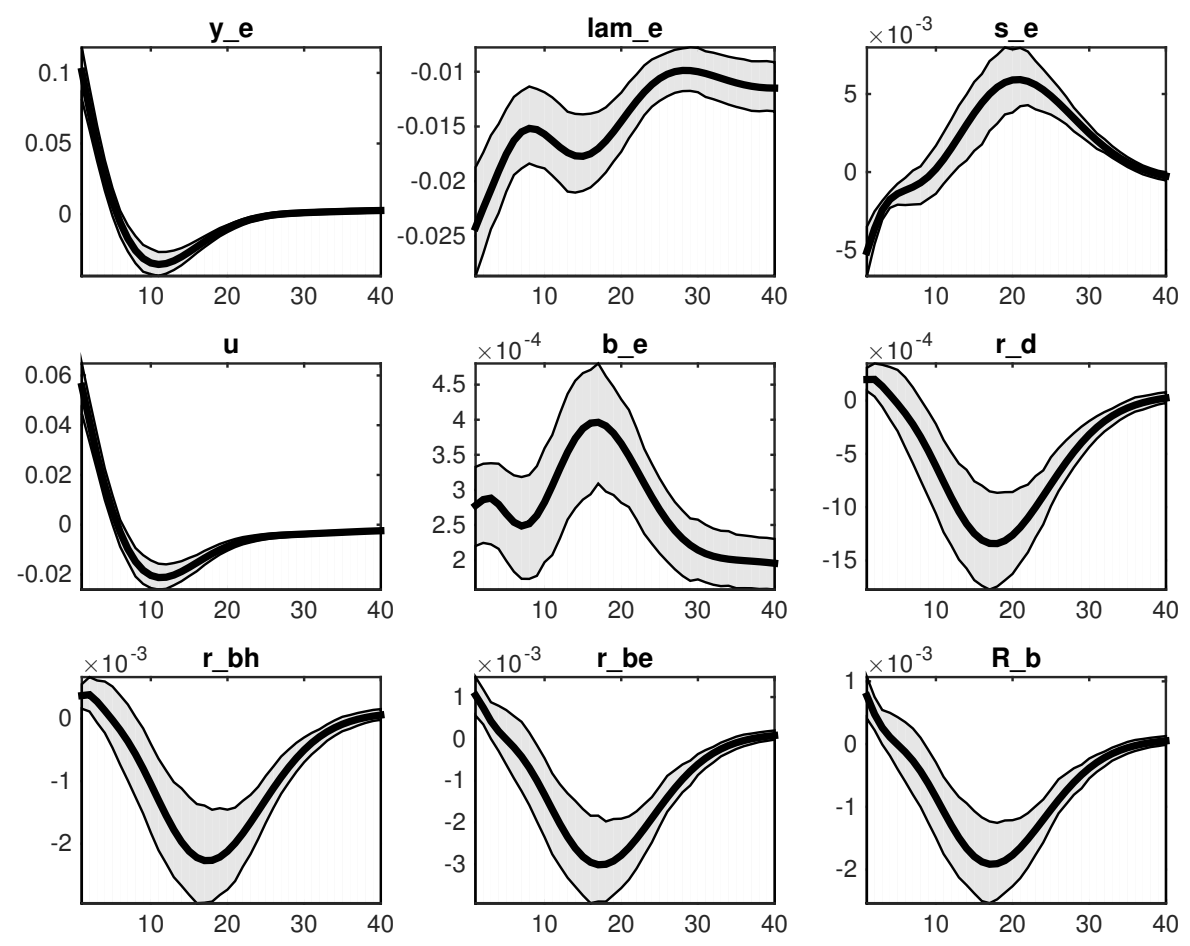

Figura 200: Efeito de um choque em $\mathrm{I}^{h}$ 

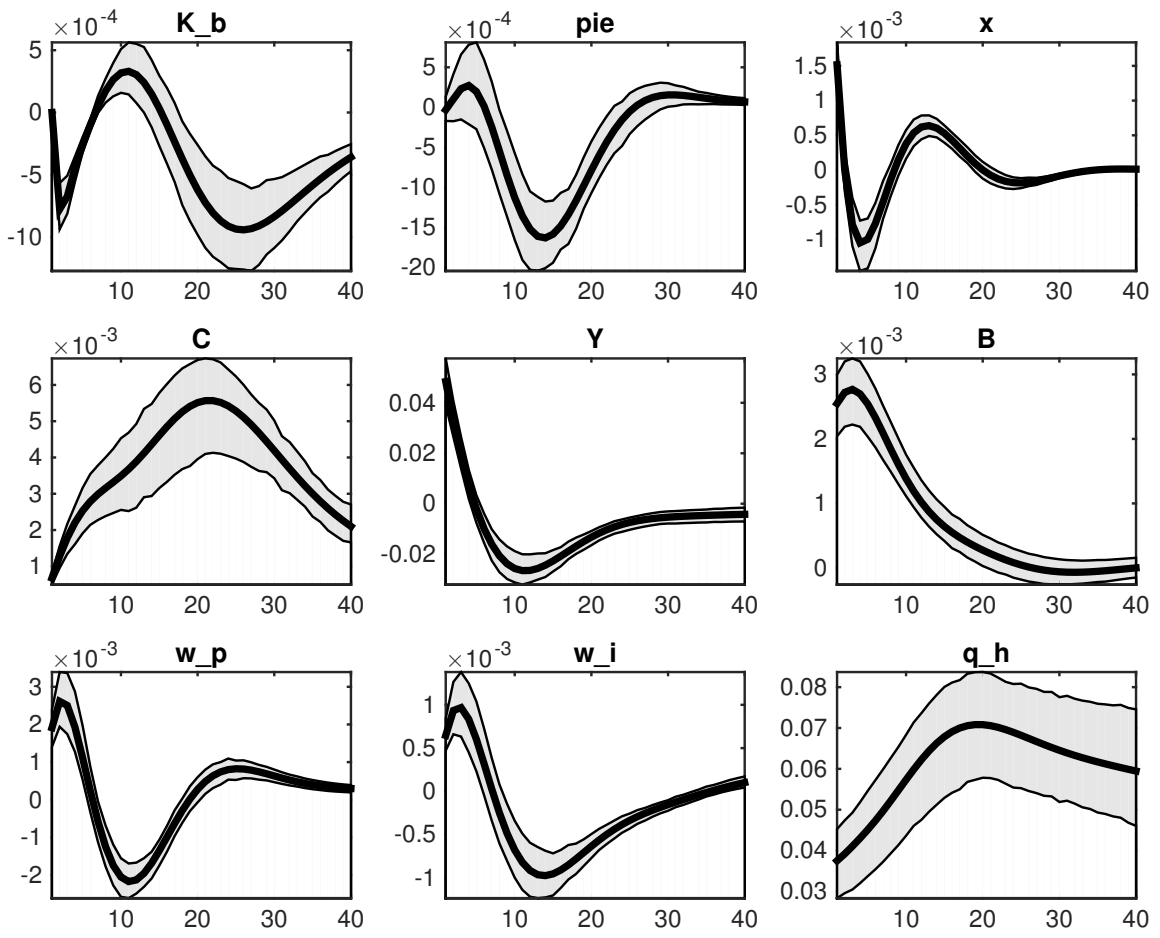

Figura 201: Efeito de um choque em I ${ }^{h}$
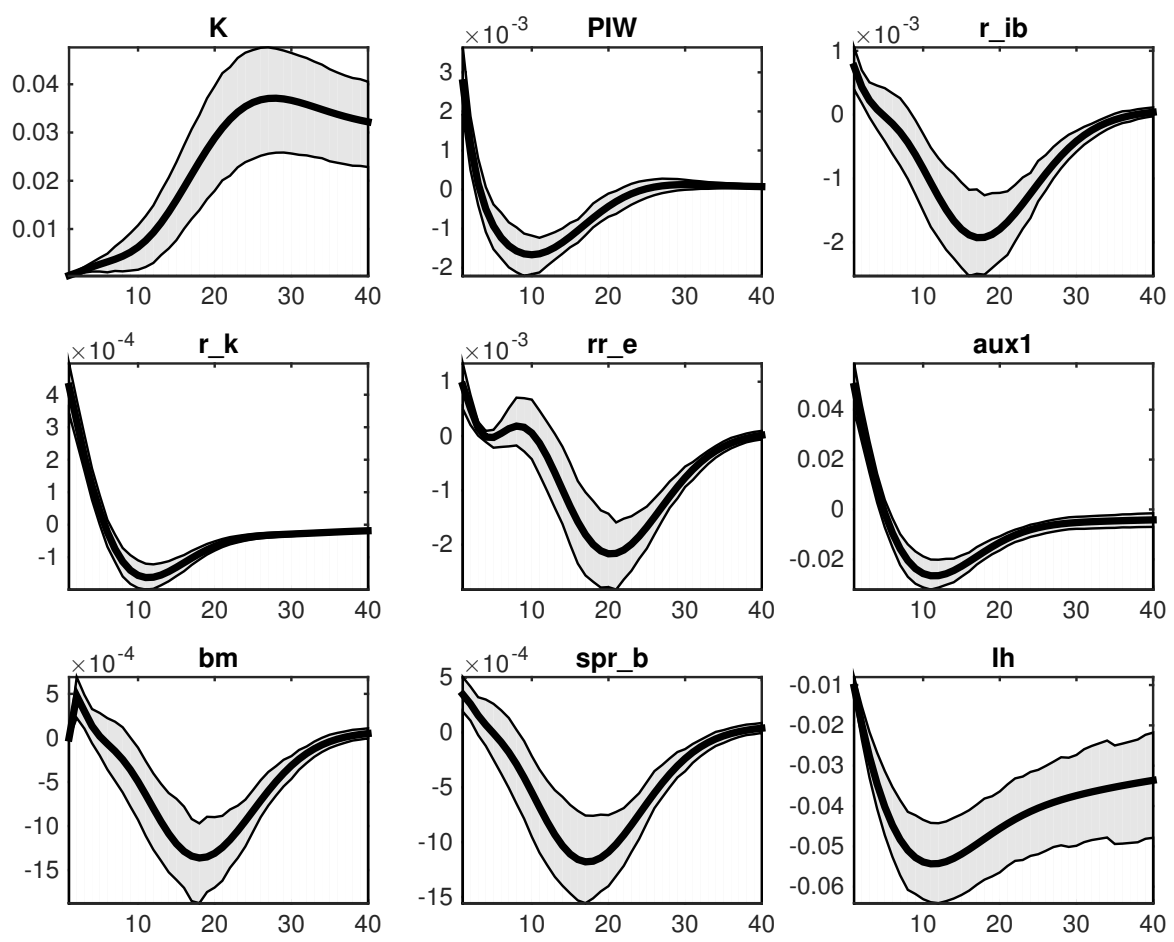

Figura 202: Efeito de um choque em $\mathrm{I}^{h}$ 

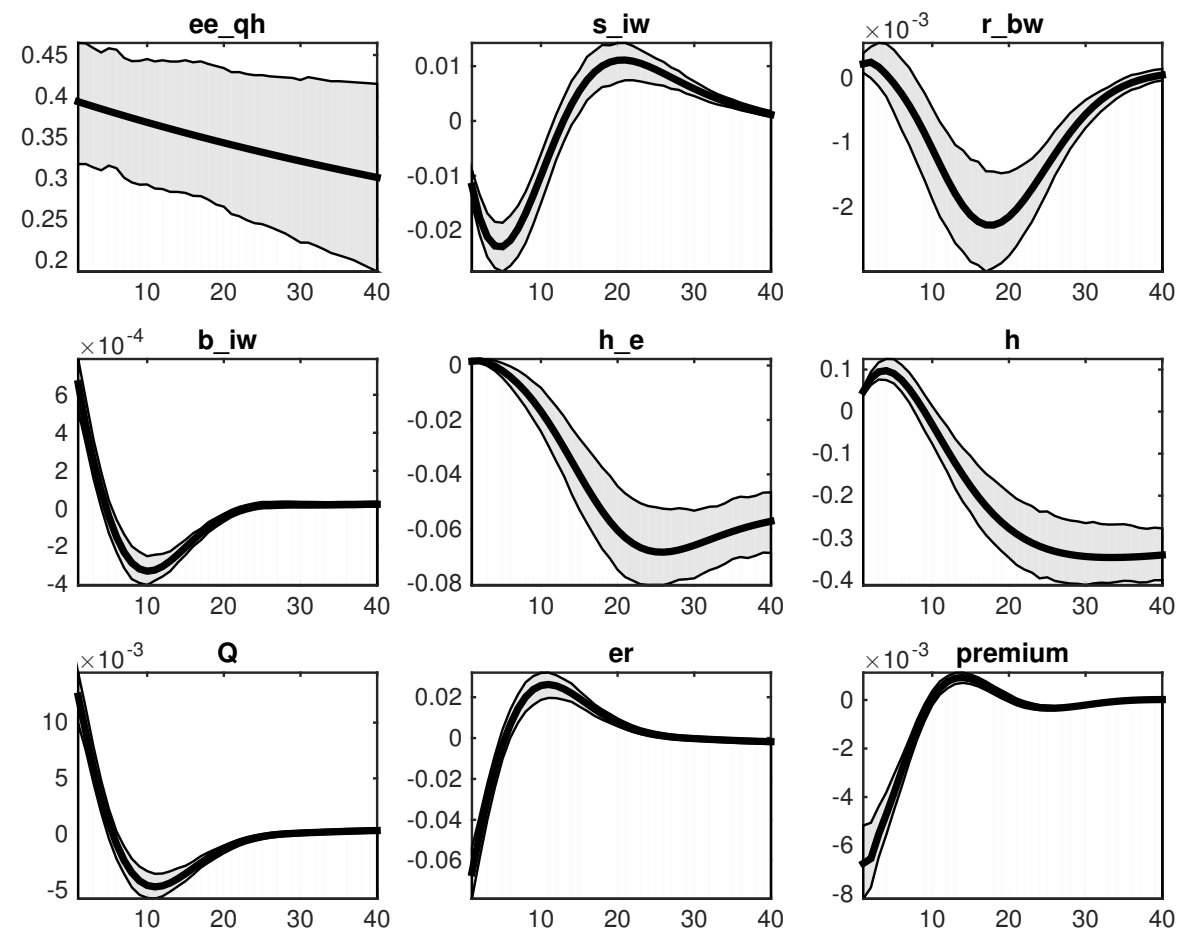

Figura 203: Efeito de um choque em $\mathrm{I}^{h}$
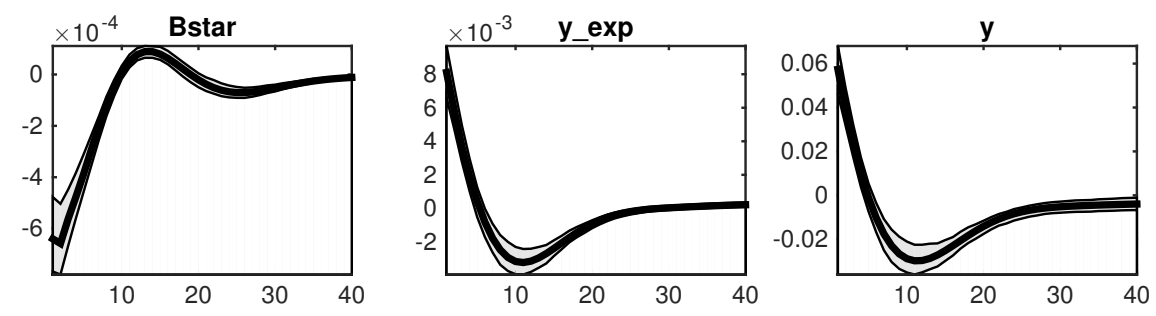

Figura 204: Efeito de um choque em I ${ }^{h}$ 


\section{B.11 Choque tecnológico}
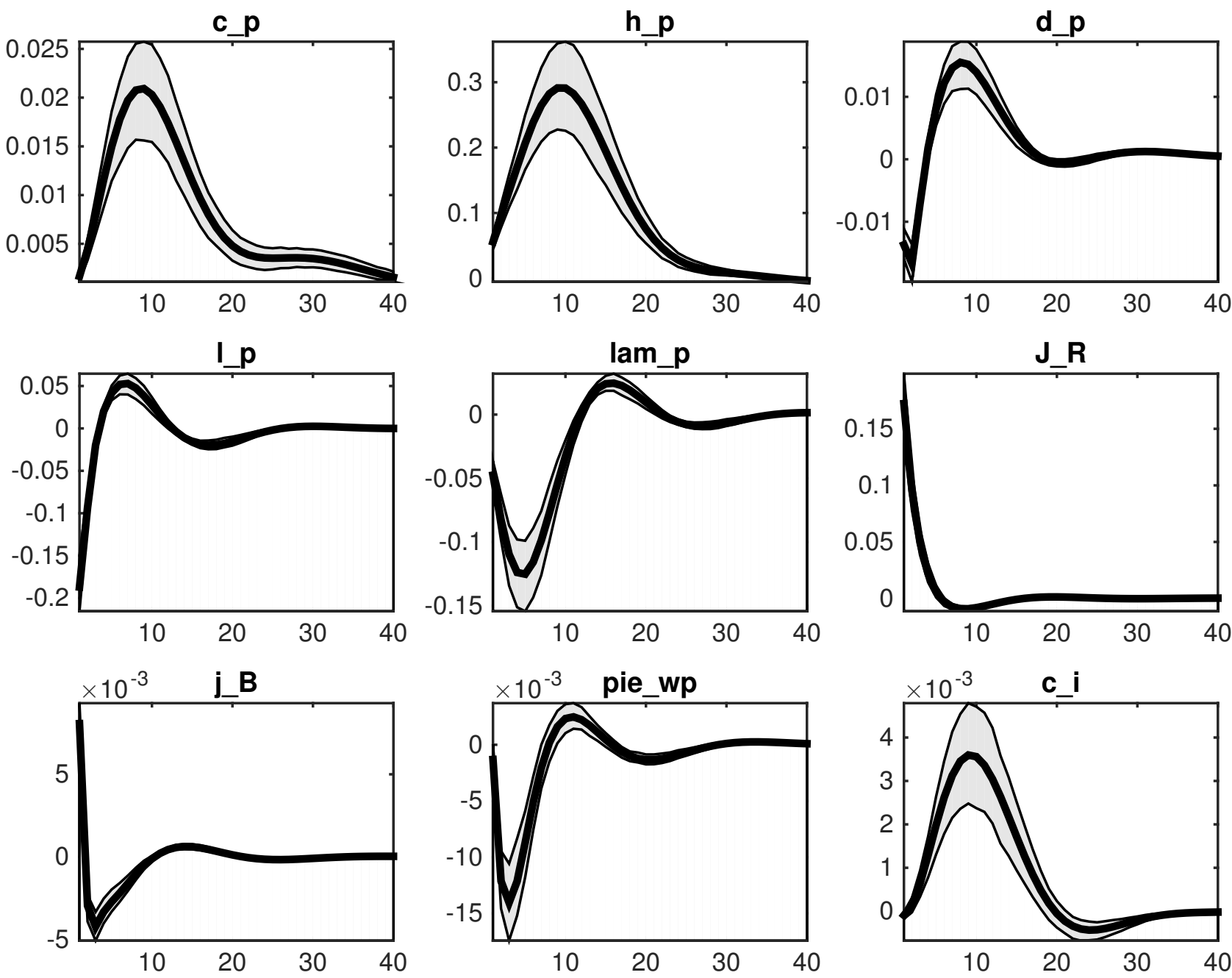

Figura 205: Efeito de um choque tecnológico 

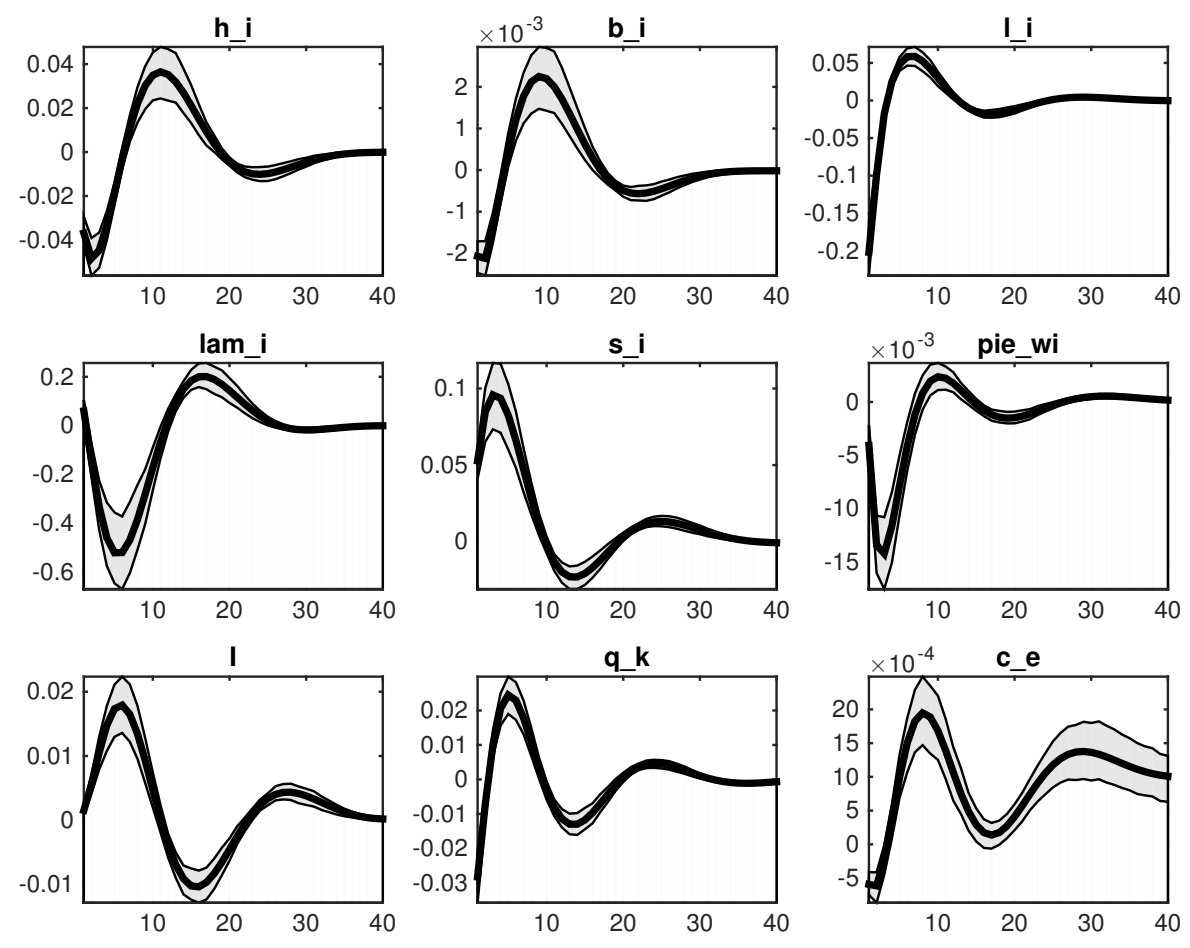

Figura 206: Efeito de um choque tecnológico
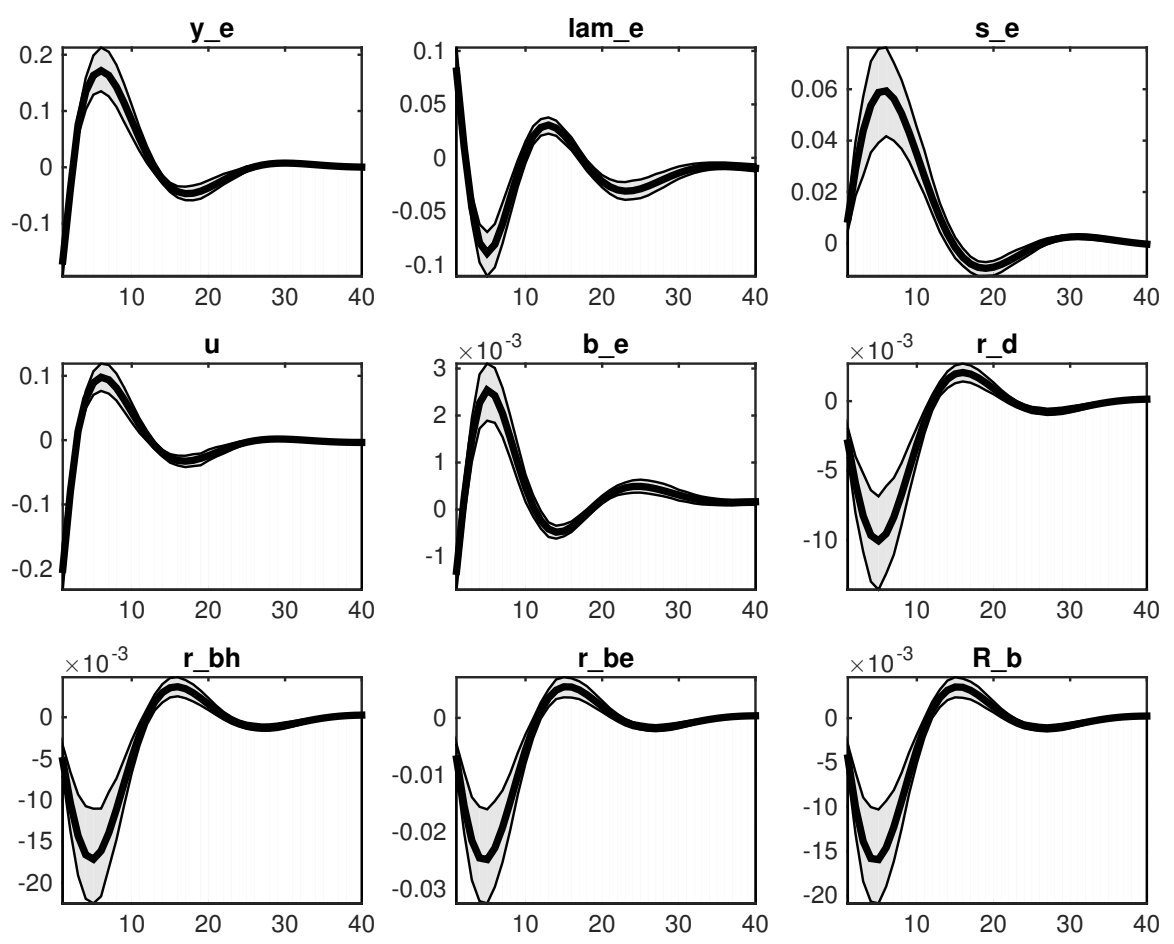

Figura 207: Efeito de um choque tecnológico 

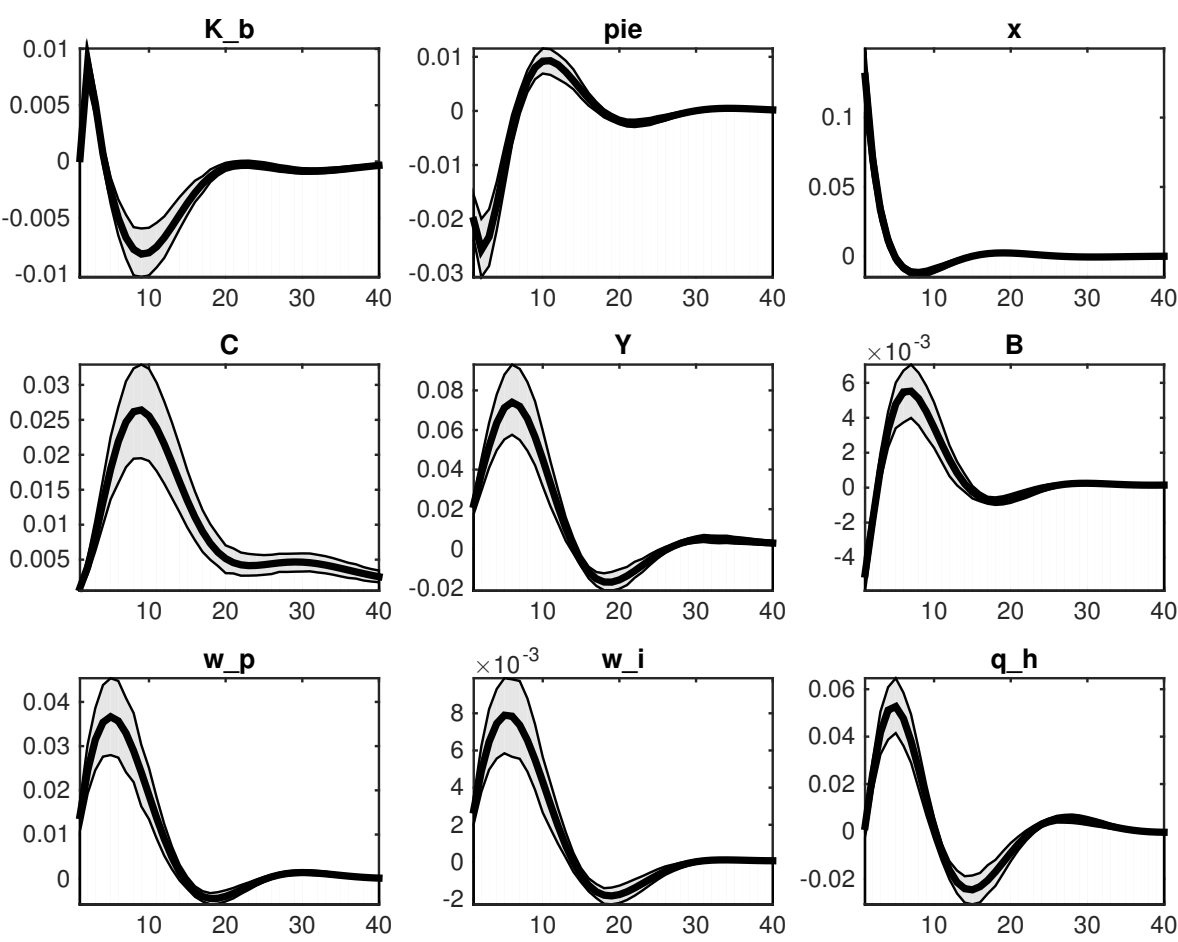

Figura 208: Efeito de um choque tecnológico
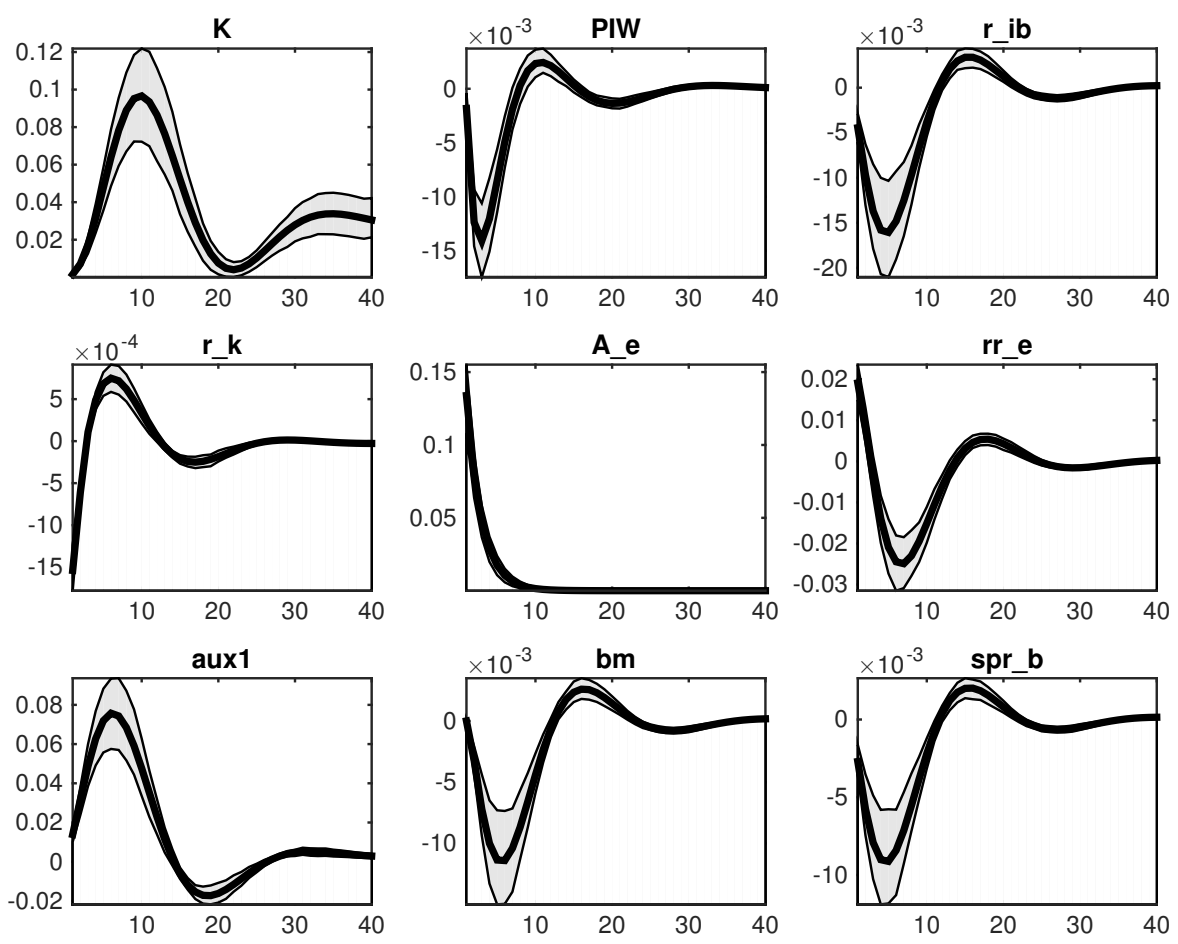

Figura 209: Efeito de um choque tecnológico 

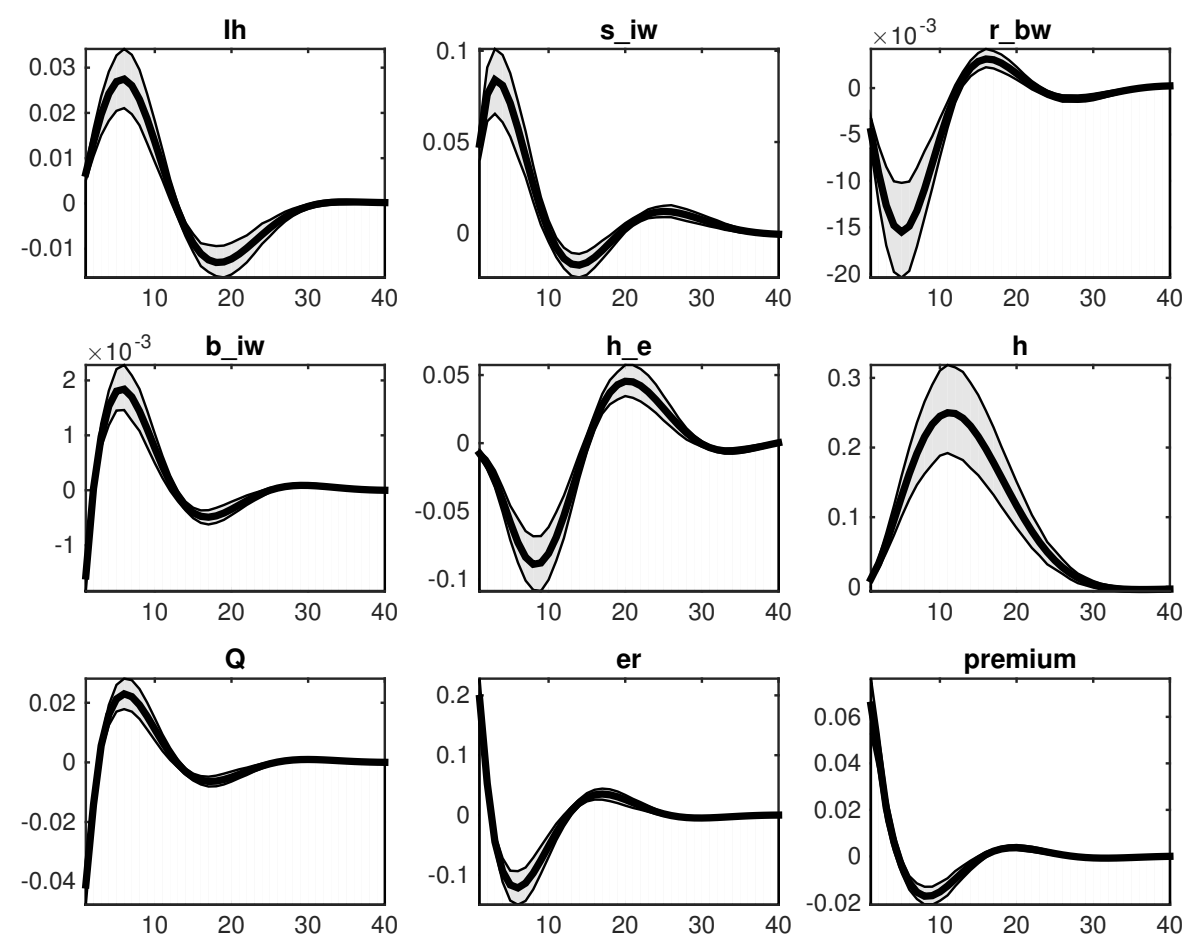

Figura 210: Efeito de um choque tecnológico
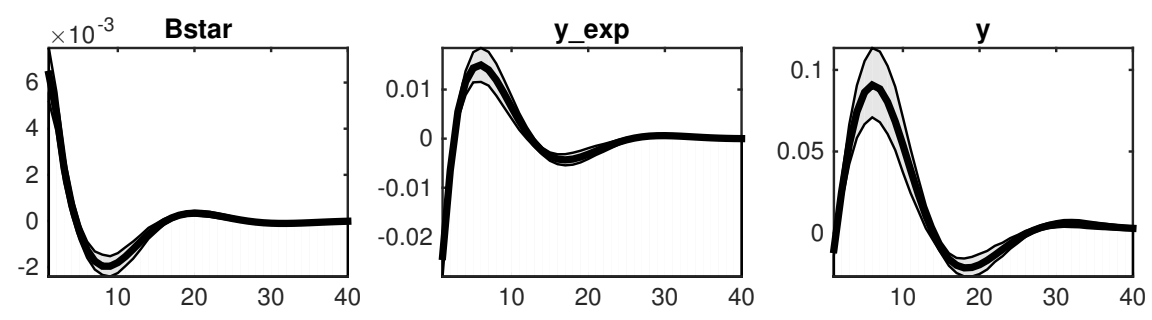

Figura 211: Efeito de um choque tecnológico 
B.12 Choque no loan-to-value dos empresários
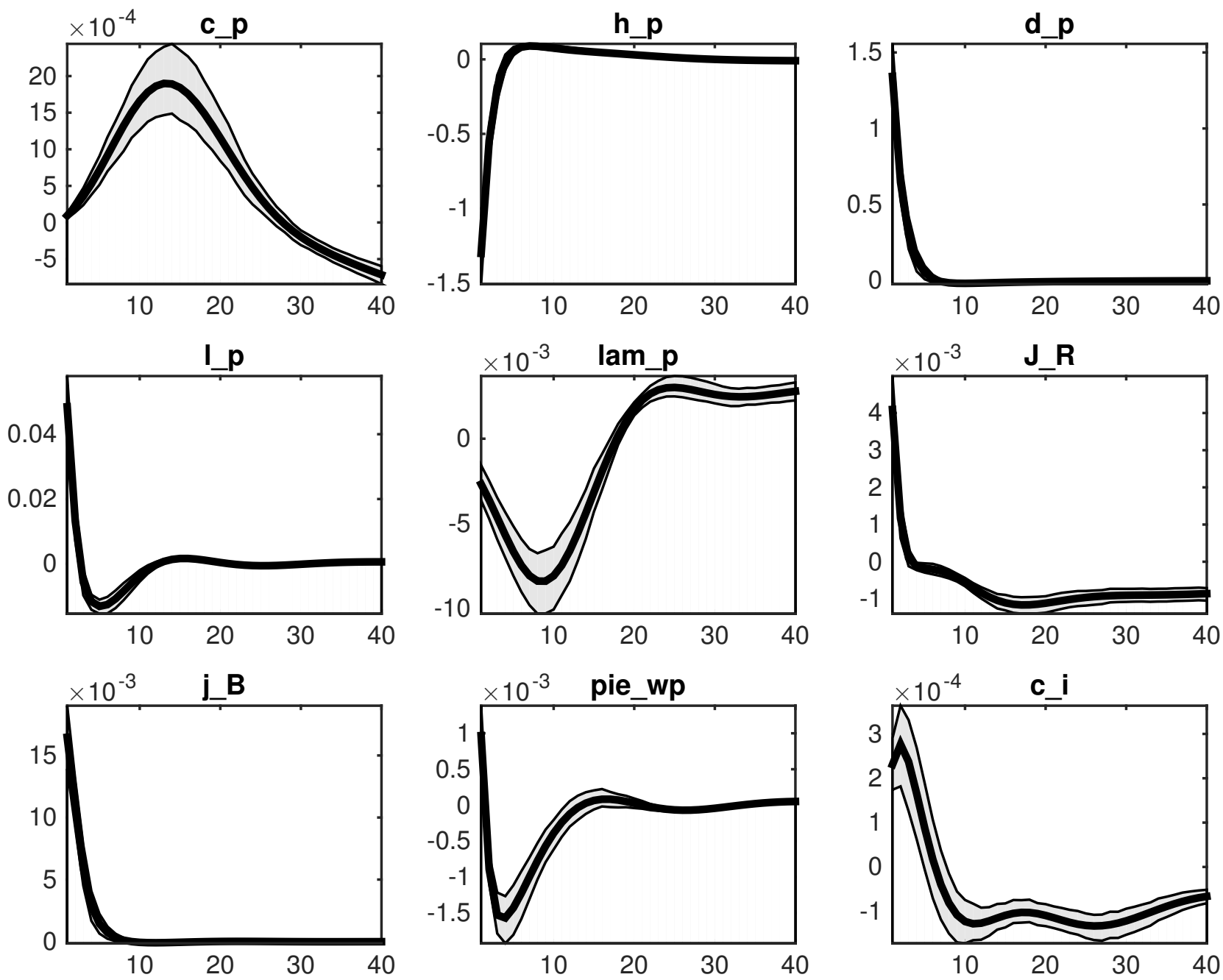

Figura 212: Efeito de um choque no loan-to-value dos empresários 

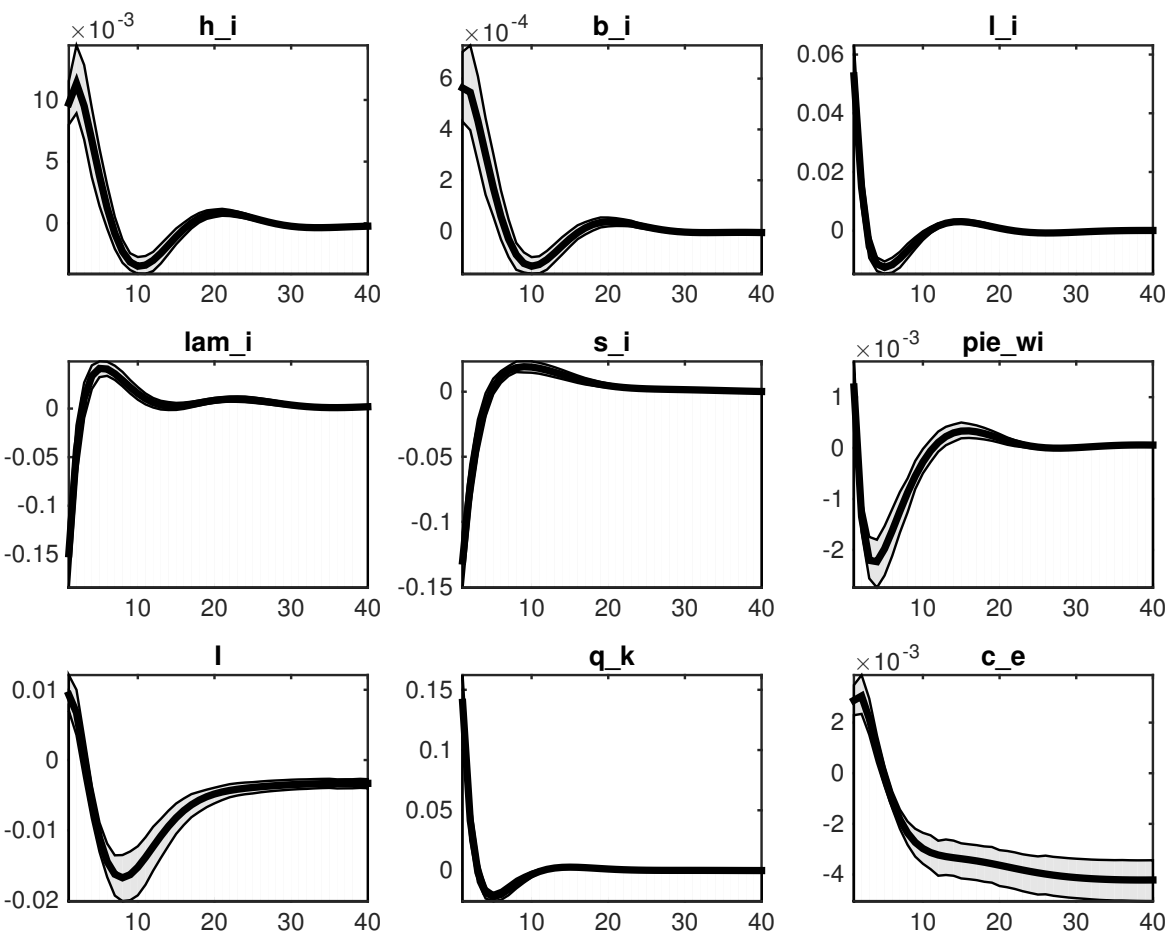

Figura 213: Efeito de um choque no loan-to-value dos empresários
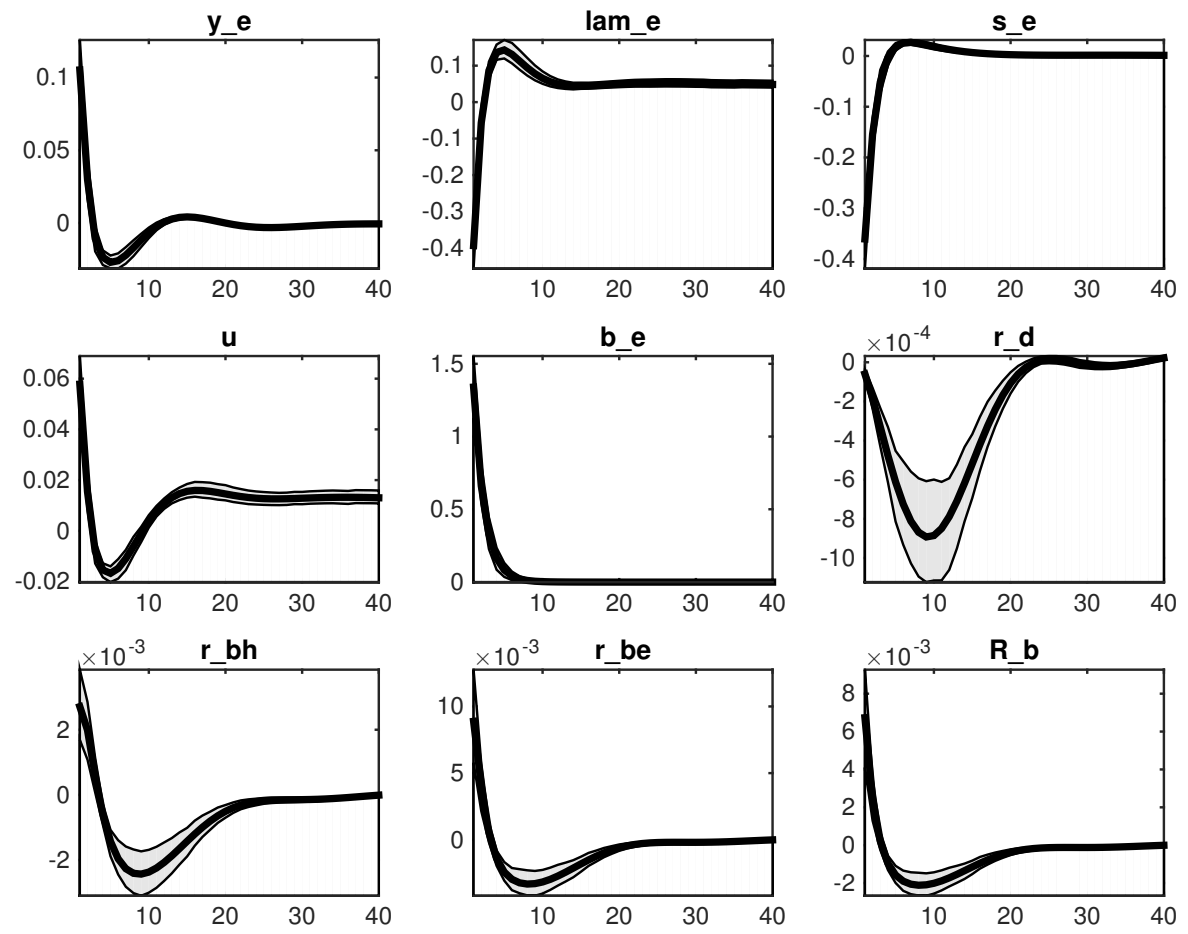

Figura 214: Efeito de um choque no loan-to-value dos empresários 

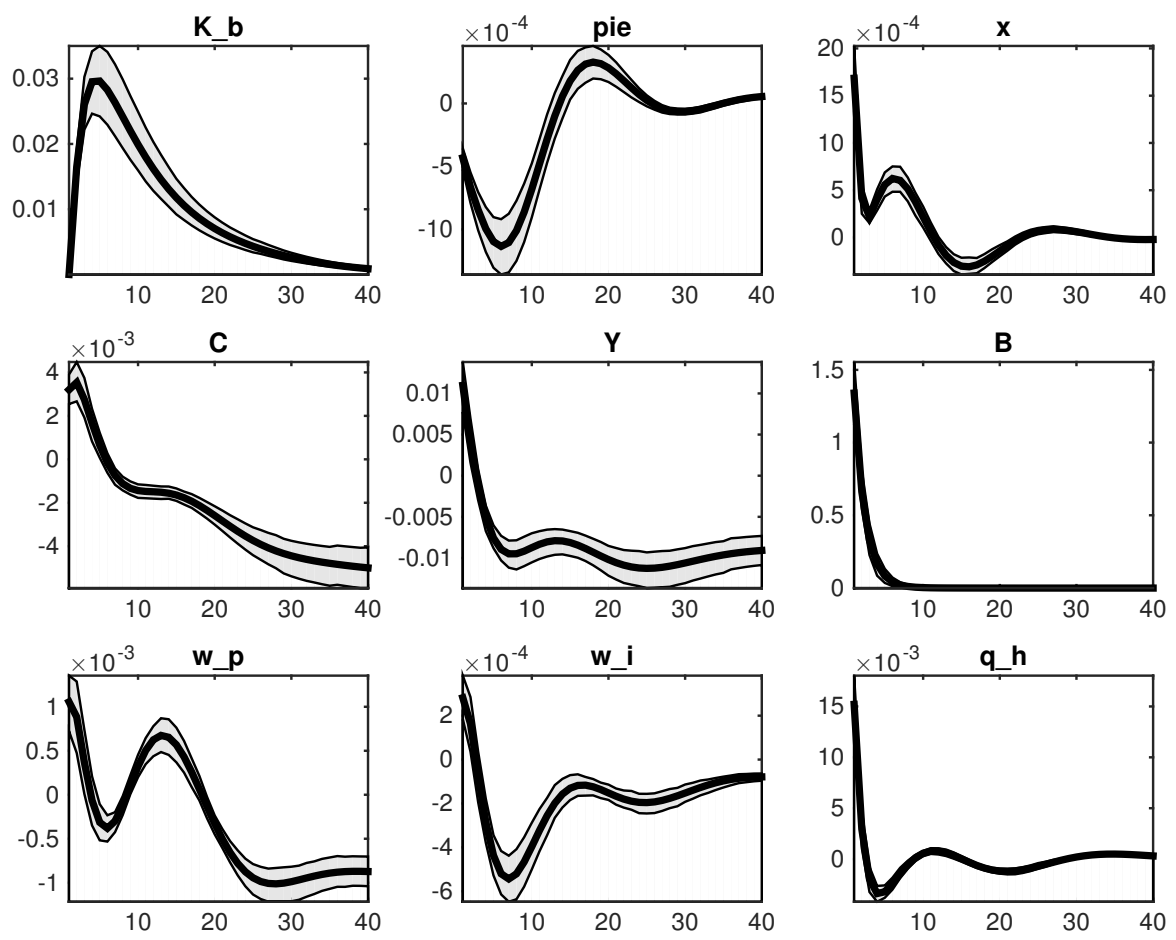

Figura 215: Efeito de um choque no loan-to-value dos empresários
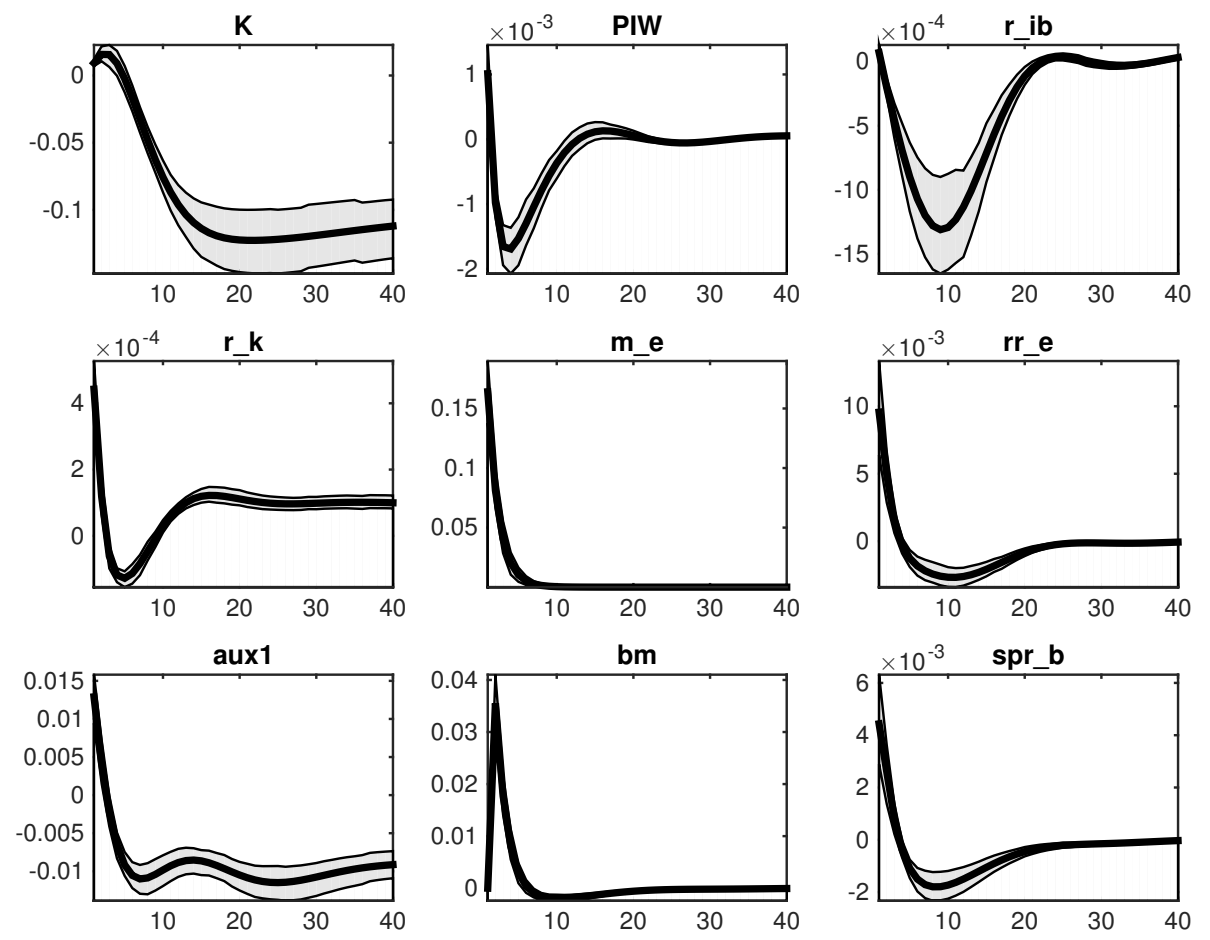

Figura 216: Efeito de um choque no loan-to-value dos empresários 

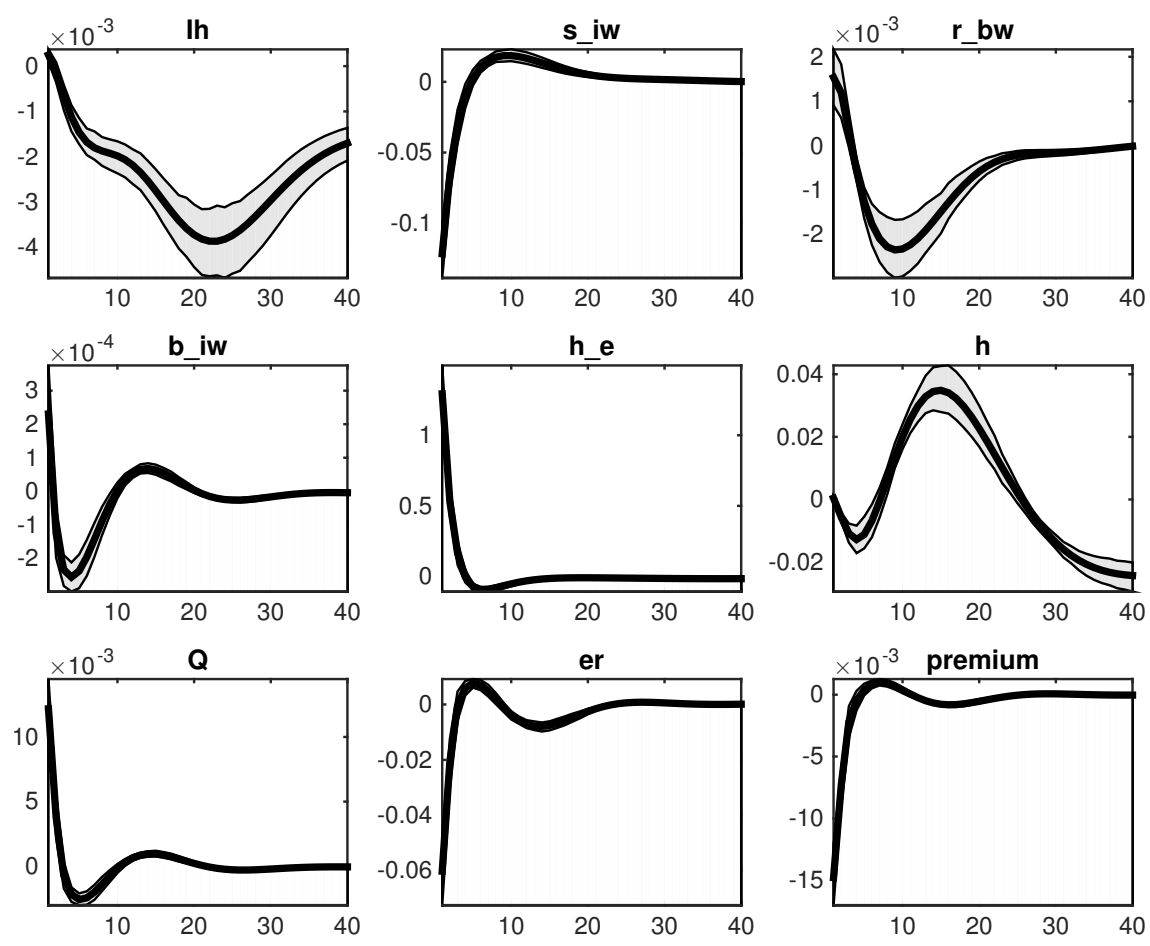

Figura 217: Efeito de um choque no loan-to-value dos empresários
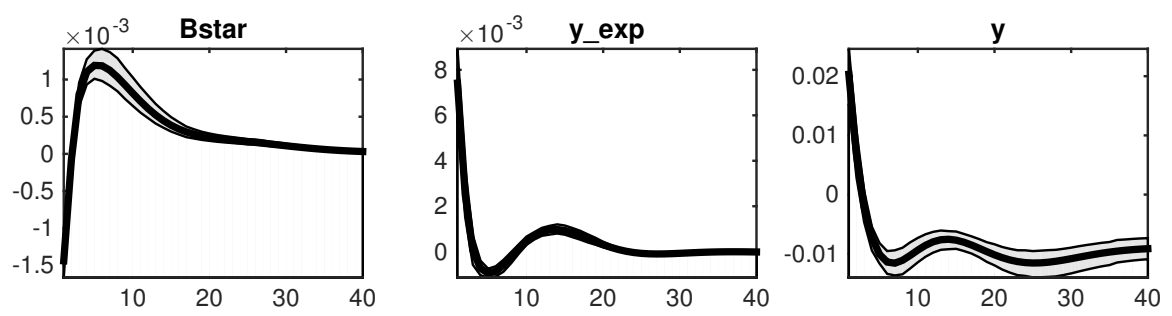

Figura 218: Efeito de um choque no loan-to-value dos empresários 
B.13 Choque no loan-to-value das famílias impacientes
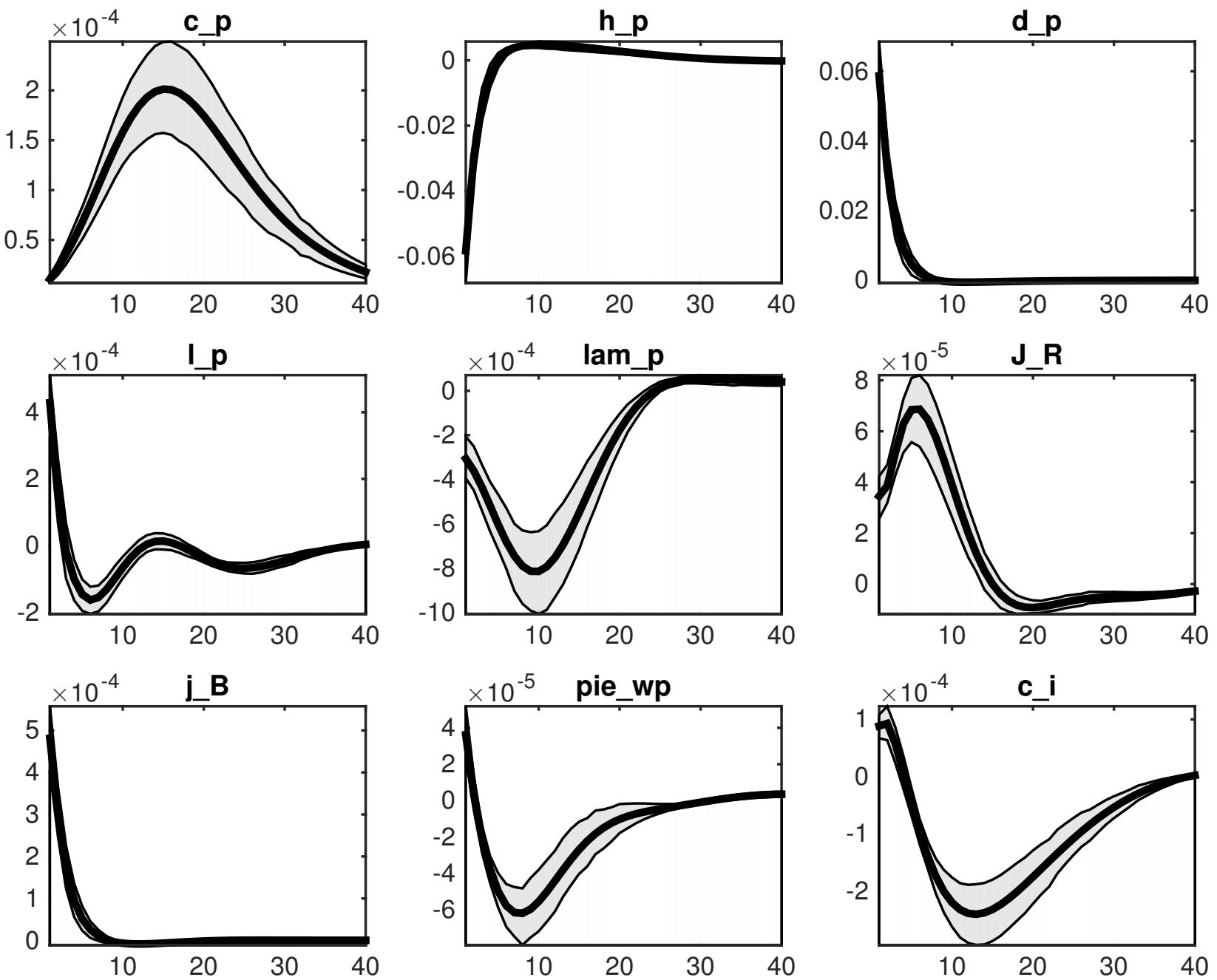

Figura 219: Efeito de um choque no loan-to-value das famílias impacientes 

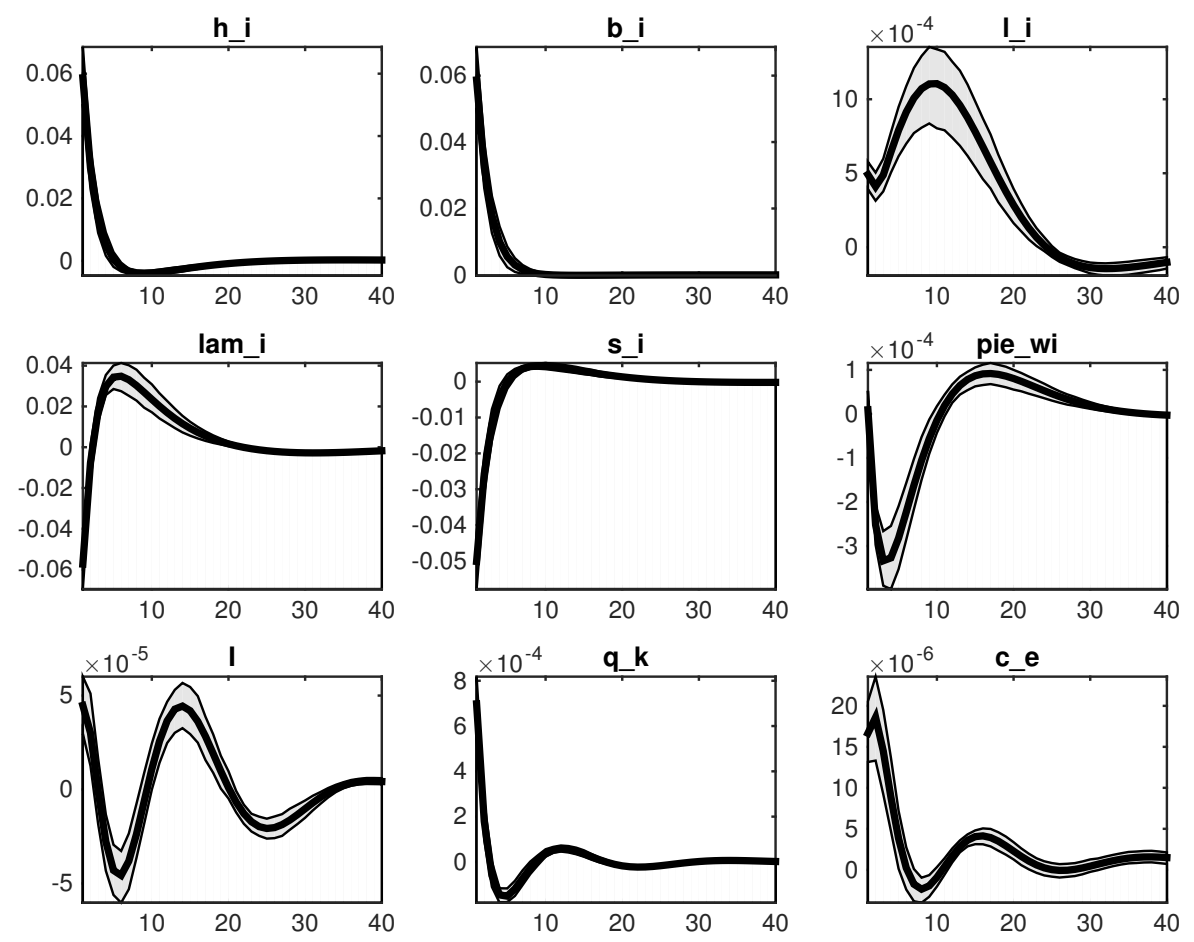

Figura 220: Efeito de um choque no loan-to-value das famílias impacientes
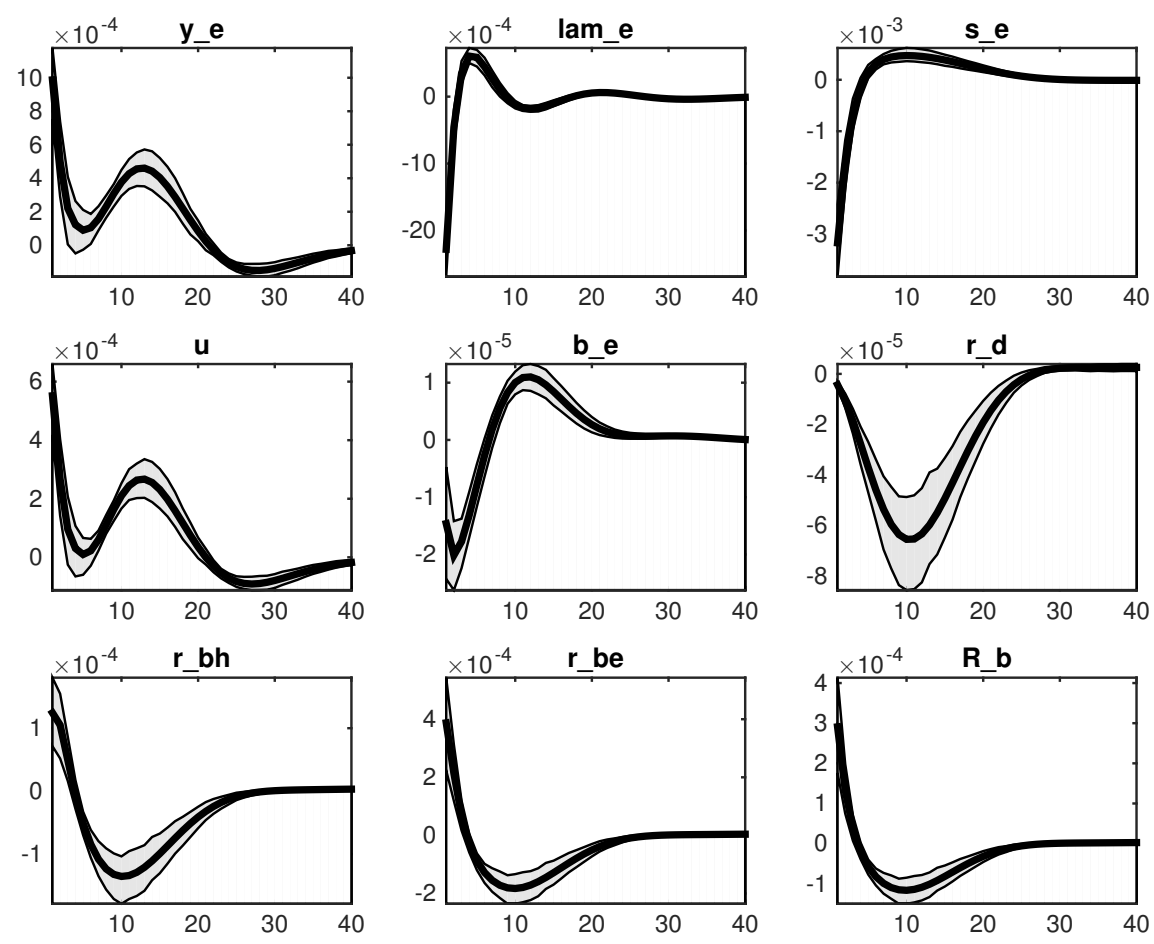

Figura 221: Efeito de um choque no loan-to-value das famílias impacientes 

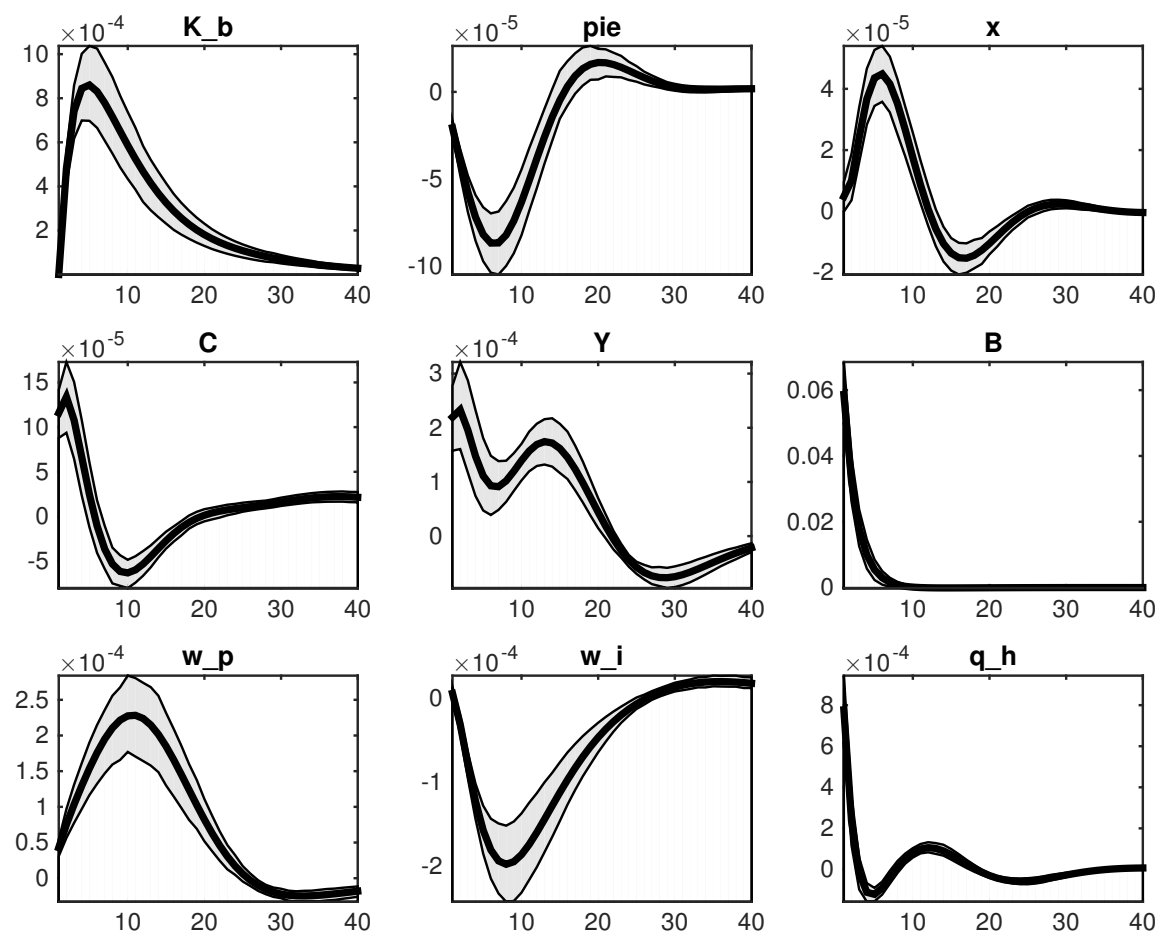

Figura 222: Efeito de um choque no loan-to-value das famílias impacientes
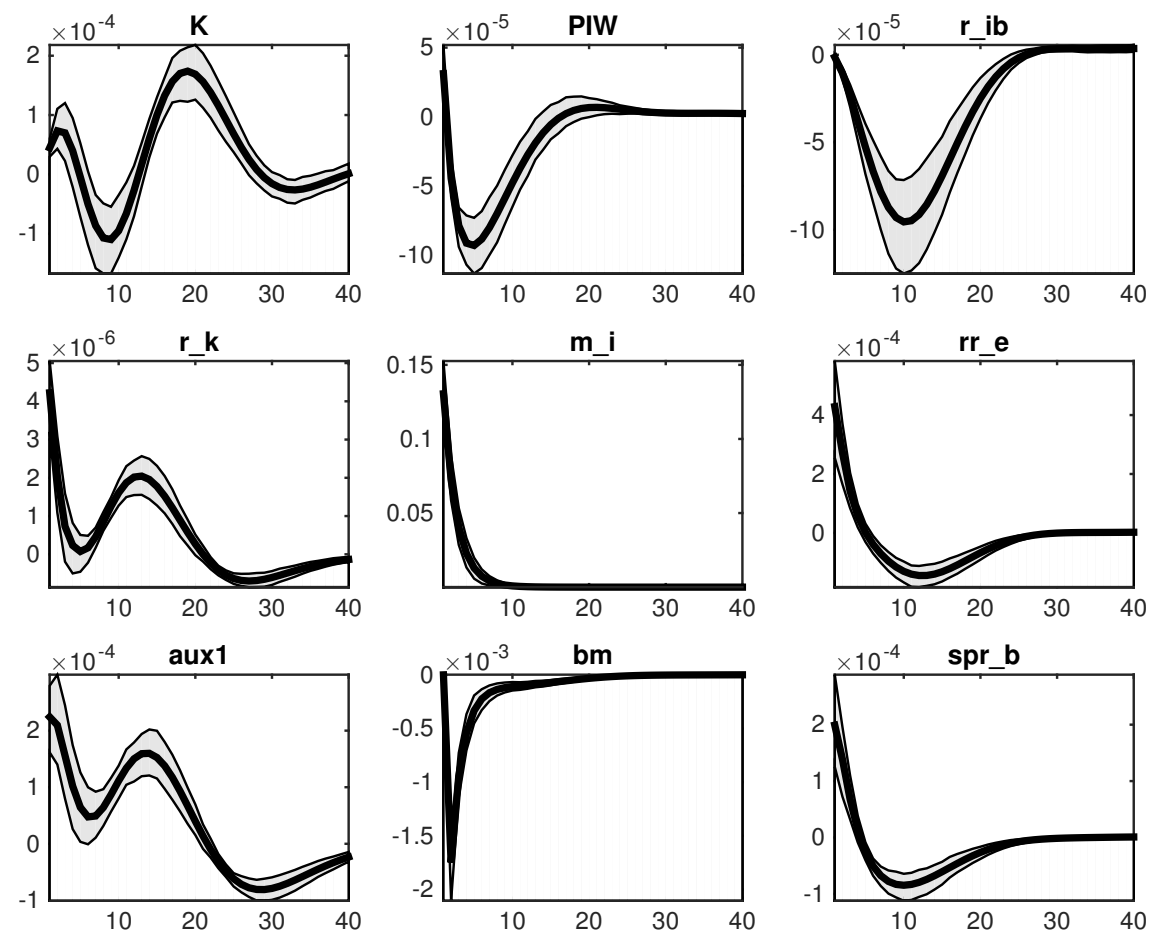

Figura 223: Efeito de um choque no loan-to-value das famílias impacientes 

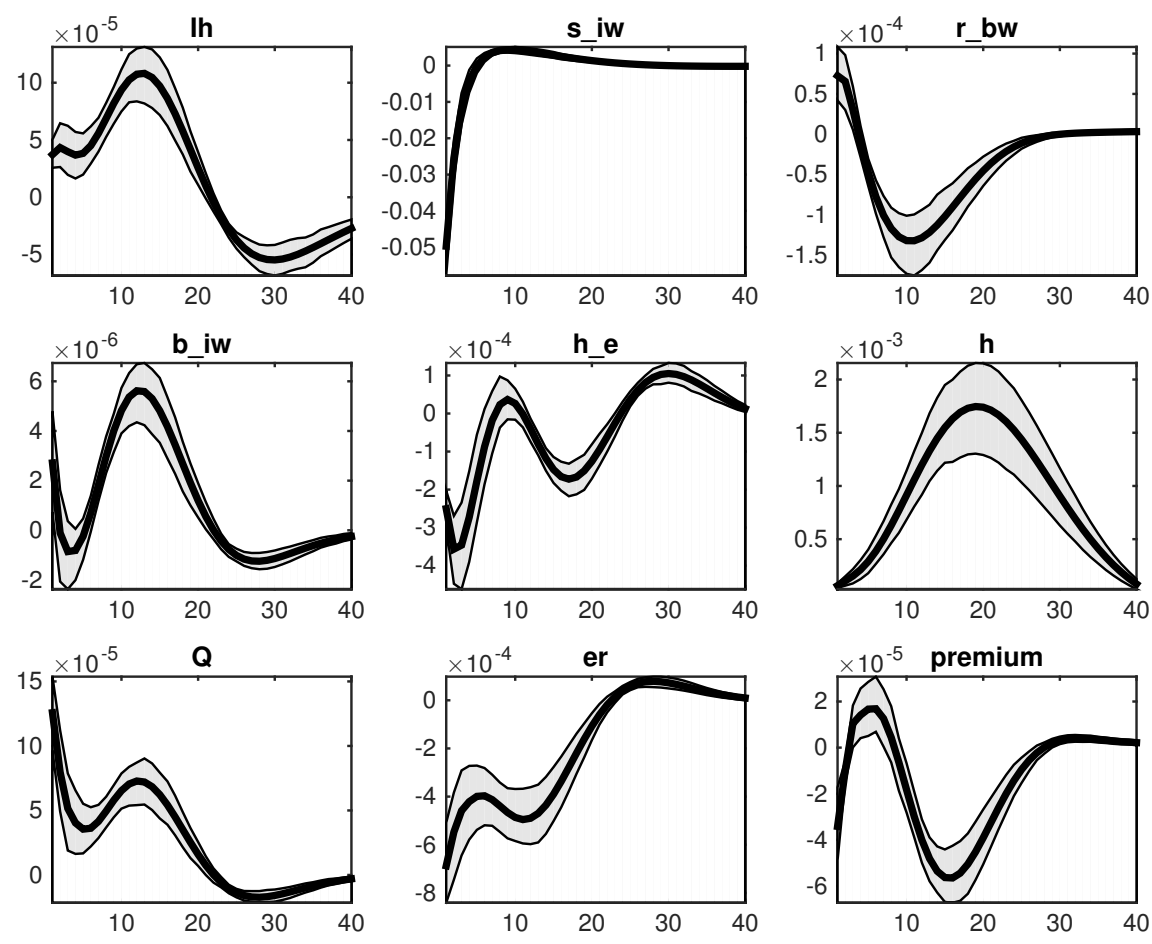

Figura 224: Efeito de um choque no loan-to-value das famílias impacientes
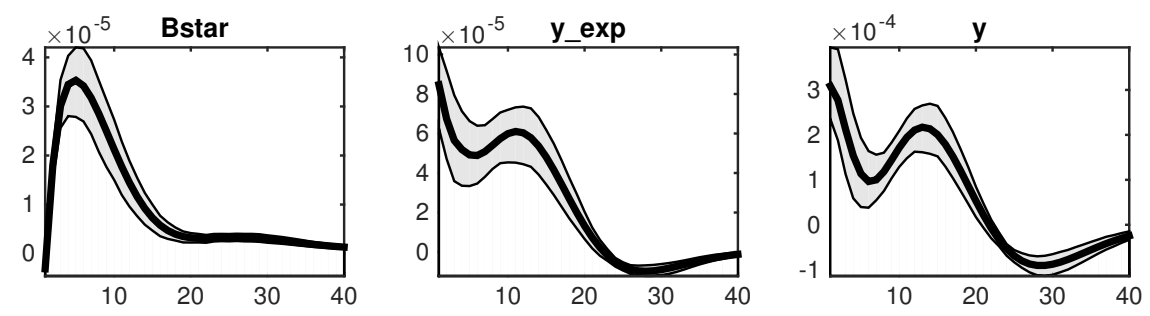

Figura 225: Efeito de um choque no loan-to-value das famílias impacientes 
B.14 Choque no Mark-up de salários
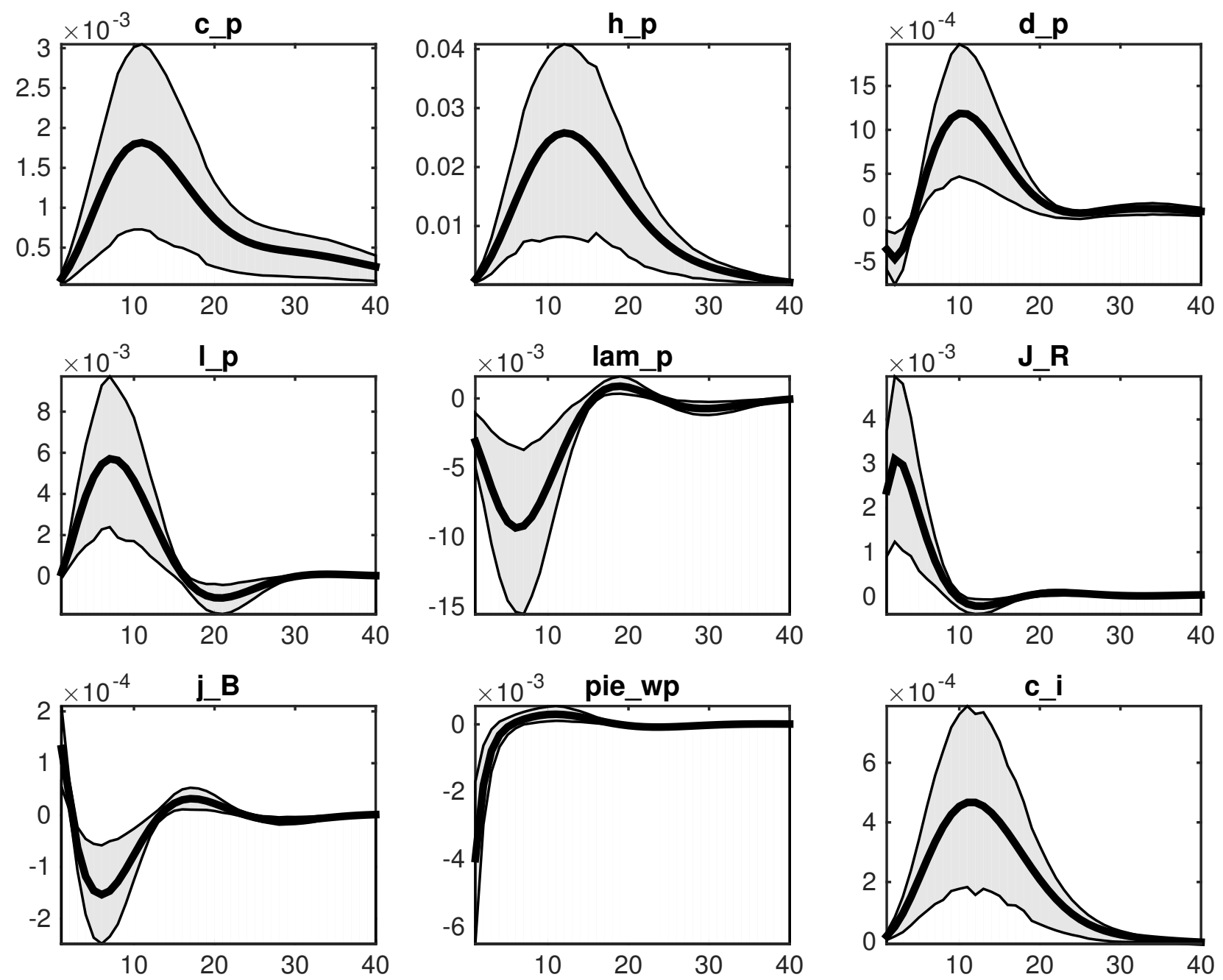

Figura 226: Efeito de um choque no Mark-up de salários 

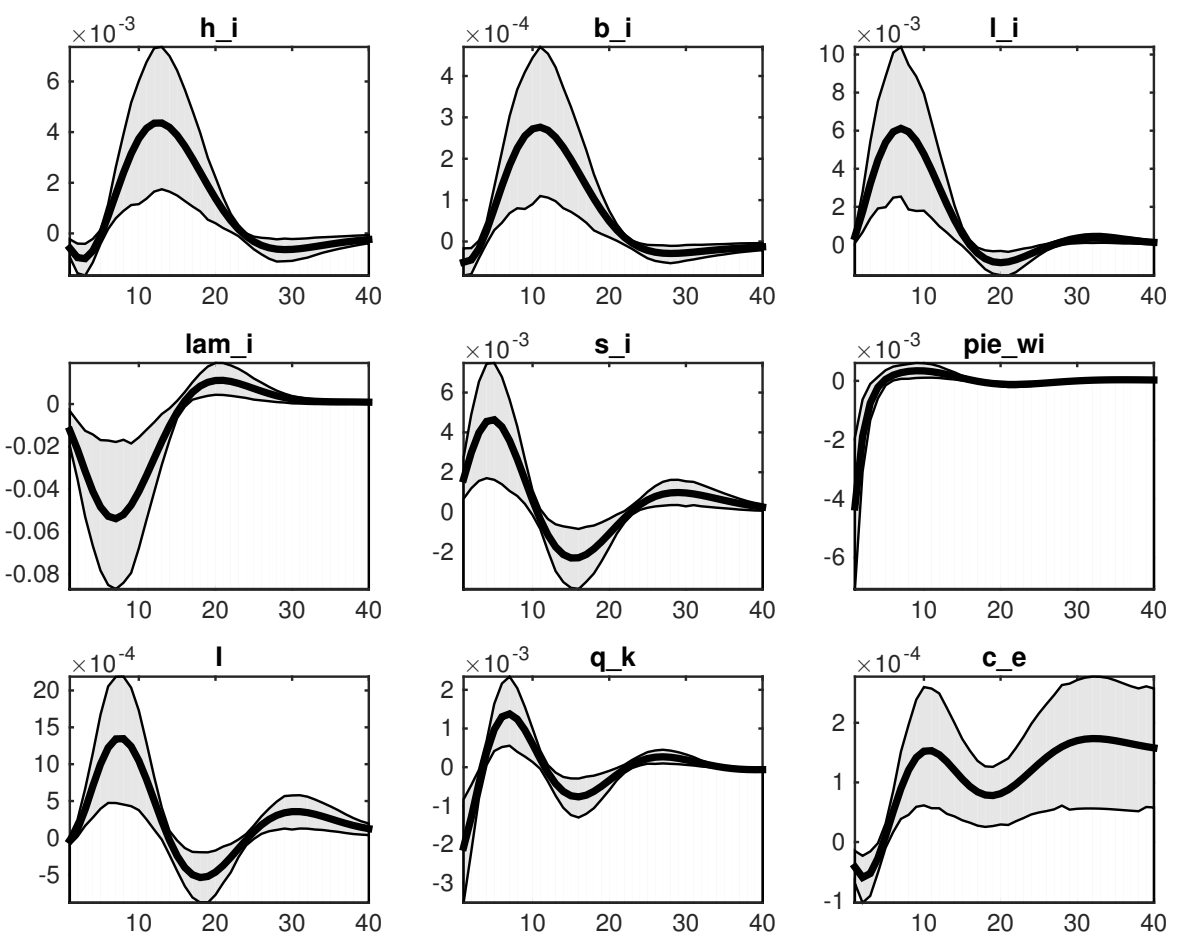

Figura 227: Efeito de um choque no Mark-up de salários
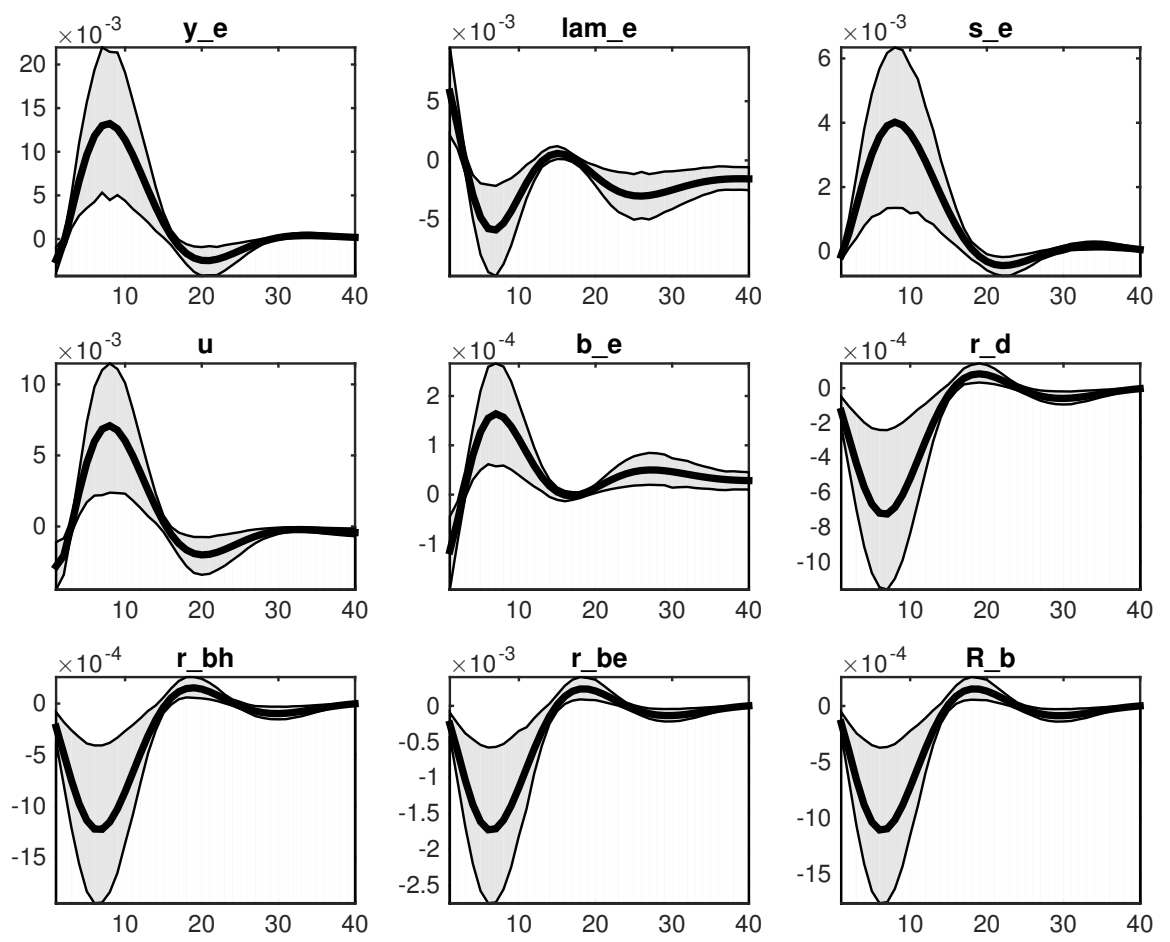

Figura 228: Efeito de um choque no Mark-up de salários 

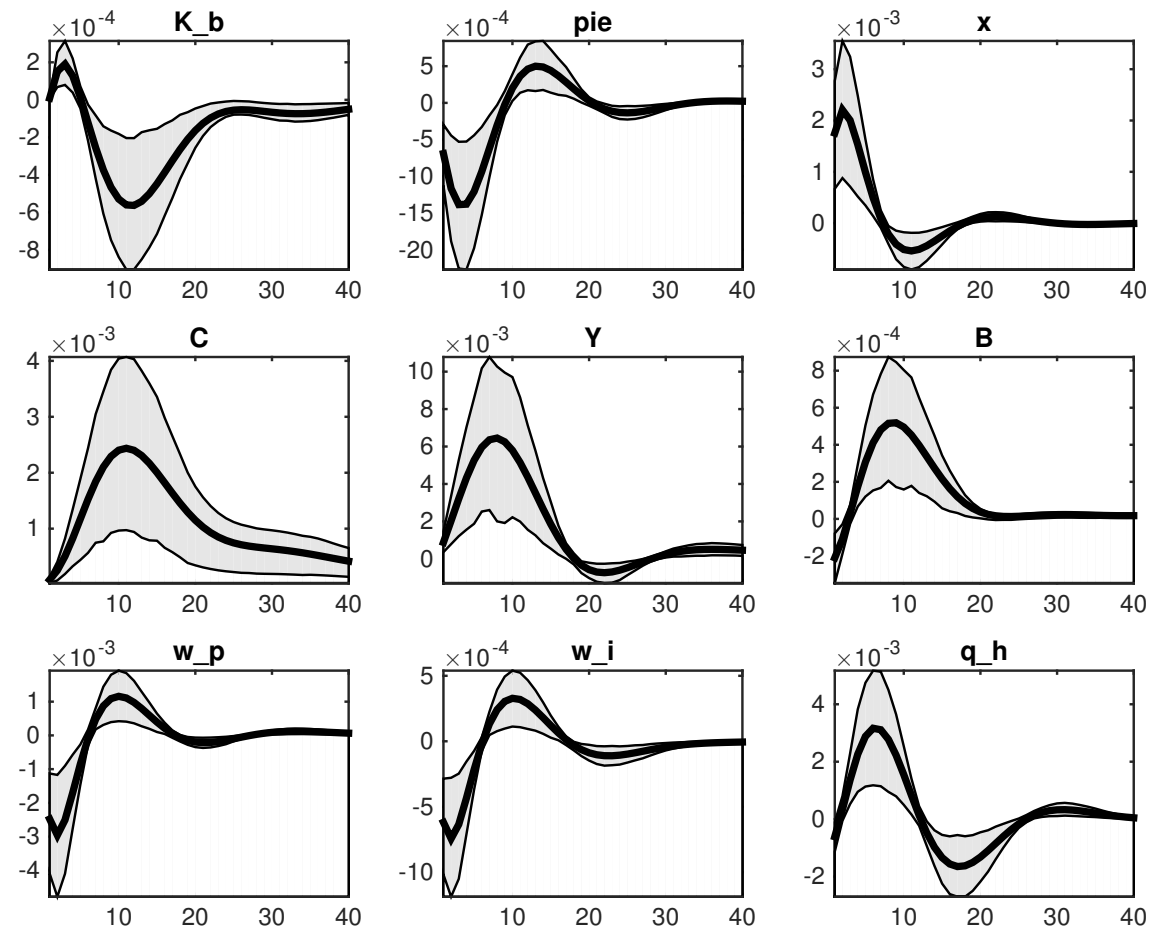

Figura 229: Efeito de um choque no Mark-up de salários
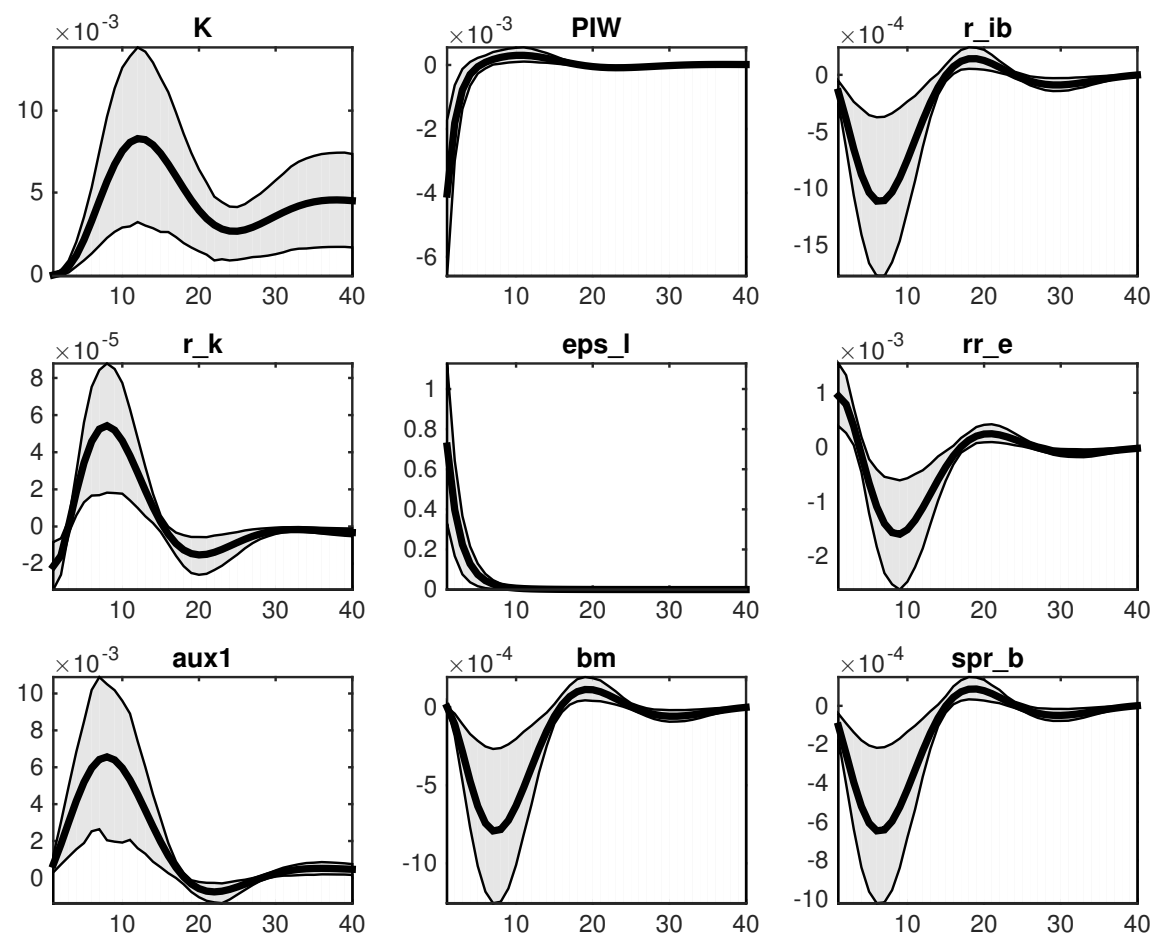

Figura 230: Efeito de um choque no Mark-up de salários 

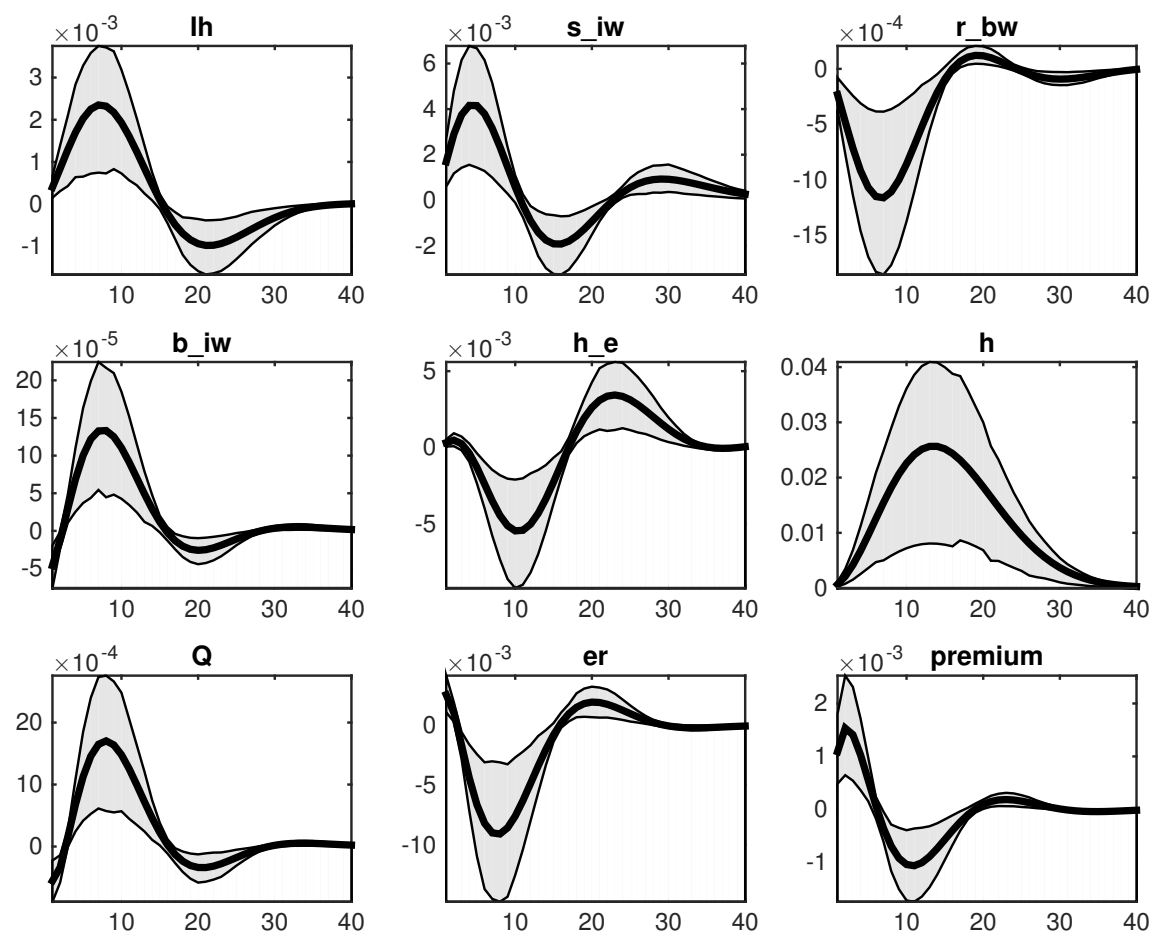

Figura 231: Efeito de um choque no Mark-up de salários
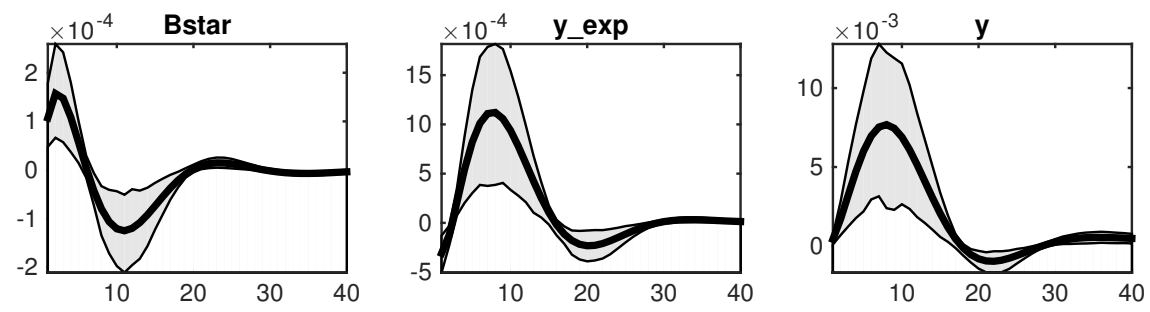

Figura 232: Efeito de um choque no Mark-up de salários 
B.15 Choque no Mark-up de taxa de juros: empréstimos com base em imóveis
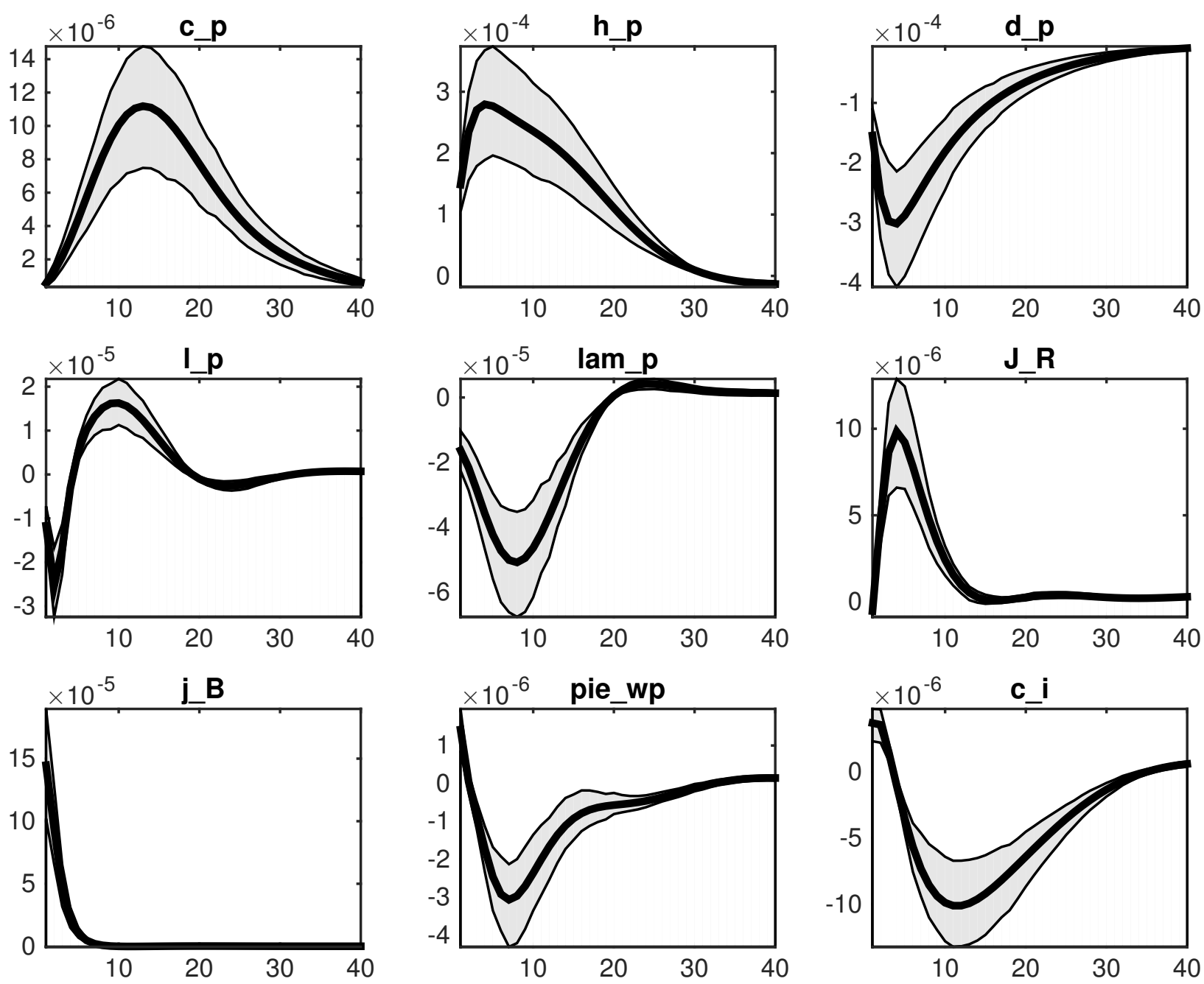

Figura 233: Efeito de um choque em $\mathrm{mk}_{b} h$ 

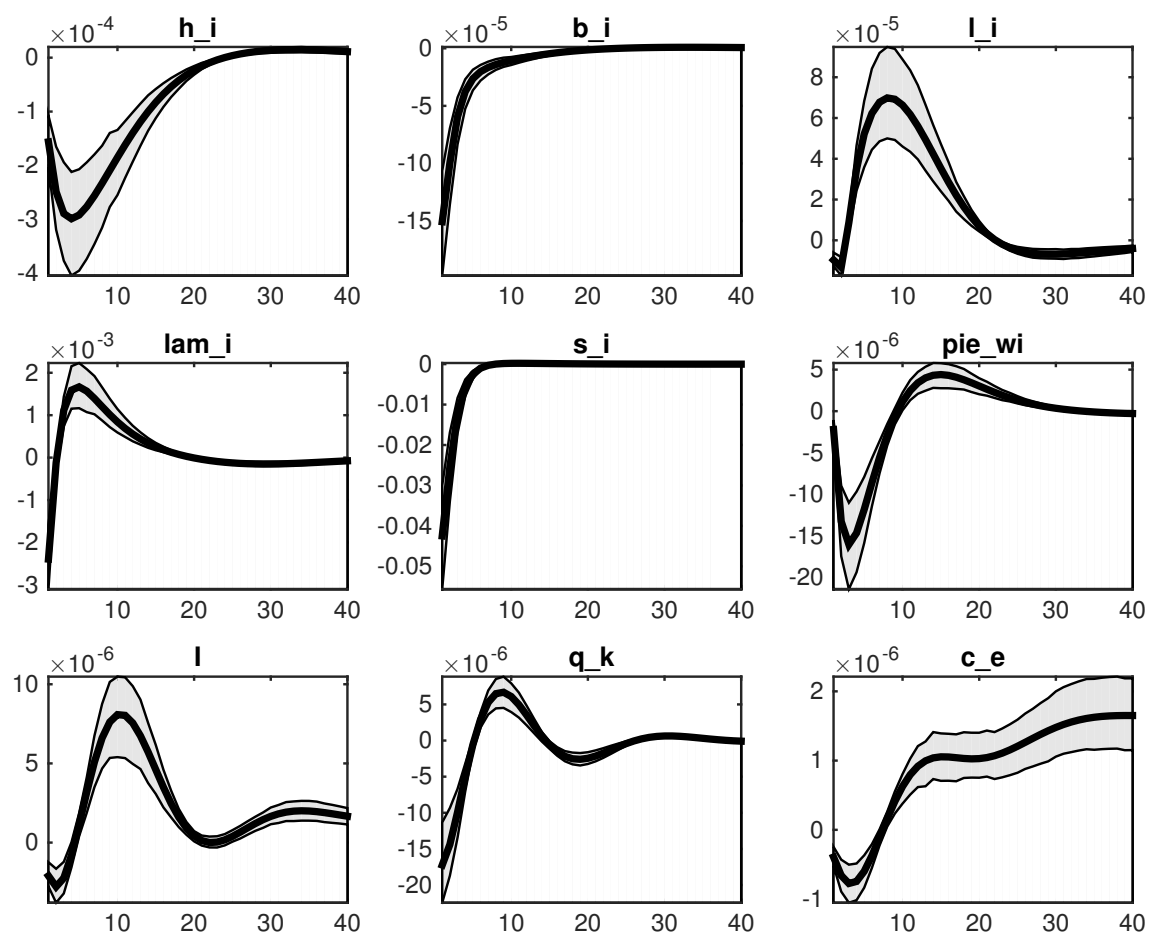

Figura 234: Efeito de um choque $\mathrm{em}^{\mathrm{mk}_{b}} h$
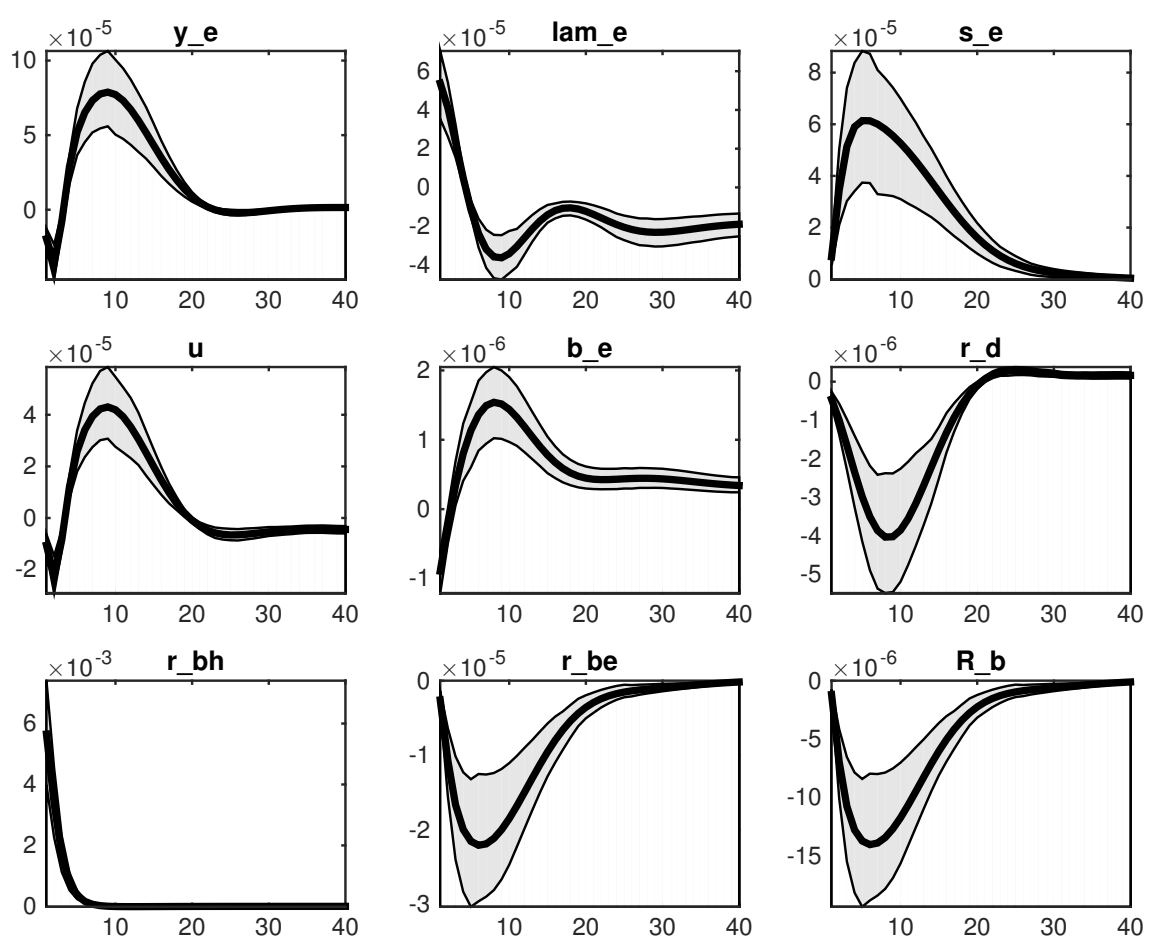

Figura 235: Efeito de um choque $\mathrm{em}^{\mathrm{mk}_{b}} h$ 

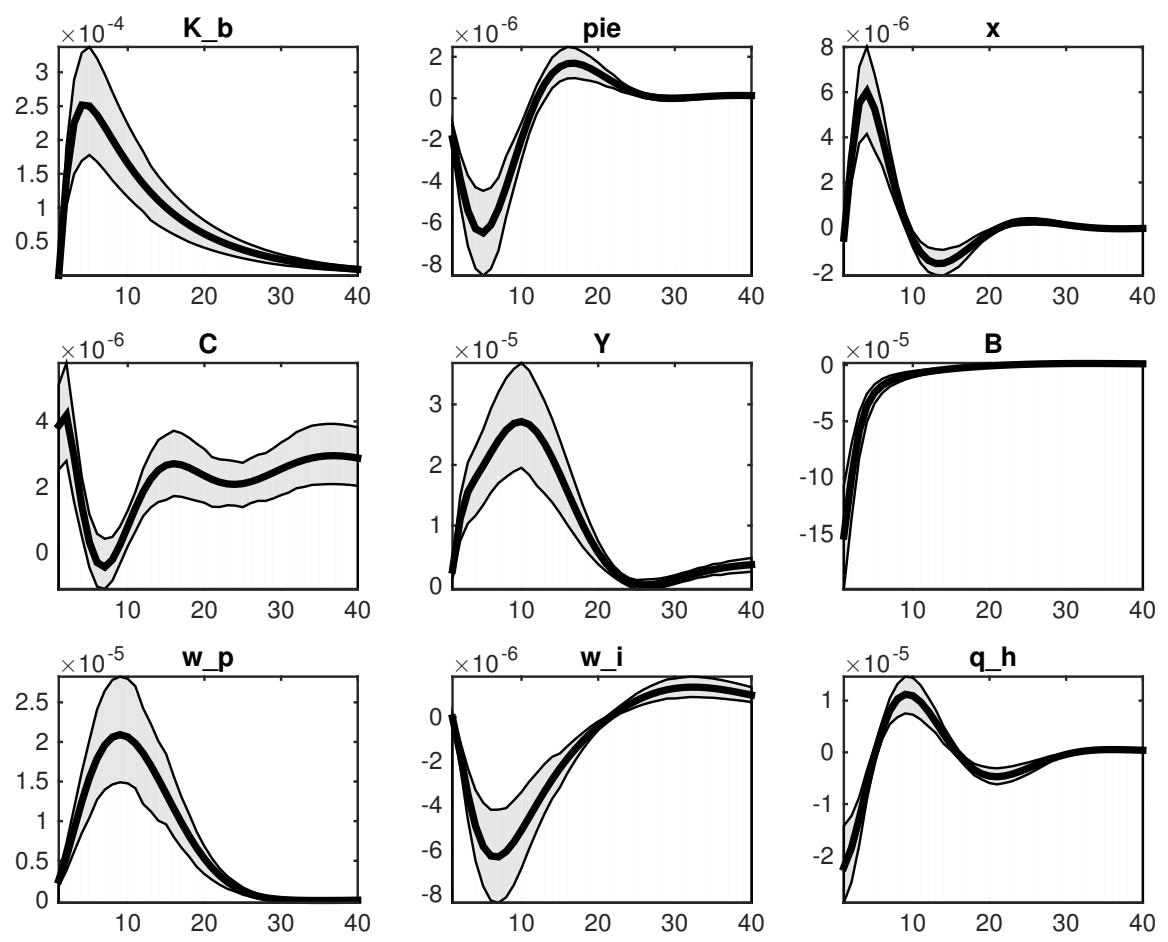

Figura 236: Efeito de um choque $\mathrm{em}^{\mathrm{mk}_{b} h}$
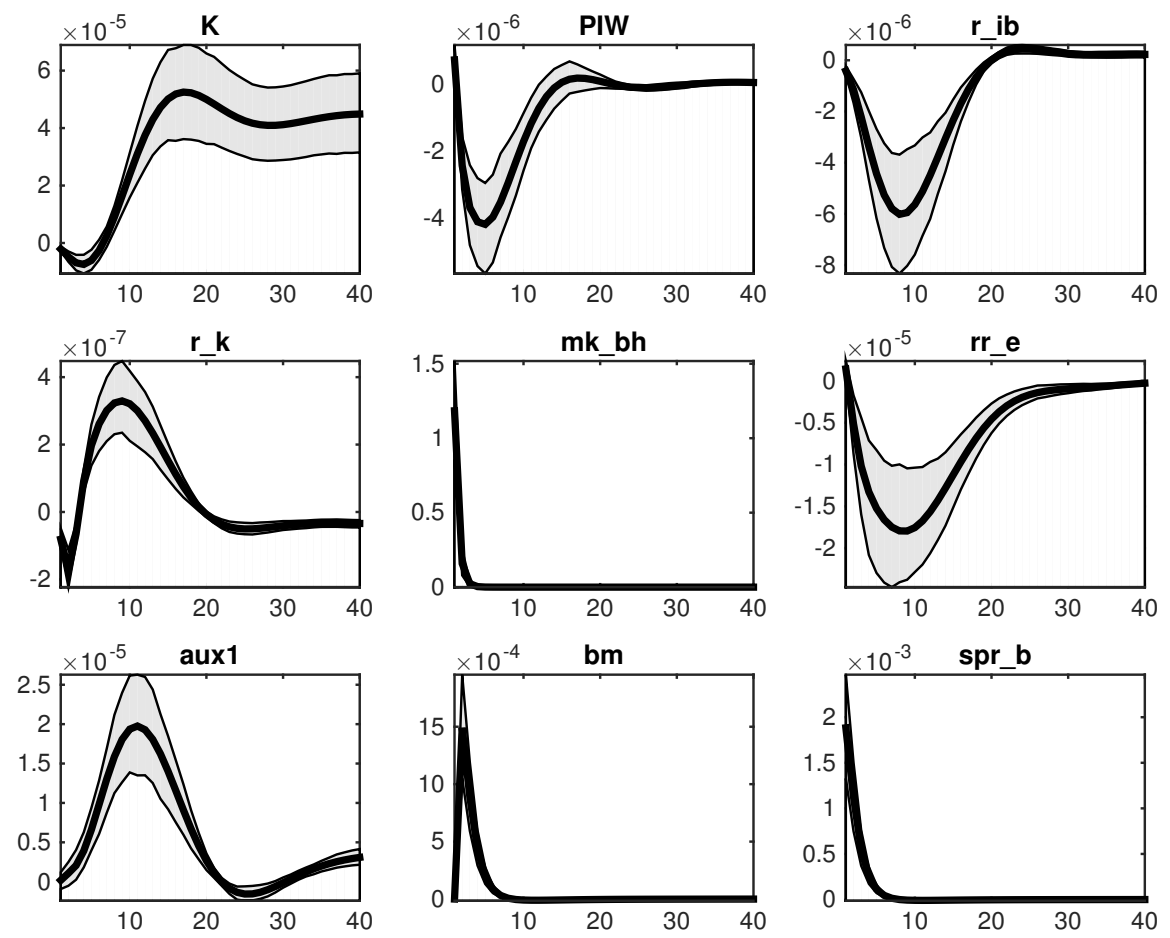

Figura 237: Efeito de um choque em $\mathrm{mk}_{b} h$ 

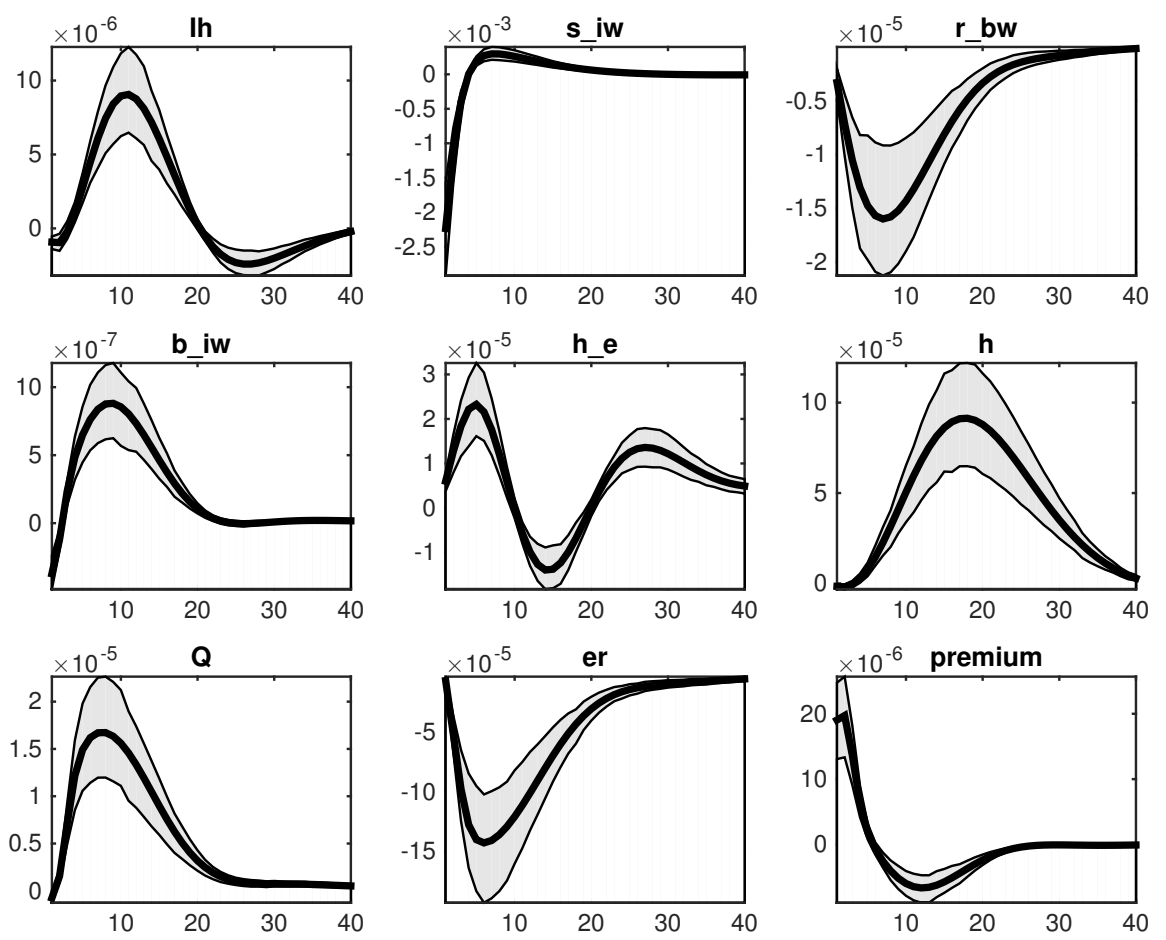

Figura 238: Efeito de um choque $\mathrm{em}^{\mathrm{mk}_{b}} h$
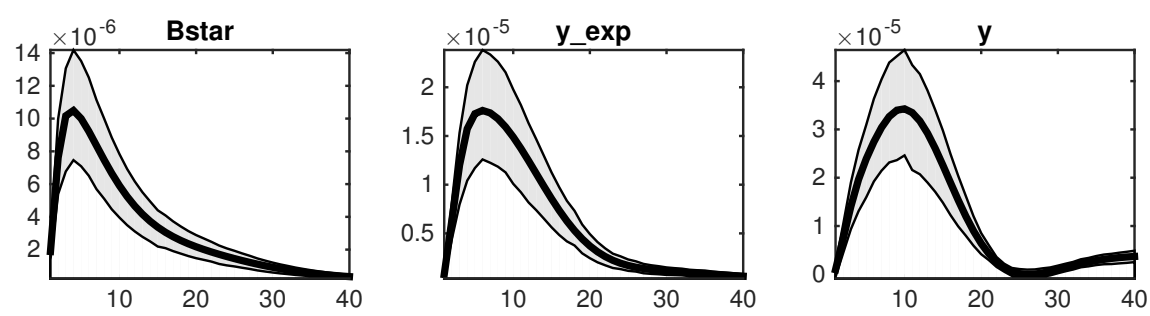

Figura 239: Efeito de um choque $\mathrm{em}^{\mathrm{mk}_{b}} h$ 
B.16 Choque no Mark-up de taxa de juros: empréstimos aos empresários
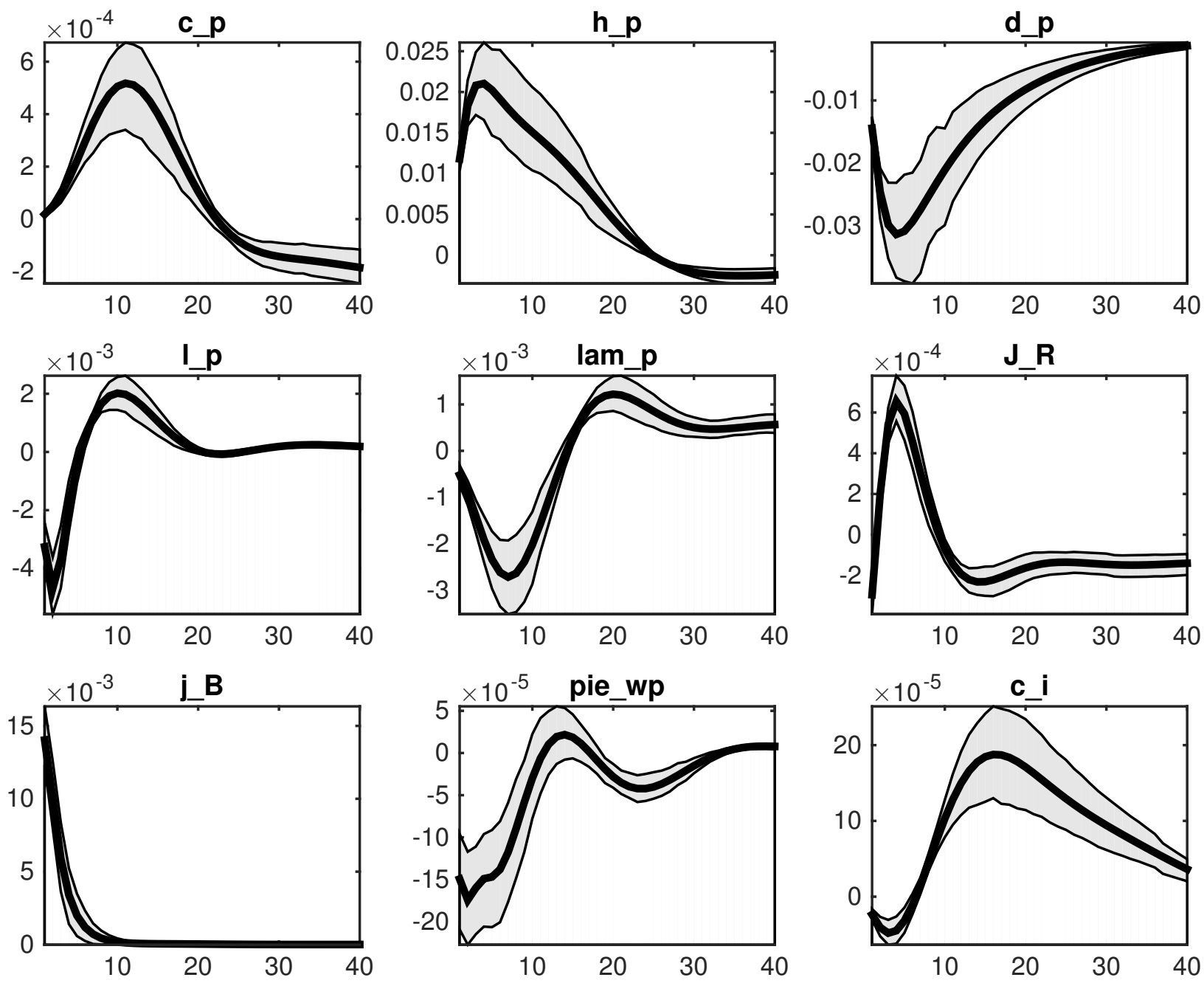

Figura 240: Efeito de um choque em $\mathrm{mk}_{b} e$ 

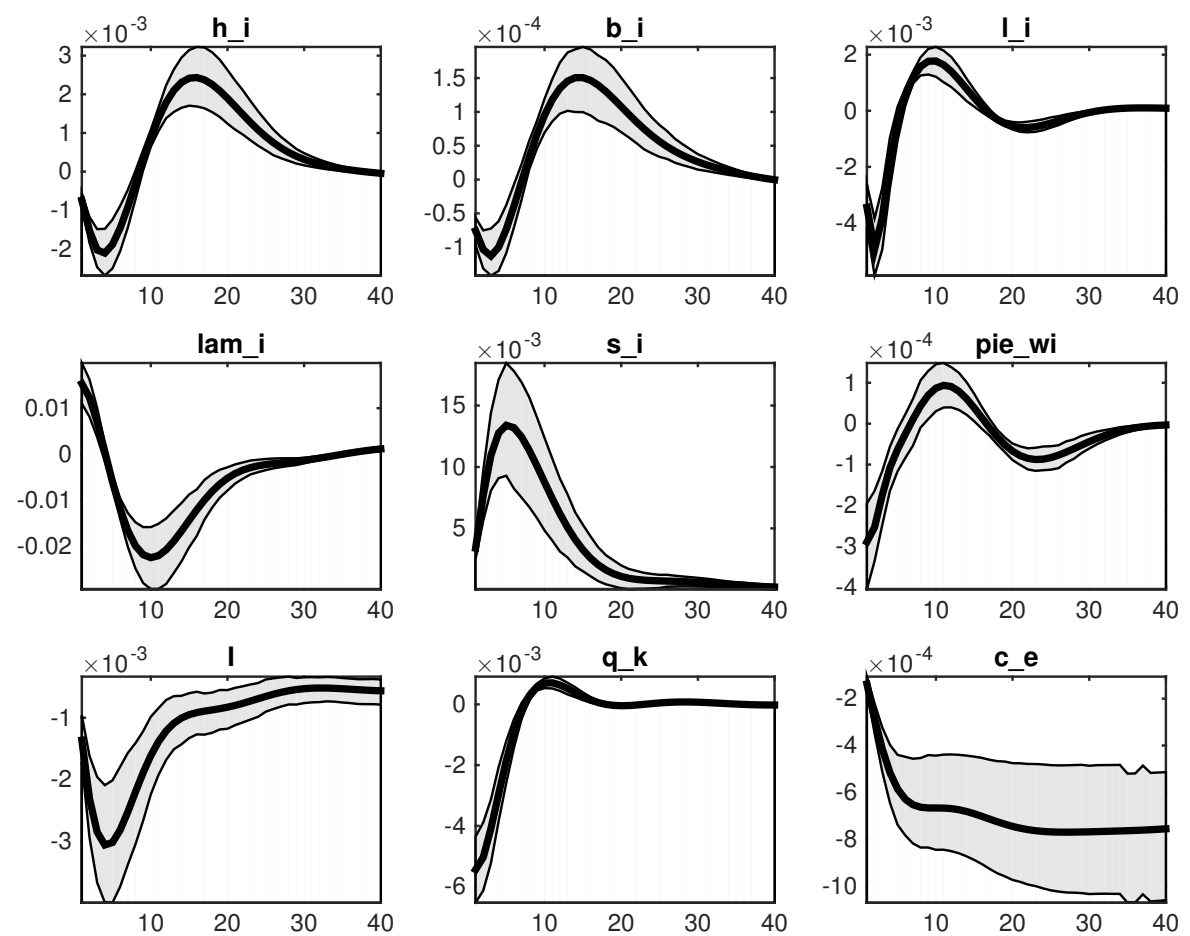

Figura 241: Efeito de um choque em $\mathrm{mk}_{b} e$
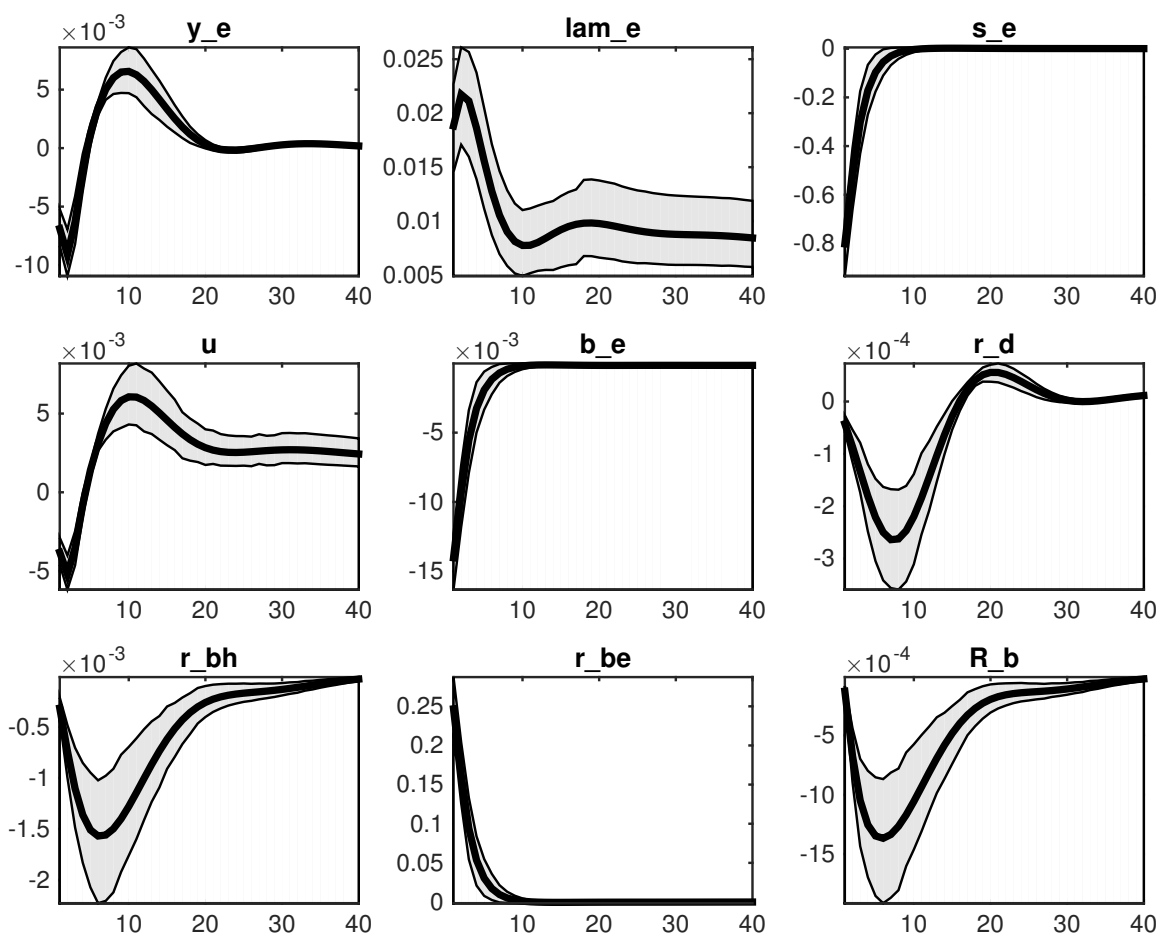

Figura 242: Efeito de um choque em $\mathrm{mk}_{b} e$ 

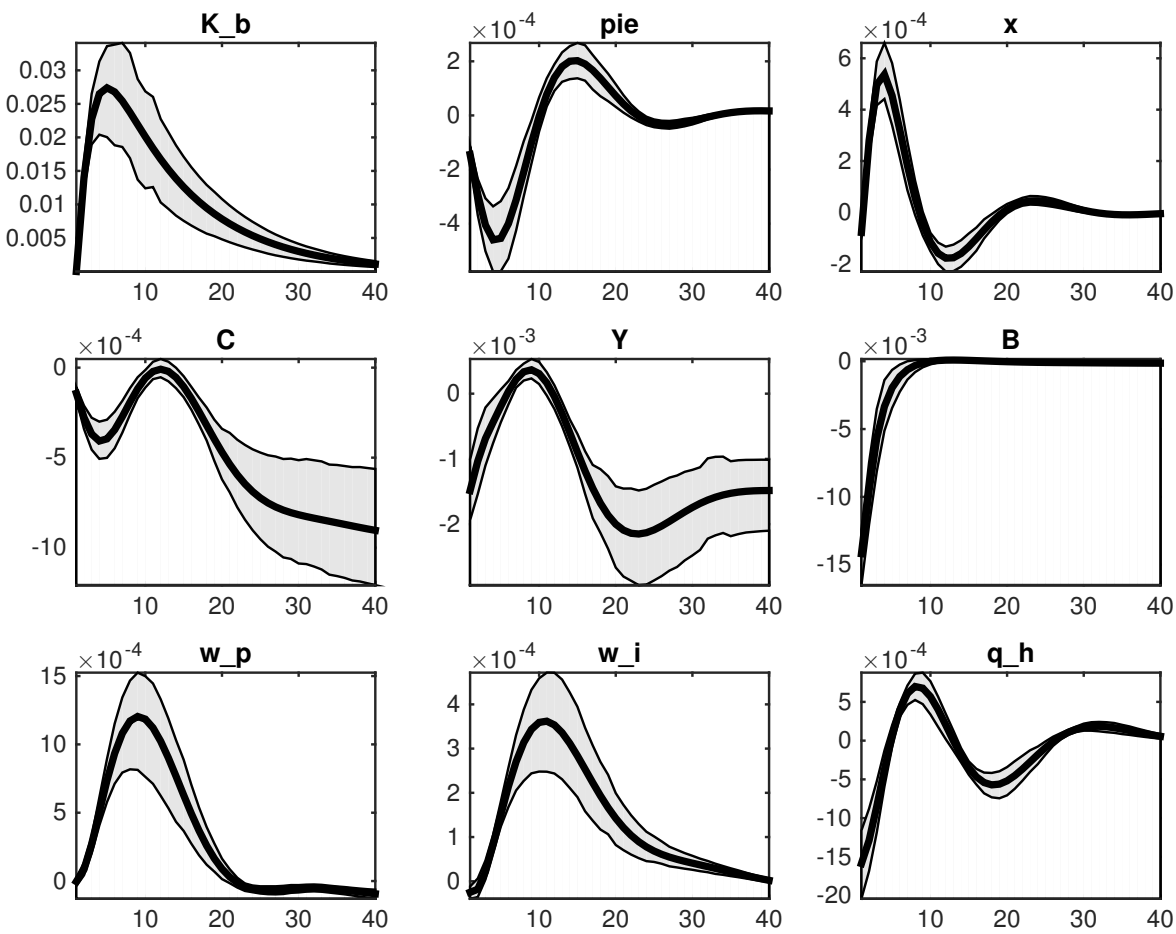

Figura 243: Efeito de um choque em $\mathrm{mk}_{b} e$
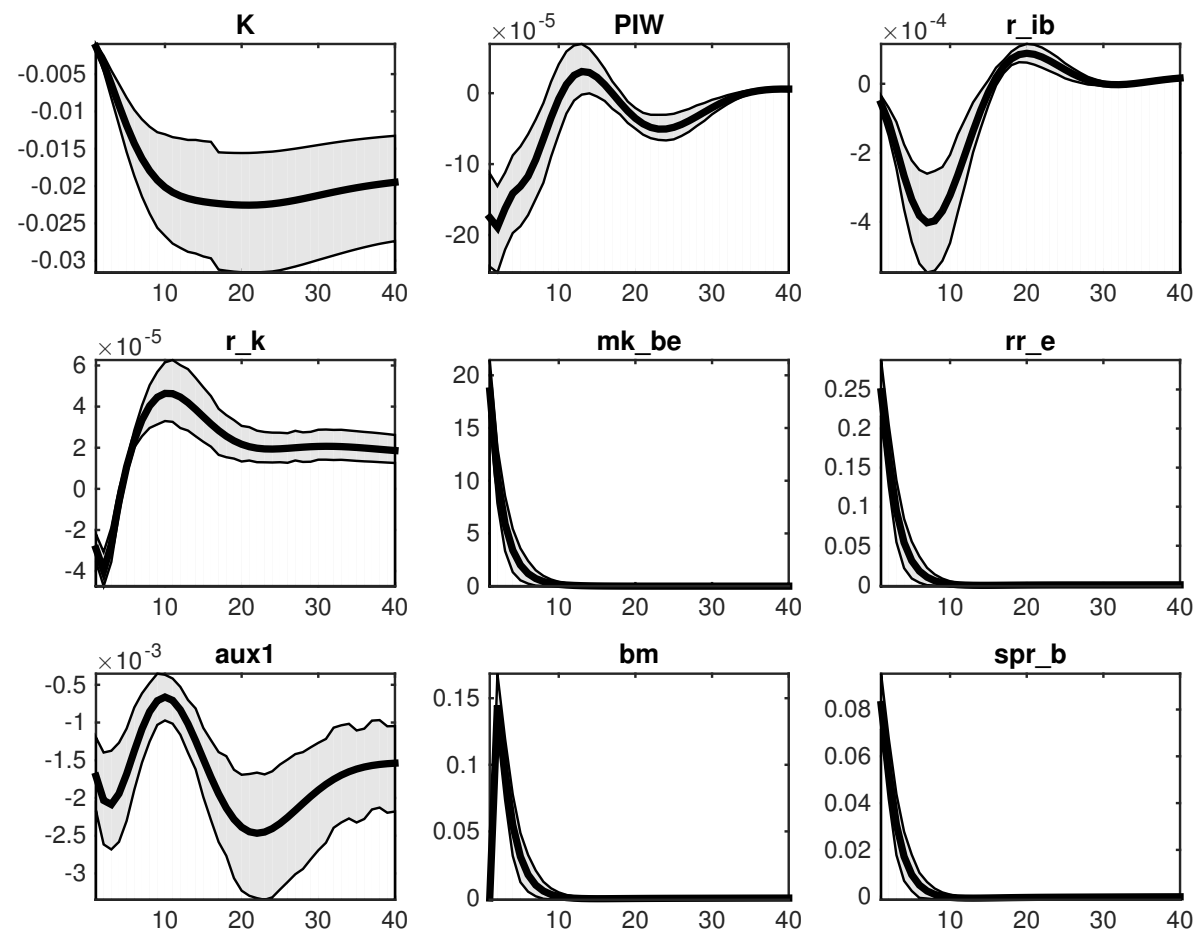

Figura 244: Efeito de um choque em $\mathrm{mk}_{b} e$ 

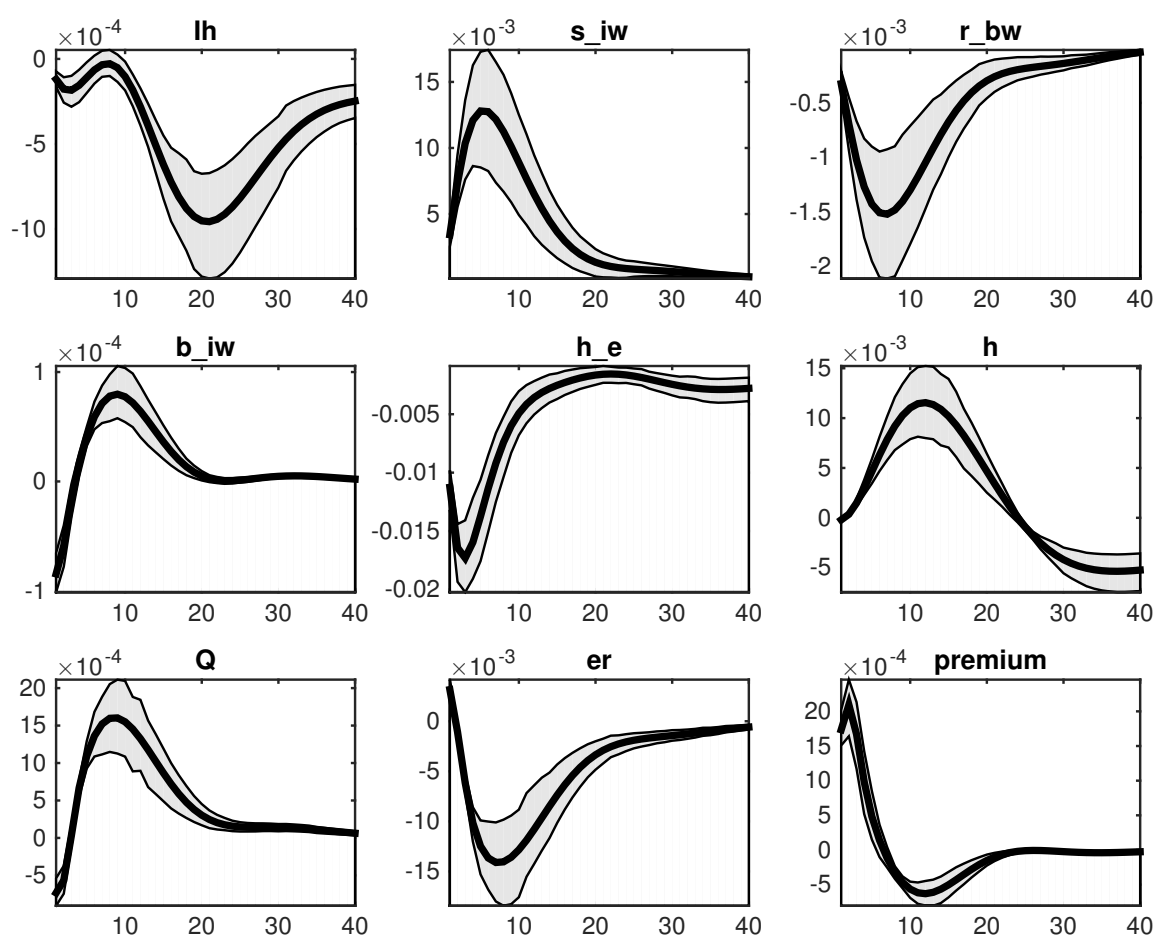

Figura 245: Efeito de um choque em $\mathrm{mk}_{b} e$
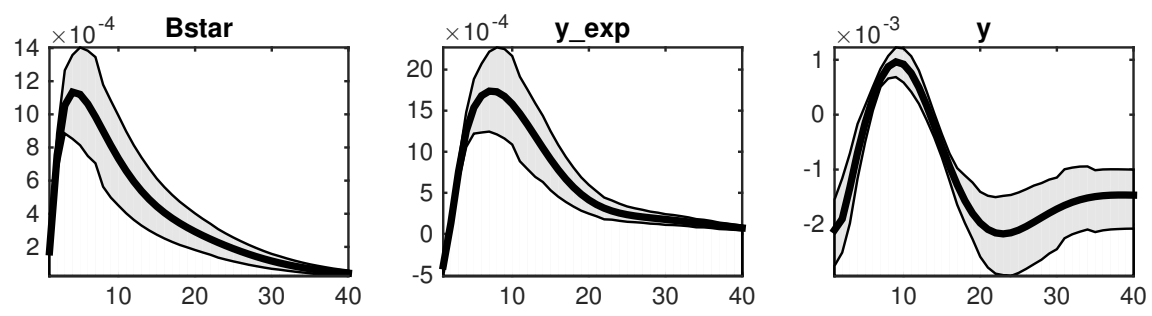

Figura 246: Efeito de um choque em $\mathrm{mk}_{b} e$ 
B.17 Choque no Mark-down de taxa de juros sobre depósitos
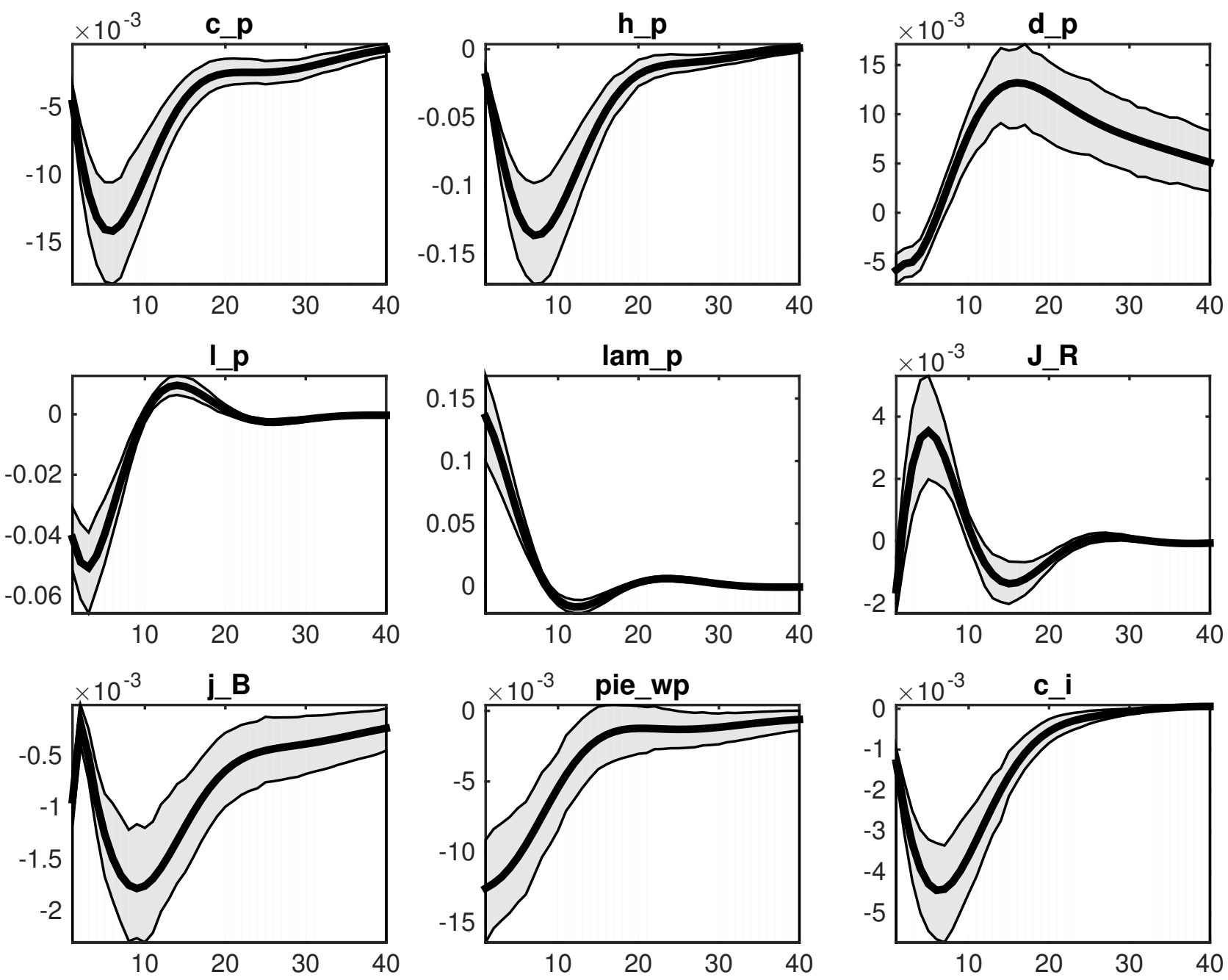

Figura 247: Efeito de um choque em $\mathrm{mk}_{d}$ 

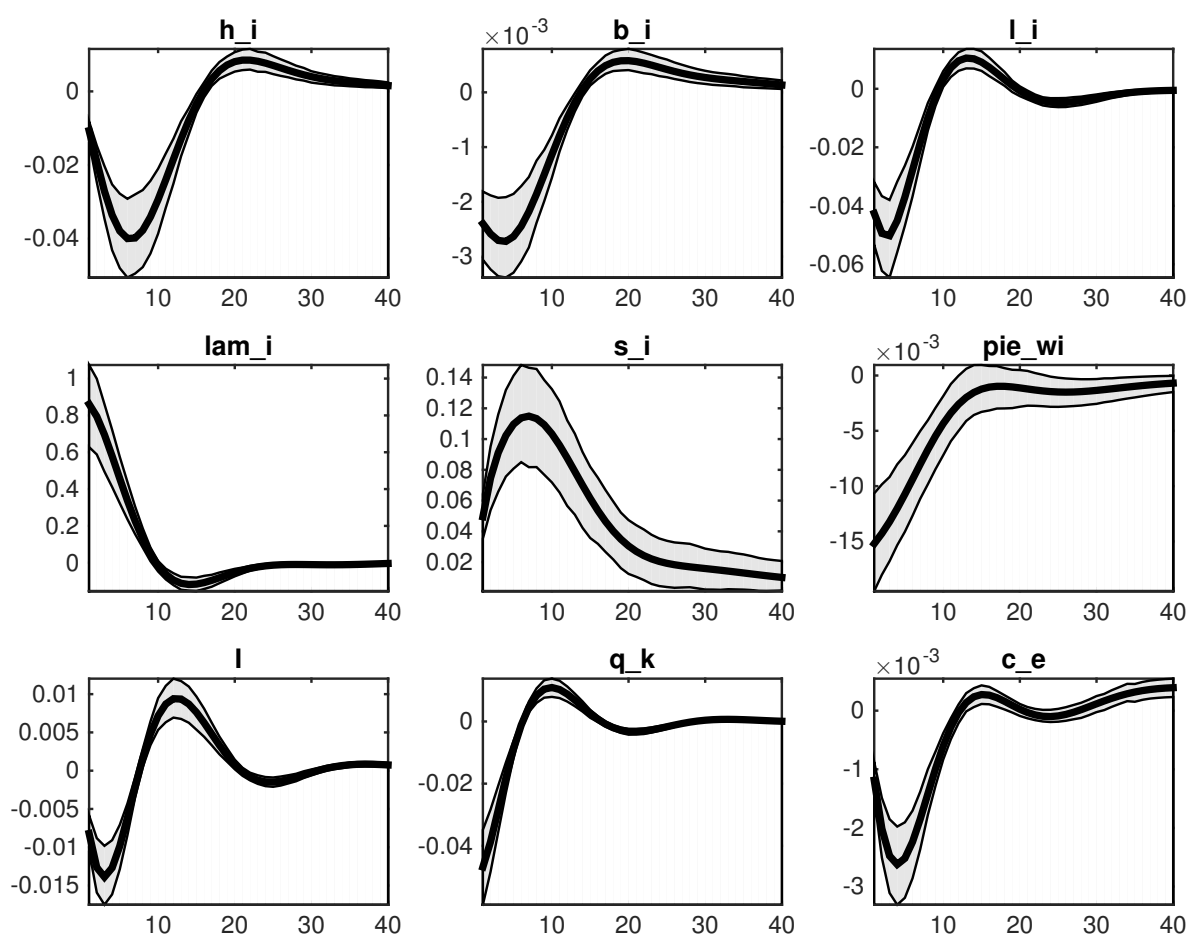

Figura 248: Efeito de um choque em $\mathrm{mk}_{d}$
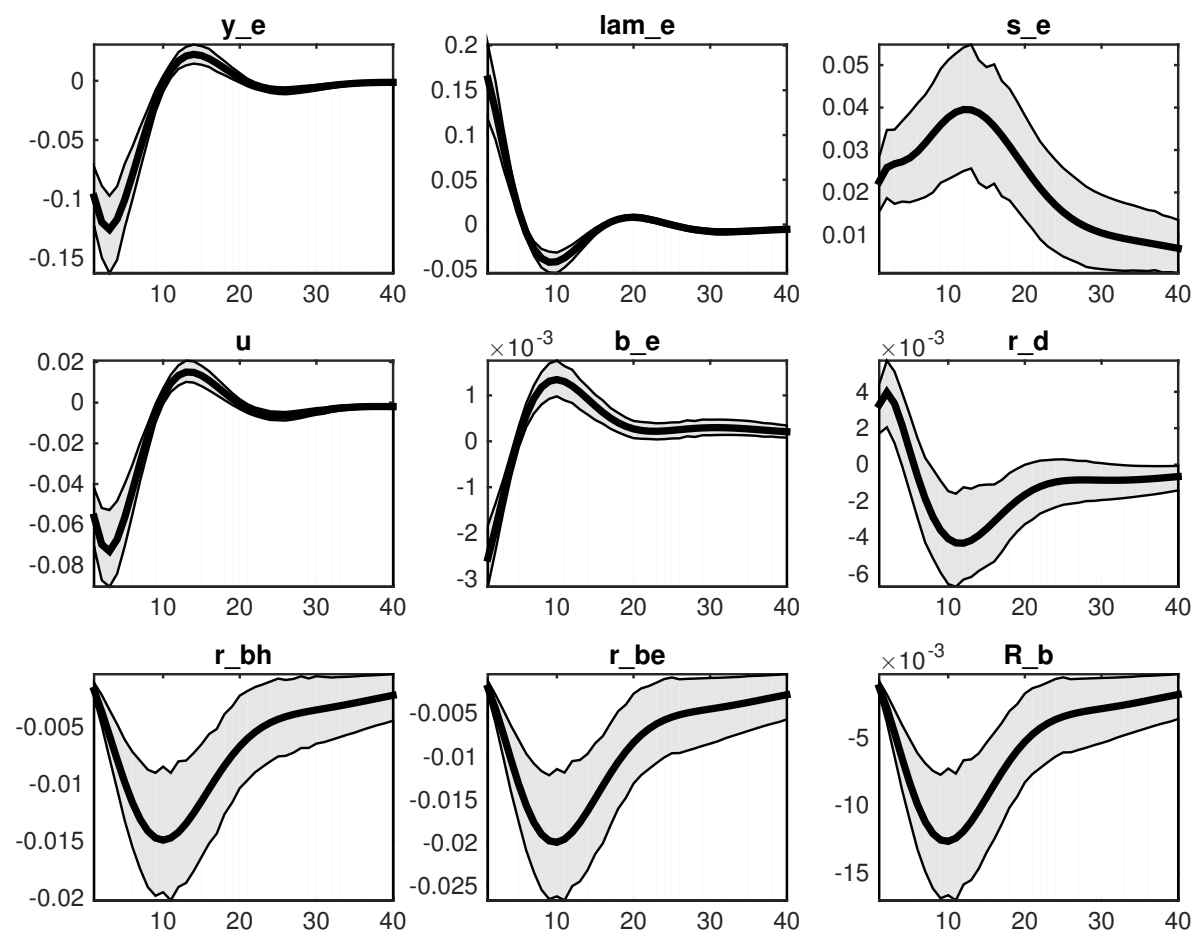

Figura 249: Efeito de um choque em $\mathrm{mk}_{d}$ 

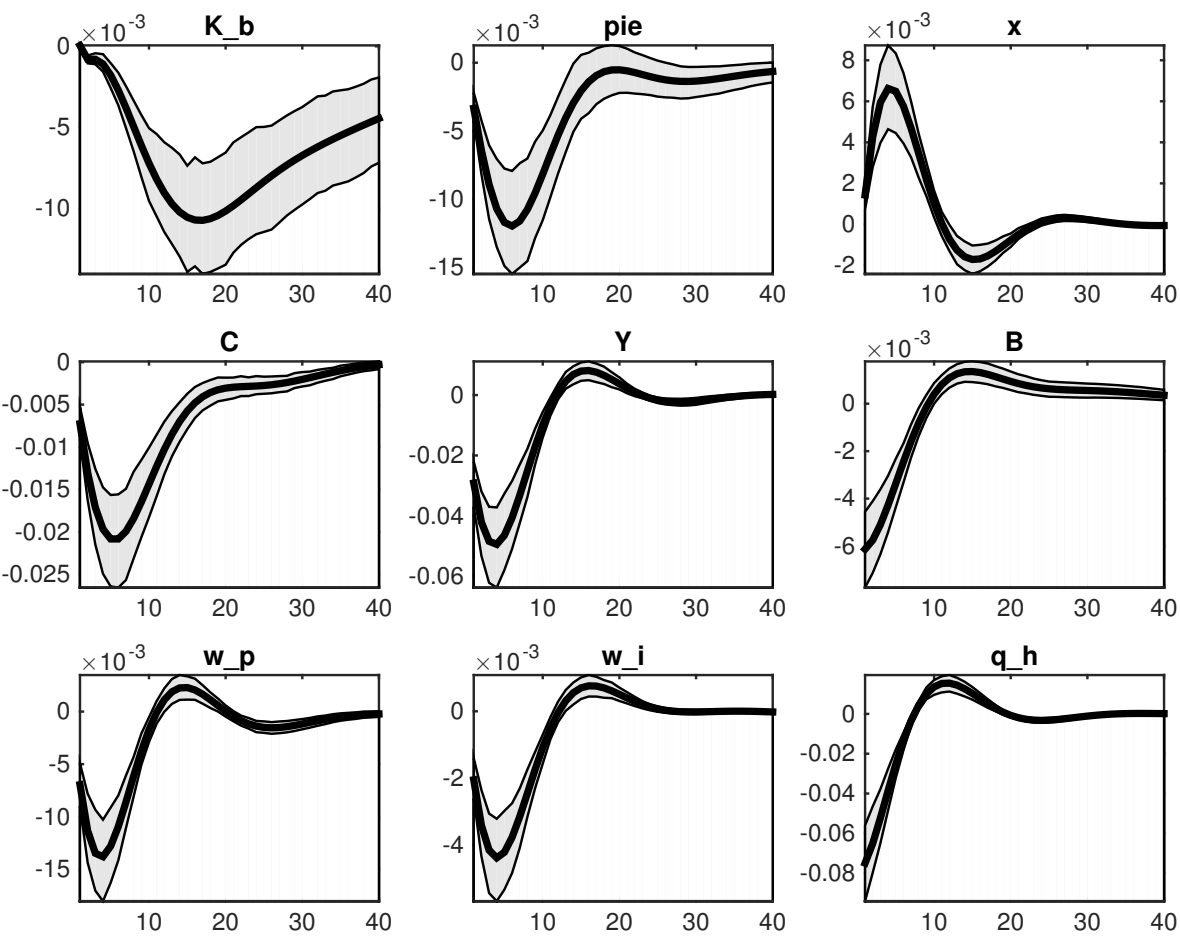

Figura 250: Efeito de um choque em $\mathrm{mk}_{d}$
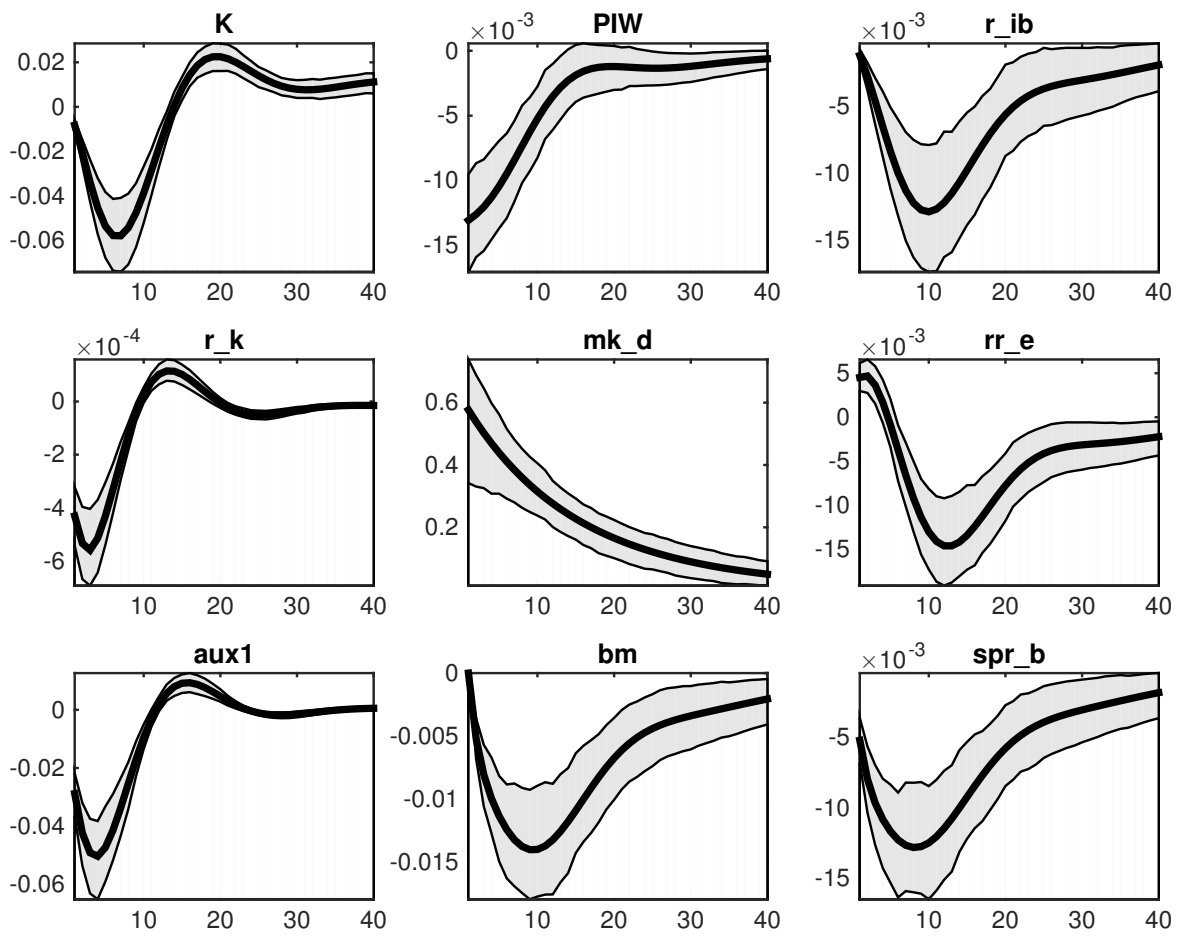

Figura 251: Efeito de um choque em $\mathrm{mk}_{d}$ 

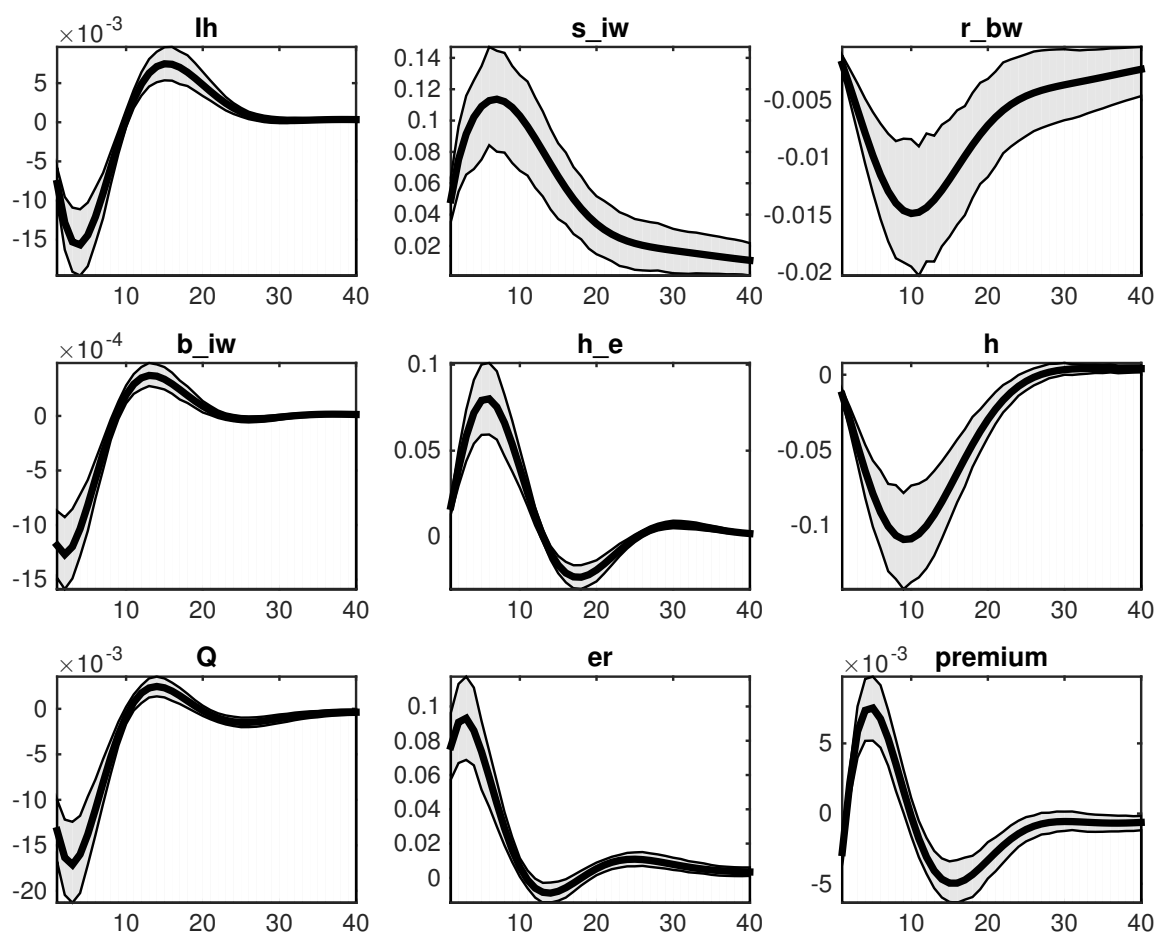

Figura 252: Efeito de um choque em $\mathrm{mk}_{d}$
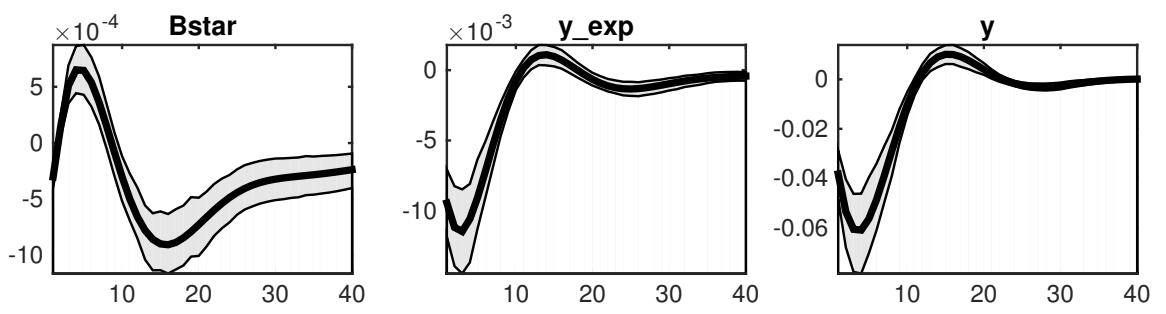

Figura 253: Efeito de um choque em $\mathrm{mk}_{d}$ 
B.18 Choque na Oferta de Capital Físico
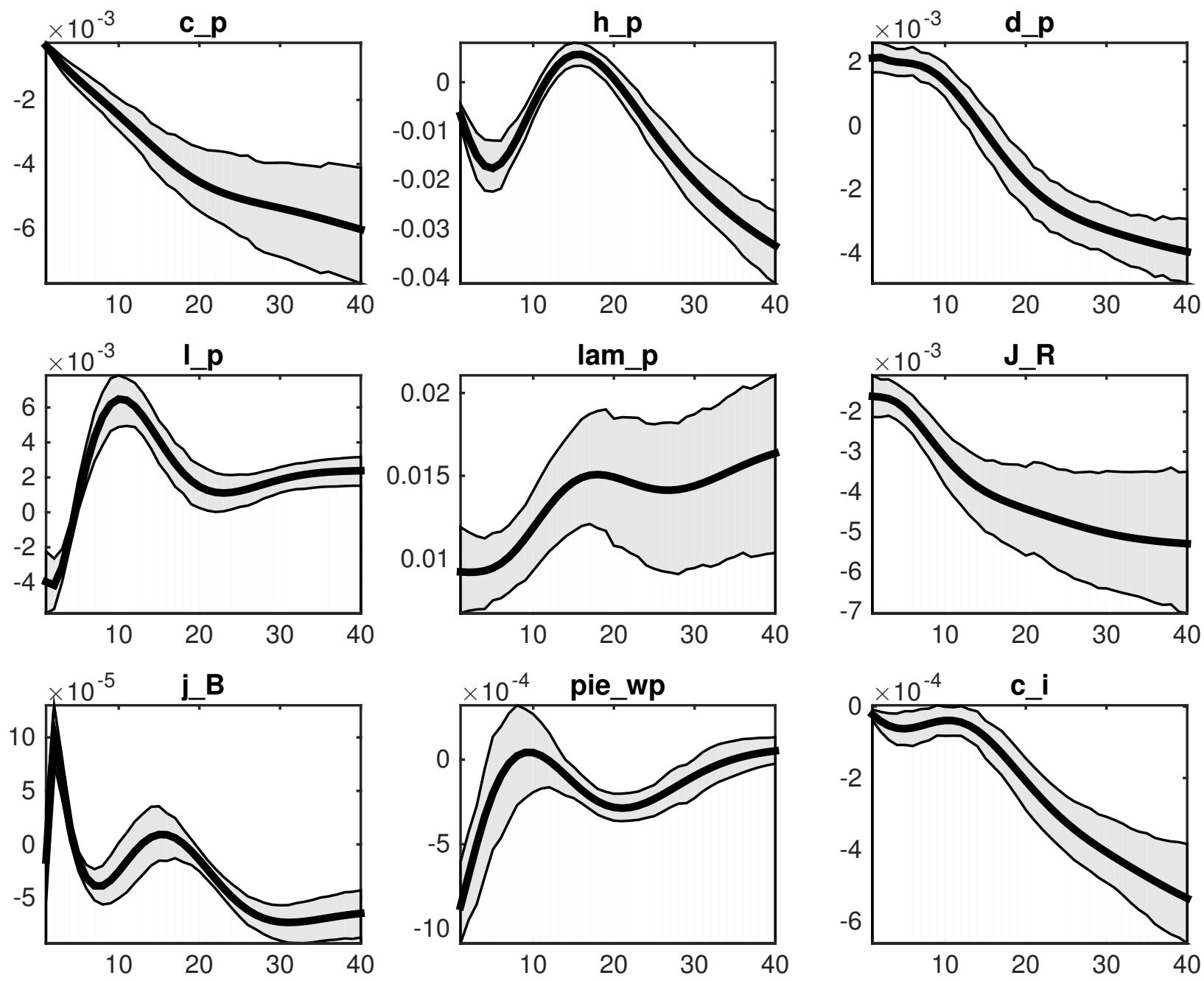

Figura 254: Efeito de um choque em I ${ }^{k}$ 

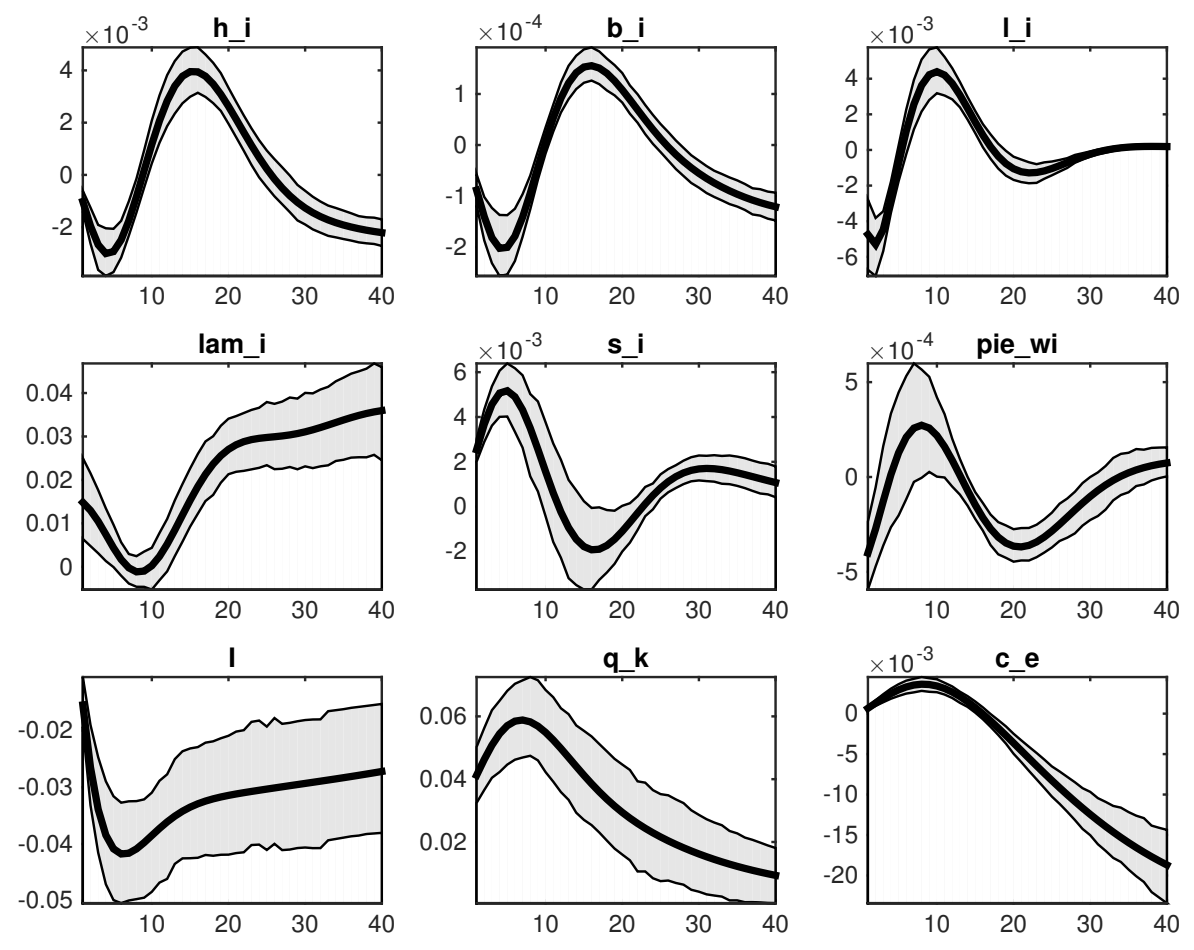

Figura 255: Efeito de um choque em $\mathrm{I}^{k}$
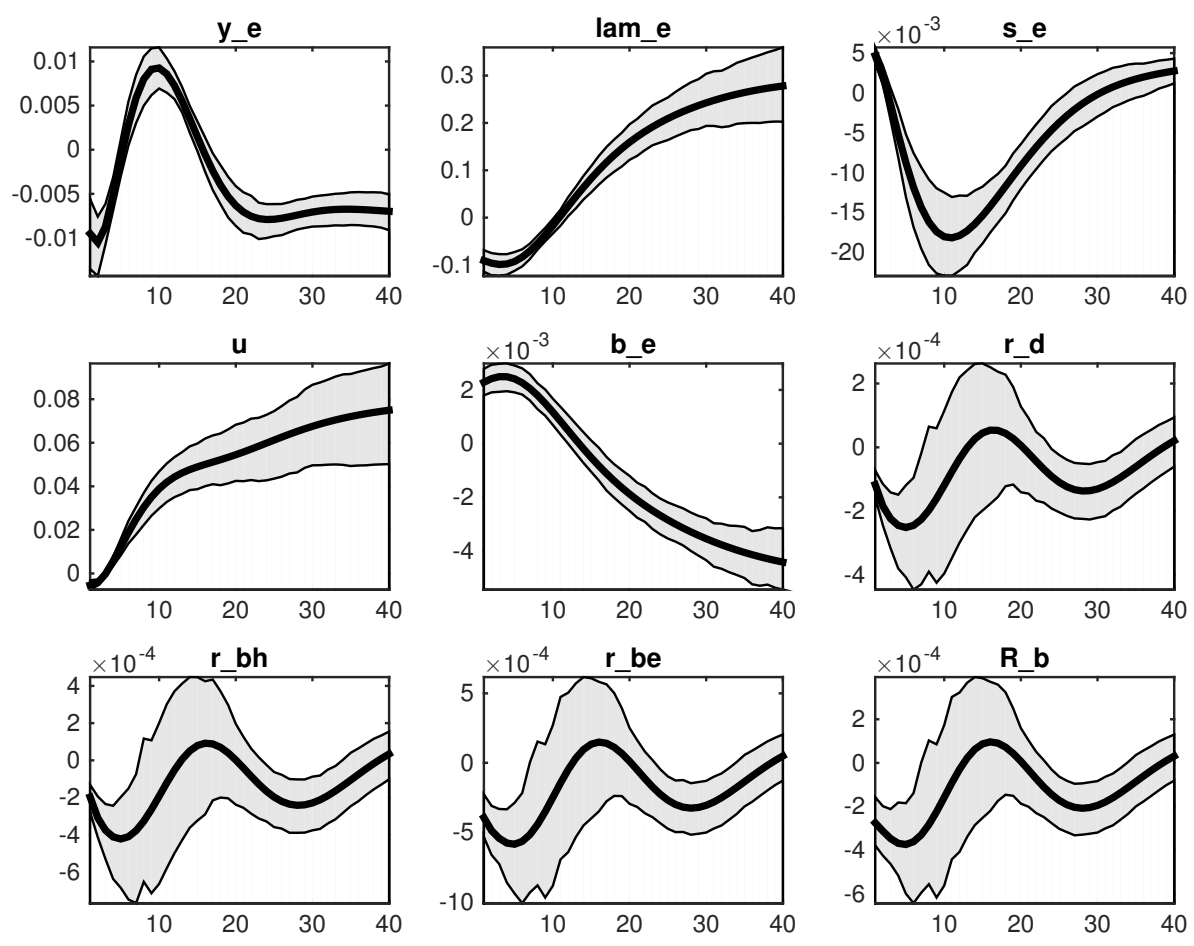

Figura 256: Efeito de um choque em $\mathrm{I}^{k}$ 

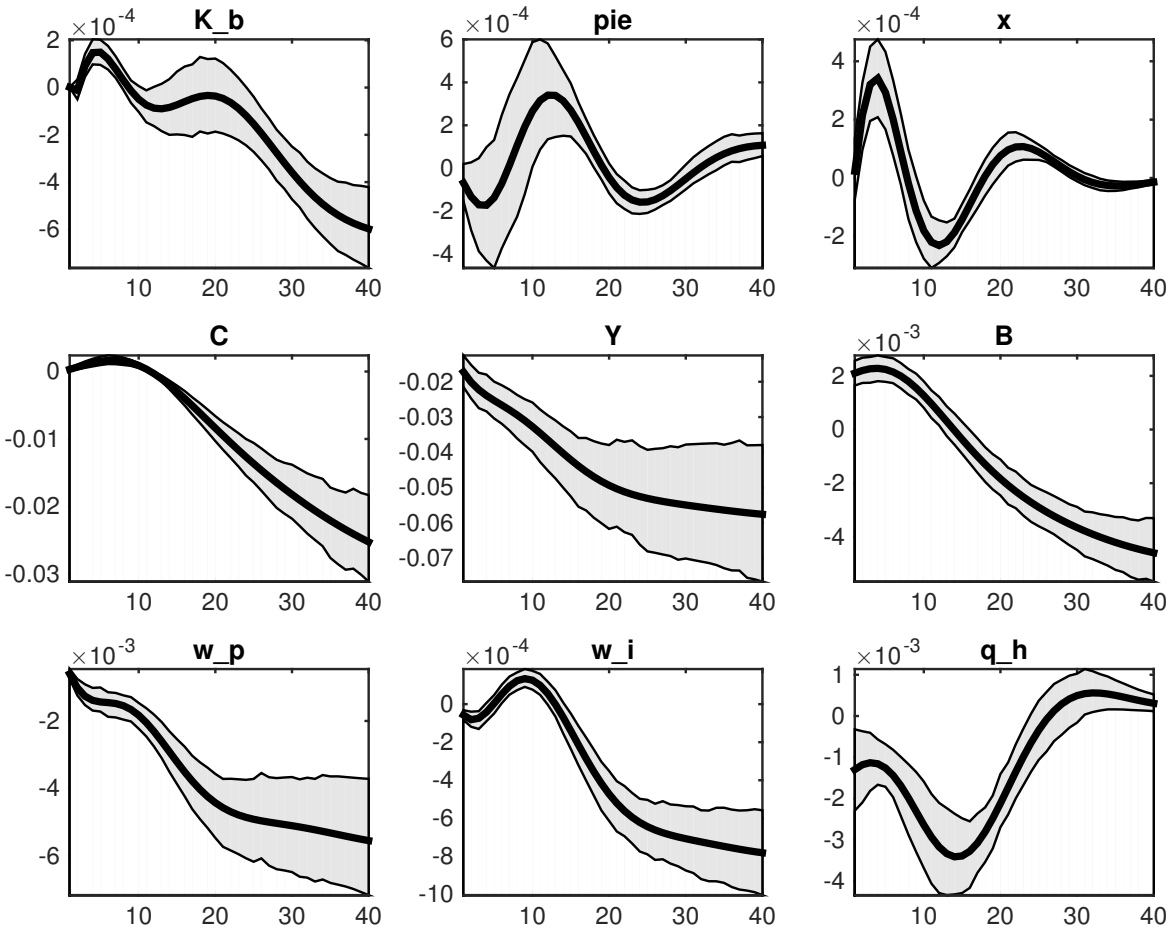

Figura 257: Efeito de um choque em $\mathrm{I}^{k}$
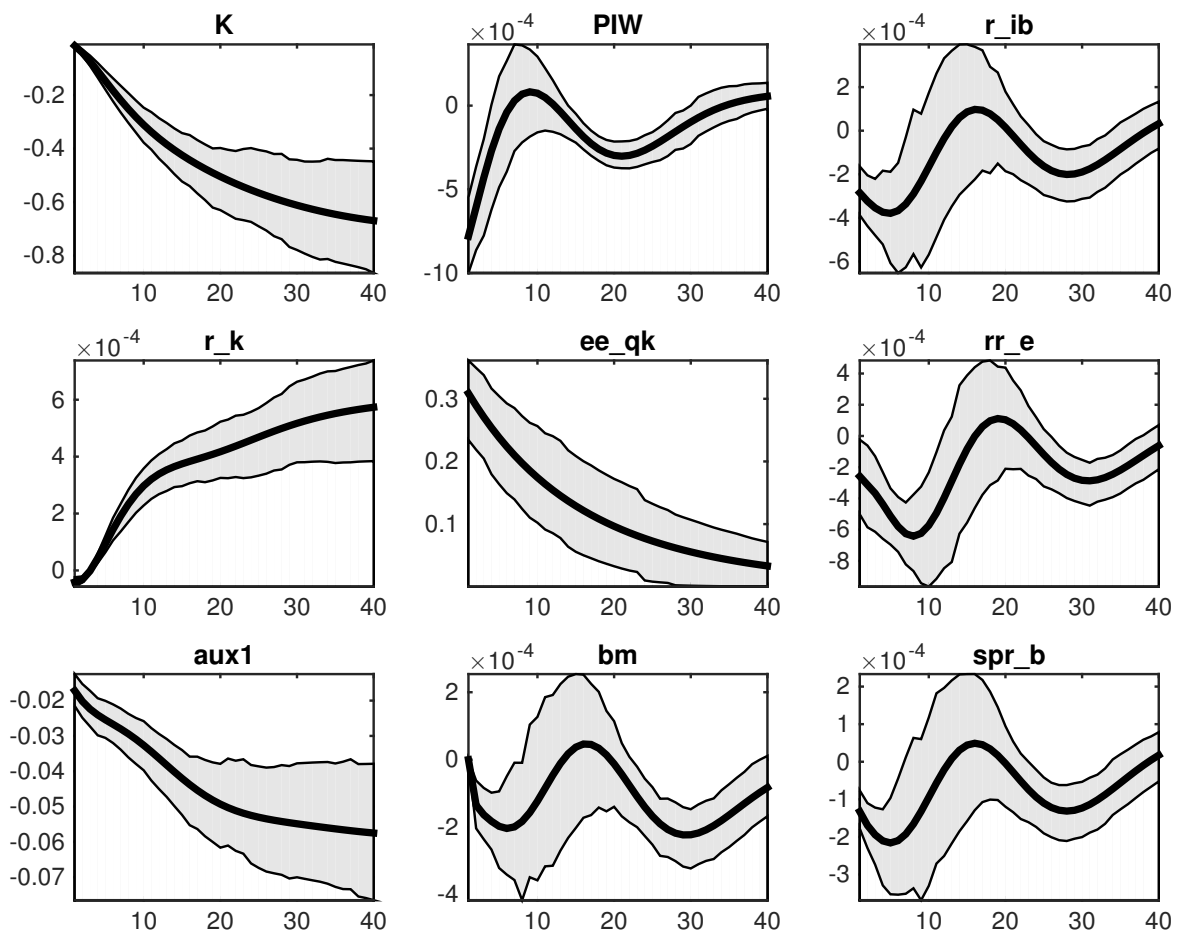

Figura 258: Efeito de um choque em $\mathrm{I}^{k}$ 

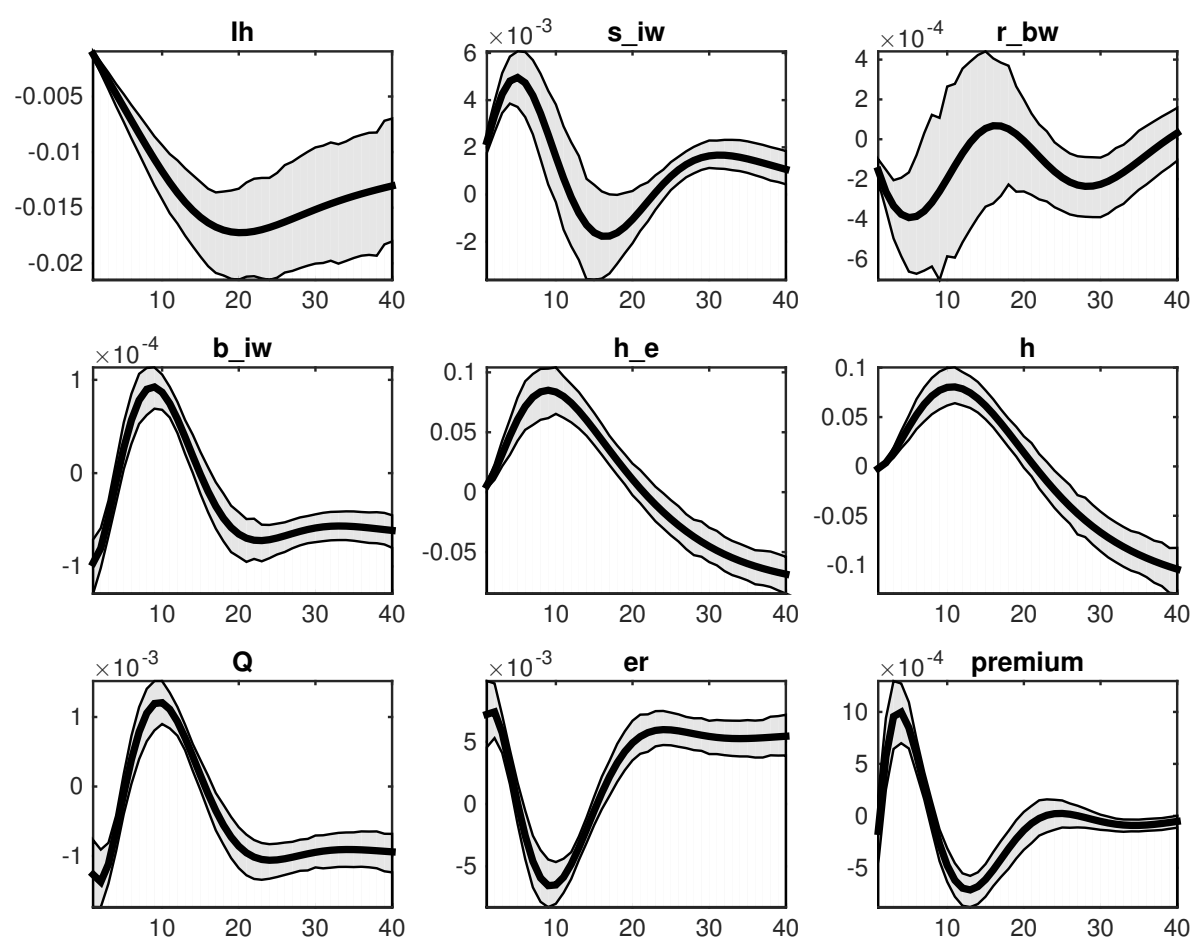

Figura 259: Efeito de um choque em $\mathrm{I}^{k}$
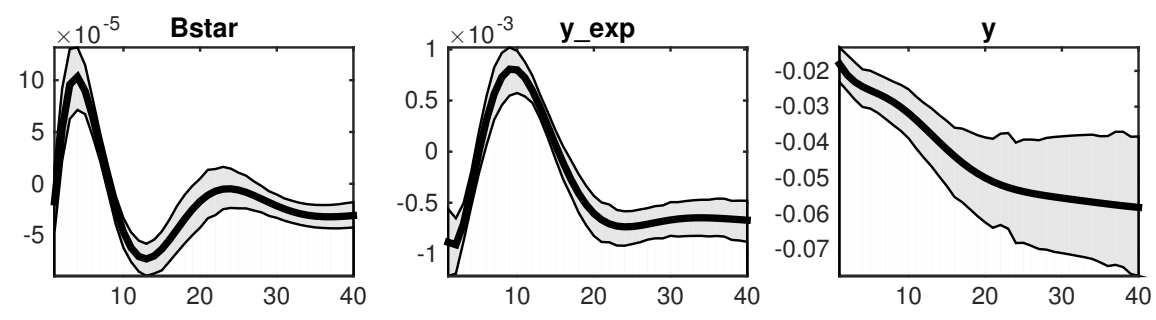

Figura 260: Efeito de um choque em I ${ }^{k}$ 
B.19 Choque de política monetária
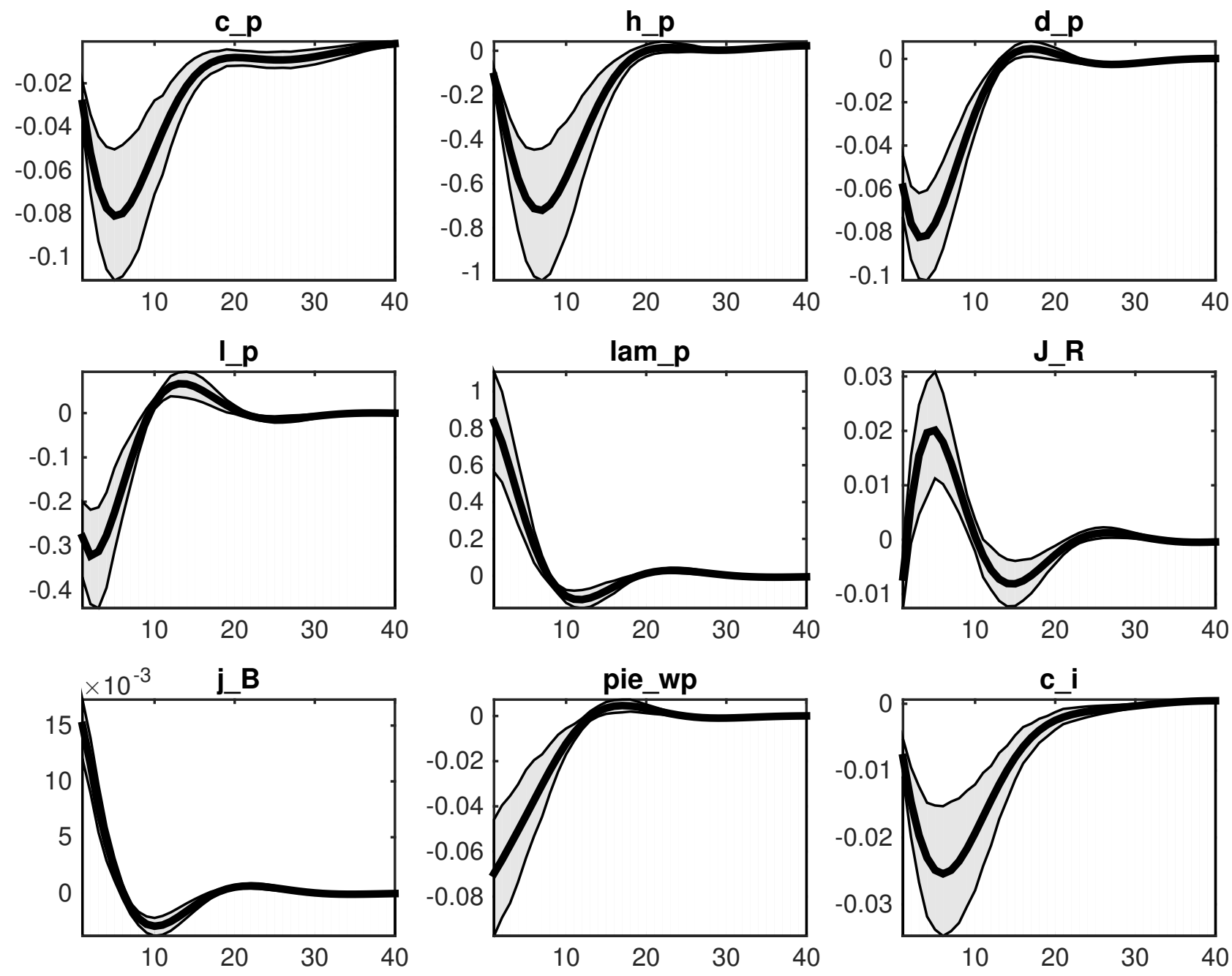

Figura 261: Efeito de um choque de PM 

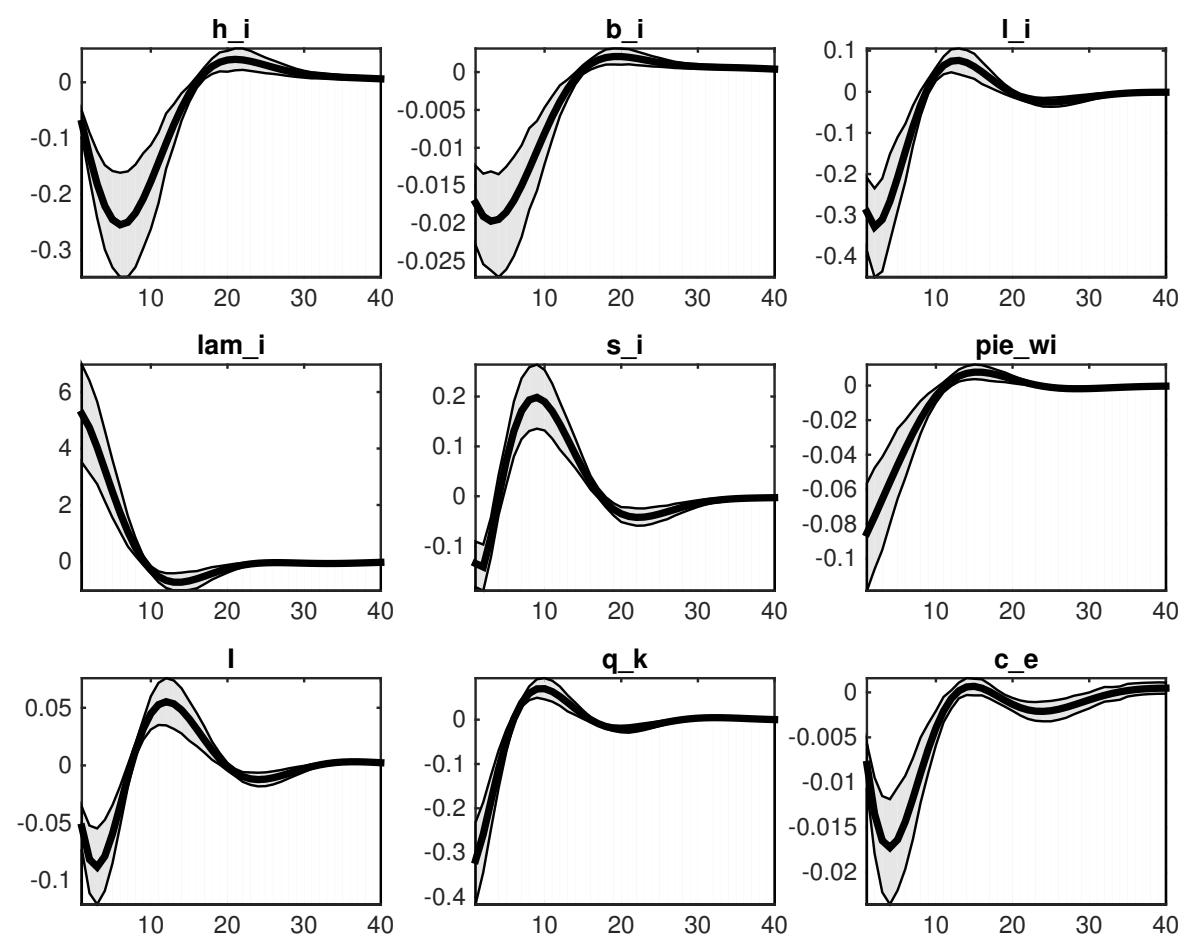

Figura 262: Efeito de um choque de PM
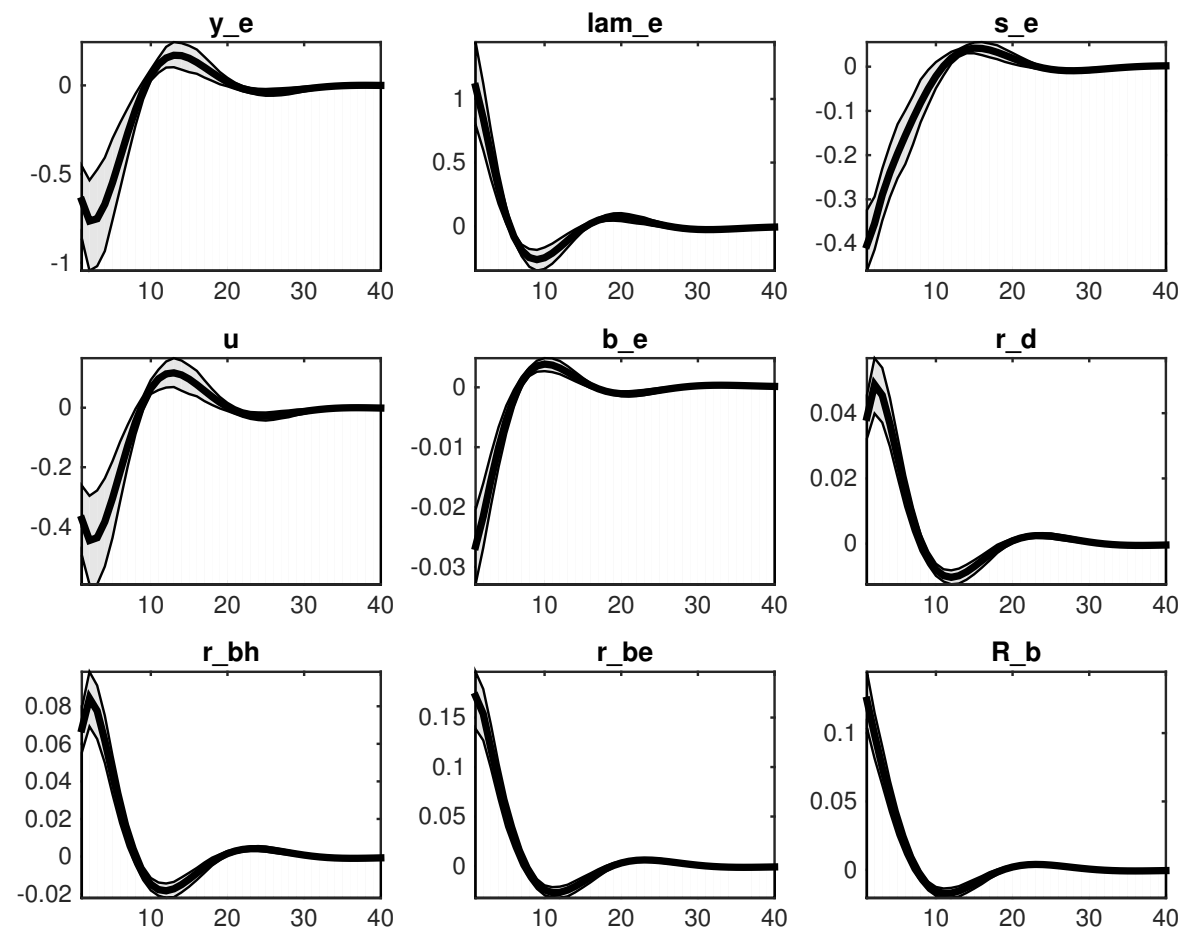

Figura 263: Efeito de um choque de PM 

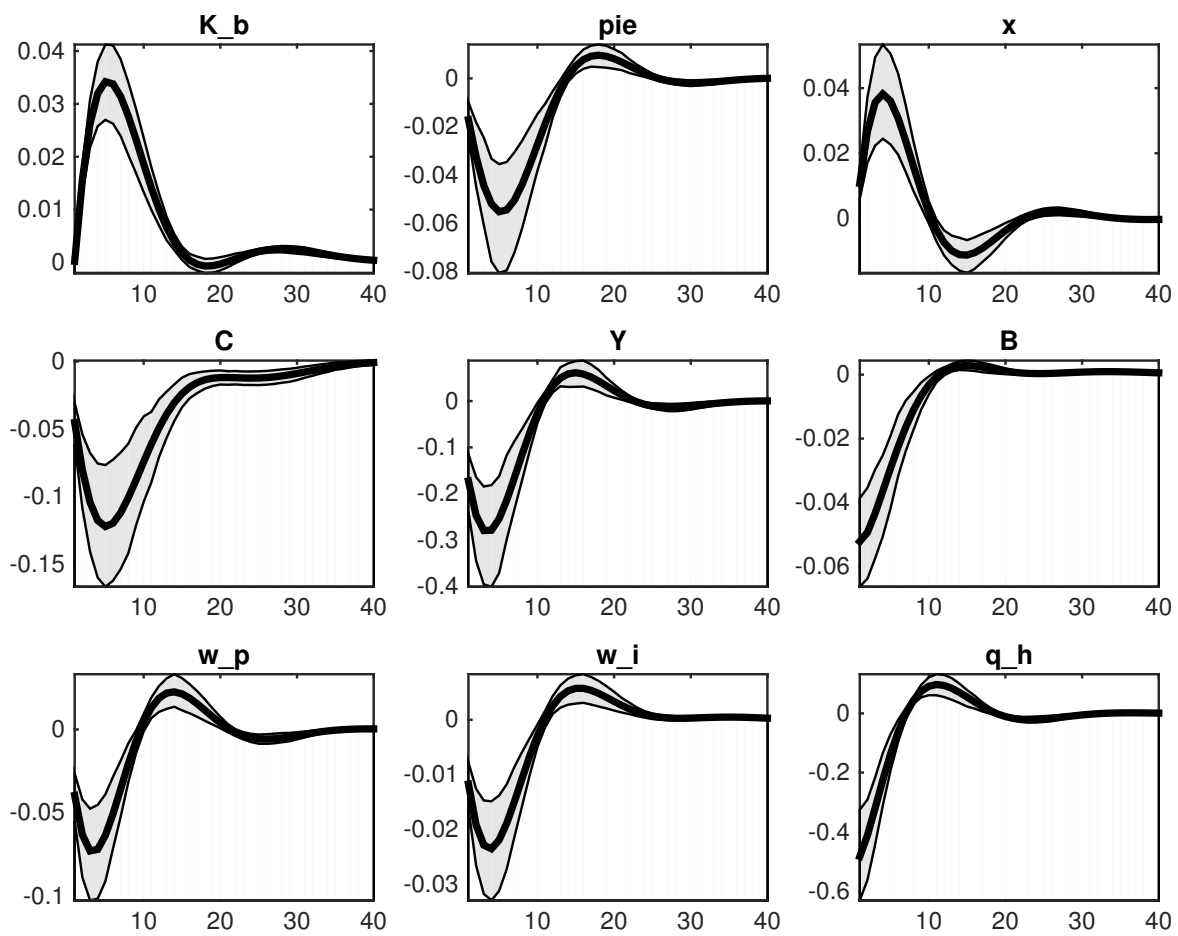

Figura 264: Efeito de um choque de PM
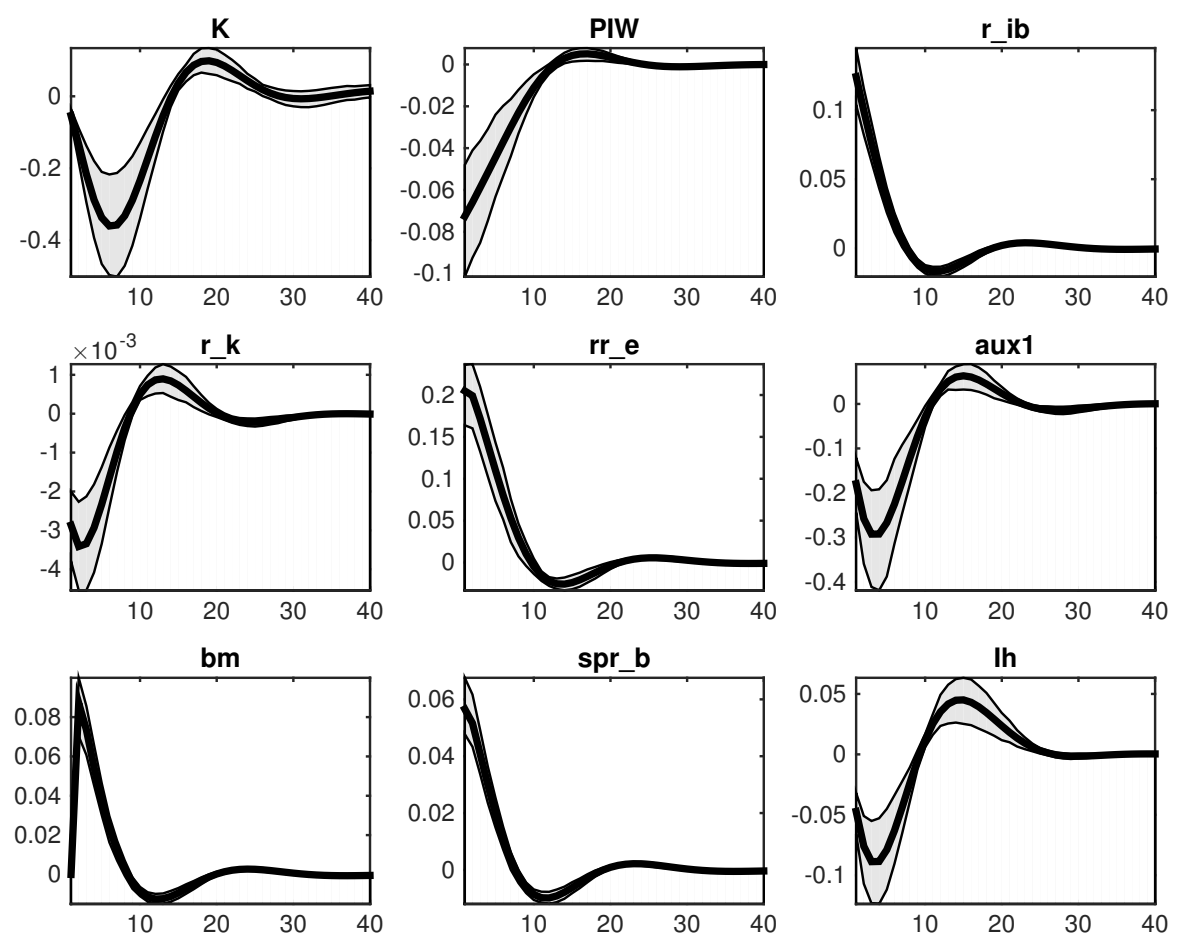

Figura 265: Efeito de um choque de PM 

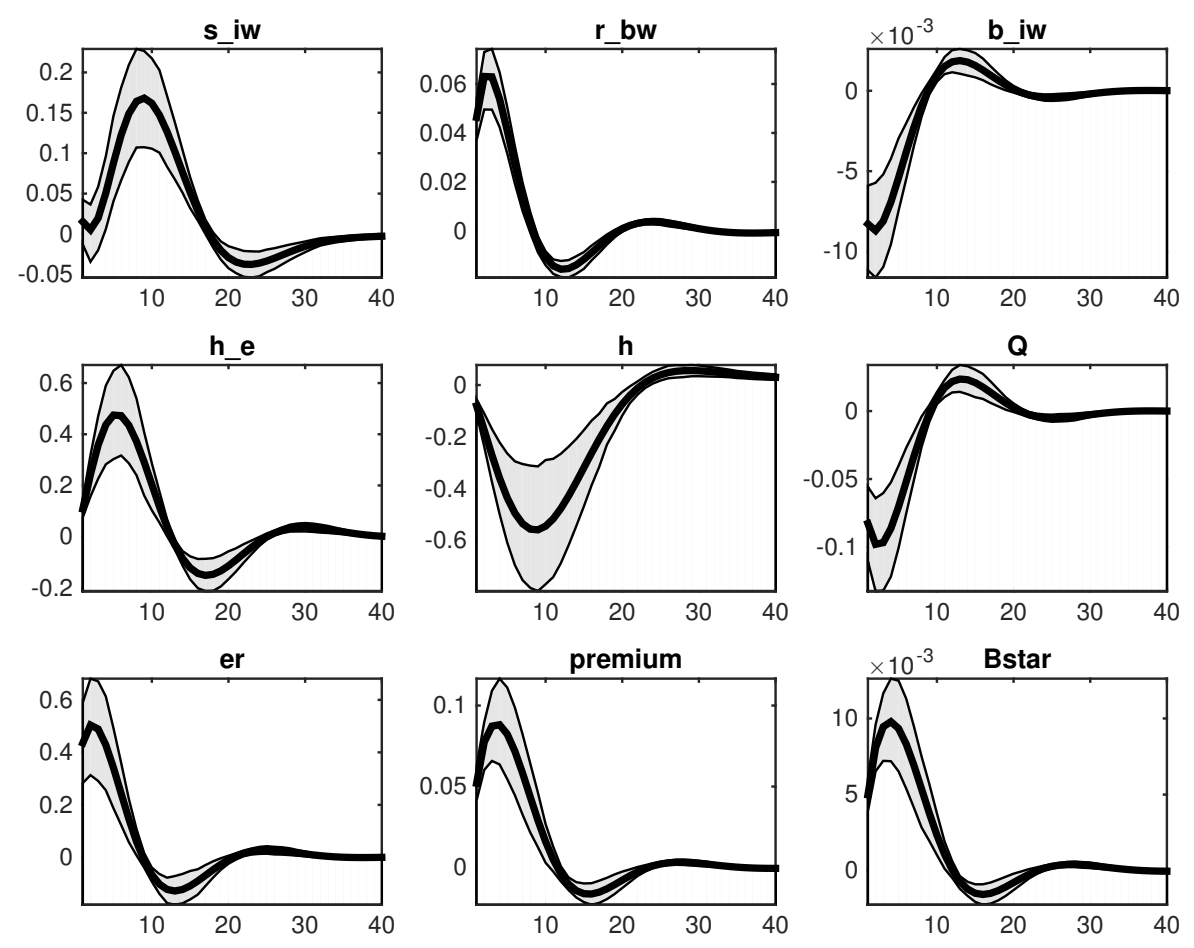

Figura 266: Efeito de um choque de PM
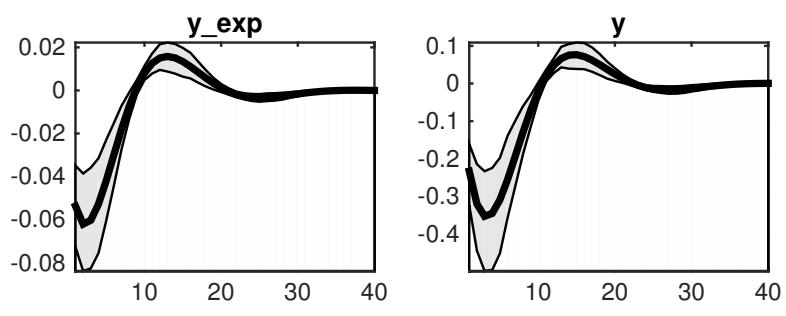

Figura 267: Efeito de um choque de PM 
B.20 Choque no Mark-up de preços
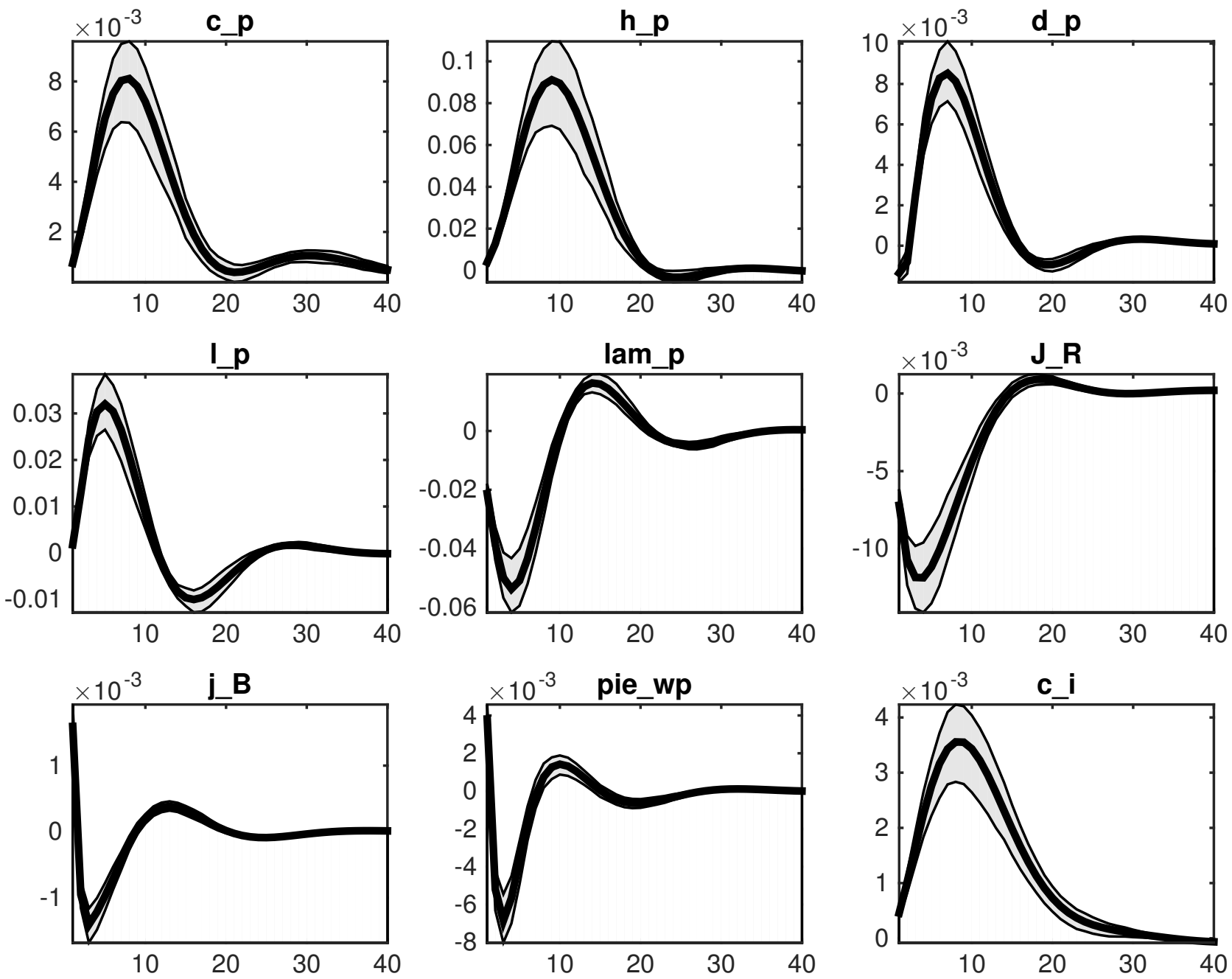

Figura 268: Efeito de um choque no mark-up de preços 

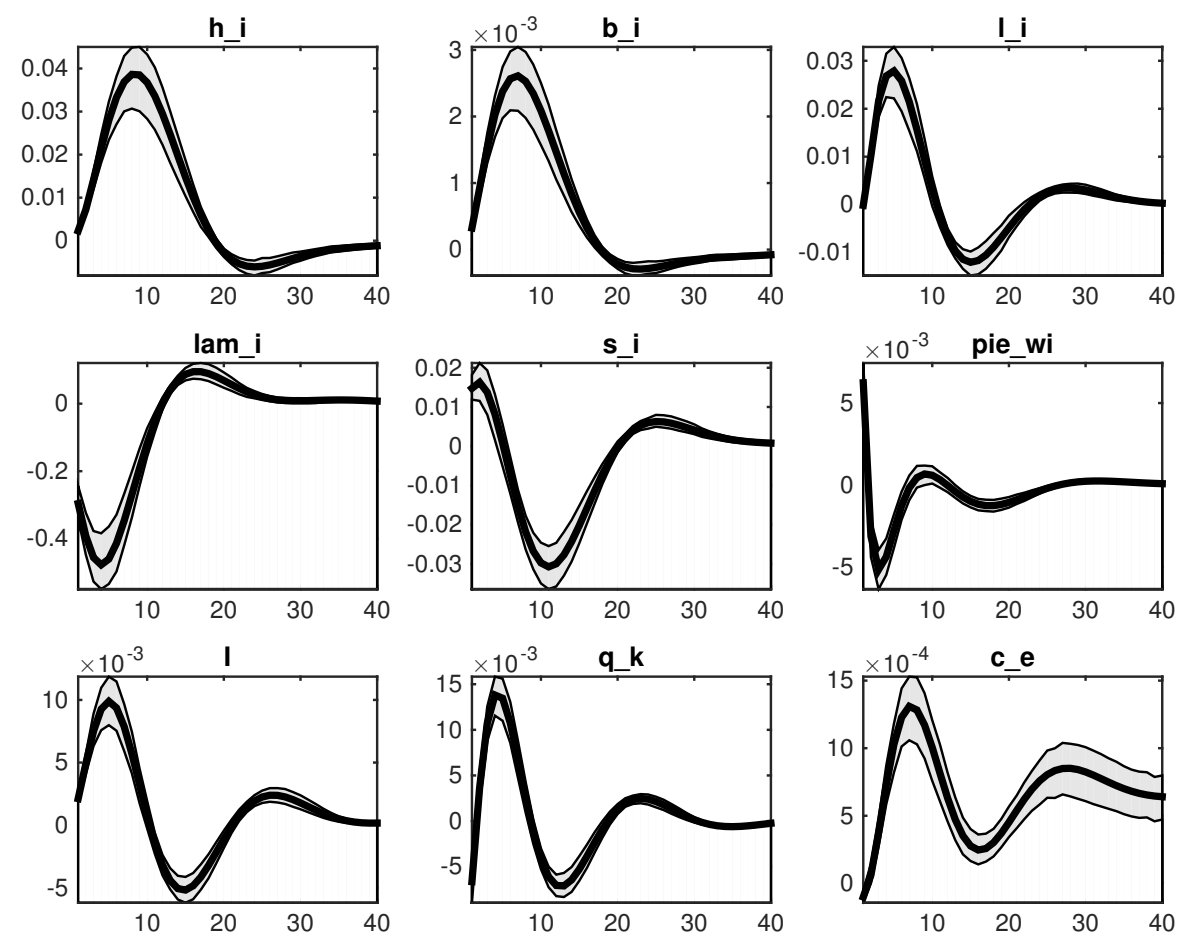

Figura 269: Efeito de um choque no mark-up de preços
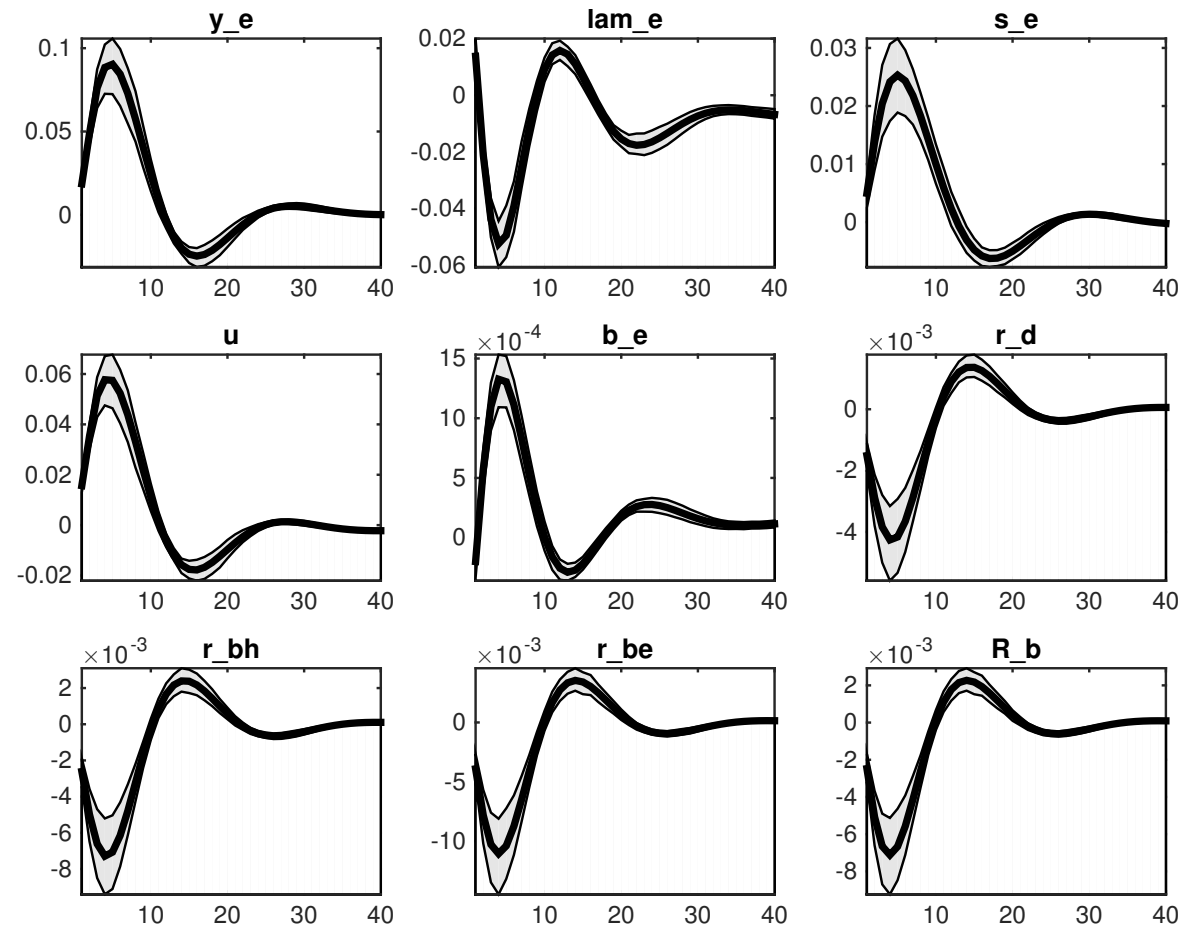

Figura 270: Efeito de um choque no mark-up de preços 

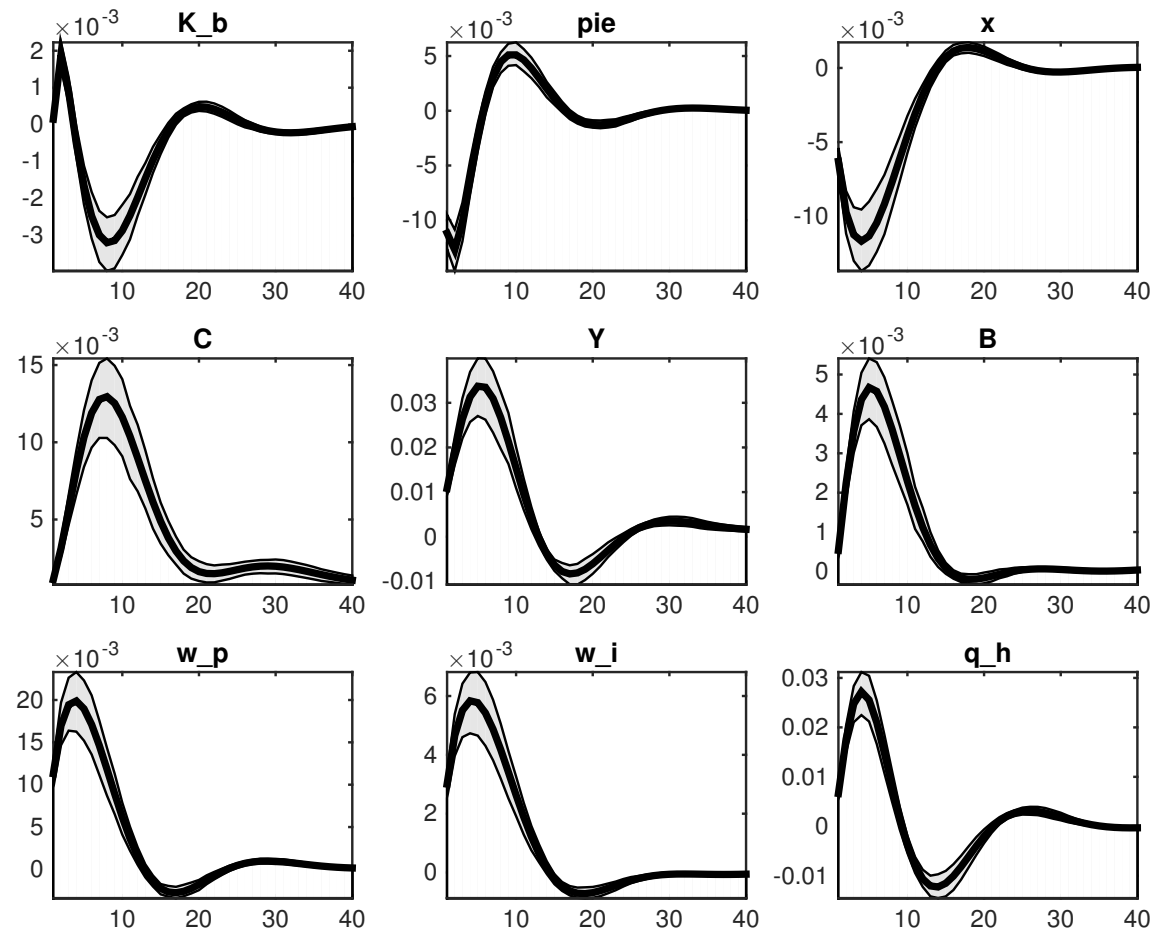

Figura 271: Efeito de um choque no mark-up de preços
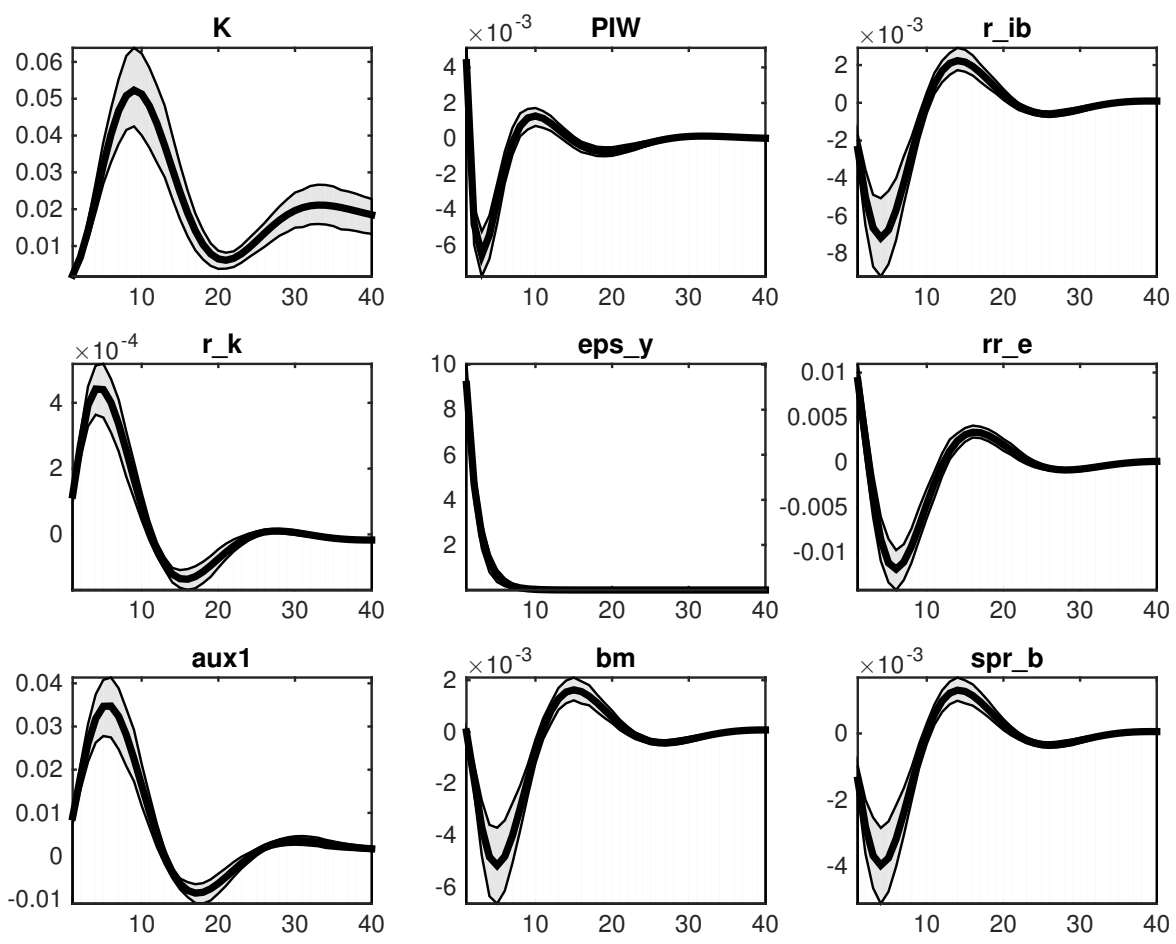

Figura 272: Efeito de um choque no mark-up de preços 

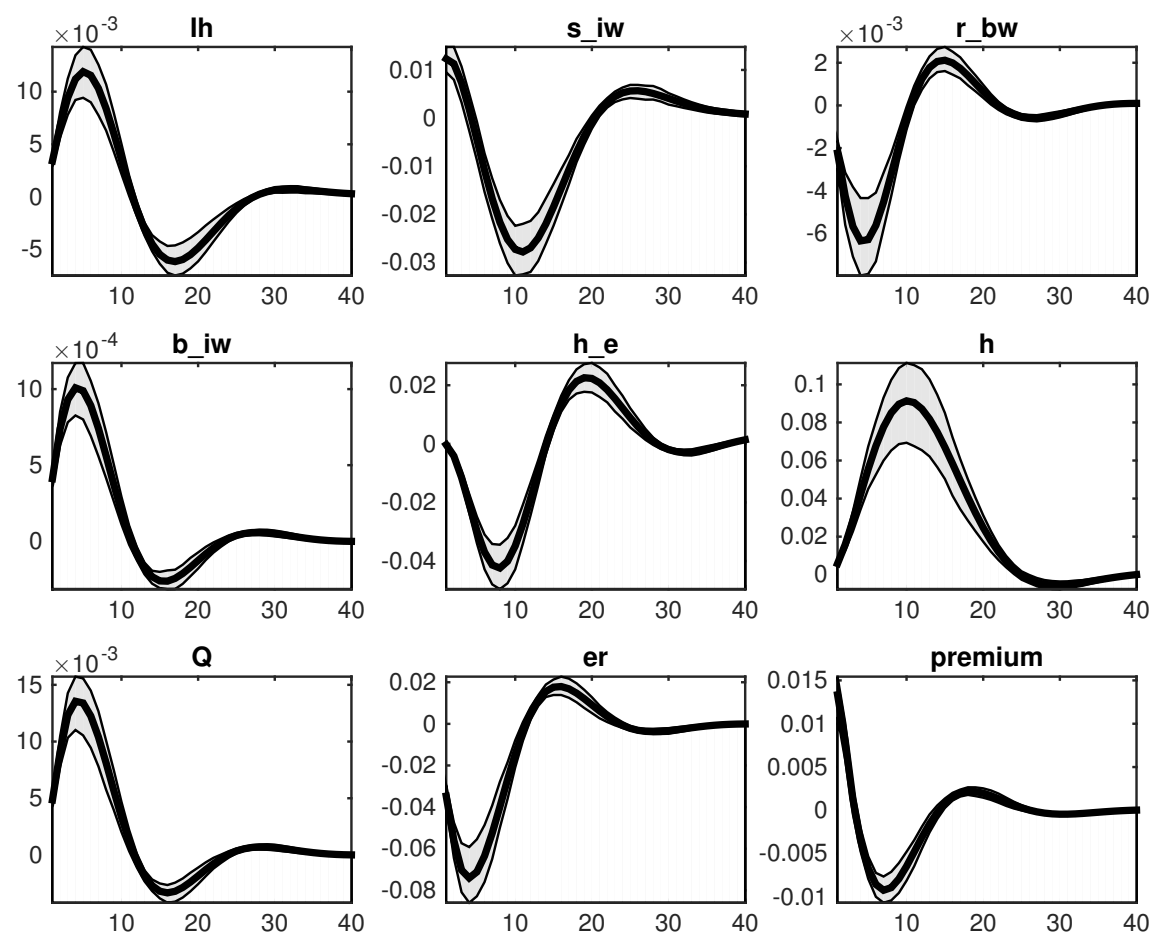

Figura 273: Efeito de um choque no mark-up de preços
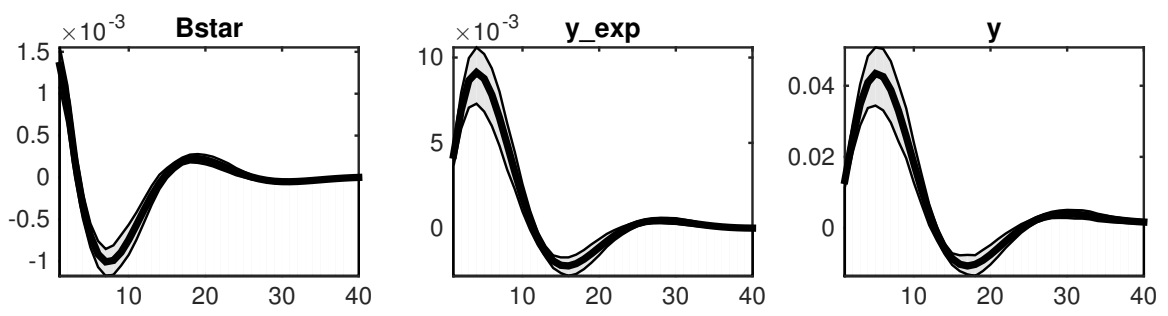

Figura 274: Efeito de um choque no mark-up de preços 
B.21 Choque na demanda por consumo
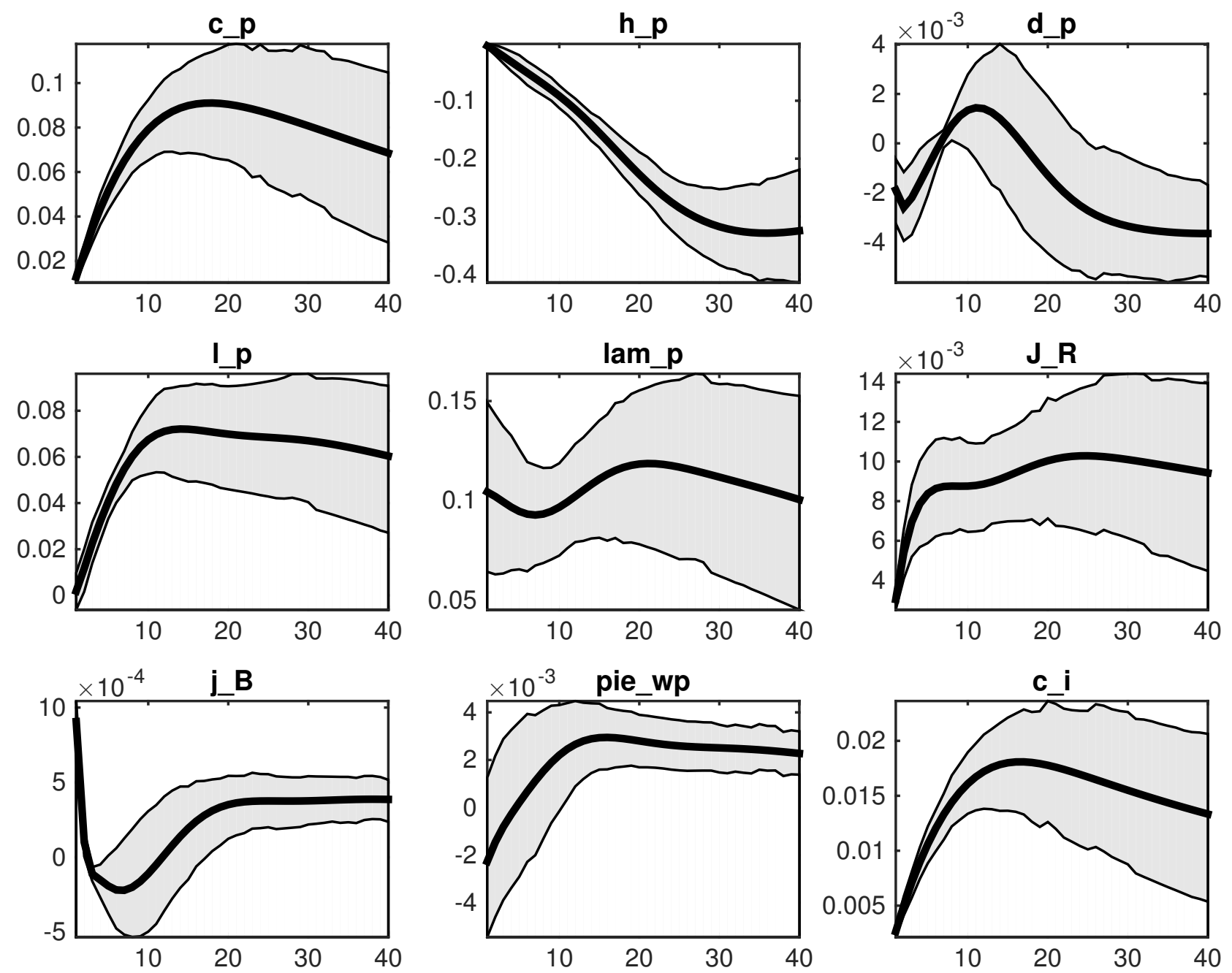

Figura 275: Efeito de um choque na demanda por consumo 

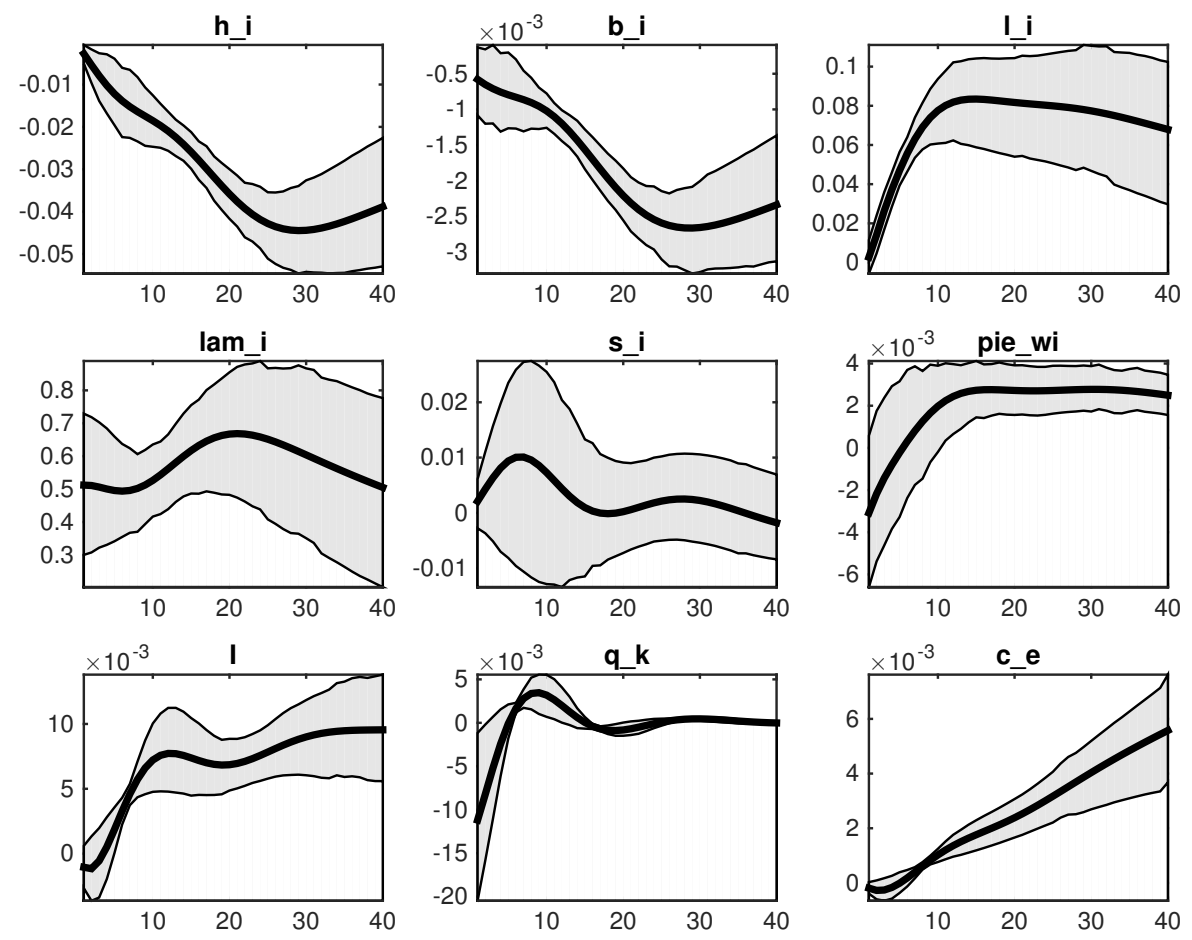

Figura 276: Efeito de um choque na demanda por consumo
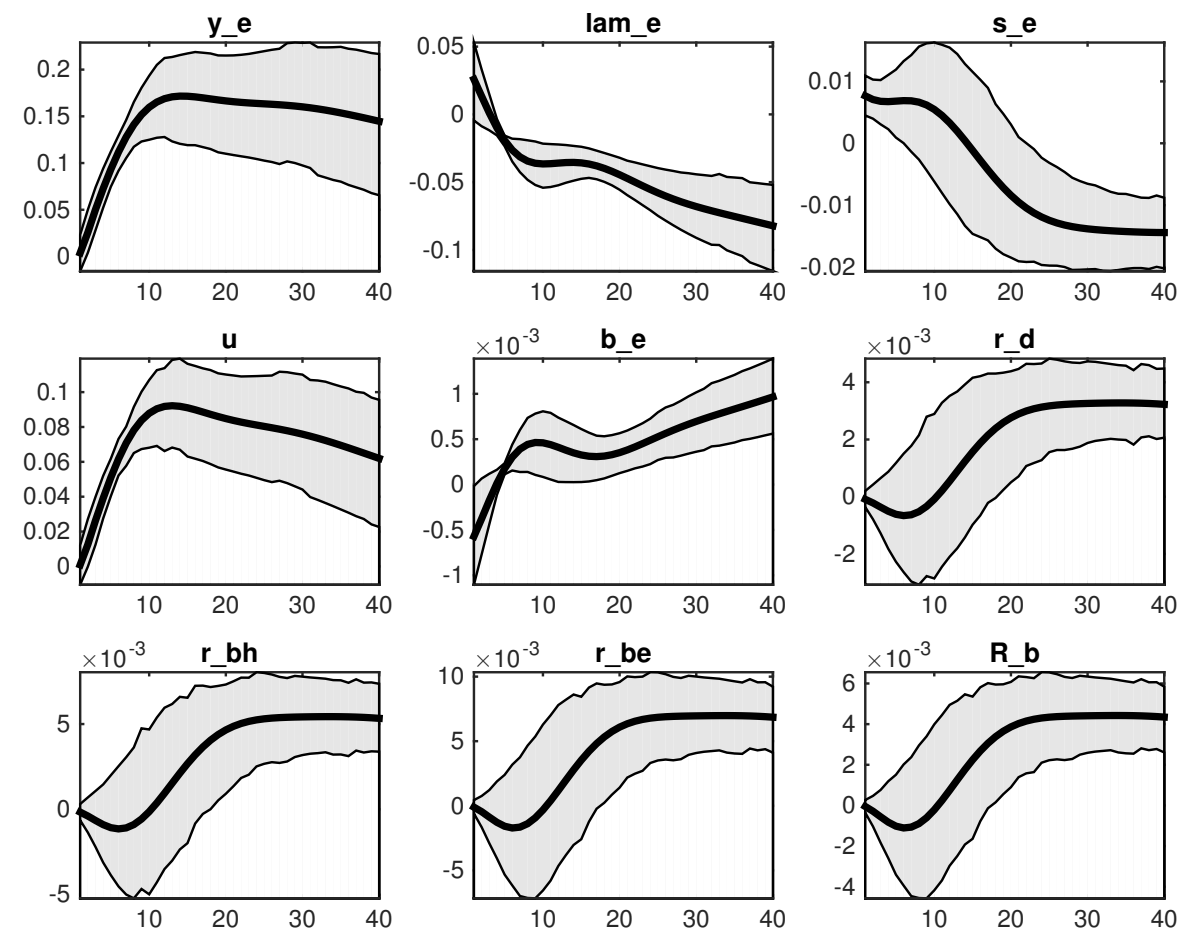

Figura 277: Efeito de um choque na demanda por consumo 

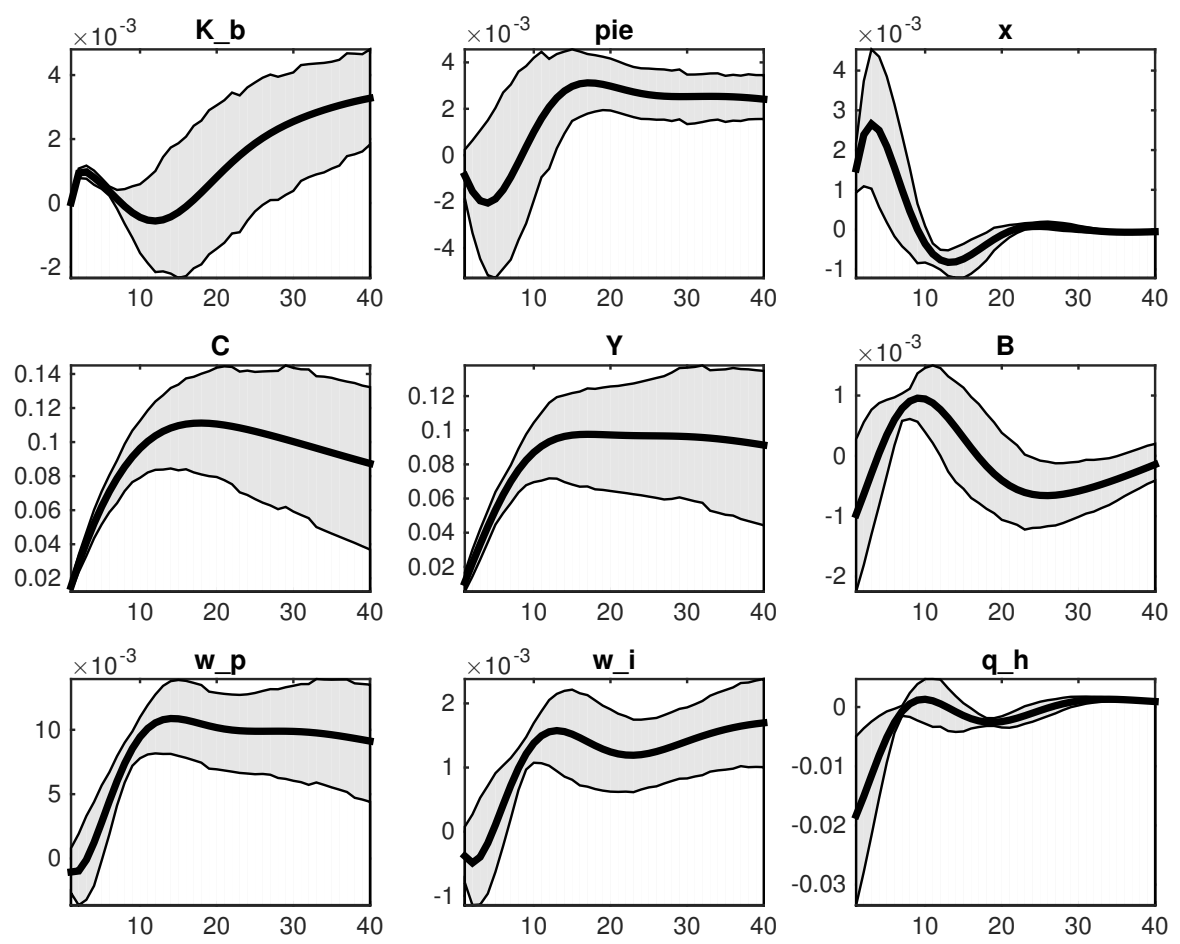

Figura 278: Efeito de um choque na demanda por consumo
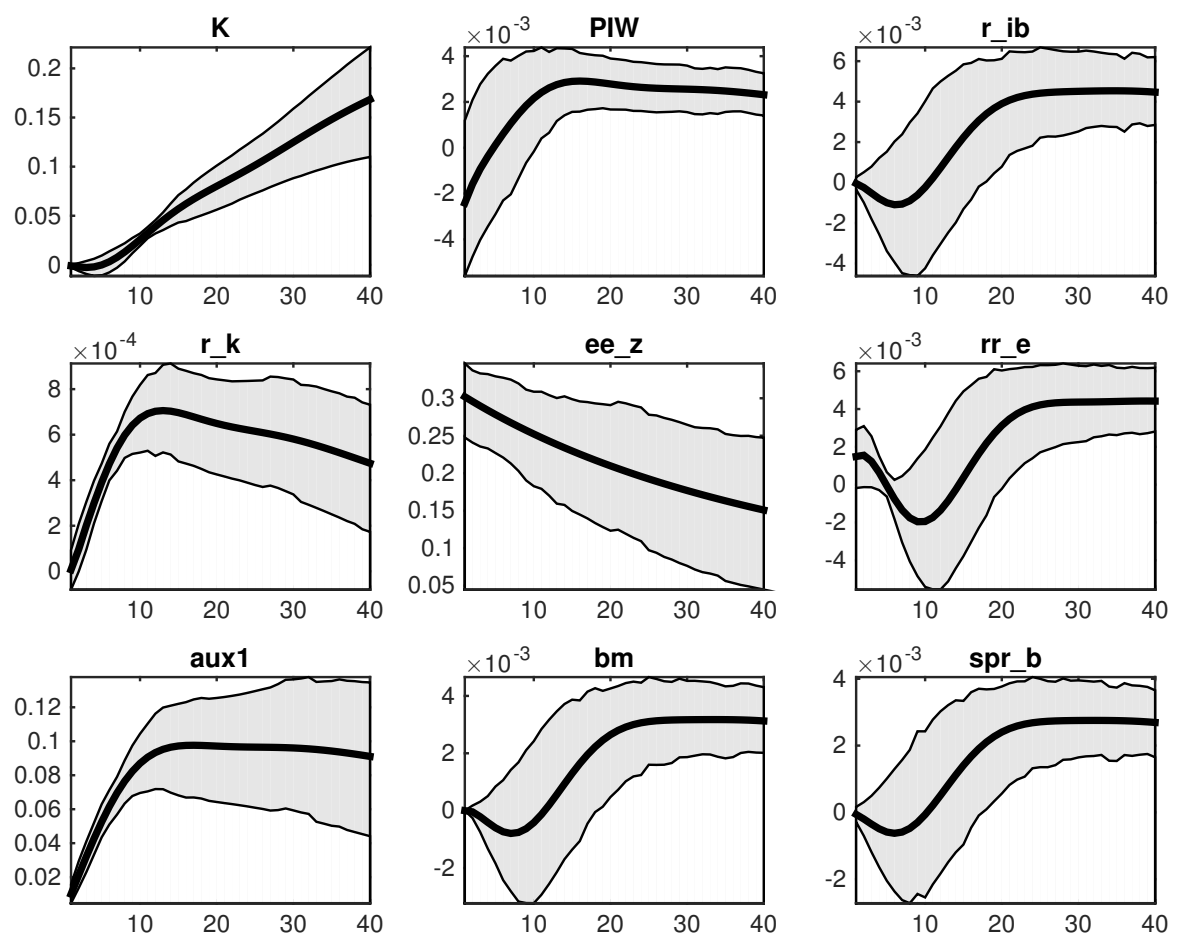

Figura 279: Efeito de um choque na demanda por consumo 

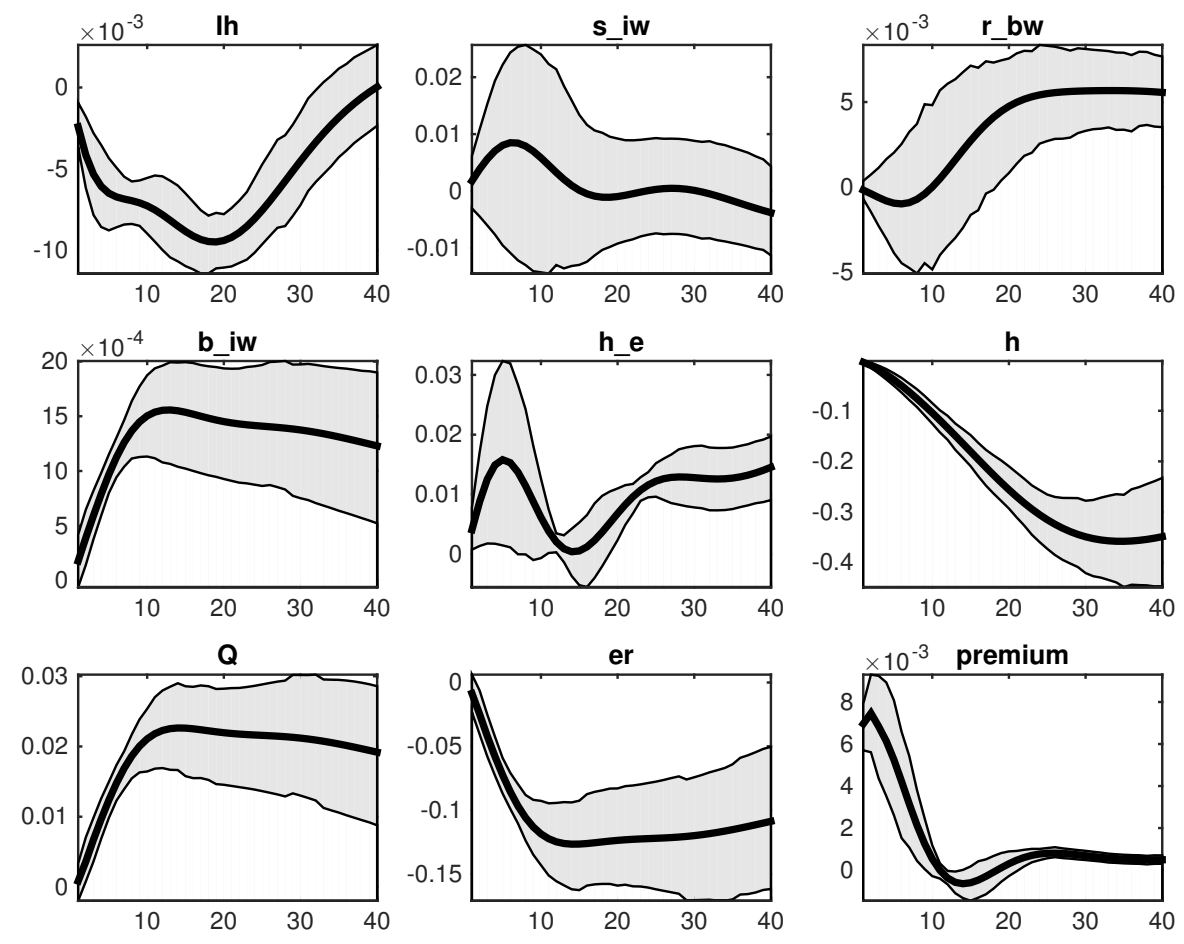

Figura 280: Efeito de um choque na demanda por consumo
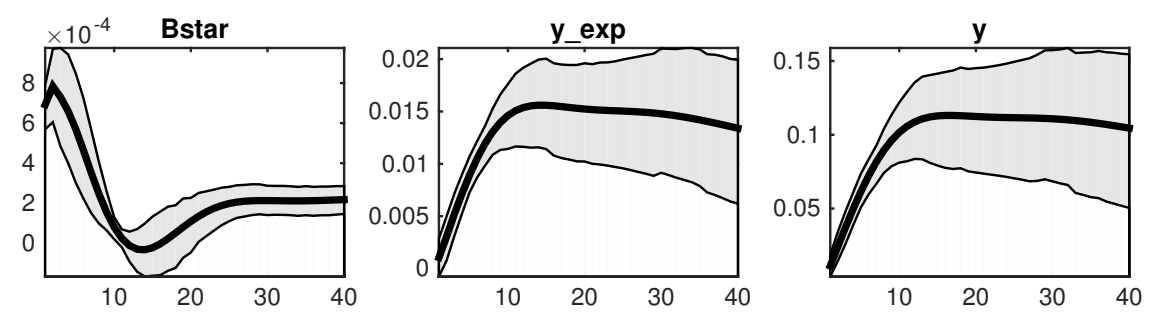

Figura 281: Efeito de um choque na demanda por consumo 


\section{APÊNDICE C - Priors e Posteriores}

\section{C.1 Economia Fechada}
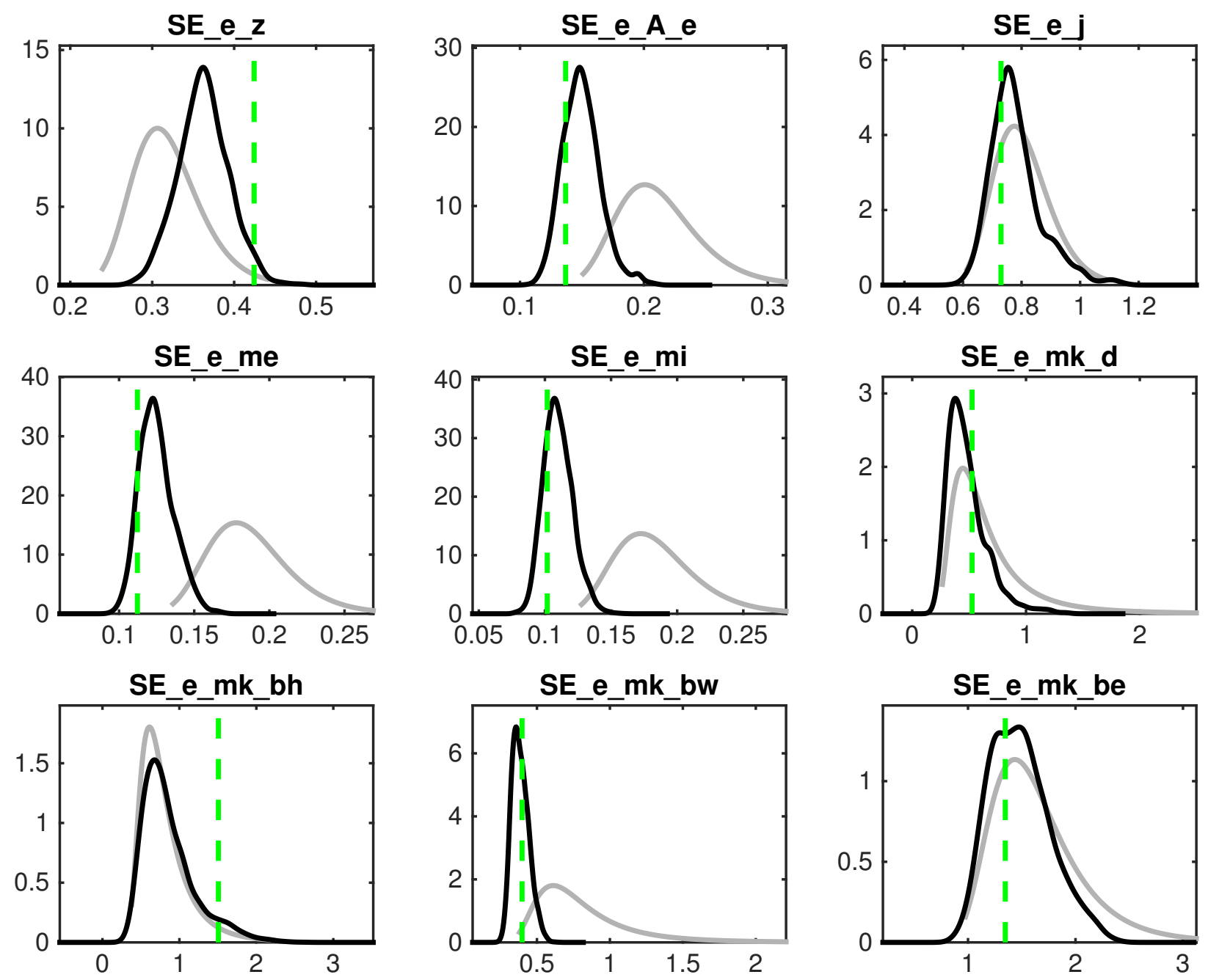

Figura 282: Priors And Posteriors 

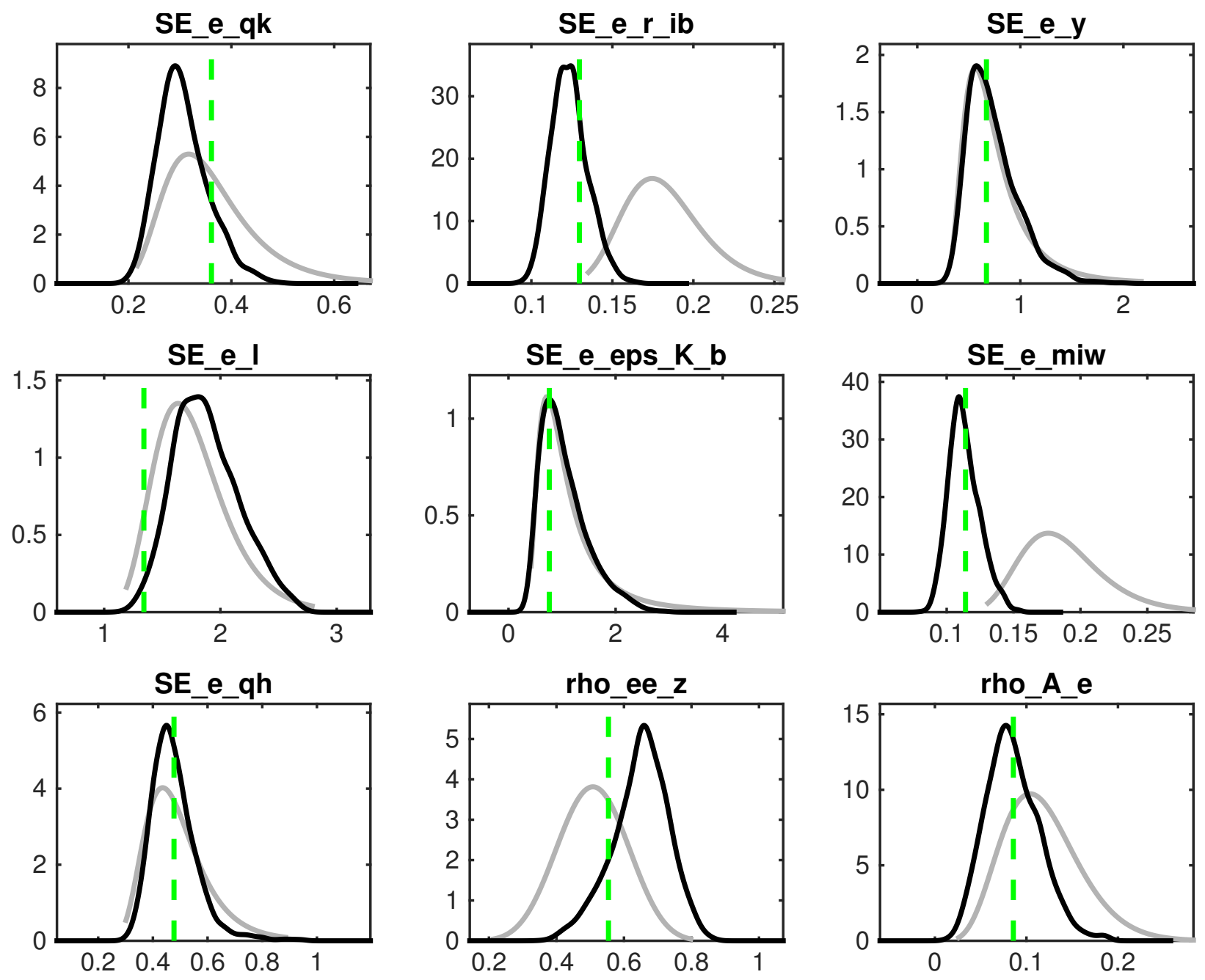

Figura 283: Priors And Posteriors 

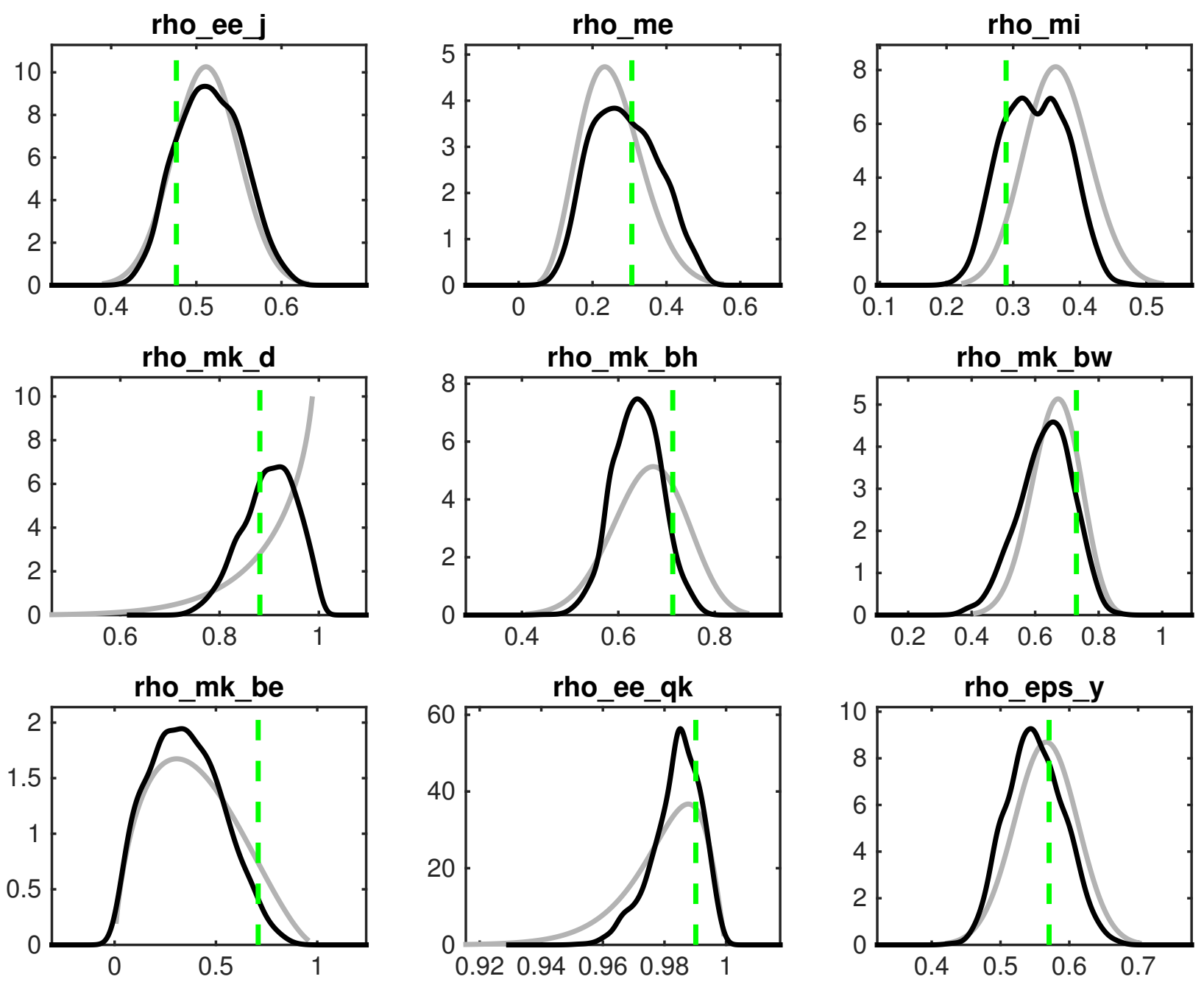

Figura 284: Priors And Posteriors 

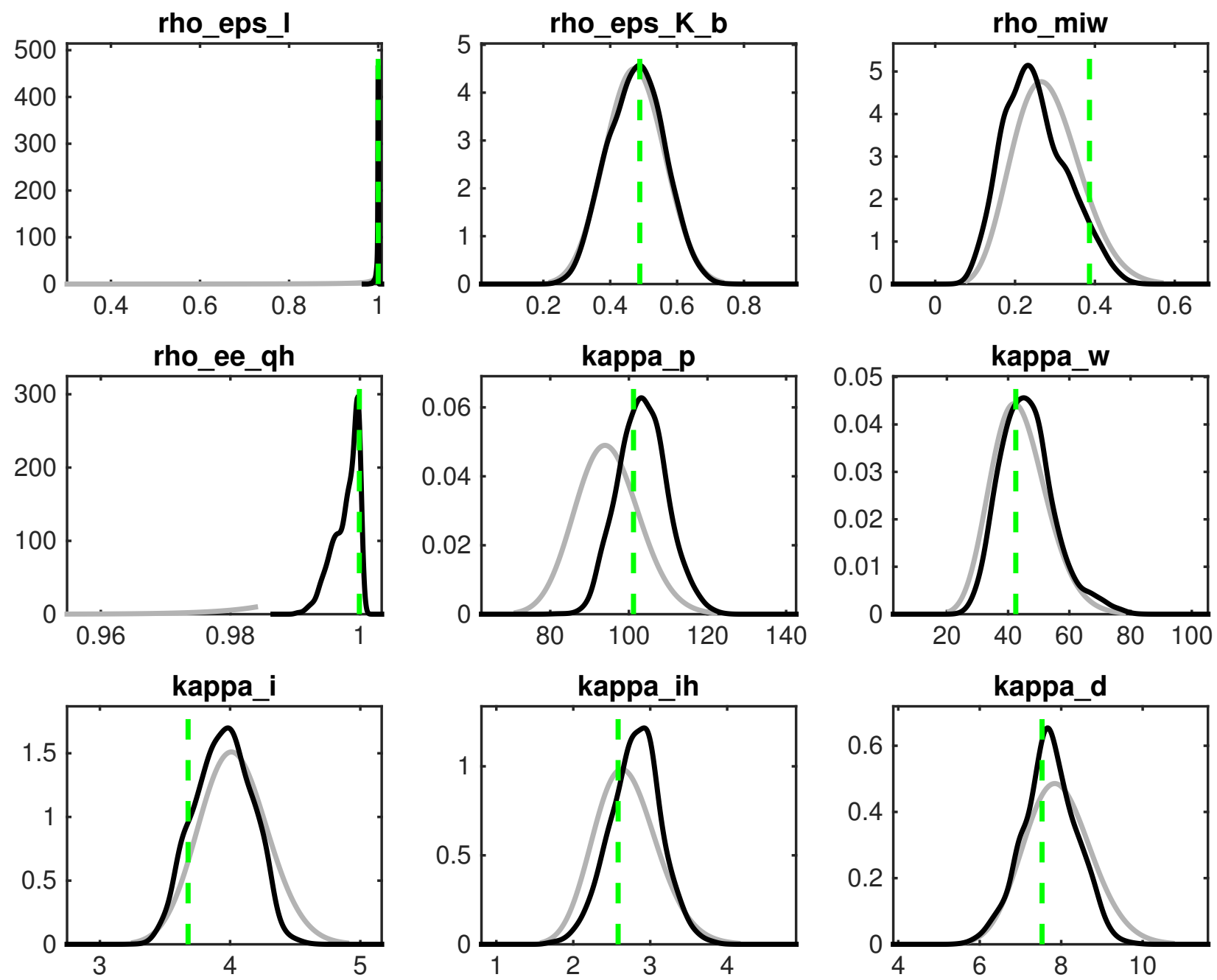

Figura 285: Priors And Posteriors 

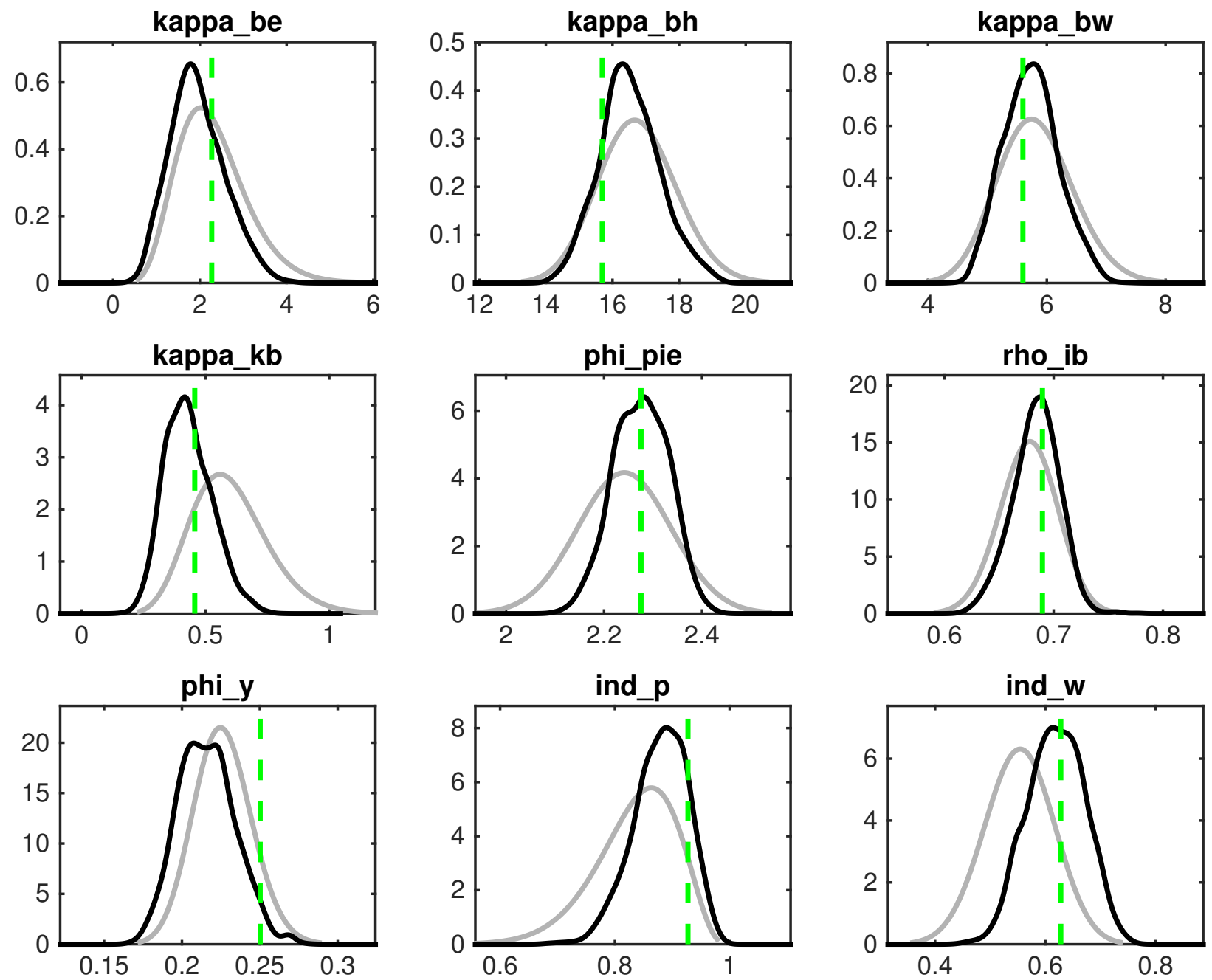

Figura 286: Priors And Posteriors

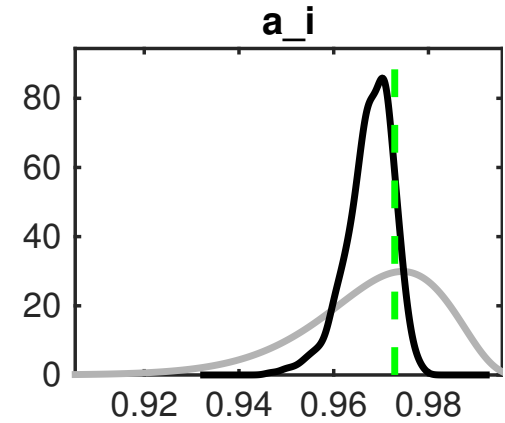

Figura 287: Priors And Posteriors 


\section{C.2 Economia Aberta}
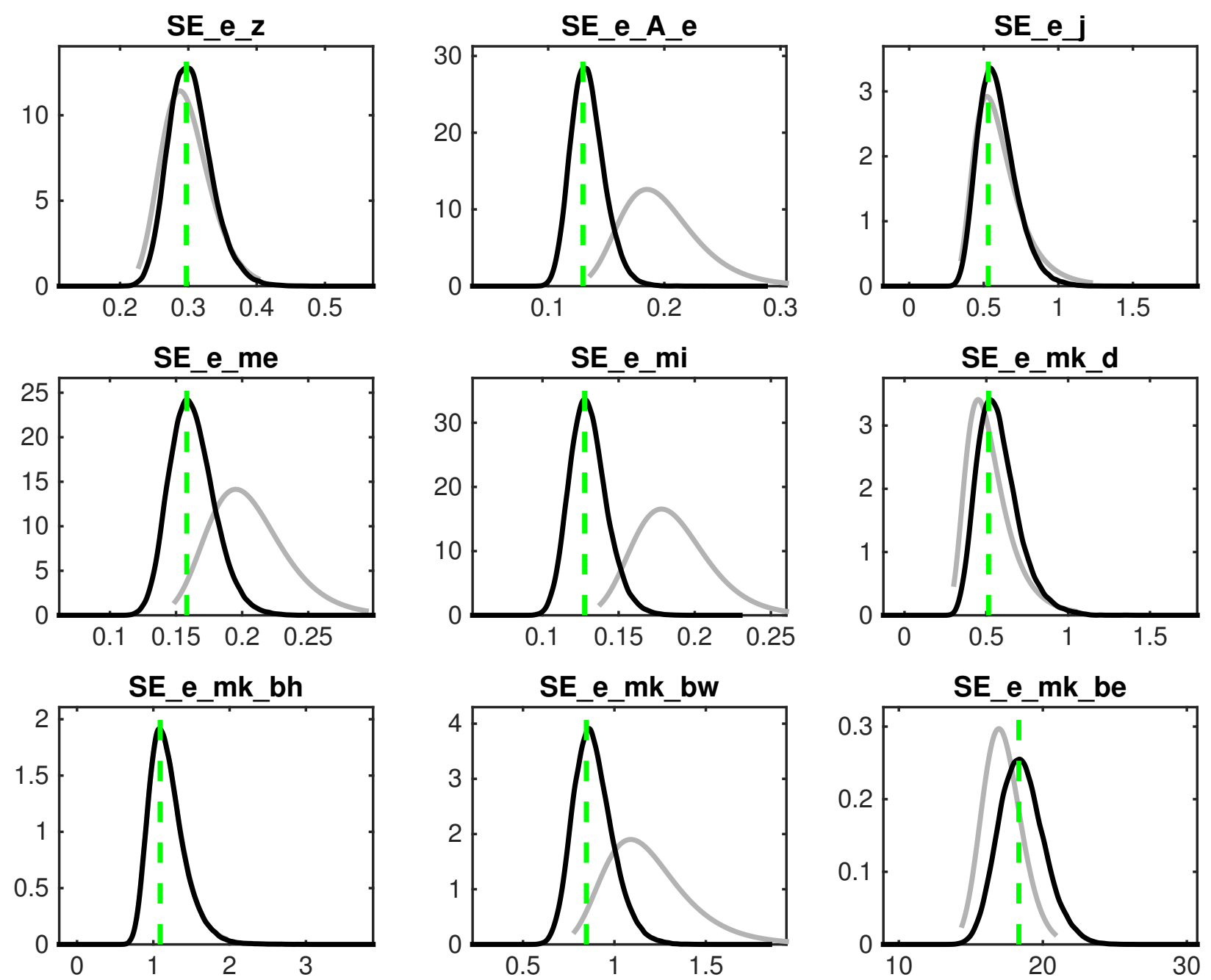

Figura 288: Priors And Posteriors 

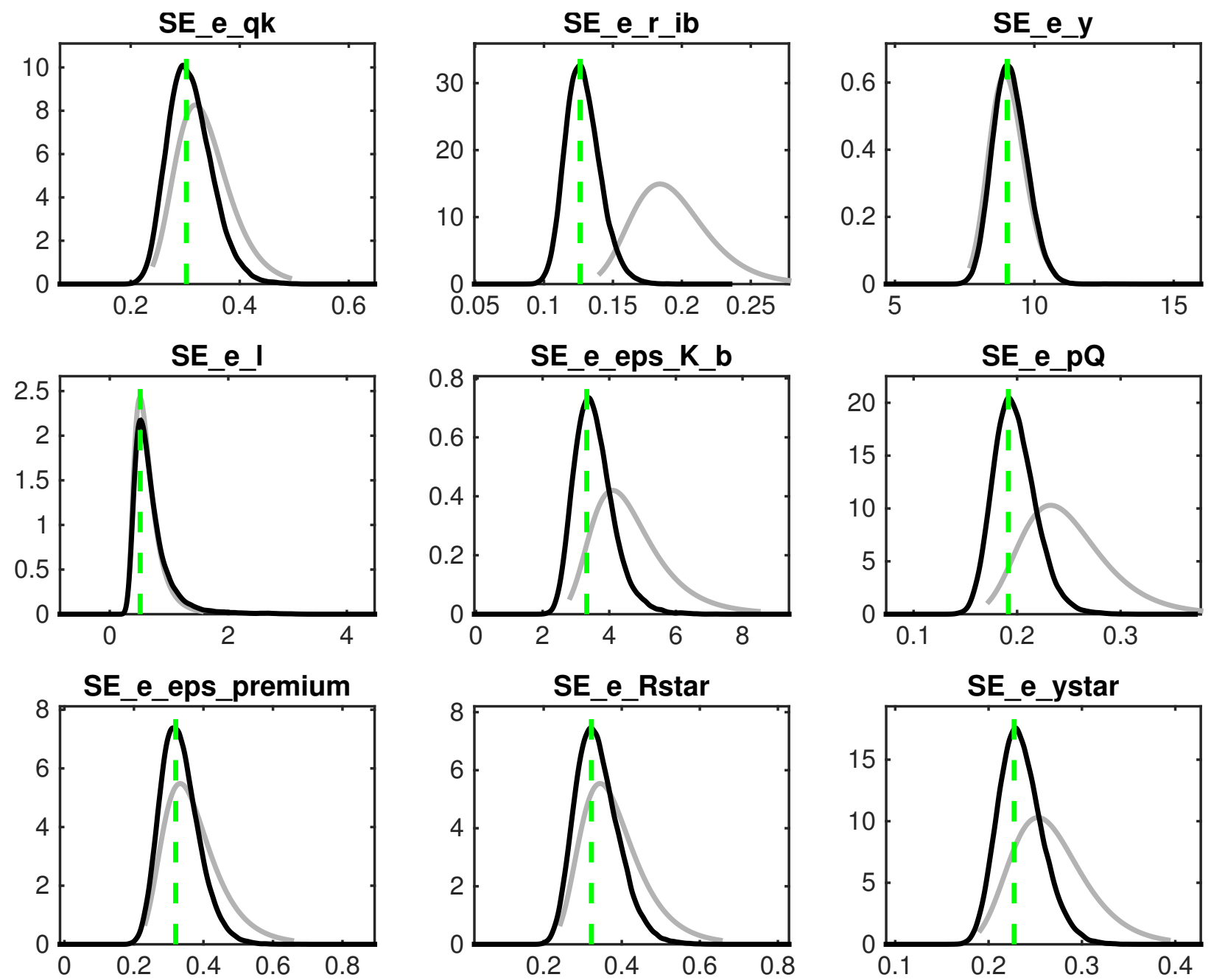

Figura 289: Priors And Posteriors 

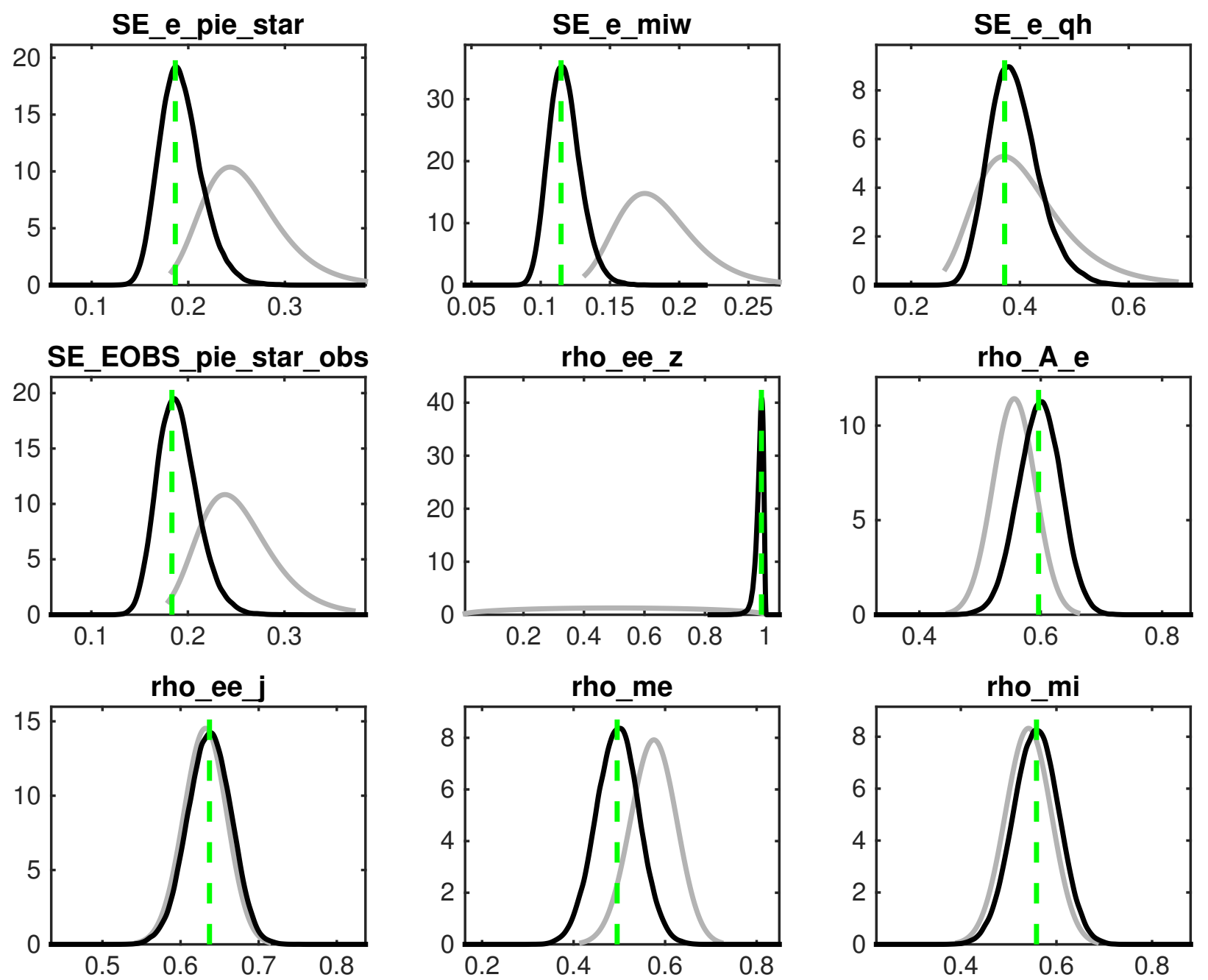

Figura 290: Priors And Posteriors 

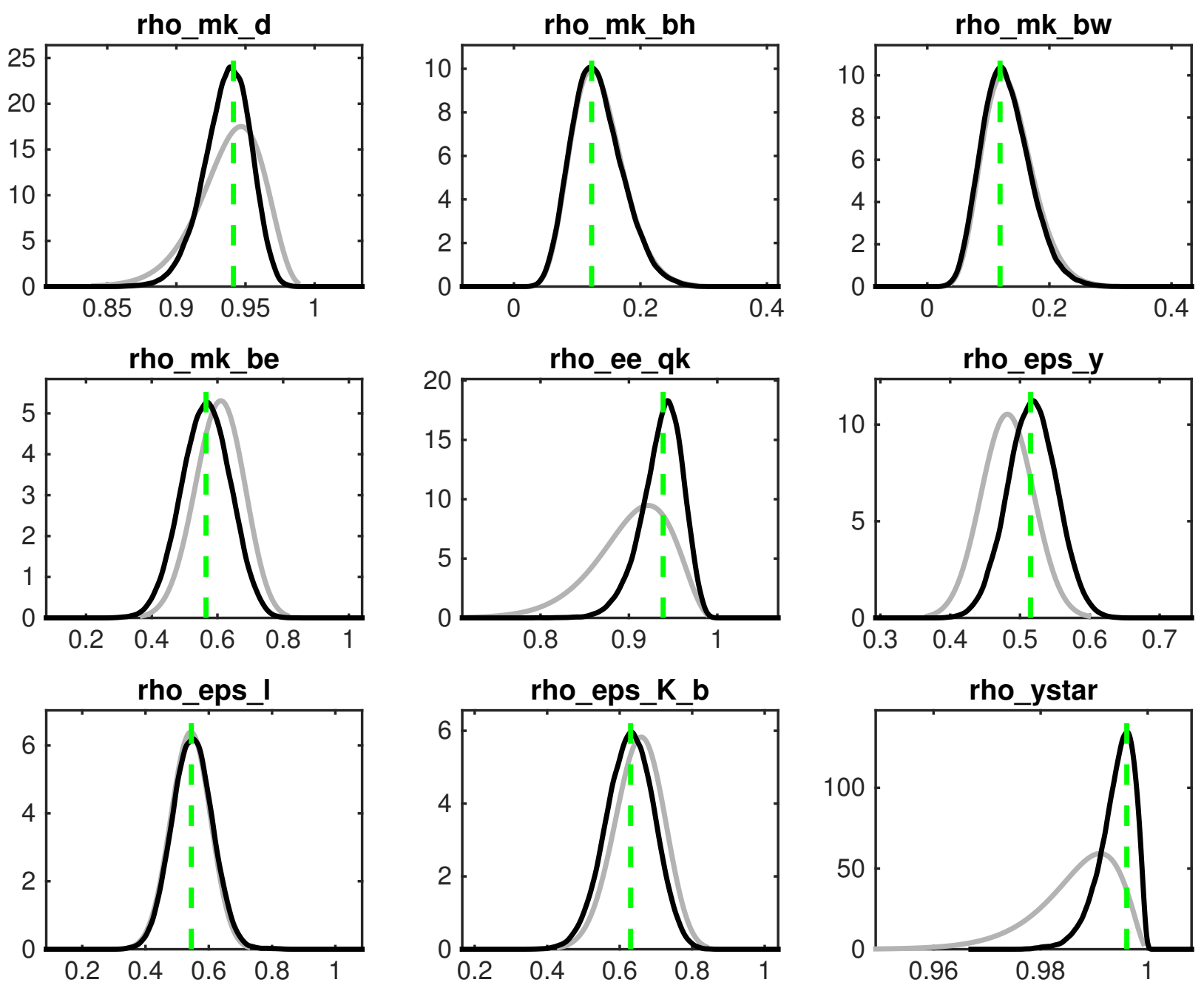

Figura 291: Priors And Posteriors 

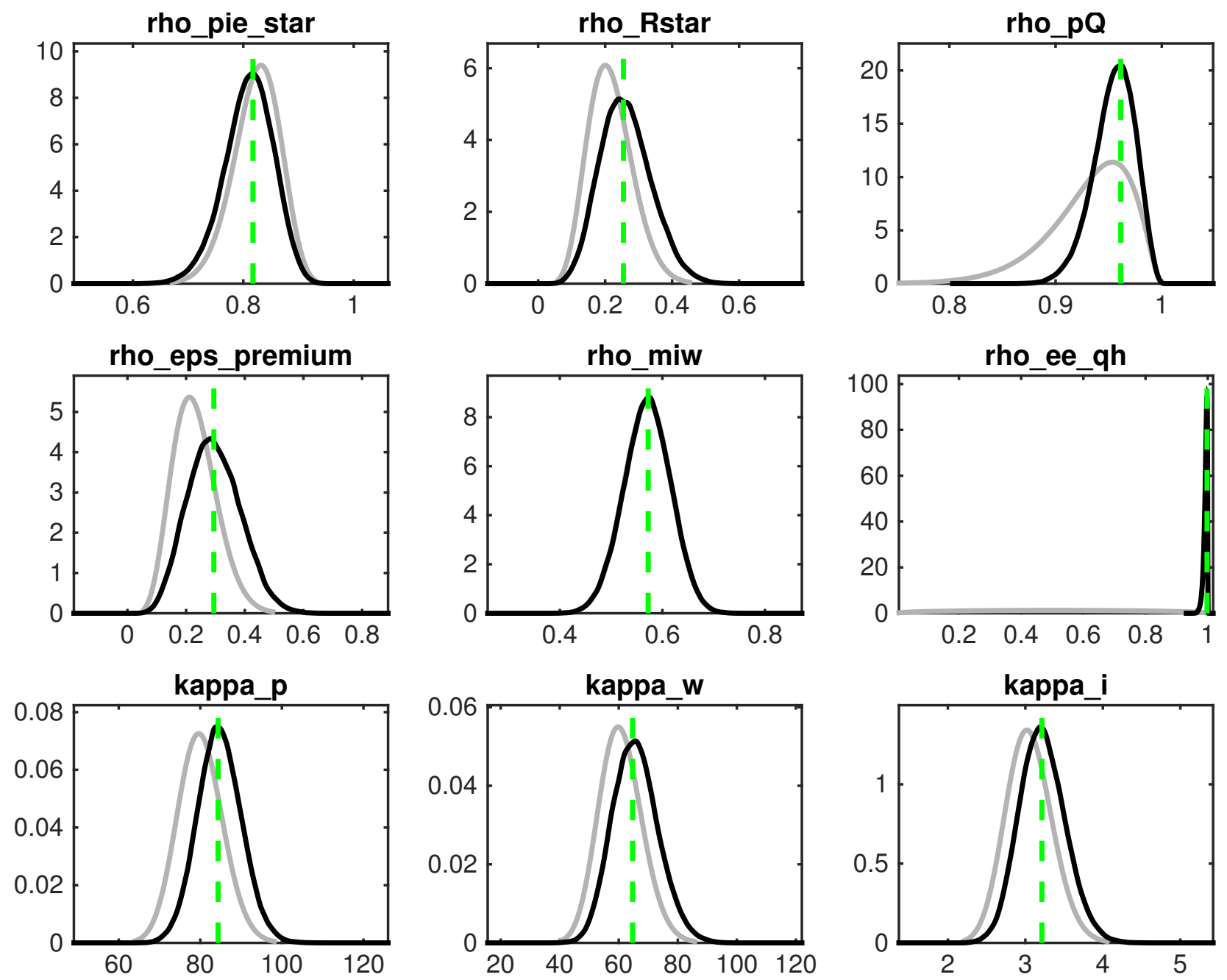

Figura 292: Priors And Posteriors 

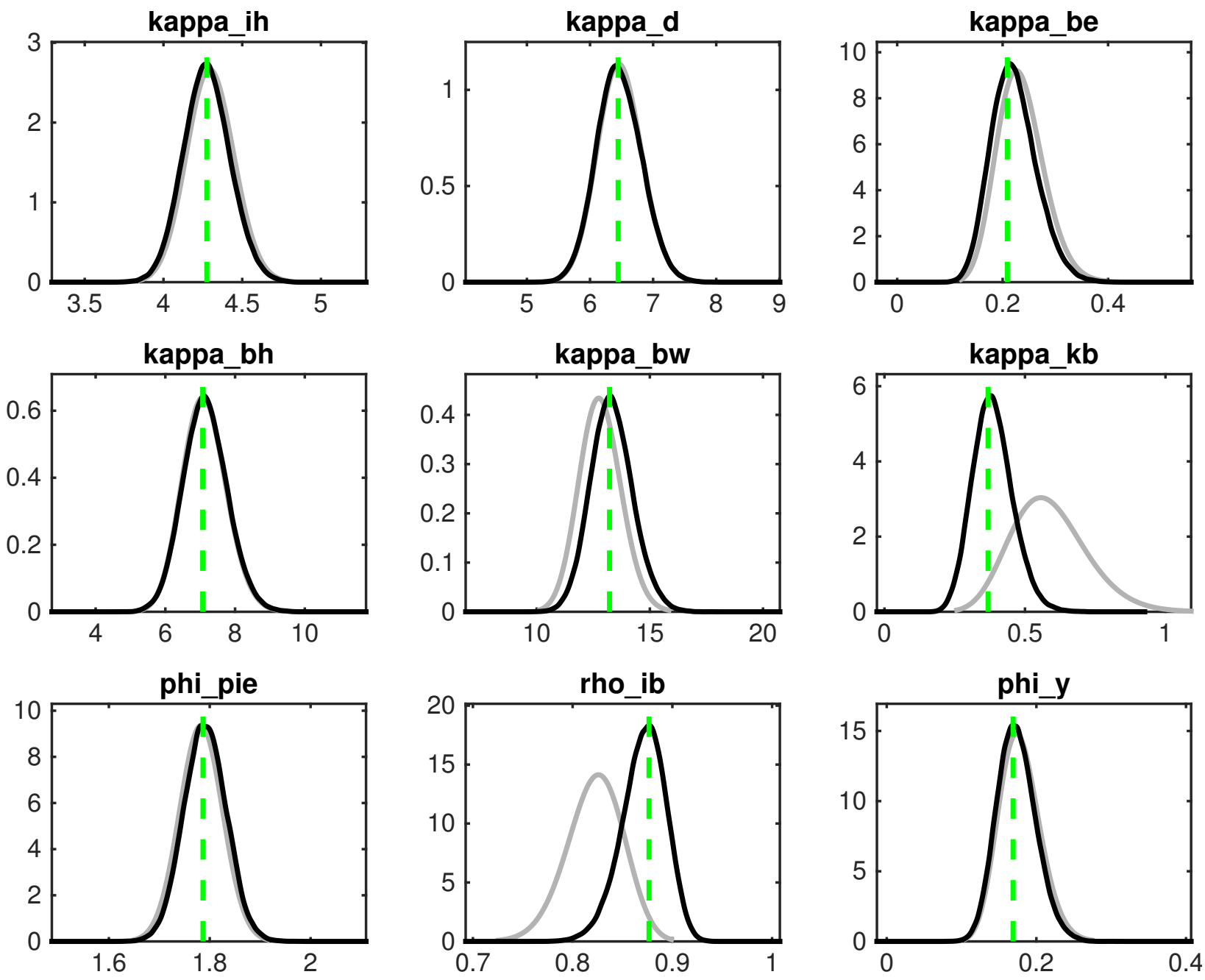

Figura 293: Priors And Posteriors 

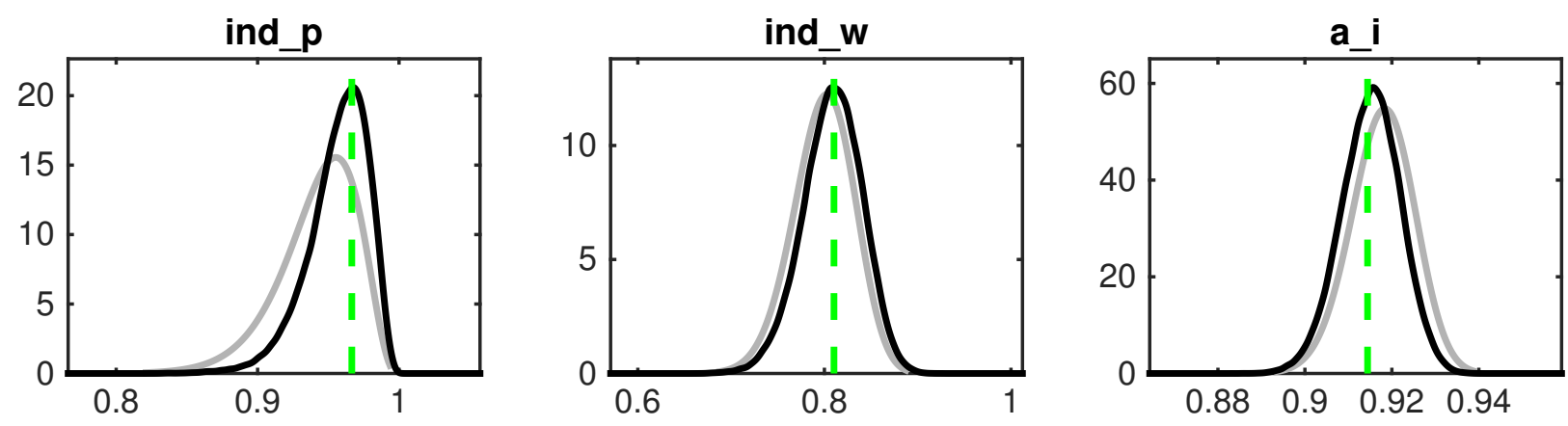

Figura 294: Priors And Posteriors 


\section{APÊNDICE D - Diagnósticos de Convergên- cia}

\section{D.1 Economia Fechada}
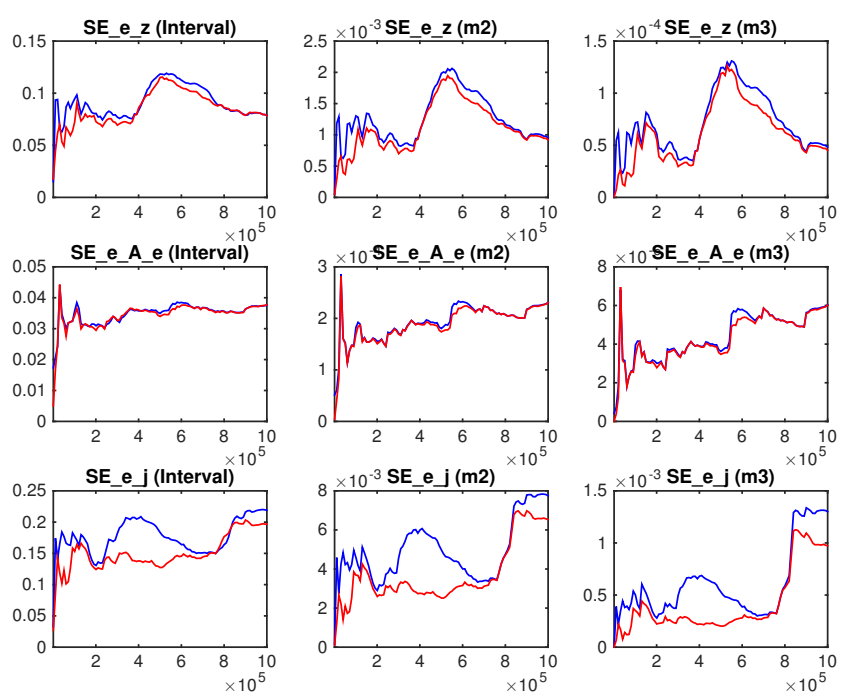

Figura 295: Diagnósticos de Convergência Univariado
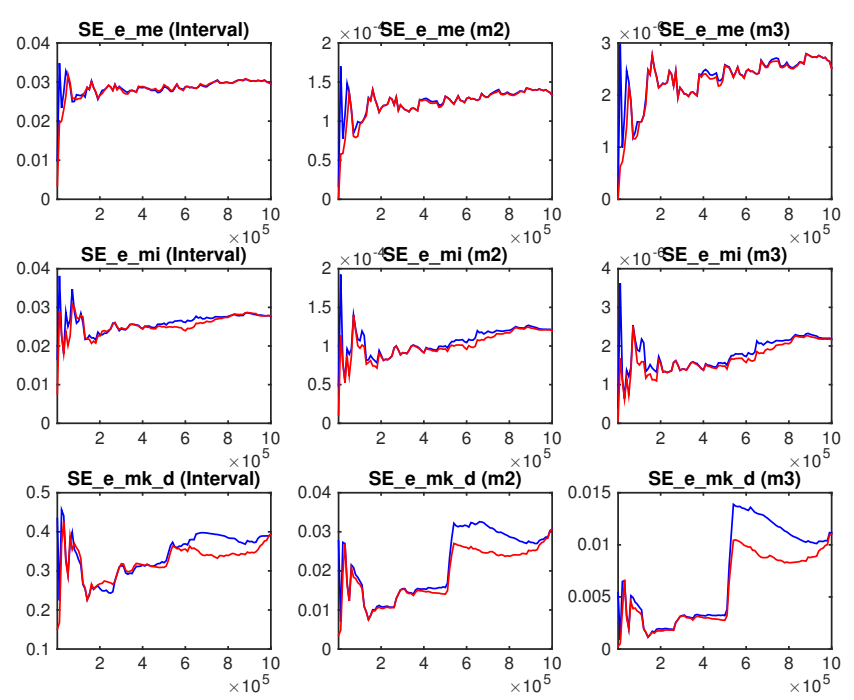

Figura 296: Diagnósticos de Convergência Univariado 

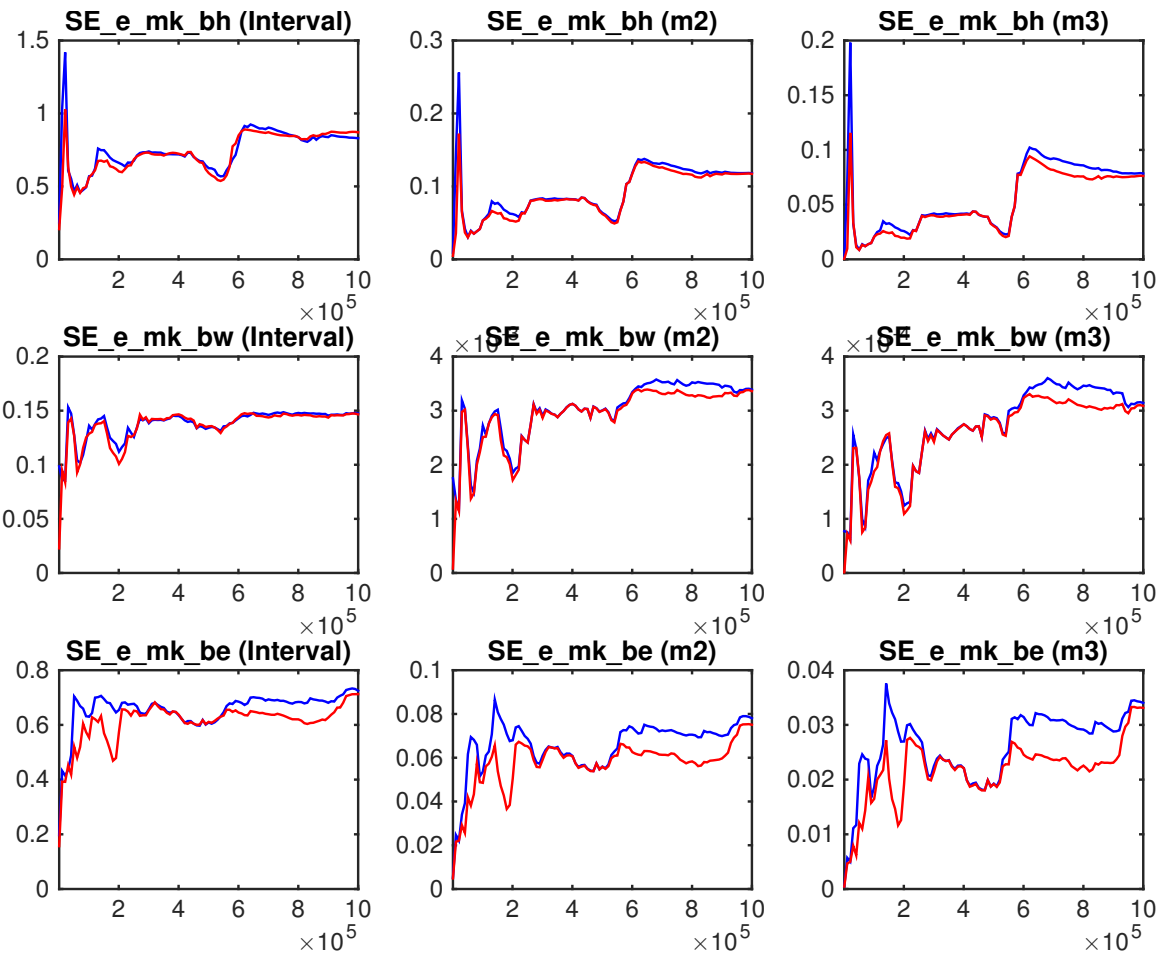

Figura 297: Diagnósticos de Convergência Univariado
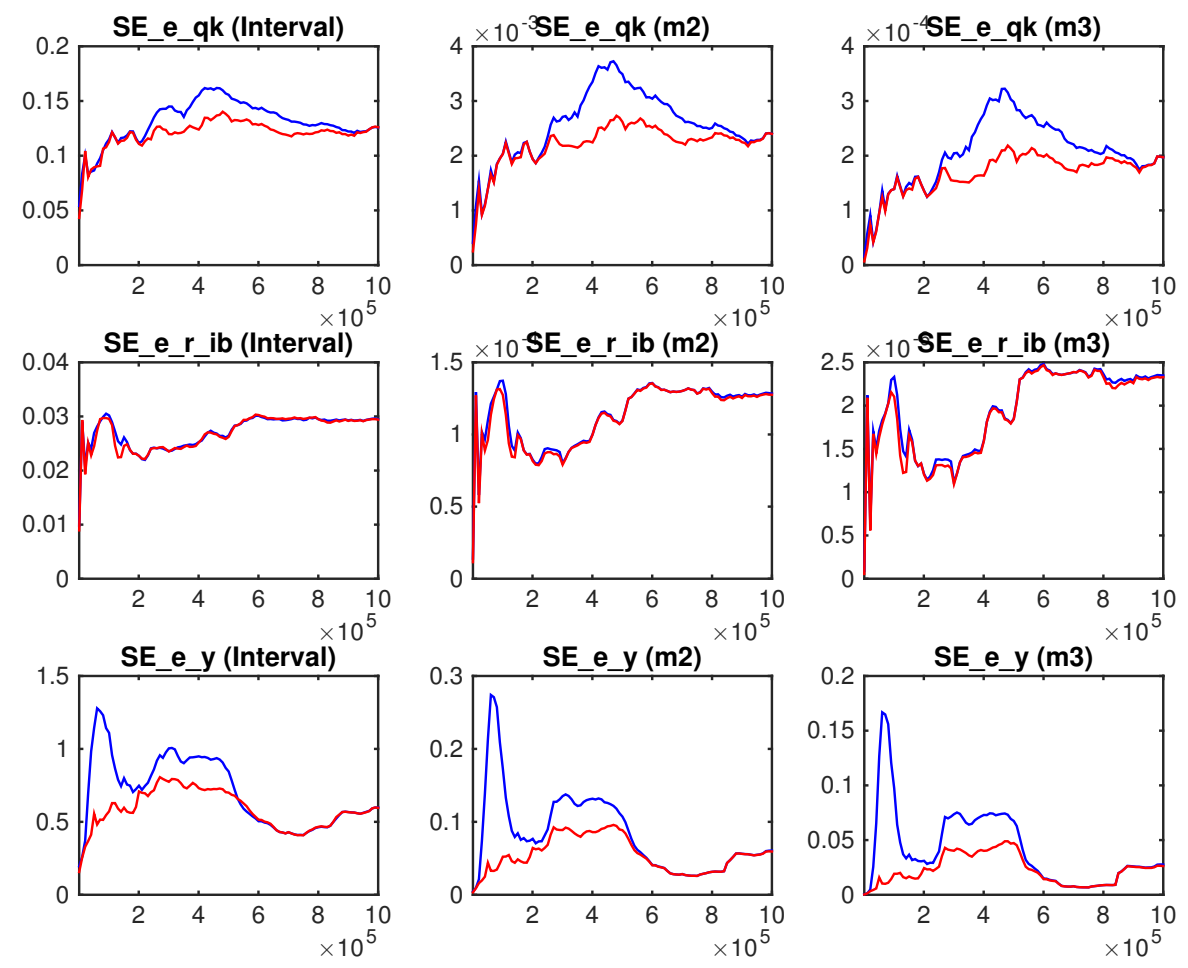

Figura 298: Diagnósticos de Convergência Univariado 

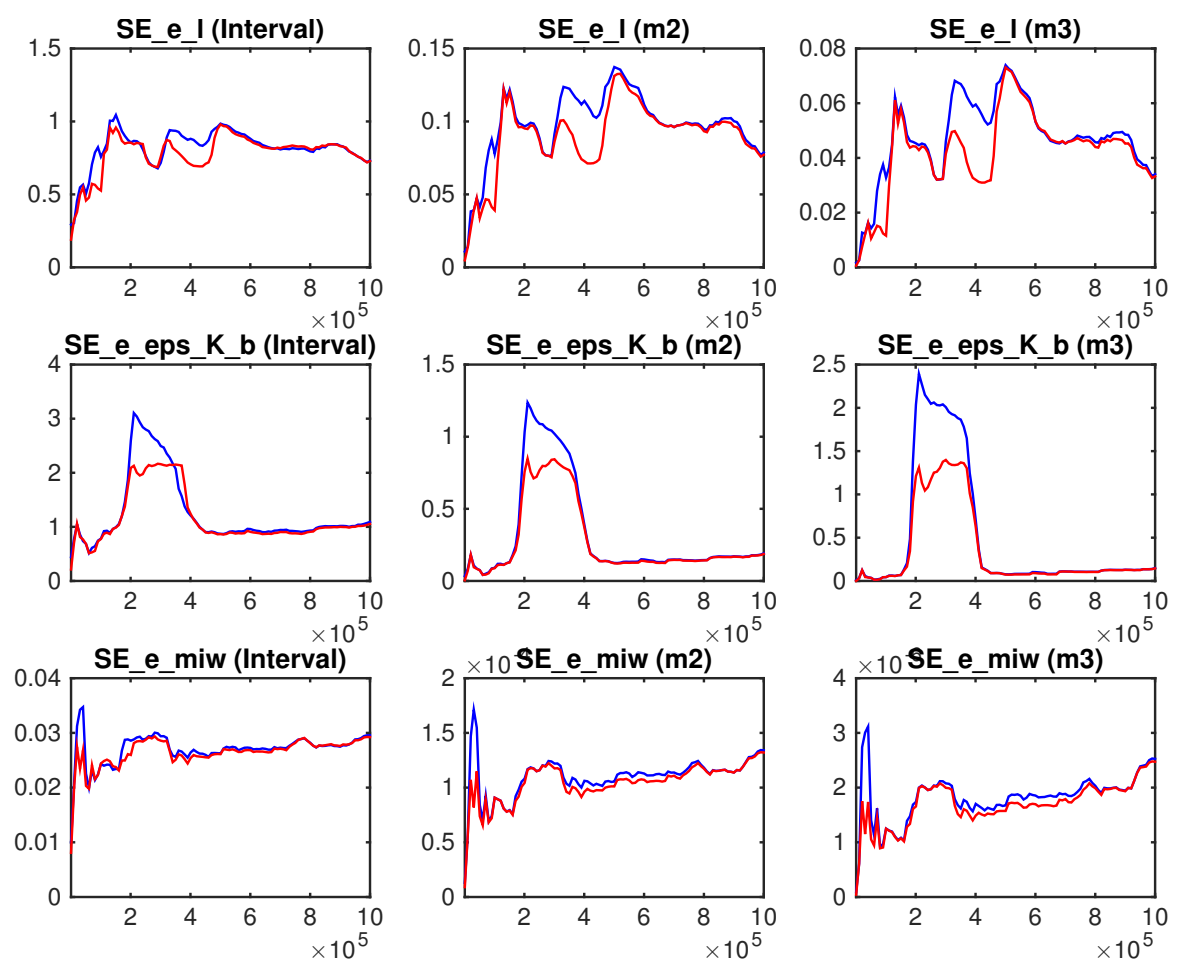

Figura 299: Diagnósticos de Convergência Univariado
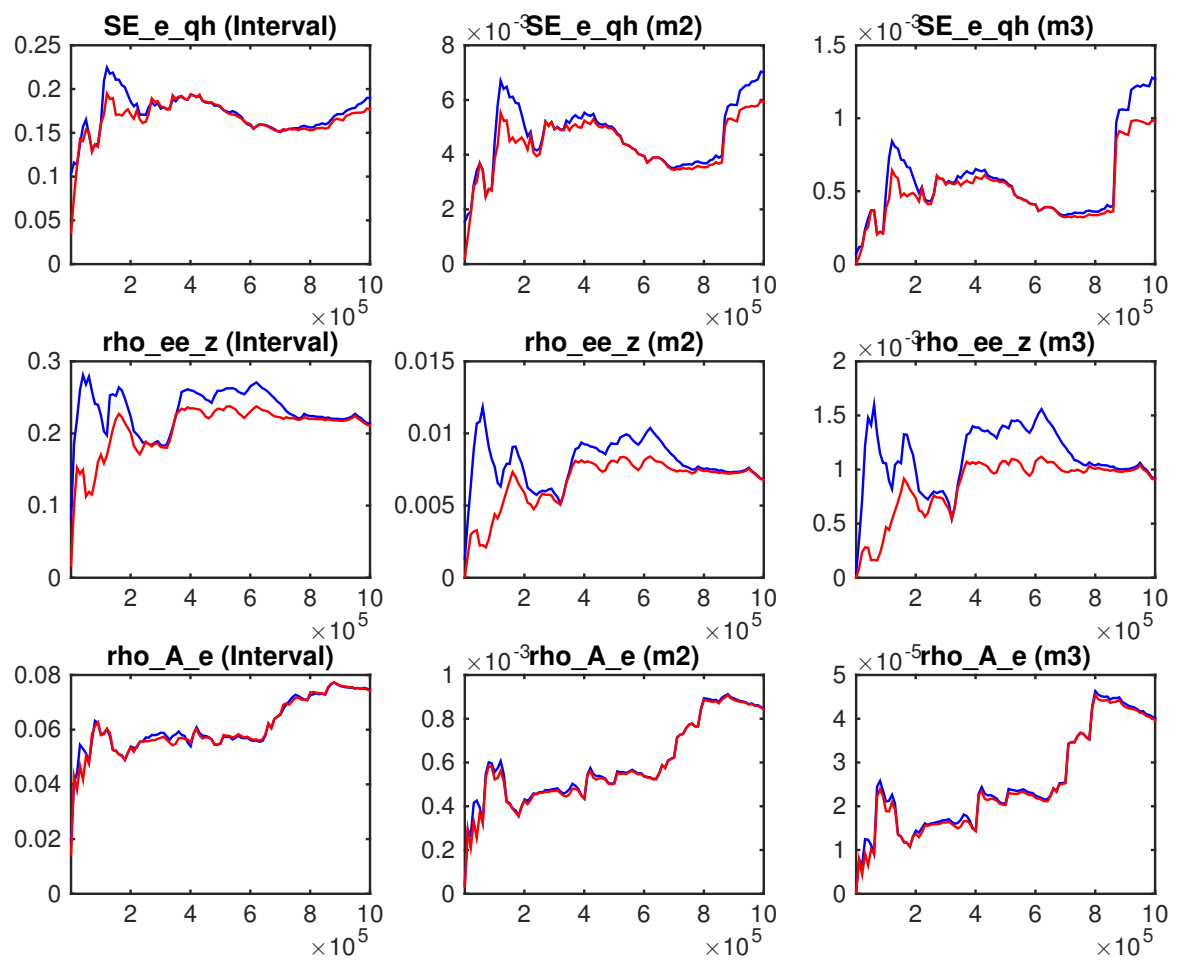

Figura 300: Diagnósticos de Convergência Univariado 

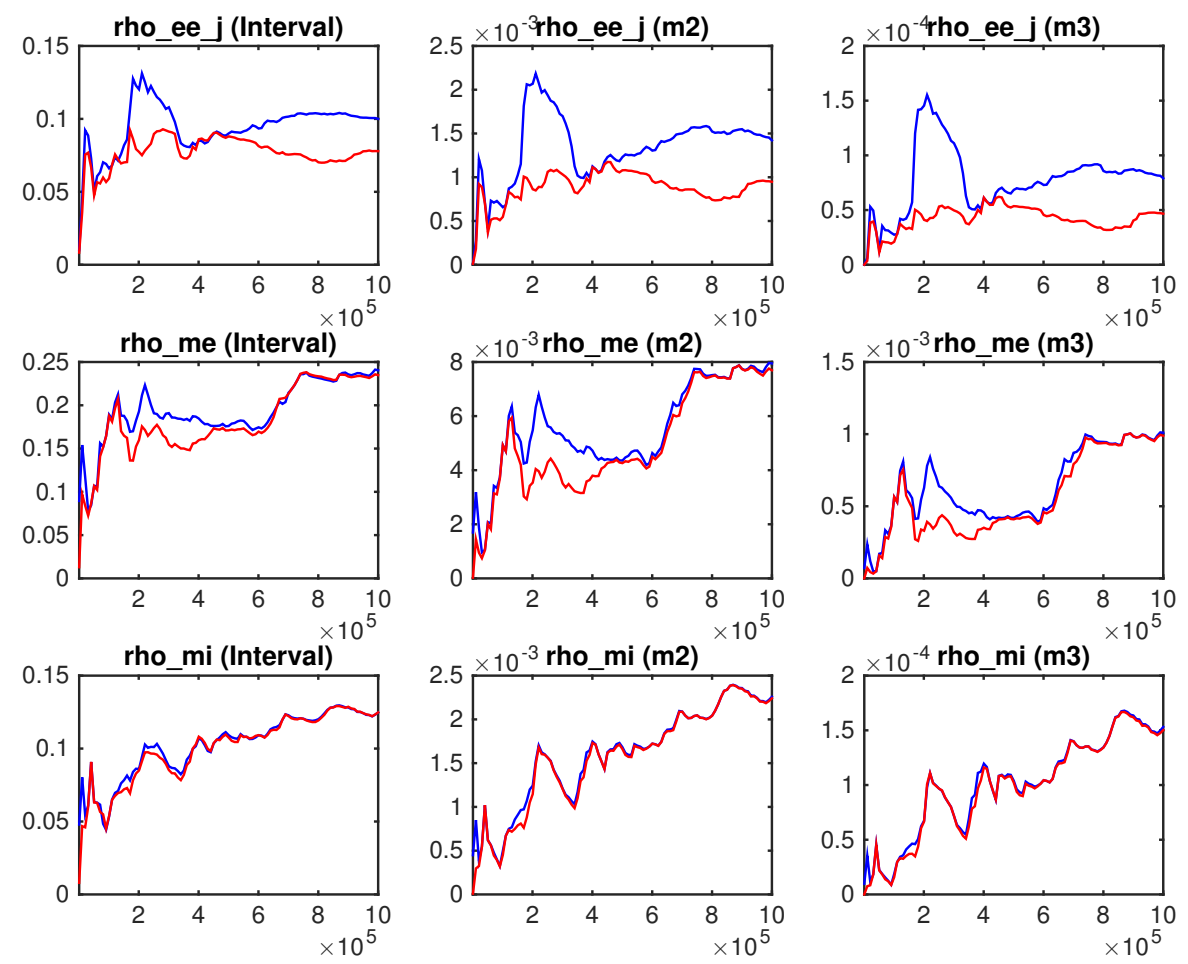

Figura 301: Diagnósticos de Convergência Univariado
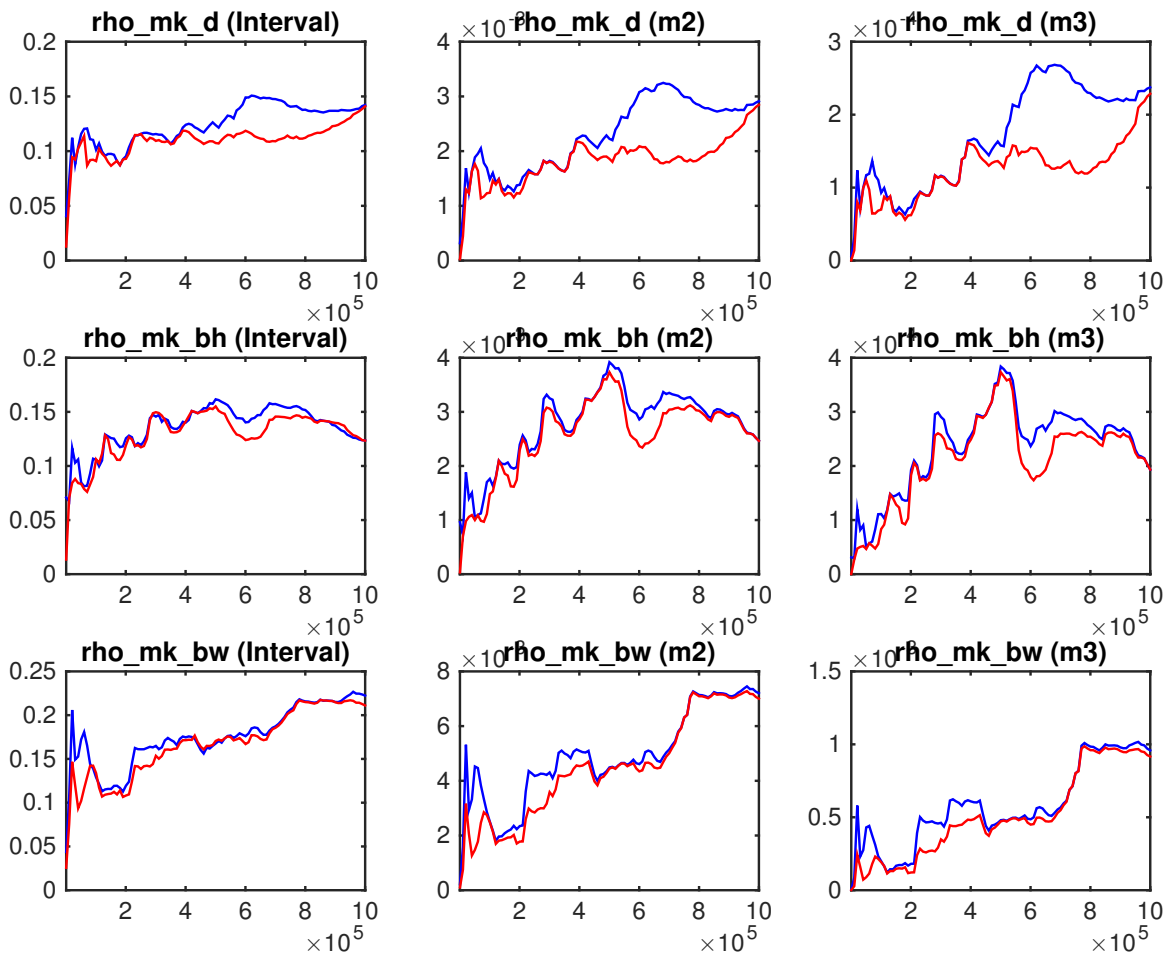

Figura 302: Diagnósticos de Convergência Univariado 

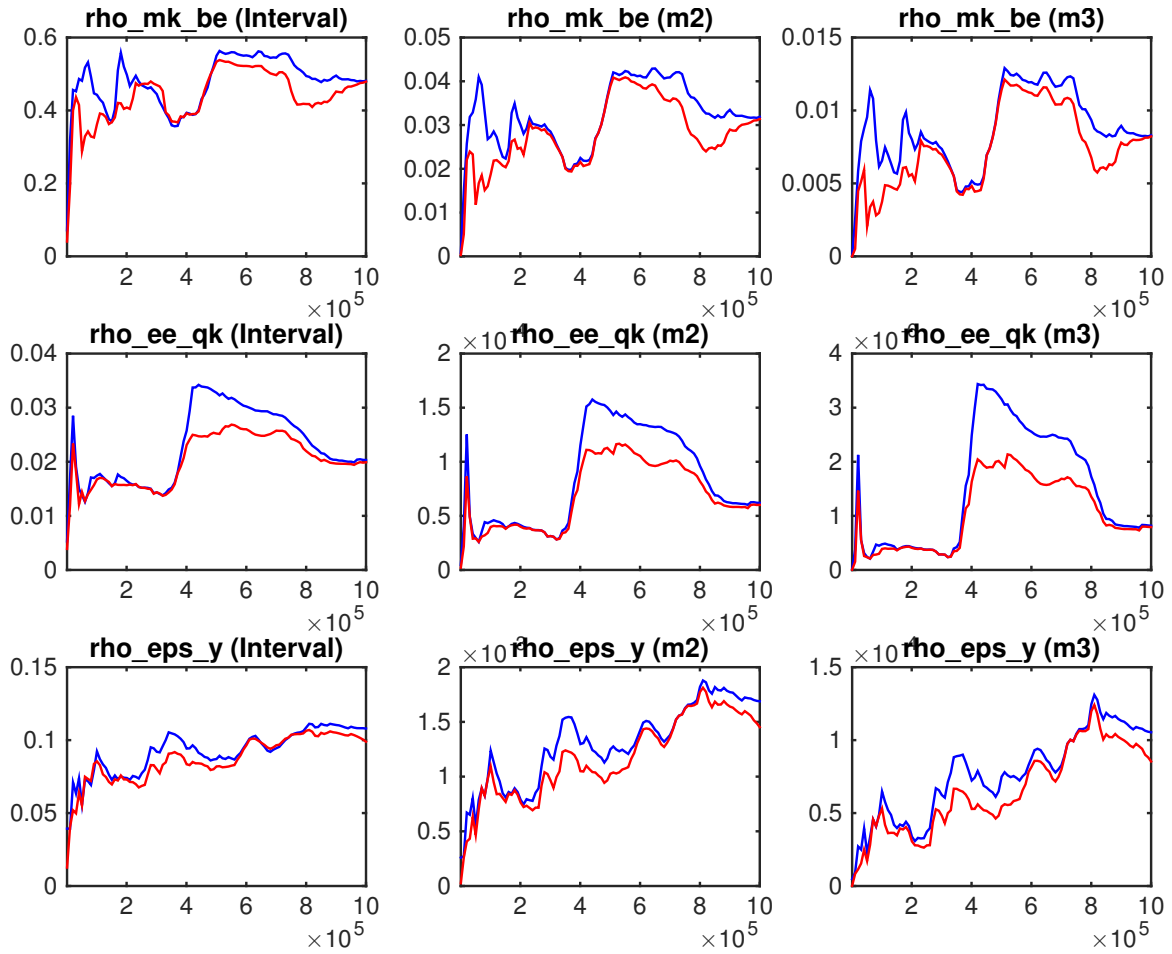

Figura 303: Diagnósticos de Convergência Univariado
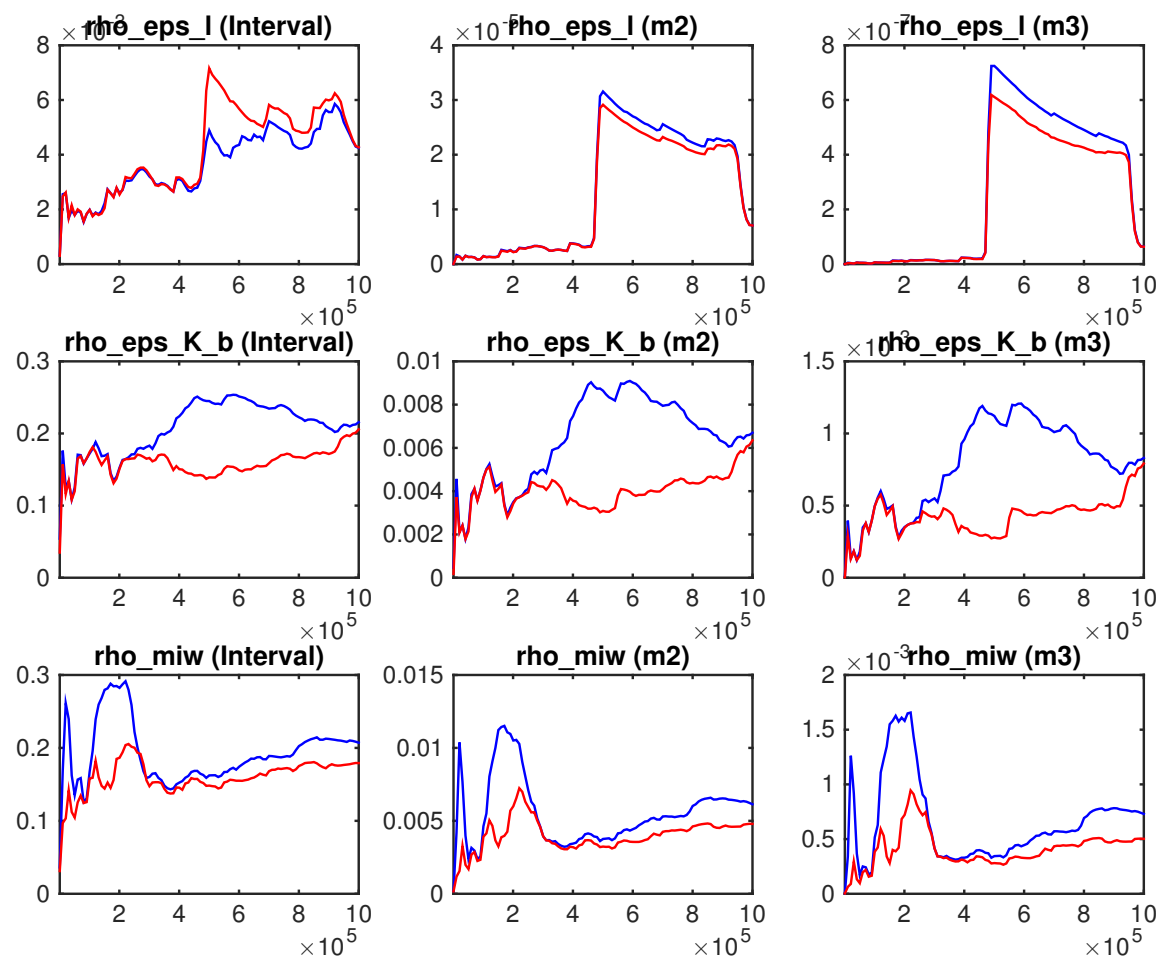

Figura 304: Diagnósticos de Convergência Univariado 

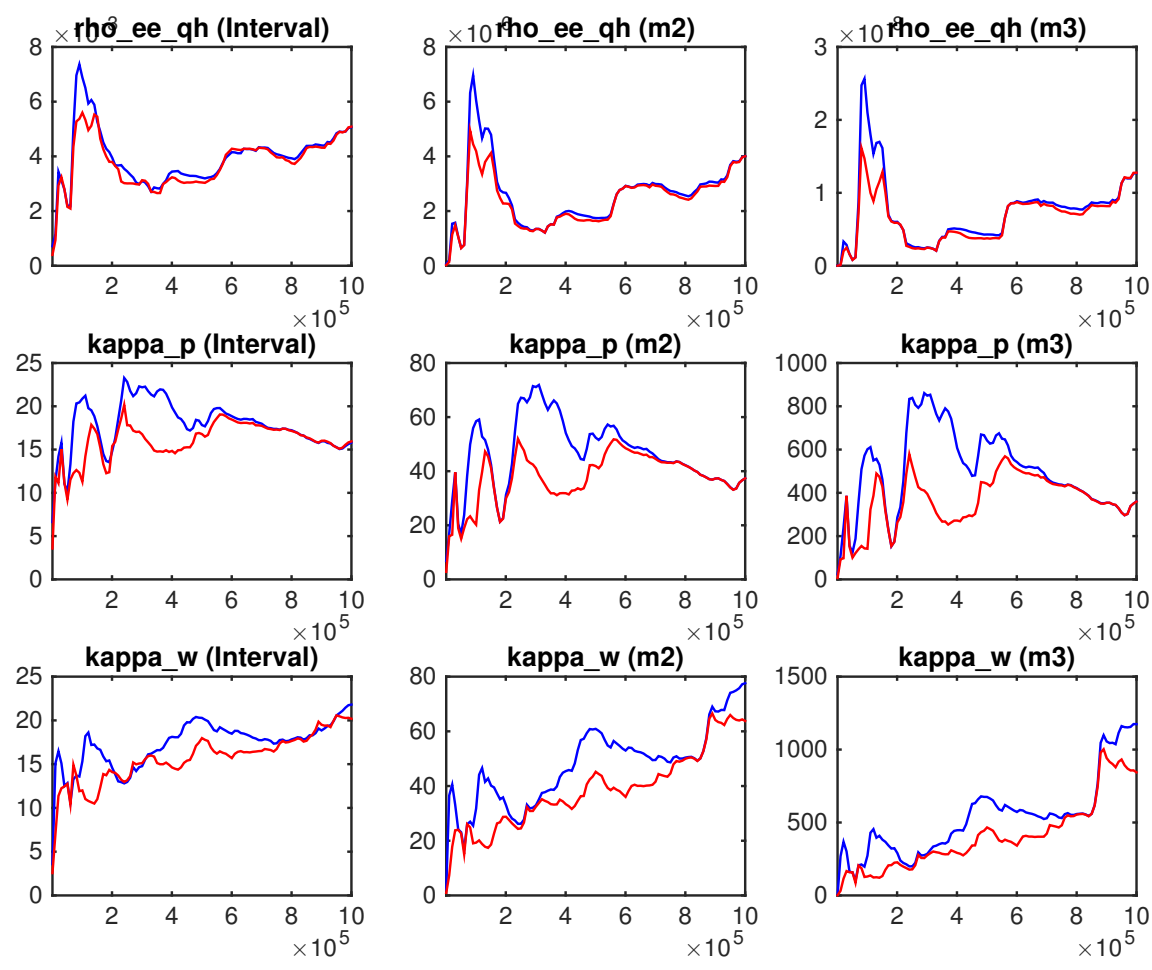

Figura 305: Diagnósticos de Convergência Univariado
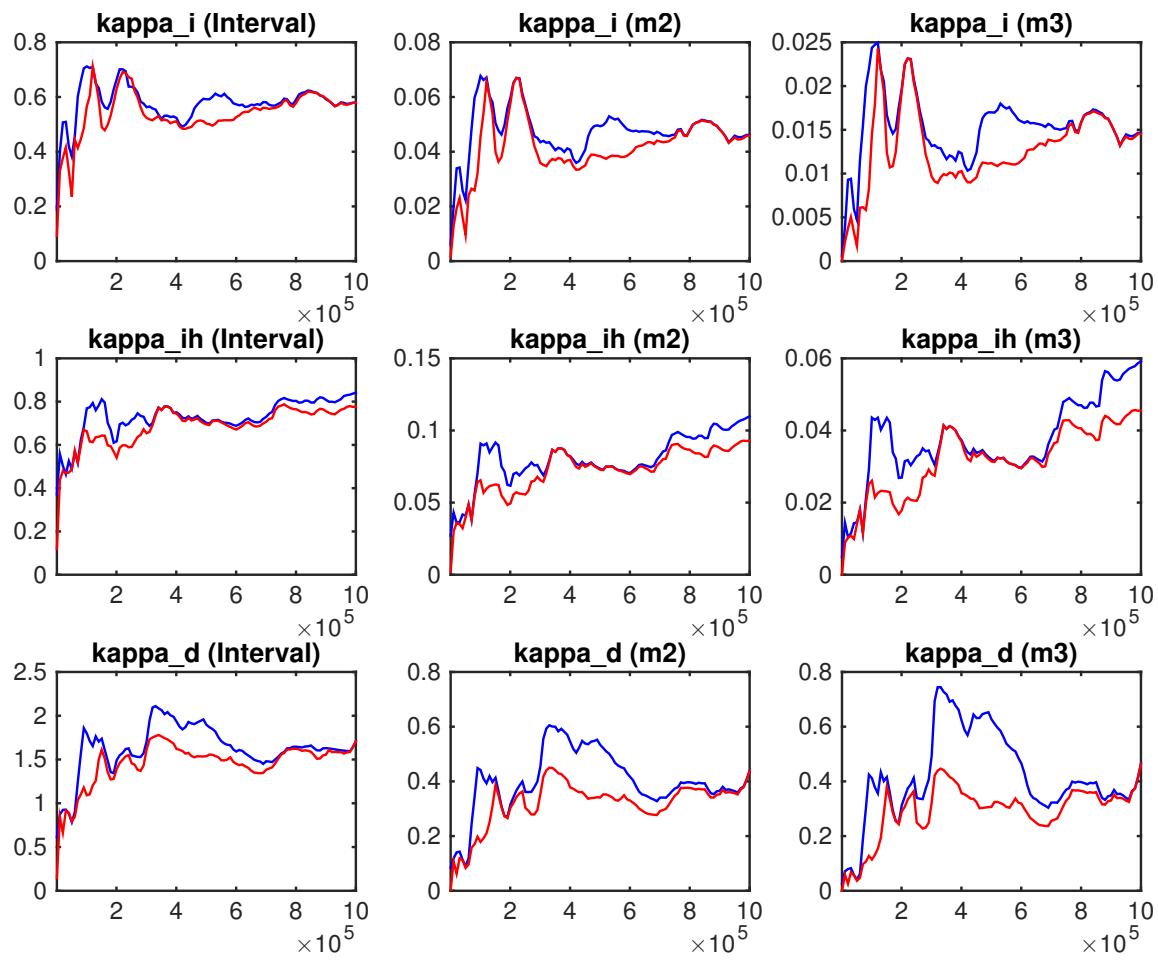

Figura 306: Diagnósticos de Convergência Univariado 

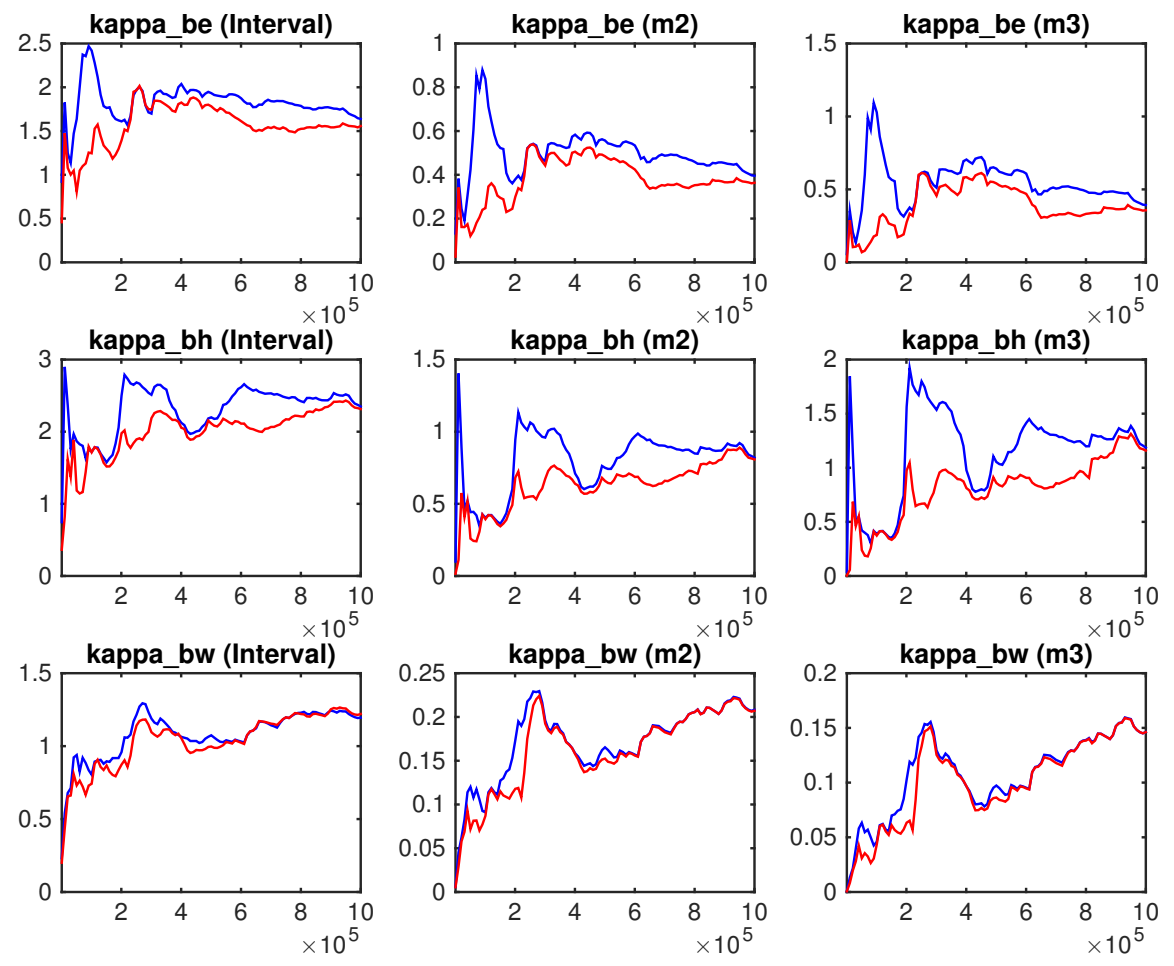

Figura 307: Diagnósticos de Convergência Univariado
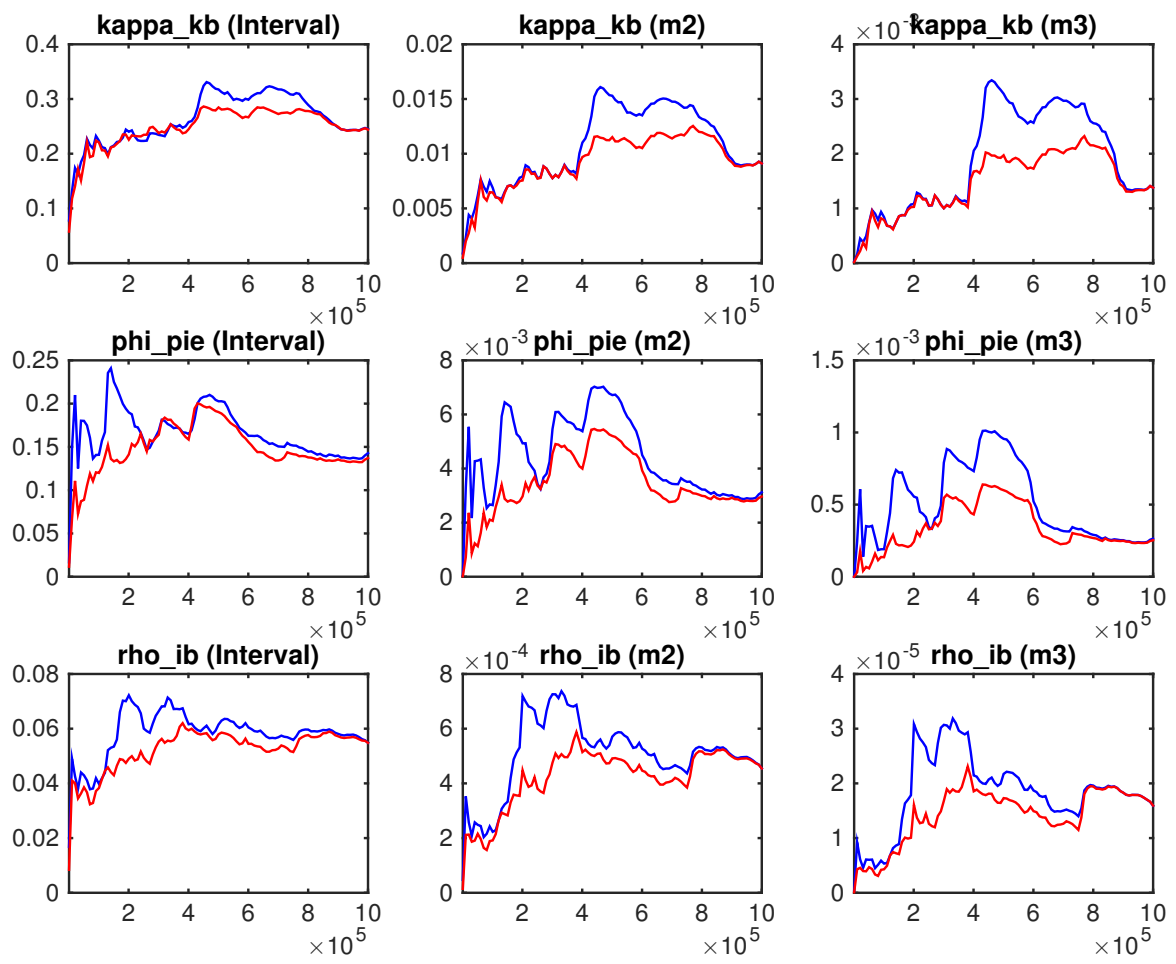

Figura 308: Diagnósticos de Convergência Univariado 

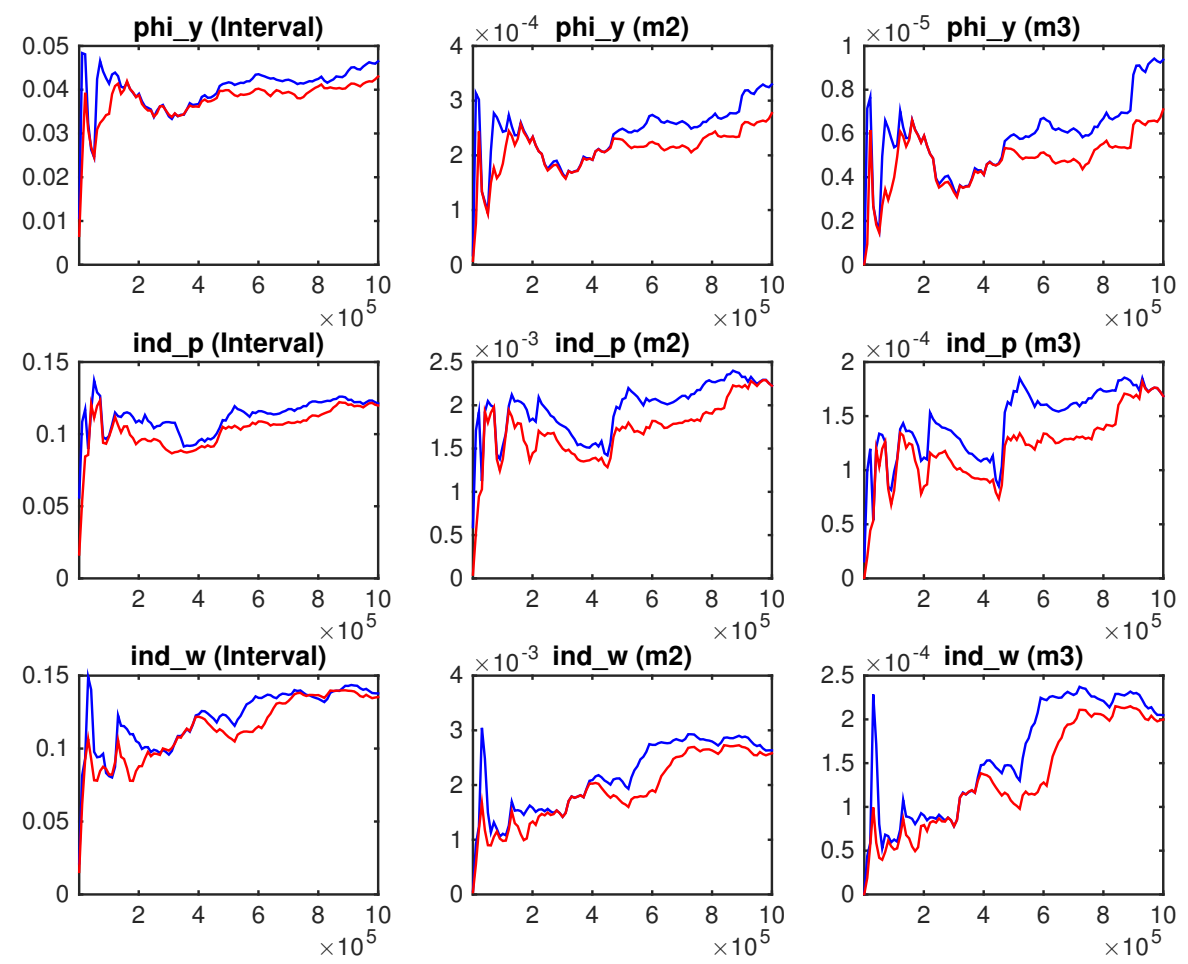

Figura 309: Diagnósticos de Convergência Univariado
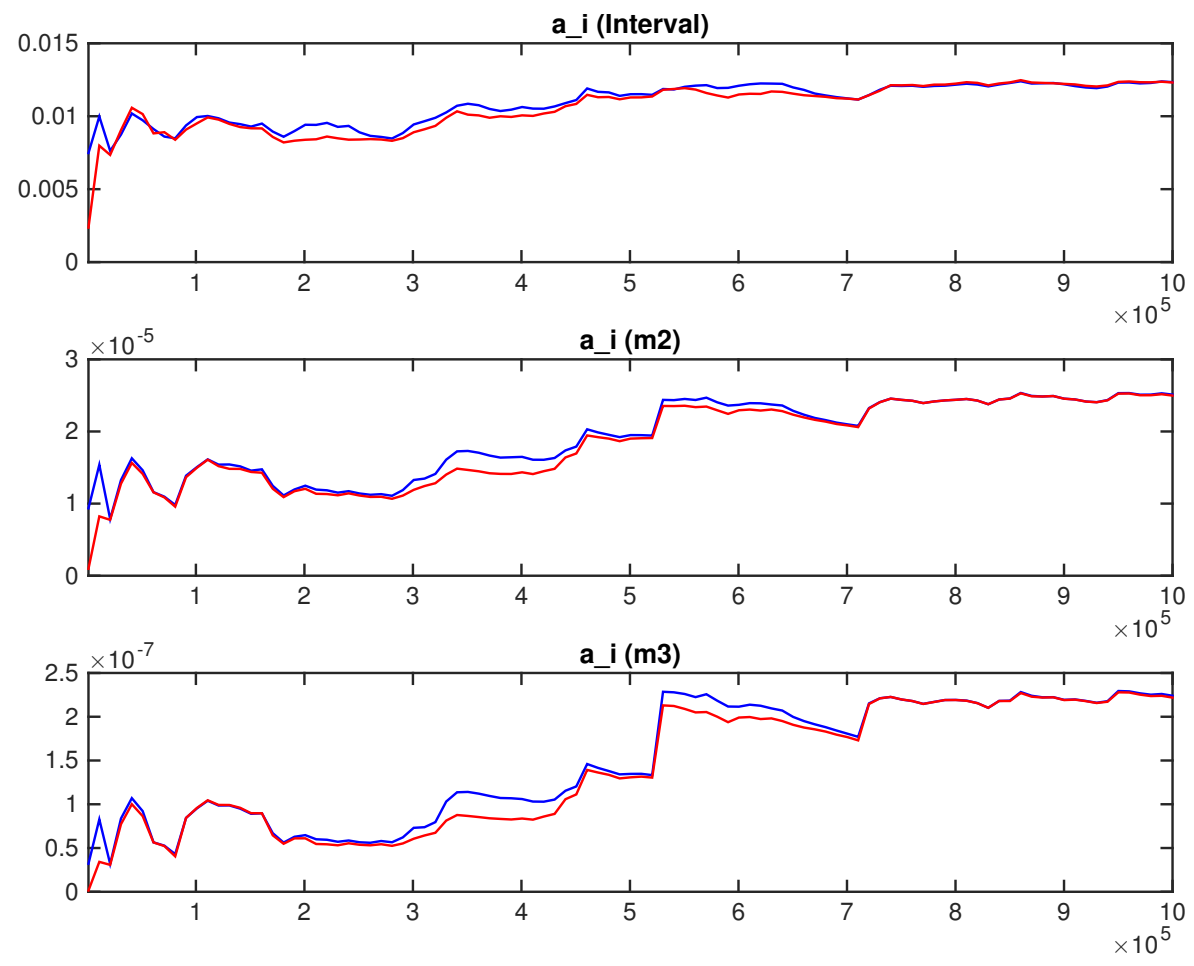

Figura 310: Diagnósticos de Convergência Univariado 

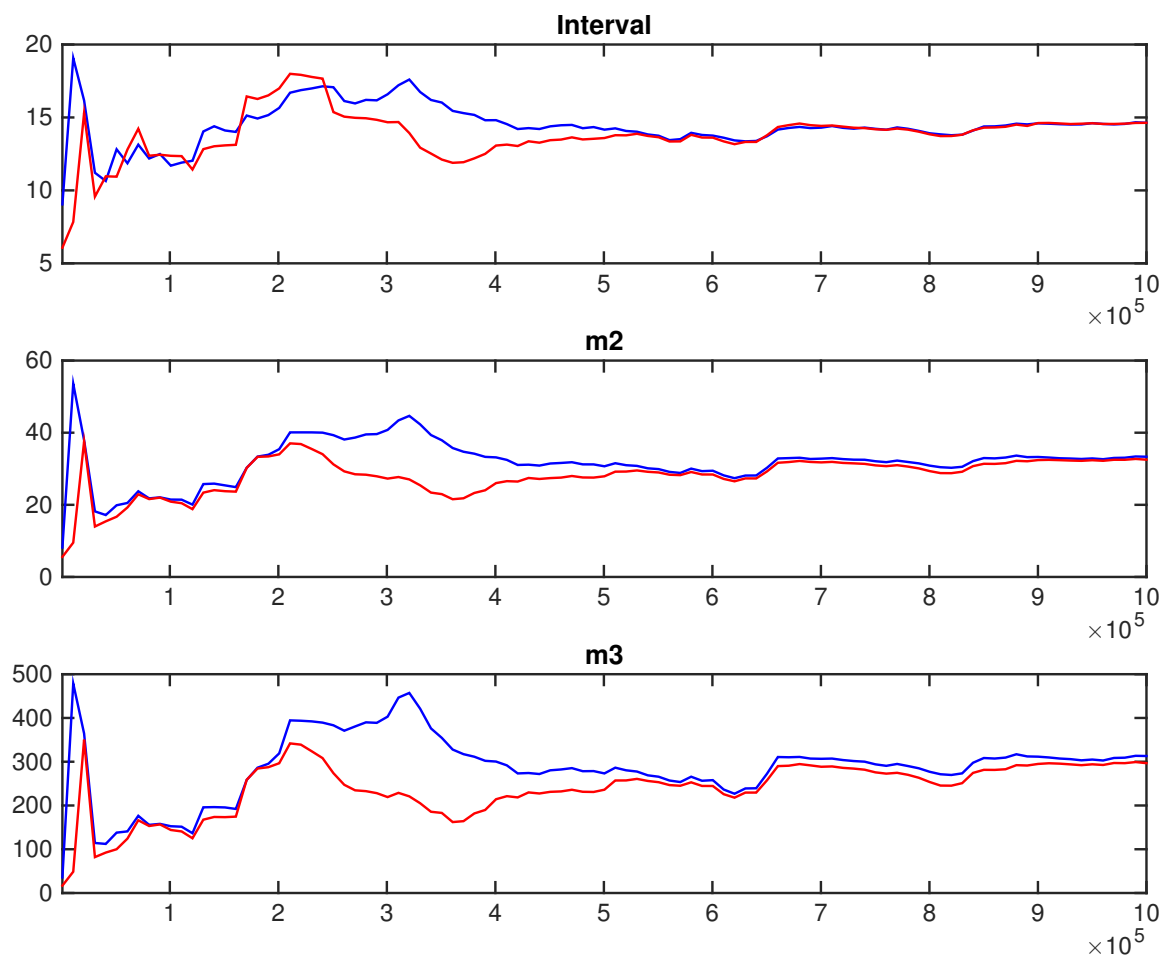

Figura 311: Diagnósticos de Convergência Multivariado 


\section{D.2 Economia Aberta}
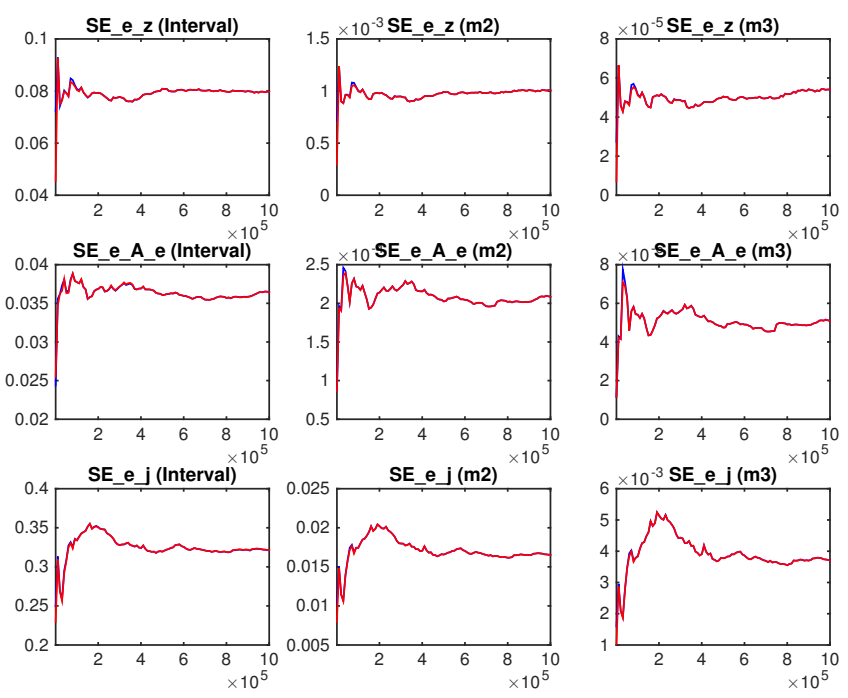

Figura 312: Diagnósticos de Convergência Univariado
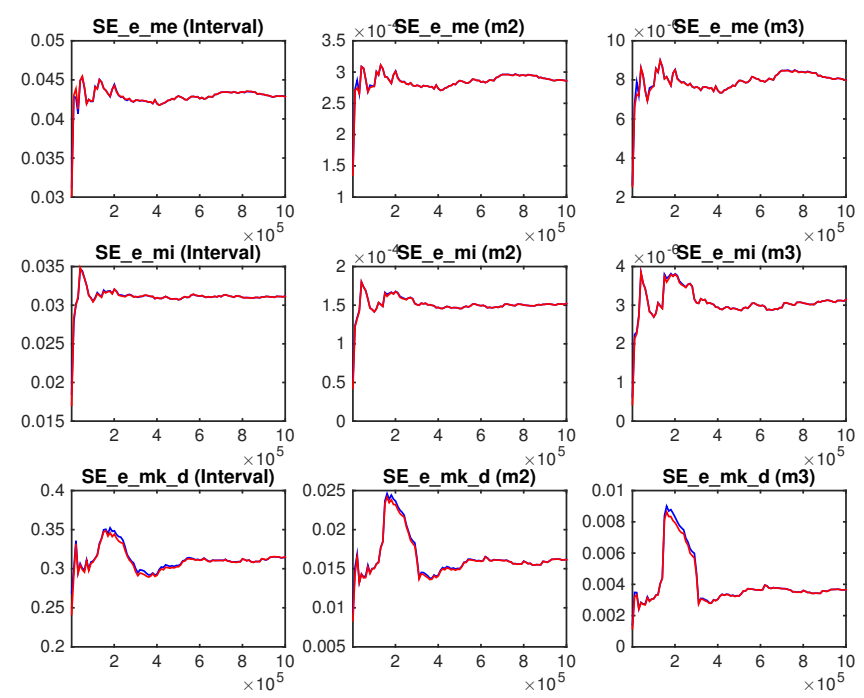

Figura 313: Diagnósticos de Convergência Univariado 

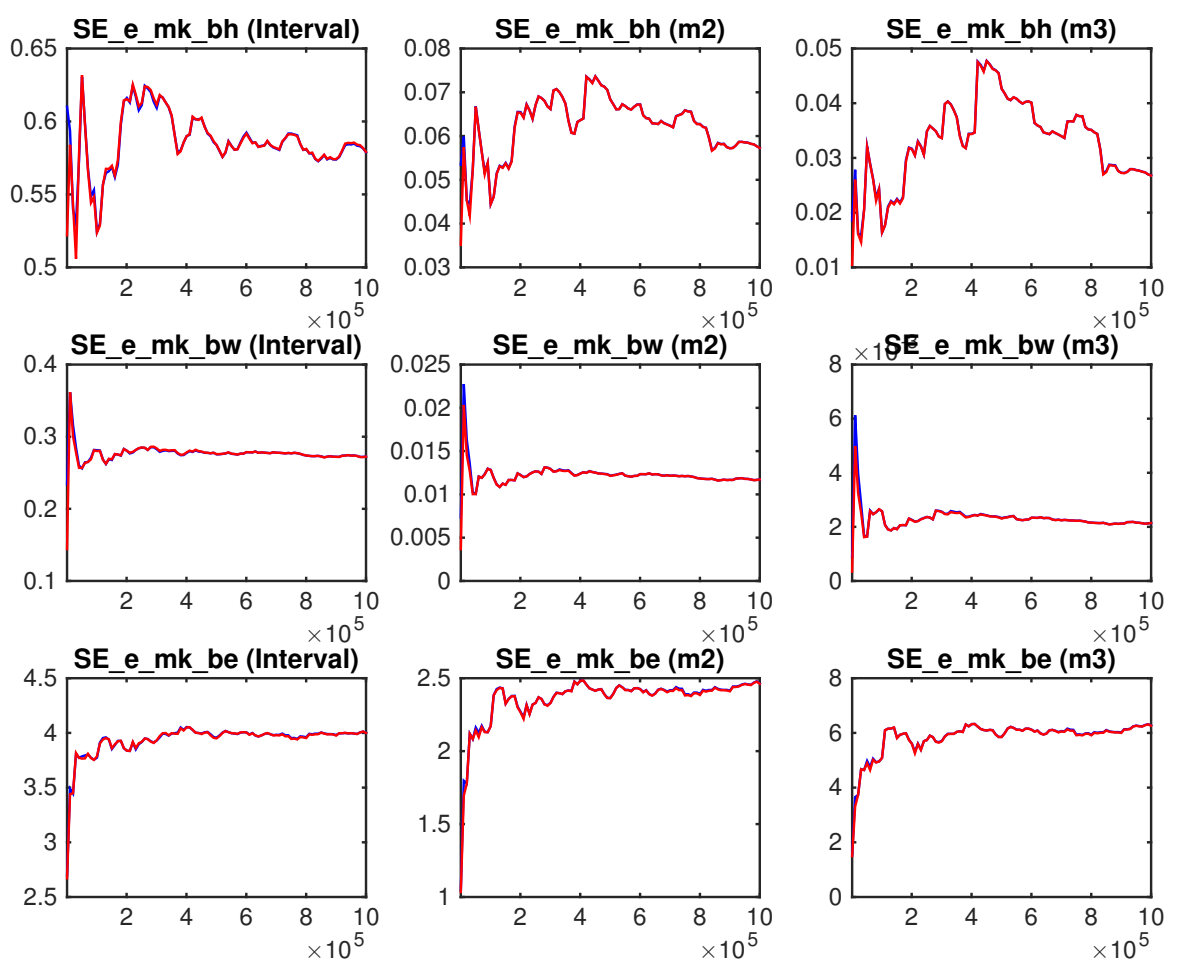

Figura 314: Diagnósticos de Convergência Univariado
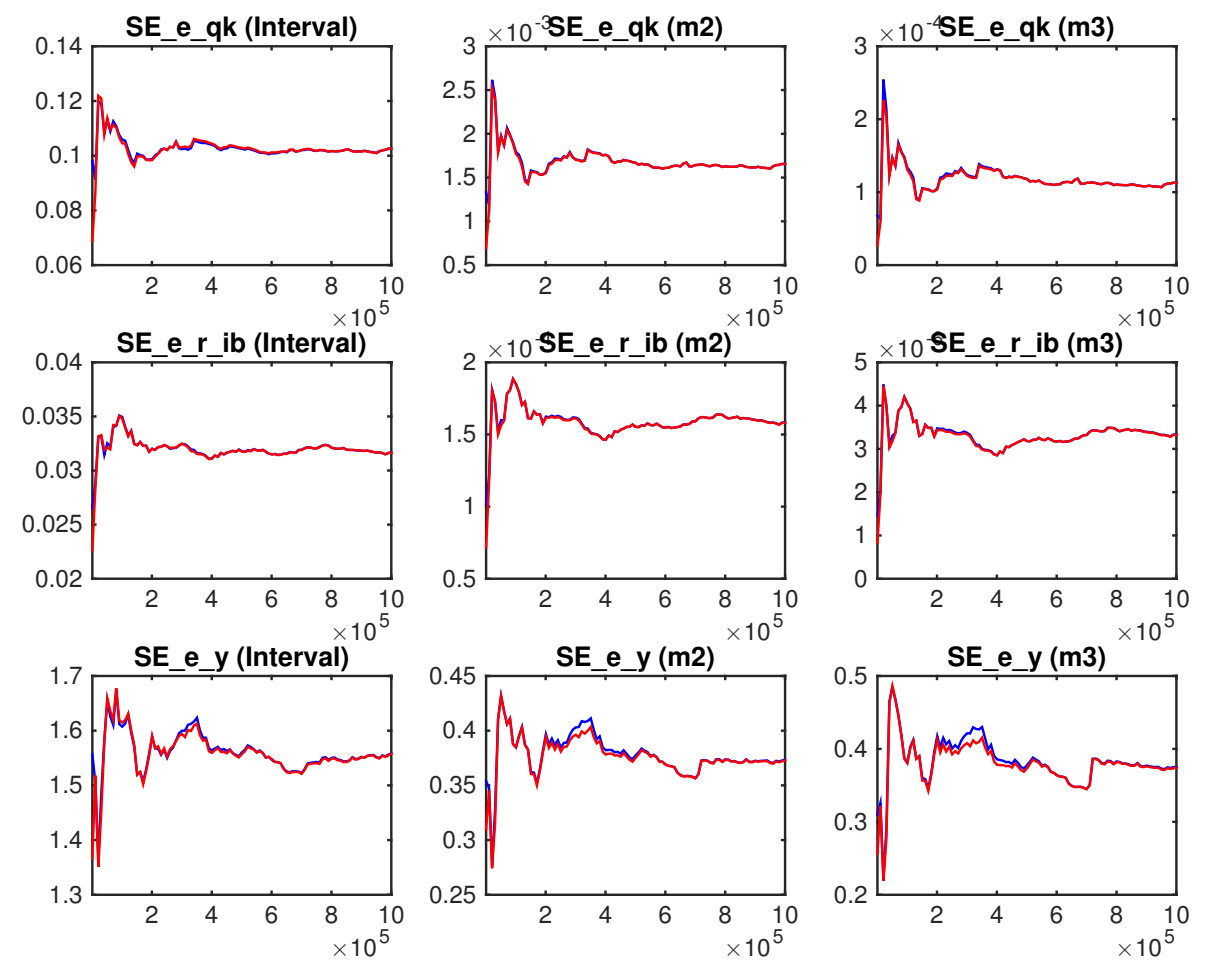

Figura 315: Diagnósticos de Convergência Univariado 

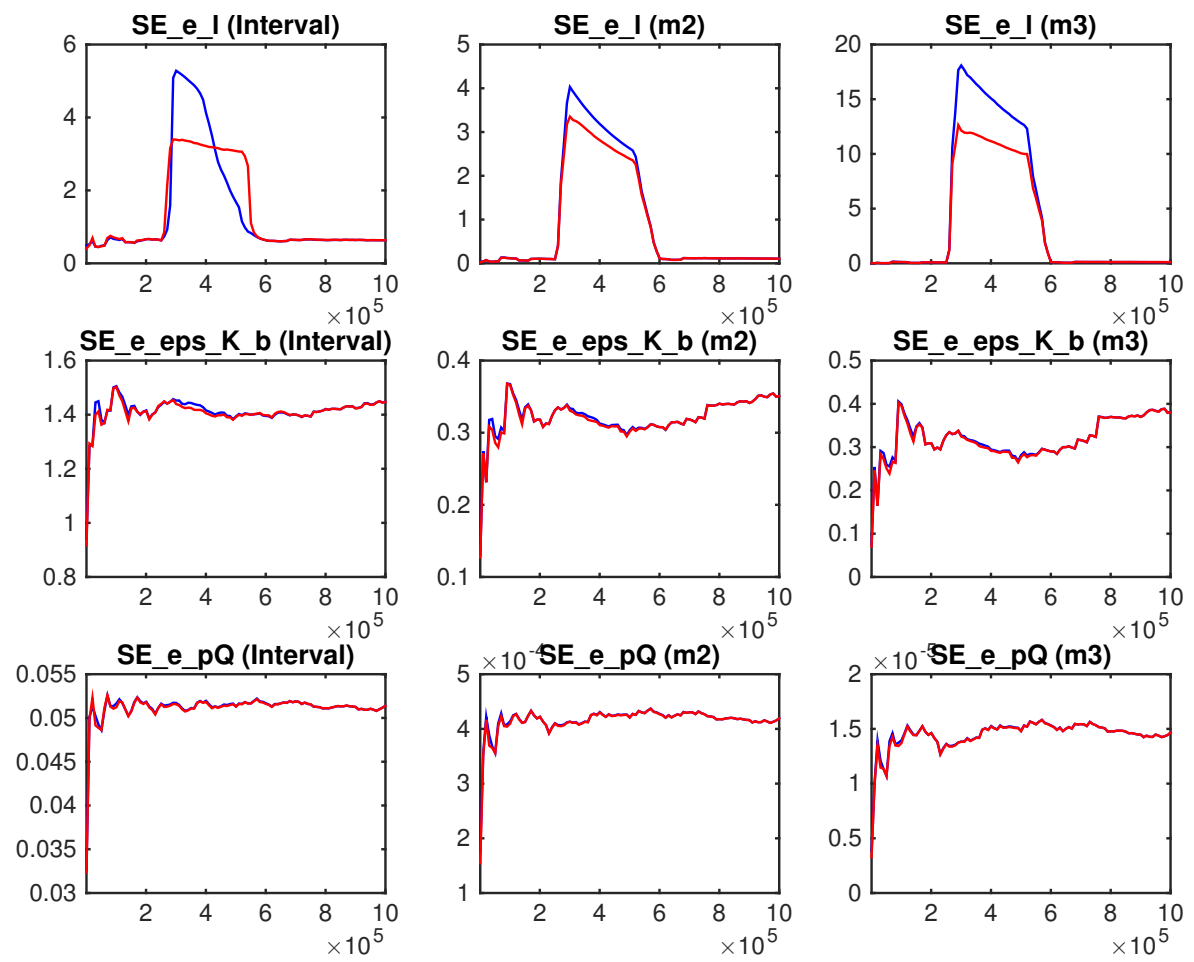

Figura 316: Diagnósticos de Convergência Univariado
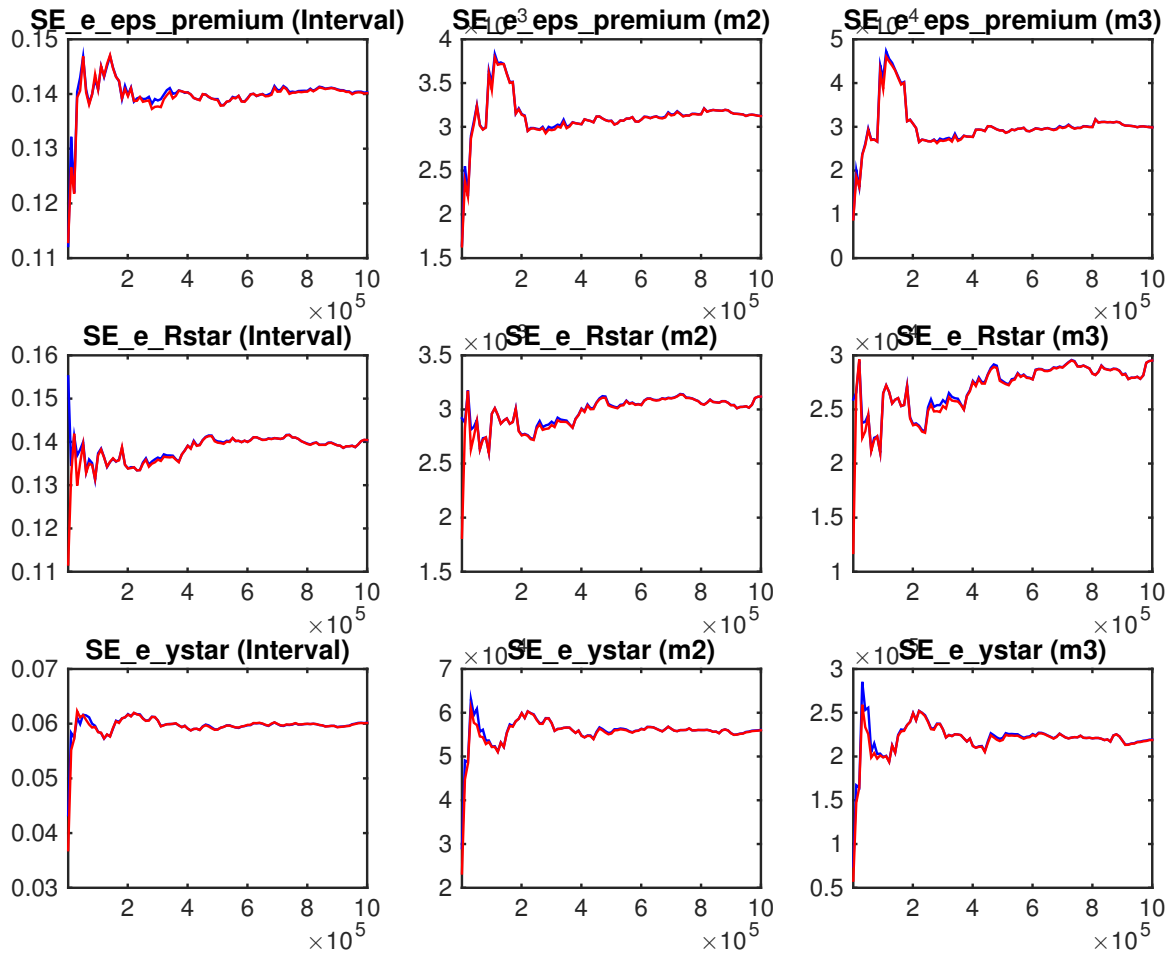

Figura 317: Diagnósticos de Convergência Univariado 

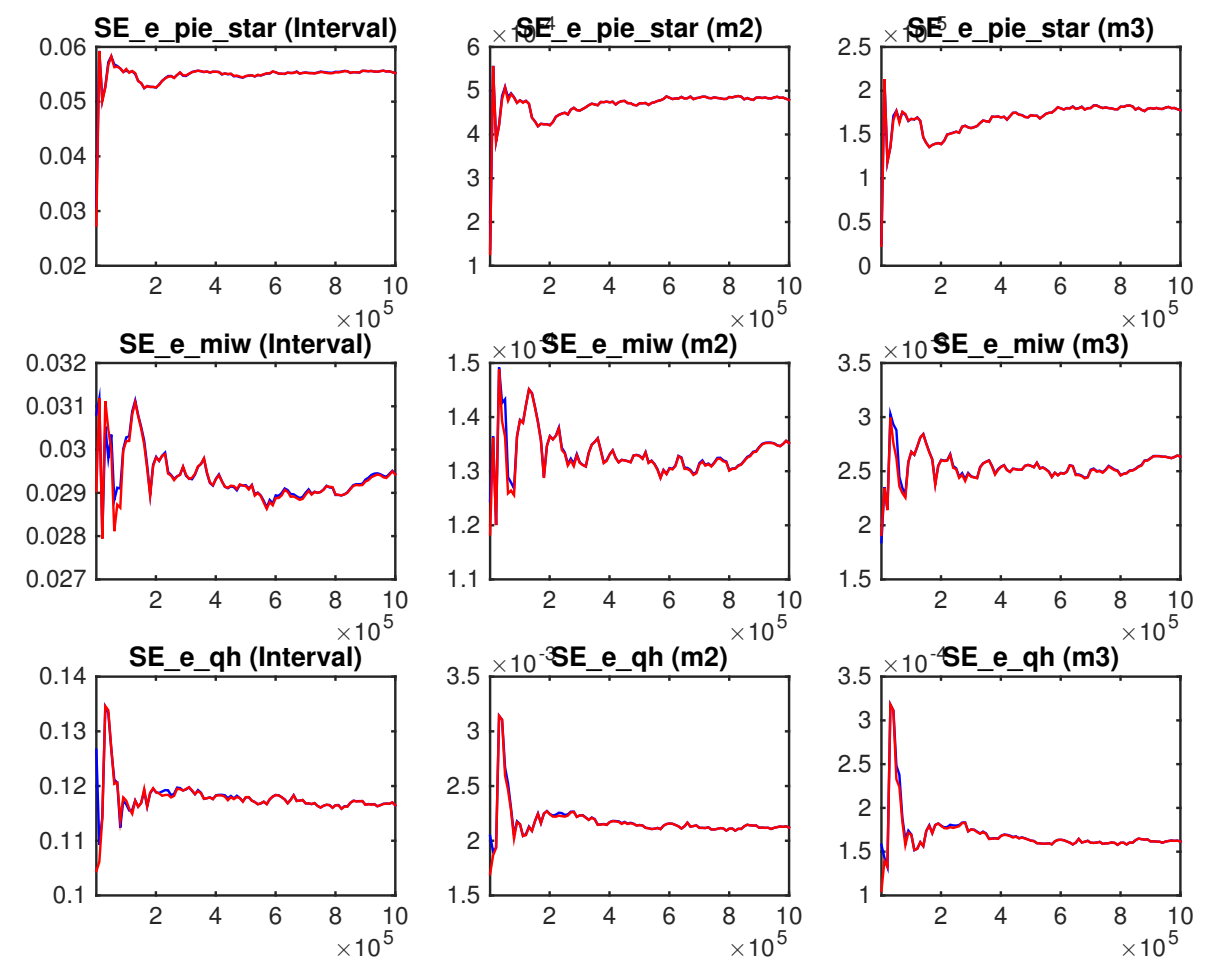

Figura 318: Diagnósticos de Convergência Univariado
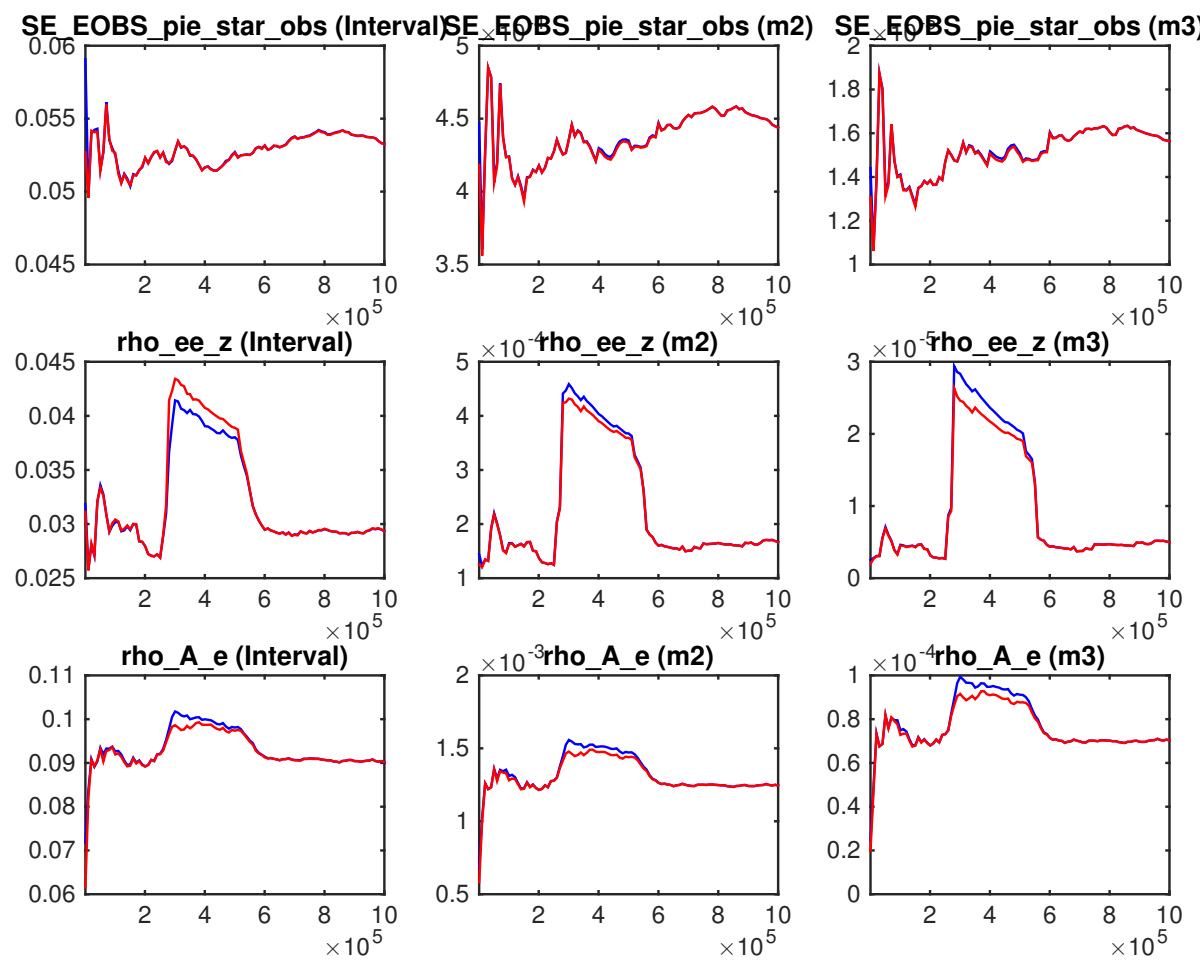

Figura 319: Diagnósticos de Convergência Univariado 

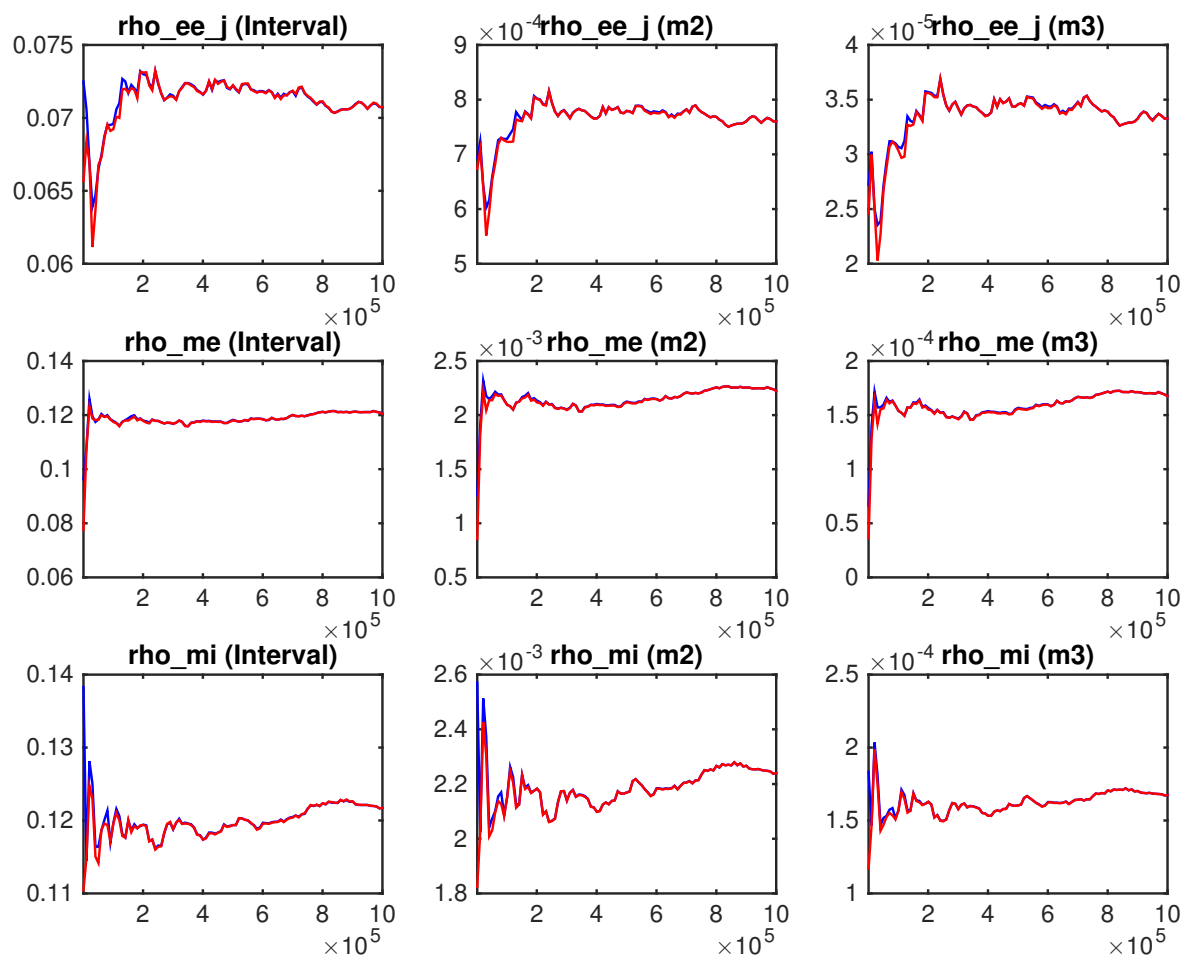

Figura 320: Diagnósticos de Convergência Univariado
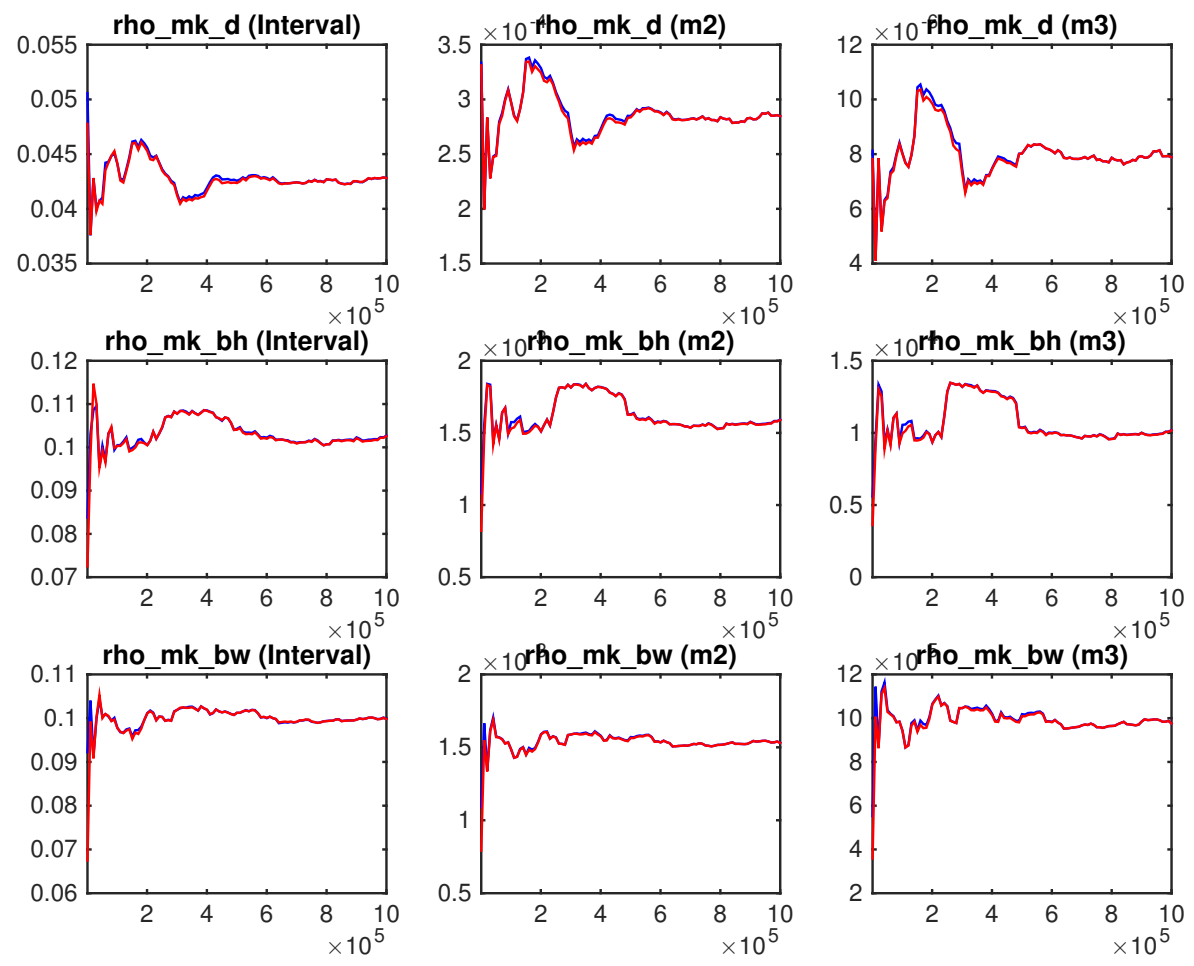

Figura 321: Diagnósticos de Convergência Univariado 

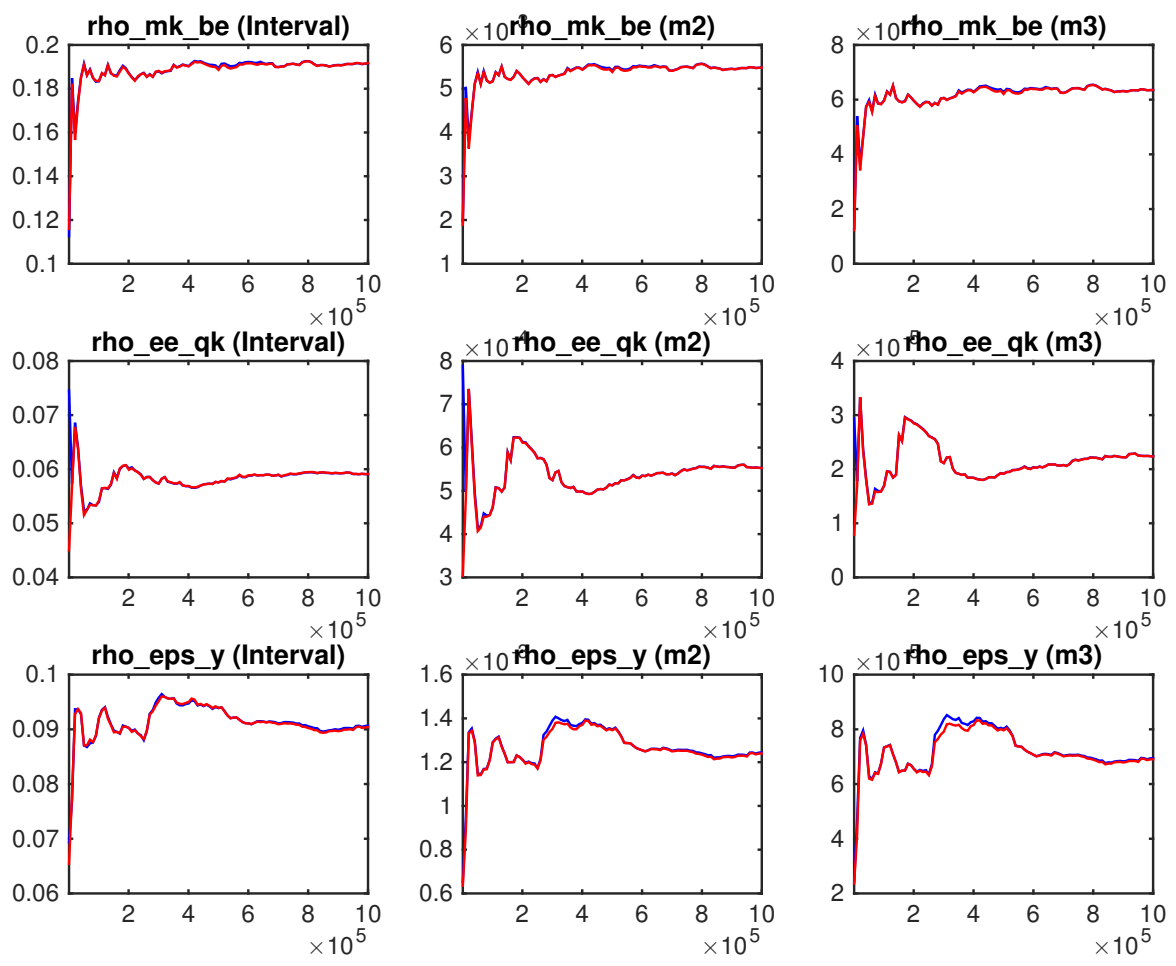

Figura 322: Diagnósticos de Convergência Univariado
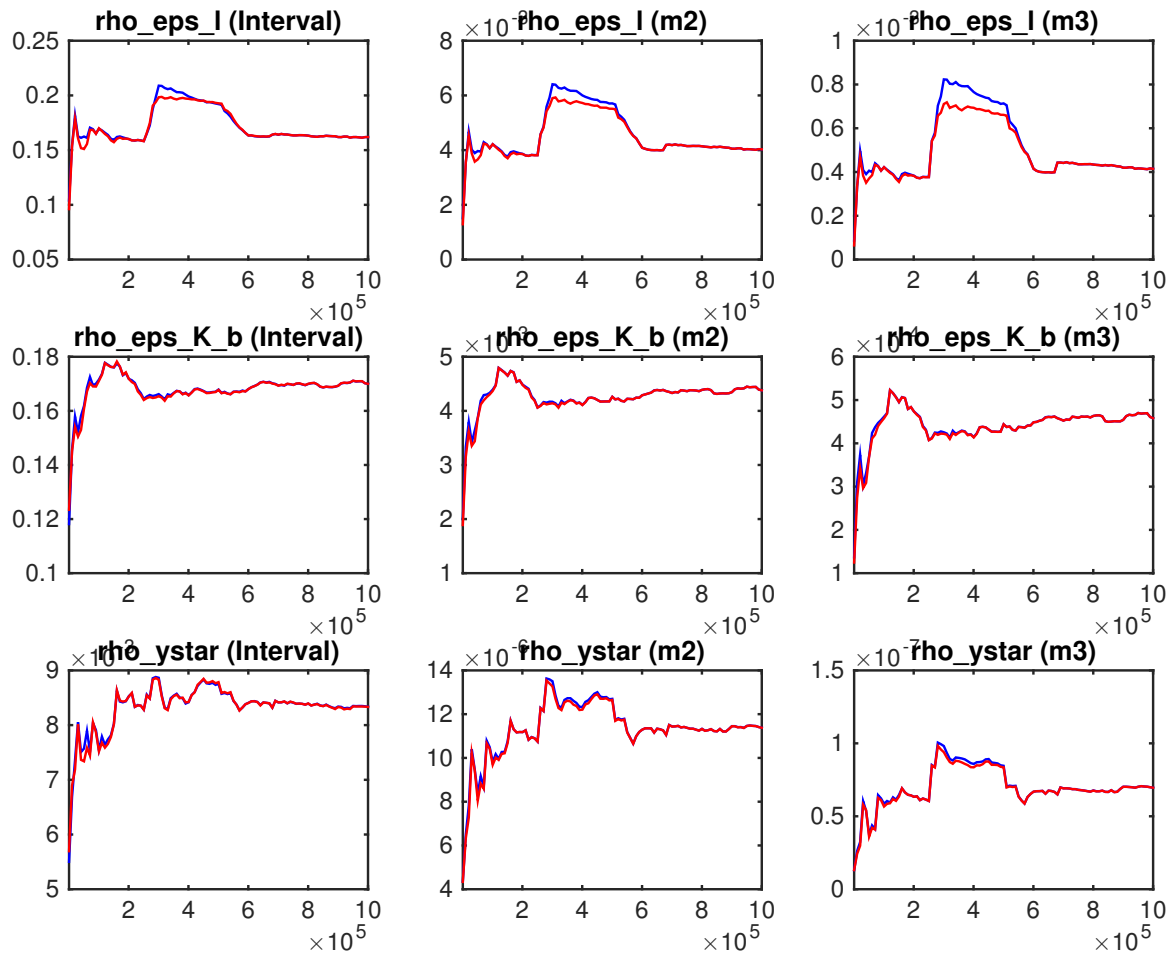

Figura 323: Diagnósticos de Convergência Univariado 

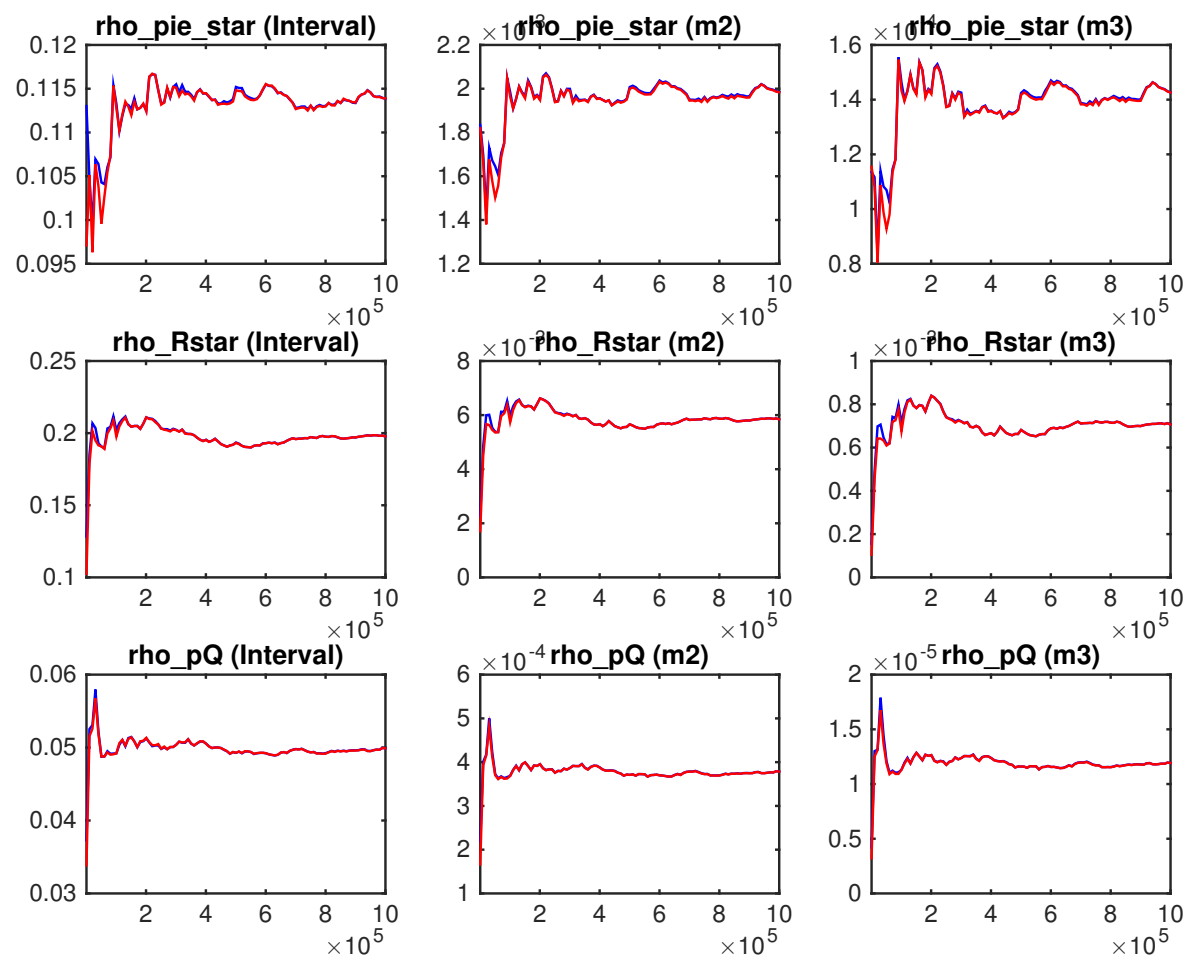

Figura 324: Diagnósticos de Convergência Univariado
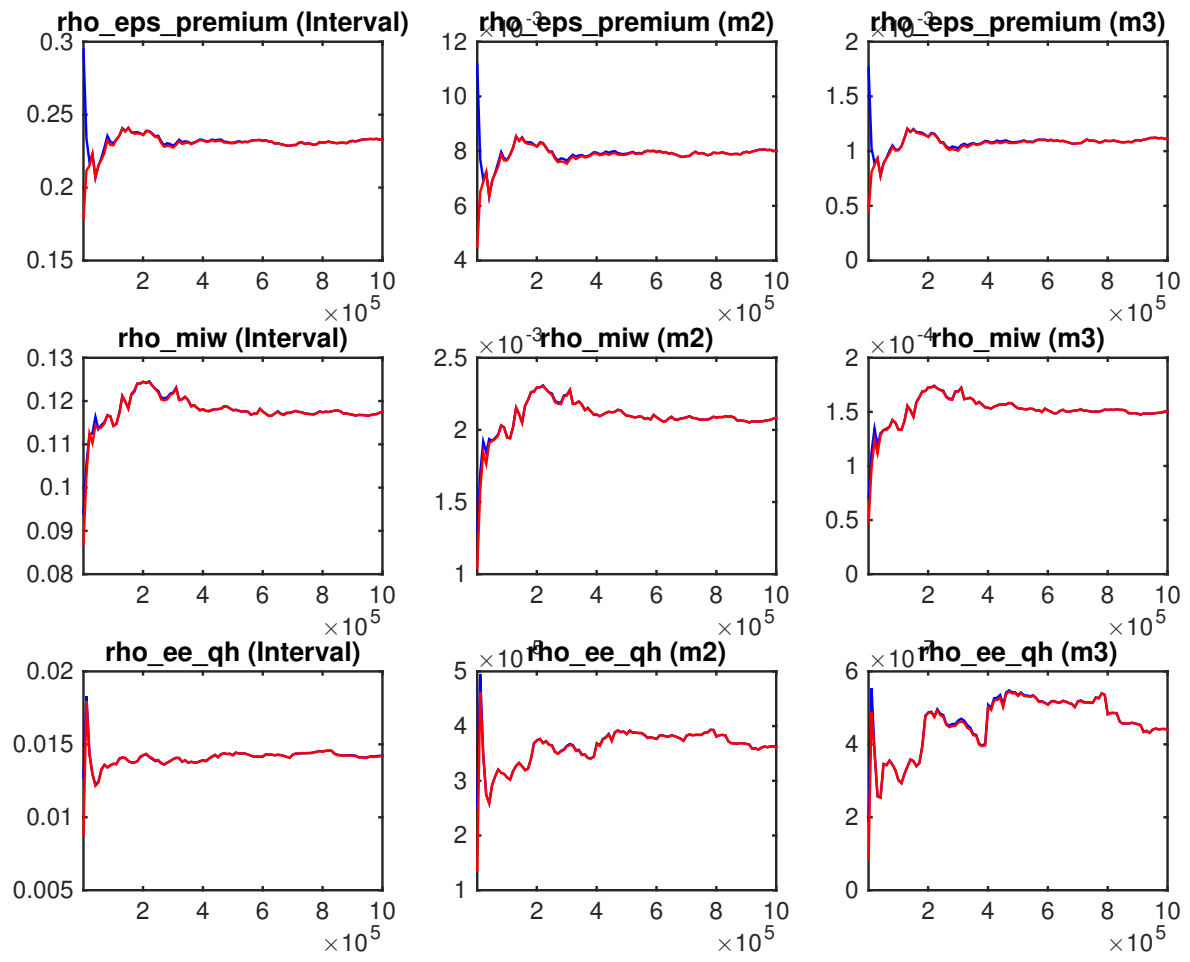

Figura 325: Diagnósticos de Convergência Univariado 

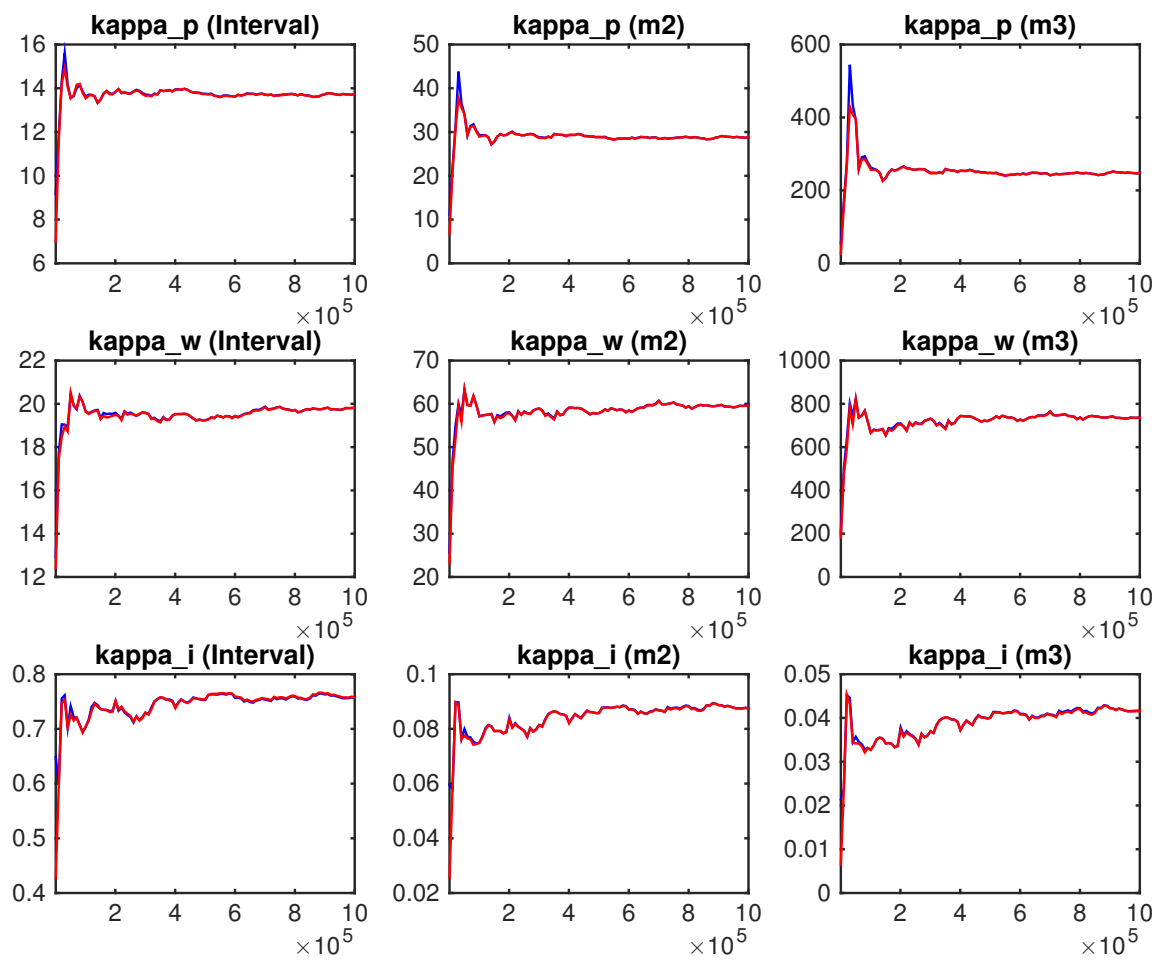

Figura 326: Diagnósticos de Convergência Univariado
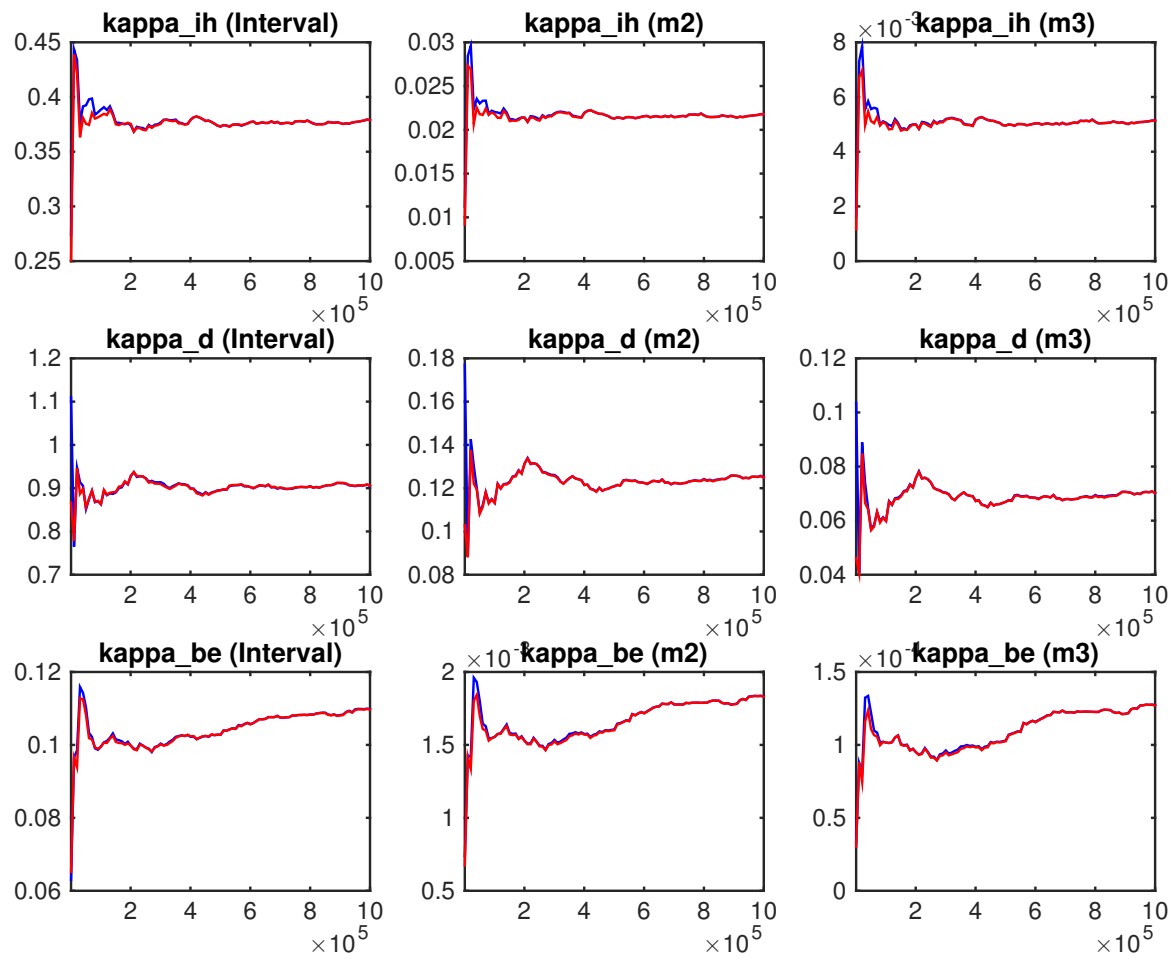

Figura 327: Diagnósticos de Convergência Univariado 

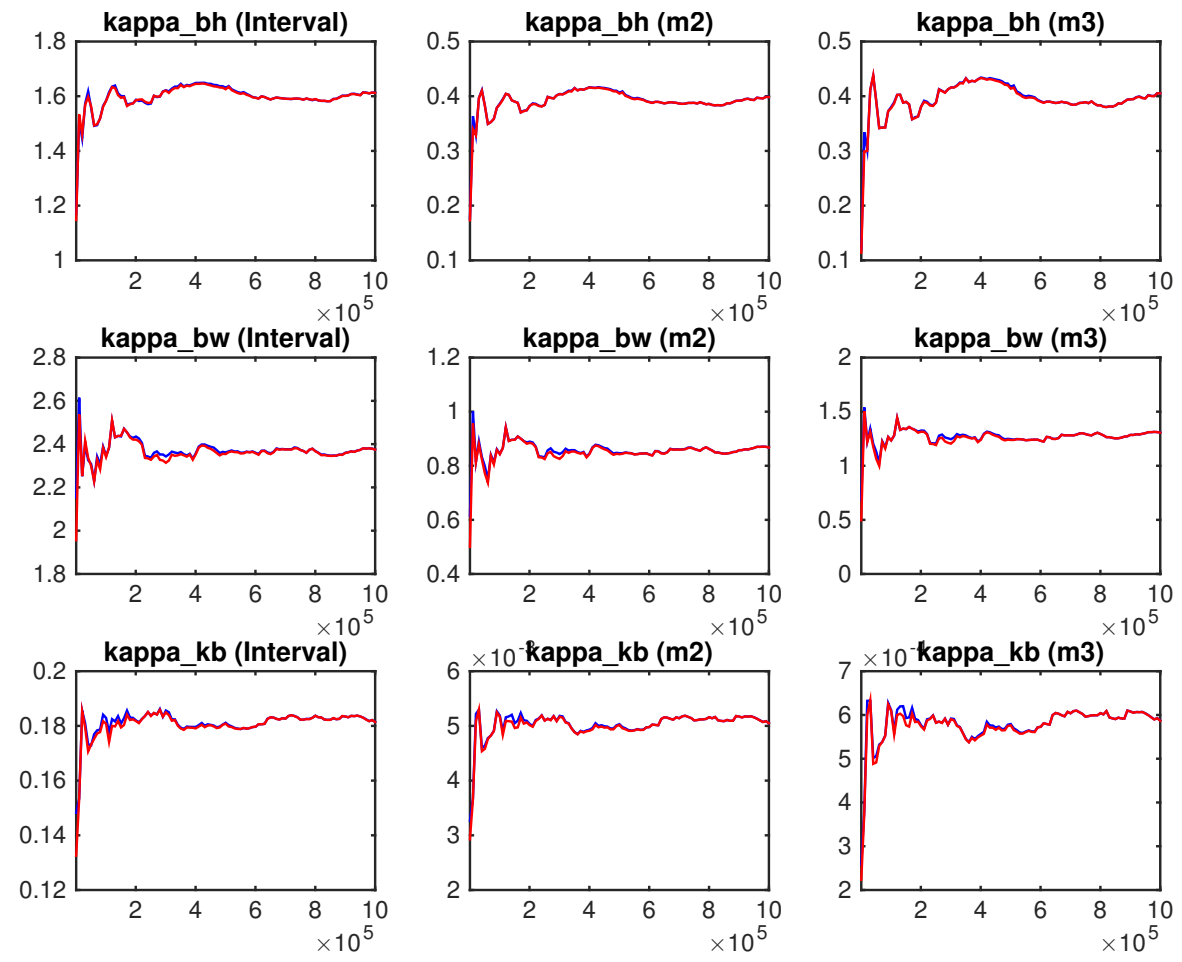

Figura 328: Diagnósticos de Convergência Univariado
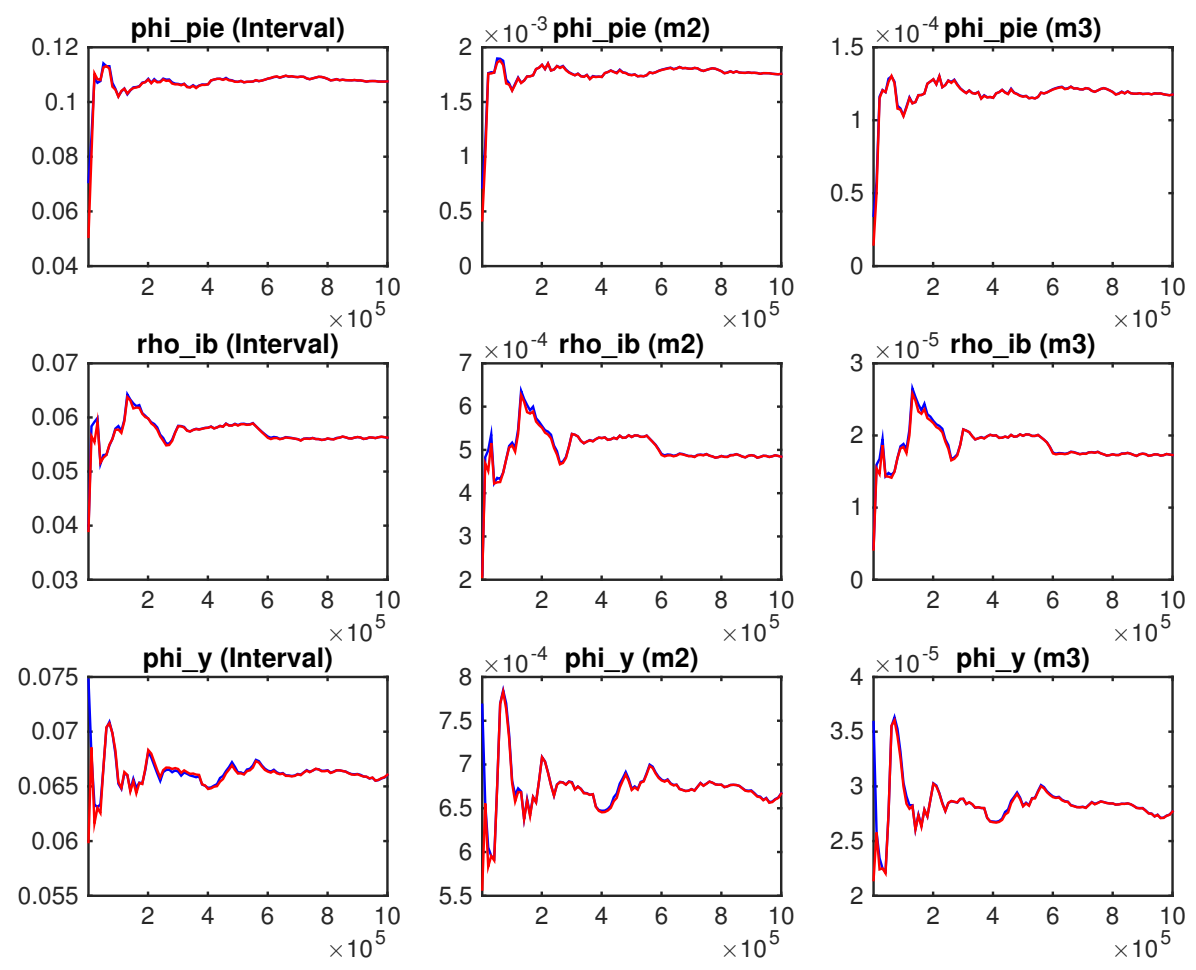

Figura 329: Diagnósticos de Convergência Univariado 

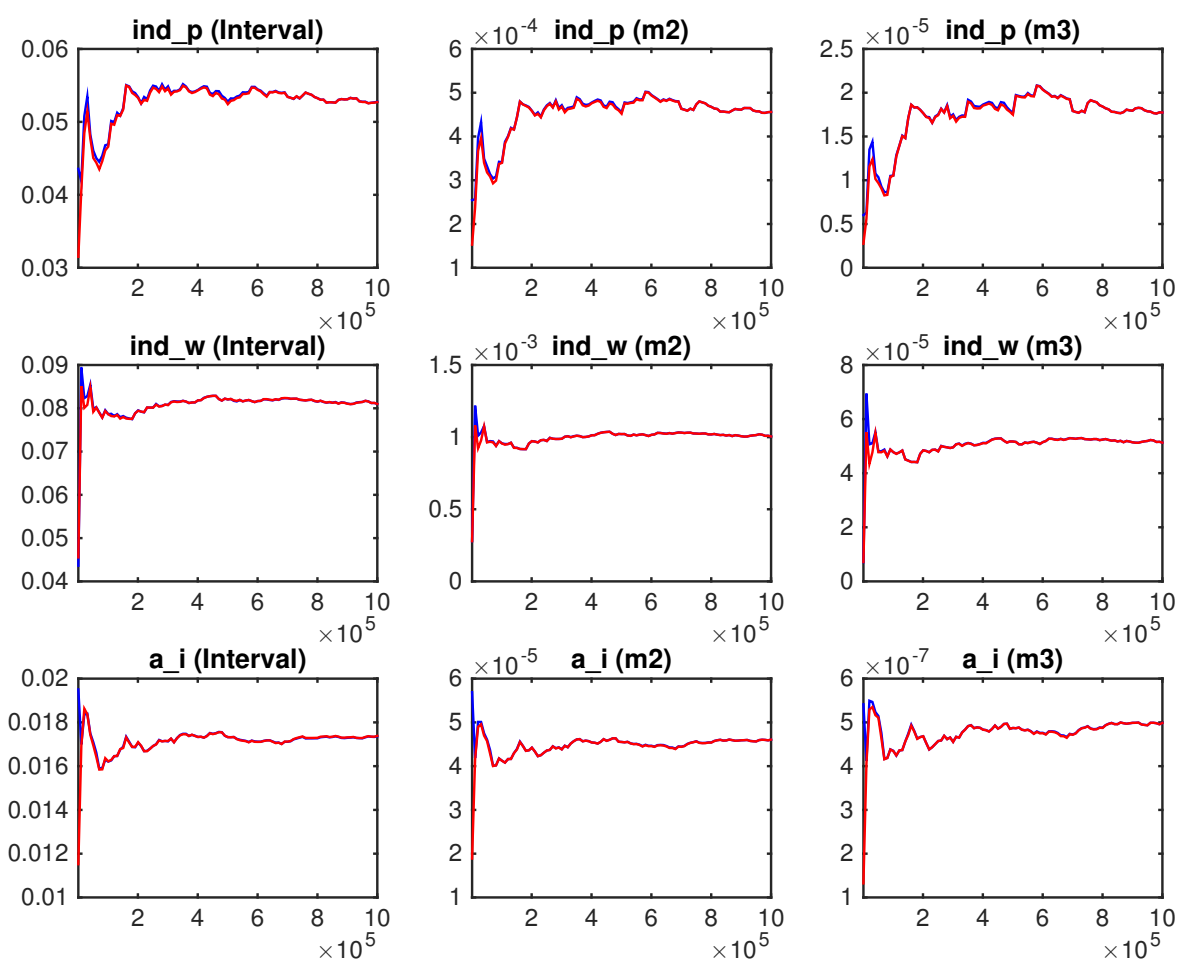

Figura 330: Diagnósticos de Convergência Univariado
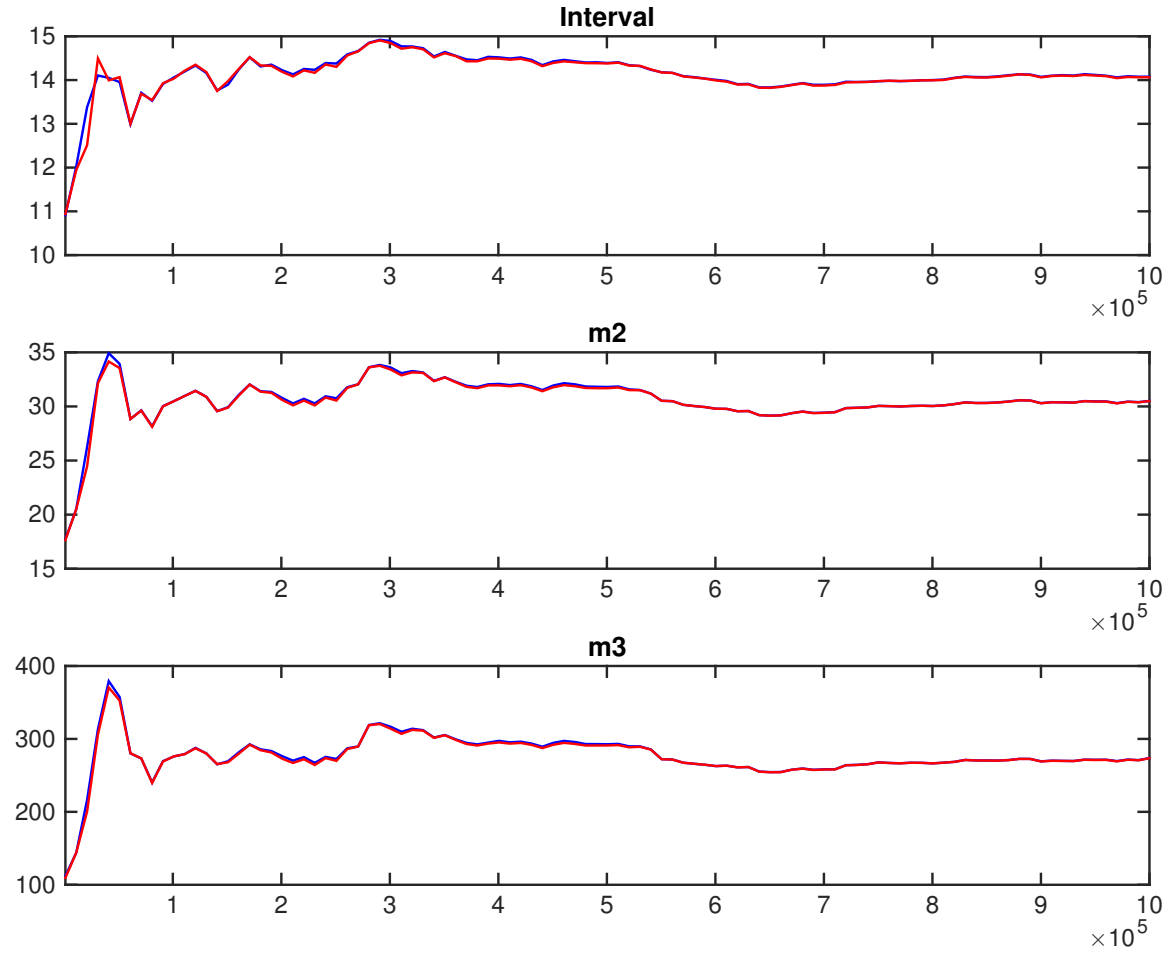

Figura 331: Diagnósticos de Convergência Multivariado 



\section{APÊNDICE E - Decomposições Históricas}

\section{E.1 Economia Fechada}

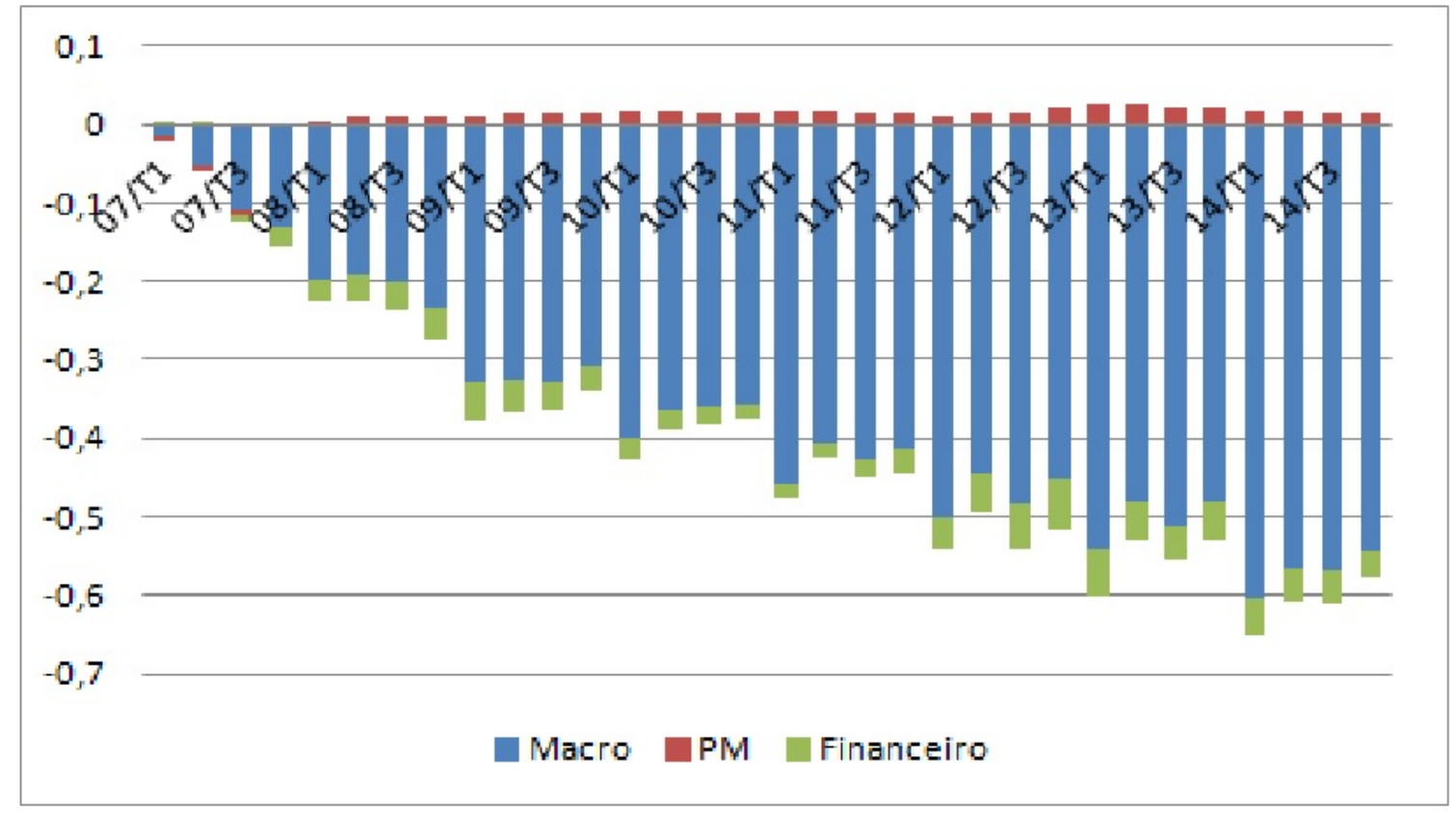

Figura 332: Decomposição Histórica: Produto 


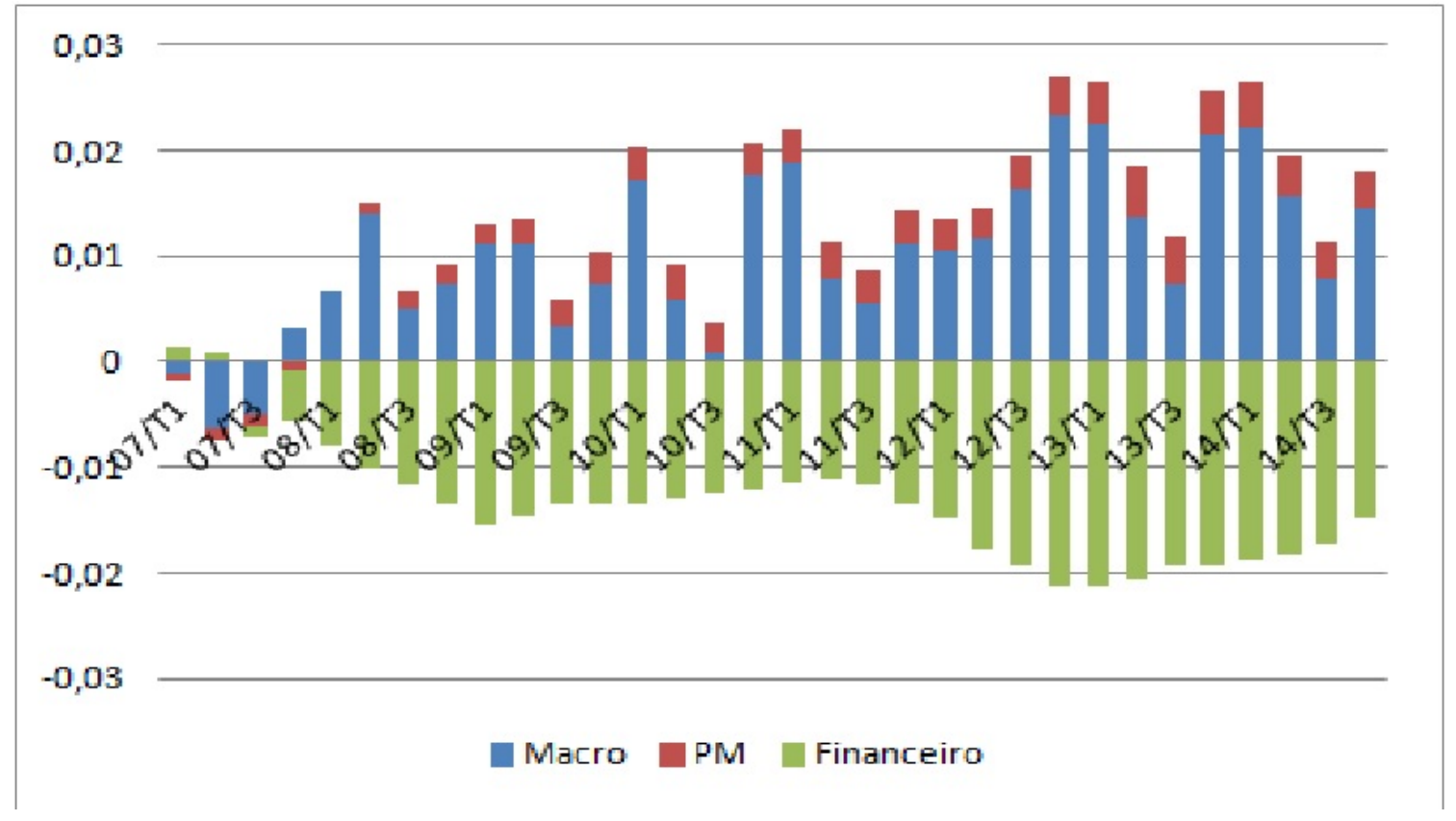

Figura 333: Decomposição Histórica: Inflação

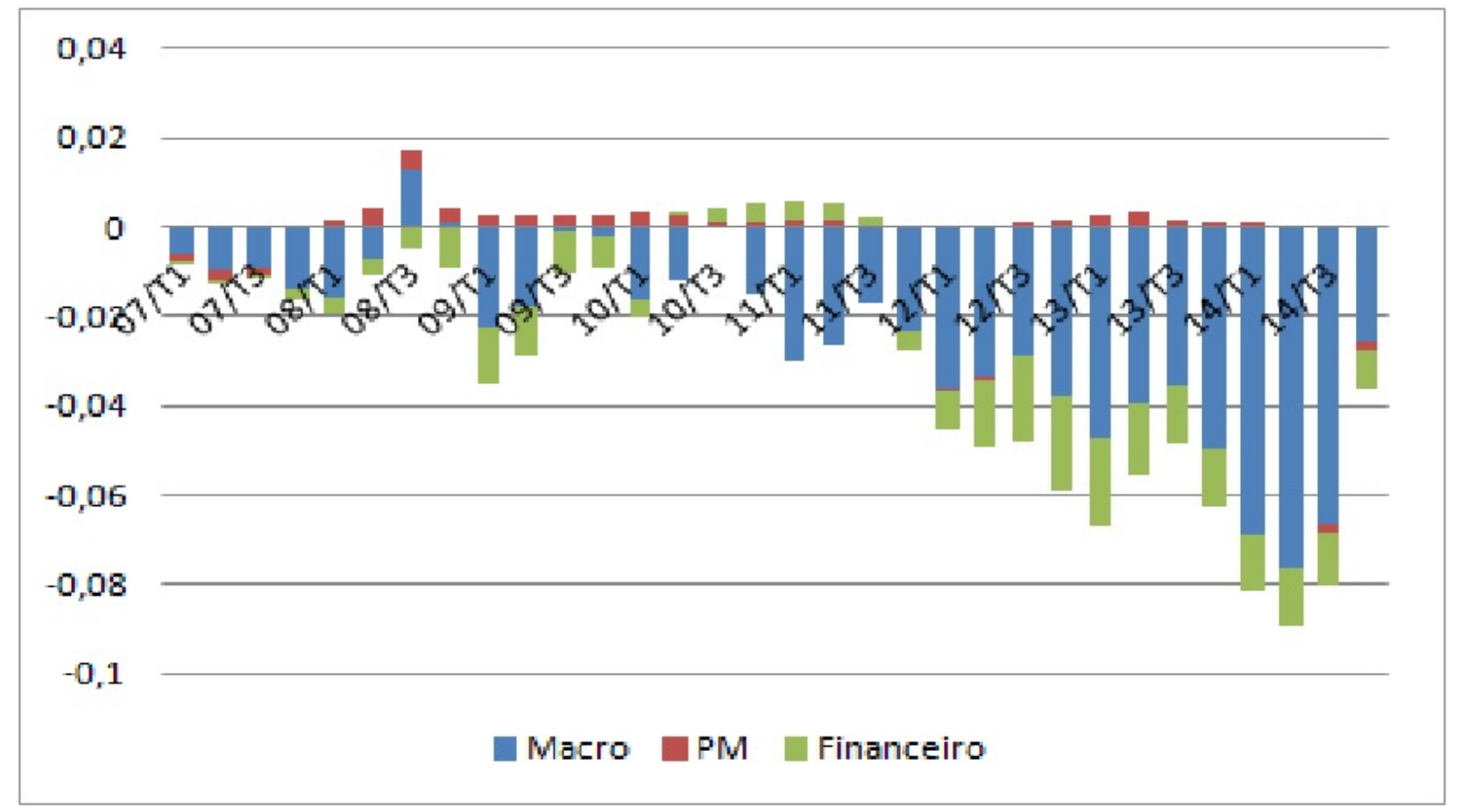

Figura 334: Decomposição Histórica: Investimento em Capital 


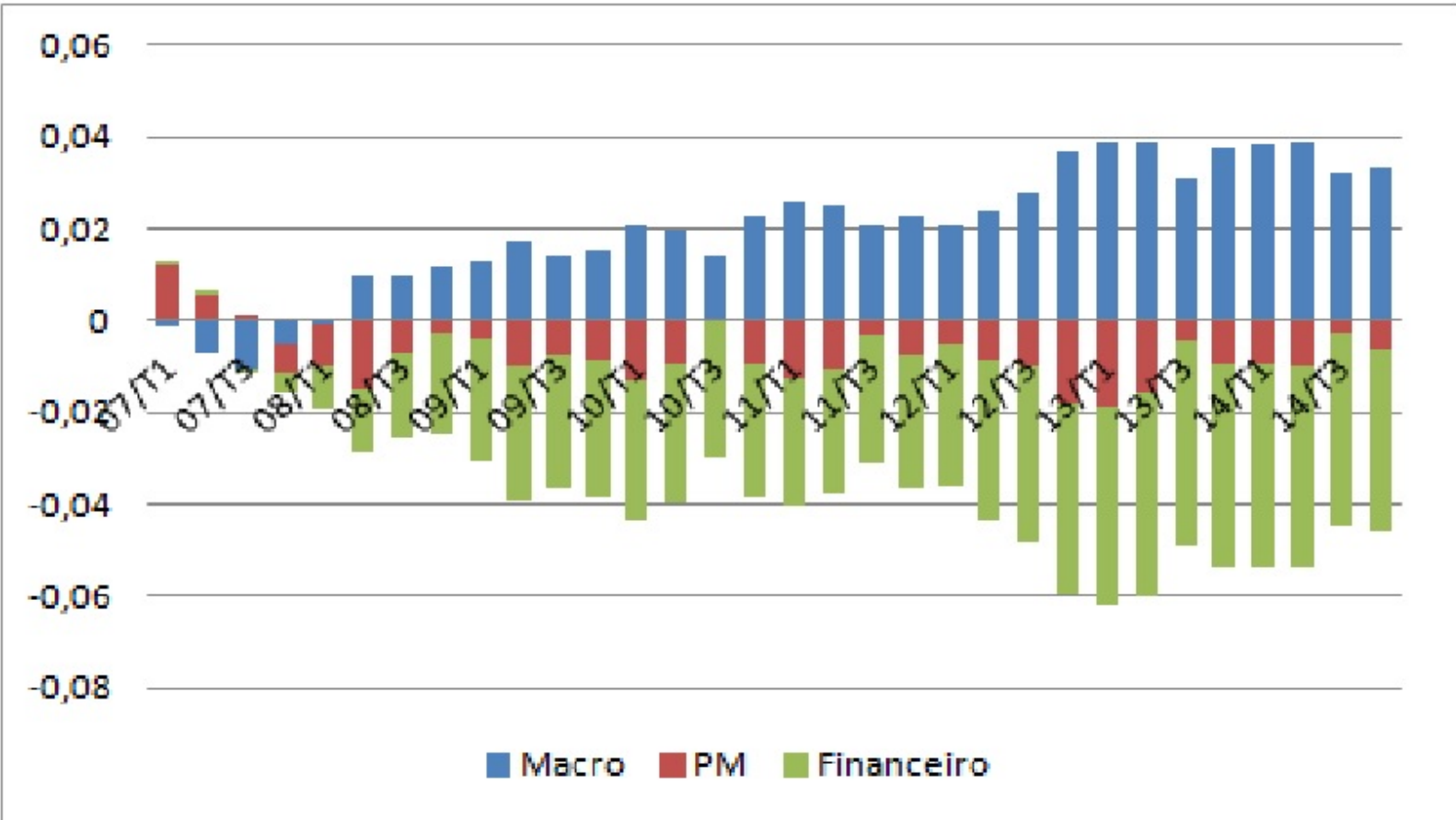

Figura 335: Decomposição Histórica: Taxa Selic

\section{E.2 Economia Aberta}

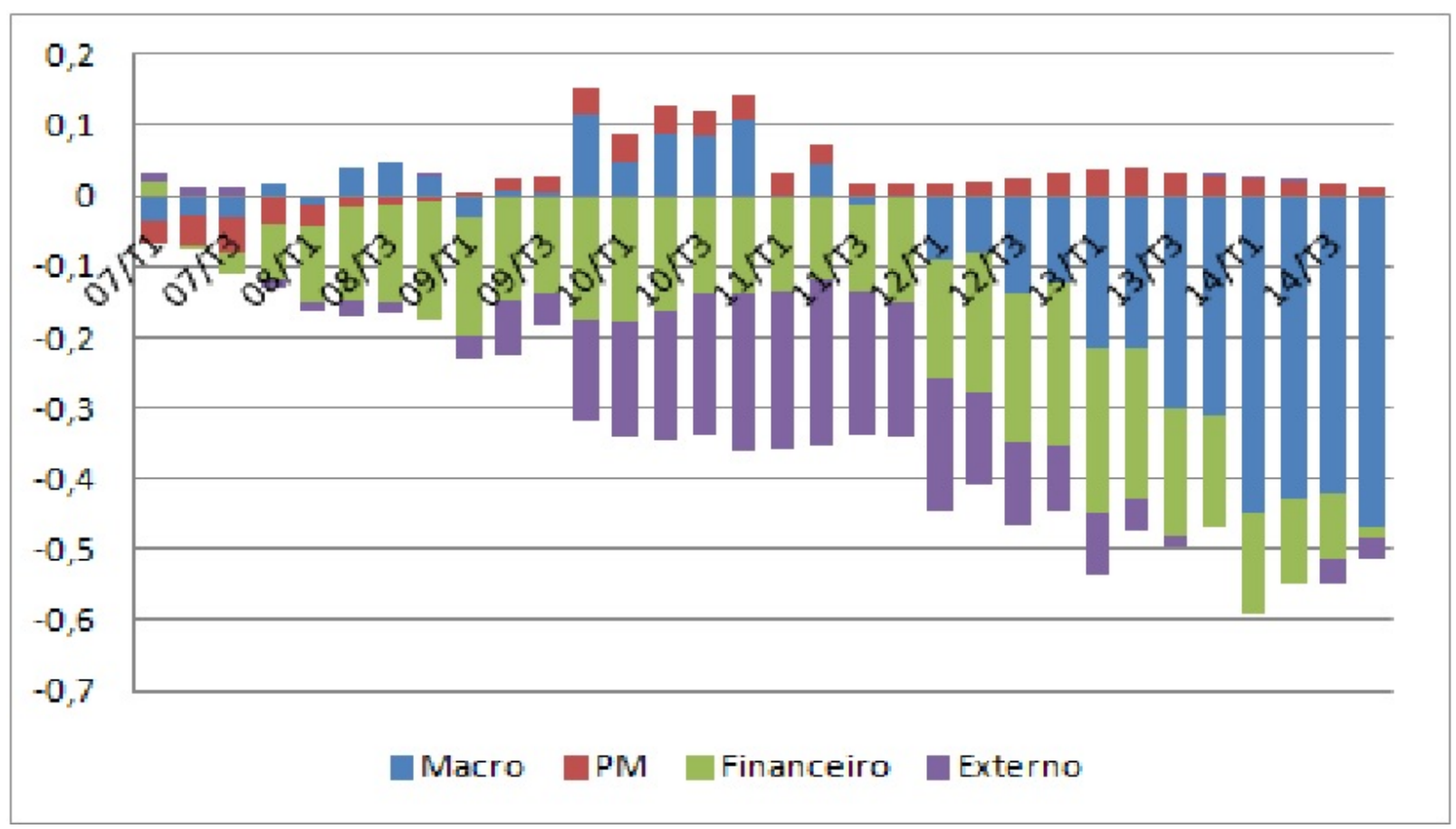

Figura 336: Decomposição Histórica: Produto 


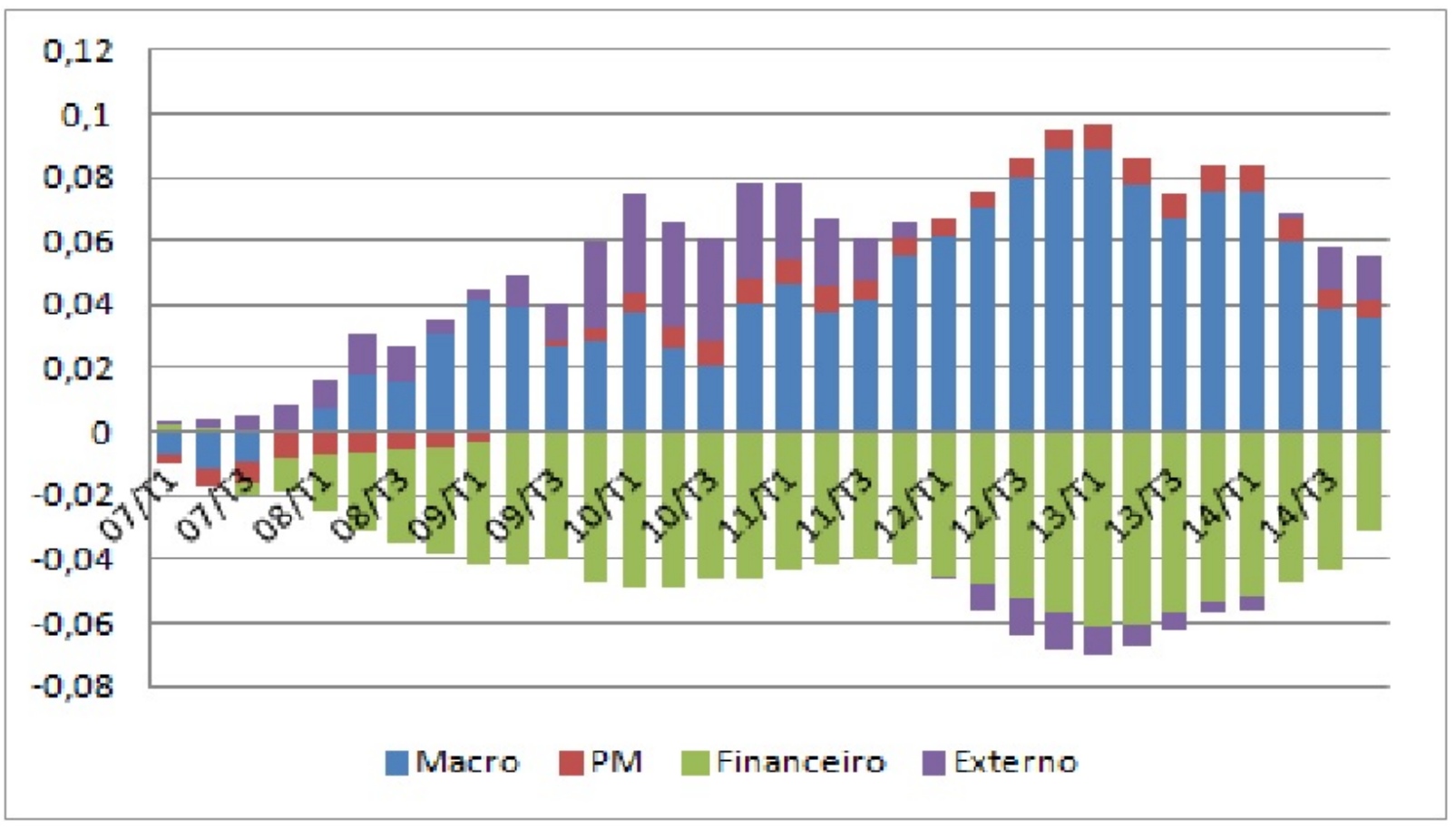

Figura 337: Decomposição Histórica: Inflação

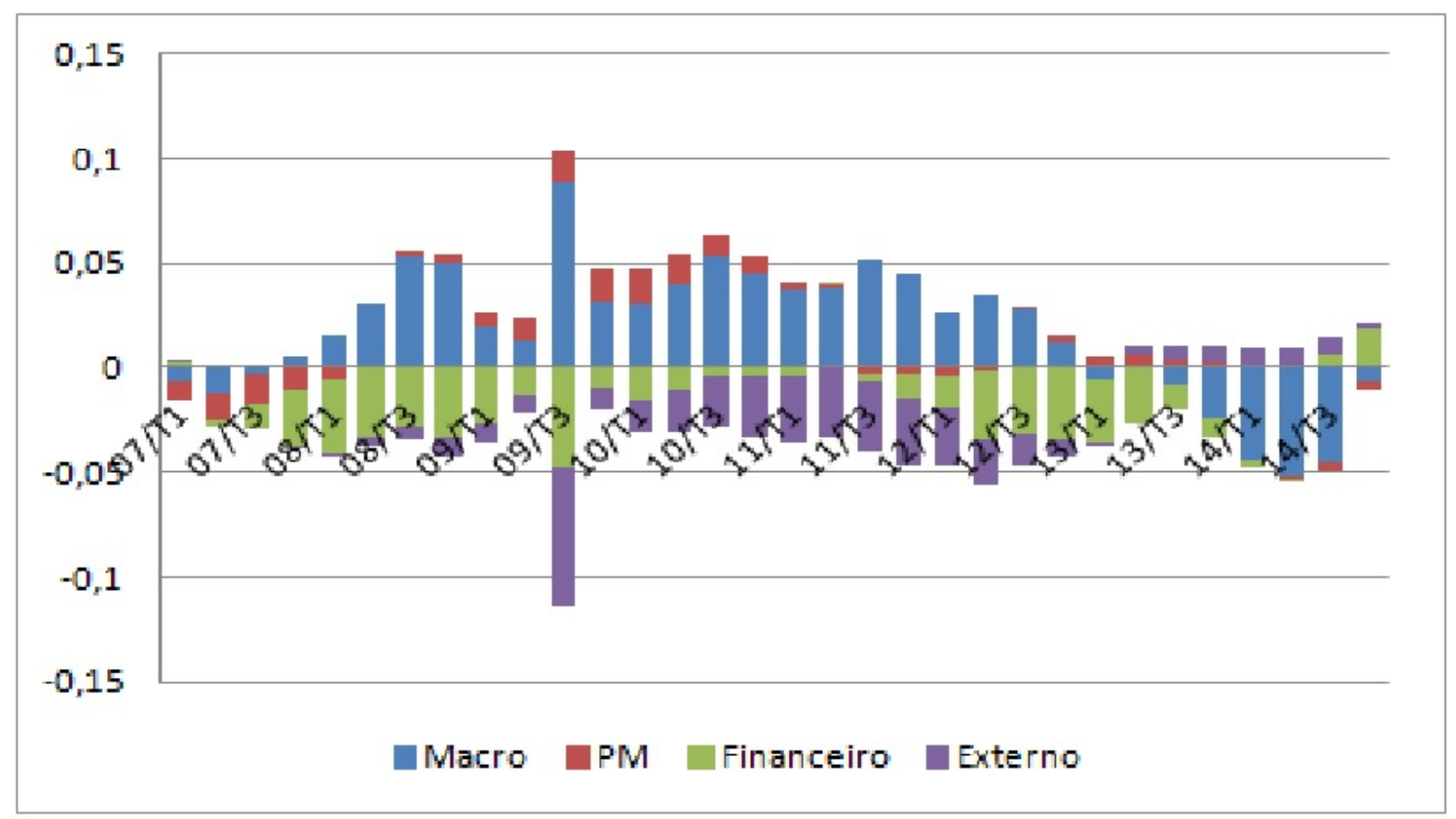

Figura 338: Decomposição Histórica: Investimento em Capital 


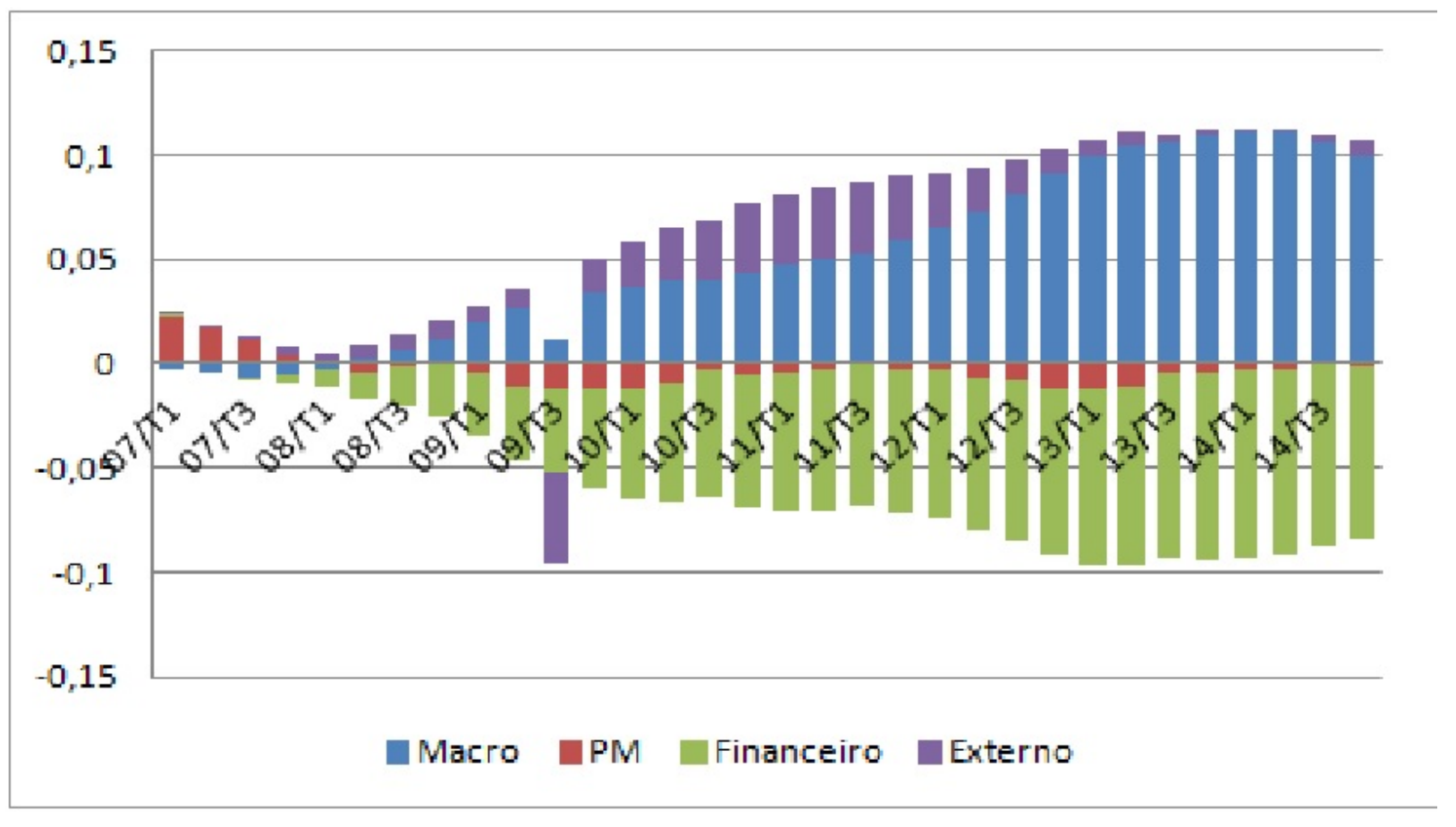

Figura 339: Decomposição Histórica: Taxa Selic

\section{E.2.1 Choques Externos}

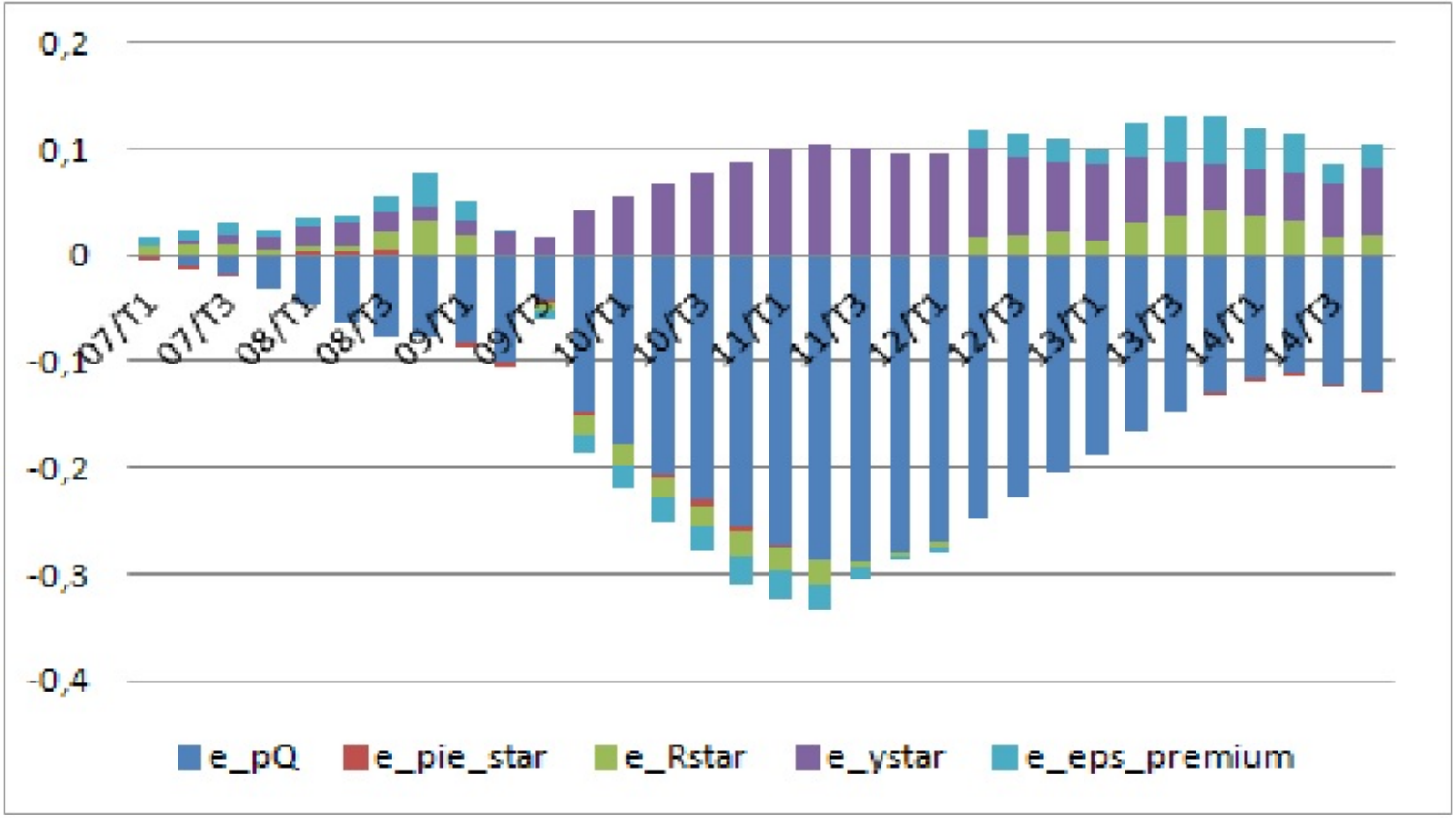

Figura 340: Decomposição Histórica: Produto 


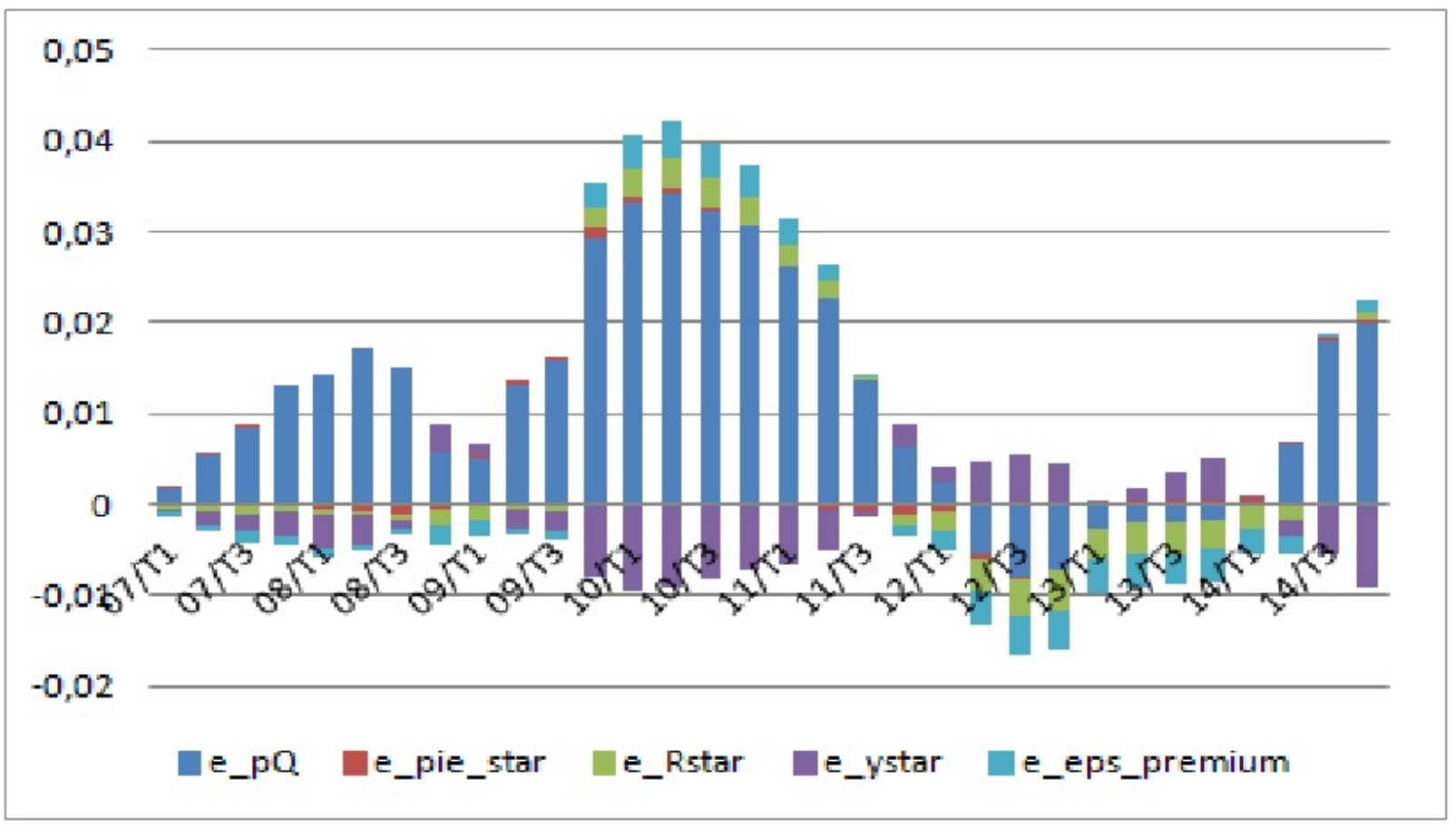

Figura 341: Decomposição Histórica: Inflação

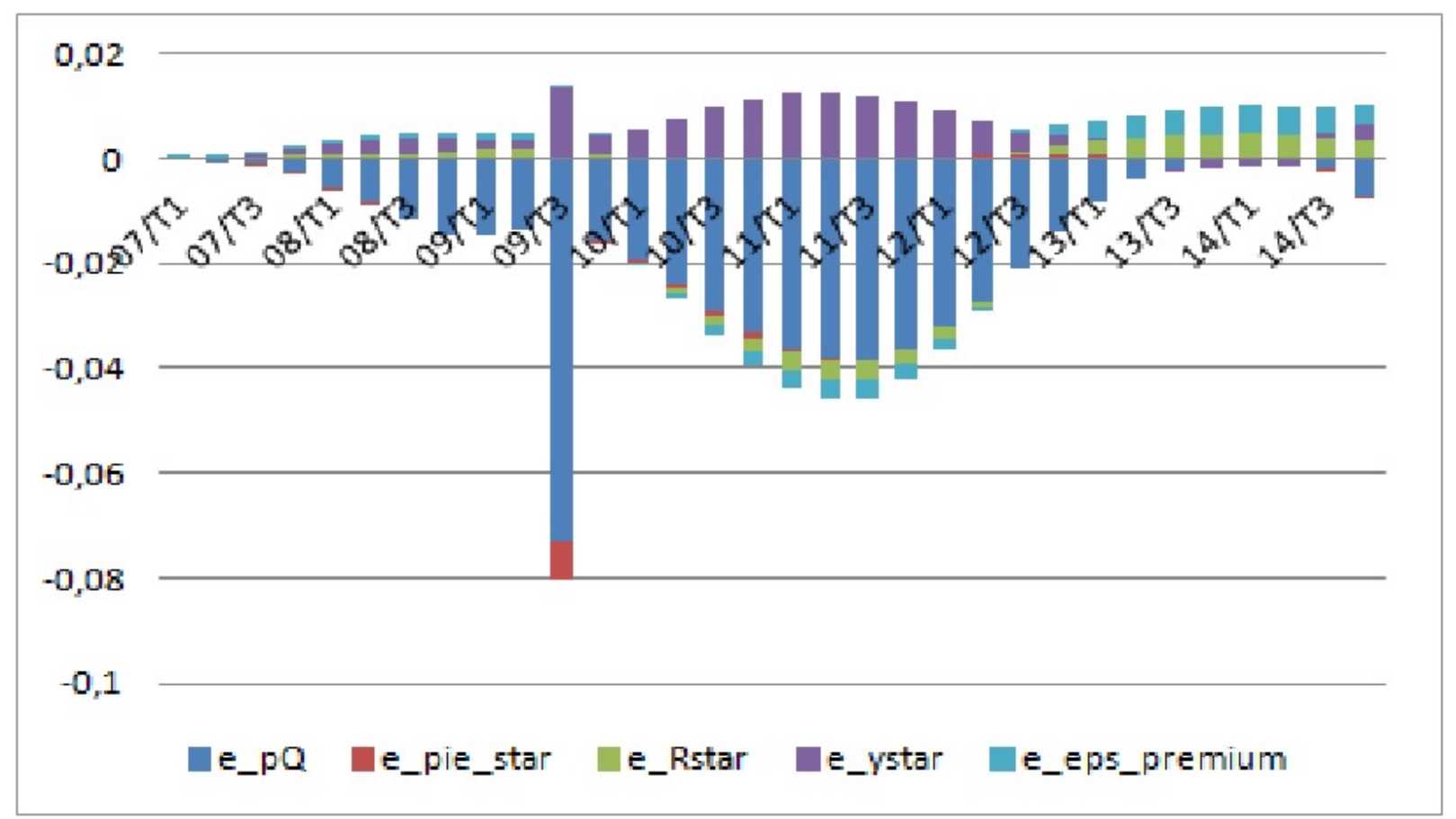

Figura 342: Decomposição Histórica: Investimento em Capital 


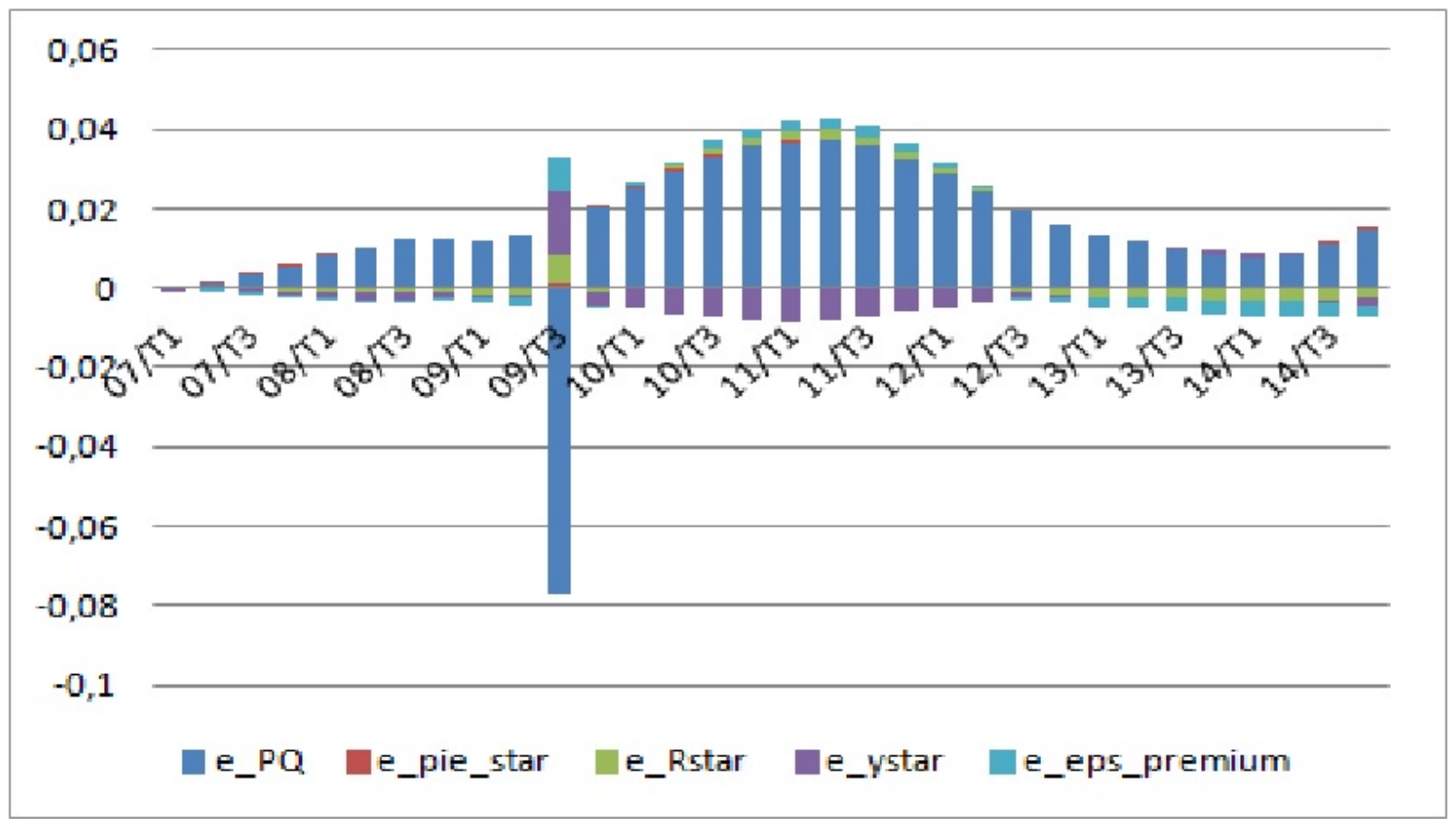

Figura 343: Decomposição Histórica: Taxa Selic 

Anexos 



\section{ANEXO A - Script para o Cálculo de Steady-State}

\section{A.1 Economia Fechada}

\section{A.1.1 Função}

\% Universidade de Brasília

\% Tese - Modelo Geralli et all para uma Economia Aberta

\% Orientador: Joaquim P de Andrade

\% Doutorando: Márcio Francisco da Silva

\% Equações que determinam o SS do modelo:

$\% \mathrm{q} \_\mathrm{k}=1$

$\% \mathrm{q} h=1$

$\% \mathrm{x} \_\mathrm{ss}=$ eps_y $/\left(\mathrm{ep \_ sy}-1\right)$

$\% \mathrm{r} \_\mathrm{d}=\operatorname{piss} /$ betap -1

$\% \mathrm{r} \_$pol $=\left((\right.$eps_d -1$\left.) / e p s \_\mathrm{d}\right) * \mathrm{r} \_\mathrm{d}$

$\%$ r_biw $=\left(\right.$ eps_biw $/($ eps_biw - 1) $){ }^{*}$ r_pol

$\%$ r_bih $=(\text { eps_bih } /(\text { eps_bih }-1))^{*}$ r_pol

$\%$ r_be $=($ eps_be $/($ eps_be -1$)){ }^{*}$ r_pol

$\%$ lam_p $=1 / \mathrm{c} \_\mathrm{p}$

$\%$ lam_i $=1 / \mathrm{c} \_\mathrm{i}$

$\%$ lam_e $=1 / \mathrm{c} \_\mathrm{e}$

$\%$ s_ih $=(1 /(1+$ r_bih $)-$ betai $/$ piss $) *$ lam_i

$\%$ s_iw $=\left(1 /\left(1+\mathrm{r} \_\right.\right.$biw $)-$betai $/$piss $) *$ lam_i

$\%$ s_e $=(1 /(1+$ r_be $)-$ betae $/$ piss $) *$ lam_e

$\% \mathrm{c} \_\mathrm{p}=\mathrm{w} \_\mathrm{p} * \mathrm{l} \_\mathrm{p}+\left(\left(1+\mathrm{r} \_\mathrm{d}\right) / \mathrm{piss}-1\right) * \mathrm{~d}+\mathrm{luc} \_\mathrm{y}-\operatorname{deltah} * \mathrm{~h} \_\mathrm{p}$

$\% c \_i=w \_i * 1 \_i-\left(\left(1+r \_b i h\right) / p i s s-1\right) * b \_i h-\left(\left(1+r \_b i w\right) / p i s s-1\right) * b \_i w-$ $\operatorname{deltah} * \mathrm{~h} \_\mathrm{i}$ 
$\% \mathrm{c} \_\mathrm{e}=\mathrm{y} \_\mathrm{e} / \mathrm{x} \_\mathrm{ss}-\mathrm{w} \_\mathrm{p} * \mathrm{l} \_\mathrm{p}-\mathrm{w} \_\mathrm{i} * \mathrm{l} \_\mathrm{i}-\left(\left(1+\mathrm{r} \_\mathrm{be}\right) / \mathrm{piss}-1\right) * \mathrm{~b} \_\mathrm{e}-\operatorname{deltak}{ }^{*} \mathrm{k}$ - deltah*h_e

$\% \mathrm{~h} \_\mathrm{p}=\mathrm{jh} /\left((1-(1-\operatorname{deltah}) *\right.$ betap $\left.) * l a m \_p\right)$

$\% \mathrm{~h} \_\mathrm{i}=\mathrm{jh} /((1-(1-$ deltah $) *$ betai $) *$ lam_i $-(1-$ deltah $) *$ s_ih*mih*piss $)$

$\% \mathrm{~h} \_\mathrm{e}=\mathrm{jh} /\left(\left(1-(1-\text { deltah }){ }^{*} \text { betae }\right)^{*}\right.$ lam_e - $(1-\text { deltah })^{*} \mathrm{~s} \_\mathrm{e}^{*} \mathrm{me} \mathrm{e}^{*}$ piss $)$

$\%$ b_ih $=\left(1 /\left(1+r \_b i h\right)\right)^{*}$ mih $^{*}$ piss $^{*} \mathrm{q} \_\mathrm{h}^{*}(1-\operatorname{deltak}) * \mathrm{~h} \_\mathrm{i}$

$\%$ b_iw $=\left(1 /\left(1+\mathrm{r} \_ \text {biw }\right)\right)^{*}$ miw $^{*}$ piss $^{*} \mathrm{w} \_\mathrm{i}^{*} \mathrm{l} \_\mathrm{i}$

$\%$ b_e $=\left(1 /\left(1+r \_b e\right)\right)^{*} m e^{*} \operatorname{piss}^{*}\left(\mathrm{q} \_\mathrm{k}^{*}(1-\operatorname{deltak}) * \mathrm{k}-\mathrm{q} \_\mathrm{h} *(1-\operatorname{deltah}) * \mathrm{~h} \_\mathrm{e}\right)$

$\% \mathrm{~d}=\mathrm{b} \_$ih $+\mathrm{b} \_$iw $+\mathrm{b} \_$e $-\mathrm{k} \_\mathrm{b}$

$\% \mathrm{w} \_\mathrm{p}=\left(\operatorname{eps} \_\mathrm{l} /\left(\mathrm{eps} \_\mathrm{l}-1\right)\right) *\left(\mathrm{l} \_\mathrm{p} \wedge \mathrm{phi}\right) / \mathrm{lam} \_\mathrm{p}$

$\% \mathrm{w} \_\mathrm{i}=\left(\right.$ eps_l $\left./\left(\operatorname{eps\_ l}-1\right)\right) *\left(1 \_\mathrm{i} \wedge \mathrm{phi}\right) /\left(\operatorname{lam\_ i}+\mathrm{s} \_\mathrm{iw} \mathrm{w}^{*} \mathrm{miw}\right)$

$\% \mathrm{y} \_\mathrm{e}=(\mathrm{k} \wedge$ alphak $) *\left(\mathrm{l} \_\mathrm{p} \wedge(\mathrm{mu} * \text { alphal })\right)^{*}\left(\mathrm{l} \_\mathrm{i} \wedge((1-\mathrm{mu}) *\right.$ alphal $\left.)\right)$

$\%$ l_p $=\left(\mathrm{mu}^{*}\right.$ alphal $\left./ \mathrm{x} \_\mathrm{ss}\right) *\left(\mathrm{y} \_\mathrm{e} / \mathrm{w} \_\mathrm{p}\right)$

$\% \mathrm{l} \_\mathrm{i}=\left((1-\mathrm{mu}) * a l p h a l / \mathrm{x} \_\mathrm{ss}\right) *\left(\mathrm{y} \_\mathrm{e} / \mathrm{w} \_\mathrm{i}\right) \mathrm{OU} \mathrm{l} \_\mathrm{i}=((1-\mathrm{mu}) / \mathrm{mu}) * \mathrm{w} \_\mathrm{p} * \mathrm{l} \_\mathrm{p} / \mathrm{w} \_\mathrm{i}$

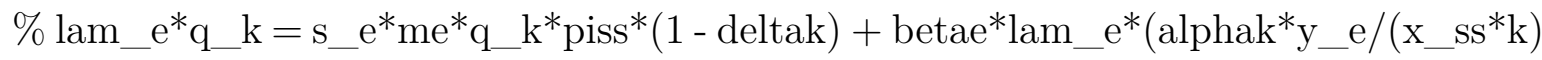
$\left.+\mathrm{q} \_\mathrm{k}^{*}(1-\operatorname{deltak})\right)$

$\% \mathrm{~h}=\mathrm{h} \_\mathrm{p}+\mathrm{h} \_\mathrm{i}+\mathrm{h} \_\mathrm{e}$

$\% \mathrm{y}=\mathrm{c} \_\mathrm{p}+\mathrm{c} \_\mathrm{i}+\mathrm{c} \_\mathrm{e}+\operatorname{deltah}^{*} \mathrm{~h}+\operatorname{deltak}^{*} \mathrm{k}$

$\%$ luc_y $=\left(1-1 / \mathrm{x} \_\mathrm{ss}\right) * \mathrm{y}$

$\% \mathrm{k} \_\mathrm{b}=(1 /(\operatorname{piss}-1+\operatorname{deltakb}))^{*}\left(\mathrm{r} \_\mathrm{bih} * \mathrm{~b} \_\mathrm{ih}+\mathrm{r} \_\right.$biw ${ }^{*} \mathrm{~b} \_$iw $+\mathrm{r} \_\mathrm{be} \mathrm{w}^{*} \mathrm{~b} \_\mathrm{e}-$ r_d $\left.{ }^{*} d\right)$ OU k_b $=\left(b \_i h+b \_i w+b \_e\right)^{*} v i$

\% Dicionário:

$\% \mathrm{x}(1):$ lam_p

$\% \mathrm{x}(2):$ lam_i

$\% \mathrm{x}(3)$ : lam_e

$\% \mathrm{x}(4): \mathrm{s} \_$ih

$\% \mathrm{x}(5): \mathrm{s} \_\mathrm{iw}$

$\% \mathrm{x}(6): \mathrm{s} \_\mathrm{e}$

$\% \mathrm{x}(7): \mathrm{c} \_\mathrm{p}$

$\% \times(8): c \_i$

$\% \times(9):$ c_e 
$\% \mathrm{x}(10): \mathrm{h} \_\mathrm{p}$

$\% \mathrm{x}(11): \mathrm{h} \_\mathrm{i}$

$\% \mathrm{x}(12): \mathrm{h} \_\mathrm{e}$

$\% \mathrm{x}(13): \mathrm{b} \_$ih

$\% x(14):$ b_iw

$\% \mathrm{x}(15): \mathrm{b} \_\mathrm{e}$

$\% \mathrm{x}(16): \mathrm{w} \_\mathrm{p}$

$\% \mathrm{x}(17): \mathrm{w} \_\mathrm{i}$

$\% \mathrm{x}(18): \mathrm{y} \_\mathrm{e}$

$\% \mathrm{x}(19): \mathrm{y}$

$\% \mathrm{x}(20): \mathrm{k}$

$\% \mathrm{x}(21): \mathrm{l} \_\mathrm{p}$

$\% \mathrm{x}(22): 1 \_\mathrm{i}$

$\% \mathrm{x}(23): \mathrm{k} \_\mathrm{b}$

function $\mathrm{F}=$ tese_Ecof $(\mathrm{x})$

global betap betai betae q_k q_h piss me mih miw deltak deltah deltakb jh eps_l phi eps_y mu alphal alphak eps_d eps_biw eps_bih eps_be x_ss vi;

$$
\begin{aligned}
& \text { r_d }=\text { piss / betap - } 1 \text {; } \\
& \mathrm{r} \_ \text {pol }=\left((\text { eps_d }-1) / e p s \_\mathrm{d}\right){ }^{*} \mathrm{r} \_\mathrm{d} \text {; } \\
& \text { r_biw }=(\text { eps_biw } /(\text { eps_biw }-1))^{*} \text { r_pol; } \\
& \text { r_bih }=(\text { eps_bih } /(\text { eps_bih }-1))^{*} \mathrm{r} \_ \text {pol; } \\
& \text { r_be }=(\text { eps_be } /(\text { eps_be }-1))^{*} \text { r_pol; } \\
& \mathrm{x} \_ \text {ss }=\text { eps_y } /(\text { eps_y }-1) \text {; } \\
& \mathrm{f} 1=-\mathrm{x}(1)+1 / \mathrm{x}(7) ; \\
& \mathrm{f} 2=-\mathrm{x}(2)+1 / \mathrm{x}(8) \text {; } \\
& \mathrm{f} 3=-\mathrm{x}(3)+1 / \mathrm{x}(9) \text {; } \\
& \mathrm{f} 4=-\mathrm{x}(4)+\left(1 /\left(1+\mathrm{r} \_ \text {bih }\right)-\text { betai } / \text { piss }\right) * \mathrm{x}(2) \text {; } \\
& \mathrm{f} 5=-\mathrm{x}(5)+\left(1 /\left(1+\mathrm{r} \_ \text {biw }\right)-\text { betai } / \text { piss }\right) * \mathrm{x}(2) \text {; } \\
& \mathrm{f} 6=-\mathrm{x}(6)+\left(1 /\left(1+\mathrm{r} \_ \text {be }\right)-\text { betae } / \text { piss }\right) * x(3) ; \\
& \mathrm{f} 7=-\mathrm{x}(7)+\mathrm{x}(16) * \mathrm{x}(21)+\left(\left(1+\mathrm{r} \_\mathrm{d}\right) / \mathrm{piss}-1\right) *(\mathrm{x}(13)+\mathrm{x}(14)+\mathrm{x}(15)-\mathrm{x}(23))
\end{aligned}
$$


$+\left(1-1 / \mathrm{x} \_\right.$ss $) * \mathrm{x}(19)-\operatorname{deltah}^{*} \mathrm{x}(10)$

$\mathrm{f} 8=-\mathrm{x}(8)+\mathrm{x}(17) * \mathrm{x}(22)-\left(\left(1+\mathrm{r} \_\right.\right.$bih $\left.) / \mathrm{piss}-1\right) * \mathrm{x}(13)-\left(\left(1+\mathrm{r} \_\right.\right.$biw $) / \mathrm{piss}-$ $1)^{*} \mathrm{x}(14)-$ deltah$^{*} \mathrm{x}(11)$;

$$
\mathrm{f} 9=-\mathrm{x}(9)+\mathrm{x}(18) / \mathrm{x} \_\mathrm{ss}-\mathrm{x}(16) * \mathrm{x}(21)-\mathrm{x}(17) * \mathrm{x}(22)-\left(\left(1+\mathrm{r} \_\mathrm{be}\right) / \mathrm{piss}-1\right) * \mathrm{x}(15)
$$

- $\operatorname{deltak}^{*} \mathrm{x}(20)-\operatorname{deltah}^{*} \mathrm{x}(12)$;

$$
\begin{aligned}
& \mathrm{f} 10=-\mathrm{x}(10)+\mathrm{jh} /\left(\left(1-(1-\operatorname{deltah})^{*} \text { betap }\right)^{*} \mathrm{x}(1)\right) ; \\
& \mathrm{f} 11=-\mathrm{x}(11)+\mathrm{jh} /\left((1-(1-\text { deltah }) * \text { betai }) * \mathrm{x}(2)-(1-\text { deltah }){ }^{*} \mathrm{x}(4){ }^{*} \mathrm{mih}^{*} \text { piss }\right) \text {; } \\
& \mathrm{f} 12=-\mathrm{x}(12)+\mathrm{jh} /\left((1-(1-\text { deltah }) * \text { betae }) * \mathrm{x}(3)-(1-\text { deltah }) * \mathrm{x}(6)^{*} \mathrm{me}^{*} \text { piss }\right) ; \\
& \mathrm{f13}=-\mathrm{x}(13)+\left(1 /\left(1+\mathrm{r} \_ \text {bih }\right)\right)^{*} \text { mih }^{*} \text { piss }^{*} \mathrm{q} \_\mathrm{h}^{*}(1-\operatorname{deltah}) * \mathrm{x}(11) ; \\
& \mathrm{f} 14=-\mathrm{x}(14)+\left(1 /\left(1+\mathrm{r} \_ \text {biw }\right)\right)^{*} \text { miw }^{*} \text { piss }^{*} \mathrm{x}(17)^{*} \mathrm{x}(22) ; \\
& \mathrm{f} 15=-\mathrm{x}(15)+\left(1 /\left(1+\mathrm{r} \_b e\right)\right)^{*} \mathrm{me}^{*} \operatorname{piss}^{*}\left(\mathrm{q} \_\mathrm{k}^{*}(1-\operatorname{deltak})^{*} \mathrm{x}(20)-\mathrm{q} \_\mathrm{h} *(1-\right.
\end{aligned}
$$
deltah)*x(12));

$$
\begin{aligned}
& \mathrm{f} 16=-\mathrm{x}(16)+(\text { eps_l } /(\text { eps_l }-1))^{*}\left(\mathrm{x}(21)^{\wedge} \mathrm{phi}\right) / \mathrm{x}(1) \\
& \mathrm{f} 17=-\mathrm{x}(17)+(\text { eps_l } /(\text { eps_l }-1))^{*}(\mathrm{x}(22) \wedge \text { phi }) /\left(\mathrm{x}(2)+\mathrm{x}(5)^{*} \mathrm{miw}\right) ; \\
& \mathrm{f} 18=-\mathrm{x}(18)+\left(\mathrm{x}(20)^{\wedge} \text { alphak }\right)^{*}\left(\mathrm{x}(21)^{\wedge}\left(\mathrm{mu}^{*} \text { alphal }\right)\right)^{*}\left(\mathrm{x}(22)^{\wedge}\left((1-\mathrm{mu})^{*} \text { alphal }\right)\right) \\
& \mathrm{f} 19=-\mathrm{x}(19)+\mathrm{x}(7)+\mathrm{x}(8)+\mathrm{x}(9)+\operatorname{deltah}^{*}(\mathrm{x}(10)+\mathrm{x}(11)+\mathrm{x}(12))+\text { del- }
\end{aligned}
$$
$\operatorname{tak}^{*} \mathrm{x}(20)$;

$\mathrm{f} 20=-\mathrm{x}(3) * \mathrm{q} \_\mathrm{k}+\mathrm{x}(6) * \mathrm{me}^{*} \mathrm{q} \_\mathrm{k}^{*} \mathrm{piss}^{*}(1-\operatorname{deltak})+$ betae $^{*} \mathrm{x}(3) *\left(\operatorname{alphak}^{*} \mathrm{x}(18) /\left(\mathrm{x} \_\mathrm{ss}{ }^{*} \mathrm{x}(20)\right)\right.$ $\left.+\mathrm{q} \_\mathrm{k}^{*}(1-\operatorname{deltak})\right)$;

$$
\begin{aligned}
& \mathrm{f} 21=-\mathrm{x}(21)+\left(\mathrm{mu}^{*} \text { alphal } / \mathrm{x} \_\mathrm{ss}\right) *(\mathrm{x}(18) / \mathrm{x}(16)) ; \\
& \mathrm{f} 22=-\mathrm{x}(22)+\left((1-\mathrm{mu}) * \text { alphal } / \mathrm{x} \_\mathrm{ss}\right) *(\mathrm{x}(18) / \mathrm{x}(17)) ; \\
& \% \mathrm{f} 22=-\mathrm{x}(22)+((1-\mathrm{mu}) / \mathrm{mu}){ }^{*} \mathrm{x}(16) * \mathrm{x}(21) / \mathrm{x}(17) ; \\
& \% \mathrm{f} 23=-\mathrm{x}(23)+(1 /(\text { piss }-1+\text { deltakb })) *\left(\mathrm{r} \_ \text {bih }{ }^{*} \mathrm{x}(13)+\mathrm{r} \_ \text {biw }{ }^{*} \mathrm{x}(14)+\mathrm{r} \_ \text {be }{ }^{*} \mathrm{x}(15)\right. \\
& \left.-\mathrm{r} \_\mathrm{d}^{*}(\mathrm{x}(13)+\mathrm{x}(14)+\mathrm{x}(15)-\mathrm{x}(23))\right) \text {; } \\
& \mathrm{f} 23=-\mathrm{x}(23)+(\mathrm{x}(13)+\mathrm{x}(14)+\mathrm{x}(15)) * \mathrm{vi} ; \\
& \mathrm{F}=[\mathrm{f} 1 ; \mathrm{f} 2 ; \mathrm{f} 3 ; \mathrm{f} 4 ; \mathrm{f} 5 ; \mathrm{f} 6 ; \mathrm{f} 7 ; \mathrm{f} 8 ; \mathrm{f} 9 ; \mathrm{f10} \text { f11; f12; f13; f14; f15; f16; f17; f18; f19; f20; }
\end{aligned}
$$
f21; f22; f23];

end

\section{A.1.2 solve}

clear all;

clc; 
global betap betai betae q_k q_h piss me mih miw deltak deltah deltakb jh eps_l phi eps_y mu alphal alphak eps_d eps_biw eps_bih eps_be x_ss vi;

$$
\begin{aligned}
& \text { betap }=0.989 ; \\
& \text { betai }=0.96 \text {; } \\
& \text { betae }=\text { betai; } \\
& \text { q_ } \mathrm{k}=1 \text {; } \\
& \mathrm{q} \_\mathrm{h}=1 \text {; } \\
& \text { x_ss }=\operatorname{epsy} /(\operatorname{epsy}-1) \text {; } \\
& \text { piss }=1 \text {; } \\
& \mathrm{me}=0.007 ; \\
& \operatorname{mih}=0.06 \text {; } \\
& \operatorname{miw}=0.1 ; \\
& \text { deltak }=0.035 ; \\
& \text { deltah }=0.025 ; \\
& \text { deltakb }=0.095 ; \\
& \mathrm{jh}=0.2 \text {; } \\
& \text { eps_l }=3 \text {; } \\
& \text { phi }=1 \text {; } \\
& \text { eps_y }=11 \text {; } \\
& \mathrm{mu}=0.8 ; \\
& \text { alphal }=0.6 \text {; } \\
& \text { alphak = } 1 \text { - alphal; } \\
& \text { eps_d }=-2.62 \text {; } \\
& \text { eps_biw }=4.5 \text {; } \\
& \text { eps_bih }=5.36 \text {; } \\
& \text { eps_be }=2.73 \text {; } \\
& \mathrm{vi}=0.17 \text {; } \\
& \mathrm{x} 0=[1 ; 1 ; 1 ; 1 ; 1 ; 1 ; 1 ; 1 ; 1 ; 1 ; 1 ; 1 ; 1 ; 1 ; 1 ; 1 ; 1 ; 1 ; 1 ; 1 ; 1 ; 1 ; 1] \text {; } \\
& \text { options }=\text { optimset('MaxFunEvals',50000000,'MaxIter',50000000); } \\
& \text { options. TolFun=1e-8; }
\end{aligned}
$$


options.Display = 'iter';

$[\mathrm{x}, \mathrm{fval}$, exitflag $]=$ fsolve(@tese_Ecof,x0,options);

if (exitflag $>0)$

$\operatorname{disp}\left(\left[{ }^{\prime} \mathrm{OK}\right]\right)$

else

$\operatorname{disp}\left(\left[{ }^{\prime} N o t \mathrm{OK}^{\prime}\right]\right)$

end;

\% Número de variáveis do sistema:

$\mathrm{N}=23$

for $\mathrm{n}=1: \mathrm{N}$

if $(\operatorname{imag}(x(n))>0.0001)$

$\operatorname{disp}([$ 'A raiz ..., num2str(n) , ... do sistema é imaginária!'] $)$

else

$\mathrm{x}(\mathrm{n})=\operatorname{real}(\mathrm{x}(\mathrm{n})) ;$

end;

end;

r_d $=$ piss/betap - 1;

r_pol $=\left((\text { eps_d - 1) } / \text { eps_d })^{*} \mathrm{r} \_\mathrm{d}\right.$;

r_biw $=(\text { eps_biw } /(\text { eps_biw }-1))^{*}$ r_pol;

r_bih $=(\text { eps_bih } /(\text { eps_bih }-1))^{*}$ r_pol;

r_be $=\left(\right.$ eps_be $/($ eps_be - 1) $){ }^{*}$ r_pol;

$\operatorname{disp}($ ' ')

$\mathrm{PIBo}=\mathrm{x}(19) ;$

$\operatorname{disp}\left(\left[\right.\right.$ 'Produto otica da oferta $={ }^{\prime}$ num2str(PIBo) $\left.]\right)$

$\operatorname{disp}('$,

PIBd $=\mathrm{x}(9)+\mathrm{x}(8)+\mathrm{x}(7)+\operatorname{deltah}^{*}(\mathrm{x}(10)+\mathrm{x}(11)+\mathrm{x}(12))+\operatorname{deltak}^{*} \mathrm{x}(20) ;$

$\operatorname{disp}\left(\left[\right.\right.$ Produto otica da demanda $\left.\left.={ }^{\prime} \operatorname{num} 2 \operatorname{str}(\mathrm{PIBd})\right]\right)$

$\operatorname{disp}('$ ')

$\mathrm{C}=\mathrm{x}(9)+\mathrm{x}(8)+\mathrm{x}(7) ;$

$\operatorname{disp}\left(\left[{ }^{\prime}\right.\right.$ Consumo agregado $=$ ' num2str(C)] $)$ 


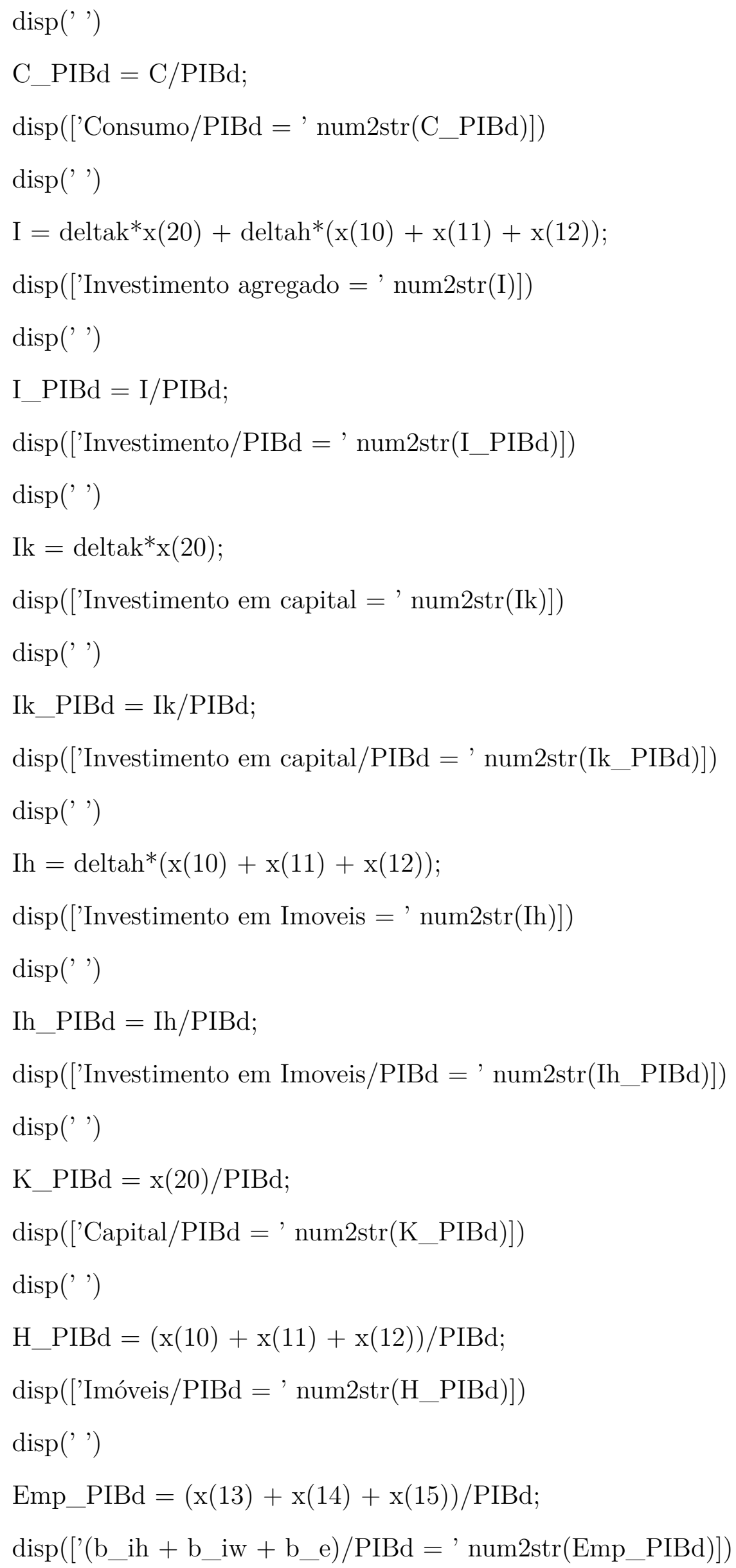


$\operatorname{disp}\left({ }^{\prime},\right)$

$\mathrm{Kb} \_\mathrm{B}=\mathrm{x}(23) /(\mathrm{x}(13)+\mathrm{x}(14)+\mathrm{x}(15)) ;$

$\operatorname{disp}\left(\left[' \mathrm{~K} \_\mathrm{b} / \mathrm{B}=\right.\right.$ ' $\left.\left.\operatorname{num} 2 \operatorname{str}\left(\mathrm{Kb} \_\mathrm{B}\right)\right]\right)$

$\operatorname{disp}('$ ')

Dep_PIBd $=(\mathrm{x}(13)+\mathrm{x}(14)+\mathrm{x}(15)-\mathrm{x}(23)) / \mathrm{PIBd}$;

$\operatorname{disp}([$ d/PIBd =' num2str(Dep_PIBd)]

$\operatorname{disp}\left({ }^{\prime}\right.$ ')

$\operatorname{disp}\left(\left[{ }^{\prime} b \_i h /\left(b \_i h+b \_i w+b \_e\right)(\%)\right.\right.$ ' $\left.\left.^{\prime} \operatorname{num} 2 \operatorname{str}((x(13) /(x(13)+x(14)+x(15))) * 100)\right]\right)$;

$\operatorname{disp}\left({ }^{\prime},\right)$

$\operatorname{disp}\left(\left[\right.\right.$ 'b_iw $/\left(\mathrm{b} \_\mathrm{ih}+\mathrm{b} \_\mathrm{iw}+\mathrm{b}_{e}\right)(\%):^{\prime}, \operatorname{num} 2 \operatorname{str}((x(14) /(x(13)+x(14)+x(15))) *$ 100)]);

$\operatorname{disp}\left({ }^{\prime},\right)$

$\operatorname{disp}\left(\left[{ }^{\prime} b \_e /\left(b \_i h+b \_i w+b \_e\right)(\%):^{\prime}, \operatorname{num} 2 \operatorname{str}\left((x(15) /(x(13)+x(14)+x(15)))^{*} 100\right)\right]\right)$;

$\operatorname{disp}('$,

$\operatorname{disp}\left(\left[{ }^{\prime} b \_i h /\left(b \_i h+b \_i w\right)(\%):{ }^{\prime}, \operatorname{num} 2 \operatorname{str}\left((x(13) /(x(13)+x(14)))^{*} 100\right)\right]\right)$;

$\operatorname{disp}('$,

$\operatorname{disp}\left(\left[' b \_i w /\left(b \_i h+b \_i w\right)(\%):\right.\right.$ ',num $\left.\left.2 \operatorname{str}\left((x(14) /(x(13)+x(14)))^{*} 100\right)\right]\right)$;

$\operatorname{disp}('$,

Razao_W $=\mathrm{x}(16) * \mathrm{x}(21) /(\mathrm{x}(17) * \mathrm{x}(22)) ;$

$\operatorname{disp}\left(\left[{ }^{\prime}\right.\right.$ __p ${ }^{*}$ l_p/w_i*l_i $=(1-\mathrm{ni}) / \mathrm{ni}$ :' $\left.\left.\operatorname{num} 2 \operatorname{str}\left(\operatorname{Razao}_{W}\right)\right]\right)$

$\operatorname{disp}('$,

r_d_anual $=\left(\left(1+\mathrm{r} \_\mathrm{d}\right) \wedge 4-1\right)$;

disp(['r_d (\%annual): ',num2str(r_d_anual)]);

$\operatorname{disp}\left({ }^{\prime}\right.$ ')

r_pol_anual $=\left(\left(1+\mathrm{r} \_\right.\right.$pol $\left.) \wedge 4-1\right)$;

$\operatorname{disp}([$ 'r_pol (\%annual): ',num2str(r_pol_anual)]);

$\operatorname{disp}('$,

r_bih_anual $=\left(\left(1+\mathrm{r} \_b i h\right) \wedge 4-1\right)$;

$\operatorname{disp}([$ 'r_bih (\%annual): ',num2str(r_bih_anual)]);

$\operatorname{disp}('$, 
r_biw_anual $=\left((1+\text { r_biw })^{\wedge} 4-1\right)$;

disp(['r_biw (\%annual): ',num2str(r_biw_anual)]);

$\operatorname{disp}('$,

r_be_anual $=((1+$ r_be $) \wedge 4-1)$;

$\operatorname{disp}([$ 'r_be (\%annual): ',num2str(r_be_anual)]);

\section{A.2 Economia Aberta}

\section{A.2.1 Função}

\% Universidade de Brasília

\% Tese - Modelo Geralli et all para uma Economia Aberta

\% Orientador: Joaquim P de Andrade

\% Doutorando: Márcio Francisco da Silva

\% Equações que determinam o SS do modelo:

$\% \mathrm{q} \_\mathrm{k}=1$

$\% \mathrm{q} h=1$

$\% \mathrm{x} \_\mathrm{ss}=$ eps_y $/($ eps_y -1$)$

$\% \mathrm{r} \_\mathrm{d}=\operatorname{piss} /$ betap -1

$\% \mathrm{r} \_$pol $=\left((\right.$eps_d -1$\left.) / e p s \_\mathrm{d}\right) * \mathrm{r} \_\mathrm{d}$

$\%$ r_biw $=($ eps_biw $/($ eps_biw -1$)) *$ r_pol

$\%$ r_bih $=\left(\right.$ eps_bih $/($ eps_bih - 1) $){ }^{*}$ r_pol

$\%$ r_be $=(\text { eps_be } /(\text { eps_be }-1))^{*}$ r_pol

$\%$ lam_p $=1 / \mathrm{c} \_\mathrm{p}$

$\%$ lam_i $=1 / \mathrm{c} \_\mathrm{i}$

$\%$ lam_e $=1 / \mathrm{c} \_\mathrm{e}$

$\%$ s_ih $=\left(1 /\left(1+r \_b i h\right)-\right.$ betai $\left./ p i s s\right) *$ lam_i

$\%$ s_iw $=\left(1 /\left(1+\mathrm{r} \_\right.\right.$biw $)-$betai $/$piss $) *$ lam_i

$\%$ s_e $=(1 /(1+$ r_be $)-$ betae $/$ piss $) *$ lam_e

$\% \mathrm{c} \_\mathrm{p}=\mathrm{w} \_\mathrm{p} * \mathrm{l} \_\mathrm{p}+\left(\left(1+\mathrm{r} \_\mathrm{d}\right) / \mathrm{piss}-1\right) * \mathrm{~d}+\mathrm{luc} \_\mathrm{y}-\operatorname{deltah} * \mathrm{~h} \_\mathrm{p}$

$\% c \_i=w \_i * 1 \_i-\left(\left(1+r \_b i h\right) / p i s s-1\right) * b \_i h-\left(\left(1+r \_b i w\right) / p i s s-1\right) * b \_i w-$ deltah*h_i 
$\% \mathrm{c} \_\mathrm{e}=\mathrm{y} \_\mathrm{e} / \mathrm{x} \_\mathrm{ss}-\mathrm{w} \_\mathrm{p}^{*} \mathrm{l} \_\mathrm{p}-\mathrm{w} \_\mathrm{i}^{*} \mathrm{l} \_\mathrm{i}-\mathrm{er}^{*} \mathrm{pQ} \mathrm{Q}^{*} \mathrm{Q}-\left(\left(1+\mathrm{r} \_\mathrm{be}\right) / \mathrm{piss}-1\right)^{*} \mathrm{~b} \_\mathrm{e}$ - deltak*k - deltah*h_e

$\% \mathrm{~h} \_\mathrm{p}=\mathrm{jh} /\left((1-(1-\operatorname{deltah}) * \text { betap })^{*}\right.$ lam_p $)$

$\% \mathrm{~h} \_\mathrm{i}=\mathrm{jh} /((1-(1-$ deltah $) *$ betai $) *$ lam_i $-(1-$ deltah $) *$ s_ih $*$ mih $*$ piss $)$

$\% \mathrm{~h} \_\mathrm{e}=\mathrm{jh} /\left(\left(1-(1-\text { deltah }){ }^{*} \text { betae }\right)^{*} \mathrm{lam} \_\mathrm{e}-(1-\operatorname{deltah})^{*} \mathrm{~s} \_\mathrm{e}^{*} \mathrm{me}^{*}\right.$ piss $)$

$\%$ b_ih $=(1 /(1+\text { r_bih }))^{*} \operatorname{mih}^{*} \mathrm{qh}^{*}(1-\operatorname{deltah}) * \mathrm{~h} \_$i*piss

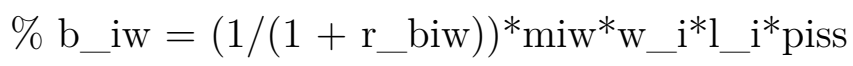

$\% \mathrm{~b} \_\mathrm{e}=\left(1 /\left(1+\mathrm{r} \_\mathrm{be}\right)\right)^{*} \mathrm{me}^{*}\left(\mathrm{q} \_\mathrm{h} *(1-\operatorname{deltah}) * \mathrm{~h} \_\mathrm{e}^{*} \mathrm{piss}+\mathrm{q} \_\mathrm{k}^{*}(1-\operatorname{deltak}) * \mathrm{k}^{*}\right.$ piss $)$

$\% \mathrm{~d}=\mathrm{b} \_\mathrm{ih}+\mathrm{b} \_\mathrm{iw}+\mathrm{b} \_\mathrm{e}-\mathrm{er}{ }^{*} \mathrm{~B} \_$star $-\mathrm{k} \_\mathrm{b}$

$\% \mathrm{w} \_\mathrm{p}=\left(\operatorname{eps\_ l} /\left(\operatorname{eps} \_\mathrm{l}-1\right)\right) *\left(\mathrm{l} \_\mathrm{p} \wedge \mathrm{phi}\right) / \mathrm{lam \_ p}$

$\% \mathrm{w} \_\mathrm{i}=\left(\text { eps_l } /\left(\operatorname{eps\_ l}-1\right)\right)^{*}\left(\mathrm{l} \_\mathrm{i} \wedge \mathrm{phi}\right) /\left(\mathrm{lam} \_\mathrm{i}+\mathrm{s} \_\mathrm{iw} * \mathrm{miw}\right)$

$\% \mathrm{y} \_\mathrm{e}=(\mathrm{k} \wedge$ alphak $) *\left(1 \_\mathrm{p} \wedge(\mathrm{mu} * \mathrm{alphal})\right)^{*}\left(1 \_\mathrm{i} \wedge((1-\mathrm{mu}) * \text { alphal })\right)^{*}\left(\mathrm{Q}^{\wedge}(1-\right.$ alphal - alphak))

$\%$ l_p $=\left(\mathrm{mu}^{*}\right.$ alphal $\left./ \mathrm{x} \_\mathrm{ss}\right) *\left(\mathrm{y} \_\mathrm{e} / \mathrm{w} \_\mathrm{p}\right)$

$\%$ l_i $=\left((1-\mathrm{mu}) * \operatorname{alphal} / \mathrm{x} \_ \text {ss }\right)^{*}\left(\mathrm{y} \_\mathrm{e} / \mathrm{w} \_\mathrm{i}\right)$

$\% \mathrm{Q}=\left((1\right.$ - alphak - alphal $\left.) / \mathrm{x} \_\mathrm{ss}\right) *\left(\mathrm{y} \_\mathrm{e} /(\mathrm{er} * \mathrm{pQ})\right)$

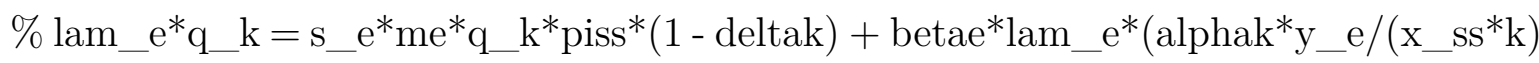
$\left.+\mathrm{q} \_\mathrm{k}^{*}(1-\operatorname{deltak})\right)$

$\%$ premium $=\exp \left(-\right.$ zeta*er*B_star $\left./ \mathrm{k} \_\mathrm{b}\right)$

$\%$ premium* $($ piss $/$ piss_star $) *\left(1-\right.$ zeta*er* $^{*} \_$star $\left./ \mathrm{k} \_\mathrm{b}\right)=\left(1+\mathrm{r} \_\right.$pol $) /\left(1+\mathrm{R} \_\right.$star $)$

$\% \mathrm{~h}=\mathrm{h} \_\mathrm{p}+\mathrm{h} \_\mathrm{i}+\mathrm{h} \_\mathrm{e}$

$\% \mathrm{y}=\mathrm{c} \_\mathrm{p}+\mathrm{c} \_\mathrm{i}+\mathrm{c} \_\mathrm{e}+\operatorname{deltah}^{*} \mathrm{~h}+\operatorname{deltak}^{*} \mathrm{k}+\mathrm{y} \_\exp$

$\%$ y_exp - er*pQ*Q $-\left(1+\left(1+\mathrm{R} \_ \text {star }\right)^{*} \text { premium/piss_star }-1 / \text { piss_star }\right)^{*}$ er*B_star $=0$

$\%$ luc_y $=\left(1-1 / \mathrm{x} \_\mathrm{ss}\right) * \mathrm{y}$

$\% \mathrm{k} \_\mathrm{b}=(1 /(\operatorname{piss}-1+\operatorname{deltakb}))^{*}\left(\mathrm{r} \_\mathrm{bih} * \mathrm{~b} \_\mathrm{ih}+\mathrm{r} \_\mathrm{biw} * \mathrm{~b} \_\mathrm{iw}+\mathrm{r} \_\mathrm{be} \mathrm{e}^{*} \mathrm{~b} \_\mathrm{e}-\right.$ $\mathrm{r} \_\mathrm{d}^{*} \mathrm{~d}+\left(1-\left(1+\mathrm{R} \_ \text {star }\right)^{*} \text { premium/piss_star }\right)^{*}$ er*B_star $)$

$\%$ y_exp $=\left(\left(1 /\left(e^{*}{ }^{*} \_ \text {ss }\right)\right)^{\wedge}-\mathrm{tau}\right)^{*} \mathrm{y} \_$star

\% Dicionário:

$\% \mathrm{x}(1):$ lam_p

$\% \mathrm{x}(2):$ lam_i 
$\% \mathrm{x}(3)$ : lam_e

$\% \mathrm{x}(4):$ s_ih

$\% \mathrm{x}(5): \mathrm{s} \_\mathrm{iw}$

$\% \mathrm{x}(6): \mathrm{s} \_\mathrm{e}$

$\%$ x(7): c_p

$\% \times(8): c \_i$

$\% \times(9):$ c_e

$\% \mathrm{x}(10): \mathrm{h} \_\mathrm{p}$

$\% \mathrm{x}(11): \mathrm{h} \_\mathrm{i}$

$\% \mathrm{x}(12): \mathrm{h} \_\mathrm{e}$

$\% \mathrm{x}(13)$ : b_ih

$\% \mathrm{x}(14): \mathrm{b} \_$iw

$\% \mathrm{x}(15): \mathrm{b} \_\mathrm{e}$

$\% \mathrm{x}(16): \mathrm{d}$

$\% \mathrm{x}(17): \mathrm{w} \_\mathrm{p}$

$\% \mathrm{x}(18): \mathrm{w} \_\mathrm{i}$

$\% \mathrm{x}(19): \mathrm{y} \_\mathrm{e}$

$\% \mathrm{x}(20): \mathrm{y}$

$\% \mathrm{x}(21): \mathrm{k}$

$\% \mathrm{x}(22): \mathrm{l} \_\mathrm{p}$

$\% \mathrm{x}(23): 1 \_\mathrm{i}$

$\% \mathrm{x}(24): \mathrm{Q}$

$\% \mathrm{x}(25): \mathrm{er}$

$\% \mathrm{x}(26):$ B_star

$\% \mathrm{x}(27)$ : premium

$\% \mathrm{x}(28): \mathrm{k} \_\mathrm{b}$

$\% \mathrm{x}(29):$ y_exp

function $\mathrm{F}=$ tese2014_rotemberg5(x)

global betap betai betae q_k q_h piss piss_star me mih miw deltak deltah deltakb jh eps_l phi eps_y mu alphal alphak eps_d eps_biw eps_bih eps_be zeta x_ss R_star 
pQ y_star tau vi share;

$$
\begin{aligned}
& \text { r_d }=\text { piss/betap - 1; } \\
& \text { r_pol }=\left((\text { eps_d - 1) } / \text { eps_d })^{*} \mathrm{r} \_\mathrm{d}\right. \text {; } \\
& \text { r_biw }=(\text { eps_biw } /(\text { eps_biw }-1))^{*} \text { r_pol; } \\
& \text { r_bih }=\left(\text { eps_bih } /(\text { eps_bih - 1) }){ }^{*}\right. \text { __pol; } \\
& \text { r_be }=(\text { eps_be } /(\text { eps_be }-1)) * \text { r_pol; } \\
& \mathrm{x} \_\mathrm{ss}=\mathrm{eps} \_\mathrm{y} /(\text { eps_y }-1) \text {; } \\
& \mathrm{f} 1=-\mathrm{x}(1)+1 / \mathrm{x}(7) ; \\
& \mathrm{f} 2=-\mathrm{x}(2)+1 / \mathrm{x}(8) \text {; } \\
& \mathrm{f} 3=-\mathrm{x}(3)+1 / \mathrm{x}(9) \text {; } \\
& \mathrm{f} 4=-\mathrm{x}(4)+\left(1 /\left(1+\mathrm{r} \_ \text {bih }\right)-\text { betai } / \text { piss }\right) * \mathrm{x}(2) \text {; } \\
& \mathrm{f} 5=-\mathrm{x}(5)+(1 /(1+\text { r_biw })-\text { betai } / \text { piss }) * \mathrm{x}(2) \text {; } \\
& \mathrm{f} 6=-\mathrm{x}(6)+\left(1 /\left(1+\mathrm{r} \_ \text {be }\right)-\text { betae } / \text { piss }\right) * \mathrm{x}(3) ; \\
& \mathrm{f} 7=-\mathrm{x}(7)+\mathrm{x}(17)^{*} \mathrm{x}(22)+\left(\left(1+\mathrm{r} \_\mathrm{d}\right) / \text { piss - } 1\right)^{*} \mathrm{x}(16)+\left(1-\left(1 / \mathrm{x} \_\mathrm{ss}\right)\right)^{*} \mathrm{x}(20)-
\end{aligned}
$$
$\operatorname{deltah}^{*} \mathrm{x}(10)$;

$\mathrm{f} 8=-\mathrm{x}(8)+\mathrm{x}(18) * \mathrm{x}(23)-\left(\left(1+\mathrm{r} \_\right.\right.$bih $\left.) / \mathrm{piss}-1\right) * \mathrm{x}(13)-\left(\left(1+\mathrm{r} \_\right.\right.$biw $) / \mathrm{piss}-$ $1) * x(14)-\operatorname{deltah}^{*} \mathrm{x}(11)$

$$
\mathrm{f} 9=-\mathrm{x}(9)+\mathrm{x}(19) / \mathrm{x} \_\mathrm{ss}-\mathrm{x}(17) * \mathrm{x}(22)-\mathrm{x}(18) * \mathrm{x}(23)-\mathrm{x}(25) * \mathrm{pQ}^{*} \mathrm{x}(24)-((1+
$$
r_be)/piss - 1)*x(15) - deltak*x(21) - deltah*x(12);

$$
\begin{aligned}
& \mathrm{f} 10=-\mathrm{x}(10)+\mathrm{jh} /\left(\left(1-(1-\text { deltah })^{*} \text { betap }\right) * \mathrm{x}(1)\right) ; \\
& \mathrm{f} 11=-\mathrm{x}(11)+\mathrm{jh} /\left(\left(1-(1-\text { deltah })^{*} \text { betai }\right)^{*} \mathrm{x}(2)-(1-\text { deltah })^{*} \mathrm{x}(4)^{*} \mathrm{mih}^{*} \text { piss }\right) ; \\
& \mathrm{f} 12=-\mathrm{x}(12)+\mathrm{jh} /\left((1-(1-\text { deltah }) * \text { betae }) * \mathrm{x}(3)-(1-\text { deltah }) * \mathrm{x}(6)^{*} \mathrm{me}^{*} \text { piss }\right) ; \\
& \mathrm{f} 13=-\mathrm{x}(13)+\left(1 /\left(1+\mathrm{r} \_ \text {bih }\right)\right)^{*} \mathrm{mih}^{*} \text { piss }^{*}(1-\operatorname{deltah}) * \mathrm{x}(11) ; \\
& \mathrm{f} 14=-\mathrm{x}(14)+\left(1 /\left(1+\mathrm{r} \_ \text {biw }\right)\right)^{*} \text { miw }^{*} \text { piss }^{*} \mathrm{x}(18) * \mathrm{x}(23) ; \\
& \mathrm{f} 15=-\mathrm{x}(15)+\left(1 /\left(1+\mathrm{r} \_b e\right)\right)^{*} \mathrm{me}^{*} \operatorname{piss}^{*}\left(\mathrm{q} \_\mathrm{k}^{*}(1-\operatorname{deltak}) * \mathrm{x}(21)+\mathrm{q} \_\mathrm{h} *(1-\right.
\end{aligned}
$$
deltah) $\left.{ }^{*} \mathrm{x}(12)\right)$;

$$
\begin{aligned}
& \mathrm{f} 16=-\mathrm{x}(16)+\mathrm{x}(13)+\mathrm{x}(14)+\mathrm{x}(15)-\mathrm{x}(25) * \mathrm{x}(26)-\mathrm{x}(28) ; \\
& \mathrm{f} 17=-\mathrm{x}(17)+(\text { eps_l } /(\text { eps_l }-1))^{*}(\mathrm{x}(22) \wedge \mathrm{phi}) / \mathrm{x}(1) \\
& \mathrm{f} 18=-\mathrm{x}(18)+(\text { eps_l } /(\text { eps_l }-1))^{*}(\mathrm{x}(23) \wedge \mathrm{phi}) /\left(\mathrm{x}(2)+\mathrm{miw}^{*} \mathrm{x}(5)\right) \text {; } \\
& \mathrm{f} 19=-\mathrm{x}(19)+(\mathrm{x}(21) \wedge \text { alphak })^{*}\left(\mathrm{x}(22) \wedge\left(\mathrm{mu}^{*} \text { alphal }\right)\right)^{*}\left(\mathrm{x}(23) \wedge\left((1-\mathrm{mu})^{*} \text { alphal }\right)\right)^{*}(\mathrm{x}(24) \\
& \text { (1 - alphal - alphak)); }
\end{aligned}
$$




$$
\begin{aligned}
& \mathrm{f} 20=-\mathrm{x}(22)+\left(\mathrm{mu}^{*} \text { alphal } / \mathrm{x} \_\mathrm{ss}\right) *(\mathrm{x}(19) / \mathrm{x}(17)) ; \\
& \mathrm{f} 21=-\mathrm{x}(23)+\left((1-\mathrm{mu}) * \text { alphal } / \mathrm{x} \_\mathrm{ss}\right) *(\mathrm{x}(19) / \mathrm{x}(18)) ; \\
& \mathrm{f} 22=-\mathrm{x}(24)+\left((1-\text { alphak - alphal }) / \mathrm{x} \_\mathrm{ss}\right) *(\mathrm{x}(19) /(\mathrm{x}(25) * \mathrm{pQ})) ; \\
& \mathrm{f} 23=-\mathrm{x}(3) * \mathrm{q} \_\mathrm{k}+\mathrm{x}(6) * \mathrm{me}^{*} \mathrm{q} \_\mathrm{k}{ }^{*} \text { piss }^{*}(1-\operatorname{deltak})+\operatorname{betae}^{*} \mathrm{x}(3) *\left(\operatorname{alphak}^{*} \mathrm{x}(19) /\left(\mathrm{x} \_\mathrm{ss} * \mathrm{x}(21)\right)\right. \\
& \left.+\mathrm{q} \_\mathrm{k}^{*}(1-\operatorname{deltak})\right) \text {; } \\
& \mathrm{f} 24=-\mathrm{x}(27)+\exp \left(- \text { zeta }^{*} \mathrm{x}(25) * \mathrm{x}(26) / \mathrm{x}(28)\right) ; \\
& \mathrm{f} 25=-\mathrm{x}(27) *\left(\mathrm{piss} / \mathrm{piss} \_ \text {star }\right) *\left(1-\text { zeta }^{*} \mathrm{x}(25) * \mathrm{x}(26) / \mathrm{x}(28)\right)+\left(1+\mathrm{r} \_ \text {pol }\right) /(1+ \\
& \text { R_star); } \\
& \mathrm{f} 26=-\mathrm{x}(20)+\mathrm{x}(7)+\mathrm{x}(8)+\mathrm{x}(9)+\operatorname{deltah}^{*}(\mathrm{x}(10)+\mathrm{x}(11)+\mathrm{x}(12))+\text { del- } \\
& \operatorname{tak}^{*} \mathrm{x}(21)+\mathrm{x}(29) \\
& \mathrm{f} 27=\mathrm{x}(29)-\mathrm{x}(25){ }^{*} \mathrm{pQ}^{*} \mathrm{x}(24)-\left(1+\left(1+\mathrm{R} \_ \text {star }\right){ }^{*} \mathrm{x}(27) / \mathrm{piss} \_ \text {star }-1 / \text { piss_star }\right)^{*} \mathrm{x}(25){ }^{*} \mathrm{x}(26) \\
& \mathrm{f} 28=-\mathrm{x}(28)+\mathrm{vi}^{*}(\mathrm{x}(13)+\mathrm{x}(14)+\mathrm{x}(15)) ; \\
& \mathrm{f} 29=-\mathrm{x}(29)+\operatorname{share}^{*}\left(\left(1 / \mathrm{x}(25)^{*} \mathrm{x} \_\mathrm{ss}\right) \wedge-\mathrm{tau}\right) * \mathrm{y} \_ \text {star; } \\
& \mathrm{F}=[\mathrm{f} 1 ; \mathrm{f} 2 ; \mathrm{f} 3 ; \mathrm{f} 4 ; \mathrm{f} 5 ; \mathrm{f} 6 ; \mathrm{f} 7 ; \mathrm{f} 8 ; \mathrm{f} 9 ; \mathrm{f} 10 ; \mathrm{f} 11 ; \mathrm{f} 12 ; \mathrm{f} 13 ; \mathrm{f} 14 ; \mathrm{f} 15 ; \mathrm{f} 16 ; \mathrm{f} 17 ; \mathrm{f} 18 ; \mathrm{f} 19 ; \mathrm{f} 20 ;
\end{aligned}
$$
f21; f22; f23; f24; f25; f26; f27; f28; f29];

end

\section{A.2.2 solve}

clear all;

clc;

global betap betai betae q_k q_h piss piss_star me mih miw deltak deltah deltakb jh eps_l phi eps_y mu alphal alphak eps_d eps_biw eps_bih eps_be zeta x_ss R_star pQ y_star tau vi share;

$$
\begin{aligned}
& \text { betap }=0.989 ; \\
& \text { betai }=0.96 ; \\
& \text { betae = betai; } \\
& \text { R_star }=0.005 ; \\
& \text { q_k }=1 ; \\
& \text { q__h }=1 ; \\
& \text { pQ }=1 ; \\
& \text { x_ss }=\text { eps_y } /(\text { eps_y }-1) ; \\
& \text { piss }=1 ;
\end{aligned}
$$




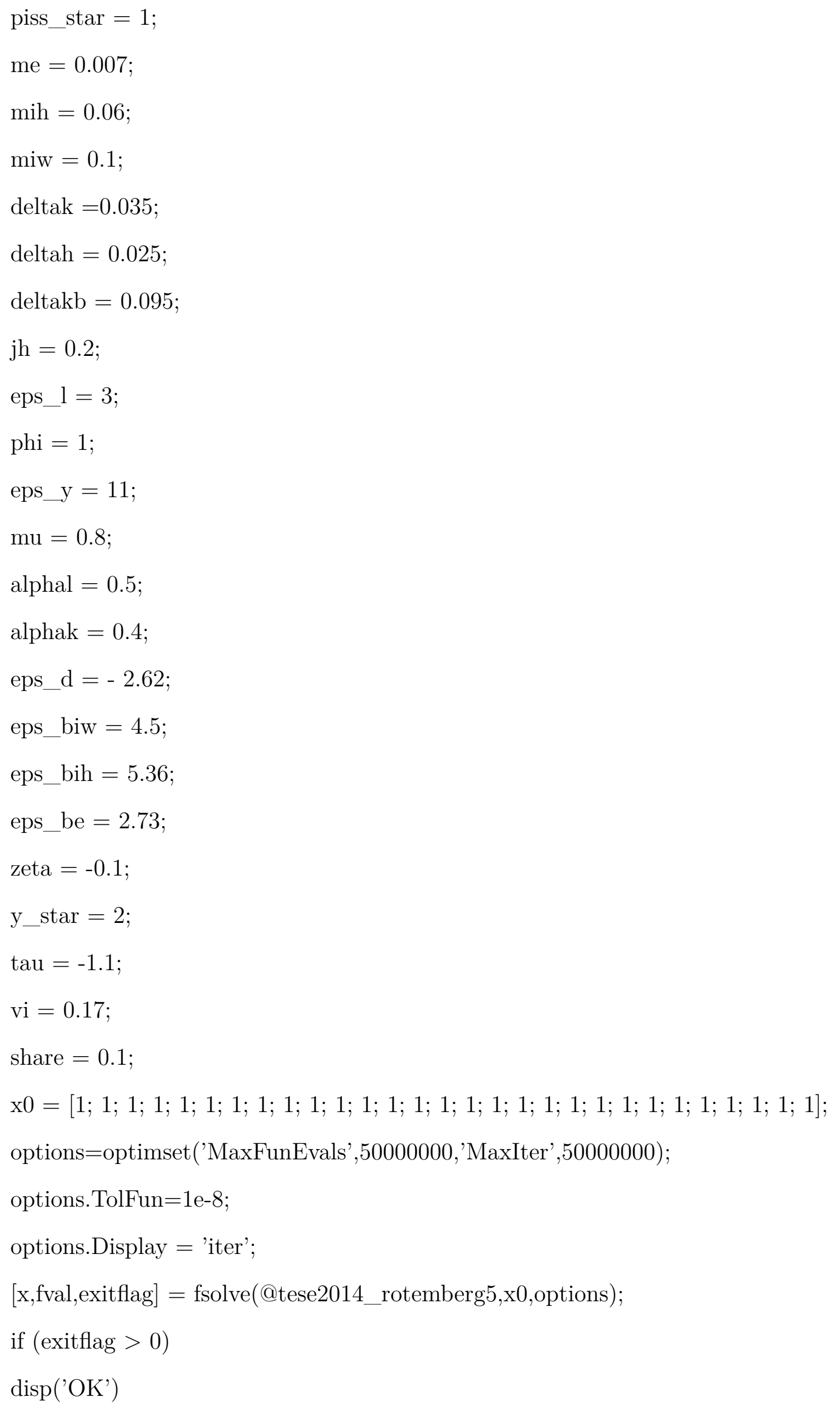


else

$\operatorname{disp}(' N o t$ OK')

end;

$\mathrm{N}=29$;

for $\mathrm{n}=1: \mathrm{N}$

if $(\operatorname{imag}(\mathrm{x}(\mathrm{n}))>0.0001)$

disp(['A raiz ..., num2str(n) ,'.. do sistema é imaginária!'])

else

$\mathrm{x}(\mathrm{n})=\operatorname{real}(\mathrm{x}(\mathrm{n}))$

end;

end;

r_d = piss/betap - 1;

$\mathrm{r} \_$pol $=\left((\text {eps_d - 1)/eps_d })^{*} \mathrm{r} \_\mathrm{d}\right.$;

r_biw $=(\text { eps_biw } /(\text { eps_biw }-1))^{*}$ r_pol;

r_bih $=($ eps_bih $/($ eps_bih - 1) $) *$ r_pol;

r_be $=($ eps_be $/($ eps_be - 1) $) *$ r_pol;

$\operatorname{disp}($ ' ')

$\mathrm{PIBo}=\mathrm{x}(20)-\mathrm{x}(25) * \mathrm{pQ}^{*} \mathrm{x}(24) ;$

$\operatorname{disp}([$ 'Produto otica da oferta $=$ ' num2str(PIBo) $])$

$\operatorname{disp}('$,

PIBd $=\mathrm{x}(9)+\mathrm{x}(8)+\mathrm{x}(7)+\operatorname{deltah}^{*}(\mathrm{x}(10)+\mathrm{x}(11)+\mathrm{x}(12))+\operatorname{deltak}^{*} \mathrm{x}(21)+$ $\mathrm{x}(29)-\mathrm{x}(25) * \mathrm{pQ}^{*} \mathrm{x}(24)$;

$\operatorname{disp}\left(\left[\right.\right.$ Produto otica da demanda $={ }^{\prime}$ num2str(PIBd) $\left.]\right)$

$\operatorname{disp}\left({ }^{\prime},\right)$

$\mathrm{C}=\mathrm{x}(9)+\mathrm{x}(8)+\mathrm{x}(7) ;$

$\operatorname{disp}\left(\left[{ }^{\prime}\right.\right.$ Consumo agregado $\left.\left.={ }^{\prime} \operatorname{num} 2 \operatorname{str}(\mathrm{C})\right]\right)$

$\operatorname{disp}($ ' ')

C_PIBd $=\mathrm{C} / \mathrm{PIBd}$;

$\operatorname{disp}\left(\left[\right.\right.$ Consumo/PIBd $=$ ' num2str $\left(\mathrm{C} \_\right.$PIBd $\left.\left.)\right]\right)$

$\operatorname{disp}('$, ') 
$\mathrm{I}=\operatorname{deltak}^{*} \mathrm{x}(21)+\operatorname{deltah}^{*}(\mathrm{x}(10)+\mathrm{x}(11)+\mathrm{x}(12)) ;$

$\operatorname{disp}([$ 'Investimento agregado $=$ ' num2str(I)] $)$

$\operatorname{disp}('$,

I_PIBd $=$ I $/$ PIBd;

$\operatorname{disp}([$ Investimento/PIBd $=$ ' num2str(I_PIBd)] $)$

$\operatorname{disp}('$,

$\mathrm{Ik}=\operatorname{deltak}^{*} \mathrm{x}(21) ;$

$\operatorname{disp}\left(\left[\right.\right.$ 'Investimento em capital $={ }^{\prime}$ num2str(Ik)] $)$

$\operatorname{disp}('$,

$\mathrm{Ik} \_\mathrm{PIBd}=\mathrm{Ik} / \mathrm{PIBd}$;

$\operatorname{disp}\left(\left[' I n v e s t i m e n t o\right.\right.$ em capital/PIBd $={ }^{\prime} \operatorname{num} 2 \operatorname{str}\left(\mathrm{Ik} \_\right.$PIBd $\left.\left.)\right]\right)$

$\operatorname{disp}('$,

Ih $=\operatorname{deltah}^{*}(\mathrm{x}(10)+\mathrm{x}(11)+\mathrm{x}(12))$;

$\operatorname{disp}([$ 'Investimento em Imoveis $=$ ' num2str(Ih)] $)$

$\operatorname{disp}('$,

Ih_PIBd $=\mathrm{Ih} / \mathrm{PIBd}$;

$\operatorname{disp}([$ 'Investimento em Imoveis/PIBd =' num2str(Ih_PIBd)]

$\operatorname{disp}\left({ }^{\prime},\right)$

K_PIBd $=x(21) / P I B d ;$

$\operatorname{disp}([$ Capital/PIBd $=$ ' num2str(K_PIBd $)])$

$\operatorname{disp}\left({ }^{\prime}\right.$ ')

H_PIBd $=(\mathrm{x}(10)+\mathrm{x}(11)+\mathrm{x}(12)) / \mathrm{PIBd}$;

$\operatorname{disp}([$ 'Imóveis $/ \mathrm{PIBd}=$ ' num2str(H_PIBd)]

$\operatorname{disp}\left({ }^{\prime},\right)$

X_PIBd $=\mathrm{x}(29) / \mathrm{PIBd}$;

$\operatorname{disp}([$ Exportações/PIBd =' num2str(X_PIBd)] $)$

$\operatorname{disp}('$,

M_PIBd $=\mathrm{x}(25) * \mathrm{pQ}^{*} \mathrm{x}(24) / \mathrm{PIBd}$;

$\operatorname{disp}([$ 'Importações/PIBd =' num2str(M_PIBd)] $)$

$\operatorname{disp}\left({ }^{\prime}\right.$ ') 


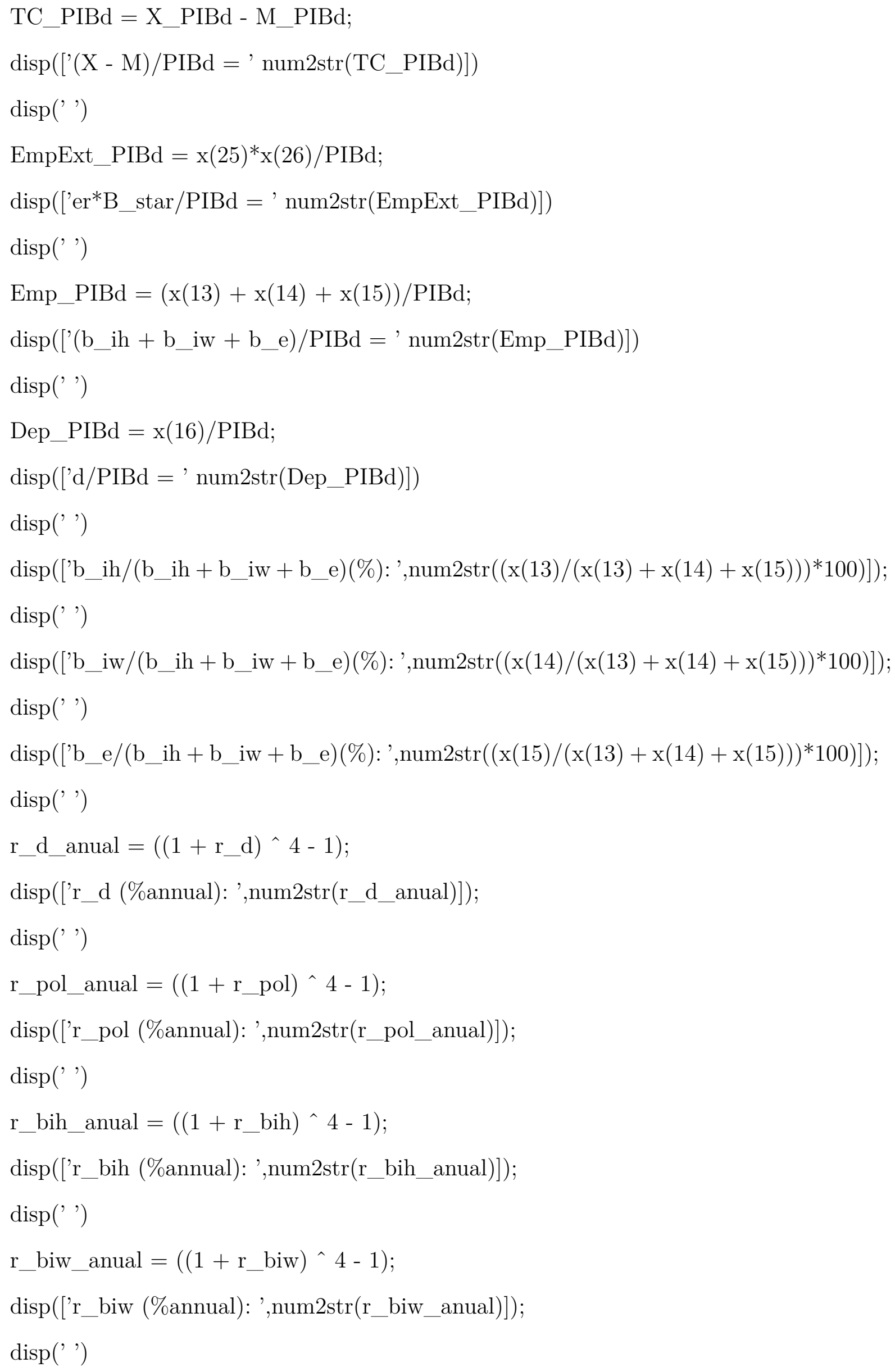


r_be_anual $=((1+$ r_be $) \wedge 4-1)$;

$\operatorname{disp}([$ 'r_be (\%annual): ',num2str(r_be_anual)]);

$\operatorname{disp}('$, ')

R_star_anual $=\left(\left(1+R \_\right.\right.$_star $\left.) \wedge 4-1\right)$;

$\operatorname{disp}\left(\left[' R \_s t a r(\%\right.\right.$ annual): ',num2str(R_star_anual)]); 


\section{ANEXO B - Script para a Estimação dos Modelos de Economia Fechada e Aberta}

\section{B.1 Economia Fechada}

var c_p // PATIENT HHs

h_p // PATIENT HHs

d_p // PATIENT HHs

l_p // PATIENT HHs

lam_p // PATIENT HHs

J_R // PATIENT HHs

j_B // PATIENT HHs

pie_wp // PATIENT HHs

c_i // IMPATIENT HHs

h_i // IMPATIENT HHs

b_i // IMPATIENT HHs

l_i // IMPATIENT HHs

lam_i // IMPATIENT HHs

s_i // IMPATIENT HHs

pie_wi // IMPATIENT HHs

I // CAPITAL PRODUCERS

q_k // CAPITAL PRODUCERS

c_e // ENTREPRENEURS

y_e // ENTREPRENEURS

lam_e // ENTREPRENEURS

s_e // ENTREPRENEURS

$\mathrm{u} / /$ ENTREPRENEURS Capital utilization rate

b_e // BANKS

r_d // BANKS

r_bh // BANKS

r_be // BANKS

$\mathrm{R} \_\mathrm{b} / / \mathrm{BANKS}$

K_b // BANKS

pie // RETAILERS 
$\mathrm{x} / /$ RETAILERS

C // AGGREGATION EQUILIBRIUM

Y // AGGREGATION EQUILIBRIUM

B // AGGREGATION EQUILIBRIUM

w_p // AGGREGATION EQUILIBRIUM

w_i // AGGREGATION EQUILIBRIUM

q_h // AGGREGATION EQUILIBRIUM

K // AGGREGATION EQUILIBRIUM

PIW // AGGREGATION EQUILIBRIUM

r_ib // MONETARY POLICY

r_k // CAPITAL RENTAL RATE

ee_z // EXOGENOUS PROCESSES

A_e // EXOGENOUS PROCESSES

ee_j // EXOGENOUS PROCESSES

mk_d // EXOGENOUS PROCESSES

mk_be // EXOGENOUS PROCESSES

mk_bh // EXOGENOUS PROCESSES

ee_qk // EXOGENOUS PROCESSES

m_i // EXOGENOUS PROCESSES (IMPATIENT LTV)

m_e // EXOGENOUS PROCESSES (ENTREPRENEURS LTV)

eps_y // EXOGENOUS PROCESSES

eps_1// EXOGENOUS PROCESSES

eps_K_b // EXOGENOUS PROCESSES

rr_e // Entrep. Real Rate

aux1 // auxiliary variable

bm // banks intermediation margins

spr_b // average bank spread (active-passive)

Ih

ee_qh

s_iw

m_iw

r_bw

b_iw

mk_bw

h_e

$\mathrm{h}$ 


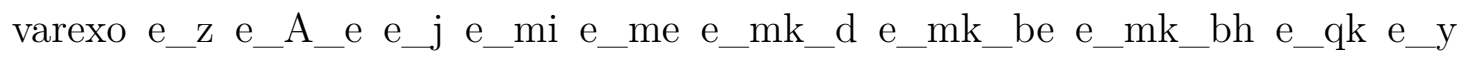

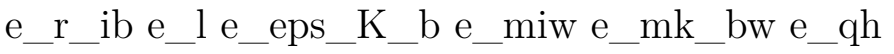

parameters beta_p j phi beta_i m_i_ss beta_e m_e_ss alpha eksi_1 eksi_2

a_i a_p a_e ni

eps_l_ss kappa_w

eps_d eps_bh eps_be

mk_d_ss mk_bh_ss mk_be_ss r_be_ss r_bh_ss r_k_ss

beta_b delta_kb vi kappa_kb

eps_y_ss kappa_p ind_p ind_w

kappa_i kappa_d kappa_be kappa_bh deltak

rho_ib phi_pie phi_y

piss r_ib_ss

rho_ee_z rho_A_e rho_ee_j rho_mi rho_me rho_eps_y

rho_mk_d rho_mk_be rho_mk_bh rho_ee_qk rho_eps_l rho_eps_K_b

ind_d ind_be ind_bh

deltah eps_bw mk_bw_ss r_bw_ss kappa_ih kappa_bw ind_bw m_iw_ss

rho_miw rho_mk_bw rho_ee_qh

\section{// CALIBRATED PARAMETERS}

/1

$$
\text { beta_p }=0.989
$$

beta_i $=0.96$;

beta_b = beta_p;

beta_e = beta_i;

$\mathrm{j}=0.2$;

phi $=1.0$;

$\mathrm{m} \_\mathrm{i} \_s s=0.06$;

$\mathrm{m} \_\mathrm{e} \_\mathrm{ss}=0.007$;

alpha $=0.40$

eps_d $=-2.62$;

eps_bh $=5.36$;

eps_be $=2.73$;

mk_d_ss $=$ eps_d / (eps_d - 1) ; 


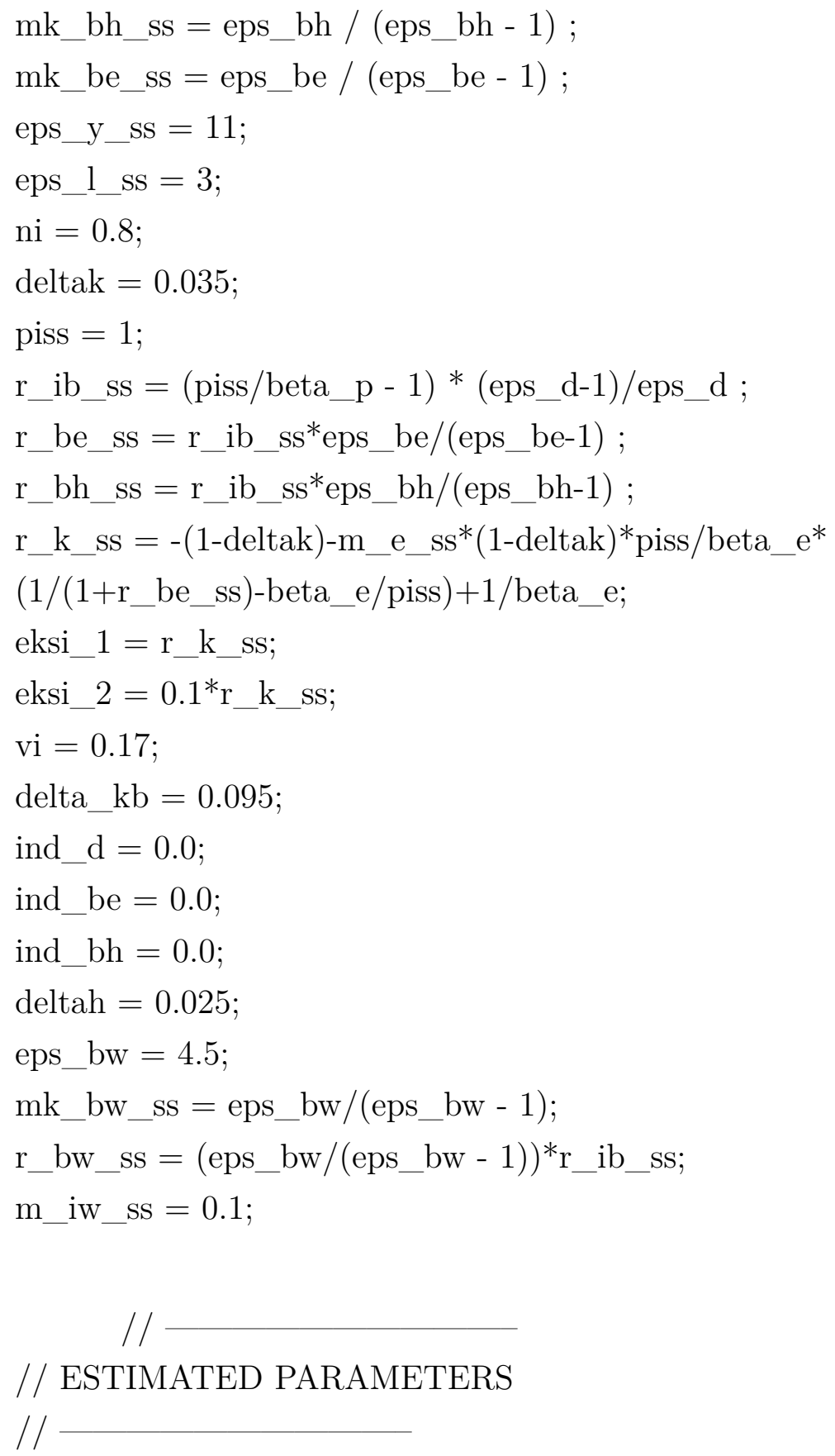

//Coloquei a média das priors

rho_ee_z $=0.385953438168178$;

rho_A_e $=0.93816527333294$;

rho_ee_j $=0.921872719102206$;

rho_me $=0.90129485520182$;

rho_mi $=0.922378382753078$;

rho_mk_d $=0.892731352899547$;

rho_mk_bh $=0.851229673864555$;

rho_mk_be $=0.873901213475799$; 
rho_ee_qk $=0.571692383714171$;

rho_eps_y $=0.294182239567384$;

rho_eps_l $=0.596186440884132$;

rho_eps_K_b $=0.813022758608552$;

kappa_p $=33.7705265016395$;

kappa_w $=$ kappa_p;

kappa_i $=10.0305562248008$;

kappa_d $=2.77537377104213$;

kappa_be $=7.98005959044637$;

kappa_bh $=9.04426718749482$;

kappa_kb $=8.91481958034669$;

phi_pie $=2.00384780180824$;

rho_ib $=0.750481873084311$;

phi_y $=0.303247771697294$;

ind_p $=0.158112794106546$;

ind $\_w=0.300197804017489$;

a_i $=0.867003766306404$;

a_e $=0.0$;

a_p $=0.0$;

kappa_ih = kappa_i;

kappa_bw = kappa_bh;

ind_bw = ind_bh;

rho_miw $=$ rho_mi;

rho_mk_bw = rho_miw;

rho_ee_qh $=$ rho_ee_qk;

// Model equations

//

model;

//— 1) PATIENT HHs

$\left(1-\mathrm{a} \_\mathrm{i}\right) * \mathrm{ee} \_\mathrm{z} *\left(\mathrm{c} \_\mathrm{p}-\mathrm{a} \_\mathrm{i} * \mathrm{c} \_\mathrm{p}(-1)\right)^{\wedge}(-1)=\mathrm{lam} \_\mathrm{p}$

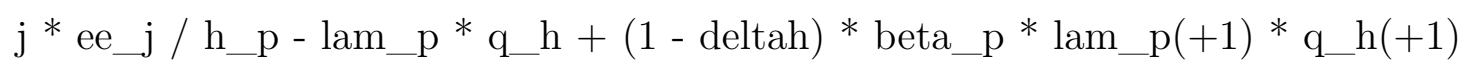
$=0$

lam_p $=$ beta_p $*$ lam_p $(+1) *\left(1+\mathrm{r} \_\mathrm{d}\right) / \mathrm{pie}(+1)$;

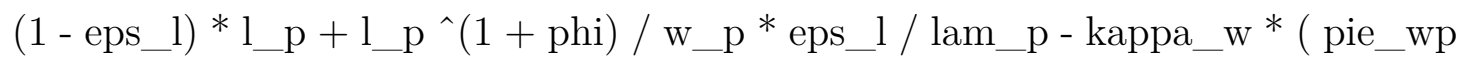




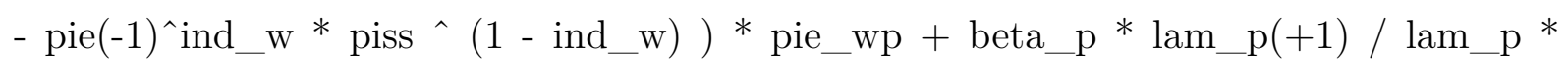
kappa_w $*\left(\text { pie_wp }(+1)-\text { pie }^{\wedge} \text { ind__w } * \text { piss }^{\wedge}(1-\text { ind_w })\right)^{*}$ pie_wp $(+1) \wedge 2 /$ pie $=$ 0 ;

$$
\begin{aligned}
& \text { pie_wp }=\mathrm{w} \_\mathrm{p} / \mathrm{w} \_\mathrm{p}(-1) * \mathrm{pie} \\
& \mathrm{c \_ p}+\mathrm{q} \_\mathrm{h} *\left(\mathrm{~h} \_\mathrm{p}-(1-\operatorname{deltah}) * \mathrm{~h} \_\mathrm{p}(-1)\right)+\mathrm{d} \_\mathrm{p}=\mathrm{w} \_\mathrm{p} * \mathrm{l} \_\mathrm{p}+\left(1+\mathrm{r} \_\mathrm{d}(-1)\right) \\
& * \mathrm{~d} \_\mathrm{p}(-1) / \mathrm{pie}+\mathrm{J} \_\mathrm{R} ;
\end{aligned}
$$

\section{$/ / 2$ IMPATIENT HHs}

$\left(1-\mathrm{a} \_\mathrm{i}\right) *$ ee_z $*\left(\mathrm{c} \_\mathrm{i}-\mathrm{a} \_\mathrm{i} * \mathrm{c} \_\mathrm{i}(-1)\right)^{\wedge}(-1)=\mathrm{lam \_ i}$

$\mathrm{j} *$ ee_j / h_i - lam_i $* \mathrm{q} \_\mathrm{h}+(1-\operatorname{deltah}) *\left(\operatorname{beta\_ i} * \operatorname{lam\_ i}(+1) * \mathrm{q} \_\mathrm{h}(+1)+\right.$ $\mathrm{s \_}$ i $\left.* \mathrm{~m} \_\mathrm{i} * \mathrm{q} \_\mathrm{h}(+1) * \operatorname{pie}(+1)\right)=0$;

$$
\begin{aligned}
& \text { lam_i - beta_i } * \text { lam_i }(+1) *\left(1+\mathrm{r} \_b h\right) / \mathrm{pie}(+1)=\mathrm{s} \_\mathrm{i} *\left(1+\mathrm{r} \_b h\right) ; \\
& \text { lam_i - beta_i } * \text { lam_i }(+1) *\left(1+\mathrm{r} \_b w\right) / \operatorname{pie}(+1)=\mathrm{s} \_i w *\left(1+\mathrm{r} \_b w\right) ; \\
& (1-\text { eps_l }) * 1 \_\mathrm{i}+\mathrm{eps \_ l}{ }^{*} \mathrm{l} \_\mathrm{i}^{\wedge}(1+\mathrm{phi}) /\left(\mathrm{w} \_\mathrm{i} *\left(\mathrm{lam} \_\mathrm{i}+\mathrm{m} \_\mathrm{iw} * \mathrm{~s} \_\mathrm{iw}\right)\right)
\end{aligned}
$$
- kappa_w $*($ pie_wi - pie $(-1) \wedge$ ind_w $*$ piss $\wedge(1-$ ind_w $)) *$ pie_wi + beta_i $*$ $\left(\operatorname{lam\_ i}(+1)+\mathrm{s} \_i w(+1)+\mathrm{m} \_i w(+1)\right) /\left(\operatorname{lam} \_\mathrm{i}+\mathrm{s} \_\mathrm{iw}+\mathrm{m} \_\mathrm{iw}\right) * \mathrm{kappa} \_\mathrm{w} *\left(\mathrm{pie} \_w i(+1)\right.$ - pie` ind_w* piss` $(1-$ ind_w $))^{*}$ pie_wi $(+1)^{\wedge} 2 / \operatorname{pie}(+1)=0$;

$$
\begin{aligned}
& \text { pie_wi }=\mathrm{w} \_\mathrm{i} / \mathrm{w} \_\mathrm{i}(-1) * \text { pie; } \\
& \mathrm{c \_} \_+\mathrm{q} \_\mathrm{h} *\left(\mathrm{~h} \_\mathrm{i}-(1-\operatorname{deltah}) * \mathrm{~h} \_\mathrm{i}(-1)\right)+\left(1+\mathrm{r} \_\mathrm{bh}(-1)\right) * \mathrm{~b} \_\mathrm{i}(-1) / \mathrm{pie}+(1+
\end{aligned}
$$
r_bw $(-1)) * b \_i w(-1) / p i e=w \_i * l \_i+b \_i+b \_i w$;

$$
\begin{aligned}
& \left(1+\mathrm{r} \_\mathrm{bh}\right) * \mathrm{~b} \_\mathrm{i}=\mathrm{m} \_\mathrm{i} * \mathrm{q}_{h}(+1) * h \_i * p i e(+1) \\
& \left(1+\mathrm{r} \_\mathrm{bw}\right) * \mathrm{~b} \_\mathrm{iw}=\mathrm{m} \_\mathrm{iw} * \mathrm{w} \_\mathrm{i}(+1) * \mathrm{l} \_\mathrm{i}(+1) * \operatorname{pie}(+1) ;
\end{aligned}
$$

$$
/ /
$$

3) CAPITAL PRODUCERS

$$
\mathrm{K}=(1-\text { deltak }) * \mathrm{~K}(-1)+\left(1-\mathrm{kappa} \_\mathrm{i} / 2 *(\mathrm{I} * \text { ee_qk/ I(-1) - } 1)^{\wedge} 2\right) * \mathrm{I} \text {; }
$$

$1=\mathrm{q} \_\mathrm{k} *\left(1-\mathrm{kappa} \_\mathrm{i} / 2 *(\mathrm{I} * \text { ee_qk } / \mathrm{I}(-1)-1)^{\wedge} 2-\mathrm{kappa} \_\mathrm{i} *\left(\mathrm{I} *\right.\right.$ ee $\_\mathrm{qk} /$ $\mathrm{I}(-1)-1) * \mathrm{I} *$ ee_qk/ I(-1) $)+$ beta_e $*($ lam_e $(+1)) /($ lam_e $) *\left(\mathrm{q} \_\mathrm{k}(+1)\right) *$ kappa_i $*((\mathrm{I}(+1)) *($ ee_qk $(+1)) /(\mathrm{I})-1) *($ ee_ $\mathrm{qk}(+1)) *((\mathrm{I}(+1)) /(\mathrm{I}))^{\wedge} 2$;

\section{//— 4) HOUSING PRODUCERS}

$\mathrm{h}=(1-\operatorname{deltah}) * \mathrm{~h}(-1)+\left(1-\right.$ kappa_ih $\left./ 2 *\left(\mathrm{Ih} * \mathrm{ee} \_\mathrm{qh} / \mathrm{I}(-1)-1\right)^{\wedge} 2\right) * \mathrm{Ih}$;

$1=\mathrm{q} \_\mathrm{h} *\left(1-\mathrm{kappa} \_\mathrm{ih} / 2 *(\mathrm{Ih} * \text { ee_qh } / \mathrm{Ih}(-1)-1)^{\wedge} 2-\mathrm{kappa}\right.$ _ih $*($ $\mathrm{Ih} *$ ee_qh $/ \operatorname{Ih}(-1)-1) * \mathrm{Ih} *$ ee_qh $/ \operatorname{Ih}(-1))+$ beta_e $*\left(\operatorname{lam} \_\mathrm{e}(+1)\right) /($ lam_e $) *$ $\left(\mathrm{q} \_\mathrm{h}(+1)\right) * \mathrm{kappa} \_\mathrm{ih} *((\operatorname{Ih}(+1)) *($ ee_qh $(+1)) /(\mathrm{Ih})-1) *($ ee_qh $(+1)) *((\operatorname{Ih}(+1)) /$ 
$(\mathrm{Ih}))^{\wedge} 2$

$$
/ 1
$$

5) ENTREPRENEURS

$$
\begin{aligned}
& \left(1-\mathrm{a} \_\mathrm{i}\right) *\left(\mathrm{c} \_\mathrm{e}-\mathrm{a} \_\mathrm{i}^{*} \mathrm{c} \_\mathrm{e}(-1)\right)^{\wedge}(-1)=\mathrm{lam} \_\mathrm{e} \text {; } \\
& \mathrm{s \_}{ }^{*} \mathrm{~m} \_\mathrm{e} * \mathrm{q}^{*} \mathrm{k}(+1) * \operatorname{pie}(+1) *(1-\text { deltak })+\text { beta_e }{ }^{*} \text { lam_e }(+1) *( \\
& \left(\mathrm{q} \_\mathrm{k}(+1)\right)^{*}(1-\text { deltak })+\left(\mathrm{r} \_\mathrm{k}(+1)\right)^{*}(\mathrm{u}(+1))-\left(\operatorname{eksi\_ } 1^{*}(\mathrm{u}(+1)-1)+\text { eksi_2 / } 2\right. \\
& \left.\left.*\left((\mathrm{u}(+1)-1)^{\wedge} 2\right)\right)\right)=\text { lam_e }{ }^{*} \mathrm{q} \_\mathrm{k} \text {; } \\
& \mathrm{j} * \text { ee_j / h_e - lam_e }{ }^{*} \mathrm{q} \_\mathrm{h}+(1-\operatorname{deltah}) *\left(\operatorname{beta\_ e}{ }^{*} \text { lam_e }(+1) * \mathrm{q} \_\mathrm{h}(+1)\right. \\
& \left.+\mathrm{s} \_\mathrm{e} *{ }^{*} \mathrm{~m} \_\mathrm{e} * \mathrm{q} \_\mathrm{h}(+1) * \operatorname{pie}(+1)\right)=0 \text {; } \\
& \mathrm{w} \_\mathrm{p}=\mathrm{ni} *(1-\mathrm{alpha}) * \mathrm{y} \_\mathrm{e} /\left(\mathrm{l} \_\mathrm{p} * \mathrm{x}\right) \text {; } \\
& \mathrm{w} \_\mathrm{i}=(1-\mathrm{ni}) *(1-\mathrm{alpha}) * \mathrm{y} \_\mathrm{e} /\left(\mathrm{l} \_\mathrm{i} * \mathrm{x}\right) \text {; } \\
& \text { lam_e-s_e }{ }^{*}\left(1+\mathrm{r} \_b e\right)=\text { beta_e }{ }^{*} \text { lam_e }(+1) *(1+\text { r_be }) / p i e(+1) \text {; } \\
& \mathrm{r} \_\mathrm{k}=\text { eksi_1 }+ \text { eksi_2 } *(\mathrm{u}-1) \\
& \text { c_e }+(1+\text { r_be }(-1)) * \text { b_e }(-1) / \mathrm{pie}+\mathrm{q} \_\mathrm{h} *\left(\mathrm{~h} \_\mathrm{e}-(1-\operatorname{deltah}) * \mathrm{~h} \_\mathrm{e}(-1)\right)+ \\
& \mathrm{w} \_\mathrm{p} * \mathrm{l} \_\mathrm{p}+\mathrm{w} \_\mathrm{i} * \mathrm{l} \_\mathrm{i}+\mathrm{q} \_\mathrm{k} * \mathrm{~K}+\left(\operatorname{eksi\_ 1}{ }^{*}(\mathrm{u}-1)+\text { eksi_2 } / 2 *(\mathrm{u}-1)^{\wedge} 2\right) * \\
& \mathrm{~K}(-1)=\mathrm{y} \_\mathrm{e} / \mathrm{x}+\mathrm{b} \_\mathrm{e}+\mathrm{q} \_\mathrm{k} *(1-\operatorname{deltak}) * \mathrm{~K}(-1) \text {; } \\
& \mathrm{y} \_\mathrm{e}=\mathrm{A} \_\mathrm{e} *(\mathrm{u} * \mathrm{~K}(-1))^{\wedge}(\mathrm{alpha}) *\left(\left(\mathrm{l} \_\mathrm{p}\right) \wedge \mathrm{ni} *\left(\mathrm{l} \_\mathrm{i}\right) \wedge(1-\mathrm{ni})\right)^{\wedge}(1-\mathrm{alpha}) \\
& \left(1+\mathrm{r} \_ \text {be }\right) * \mathrm{~b} \_\mathrm{e}=\mathrm{m} \_\mathrm{e} *\left(\mathrm{q} \_\mathrm{k}(+1) * \operatorname{pie}(+1) * \mathrm{~K} *(1-\operatorname{deltak})+\mathrm{q} \_\mathrm{h}(+1) *\right. \\
& \left.\operatorname{pie}(+1) * \mathrm{~h} \_\mathrm{e} *(1-\operatorname{deltah})\right) \text {; } \\
& \mathrm{r} \_\mathrm{k}=\operatorname{alpha} * \mathrm{~A} \_\mathrm{e} *(\mathrm{u})^{\wedge}(\operatorname{alpha}-1) *(\mathrm{~K}(-1))^{\wedge}(\operatorname{alpha}-1) *\left(\left(\mathrm{l} \_\mathrm{p}\right)^{\wedge} \mathrm{ni} *\left(\mathrm{l} \_\mathrm{i}\right)^{\wedge}(1\right. \\
& \text { - ni) )^(1 - alpha) / x; } \\
& / /
\end{aligned}
$$$$
\text { 6)BANKS }
$$

$$
\mathrm{R} \_\mathrm{b}=-\mathrm{kappa} \_\mathrm{kb} *\left(\mathrm{~K} \_\mathrm{b} / \mathrm{B}-\mathrm{vi}\right) *\left(\mathrm{~K} \_\mathrm{b} / \mathrm{B}\right)^{\wedge} 2+\mathrm{r} \_\mathrm{ib} ;
$$$$
\mathrm{K} \_\mathrm{b} * \mathrm{pie}=\left(1-\operatorname{delta} \_\mathrm{kb}\right) * \mathrm{~K} \_\mathrm{b}(-1) / \mathrm{eps} \_\mathrm{K} \_\mathrm{b}+\mathrm{j} \_\mathrm{B}(-1) \text {; }
$$$$
\text { b_i }+ \text { b_iw }+ \text { b_e }=d \_p+K \_b ;
$$

$-1+\mathrm{mk} \_\mathrm{d} /\left(\mathrm{mk} \_\mathrm{d}-1\right)-\mathrm{mk} \_\mathrm{d} /\left(\mathrm{mk} \_\mathrm{d}-1\right) * \mathrm{r} \_\mathrm{ib} / \mathrm{r} \_\mathrm{d}-\mathrm{kappa} \_\mathrm{d} *($ $\left.\mathrm{r} \_\mathrm{d} / \mathrm{r} \_\mathrm{d}(-1)-1\right) * \mathrm{r} \_\mathrm{d} / \mathrm{r} \_\mathrm{d}(-1)+\operatorname{beta\_ p} *\left(\mathrm{lam} \_\mathrm{p}(+1) / \mathrm{lam} \_\mathrm{p}\right) *$ kappa_d $*($ $\mathrm{r} \_\mathrm{d}(+1) / \mathrm{r} \_\mathrm{d}-\left(\mathrm{r} \_\mathrm{d} / \mathrm{r} \_\mathrm{d}(-1)\right)^{\wedge}$ ind $\left.\_\mathrm{d}\right) *\left(\left(\mathrm{r} \_\mathrm{d}(+1) / \mathrm{r} \_\mathrm{d}\right)^{\wedge} 2\right) *\left(\mathrm{~d} \_\mathrm{p}(+1) / \mathrm{d} \_\mathrm{p}\right)$ $=0$;

+1 - mk_be $/\left(\mathrm{mk} \_b e-1\right)+\mathrm{mk} \_b e /\left(\mathrm{mk} \_b e-1\right) * \mathrm{R} \_\mathrm{b} / \mathrm{r} \_b e-k a p p a \_b e$ $*\left(\mathrm{r} \_b e / \mathrm{r} \_b e(-1)-1\right) * \mathrm{r} \_b e / \mathrm{r} \_b e(-1)+\operatorname{beta} \_\mathrm{p} *\left(\operatorname{lam} \_\mathrm{p}(+1) / \mathrm{lam} \_\mathrm{p}\right) *$ kappa_be $*\left(\mathrm{r} \_b e(+1) / \mathrm{r} \_b e-\left(\mathrm{r} \_b e / \mathrm{r} \_b e(-1)\right) \wedge\right.$ ind _be $) *\left(\left(\mathrm{r} \_b e(+1) / \mathrm{r} \_b e\right)\right.$ 
$\hat{2}) *\left(\mathrm{~b} \_\mathrm{e}(+1) / \mathrm{b} \_\mathrm{e}\right)=0$;

$+1-\mathrm{mk} \_b h /\left(\mathrm{mk} \_b h-1\right)+\mathrm{mk} \_b h /\left(\mathrm{mk} \_b h-1\right) * \mathrm{R} \_\mathrm{b} / \mathrm{r} \_b h-k a p p a \_b h$

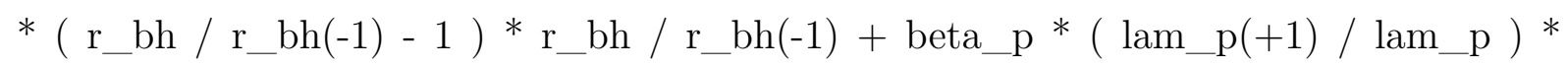
kappa_bh $*\left(\mathrm{r} \_b h(+1) / \mathrm{r} \_b h-\left(\mathrm{r} \_b h / \mathrm{r} \_b h(-1)\right) \wedge\right.$ ind_bh $) *\left(\left(\mathrm{r} \_b h(+1) / \mathrm{r} \_b h\right)\right.$ ^ 2$) *($ b_i $(+1) /$ b_i $)=0$;

$+1-\mathrm{mk} \_b w /\left(m k \_b w-1\right)+m k \_b w /\left(m k \_b w-1\right) * R \_b / r \_b w-k a p p a \_b w$ * $\left(\mathrm{r} \_b w / \mathrm{r} \_b w(-1)-1\right) * \mathrm{r} \_b w / \mathrm{r} \_b w(-1)+\operatorname{beta\_ p} *\left(\operatorname{lam} \_\mathrm{p}(+1) / \mathrm{lam} \_\mathrm{p}\right) *$ kappa_bw $*\left(\mathrm{r} \_b w(+1) / \mathrm{r} \_b w-\left(\mathrm{r} \_b w / r \_b w(-1)\right) \wedge\right.$ ind $\left.\_b w\right) *\left(\left(r \_b w(+1) /\right.\right.$ r_bw $) \wedge 2) *\left(b \_i w(+1) / b \_i w\right)=0$;

j_B $=+r \_b h * b \_i$

$+\mathrm{r} \_\mathrm{bw} * \mathrm{~b} \_\mathrm{iw}$

$+\mathrm{r} \_b e^{*} \mathrm{~b} \_\mathrm{e}$

- r_d $*$ d_p

- kappa_d $/ 2 *\left(\left(\mathrm{r} \_\mathrm{d} / \mathrm{r} \_\mathrm{d}(-1)-1\right) \wedge 2\right) * \mathrm{r} \_\mathrm{d} * \mathrm{~d} \_\mathrm{p}$

- kappa_be $/ 2 *\left(\left(\mathrm{r} \_b e / \mathrm{r} \_b e(-1)-1\right) \wedge 2\right) * \mathrm{r} \_b e *$ b_e

- kappa_bh $/ 2 *\left(\left(\mathrm{r} \_b h / r \_b h(-1)-1\right) \wedge 2\right) * r \_b h * b \_i$

- kappa_bw $/ 2 *\left(\left(\mathrm{r} \_b w / r \_b w(-1)-1\right) \wedge 2\right) * r \_b w * b \_i w$

- kappa_kb / $2 *\left(\left(\mathrm{~K} \_\mathrm{b} / \mathrm{B}-\mathrm{vi}\right) \wedge 2\right)^{*} \mathrm{~K} \_\mathrm{b}$;

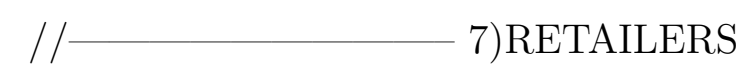

$\mathrm{J} \_\mathrm{R}=\mathrm{Y}^{*}\left(1-1 / \mathrm{x}-\mathrm{kappa \_ p} / 2^{*}\left(\mathrm{pie}-\left(\mathrm{pie}(-1)^{\wedge}\right.\right.\right.$ ind_p ${ }^{*} \mathrm{piss}^{\wedge}(1-$ ind_p $)$ )$\left.)^{\wedge} 2\right)$

$1-$ eps $\_y+e p s \_y / x-k a p p a \_p *\left(\operatorname{pie}-\left(\operatorname{pie}(-1) \wedge\right.\right.$ ind _p $* \operatorname{piss}^{\wedge}(1-$ ind _p $)$ )$)^{*}$ pie + beta_p $*(\text { lam_p }(+1) / \text { lam_p })^{*}$ kappa_p $*\left(\operatorname{pie}(+1)-\left(\right.\right.$ pie ${ }^{\wedge}$ ind_p $*$ piss ^ $(1$ - ind_p $)) * \operatorname{pie}(+1) *(\mathrm{Y}(+1) / \mathrm{Y})=0$;

$$
\begin{aligned}
& \mathrm{C}=\mathrm{c} \_\mathrm{p}+\mathrm{c} \_\mathrm{i}+\mathrm{c} \_\mathrm{e} \\
& \mathrm{h}=\mathrm{h} \_\mathrm{p}+\mathrm{h} \_\mathrm{i}+\mathrm{h} \_\mathrm{e} \\
& \mathrm{B}=\mathrm{b} \_\mathrm{i}+\mathrm{b} \_\mathrm{iw}+\mathrm{b} \_\mathrm{e} \\
& \mathrm{Y}=\mathrm{C}+(\mathrm{K}-(1-\operatorname{deltak}) * \mathrm{~K}(-1))+\left(\mathrm{h}-(1-\operatorname{deltah})^{*} \mathrm{~h}(-1)\right) \\
& \mathrm{PIW}=\left(\mathrm{w} \_\mathrm{p}+\mathrm{w} \_\mathrm{i}\right) /\left(\mathrm{w} \_\mathrm{p}(-1)+\mathrm{w} \_\mathrm{i}(-1)\right)^{*} \mathrm{pie} ;
\end{aligned}
$$$$
/ / \text { - 9) TAYLOR RULE PROFITS CB }
$$

$\left.\left(1+\mathrm{r} \_\mathrm{ib}\right)=\left(1+\mathrm{r} \_\mathrm{ib} \_\mathrm{ss}\right) \wedge\left(1-\mathrm{rho \_} \mathrm{ib}\right) *\left(1+\mathrm{r} \_\mathrm{ib}(-1)\right)^{\wedge}\right)^{\wedge h o \_i b} *((\mathrm{pie} /$ piss $)^{\wedge} \operatorname{phi} \_p i e^{*}(\mathrm{Y} / \mathrm{Y}(-1))^{\wedge}$ phi_y $) \wedge\left(1-\mathrm{rho} \_\mathrm{ib}\right) *\left(1+\mathrm{e} \_\mathrm{r} \_\mathrm{ib}\right)$; 
$/ /$ 10) EXOGENOUS PROCESSES

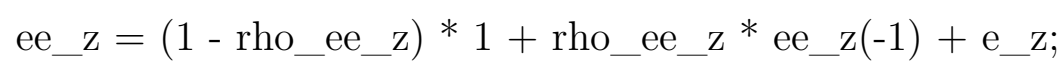

$\mathrm{A} \_\mathrm{e}=\left(1-\mathrm{rho} \_\mathrm{A} \_\mathrm{e}\right) * 1+\mathrm{rho} \_\mathrm{A} \_\mathrm{e}{ }^{*} \mathrm{~A} \_\mathrm{e}(-1)+\mathrm{e} \_\mathrm{A} \_\mathrm{e}$;

ee_j $=(1-$ rho_ee_j $) * 1+$ rho_ee_j $*$ ee_j $(-1)+e \_j$;

$\mathrm{m} \_\mathrm{i}=\left(1-\mathrm{rho \_ mi}\right) * \mathrm{~m} \_\mathrm{i} \_\mathrm{ss}+\mathrm{rho \_ mi} * \mathrm{~m}$ _i $(-1)+\mathrm{e} \_\mathrm{mi} ;$

$\mathrm{m} \_\mathrm{iw}=\left(1-\mathrm{rho \_ miw}\right) * \mathrm{~m} \_\mathrm{iw} \_\mathrm{ss}+\mathrm{rho \_ miw} * \mathrm{~m} \_$iw $(-1)+\mathrm{e} \_$miw

$\mathrm{m} \_\mathrm{e}=\left(1-\mathrm{rho \_ me}\right) * \mathrm{~m} \_\mathrm{e} \_\mathrm{ss}+\mathrm{rho \_ me} * \mathrm{~m} \mathrm{~m} \mathrm{e}(-1)+\mathrm{e} \_\mathrm{me} ;$

$\mathrm{mk} \_\mathrm{d}=\left(1-\mathrm{rho \_ mk \_ d}\right) * \mathrm{mk} \_\mathrm{d} \_\mathrm{ss}+\mathrm{rho} \_\mathrm{mk} \_\mathrm{d} * \mathrm{mk} \_\mathrm{d}(-1)+\mathrm{e} \_\mathrm{mk} \_\mathrm{d}$;

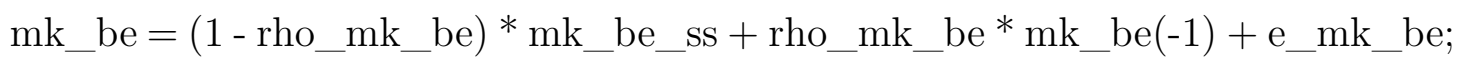

$\mathrm{mk} \_\mathrm{bh}=\left(1-\mathrm{rho \_} \mathrm{mk} \_\mathrm{bh}\right) * \mathrm{mk} \_\mathrm{bh} \_\mathrm{ss}+\mathrm{rho \_}$ mk_bh $* \mathrm{mk} \_\mathrm{bh}(-1)+\mathrm{e} \_\mathrm{mk} \_b h$;

$\mathrm{mk} \_\mathrm{bw}=\left(1-\mathrm{rho \_} \mathrm{mk} \_\mathrm{bw}\right) * \mathrm{mk} \_\mathrm{bw} \_\mathrm{ss}+\mathrm{rho \_ mk \_ bw} * \mathrm{mk} \_\mathrm{bw}(-1)+\mathrm{e} \_\mathrm{mk} \_\mathrm{bw}$;

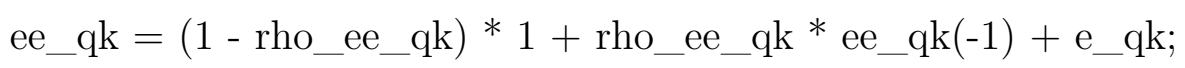

ee_qh $=(1-$ rho_ee_qh $) * 1+$ rho_ee_qh $*$ ee_qh $(-1)+$ e_qh;

eps_y $=(1-$ rho_eps_y $) *$ eps_y_ss + rho_eps_y $*$ eps__y $(-1)+$ e_y;

eps_l $=(1-$ rho_eps_l $) *$ eps_l_ss + rho_eps_l ${ }^{*}$ eps_l $(-1)+$ e_l;

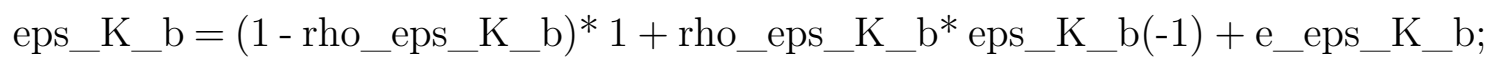

//—11) AUXILIARY VARIABLES

$$
\begin{aligned}
& \text { rr_e }=(1+\text { r_be }) / \operatorname{pie}(+1)-1 \text {; } \\
& \operatorname{aux} 1=\mathrm{C}+\mathrm{K}-(1-\operatorname{deltak}) * \mathrm{~K}(-1)+\mathrm{h}-(1-\operatorname{deltah}) * \mathrm{~h}(-1) \text {; } \\
& \mathrm{bm}=\left(\mathrm{b} \_\mathrm{i}(-1) /\left(\mathrm{b} \_\mathrm{i}(-1)+\mathrm{b} \_\mathrm{e}(-1)\right) * \mathrm{r} \_\mathrm{bh}(-1)+\mathrm{b} \_\mathrm{e}(-1) /\left(\mathrm{b} \_\mathrm{i}(-1)+\mathrm{b} \_\mathrm{e}(-1)\right.\right. \\
& \text { ) * r_be(-1)) - r_d }(-1) \text {; } \\
& \mathrm{spr \_ b}=(1 / 3) * \mathrm{r} \_\mathrm{bh}+(1 / 3) * \mathrm{r} \_\mathrm{be}+(1 / 3) * \mathrm{r} \_\mathrm{bw}-\mathrm{r} \_\mathrm{d} \text {; }
\end{aligned}
$$




$$
\begin{aligned}
& \text { q_k }=1 \text {; } \\
& \mathrm{q} \_\mathrm{h}=1 ; \\
& \text { ee_z }=1 \text {; } \\
& \text { A_e }=1 \text {; } \\
& \text { ee_ } \mathrm{j}=1 \text {; } \\
& \text { ee } \_\mathrm{qk}=1 \text {; } \\
& \text { eps_K_b }=1 \text {; } \\
& \text { ee_qh }=1 \text {; } \\
& \text { r_d }=0.0111 \text {; } \\
& \text { r_bh }=0.0189 \text {; } \\
& \text { r_bw }=0.0198 \text {; } \\
& \text { r_be }=0.0243 \text {; } \\
& \text { R_b = 0.0154; } \\
& \text { r_ib }=0.0154 \text {; } \\
& \mathrm{r} \_\mathrm{k}=\mathrm{r} \_\mathrm{k} \_\mathrm{ss} \text {; } \\
& \mathrm{x}=1.1 ; \\
& \mathrm{mk} \_\mathrm{d}=\mathrm{mk} \_\mathrm{d} \_\mathrm{ss} \text {; } \\
& \mathrm{mk} \_b e=m k \_b e \_s s ; \\
& \mathrm{mk} \_\mathrm{bh}=\mathrm{mk} \_b h \_s s ; \\
& \mathrm{mk} \_b w=m k \_b w \_s s ; \\
& \mathrm{m} \_\mathrm{i}=0.06 \text {; } \\
& \mathrm{m} \_\mathrm{e}=0.007 \text {; } \\
& \mathrm{m} \_\mathrm{iw}=0.1 \text {; } \\
& \text { eps_y }=11 \text {; } \\
& \text { eps_l }=3 \text {; } \\
& \text { lam_p }=0.9506 \text {; } \\
& \text { lam_i }=4.3779 \text {; } \\
& \text { lam_e }=2.4123 \text {; } \\
& \text { s_i }=0.0939 \text {; } \\
& \mathrm{s} \_\mathrm{iw}=0.0903 ;
\end{aligned}
$$




$$
\begin{aligned}
& \text { s_e }=0.0394 \text {; } \\
& \text { c_p }=1.0519 \text {; } \\
& \text { c_ } \mathrm{i}=0.2284 \text {; } \\
& \text { c_e }=0.4145 \text {; } \\
& \text { h_p }=5.8891 \text {; } \\
& \text { h_i }=0.7281 \text {; } \\
& \text { h_e = 1.2977; } \\
& \text { d_p }=0.1068 \text {; } \\
& \text { b_ } \mathrm{i}=0.0418 \text {; } \\
& \text { b_iw }=0.0243 \text {; } \\
& \text { b_e }=0.0625 \text {; } \\
& \text { l_p }=0.7927 \text {; } \\
& \mathrm{l} \mathrm{i}=0.8515 \text {; } \\
& \mathrm{w} \_\mathrm{p}=1.2508 \\
& \mathrm{w} \_\mathrm{i}=0.2911 \text {; } \\
& \mathrm{I}=0.3778 \\
& \mathrm{Ih}=0.1979 \text {; } \\
& \mathrm{K}=10.794 \text {; } \\
& \mathrm{K} \_b=0.0219 \text {; } \\
& \text { y_e }=2.2723 \text {; } \\
& \mathrm{h}=7.9149 \text {; } \\
& \mathrm{C}=1.6948 \text {; } \\
& \mathrm{Y}=2.2723 \\
& \mathrm{~B}=0.1286 \\
& \text { rr_e }=0.0243 \text {; } \\
& \operatorname{aux} 1=2.2705 ; \\
& \mathrm{bm}=\exp (-4.259443) \text {; } \\
& \text { spr_b }=0.0098 \text {; } \\
& \mathrm{J} \_\mathrm{R}=0.2064 \text {; } \\
& \text { j_B }=0.0021 \text {; }
\end{aligned}
$$


end;

steady;

model_diagnostics;

shocks;

var $\mathrm{e}_{-} \mathrm{z}=0.0144^{\wedge} 2$;

$\operatorname{var} \mathrm{e} \_\mathrm{A} \_\mathrm{e}=0.185807999596714^{\wedge} 2$;

$\operatorname{var} \mathrm{e}_{\mathrm{j}} \mathrm{j}=0.0658^{\wedge} 2$;

var e_me $=0.0034^{\wedge} 2$;

var e_mi $=0.0023^{\wedge} 2$;

var e_miw $=0.0023^{\wedge} 2$;

var e_mk $\_d=0.0488^{\wedge} 2$;

var e_mk_bh $=0.0051^{\wedge} 2$;

var e_mk $\_b w=0.0051^{\wedge} 2$;

var e_mk_be $=0.1454^{\wedge} 2$;

var $\mathrm{e} \_\mathrm{qk}=0.0125^{\wedge} 2$;

var e_qh $=0.0125^{\wedge} 2$;

var e_r_ib $=0.0013^{\wedge} 2$;

$\operatorname{var} \mathrm{e} \_\mathrm{y}=1.0099^{\wedge} 2$;

var e $\_l=0.3721^{\wedge} 2$;

var e_eps_ $\mathrm{K}_{b}=0.05 \% 2$;

end;

$/ /$ stoch_simul $($ order $=1, \operatorname{irf}=20)$;

$/ /$

\section{// BAYESIAN ESTIMATION}

$1 /$

varobs Y C I r_ib pie $q \_h j \_B$ b_i b_iw $r \_b w$;

estimated_params ;

// Initial conditions PRIOR shape MEAN STD

stderr e_z , inv_gamma_pdf, 1.0000, 5.00 ;

stderr e_A_e, , inv_gamma_pdf, 1.0000, 5.00 ; 
stderr e_j , , inv_gamma_pdf, 1.0000, 5.00 ;

stderr e_me,, inv_gamma_pdf, 1.0000, 5.00 ;

stderr e_mi , , inv_gamma_pdf, 1.0000, 5.00 ;

stderr e_mk_d , , inv_gamma_pdf, 1.0000, 5.00 ;

stderr e_mk_bh, , inv_gamma_pdf, 1.0000, 5.00 ;

stderr e_mk_be , , inv_gamma_pdf, 1.0000, 5.00 ;

stderr e_qk, , inv_gamma_pdf, 1.0000, 5.00 ;

stderr e_r_ib , , inv_gamma_pdf, 1.0000, 5.00 ;

stderr e_y , , inv_gamma_pdf, 1.0000, 5.00 ;

stderr e_l, , inv_gamma_pdf, 1.0000, 5.00 ;

stderr e_eps_K_b , , inv_gamma_pdf, 1.0000, 5.00 ;

stderr e_miw , , inv_gamma_pdf, 1.0000, 5.00 ;

stderr e_qh , , inv_gamma_pdf, 1.0000, 5.00 ;

rho_ee_z , , beta_pdf, 0.50, 0.25 ;

rho_A_e, , beta_pdf, 0.50, 0.25 ;

rho_ee_j, , beta_pdf, 0.50, 0.25 ;

rho_me, , beta_pdf, 0.50, 0.25 ;

rho_mi, , beta_pdf, $0.50,0.25$;

rho_mk_d, , beta_pdf, 0.50, 0.25 ;

rho_mk_bh, beta_pdf, 0.50, 0.25 ;

rho_mk_be, beta_pdf, $0.50,0.25$;

rho_ee_qk, , beta_pdf, 0.50, 0.25 ;

rho_eps_y, , beta_pdf, 0.50, 0.25 ;

rho_eps_1, , beta_pdf, 0.50, 0.25 ;

rho_eps_K_b, beta_pdf, 0.50, 0.25 ;

rho_miw , beta_pdf, 0.50, 0.25 ;

rho_ee_qh, , beta_pdf, 0.50, 0.25 ;

kappa_p , , gamma_pdf, 50, 20 ;

kappa_w , gamma_pdf, 50, 20 ;

kappa_i , , gamma_pdf, 2.5, 1.0 ; 
kappa_ih , , gamma_pdf, 2.5, 1.0 ;

kappa_d, gamma_pdf, 10, 2.5 ;

kappa_be , gamma_pdf, 3, 2.5 ;

kappa_bh , , gamma_pdf, 6, 2.5;

kappa_bw , gamma_pdf, 6, 2.5 ;

kappa_kb , , gamma_pdf, 10.0, 5.0 ;

phi_pie, , normal_pdf, 2.0, 0.35 ;

rho_ib , , beta_pdf, 0.6, 0.15 ;

phi_y , gamma_pdf, 0.25, 0.10 ;

ind_p , , beta_pdf, 0.65, 0.20 ;

ind_w , , beta_pdf, 0.65, 0.20 ;

a_i , , beta_pdf, 0.85, 0.05 ;

end;

estimation $($ datafile $=$ dados_tese 1, mode_compute $=6$, mh_jscale $=0.30$,presample $=1$,prefilter $=0$,prior_trunc $=1 \mathrm{e}-14$, mh_replic $=100000$, mh_nblocks $=2$ ,filtered_vars , lik_init $=1$, order $=1$, mode_check, $\operatorname{rrf}=40$, bayesian_irf ,nobs $=20$, tex )

\section{B.2 Economia Aberta}

var

c_p // 1 PATIENT HHs

h_p // 2 PATIENT HHs

d_p // 3 PATIENT HHs

l_p // 4 PATIENT HHs

lam_p // 5 PATIENT HHs

J_R // 6 PATIENT HHs

j_B // 7 PATIENT HHs

pie_wp // 8 PATIENT HHs

c_i // 9 IMPATIENT HHs

h_i // 10 IMPATIENT HHs

b_i // 11 IMPATIENT HHs

l_i // 12 IMPATIENT HHs

lam_i // 13 IMPATIENT HHs

s_i // 14 IMPATIENT HHs 
pie_wi // 15 IMPATIENT HHs

I // 16 CAPITAL PRODUCERS

q_k // 17 CAPITAL PRODUCERS

c_e // 18 ENTREPRENEURS

y_e // 23 ENTREPRENEURS

lam_e // 24 ENTREPRENEURS

s_e // 25 ENTREPRENEURS

u // 26 ENTREPRENEURS Capital utilization rate

b_e // 29 BANKS

r_d // 30 BANKS

r_bh // 31 BANKS

r_be // 32 BANKS

$\mathrm{R} \_\mathrm{b} / / 33$ BANKS

K_b // 34 BANKS

pie // 35 RETAILERS

$\mathrm{x} / / 36$ RETAILERS

C // 37 AGGREGATION EQUILIBRIUM

Y // 38 AGGREGATION EQUILIBRIUM

B // 42 AGGREGATION EQUILIBRIUM

w_p // 43 AGGREGATION EQUILIBRIUM

w_i // 44 AGGREGATION EQUILIBRIUM

q_h // 46 AGGREGATION EQUILIBRIUM

K // 47 AGGREGATION EQUILIBRIUM

PIW // 48 AGGREGATION EQUILIBRIUM

$\mathrm{r} \_\mathrm{ib} / / 49$ MONETARY POLICY

$\mathrm{r} \_\mathrm{k} / / 50$ CAPITAL RENTAL RATE

ee_z // 51 EXOGENOUS PROCESSES

A_e // 52 EXOGENOUS PROCESSES

ee_ $\mathrm{j} / / 53$ EXOGENOUS PROCESSES

mk_d // 54 EXOGENOUS PROCESSES

mk_be // 55 EXOGENOUS PROCESSES

mk_bh // 56 EXOGENOUS PROCESSES

ee_qk // 57 EXOGENOUS PROCESSES

m_i // 58 EXOGENOUS PROCESSES (IMPATIENT LTV)

m_e // 59 EXOGENOUS PROCESSES (ENTREPRENEURS LTV)

eps_y // 60 EXOGENOUS PROCESSES

eps_1 // 61 EXOGENOUS PROCESSES

eps_K_b // 62 EXOGENOUS PROCESSES

rr_e // 64 Entrep. Real Rate 
aux1 // 65 auxiliary variable

$\mathrm{bm} / / 66$ banks intermediation margins

spr_b // 67 average bank spread (active-passive)

Ih

ee_qh

s_iw

m_iw

r_bw

b_iw

mk_bw

h_e

$\mathrm{h}$

$\mathrm{pQ}$

$\mathrm{Q}$

er

premium

Rstar

Bstar

ystar

pie_star

y_exp

eps_premium

$\mathrm{y}$

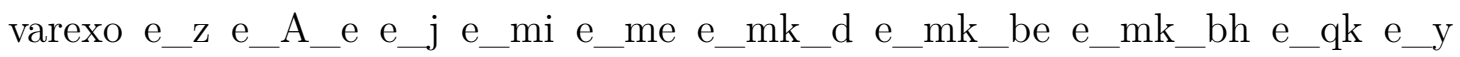
e_r_ib e_l e_eps_K_b e_miw e_mk_bw e_qh e_pQ e_pie_star e_Rstar e_ystar e_eps_premium;

parameters beta_p j phi beta_i m_i_ss beta_e m_e_ss eksi_1 eksi_2 a_i a_p a_e ni eps__l_ss kappa_w eps_d eps_bh eps_be mk_d_ss mk_bh_ss mk_be_ss r_be_ss r_bh_ss r_k_ss beta_b delta_kb vi kappa_kb eps_y_ss kappa_p ind_p ind_w kappa_i kappa_d kappa_be kappa_bh deltak rho_ib phi_pie phi_y piss r_ib_ss rho_ee_z rho_A_e rho_ee_j rho_mi rho_me rho_eps_y rho_mk_d rho_mk_be rho_mk_bh rho_ee_qk rho_eps_l rho_eps_K_b ind_d ind_be ind_bh deltah eps_bw mk_bw_ss r_bw_ss kappa_ih kappa_bw ind_bw m_iw_ss rho_miw rho_mk_bw rho_ee_qh Rstar_ss ystar_ss pie_star_ss alphak alphal chi tau zeta rho_ystar rho_pie_star rho_Rstar rho_pQ rho_eps_premium 


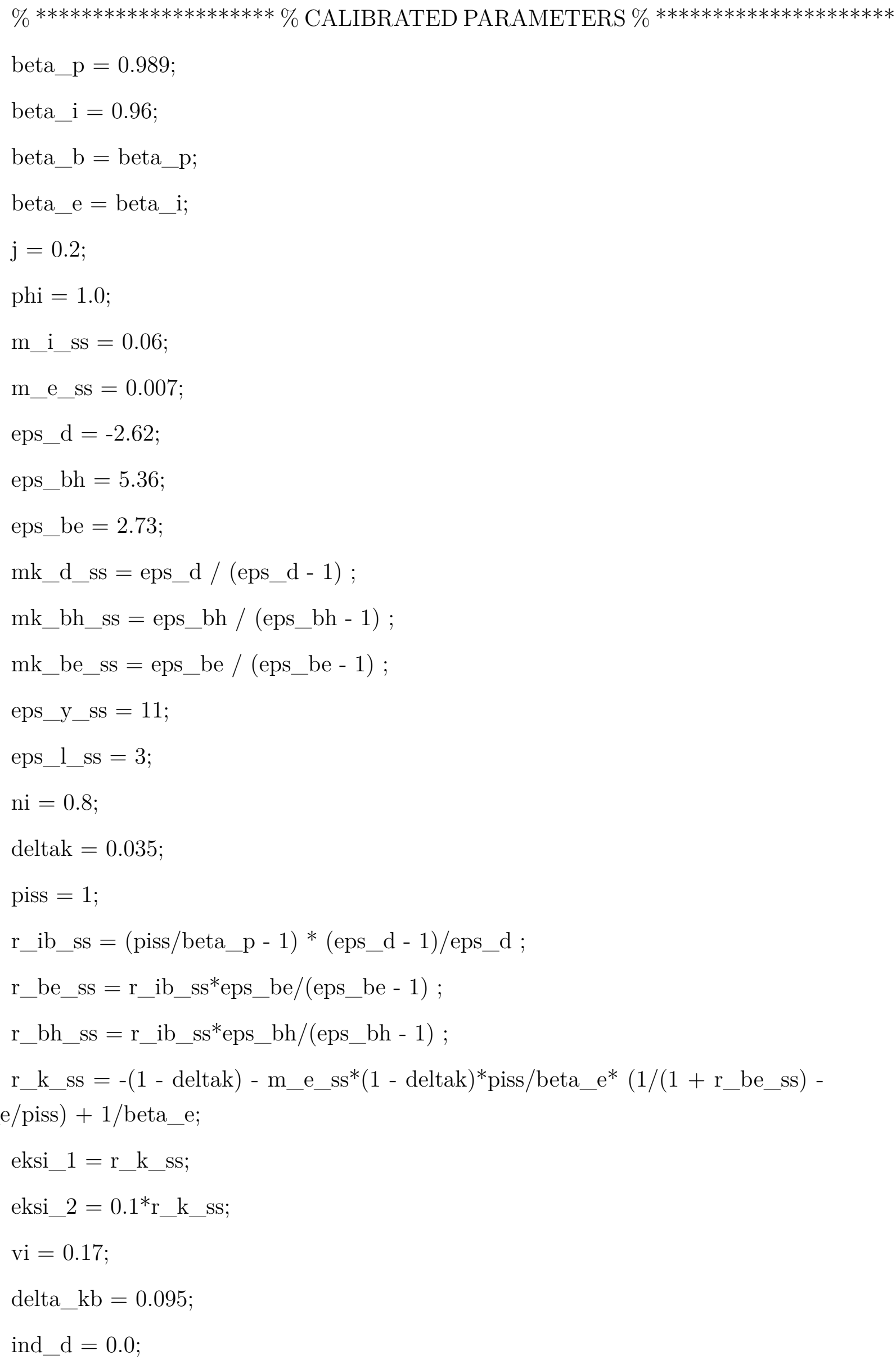




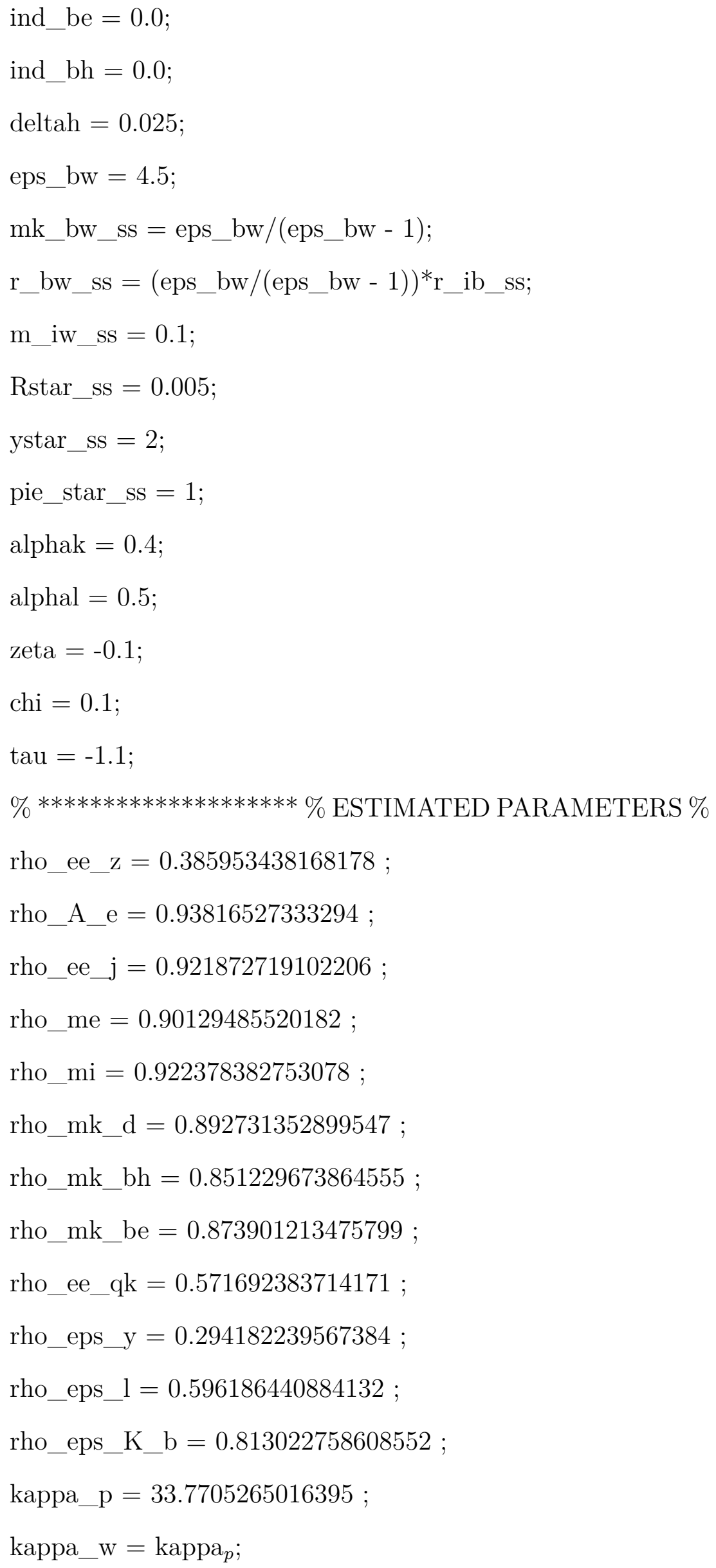


kappa_i $=10.0305562248008$;

kappa_d $=2.77537377104213$;

kappa_be $=7.98005959044637$;

kappa_bh $=9.04426718749482$;

kappa_kb $=8.91481958034669$;

phi_pie $=2.00384780180824$;

rho_ib $=0.750481873084311$;

phi_y $=0.303247771697294$;

ind_p $=0.158112794106546$;

ind_w $=0.300197804017489$;

a_i $=0.867003766306404$;

a_e $=0.0 ;$

a_p $=0.0$;

kappa_ih = kappa_i;

kappa_bw = kappa_bh;

ind _ bw = ind_bh;

rho_miw $=$ rho_mi;

rho_mk_bw $=$ rho_miw;

rho_ee_qh $=$ rho_ee_qk;

rho_ystar $=0.9$;

rho_pie_star $=0.9$;

rho_Rstar $=0.9$;

rho_pQ $=0.9$;

rho_eps_premium $=0.9$;

$/ / / / 1$

model;

//*********** 1) PATIENT HHs

$\left(1-\mathrm{a} \_\mathrm{i}\right) *$ ee_z $*\left(\mathrm{c} \_\mathrm{p}-\mathrm{a} \_\mathrm{i} * \mathrm{c} \_\mathrm{p}(-1)\right)^{\wedge}(-1)=\mathrm{lam} \_\mathrm{p}$

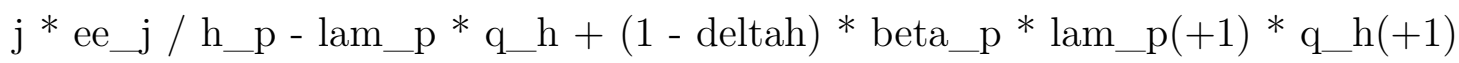
$=0$; 
lam_p = beta_p $*$ lam_p $(+1) *\left(1+\mathrm{r} \_\mathrm{d}\right) / \mathrm{pie}(+1)$;

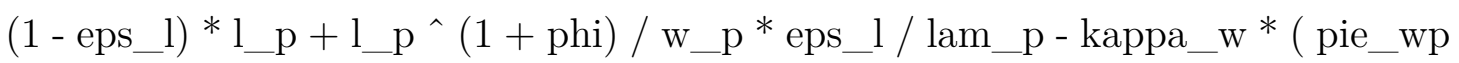

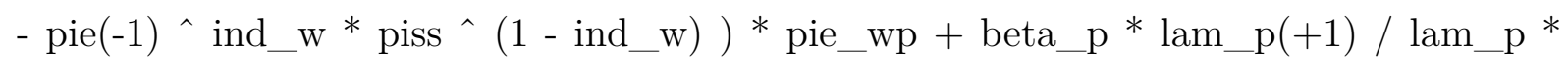
kappa_w $*\left(\text { pie_wp }(+1)-\text { pie }^{\wedge} \text { ind__w } * \text { piss }{ }^{\wedge}(1-\text { ind__w })\right)^{*}$ pie_wp $(+1) \wedge 2 /$ pie $=$ 0 ;

pie_wp $=\mathrm{w} \_\mathrm{p} / \mathrm{w} \_\mathrm{p}(-1) *$ pie;

$\mathrm{c} \_\mathrm{p}+\mathrm{q} \_\mathrm{h} *\left(\mathrm{~h} \_\mathrm{p}-(1-\operatorname{deltah}) * \mathrm{~h} \_\mathrm{p}(-1)\right)+\mathrm{d} \_\mathrm{p}=\mathrm{w} \_\mathrm{p} * \mathrm{l} \_\mathrm{p}+\left(1+\mathrm{r} \_\mathrm{d}(-1)\right)$ * d__p $(-1) /$ pie + J_R;

\section{$/ / * * * * * * * * * * * 2)$ IMPATIENT HHs}

$\left(1-\mathrm{a} \_\mathrm{i}\right) *$ ee_z $*\left(\mathrm{c} \_\mathrm{i}-\mathrm{a} \_\mathrm{i} * \mathrm{c} \_\mathrm{i}(-1)\right)^{\wedge}(-1)=\mathrm{lam} \_\mathrm{i} ;$

$\mathrm{j} *$ ee_j / h_i - lam_i $* \mathrm{q} \_\mathrm{h}+(1-\operatorname{deltah}) *\left(\operatorname{beta} \_\mathrm{i} * \mathrm{lam \_ i}(+1) * \mathrm{q} \_\mathrm{h}(+1)+\right.$ $\left.\mathrm{s} \_\mathrm{i} * \mathrm{~m} \_\mathrm{i} * \mathrm{q} \_\mathrm{h}(+1) * \operatorname{pie}(+1)\right)=0$;

lam_i - beta_i $*$ lam_i $(+1) *\left(1+\mathrm{r} \_b h\right) / \mathrm{pie}(+1)=\mathrm{s} \_\mathrm{i} *\left(1+\mathrm{r} \_b h\right)$;

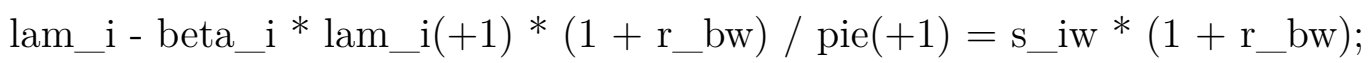

$\left(1-\operatorname{eps} \_l\right) * 1 \_\mathrm{i}+\mathrm{eps \_ l} * \mathrm{l} \_\mathrm{i} \wedge(1+\mathrm{phi}) /\left(\mathrm{w} \_\mathrm{i} *\left(\mathrm{lam \_ i}+\mathrm{m} \_\mathrm{iw} * \mathrm{~s} \_\mathrm{iw}\right)\right)$ - kappa_w $*\left(\right.$ pie_wi $-\operatorname{pie}(-1) \wedge$ ind_w $* \operatorname{piss}^{\wedge}(1-$ ind_w $\left.)\right) *$ pie_wi + beta_i $*\left(\right.$ lam_i $\left.(+1)+\mathrm{s} \_\mathrm{iw}(+1)+\mathrm{m} \_\mathrm{iw}(+1)\right) /\left(\mathrm{lam \_ i}+\mathrm{s} \_\mathrm{iw}+\mathrm{m} \_\mathrm{iw}\right) *$ kappa_w$*($ pie_wi $(+1)-$ pie $^{\wedge}$ ind_w $*$ piss ${ }^{\wedge}(1-$ ind_w $\left.)\right) *$ pie_wi $(+1)^{\wedge} 2 / \operatorname{pie}(+1)=0$;

pie_wi $=\mathrm{w} \_\mathrm{i} / \mathrm{w} \_\mathrm{i}(-1) *$ pie;

$\mathrm{c} \_\mathrm{i}+\mathrm{q} \_\mathrm{h} *\left(\mathrm{~h} \_\mathrm{i}-(1-\operatorname{deltah}) * \mathrm{~h} \_\mathrm{i}(-1)\right)+\left(1+\mathrm{r} \_\mathrm{bh}(-1)\right) * \mathrm{~b} \_\mathrm{i}(-1) / \mathrm{pie}+(1$

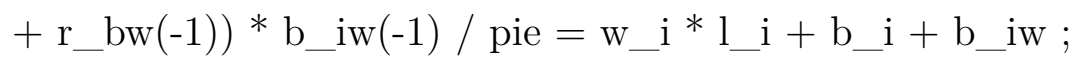

$\left(1+\mathrm{r} \_b h\right) * b \_i=m \_i * q\left[h(+1) * h \_i * p i e(+1)\right.$;

$\left(1+\mathrm{r} \_\mathrm{bw}\right) * \mathrm{~b} \_\mathrm{iw}=\mathrm{m} \_\mathrm{iw} * \mathrm{w} \_\mathrm{i}(+1) * \mathrm{l} \_\mathrm{i}(+1) * \operatorname{pie}(+1)$;

// $* * * * * * * * * * *$ 3) CAPITAL PRODUCERS $* * * * * * * * * * * * * * * * * * * * * * * * * * * * * * * * * * * * * *$

$\mathrm{K}=(1-\operatorname{deltak}) * \mathrm{~K}(-1)+\left(1-\mathrm{kappa} \_\mathrm{i} / 2 *(\mathrm{I} *\right.$ ee_qk $\left./ \mathrm{I}(-1)-1) \wedge 2\right) * \mathrm{I}$;

$1=\mathrm{q} \_\mathrm{k} *\left(1-\mathrm{kappa \_ i} / 2 *(\mathrm{I} * \text { ee_qk } / \mathrm{I}(-1)-1)^{\wedge} 2-\mathrm{kappa \_ i} *(\mathrm{I} *\right.$ ee_qk $/ \mathrm{I}(-1)-1) * \mathrm{I} *$ ee_qk / I (-1) ) + beta_e $*$ lam_e $(+1) /$ lam_e $*$ q_k $(+1) *$ kappa_i $*(\mathrm{I}(+1) *$ ee_qk $(+1) / \mathrm{I}-1) *$ ee_qk $(+1) *(\mathrm{I}(+1) / \mathrm{I}) \wedge 2$;

$/ /$ / *********** 4) HOUSING PRODUCERS $* * * * * * * * * * * * * * * * * * * * * * * * * * * * * * * * * * * *$

$\mathrm{h}=(1-\operatorname{deltah}) * \mathrm{~h}(-1)+\left(1-\mathrm{kappa} \_\mathrm{ih} / 2 *(\mathrm{Ih} *\right.$ ee_qh $\left./ \mathrm{I}(-1)-1) \wedge 2\right) * \mathrm{Ih}$;

$1=\mathrm{q} \_\mathrm{h} *\left(1-\mathrm{kappa} \_\mathrm{ih} / 2 *(\mathrm{Ih} * \text { ee_qh } / \mathrm{Ih}(-1)-1)^{\wedge} 2-\mathrm{kappa} \_\mathrm{ih} *(\mathrm{Ih} *\right.$ ee_qh $/ \operatorname{Ih}(-1)-1) * \mathrm{Ih} *$ ee_qh $/ \operatorname{Ih}(-1))+$ beta_e $*$ lam_e $(+1) /$ lam_e $*$ q_h $(+1)$ * kappa_ih * $(\operatorname{Ih}(+1) *$ ee_qh $(+1) / \mathrm{Ih}-1) *$ ee_qh $(+1) *(\operatorname{Ih}(+1) / \mathrm{Ih}) \wedge 2$; 


\section{$/ /$ /************5) ENTREPRENEURS}

$\left(1-\mathrm{a} \_\mathrm{i}\right) *\left(\mathrm{c} \_\mathrm{e}-\mathrm{a} \_\mathrm{i} * \mathrm{c} \_\mathrm{e}(-1)\right) \wedge(-1)=\mathrm{lam} \_\mathrm{e} ;$

s_e ${ }^{*} \mathrm{~m} \_\mathrm{e}^{*} \mathrm{q} \_\mathrm{k}(+1) * \operatorname{pie}(+1) *(1-$ deltak $)+$ beta_e $*$ lam_e $(+1) *\left(\mathrm{q} \_\mathrm{k}(+1)\right.$

$*(1-\operatorname{deltak})+\mathrm{r} \_\mathrm{k}(+1) * \mathrm{u}(+1)-\left(\operatorname{eksi} 1^{*}(\mathrm{u}(+1)-1)+\right.$ eksi_2 / $2 *((\mathrm{u}(+1)-1)$ ^

2 ) ) ) $=$ lam_e ${ }^{*}$ q_k ;

$\mathrm{j} *$ ee $\_\mathrm{j} / \mathrm{h} \_\mathrm{e}-\mathrm{lam} \_\mathrm{e}^{*} \mathrm{q} \_\mathrm{h}+(1-\operatorname{deltah}) *\left(\operatorname{beta\_ } \mathrm{e}^{*} \operatorname{lam} \_\mathrm{e}(+1){ }^{*} \mathrm{q} \_\mathrm{h}(+1)\right.$ $\left.+\mathrm{s} \_\mathrm{e}^{*} \mathrm{~m} \_\mathrm{e}{ }^{*} \mathrm{q} \_\mathrm{h}(+1) * \operatorname{pie}(+1)\right)=0$;

$\mathrm{w} \_\mathrm{p}=\mathrm{ni} *$ alphal $* \mathrm{y} \_\mathrm{e} /\left(\mathrm{l} \_\mathrm{p} * \mathrm{x}\right)$;

$\mathrm{w} \_\mathrm{i}=(1-\mathrm{ni}) *$ alphal $* \mathrm{y} \_\mathrm{e} /\left(\mathrm{l} \_\mathrm{i} * \mathrm{x}\right)$;

er*pQ $=(1-$ alphak - alphal $){ }^{*} \mathrm{y}_{\text {_e }} /\left(\mathrm{Q}^{*} \mathrm{x}\right)$;

lam_e-s_e ${ }^{*}\left(1+\mathrm{r} \_b e\right)=$ beta_e ${ }^{*}$ lam_e $(+1) *\left(1+\mathrm{r} \_b e\right) / \mathrm{pie}(+1)$;

$\mathrm{r} \_\mathrm{k}=$ eksi_1 + eksi_2 $*(\mathrm{u}-1)$;

$\left.\mathrm{c} \_\mathrm{e}+\left(\left(1+\mathrm{r} \_\mathrm{be}(-1)\right) * \mathrm{~b} \_\mathrm{e}(-1)\right) / \mathrm{pie}\right)+\mathrm{q} \_\mathrm{h} *\left(\mathrm{~h} \_\mathrm{e}-(1-\operatorname{deltah}) * \mathrm{~h} \_\mathrm{e}(-1)\right)$ $+\mathrm{w} \_\mathrm{p} * \mathrm{l} \_\mathrm{p}+\mathrm{w} \_\mathrm{i} * \mathrm{l} \_\mathrm{i}+\mathrm{q} \_\mathrm{k} * \mathrm{~K}+\left(\right.$ eksi_1* $\left.(\mathrm{u}-1)+\mathrm{eksi} \_2 / 2 *(\mathrm{u}-1)^{\wedge} 2\right)$ $* \mathrm{~K}(-1)+\mathrm{er}^{*} \mathrm{pQ} * \mathrm{Q}=\mathrm{y} \_\mathrm{e} / \mathrm{x}+\mathrm{b} \_\mathrm{e}+\mathrm{q} \_\mathrm{k} *(1-\operatorname{deltak}) * \mathrm{~K}(-1)$;

$\mathrm{y \_} \_=\mathrm{A} \_\mathrm{e} *(\mathrm{u} * \mathrm{~K}(-1))^{\wedge}(\operatorname{alphak}) *\left(\left(\mathrm{l} \_\mathrm{p}\right) \wedge \mathrm{ni} *\left(\mathrm{l} \_\mathrm{i}\right) \wedge(1-\mathrm{ni})\right)^{\wedge}(\text { alphal }) *$ (Q)^(1 - alphak - alphal);

$\left(1+\mathrm{r} \_\right.$be $) * \mathrm{~b} \_\mathrm{e}=\mathrm{m} \_\mathrm{e} *\left(\mathrm{q} \_\mathrm{k}(+1) * \operatorname{pie}(+1) * \mathrm{~K} *(1-\operatorname{deltak})+\mathrm{q} \_\mathrm{h}(+1) *\right.$ $\left.\operatorname{pie}(+1) * \mathrm{~h} \_\mathrm{e} *(1-\operatorname{deltah})\right)$;

$\mathrm{r} \_\mathrm{k}=\operatorname{alphak} *$ A_e $*(\mathrm{u}) \wedge(\operatorname{alphak}-1) *(\mathrm{~K}(-1))^{\wedge}(\operatorname{alphak}-1) *\left(\left(\mathrm{l} \_\mathrm{p}\right) \wedge \mathrm{ni} *\right.$ $\left.\left(1 \_\mathrm{i}\right) \wedge(1-\mathrm{ni})\right)^{\wedge}($ alphal $) *(\mathrm{Q}) \wedge(1-$ alphak - alphal $) / \mathrm{x}$;

$/ / * * * * * * * * * * * * *$ 5) $\mathrm{BANKS} * * * * * * * * * * * * * * * * * * * * * * * * * * * * * * * * * * * * * * * * * * * * * * * * * *$

$\mathrm{R} \_\mathrm{b}=-\mathrm{kappa} \_\mathrm{kb} *\left(\mathrm{~K} \_\mathrm{b} / \mathrm{B}-\mathrm{vi}\right) *\left(\mathrm{~K} \_\mathrm{b} / \mathrm{B}\right) \wedge 2+\mathrm{r} \_\mathrm{ib}$;

$\mathrm{K} \_\mathrm{b} * \mathrm{pie}=\left(1-\right.$ delta_kb) $* \mathrm{~K} \_\mathrm{b}(-1) /$ eps_K_b $+\mathrm{j} \_\mathrm{B}(-1)$;

b_i + b_iw + b_e $=d \_p+e r *$ Bstar + K_b;

premium $=\exp \left(-\right.$ zeta $*$ er $*$ Bstar $\left./ \mathrm{K} \_\mathrm{b}\right) *$ eps_premium;

$(1+$ Rstar $) *$ premium * $(1-$ zeta $*$ er $*$ Bstar / K_b $) *(\operatorname{er}(+1) /$ er $) *(\operatorname{pie}(+1)$ $/$ pie_star $(+1))=1+$ r__ib;

$-1+\mathrm{mk} \_\mathrm{d} /\left(\mathrm{mk} \_\mathrm{d}-1\right)-\mathrm{mk} \_\mathrm{d} /\left(\mathrm{mk} \_\mathrm{d}-1\right) * \mathrm{r} \_\mathrm{ib} / \mathrm{r} \_\mathrm{d}-\mathrm{kappa} \_\mathrm{d} *($ $\left.\mathrm{r} \_\mathrm{d} / \mathrm{r} \_\mathrm{d}(-1)-1\right) * \mathrm{r} \_\mathrm{d} / \mathrm{r} \_\mathrm{d}(-1)+\operatorname{beta\_ p} *\left(\mathrm{lam} \_\mathrm{p}(+1) / \mathrm{lam} \_\mathrm{p}\right) *$ kappa $\_\mathrm{d} *($ $\mathrm{r} \_\mathrm{d}(+1) / \mathrm{r} \_\mathrm{d}-\left(\mathrm{r} \_\mathrm{d} / \mathrm{r} \_\mathrm{d}(-1)\right)^{\wedge}$ ind $\left.\_\mathrm{d}\right) *\left(\left(\mathrm{r} \_\mathrm{d}(+1) / \mathrm{r} \_\mathrm{d}\right) \wedge 2\right) *\left(\mathrm{~d} \_\mathrm{p}(+1) /\right.$ d__p) $=0$;

+1 - mk_be $/($ mk_be -1$)+$ mk_be $/($ mk_be -1$) *$ R_b / r_be - kappa_be $*$ 


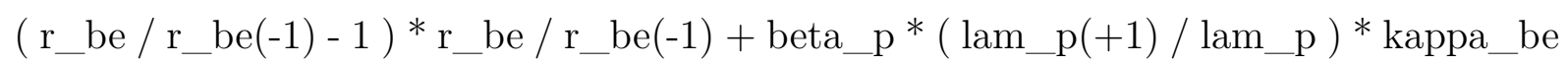
$*\left(\mathrm{r} \_b e(+1) / \mathrm{r} \_b e-\left(\mathrm{r} \_b e / \mathrm{r} \_b e(-1)\right) \wedge\right.$ ind_be $) *\left(\left(\mathrm{r} \_b e(+1) / \mathrm{r} \_b e\right) \wedge 2\right) *($ b_e $(+1) /$ b_e $)=0$;

$+1-\mathrm{mk} \_b h /\left(\mathrm{mk} \_b h-1\right)+\mathrm{mk} \_b h /\left(\mathrm{mk} \_b h-1\right) * \mathrm{R} \_\mathrm{b} / \mathrm{r} \_b h-k a p p a \_b h$

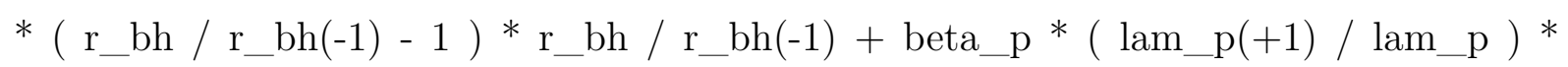
kappa_bh $*\left(\mathrm{r} \_b h(+1) / \mathrm{r} \_b h-\left(\mathrm{r} \_b h / \mathrm{r} \_b h(-1)\right) \wedge\right.$ ind $\left.\_b h\right) *\left(\left(\mathrm{r} \_b h(+1) / \mathrm{r} \_b h\right)\right.$ ^ 2$) *($ b_i $(+1) /$ b_i $)=0$;

$+1-\mathrm{mk} \_b w /\left(m k \_b w-1\right)+m k \_b w /\left(m k \_b w-1\right) * R \_b / r \_b w-k a p p a \_b w$ * $\left(\mathrm{r} \_b w / \mathrm{r} \_b w(-1)-1\right) * \mathrm{r} \_b w / \mathrm{r} \_b w(-1)+\operatorname{beta\_ p} *\left(\operatorname{lam} \_\mathrm{p}(+1) / \mathrm{lam} \_\mathrm{p}\right) *$ kappa_bw $*\left(\mathrm{r} \_b w(+1) / \mathrm{r} \_b w-\left(\mathrm{r} \_b w / r \_b w(-1)\right) \wedge\right.$ ind _ bw $) *\left(\left(r \_b w(+1) /\right.\right.$ r_bw $) \wedge 2) *($ b_iw $(+1) /$ b_iw $)=0$;

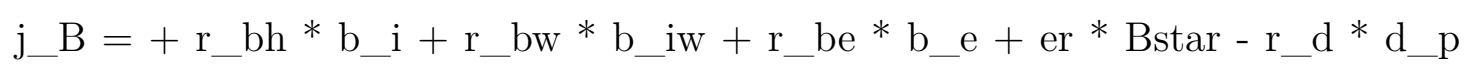
- kappa_d / $2 *\left(\left(\mathrm{r} \_\mathrm{d} / \mathrm{r} \_\mathrm{d}(-1)-1\right) \wedge 2\right) * \mathrm{r} \_\mathrm{d} * \mathrm{~d} \_\mathrm{p}-\mathrm{kappa} \_b e / 2 *\left(\left(\mathrm{r} \_\right.\right.$be $/$ r_be(-1) - 1)^2 $)^{*} \mathrm{r} \_b e^{*}$ b_e - kappa_bh $/ 2 *\left(\left(\mathrm{r} \_b h / r \_b h(-1)-1\right) \wedge 2\right) * r \_b h *$ b_i - kappa_bw $/ 2 *\left(\left(\mathrm{r} \_b w / r \_b w(-1)-1\right) \wedge 2\right) * r \_b w * b \_i w-k a p p a \_k b / 2 *($ $\left.\left(\mathrm{K} \_\mathrm{b} / \mathrm{B}-\mathrm{vi}\right) \wedge 2\right) * \mathrm{~K} \_\mathrm{b}-(1+\operatorname{Rstar}(-1)) * \operatorname{premium}(-1) *$ er $* \operatorname{Bstar}(-1)$;

//************* 6)RETAILERS $* * * * * * * * * * * * * * * * * * * * * * * * * * * * * * * * * * * * * * * * * * * * * * * * *$

$\mathrm{J} \_\mathrm{R}=\mathrm{y}^{*}\left(1-1 / \mathrm{x}-\left(\mathrm{kappa} \_\mathrm{p} / 2\right) *\left(\mathrm{pie}-\left(\mathrm{pie}(-1)^{\wedge}\right.\right.\right.$ ind_p $*$ piss $`(1-$ ind_p $)$ )) 2$)$

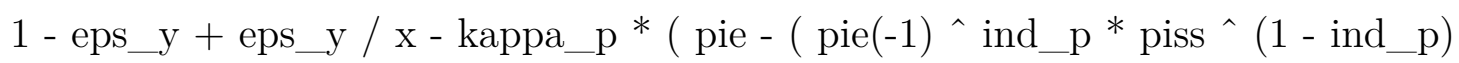
)$)^{*}$ pie + beta_p ${ }^{*}\left(\operatorname{lam} \_\mathrm{p}(+1) / \operatorname{lam\_ p}\right)^{*}$ kappa_p $*\left(\operatorname{pie}(+1)-\left(\mathrm{pie}^{\wedge}\right.\right.$ ind _p ${ }^{*}$ piss ^ $(1$ - ind_p $)) * \operatorname{pie}(+1) *(\mathrm{y}(+1) / \mathrm{y})=0$;

$$
\begin{array}{rl} 
& / / * * * * * * * * * * * * 7) \text { AGGREGATION EQUILIBRIUM } * * * * * * * * * * * * * * * * * * * * * * * * \\
& \mathrm{C}=\mathrm{c} \_\mathrm{p}+\mathrm{c} \_\mathrm{i}+\mathrm{c} \_\mathrm{e} ; \\
& \mathrm{y} \_\mathrm{exp}=\mathrm{chi} *(1 / \mathrm{er}) \wedge(-\mathrm{tau}) * \mathrm{ystar} ; \\
& \mathrm{y} \_\mathrm{exp}-\mathrm{er} * \mathrm{pQ} * \mathrm{Q}-\left((1+\mathrm{R} \operatorname{star}(-1)) / \mathrm{pie} \_\mathrm{star}\right) * \operatorname{premium}(-1) * \mathrm{er} * \operatorname{Bstar}(-1) \\
=\mathrm{er} * & \mathrm{Bstar}-\mathrm{er} * \operatorname{Bstar}(-1) / \mathrm{pie} \_\mathrm{star} ; \\
& \mathrm{h}=\mathrm{h} \_\mathrm{p}+\mathrm{h} \_\mathrm{i}+\mathrm{h} \_\mathrm{e} ; \\
& \mathrm{B}=\mathrm{b} \_\mathrm{i}+\mathrm{b} \_\mathrm{i}+\mathrm{b} \_\mathrm{e} ; \\
& \mathrm{y}=\mathrm{C}+(\mathrm{K}-(1-\mathrm{deltak}) * \mathrm{~K}(-1))+(\mathrm{h}-(1-\mathrm{deltah}) * \mathrm{~h}(-1))+\mathrm{y} \_\mathrm{exp} ; \\
& \mathrm{Y}=\mathrm{y}-\mathrm{er} * \mathrm{pQ} * \mathrm{Q} ; \\
& \mathrm{PIW}=\left(\mathrm{w} \_\mathrm{p}+\mathrm{w} \_\mathrm{i}\right) /\left(\mathrm{w} \_\mathrm{p}(-1)+\mathrm{w} \_\mathrm{i}(-1)\right) * \mathrm{pie} ; \\
& / / * * * * * * * * * * 8) \mathrm{TAYLOR} \mathrm{RULE} \operatorname{PROFITS~CB} * * * * * * * * * * * * * * * * * * * * * * * * *
\end{array}
$$$$
\left(1+\mathrm{r} \_\mathrm{ib}\right)=\left(1+\mathrm{r} \_\mathrm{ib} \_\mathrm{ss}\right) \wedge\left(1-\mathrm{rho \_ ib}\right) *\left(1+\mathrm{r} \_\mathrm{ib}(-1)\right) \wedge \mathrm{rho \_ ib} *((\mathrm{pie} /
$$ 
piss $)^{\wedge}$ phi_pie $*(\mathrm{Y} / \mathrm{Y}(-1))^{\wedge}$ phi_y $)^{\wedge}\left(1-\mathrm{rho} \_\mathrm{ib}\right) *\left(1+\mathrm{e} \_\mathrm{r} \_\mathrm{ib}\right)$;

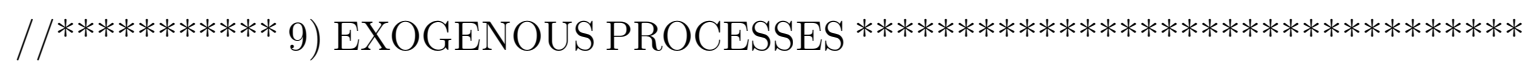
ee_z $=(1-$ rho_ee_z $) * 1+$ rho_ee_z $*$ ee_z $(-1)+$ e_z;

$\mathrm{A} \_\mathrm{e}=\left(1-\mathrm{rho} \_\mathrm{A} \_\mathrm{e}\right) * 1+\mathrm{rho} \_\mathrm{A} \_\mathrm{e}{ }^{*} \mathrm{~A} \_\mathrm{e}(-1)+\mathrm{e} \_\mathrm{A} \_\mathrm{e}$;

ee_j $=(1-$ rho_ee_j $) * 1+$ rho_ee_ $\mathrm{j} *$ ee_ $\mathrm{j}(-1)+$ e_ $\mathrm{j}$;

$\mathrm{m} \_\mathrm{i}=\left(1-\mathrm{rho \_ mi}\right) * \mathrm{~m} \_\mathrm{i} \_s s+\mathrm{rho \_ mi} * \mathrm{~m} \_\mathrm{i}(-1)+\mathrm{e} \_\mathrm{mi}$

$\mathrm{m} \_\mathrm{iw}=\left(1-\mathrm{rho} \_\mathrm{miw}\right) * \mathrm{~m} \_\mathrm{iw} \_\mathrm{ss}+\mathrm{rho} \_\mathrm{miw} * \mathrm{~m} \_\mathrm{iw}(-1)+\mathrm{e} \_\mathrm{miw} ;$

$\mathrm{m} \_\mathrm{e}=\left(1-\mathrm{rho \_} \mathrm{me}\right) * \mathrm{~m} \_\mathrm{e} \_\mathrm{ss}+\mathrm{rho \_ me} * \mathrm{~m} \_\mathrm{e}(-1)+\mathrm{e} \_\mathrm{me} ;$

$\mathrm{mk} \_\mathrm{d}=\left(1-\mathrm{rho \_ mk} \_\mathrm{d}\right) * \mathrm{mk} \_\mathrm{d} \_\mathrm{ss}+\mathrm{rho} \_\mathrm{mk} \_\mathrm{d} * \mathrm{mk} \_\mathrm{d}(-1)+\mathrm{e} \_\mathrm{mk} \_\mathrm{d}$;

$\mathrm{mk} \_b e=\left(1-\mathrm{rho} \_\mathrm{mk} \_b e\right){ }^{*} \mathrm{mk} \_b e \_s s+\mathrm{rho} \_\mathrm{mk} \_b{ }^{*} \mathrm{mk} \_b e(-1)+\mathrm{e} \_\mathrm{mk} \_b e ;$

$\mathrm{mk} \_\mathrm{bh}=\left(1-\mathrm{rho \_} \mathrm{mk} \_\mathrm{bh}\right) * \mathrm{mk} \_\mathrm{bh} \_\mathrm{ss}+\mathrm{rho \_ mk \_ bh} * \mathrm{mk} \_\mathrm{bh}(-1)+\mathrm{e} \_\mathrm{mk} \_b h$;

$\mathrm{mk} \_\mathrm{bw}=\left(1-\mathrm{rho \_ mk \_ bw}\right) * \mathrm{mk} \_b w \_s s+\mathrm{rho \_ mk} \_b w * m k \_b w(-1)+\mathrm{e} \_\mathrm{mk} \_b w ;$

ee_qk $=(1-$ rho_ee_qk $) * 1+$ rho_ee_qk $*$ ee_qk $(-1)+$ e_qk;

ee_qh $=(1-$ rho_ee_qh $) * 1+$ rho_ee_qh $*$ ee_qh $(-1)+$ e_qh;

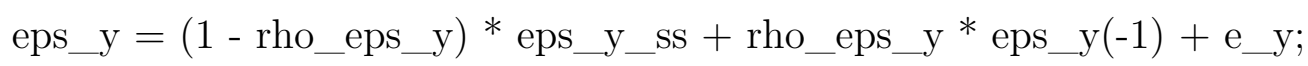

eps_l $=(1-$ rho_eps_l $) *$ eps_l__ss + rho_eps_l $*$ eps_l $(-1)+$ e_l

eps_K_b $=(1-\text { rho_eps_K_b })^{*} 1+$ rho_eps_K_b ${ }^{*}$ eps_K_b $(-1)+$ e_eps_K_b;

eps_premium $=(1-$ rho_eps_premium $) * 1+$ rho_eps_premium $*$ eps_premium $(-$

1) + e_eps_premium;

$\mathrm{pQ}=\left(1-\mathrm{rho} \_\mathrm{pQ}\right) * 1+\mathrm{rho} \_\mathrm{pQ} * \mathrm{pQ}(-1)+\mathrm{e} \_\mathrm{pQ}$

Rstar $=(1$ - rho_Rstar $) *$ Rstar_ss + rho_Rstar $*$ Rstar $(-1)+$ e_Rstar;

ystar $=(1$ - rho_ystar $) *$ ystar_ss + rho_ystar $*$ ystar $(-1)+$ e_ystar;

pie_star $=(1 \text { - rho_pie_star })^{*}$ pie_star_ss + rho_pie_star* pie_star $(-1)+$ e_pie_star;

// $* * * * * * * * * * * 10)$ AUXILIARY VARIABLES $* * * * * * * * * * * * * * * * * * * * * * * * * * * * * * * * * *$

rr_e $=(1+$ r_be $) / \operatorname{pie}(+1)-1$;

aux $1=\mathrm{C}+\mathrm{K}-(1-\text { deltak })^{*} \mathrm{~K}(-1)+\mathrm{h}-(1-\operatorname{deltah})^{*} \mathrm{~h}(-1)$;

$\mathrm{bm}=\left(\mathrm{b} \_\mathrm{i}(-1) /\left(\mathrm{b} \_\mathrm{i}(-1)+\mathrm{b} \_\mathrm{iw}(-1)+\mathrm{b} \_\mathrm{e}(-1)\right) * \mathrm{r} \_\mathrm{bh}(-1)+\mathrm{b} \_\mathrm{iw}(-1) /\left(\mathrm{b} \_\mathrm{i}(-\right.\right.$

$\left.1)+b \_i w(-1)+b \_e(-1)\right) *$ r _ bw $(-1)+b \_e(-1) /\left(b \_i(-1)+b \_i w(-1)+b \_e(-1)\right) *$

r_be $(-1))-\mathrm{r} \_\mathrm{d}(-1)$;

$\mathrm{spr} \_\mathrm{b}=(1 / 3) * \mathrm{r} \_\mathrm{bh}+(1 / 3) * \mathrm{r} \_\mathrm{be}+(1 / 3) * \mathrm{r} \_\mathrm{bw}-\mathrm{r} \_\mathrm{d} ;$ 
end;

initval;

pie $=1$

pie_wp $=1$;

pie_wi $=1$;

$\mathrm{PIW}=1$;

$\mathrm{u}=1$;

$\mathrm{q} \_\mathrm{k}=1$;

$\mathrm{q} \_\mathrm{h}=1$;

ee_ $\_$z $=1$;

A_e $=1$;

ee_ $\mathrm{j}=1$;

ee_qk $=1$;

eps_K_b = 1;

ee_qh $=1$;

eps_premium $=1$;

$\mathrm{pQ}=1 ;$

pie_star $=1$;

Rstar $=0.005$;

ystar $=2$;

r_d = 0.0111;

r_bh $=0.0189$;

r_bw $=0.0198$;

r_be =0.0243;

R_b = 0.0154;

$\mathrm{r} \_\mathrm{ib}=0.0154$;

$\mathrm{r} \_\mathrm{k}=\mathrm{r} \_\mathrm{k} \_\mathrm{ss}$;

$\mathrm{x}=1.1$;

$\mathrm{mk} \_\mathrm{d}=\mathrm{mk} \_\mathrm{d} \_\mathrm{ss}$;

mk_be $=$ mk_be_ss; 


$$
\begin{aligned}
& \mathrm{mk} \_b h=m k \_b h \_s s ; \\
& \mathrm{mk} \_b w=m k \_b w \_s s ; \\
& \mathrm{m} \_\mathrm{i}=0.06 \text {; } \\
& \mathrm{m} \_\mathrm{e}=0.007 \text {; } \\
& \mathrm{m} \_\mathrm{iw}=0.1 \text {; } \\
& \text { eps_y }=11 \text {; } \\
& \text { eps_l }=3 \text {; } \\
& \text { lam_p }=1.5861 \text {; } \\
& \text { lam } \_\mathrm{i}=7.5585 \text {; } \\
& \text { lam_e = 3.4739; } \\
& \mathrm{s} \_\mathrm{i}=0.1622 \text {; } \\
& \text { s_iw }=0.1559 \text {; } \\
& \mathrm{s} \_\mathrm{e}=0.0567 \text {; } \\
& \text { c_p }=0.6305 \text {; } \\
& \text { c_i }=0.1323 \text {; } \\
& \text { c_e }=0.2879 \text {; } \\
& \mathrm{h} \_\mathrm{p}=3.5296 \text {; } \\
& \mathrm{h} \_\mathrm{i}=0.4217 \text {; } \\
& \text { h_e }=0.9011 \text {; } \\
& \mathrm{d} \_\mathrm{p}=0.077 \text {; } \\
& \text { b_ } \mathrm{i}=0.0242 \text {; } \\
& \text { b_iw }=0.0141 \text {; } \\
& \text { b_e }=0.0555 \text {; } \\
& \text { l_p }=0.7793 \text {; } \\
& \mathrm{l} \_\mathrm{i}=0.8515 \text {; } \\
& \mathrm{w} \_\mathrm{p}=0.737 \\
& \mathrm{w} \_\mathrm{i}=0.1686 \text {; } \\
& I=0.262584 \text {; } \\
& \mathrm{Ih}=0.12131 \text {; } \\
& \mathrm{K}=7.5024 ;
\end{aligned}
$$




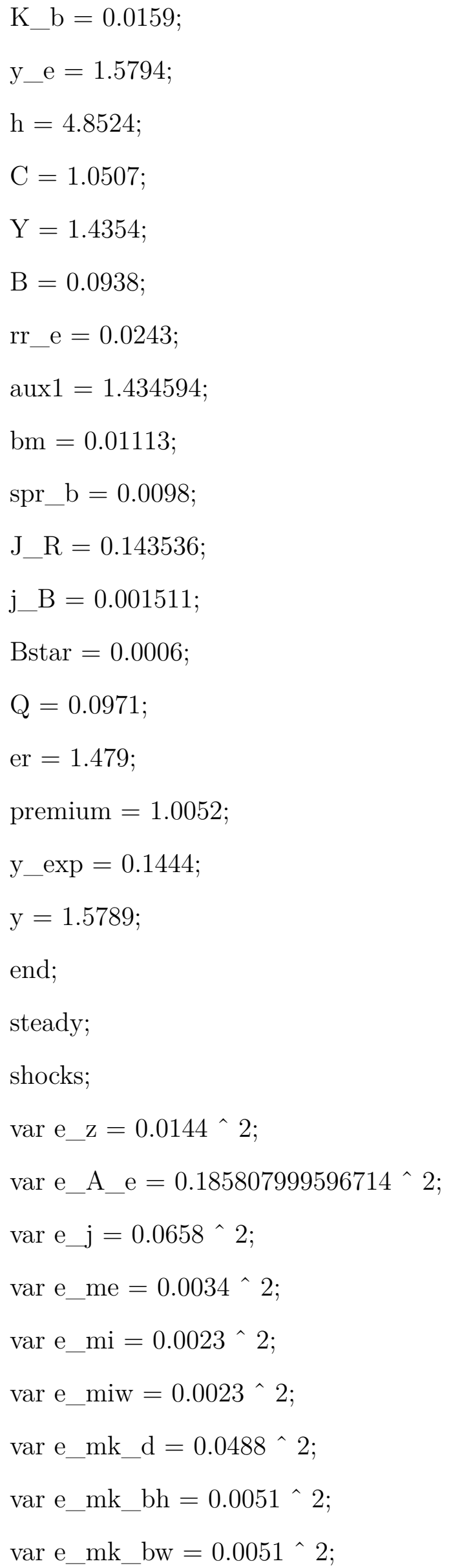


var e_mk_be $=0.1454^{\wedge} 2$;

var e_qk $=0.0125^{\wedge} 2$;

var e_qh $=0.0125^{\wedge} 2$;

var e_r $\_$ib $=0.0013^{\wedge} 2$;

var e_y $=1.0099^{\wedge} 2$;

var e_l $=0.3721^{\wedge} 2$;

var e_eps_K_b $=0.050^{\wedge} 2$;

var e_pQ $=0.050^{\wedge} 2$;

var e_eps_premium $=0.050^{\wedge} 2$;

var e_Rstar $=0.050^{\wedge} 2$;

var e_ystar $=0.050^{\wedge} 2$;

var e_pie_star $=0.050^{\wedge} 2$;

end;

//TO BE INSERTED: ESTIMATED ST.DEV.

// Stochastic simulations

$/ /$ stoch_simul $($ order $=1, \operatorname{irf}=20)$;

/1

//

varobs Bstar C I Q Y b_i b_iw er j_B pie pie_star q_h r_bw r_ib y_exp;

estimated_params ;

\% Initial conditions PRIOR shape MEAN STD

stderr e_z , , inv_gamma_pdf, 1.0000, 5.00 ;

stderr e_A_e, , inv_gamma_pdf, 1.0000, 5.00 ;

stderr e_j , , inv_gamma_pdf, 1.0000, 5.00 ;

stderr e_me, , inv_gamma_pdf, 1.0000, 5.00 ;

stderr e_mi , , inv_gamma_pdf, 1.0000, 5.00 ;

stderr e_mk_d, , inv_gamma_pdf, 1.0000, 5.00 ;

stderr e_mk_bh, , inv_gamma_pdf, 1.0000, 5.00 ;

stderr e_mk_be, , inv_gamma_pdf, 1.0000, 5.00 ; 
stderr e_qk, inv_gamma_pdf, 1.0000, 5.00 ;

stderr e_r_ib , , inv_gamma_pdf, 1.0000, 5.00 ;

stderr e_y , , inv_gamma_pdf, 1.0000, 5.00;

stderr e_l, , inv_gamma_pdf, 1.0000, 5.00 ;

stderr e_eps_K_b, , inv_gamma_pdf, 1.0000, 5.00;

stderr e_pQ , , inv_gamma_pdf, 1.0000, 5.00 ;

stderr e_eps_premium, , inv_gamma_pdf, 1.0000, 5.00 ;

stderr e_Rstar , , inv_gamma_pdf, 1.0000, 5.00 ;

stderr e_ystar , , inv_gamma_pdf, 1.0000, 5.00 ;

stderr e_pie_star, inv_gamma_pdf, 1.0000, 5.00 ;

stderr e_miw , , inv_gamma_pdf, 1.0000, 5.00 ;

stderr e_qh , inv_gamma_pdf, 1.0000, 5.00 ;

rho_ee_z, , beta_pdf, 0.50, 0.25 ;

rho_A_e, , beta_pdf, 0.50, 0.25 ;

rho_ee_j, , beta_pdf, 0.50, 0.25;

rho_me, , beta_pdf, 0.50, 0.25 ;

rho_mi , , beta_pdf, 0.50, 0.25 ;

rho_mk_d, , beta_pdf, 0.50, 0.25 ;

rho_mk_bh, , beta_pdf, 0.50, 0.25 ;

rho_mk_be, , beta_pdf, 0.50, 0.25;

rho_ee_qk, , beta_pdf, 0.50, 0.25 ;

rho_eps_y, , beta_pdf, 0.50, 0.25 ;

rho_eps_1, , beta_pdf, 0.50, 0.25 ;

rho_eps_K_b, beta_pdf, 0.50, 0.25 ;

rho_ystar, , beta_pdf, 0.50, 0.25 ;

rho_pie_star, , beta_pdf, 0.50, 0.25 ;

rho_Rstar , beta_pdf, 0.50, 0.25 ;

rho_pQ，, beta_pdf, 0.50, 0.25 ;

rho_eps_premium, , beta_pdf, 0.50, 0.25 ;

rho_miw, , beta_pdf, 0.50, 0.25 ; 
rho_ee_qh, , beta_pdf, 0.50, 0.25 ;

kappa_p, gamma_pdf, 50, 20 ;

kappa_w , , gamma_pdf, 50, 20 ;

kappa_i , , gamma_pdf, 2.5, 1.0 ;

kappa_ih , , gamma_pdf, 2.5, 1.0 ;

kappa_d, , gamma_pdf, 10, 2.5 ;

kappa_be, ,gamma_pdf, 3, 2.5 ;

kappa_bh , , gamma_pdf, 6, 2.5 ;

kappa_bw , gamma_pdf, 6, 2.5;

kappa_kb , , gamma_pdf, 10.0, 5.0 ;

phi_pie, , normal_pdf, 2.0, 0.35 ;

rho_ib , , beta_pdf, 0.6, 0.15 ;

phi_y , , gamma_pdf, 0.25, 0.10 ;

ind_p , , beta_pdf, 0.65, 0.20 ;

ind_w, , beta_pdf, 0.65, 0.20 ;

a_i , , beta_pdf, $0.85,0.05$;

end;

estimation $($ datafile $=$ dados_tese 1, mode_compute $=6$, mh_jscale $=0.30$,presample $=1$,prefilter $=0$,prior_trunc $=1 \mathrm{e}-14, \mathrm{mh} \_$replic $=1000000$, mh_nblocks $=2$ ,filtered_vars , lik_init $=1$, order $=1$, mode_check, $\operatorname{irf}=40$,bayesian_irf ,tex ); 